UNIVERSIDADE DE SÃO PAULO

INSTITUTO DE GEOCIÊNCIAS

RECONSTITUIÇÃO PALEOAMBIENTAL DE AMBIENTES

MARINHOS NAS REGIÕES SUDESTE E SUL BRASILEIRAS (SP, RS)

BASEADA EM ANÁLISES MICROFAUNÍSTICAS E GEOQUIIMICAS DE SEDIMENTOS

\author{
Juliana Braga Silva \\ Orientadora: Profa. Dra. Wânia Duleba
}

TESE DE DOUTORAMENTO

Programa de Pós-Graduação em Geoquímica dos Processos Exógenos

REVISADA

SÃO PAULO

2013 
UNIVERSIDADE DE SÃO PAULO

INSTITUTO DE GEOCIÊNCIAS

RECONSTITUIÇÃO PALEOAMBIENTAL DE AMBIENTES

MARINHOS NAS REGIÕES SUDESTE E SUL BRASILEIRAS (SP, RS)

BASEADA EM ANÁLISES MICROFAUNÍSTICAS E GEOQUIIMICAS DE SEDIMENTOS

\author{
Juliana Braga Silva \\ Orientadora: Profa. Dra. Wânia Duleba
}

TESE DE DOUTORAMENTO

Programa de Pós-Graduação em Geoquímica dos Processos Exógenos

SÃO PAULO

2013 
Autorizo a reprodução e divulgação total ou parcial deste trabalho, por qualquer meio convencional ou eletrônico, para fins de estudo e pesquisa, desde que citada a fonte.

Local e Data: São Paulo, março de 2013

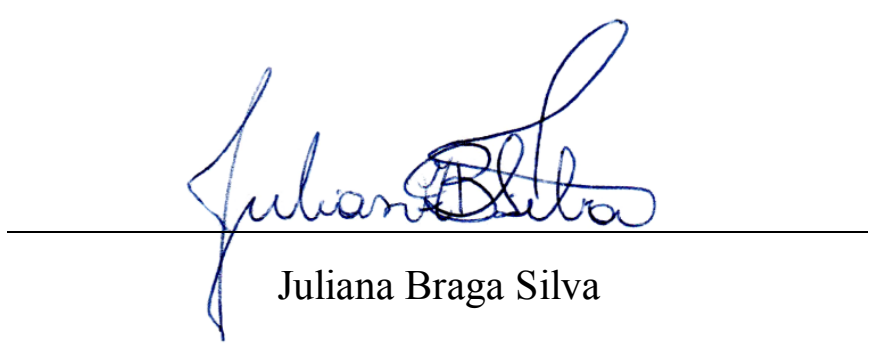

Contato: Juliana_bs2002@yahoo.com.br 
UNIVERSIDADE DE SÃO PAULO

INSTITUTO DE GEOCIÊNCIAS

\title{
RECONSTITUIÇÃO PALEOAMBIENTAL DE AMBIENTES \\ MARINHOS NAS REGIÕES SUDESTE E SUL BRASILEIRAS (SP, RS) \\ BASEADA EM ANÁLISES MICROFAUNÍSTICAS E GEOQUÍMICAS \\ DE SEDIMENTOS
}

\author{
Juliana Braga Silva \\ Orientadora: Profa. Dra. Wânia Duleba \\ TESE DE DOUTORAMENTO \\ COMISSÃO JULGADORA
}

Nome

Presidente: Profa. Dra. Wânia Duleba

Examinadores: Alethea Ernandes Martins Sallun

Profa. Dra. Sonia Maria Barros de Oliveira

Profa. Dra. Silvia Helena de Mello e Sousa

Prof. Dr. Cristiano Mazur Chiessi
Assinaturas
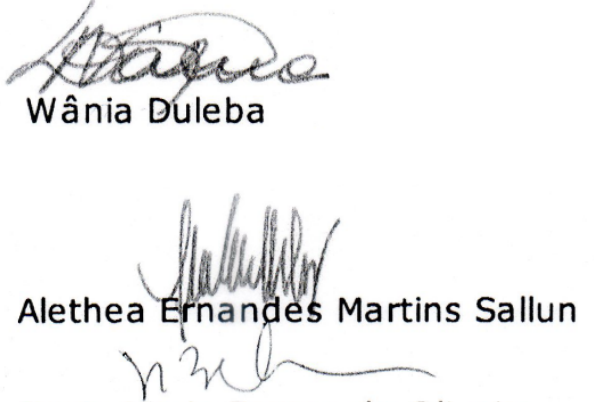

Sonia Maria Barros de Oliveira

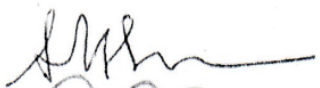

Silvia Helena de Mello e Sousa

Cristiano Mazur Chièssi

SÃO PAULO 
Aos meus pais, Marlene e José, meus pilares.

À Marina, minha irmã, minha luz.

Ao Vitor, meu amor, meu coração. 


\section{AGRADECIMENTOS}

À minha orientadora, Profa. Dra. Wânia Duleba, pela excelente orientação, e pela amizade de todos esses anos, que me permitiram, ambos, concluir mais este processo de formação acadêmica com paixão cada vez maior pelo tema.

À FAPESP, Fundação de Amparo à Pesquisa do Estado de São Paulo, pelo apoio financeiro durante esse processo (Proc. $\mathrm{N}^{\circ}$ 2008/57035-2).

Ao Instituto de Geociências da USP, pelas estruturas e oportunidades oferecidas, e a todos os seus funcionários que, de uma forma ou outra, contribuíram para a conclusão de mais esta etapa.

À Magali, Leonardo e Ana Paula, por toda a pronta ajuda oferecidos nesses anos.

Ao GeoB Core Repository do MARUM (Center for Marine Environmental Sciences) da Universidade de Bremen, pela cessão das amostras dos testemunhos GeoB6211-2 e GeoB6211-1.

Ao Prof. Dr. Cristiano Chiessi, pela cessão das amostras do testemunho GeoB6211-2, por toda ajuda e orientação referentes às análises de $\mathrm{Mg} / \mathrm{Ca}$ em testas de foraminíferos, e pelas sugestões referentes a todo trabalho com o testemunho GeoB6211-2.

À Universidade de Bremen e, em especial, ao Dr. Jeroen Groeneveld, pela acolhida na Alemanha, e pelos ensinamentos da técnica de preparação e medições de $\mathrm{Mg} / \mathrm{Ca}$ em testas de foraminíferos planctônicos, possibilitando parte da realização desse trabalho.

À Profa. Dra. Silvia Helena de Mello e Souza, e ao Prof. Dr. Andreas Mackensen, pela ajuda com a interpretação dos dados das associações de foraminíferos do testemunho GeoB6211-2.

Ao Prof. Maurício M. Mata, ao Fabio de A. Schroeder e ao Msc. Ricardo Acosta, por todos os esclarecimentos acerca dos aspectos de circulação oceanográfica no Sul do Brasil.

Ao Prof. Dr. Kenitiro Suguio e à Alethéa M. Sallum, pela cessão das amostras do testemunho S03, e por toda a ajuda na interpretação de seus dados.

Aos amigos do laboratório, Lu, Fernanda, Andréia, Silas, Raquel e Edna, e ao prof. Rocha-Campos, pelos momentos de descontração, pelo companheirismo e pelas trocas de ideia, que muito ajudaram durante todo esse tempo. A todos os demais grandes amigos, e à segunda família que, de longe ou de perto, contribuíram para que eu pudesse chegar até aqui.

Aos meus pais, à minha irmã Marina, e ao Vitor, que foram essenciais durante essa etapa. Obrigada pela compreensão, amor e amizade que me dedicaram e sem os quais esta finalização não seria possível. Amo vocês. 
"O aumento do conhecimento é como uma esfera dilatando-se no espaço: quanto maior a nossa compreensão, maior o nosso contacto com o desconhecido." Blaise Pascal 


\section{Resumo}

SILVA, J.B. Reconstituição paleoambiental de ambientes marinhos nas regiões sudeste e sul brasileiras (SP, RS) baseada em análises microfaunísticas e geoquímicas de sedimentos. 2012. Tese (Doutorado) - Instituto de Geociências, Universidade de São Paulo, São Paulo.

O presente trabalho é um estudo de reconstituição paleoambiental da Baixada Litorânea do Mosaico da Juréia-Itatins (MJI) e da região marinnha do Cone do Rio Grande (CRG), talude superior defronte ao Estado do Rio Grande do Sul, inferido a partir da análise de associações de foraminíferos bentônicos, durante os últimos 19.000 anos. Foram também realizadas análises geoquímica da razão $\mathrm{Mg} / \mathrm{Ca}$ de Globigerinoides ruber (white, stricto sensu), bem como tafonômicas e morfométricas de testas bentônicas, com o intuito de refinar as interpretações paleoambientais, principalmente as obtidas na região do CRG. A Transgressão Santos ( 21.227-20.448 a 5.558-4.558 anos cal A.P.) foi detectada somente no período de 9.400 a 8.385 anos cal A.P. na região costeira do MJI, devido à presença de sedimentos continentais na porção superior do testemunho S03. Durante este intervalo de tempo, as análises microfaunísticas e tafonômicas permitiram reconhecer quatro fases conspícuas de incursões de águas marinhas (9.400-9.338; 9.072-8.894; 8.656-8.641 e 8.5948.500 anos cal A.P.) intercaladas por quatro fases de proeminente contribuição continental (9.338-9.072; 8.500-8.385; 8.806-8.672 e 8.625-8.594 anos cal A.P.) na paleolaguna do MJI. Durante as incursões de águas marinhas, observou-se aumento da diversidade de espécies calcárias, com a predominância de Pararotalia cananeiaensis, Ammonia spp. e Elphidium spp. Nos dois períodos de maior aporte continental em que foram encontradas testas de foraminíferos bentônicos, a diversidade diminuiu drasticamente, e houve o concomitante predomínio do gênero Blysmaphaaera. Após 8.385 anos cal A.P. as associações de foraminíferos bentônicos desapareceram dos sedimentos da paleolaguna, que passou a apresentar características cada vez mais continentais. $\mathrm{Na}$ região do $\mathrm{CRG}$, as análises microfaunísticas bentônicas e tafonômicas permitiram o reconhecimento de cinco fases com características paleoambientais distintas. A primeira fase (19.000 a 18.600 anos cal A.P.) caracterizou-se por uma maior taxa de sedimentação, e pela presença de testas ricas em sulfeto e monossulfeto de ferro. A segunda (entre 18.600 e 17.000 anos cal A.P.) teve como principal característica o aumento do grau de oxigenação do meio, indicado pela presença de espécies epifaunais típicas de ambientes mais oxigenados, tais como Quinqueloculina spp., Pyrgo spp. e Eponides repandus, e pelo aumento do índice Benthic Foraminiferal Oxygen 
Index (BFOI). A terceira fase (17.000 a 16.000 anos cal A.P.) se caracterizou pela diminuição da energia de fundo do meio, o que propiciou maior acúmulo de matéria orgânica nos sedimentos e baixos teores de oxigênio no meio bentônico, tal como indicado pelos maiores valores do índice Benthic Foraminifera High Productivity (BFHP). Essas primeiras três fases corresponderam ao período Heinrich Stadial 1 (HS1). A quarta fase (16.000 e 14.700 anos cal A.P.) foi configurada pela transição entre o HS1 e a Reversão Fria Antártica (Antarctic Cold Reversal - ACR), e foi marcada por modificações significativas no nível da oxigenação do meio, especialmente em $\sim 15.000$ anos cal A.P., e provável aumento da temperatura das águas de fundo do $\mathrm{CRG}$, conforme indicado pela presença de Bulimina marginata, Uvigerina peregrina e Quinqueloculina spp. A quinta e última fase (14.700 e 14.000 anos cal A.P.) correspondeu ao início do ACR, com diminuição do hidrodinamismo e da oxigenação do meio e aumento do acúmulo de matéria orgânica nos sedimentos, como demonstrado pelo menor grau de desgaste das testas e pelos índices BFHP e BFOI. Já a análise geoquímica da razão $\mathrm{Mg} / \mathrm{Ca}$ em testas de $G$. ruber indicou que as paleotemperaturas superficiais marinhas (Mg/Ca SST) tenderam a aumentar de 19.000 anos cal A.P. ao Presente. Os valores de paleossalinidades superficiais marinhas (SSS) dessa região inferidas pelos valores de $\delta^{18} \mathrm{O}_{\text {ivc- }}$ sw, não apresentaram padrão definido de 19.000 a $~ 8.500$ anos cal A.P. A partir dessa idade, elas tiveram leve tendência à diminuição até o Presente. As variações secundárias dos valores de $\mathrm{Mg} / \mathrm{Ca} \mathrm{SST}$ e de $\delta^{18} \mathrm{O}_{\text {ivc-sw }}$ parecem ter sido influenciadas principalmente pelas alterações da circulação oceânica atlântica e por fenômenos atmosferico-climáticos associados a Última Deglaciação. No Holoceno, estes fatores se tornaram secundários, e os valores de $\mathrm{Mg} / \mathrm{Ca} \mathrm{SST}$ e de $\delta^{18} \mathrm{O}_{\text {ivc-sw }}$ passaram a ser influenciados pelas variações climatico-atmosféricas do hemisfério sul, especialmente as que se deram na região antártica. Também foram influenciadas por aumento da temperatura global, pluviosidade sobre a América do Sul, oscilações secundárias do paleonível relativo do mar durante a Transgressão Santos, variações da pluma de águas menos salinas do Rio de La Plata e por ocorrência de fenômenos tais como a Oscilação Atlântica Multidecadal e o El-Niño - Oscilação Sul.

Palavras-chave: Reconstituição Paleoambiental, foraminíferos, Quaternário, Heinrich Stadial 1, Última Deglaciação, Nível do Mar. 


\begin{abstract}
SILVA, J.B. Reconstituição paleoambiental de ambientes marinhos nas regiões sudeste e sul brasileiras (SP, RS) baseada em análises microfaunísticas e geoquímicas de sedimentos. 2012. Tese (Doutorado) - Instituto de Geociências, Universidade de São Paulo, São Paulo.
\end{abstract}

This thesis is a study of the paleoenvironmental reconstruction of the Juréia-Itatins Mosaic coastal lowlands (JIM) and the marine region of Rio Grande Cone (CRG), upper slope in front of Rio Grande do Sul State, inferred from analyses of benthic foraminiferal assemblages during the last 19.000 years. Geochemical analyses of Globigerinoides ruber (white, stricto sensu) along with taphonomical and morphometric analyses of benthic tests were also performed in order to refine the paleoenvironmental interpretations, especially those obtained at CRG. The Santos Transgression ( 21,227-20,448 to $\sim 5,558-4,558$ cal yr B.P.) was detected only during the period from 9,400 to 8,385 cal yr B.P. in the coastal lowlands of JIM, due to the presence of continental sediments in the upper portion of the S03 core. During this time interval the microfaunistic and taphonomical analyses allowed the recognition of four phases of conspicuous marine waters incursions $(9,400-9,338 ; 9,072-8,894 ; 8,656-8,641$ and 8,594-8,500 cal yr B.P.) interspersed by four phases of prominent continental contribution $(9,338-9,072 ; 8,500-8,385 ; 8,806-8,672$ and 8,625-8,594 cal yr B.P.) in the paleolagoon of JIM. During the marine waters incursions, there was an increase of diversity of calcareous species, with the predominance of Pararotalia cananeiaensis, Ammonia spp. and Elphidium spp. In the two periods of higher continental inflow in which benthic foraminiferal tests were found the diversity decreased drastically, and there was a concomitant predominance of Blysmaphaaera genus. After 8,385 cal yr B.P. the benthic foraminiferal assemblages disappeared of paleolagoon sediments, which began to show increased continental features. In the CRG's region, the benthic microfaunistic and taphonomical analyses allowed the recognition of five phases with distinct paleoenvironmental characteristics. The first phase $(19,000$ to 18,600 cal yr B.P.) was characterized by a higher sedimentation rate, and the presence of tests containing iron sulphide and monossulphide. The second (between 18,600 and 17,000 cal yr B.P.) had as main characteristic the increase of the oxygenation grade of the environment, evidenced by both the presence of epifaunal species typical of more oxygenated environments, such as Quinqueloculina spp., Pyrgo spp. and Eponides repandus, and by the Benthic Foraminiferal Oxygen Index (BFOI). The third phase (17,000 to 16,000 cal yr B.P.) was characterized by the decrease of bottom hydrodynamic energy, which provided higher 
organic matter accumulation in the sediments and the low levels of oxygen in the benthic environment, as indicated by the higher values of Benthic Foraminifera High Productivity (BFHP) index. These first three phases corresponded to the Heinrich Stadial 1 (HS1) period. The fourth phase (16,000 to 14,700 cal yr B.P.) was configured by the transition between the HS1 and the Antarctic Cold Reversal (ACR). It was marked by significant changes in the environment oxygen level especially at $\sim 15,000 \mathrm{cal}$ yr B.P. and by the correspondent increase of bottom water temperature in the CRG, as indicated by the presence of Bulimina marginata, Uvigerina peregrina and Quinqueloculina spp. The fifth and last phase (14,700 to 14,000 cal yr B.P.) corresponded to the beginning of ACR, with decrease of hydrodynamics and oxygenation grade of the environment and increase of organic matter accumulation in the sediments, as demonstrated by both the lower degree of tests wear and by the BFOI and BFHP indexes. The geochemistry analysis of $\mathrm{Mg} / \mathrm{Ca}$ ratio in $\mathrm{G}$. ruber tests indicated that the paleo-sea surface temperatures $(\mathrm{Mg} / \mathrm{Ca} \mathrm{SST})$ tended to increase from 19,000 cal yr B.P. to the Present. Meanwhile the paleo-sea surface salinities (SSS) inferred by the values of $\delta^{18} \mathrm{O}_{\text {ivc-sw, }}$ did not had a defined pattern from 19.000 to $\sim 8,500$ cal yr B.P. Since then they have registered a slight tendency to decrease. The secondary variations of $\mathrm{Mg} / \mathrm{Ca} \mathrm{SST}$ and $\delta^{18} \mathrm{O}_{\text {ivc- }}$ sw values appear to have been influenced primarily by the variations of Atlantic Ocean circulation and by the atmospheric-climatic phenomena associated with the Last Deglaciation. In the Holocene however these paleoclimatic factors became secondary, and the $\mathrm{Mg} / \mathrm{Ca} \mathrm{SST}$ and $\delta^{18} \mathrm{O}_{\text {ivc-sw }}$ values became influenced by climatic-atmospheric variations of the southern hemisphere, especially those that occurred over the Antarctic region. They were also influenced by the increase in global temperature, the rainfall regimen over South America, the secondary oscillations of the plume of less saline waters from La Plata River, and by the occurrence of phenomena such as the Atlantic Multidecadal Oscillation and the El-NiñoSouthern Oscilation.

Keywords: Paleoenvironmental reconstruction, foraminifera, Quaternary, Heinrich Stadial 1, Last Deglaciation, sea level. 


\section{Lista de Figuras}

Figura 1: Célula de Revolvimento Meridional do Atlântico (AMOC). 4

Figura 2: Compilação das curvas de paleoníveis marinhos disponíveis com dados isolados dos últimos 40.000 anos das regiões plataformal e costeira sudeste brasileiras. 11

Figura 3: Modelo de variação do nível médio do mar nos últimos $8 \mathrm{ka}$ cal A.P. 12

Figura 4: Espécies de foraminíferos bentônicos e planctônicos encontrados na margem continental brasileira. 13

Figura 5: Limites do Mosaico da Juréia-Itatins (MJ) no Estado de São Paulo, conforme nova proposta da Secretaria do Meio Ambiente (05/06/2006), e principais vias de acesso, com destaque para o Morro da Juréia, Serra de Itatins, e principais cursos de água da região.__18

Figura 6: Mapa geológico do Mosaico da Juréia-Itatins. 20

Figura 7: Estágios da evolução geológica entre o Pleistoceno Superior e o Holoceno da região circundante ao Morro da Juréia. 21

Figura 8: A. Fisiografia do fundo marinho na região do Rio Grande do Sul. Modificada de Tessler e Mahiques (2000). B. Imagem do Cone do Rio Grande com sua localização em relação ao Rio Grande do Sul e à foz do Rio de La Plata. 23

Figura 9: Mapa de domínios tectônicos do Estado do Rio Grande do Sul. 25

Figura 10: Perfil esquemático transversal aos sistemas de ilha barreira/lagunas do Estado do Rio Grande do Sul. 26

Figura 11: Circulação atual atmosférica com padrões reais de ventos devido à distribuição de massas de terra. 27

Figura 12: Áreas fontes e principais trajetórias dos sistemas atmosféricos da América do Sul em A. média anual, B. meses de verão e C. meses de inverno. 28

Figura 13: Precipitação total sazonal (em mm) de longo termo (1979-2000) CMAP para A.

Dezembro-Fevereiro e B. Junho-Agosto. 30

Figura 14: Circulação superficial geral do Oceano Atlântico Sul. 31

Figura 15: Massas de água da costa sudeste brasileira. 32

Figura 16: Localização do testemunho S03. 34

Figura 17: A. Circulação geral do Atlântico Sul, modificada de Peterson e Stramma (1991), com localização do GeoB6211-2. B. Diagrama de salinidade vs. temperatura vs. profundidade da região do testemunho GeoB6211-2. 35

Figura 18: Valores típicos de $\delta^{13} \mathrm{C}$ e $\mathrm{C}_{\text {org }} / \mathrm{N}_{\text {total }}$ para origem da matéria orgânica em ambientes costeiros. 40 
Figura 19: Modelo de idades para o testemunho S03. 50

Figura 20: Dados de granulometria (\% total de areias e \% total de pelitos), diâmetro médio em escala phi $(\varnothing)$, assimetria $\left(\mathrm{SK}_{1}\right)$, curtose $\left(\mathrm{K}_{\mathrm{G}}\right)$, porcentagem de carbonatos $(\% \mathrm{CaO})$, porcentagens de carbono orgânico $\left(\mathrm{C}_{\text {org }}\right)$ e nitrogênio total $\left(\mathrm{N}_{\text {total }}\right)$ do testemunho $\mathrm{S} 03$ __ 52

Figura 21: Valores dos elementos químicos obtidos ao longo do testemunho S03. 53

Figura 22: Densidade (número de testas $/ 10 \mathrm{~cm}^{3}$ de sedimento), equitatividade de Pielou (J'), riqueza (número de espécies/amostra) e diversidade de Shannon-Wiener (H') das associações de foraminíferos bentônicos do testemunho S03. 55

Figura 23: Porcentagens das principais espécies de foraminíferos bentônicos encontradas entre 9.400 e 8.385 anos cal A.P. no testemunho S03. 57

Figura 24: Porcentagens das espécies de foraminíferos bentônicos bioindicadores do testemunho S03. 59

Figura 25: Análise tafonômica dos foraminíferos do testemunho S03. 62

Figura 26: Dendrograma da análise estatística de agrupamento modo-R. 63

Figura 27: Distribuições das três diferentes associações microfaunísticas do testemunho S03 obtidas pela análise estatística de agrupamento modo-R. 64

Figura 28: Modelo de Idades para o testemunho GeoB6211-2. 65

Figura 29: Dados de granulometria (\% total de areias e \% total de pelitos), diâmetro médio em escala phi (ø), assimetria $\left(\mathrm{SK}_{1}\right)$, curtose $\left(\mathrm{K}_{\mathrm{G}}\right)$, porcentagem de carbonatos fluxo de carbonato de cálcio (Fluxo $\mathrm{CaCO}_{3}$ ), taxa de sedimentação (TS), porcentagens de carbono orgânico $\left(\mathrm{C}_{\text {org }}\right)$ e nitrogênio total $\left(\mathrm{N}_{\text {total }}\right)$, e razão $\mathrm{C} / \mathrm{N}$ do testemunho GeoB6211-2. 67

Figura 30: Valores dos elementos químicos obtidos ao longo do testemunho GeoB6211-2. 69

Figura 31: Densidade total de testas [(testas plactônicas + bentônicas)/1g de sedimento seco], porcentagem de testas bentônicas (\% bentônicos) e planctônicas (\% planctônicos) e razão planctônicos/bentônicos $\left(\left[\mathrm{n}^{\circ}\right.\right.$ de planctônicos $\left./\left(\mathrm{n}^{\circ} \text { total de testas }\right)^{*} 100\right]$ do testemunho GeoB6211-2. 70

Figura 32: Densidade (número de testas/ $1 \mathrm{~g}$ de sedimento seco), índice BFAR (Benthic Foraminiferal Accumulation Rate - testas $/ \mathrm{ka}^{*} \mathrm{~cm}^{2}$ ) equitatividade de Pielou (J'), riqueza (número de espécies/amostra) e diversidade de Shannon-Wiener (H’) das associações de foraminíferos bentônicos do testemunho GeoB6211-2. 72

Figura 33: Porcentagens das principais espécies de foraminíferos bentônicos encontradas ao longo do testemunho GeoB6211-2. 74 
Figura 34: Porcentagens das espécies de foraminíferos bentônicos bioindicadores do testemunho GeoB6211-2.__ 76

Figura 35: Variações paleoclimáticas entre 19.000 e 14.000 anos cal A.P.___ 77

Figura 36: Análise tafonômica dos foraminíferos do testemunho GeoB6211-2. ___ 80

Figura 37: Dendrograma da análise estatística de agrupamento modo-R das 22 espécies mais abundantes do testemunho GeoB6211-2 entre 19.000 e 14.000 anos cal A.P. 81

Figura 38: Distribuições das quatro diferentes associações microfaunísticas do testemunho GeoB6211-2 obtidas pela análise estatística de agrupamento modo-R. 81

Figura 39: Valores de $\mathrm{Mg} / \mathrm{Ca} \operatorname{SST}\left({ }^{\circ} \mathrm{C}\right)$ e $\delta^{18} \mathrm{O}_{\text {ivc-sw }}(\%$ VSMOW) de testas de G. ruber (white, s.s.) do testemunho GeoB6211-2. 83

Figura 40: Valores de paleotemperaturas e paleossalinidades para o atlântico subtropical sudoeste. 86

Figura 41: Valores de paleotemperaturas e paleossalinidades para o atlântico subtropical sudoeste. 88

Figura 42: Comparação entre os dados dos testemunhos S03 e GeoB6211CC entre 9.400 e 8.385 anos cal A.P. 89

Figura 43: Comparação entre os dados do testemunho GeoB6211-2 entre 19.000 e 8.000 anos cal A.P. 90

Prancha 1: Espécies de foraminíferos e exemplos de processos tafonômicos do testemunho S03. Anexo.

Prancha 2: Espécies de foraminíferos do testemunho GeoB6211-2. Anexo.

Prancha 3: Exemplos de processos tafonômicos do testemunho GeoB6211-2.__ Anexo. 


\section{Lista de Tabelas}

Tabela 1: Espécies de foraminíferos bentônicos utilizadas para a confecção do índice BFOI.

Tabela 2: Idades geológicas obtidas para o testemunho S03. 50

Tabela 3: Distribuição granulométrica dos sedimentos do testemunho S03. Anexo.

Tabela 4: Dados geoquímicos do testemunho S03_. Anexo.

Tabela 5: Espécies de foraminíferos encontradas ao longo do testemunho S03. Anexo.

Tabela 6: Idades geológicas obtidas para o testemunho GeoB6211-2. 65

Tabela 7: Distribuição granulométrica dos sedimentos do testemunho GeoB6211-2.

Anexo.

Tabela 8: Dados geoquímicos do testemunho GeoB6211-2 Anexo.

Tabela 9: Espécies de foraminíferos encontradas ao longo do testemunho GeoB6211-2_ Anexo.

Tabela 10: Características das diferentes associações de foraminíferos bentônicos do testemunho GeoB6211-2. 82

Tabela 11: Dados de paleotemperaturas $(\mathrm{Mg} / \mathrm{Ca} \mathrm{SST})$ e paleossalinidades $\left(\delta^{18} \mathrm{O}_{\mathrm{ivc}-\mathrm{sw}}\right)$ do testemunho GeoB6211-2. Anexo. 


\section{Lista de Abreviaturas}

${ }^{14}$ C anos A.P.: Anos de datação radiométrica de carbono Antes do Presente.

AC: Água Costeira.

ACAS: Água Central do Atlântico Sul.

ACR: Reversão Fria Antártica. Em inglês: Antarctic Cold Reversal.

AIA: Água Intermediária Antártica.

AMAS: Água Modal do Atlântico Sul.

AMOC: Célula de Revolvimento do Atlântico. Em inglês: Atlantic Meridional Overturning Circulation.

AMSA: Água Modal Subantártica.

AMSAS: Água Modal Subtropical do Atlântico Sul.

Anos cal A.P.: anos calculados Antes do Presente.

APAN: Água Profunda do Atlântico Norte.

APM: Anticiclones Polares Migratórios.

ASAS: Água Superficial do Atlântico Sul.

ATAS: Anticiclone Tropical do Atlântico Sul.

AT: Água Tropical.

B-A: Evento Bølling-Allerød.

BFAR: Benthic Foraminiferal Accumulation Rate.

BFHP: Benthic Foraminifer High Productivity Index.

BFOI: Benthic Foraminiferal Oxygen Index.

CB: Corrente do Brasil.

CCOI: Corrente de Contorno Oeste Intermediária.

CM: Corrente das Malvinas.

CNB: Corrente Norte do Brasil.

CRG: Cone do Rio Grande.

ENOS: El-Niño-Oscilação Sul.

FPA: Frente Polar Atlântica.

FST: Frente Subtropical

HS1: Evento Heinrich Stadial 1.

IRD: Ice-Rafted Debris.

ISACW: Água Central do Atlântico Sul leve. Em inglês: light South Atlantic Central Water.

MJI: Mosaico da Juréia-Itatins. 
M.O.: Matéria orgânica.

Mg/Ca SST: temperatura superficial marinha obtida por meio da razão $\mathrm{Mg} / \mathrm{Ca}$. Em inglês: SST $=$ Sea Surface Temperature.

MVAS: Monção de Verão da América do Sul.

mwp-1A: Meltwater Pulse 1A.

OAM: Oscilação Atlântica Multidecadal.

PPW: Pluma de Água Pouco Salina do Rio de La Plata. Em inglês: La Plata Plume Water.

Razão P/B: Razão planctônicos/bentônicos.

SALLJ: Jato de Baixo Nível da América do Sul. Em inglês: South Atlantic Low Level Jet.

SSS: Salinidade superficial marinha. Em inglês: Sea Surface Salinity.

TSM: Temperatura Superficial Marinha.

UMG: Último Máximo Glacial.

YD: Younger Dryas.

ZCAS: Zona de Convergência do Atlântico Sul.

ZCIT: Zona de Convergência Intertropical.

$\delta^{18} \mathbf{O}_{\text {ivc-sw: }} \delta^{18}$ do oxigênio com correção do volume total de gelo e do paleonível marinho.

$\mathrm{IVC}=$ ice volume corrected. $\mathrm{SW}=$ sea water . 
CAPÍTULO 1: Introdução 1

CAPÍTULO 2: Contextos climatológico, marinho e de proxies paleoambientais: estudos prévios 4

2.1. Evolução paleoambiental dos últimos 19.000 anos cal A.P. 4

2.2. Paleoníveis Marinhos dos últimos 19.000 anos: a Transgressão Santos_9

2.3. Foraminíferos: proxies paleoambientais marinhos 12

CAPÍTULO 3: Objetivos 14

3.1. Objetivos Gerais 14

3.2. Objetivos Específicos 14

3.3. Justificativa 15

CAPÍTULO 4: Organização da Tese 17 CAPÍTULO 5: Área de Estudos 18

5.1. Aspectos Geológicos das Áreas de Estudo 18

5.1.1. Mosaico da Juréia-Itatins 18

5.1.2. Cone do Rio Grande e Região Continental Adjacente 22

5.2. Aspectos Climatológicos das Áreas de Estudo 26

5.3. Aspectos Oceanográficos das Áreas de estudo 30

CAPÍTULO 6: Materiais e Métodos 34

6.1. Procedência, coleta e datação das amostras 34

6.2. Análises Sedimentológicas 37

6.3. Análises Químicas dos Sedimentos 37

6.4. Análises isotópicas de sedimentos e de testas de foraminíferos 39

6.5. Mg/Ca em testas da espécie planctônica Globigerinoides ruber (white, s.s.)_ 41

6.6. Análises Microfaunísticas 43

CAPÍTULO 7: Resultados 50

7.1. Testemunho S03 50

7.1.1. Resultados Abióticos 50

7.1.2. Resultados Microfaunísticos 54

7.2. Testemunho GeoB6211-2 65

7.2.1. Resultados Abióticos 65

7.2.2. Resultados Microfaunísticos 69

7.2.3. Resultados geoquímicos em testa de Globigerinoides ruber 83 
CAPÍTULO 8: Discussão 91

8.1. Testemunho S03 91

8.2. Testemunho GeoB6211-2 103

8.2.1. Associação total: foraminíferos planctônicos e bentônicos 103

8.2.2. Análises microfaunísticas bentônicas 105

8.2.3. $\mathrm{Mg} / \mathrm{Ca} S S T \delta^{18} \mathrm{O}_{\text {ivc-sw }}$ em testas de G. ruber (white, s.s.) 114 8.3. Evolução paleoceanográfica das margens sudeste e sul brasileiras 122 CAPÍTULO 9: Conclusões 129

Referências Bibliográficas 132

Anexos 164

Artigo Anexo 


\section{CAPÍTULO 1: Introdução}

Nas últimas décadas, os estudos sobre mudanças paleoambientais quaternárias vêm adquirindo atenção cada vez maior da comunidade científica. A crescente preocupação com as variações climáticas terrestres, e com suas consequências para esta e para futuras gerações, tem levado cientistas a analisarem uma série de modelos climáticos de diferentes complexidades e de proxies paleoambientais que englobam desde fatores históricos, geoquímicos, geológicos e geofísicos até organismos sensíveis às modificações investigadas.

Esses estudos tentam distinguir os padrões de alterações ambientais passadas, estabelecer as interações entre essas alterações e as antigas civilizações, reconhecer e caracterizar os seus fatores controladores e a resposta dos sistemas climáticos a esses fatores controladores, para prever e, se necessário, prevenir as futuras transformações ambientais terrestres (e.g., Suguio e Martin, 1978a; Tomazelli e Villwock 1996; Arz et al., 1999; Manabe e Stoufer, 2000; Kaminski et al., 2002; Ybert et al., 2003; Duleba et al., 2005; Angulo et al., 2006; Weldeab et al., 2006; Jaeschke et al., 2007; Martins et al., 2007; Mangini et al., 2010; Stanford et al., 2011).

Dentre os proxies paleoambientais utilizados para se estabelecer mudanças climáticas pretéritas, foraminíferos são excelentes bioindicadores sobre variações paleoceanográficas, devido à facilidade de coleta, baixo custo de análise, ampla distribuição geográfica e batimétrica, por serem majoritariamente estenobióticos (i.e., sensíveis às variações do ambiente em que vivem), e por possuírem baixa capacidade de locomoção e terem características ecológicas, biológicas e taxonômicas bem conhecidas (Boltovskoy e Wright, 1976; Boltovskoy et al., 1991; Loeblich e Tappan, 1988).

Esses microorganismos marinhos, quando analisados em conjunto com outros importantes fatores abióticos (e.g., geoquímicos, geofísicos, isotópicos, sedimentológicos) relacionados ao mesmo indicador paleoambiental (por exemplo, um testemunho), tornam possível a identificação de mudanças paleoceanográficas e paleoambientais ocorridas na interface sedimento-água e nos sedimentos marinhos (foraminíferos bentônicos), bem como na coluna da água (foraminíferos planctônicos) de determinada região oceânica.

Nos últimos 19.000 anos cal A.P., o clima global passou por intensas transformações enquanto a Última Deglaciação ( 19.000 a 10.000 anos cal A.P.) dava lugar ao Holoceno $(\sim 11.700$ anos cal A.P. ao Presente).

As mudanças paleoambientais que ocorreram durante a Última Deglaciação foram quase simultâneas nos dois hemisférios, e apresentaram flutuações de temperatura que 
tiveram comportamentos opostos na Groelândia e na Antártica (EPICA, 2006). Esse comportamento contrastante das temperaturas nas altas latitudes dos hemisférios norte e sul é denominado Termal Bipolar Seesaw (Stocker e Johnsen, 2003; EPICA, 2006; Barker et al., 2009), ou Gangorra Bipolar em Português. Esse conceito argumenta que a oscilação do regime da Circulação Termohalina Atlântica, também denominada Célula de Revolvimento Meridional do Atlântico (em inglês, AMOC - Atlantic Meridional Termohaline Circulation) (Rahmstorf, 2003; Delworth et al., 2008; Campos et al., 2012) afeta a distribuição de calor entre o Atlântico Norte e o Atlântico Sul, o que influencia o clima nas altas latitudes globais. E que, além disso, a capacidade do Oceano Austral em reter calor proporciona à região antártica a aptidão de apresentar mudanças de temperatura mais graduais que aquelas do hemisfério norte (Stocker e Johnsen, 2003; EPICA, 2006; Barker et al., 2009).

Seguindo-se à Última Deglaciação, o Holoceno teve início já em 11.700 anos cal A.P., mas foi em $\sim 10.000$ que a transição climática entre esses dois períodos se completou (Barker et al., 2009). Esta época geológica é comumente dividida em Holoceno Inferior (11.500$\sim 8.200$ anos cal A.P.); Holoceno Médio ( 8.200- 4.200 anos cal A.P.) e Holoceno Tardio ( 4.200 anos cal A.P. ao Presente) (Barron e Anderson, 2011; Tabela International Estratigráfica 2013).

Apesar de representar um estágio interglacial, com aparentemente menores amplitudes paleoclimáticas que aquelas que ocorreram no período anterior, o Holoceno é um período geológico cujo clima foi altamente variável, alterando-se entre seco, úmido, frio e quente (Mayweski et al., 2004; Wanner et al., 2011). A despeito das mais baixas amplitudes de temperatura, houve amplas modificações nos registros de precipitação durante esse período (Dansgaard et al., 1989; Mayewski et al., 2004; Wanner et al., 2008).

Essa intensa variabilidade climática possuiu múltiplos controles responsáveis. Dentre eles, as mudanças na insolação relacionadas tanto às variações orbitais terrestres quanto à variabilidade solar parecem exercer papel principal nas modificações paleoclimáticas globais dos últimos 11.700 anos cal A.P. (Mayweski et al., 2004; Wanner et al., 2011). Ainda, o ciclo hidrológico que rege a distribuição do calor latente encontrado na atmosfera contribuiu largamente para as modificações climáticas holocênicas (Mayweski et al., 2004).

O comportamento oceânico durante esses últimos 19.000 anos cal A.P. foi transgressivo (e.g., Corrêa, 1996; Fleming et al., 1998; Lambeck e Chappell, 2001). Essa transgressão foi denominada Transgressão Santos na costa sudeste brasileira; Sistema Laguna/Barreira IV na costa sul brasileira, e Transgressão Flandriana na região da Bélgica 
(Suguio e Martin, 1978a). Ela atingiu seu máximo, entre $\sim 5.100$ e $\sim 5.700$ anos cal A.P. na região marginal atlântica brasileira (Angulo et al., 2006).

Apesar da numerosa literatura sobre o comportamento paleoambiental e paleoceanográfico que abrange o período do Quaternário, especialmente entre $\sim 20.000$ anos e o Presente no hemisfério norte, nas regiões tropicais e nas altas latitudes (e.g., Blunier et al., 1997; Mackensen et al., 2001; EPICA, 2006; Weldeab et al., 2006; Jaeschke et al., 2007; Unkel et al., 2008; Putnam et al., 2010; Stanford et al., 2011), ainda existem lacunas de conhecimento, especialmente na região do Atlântico sudoeste subtropical, devido à escassez de dados, aos diferentes métodos, interpretações e proxies utilizados nessas pesquisas (Sallun et al., 2012).

A utilização de proxies paleoambientais tais como foraminíferos, dados geoquímicos e isotópicos de suas testas, obtidos de testemunhos, e as comparações desses proxies com indicadores geoquímicos e sedimentares desses mesmos testemunhos e com dados paleoclimáticos existentes na literatura, nos permitem tentar sanar algumas dessas lacunas, por meio de inferências acerca do comportamento oceanográfico e paleoclimático das regiões de coleta dos testemunhos analisados. 


\section{CAPÍTULO 2: Contextos climatológico, marinho e de proxies paleoambientais: estudos prévios}

\subsection{Evolução paleoambiental dos últimos 19.000 anos cal A.P.}

Durante a Última Deglaciação, amplas geleiras que recobriam as altas latitudes do Hemisfério Norte começaram a derreter devido a modificações na insolação de verão setentrional e lançaram grandes quantidades de água doce no Oceano Atlântico Norte (Barker et al., 2009; Stanford et al., 2011). Esses pulsos de degelo geraram intensa dessalinização nessa região atlântica (Bond et al., 1992; Maslin et al., 1995) e, já em torno de 19.000 anos cal A.P., começaram a causar enfraquecimento da Água Profunda do Atlântico Norte (APAN) e, por conseguinte, da Célula de Revolvimento Meridional do Atlântico (AMOC, Fig.1) (Stanford et al., 2011).

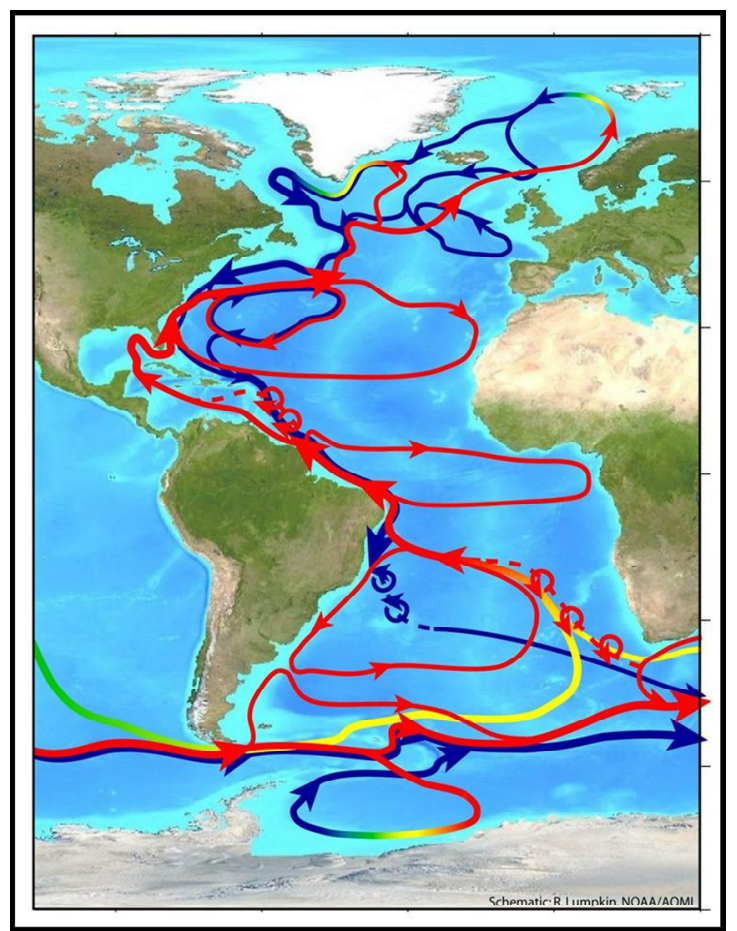

Figura 1: Célula de Revolvimento Meridional do Attântico (AMOC). Em vermelho, o transporte de águas quentes em direção ao norte. Em azul, o transporte de águas frias em direção ao sul. Retirado de www.aoml.nooa.gov.

Nos 4.300 anos seguintes, entre 19.000 e $\sim 14.700$ anos cal A.P., esses pulsos de degelo mantiveram a APAN enfraquecida (Stanford et al., 2011) e, com isso, modificaram toda a circulação atlântica. Esse período paleoclimático, conhecido como Heinrich Stadial 1 
(HS1), apresentou evolução complexa (Bard et al., 2000; Stanford et al., 2011) em que não apenas a circulação atlântica se alterou, mas também todo o clima global sofreu modificações.

O enfraquecimento cada vez maior da AMOC, com início já em 19.000 anos cal A.P. (Stanford et al., 2011), foi acompanhado pelo aquecimento da margem norte da Corrente Circumpolar Antártica (CCA) (Lamy et al., 2007). A margem norte da CCA também deve ter se avigorado e se deslocado mais para sul, muito provavelmente devido à migração para sul e ao fortalecimento dos Ventos de Oeste (Rind et al., 2001; Lamy et al., 2007; Barker et al., 2009). Concomitantemente, Shemesh et al. (2002) descreveram diminuição do manto de gelo e aumento da produtividade primária oceânica no setor Atlântico do Oceano Austral, ao sul da atual Frente Polar; e Pahnke et al. (2008) propuseram aumento da intensidade de formação da Água Intermediária Antártica (AIA) no Pacífico sudeste e no Atlântico sudoeste que, segundo esses autores, passou a atingir regiões mais ao norte no Oceano Atlântico.

Ainda no setor atlântico do Oceano Austral, ocorreu aumento da ressurgência das águas profundas circumpolares, associada à ventilação das águas intermediárias e profundas do Atlântico Sul, ao aumento do $\rho \mathrm{CO}_{2}$ atmosférico, à intensidade da produtividade primária marinha, aos parâmetros físico-químicos da AIA e da Água Modal do Atlântico Sul (AMAS), e ao posicionamento, mais ao sul, dos Ventos de Oeste (Pahnke e Zahn, 2005; Anderson et al., 2009; Skinner et al., 2010).

A produtividade marinha primária aumentou não apenas o Oceano Austral, mas também em regiões do Atlântico Tropical, em áreas que migraram de suas posições anteriores (Mackensen et al., 2001; Shemesh et al., 2002; Toledo et al., 2007a). No NE do Brasil e no Atlântico tropical leste, aumentos nas temperaturas e salinidades das águas oceânicas superficiais foram detectados por Arz et al. (1999), Rühlemann et al. (2004) e Weldeab et al. (2006), entre outros. Segundo esses autores, esse padrão indica ter havido menor transporte inter-hemisférico das massas de água durante o HS1.

Os Ventos Alíseos de NE (Alíseos NE) se fortaleciam, enquanto os Ventos Alíseos de SE (Alíseos SE) se enfraqueciam, o que ocasionou o deslocamento, cada vez mais para sul, da Zona de Convergência Intertropical (ZCIT) (Cruz Jr. et al., 2006; Jaeschke et al., 2007). O posicionamento mais ao sul da ZCIT causou aumento da convecção na Bacia Amazônica, avigorando a Monção de Verão da América do Sul (MVAS) e a Zona de Convergência da América do Sul (ZCAS). Ainda, fez com que a ZCAS se deslocasse mais para sul (Cruz Jr. et al., 2006; Jaeschke et al., 2007; Chiessi et al., 2009).

A reorganização dos padrões dos sistemas atmosféricos sobre a América do Sul teria causado aumento da precipitação nas regiões brasileiras sob influência desses sistemas 
climatológicos como, por exemplo, o NE brasileiro e a área brasileira da bacia do Rio de La Plata (Cruz Jr. et al., 2006; Behling et al., 2007; Jaeschke et al., 2007; Chiessi et al., 2009). Arz et al. (1999) detectaram fortalecimento da Corrente do Brasil (CB) e enfraquecimento da Corrente Norte do Brasil (CNB), que foram atribuídos à mudança no padrão dos Ventos Alíseos.

Há 17.500 anos cal A.P., a AMOC alcançou o estado de quase-colapso, estado este em que se manteve pelos 800 anos seguintes, entre $\sim 17.500$ e 16.700 anos cal A.P. (Stanford et al., 2011). Segundo Bard et al. (2000), foi há 17.500 e há 16.000 anos cal A.P. que ocorreram os pulsos de degelo mais acentuados no Oceano Atlântico Norte. Nessa mesma época, Shemesh et al. (2002) encontraram a menor extensão do manto de gelo no mar antártico em 17.000 anos cal A.P., quando, segundo esses mesmos autores, a quantidade de $\mathrm{CO}_{2}$ lançada à atmosfera passou a aumentar no setor atlântico sudeste do Oceano Austral. McCulloch et al. (2000) encontraram aquecimento no Chile em torno de 17.500 a 17.100 anos cal A.P., e Weldeab et al. (2006) detectaram aumento de $2,5^{\circ} \mathrm{C}$ na temperatura em conjunto com aumento da salinidade na margem nordeste brasileira a partir de 17.500 anos cal A.P. Chiessi et al. (2009) encontraram aumento do $\delta^{18} \mathrm{O}$ de G. ruber na margem sul brasileira até $\sim 17.700$ anos cal A.P.

No final do HS1 a reestruturação completa da AMOC em torno de 15.000 anos cal A.P. (McManus et al., 2004; Stanford et al., 2011) foi vinculada ao aquecimento do hemisfério sul, ao deslocamento para norte da ZCIT, ao fortalecimento dos Alíseos SE, ao enfraquecimento dos Alíseos NE (Jaeschke et al., 2007; Chiessi et al., 2009), e ao fortalecimento da Passagem das Agulhas, que ocorrera em torno de 15.000 anos cal A.P. (Chiessi et al., 2008). Esses fatores, em conjunto, permitiram a recuperação da APAN e modificaram as condições de densidade dessa massa de água e da AIA (Rickaby e Elderfield, 2005; Chiessi et al., 2008), revigorando a AMOC.

Já na transição entre o HS1 e o período paleoclimático conhecido como Reversão Fria Antártica (em inglês, ACR - Antarctic Cold Reversal) no hemisfério sul, e Bølling-Allerød, (B-A) no hemisfério norte, em torno de 14.600 anos cal A.P., (Stenni et al., 2001; Kohler et al., 2011; Stanford et al., 2011) houve resfriamento (aquecimento) climático no hemisfério sul (hemisfério norte), devido a migração para norte da Frente Subtropical (FST) e concomitante expansão para norte das águas frias do Oceano Austral (Putnam et al., 2010).

O período conhecido como ACR durou entre, aproximadamente, 14.600 anos cal A.P. e 12.500 anos cal A.P. (Blunier et al., 1997; Stenni et al., 2001; Liu et al., 2009). Alguns autores propõem que as modificações de temperatura na transição entre o HS1 e o ACR (B- 
A), em ambos os hemisférios, teriam sido ocasionadas pelo aumento do $\mathrm{CO}_{2}$ atmosférico (Liu et al., 2009). Outros indicam que, durante o ACR, houve diminuição da quantidade de $\mathrm{CO}_{2}$ lançado à atmosfera na região da Antártica (Ahn et al., 2004). Alguns atribuem essa transição climática ao pulso de degelo denominado Meltwater Pulse $1 \mathrm{~A}$ (mwp-1A), que teria ocorrido na região da Antártica em $\sim 14.600$ anos cal A.P. (Weaver et al., 2003; Rickaby e Elderfield, 2005; Liu et al., 2009). Outros, entretanto, indicam que o mwp-1A teria ocorrido em torno de 14.200 anos cal A.P. e que, portanto, não teria causado o início do ACR (B-A), mas sim o término do B-A no hemisfério norte (Fairbanks, 1989; Stanford et al., 2006; Leventer et al., 2006).

Durante este período, parece ter havido diminuição da temperatura e salinidade das águas superficiais atlânticas no NE e SE brasileiros, indicando maior transporte interhemisférico das massas de água (Arz et al., 1999; Weldeab et al., 2006); migração para norte da ZCIT, da ZCAS, fortalecimento dos Alíseos SE e enfraquecimento dos Alíseos NE (Peterson e Haug, 2006; Chiessi et al., 2009); modificação no gradiente de salinidade (densidade) entre a AIA e a APAN (Rickaby e Elderfield, 2005) e diminuição da produção da AIA no Pacífico sudeste e Atlântico sudoeste (Pahnke et al., 2008).

Durante a fase seguinte, denominada Younger Dryas (YD), entre aproximadamente 12.500 e 11.500 anos cal A.P. (Boyle e Keigwin, 1997; Came et al., 2003), a temperatura voltou a aumentar na região da Antártica (EPICA, 2004). Paralelamente, no hemisfério norte, padrão semelhante ao encontrado durante o HS1 ocorreu, com o derretimento de geleiras que dessalinizaram as águas do Atlântico Norte e ocasionaram um segundo enfraquecimento da AMOC e, consequentemente, menor transporte inter-hemisférico das massas de água atlânticas (Boyle e Keigwin, 1997; Came et al., 2003). Lea et al. (2003) sugeriram haver vínculo entre essas modificações e nova migração para sul da ZCIT, tal qual descrito anteriormente para o período do HS1.

No SE do Brasil, Came et al. (2003) detectaram maior influência de águas intermediárias do Atlântico Sul em detrimento da APAN. A precipitação no SE e no NE do Brasil deve ter permanecido mais intensa quando comparada à da época anterior (Behling et al., 2007; Jaeschke et al., 2007). E, no SE e NE brasileiros e no Atlântico tropical, houve acúmulo de calor e salinidade nas águas superficiais atlânticas (Arz et al., 1999; Rühlemann et al., 2004; Weldeab et al., 2006).

Durante a Oscilação Pré-Boreal, entre 11.400 e 11.270 anos cal A.P., o hemisfério norte sofreu pequeno resfriamento, que pode estar relacionado a uma descarga massiva do lago glacial Agassiz (Fisher et al., 2002; Kobashi et al., 2008). Na região antártica, essa época 
equivale ao início da deglaciação da porção leste do continente antártico que, de acordo com Leventer et al. (2006), durou entre 11.500 e 10.500 anos cal A.P. De acordo com esses autores e com Liu e Milliman (2004), essa também foi a fase do pulso de degelo denominado Meltwater pulse 1-B.

$\mathrm{Na}$ Antártica, um Ótimo Climático Holocênico foi encontrado entre 11.500 e 9.000 anos cal A.P. (Masson et al., 2000). Esses autores indicaram que a causa desse ótimo climático provavelmente inclui a redução do transporte de calor inter-hemisférico devido ao enfraquecimento da AMOC durante o final da deglaciação no hemisfério norte. Ljung e Björck (2007) indicaram que durante o ótimo climático na Antártica houve retração do mar de gelo e, concomitantemente, reposicionamento para sul dos Ventos de Oeste, aquecendo o Atlântico Sul superficial.

No NE do Brasil, Arz et al. (1999) encontraram valores de $\delta^{18} \mathrm{O}$ que, segundo esses autores, indicam aumento da temperatura e da salinidade superficiais atlânticas até $\sim 11.000$ anos cal A. P., e valores mais leves de $\delta^{18} \mathrm{O}$ em torno de 10.000 anos cal A.P. Weldeab et al. (2006) descreveram pico de pequeno aumento de temperatura superficial oceânica no NE do Brasil entre $\sim 10.800$ e $\sim 10.300$ anos cal A.P. Eles também indicaram que a salinidade superficial atlântica apresentou pico positivo nessa época, apesar de continuar diminuída em relação aos períodos anteriores. Já Carlson et al. (2008) detectaram diminuição de temperatura e leve aumento da salinidade na margem brasileira entre $\sim 12.000$ e $\sim 9.700$ anos cal A.P. Chiessi et al. (2008) detectaram diminuição da temperatura e da salinidade da região da termoclina permanente da margem sul brasileira entre $\sim 11.000$ e 10.300 anos cal A.P.

Unkel et al. (2008) encontraram clima mais quente e mais seco em torno de 10.600 anos cal A.P., concomitante ao Ótimo Climático Antártico, no sul da América do Sul. Houve elevação considerável do $\mathrm{CO}_{2}$ lançado na atmosfera na Antártica entre $\sim 12.000$ e $\sim 11.000$ anos cal A.P., que passou a manter valores mais elevados a partir de então.

De Oliveira (1992) e Ledru et al. (1996) descreveram alterações climáticas que migraram de mais úmidas a mais secas na região sudeste brasileira há $10.000{ }^{14} \mathrm{C}$ anos A.P. (entre 11.404 e 11.249 anos cal A.P.). Garcia et al. (2004) indicaram clima mais frio e mais úmido na faixa florestal da região costeira do estado de São Paulo entre 9.700 e $8.200{ }^{14} \mathrm{C}$ anos A.P. (entre $\sim 11.175$ e 9.900 anos cal A.P.) e clima mais quente entre 8.200 e $5.400{ }^{14} \mathrm{C}$ anos A. P. (9.900 e 6.000 anos cal A.P.). Coelho et al. (2002) indicaram clima mais úmido entre 6.300 e 4.650 anos A.P. na região de Guaratiba, RJ, e redução dessa umidade entre 4.650 e 1.350 anos A.P. Já Behling et al. (2004) descobriram clima mais quente e seco entre 
11.528 e 10.876 anos cal A.P. na região de São Francisco, RS. Esses autores descreveram condições mais úmidas a partir de 5.170 anos cal A.P. para esta região.

Cordeiro et al. (2008) encontraram duas fases secas no Holoceno da região de Carajás: a primeira entre 11.800 e 4.750 anos cal A.P., e a segunda entre 1.300 e 70 anos cal A.P. Já Stríkis et al. (2011) expuseram aumento da precipitação no estado de Minas Gerais centralizados há 9.200, 8.200, 7.400, 7.000, 6.600, 5.200, 4.000, 3.200, 2.700, 2.300, 2.200 e 1.900 anos A.P., com duração de 300 anos durante os Holocenos Inferior e Médio, e de 100 anos durante o Holoceno Superior. Segundo esses autores, esses eventos de precipitação ocorreram em antifase com a Monção Asiática.

Thornalley et al. (2009) detectaram dessalinização da termoclina nas altas latitudes do Atlântico Norte entre 9.000 e 8.000 anos cal A.P., vinculadas ao evento paleoclimático $8.2 \mathrm{ka}$ ocorrido na porção mais setentrional do hemisfério norte (Teller et al., 2002; Rohling e Pälike, 2005; Alley e Ágústsdóttir, 2005). Ljung e Biörck (2007) indicaram que houve mudança climática em torno de 8.600 anos cal A.P., com aumento da umidade devido ao reavanço do gelo antártico e reposicionamento para norte dos Ventos de Oeste, após o ótimo climático no polo sul. Na região costeira do SE do Brasil houve modificação climática em 8.400 anos cal A.P. vinculada à transgressão marinha (Sallun et al., 2012). A Monção de Verão da América do Sul se intensificou no Brasil entre 8.300 e 8.200 anos cal A.P. (Cheng et al., 2009). Masson et al. (2000) encontraram clima mais frio na Antártica a partir do final do ótimo climático antártico, com mínimo em $~ 8.000$ anos cal A.P. Já Cremer et al. (2007) encontraram melhora climática na costa leste da Antártica entre 8.600 e 8.200 anos cal A.P. que, segundo esses autores, pode estar vinculado ao evento $8.2 \mathrm{ka}$.

A partir do Holoceno Médio ( 8.200 a 4.200), a AMOC não apresentou mais oscilações de força significativas (e.g., Keigwin e Boyle, 2000; Schulz et al., 2007; Thornalley et al., 2009). A transgressão marinha na costa do Rio Grande do Sul se tornou mais rápida ( 1,9 cm/yr entre 8.000 e 6.500 anos cal A.P.) (Dillenburg e Hesp, 2009). A plataforma continental sul-brasileira não estava mais exposta entre 7.700 e 6.900 anos cal A.P. (Angulo et al., 2006). Os padrões climáticos foram se tornando cada vez mais semelhantes aos atuais, até os atingirem.

\subsection{Paleoníveis Marinhos dos últimos 19.000 anos: a Transgressão Santos}

A Transgressão Santos (ou Transgressão Flandriana) teve início ainda durante o Último Máximo Glacial (UMG), entre 21.227 e 20.488 anos cal A.P.(equivalentes há 
aproximadamente $17.500{ }^{14} \mathrm{C}$ anos A.P.) (Suguio e Martin, 1978a; Villwock et al., 1986). De acordo com Corrêa (1996), há aproximadamente 19.000 anos cal A.P., o nível do mar se encontrava $\sim 130 \mathrm{~m}$ abaixo do nível atual. Ainda de acordo com Corrêa (1996), durante a Transgressão Santos houve três episódios de estabilização do nível do mar: a primeira entre 60 e $-70 \mathrm{~m}$ (há $11.000{ }^{14} \mathrm{C}$ anos A.P., equivalentes a $\sim 12.600-11.400$ anos cal A.P.); a segunda entre -32 e $-45 \mathrm{~m}$ (há $9.000{ }^{14} \mathrm{C}$ anos A.P., equivalentes a $\sim 10.200-9.400$ anos cal A.P.); e a terceira entre -20 e $-25 \mathrm{~m}$ (há $8.000{ }^{14} \mathrm{C}$ anos A.P., equivalentes a 9.000-8.600 anos cal A.P.) (Corrêa, 1996).

Essa transgressão durou até, aproximadamente, $\sim 5.100-5.700$ anos cal A.P. (Suguio e Martin, 1978a; Angulo et al., 2006), quando o nível do mar atingiu entre $\sim 2$ e $\sim 5 \mathrm{~m}$ acima do nível atual do mar ao longo da costa brasileira (Dominguez et al., 1990; Angulo et al., 1999, 2006). Muitos são os trabalhos sobre o comportamento do nível relativo do mar ao longo da costa brasileira para o período dessa transgressão compreendido entre $\sim 7.800$ anos cal A.P. e o Presente (e.g., Suguio e Tessler, 1984; Suguio et al., 1985, 2001; Villwock et al. 1986; Dominguez et al., 1990; Angulo e Suguio, 1995; Martin et al., 1996, 1998, 2003; Tomazelli e Villwock 1996; Angulo et al., 1999, 2006; Tomazelli et al., 2000; Ybert et al., 2003; Caldas et al., 2006), mas poucos trabalhos versam sobre a fase compreendida entre o início do Holoceno ( 11.700 anos cal A.P.) e 7.800 anos cal A.P.

$\mathrm{Na}$ costa sul brasileira, a Transgressão Santos equivale ao Sistema de LagunasBarreiras Holocênicas, conhecidas por Sistema de Ilhas-Barreira/Lagunas IV, de Villwock et al. (1986) e Tomazelli e Villwock (1996). Suguio e Martin (1978a) propuseram que essa transgressão equivaleria à época entre o terceiro e o sexto estágios evolutivos geológicos da região do Mosaico da Juréia-Itatins, na região costeira sudeste brasileira.

De acordo com Dominguez (2011), a plataforma continental leste brasileira começou a ser inundada entre 10.000 e 9.000 anos cal A.P., após o período paleoclimático denominado Younger Dryas. Ainda de acordo com esse autor, em alguns locais da plataforma e da zona costeira leste brasileiras formaram-se bacias hidrográficas durante a fase de paleonível marinho mais baixo que o atual, o que rebaixou topograficamente essas regiões que, durante a Transgressão Santos, foram inundadas formando temporariamente baías.

Dominguez (2011) ainda argumentou que existem evidências da presença de estuários nos vales incisos escavados na plataforma leste brasileira que se estenderiam desde a quebra da plataforma/talude continental até a zona costeira atual, em $\sim 8.000$ anos cal A.P. Esse autor indicou que a geomorfologia costeira dessa época era diferenciada da atual, recortada por inúmeros estuários e baías, especialmente na porção inferior dos vales dos principais rios que 
deságuam atualmente na zona costeira. Sallun et al. (2012) indicaram que já em torno de 9.400 anos cal A.P., a região da baixada litorânea da Juréia havia sido alcançada por águas marinhas e formava ambiente lagunar com contribuições marinhas e continentais.

Corrêa (1996) apresentou uma curva de paleoníveis marinhos para a região costeira do Rio Grande do Sul que engloba uns últimos 32.000 anos A.P., que mais tarde foi compilada a outros indicadores de paleoníveis marinhos por Mahiques et al. (2010) (Fig. 2).
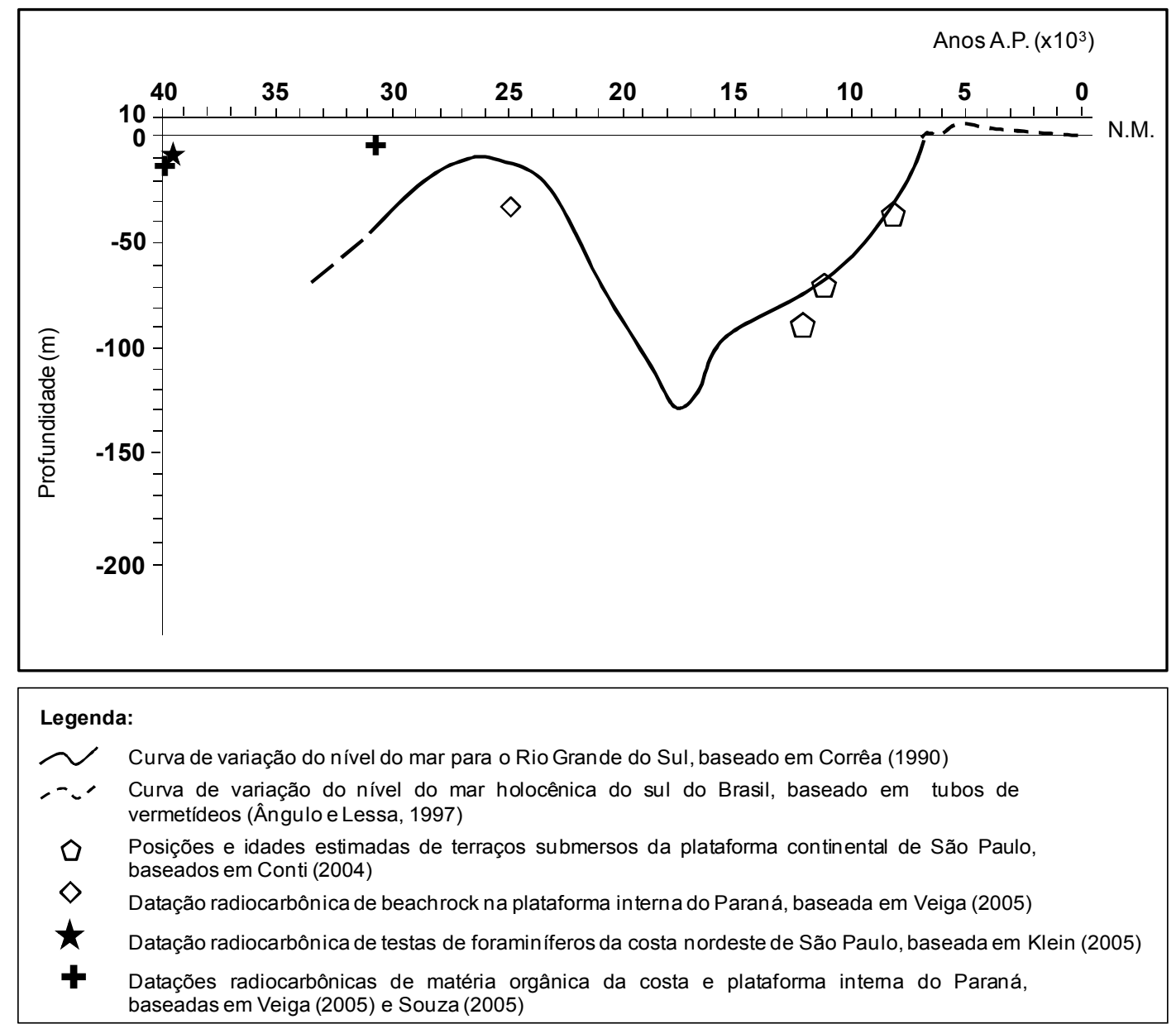

Figura 2: Compilação das curvas de paleoníveis marinhos disponíveis com dados isolados dos últimos 40.000 anos das regiões plataformal e costeira sudeste brasileiras. Retirado de Mahiques et al. (2010).

A curva mais completa da Transgressão Santos foi construída para o estado da Bahía (Dominguez et al., 1981). No final da década de 70, Martin et al. (1979/1980) publicaram a curva que se tornou referência para os estudos sobre paleoníveis marinhos da costa brasileira (Fig. 3). Esta curva, e as demais mais detalhadas existentes para esses paleoníveis marinhos, abrangem apenas os últimos 7.000 anos ( 6.900-7.700 anos cal A.P.), e ainda são fortemente debatidas por diversos autores (Angulo et al., 2006). 


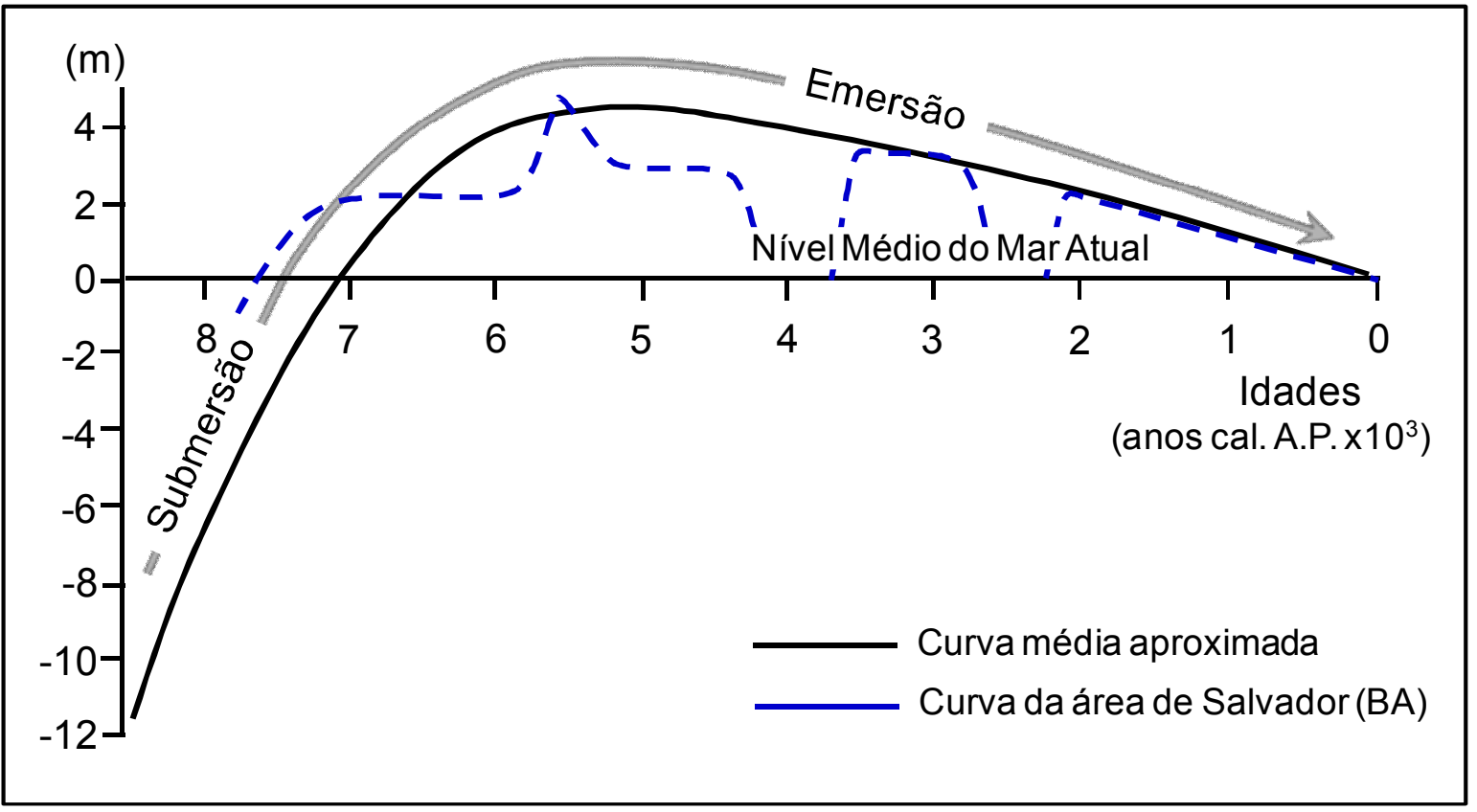

Figura 3: Modelo de variação do nível médio do mar nos últimos 8ka cal. A.P. Modificado de Martin et al. (2003) e Suguio et al. (2005).

\subsection{Foraminíferos: proxies paleoambientais marinhos}

Foramíníferos são microorganismos protozoários rizópodes que surgiram de um ancestral comum, denominado Cercozoa (Pawlowski et al., 2003). Eles pertencem ao Reino Protista, Filo Granuloreticulosa, Classe Foraminífera (Sen Gupta, 1999). Dividem-se em espécies bentônicas, que vivem sobre (espécies epifaunais) e/ou sob (espécies infaunais) o assoalho oceânico, e em espécies planctônicas, que vivem na coluna de água oceânica (Duleba et al., 2005).

Espécies bentônicas surgiram em torno de 550 milhões de anos (Langer, 1999) e se irradiaram adaptativamente, passando a habitar todas as zonas climáticas, em todos os ambientes estuarinos, lagunares e marinhos, e em todas as profundidades subaquáticas (Debenay et al., 1996). Já as formas planctônicas se originaram a partir das bentônicas, há aproximadamente 190 milhões de anos, tornando-se mais abundantes durante o Cretáceo (Hart et al., 2003; Duleba et al., 2005). Elas são exclusivamente marinhas, e necessitam de águas limpas e de profundidades suficientes para realizarem suas migrações verticais ontogenéticas (Duleba et al., 2005) (Fig. 4). 


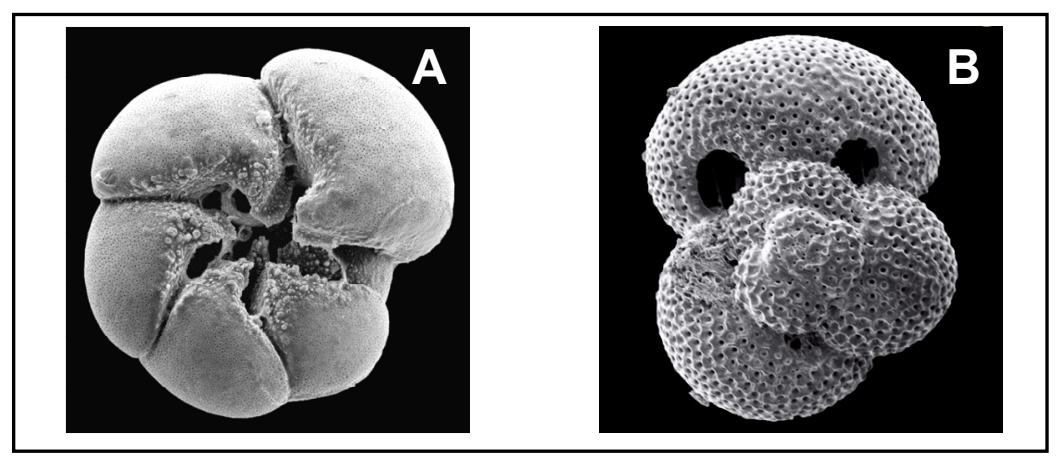

Figura 4: Espécies de foraminíferos bentônicos e planctônicos encontrados na margem continental brasileira. A: Ammonia tepida (espécie bentônica) B: Globigerinoides ruber (espécie planctônica).

Foraminíferos são importante componente da microfauna oceânica, e um dos indicadores mais utilizados de mudanças paleoceanográficas, devido à sua alta sensibilidade às mudanças ambientais, grande biodiversidade e alto potencial de fossilização (Murray, 1991; Boltovskoy et al., 1996; De e Gupta, 2010). Sua distribuição é controlada por diversos fatores ambientais, tais como tipo de subtrato, energia hidrodinâmica do meio, temperatura e salinidade das águas nas quais ou sob as quais vivem, profundidade da camada de mistura, concentração de nutrientes na coluna de água e no assoalho oceânico, quantidade e qualidade de matéria orgânica na superfície e no substrato oceânicos e grau de oxigenação do meio (e.g., Boersma, 1998; Sen Gupta, 1999; Murray, 2001).

Dentre as variáveis que influenciam a distribuição e ocorrência dos foraminíferos bentônicos, duas desempenham importante papel no seu padrão de distribuição em regiões oceânicas: o fluxo de matéria orgânica (alimento) para o assoalho oceânico e as concentrações de oxigênio nas águas de fundo e intersticiais (Sen Gupta et al., 1996; Den Dulk et al., 2000; Smart, 2008). As alterações das associações de foraminíferos bentônicos ligadas a esses fatores estão, por sua vez, relacionadas às características das massas de água que se movimentam pelo assoalho oceânico (Murgese e De Deckker, 2007; Smart et al., 2010; Kosh e Friedrish, 2012).

Estudos isotópicos $\left(\delta^{18} \mathrm{O}, \delta^{13} \mathrm{C}\right)$ e geoquímicos $(\mathrm{Mg} / \mathrm{Ca}, \mathrm{Sr} / \mathrm{Ca})$ em testas de foraminíferos planctônicos e bentônicos também fornecem dados acerca das variações das propriedades físico-químicas (temperatura, salinidade, concentração de oxigênio e carbono nas águas marinhas, paleoprodutividade) das águas oceânicas superficiais, intermediárias e de fundo (e.g.,Cléroux et al., 2008; Sato et al., 2008; Basak et al., 2009; Regenberg et al., 2009).

Além disso, estudos tafonômicos das associações bentônicas e/ou planctônicas permitem estabelecer criteriosamente se essas associações são condizentes com suas contrapartes pretéritas e, portanto, se as análises paleoecológicas obtidas por meio dessas associações são confiáveis (Berkeley et al., 2009). 


\section{CAPÍTULO 3: Objetivos}

\subsection{Objetivos gerais}

Esse trabalho tem por objetivo detectar mudanças paleoambientais, com ênfase em variações do nível do mar e modificações do comportamento oceânico, a partir de caracterizações das associações de foraminíferos bentônicos e de análise geoquímica da razão $\mathrm{Mg} / \mathrm{Ca}$ em testas da espécie planctônica Globigerinoides ruber (white) stricto sensu de duas áreas: a primeira situada na região costeira do Estado de São Paulo (Mosaico da Juréia-Itatins) e a segunda na margem continental do Estado do Rio Grande do Sul (Cone do Rio Grande).

Com a correlação entre os resultados microfaunísticos obtidos, os dados geoquímicos, sedimentológicos e isotópicos provenientes das mesmas amostras dos testemunhos, as curvas de variação do nível do mar da costa brasileira e os dados paleoclimatológicos existentes na literatura, esperou-se: i) identificar oscilações holocênicas dos paleoníveis marinhos na região do Mosaico Juréia-Itatins e, ii) determinar a evolução paleoambiental marinha de fundo da região do talude superior defronte ao estado do Rio Grande do Sul para o período paleoclimático conhecido como Heinrich Stadial 1, durante o Pleistoceno.

\subsection{Objetivos específicos}

- Analisar a resposta das associações de foraminíferos bentônicos presentes ao longo do testemunho S03, coletado no Mosaico Juréia Itatins (ambiente costeiro do Estado de São Paulo) às variações dos paleoníveis marinhos durante o Holoceno;

- Analisar a resposta das associações de foraminíferos bentônicos do testemunho GeoB6211-2, coletado no Cone do Rio Grande (talude superior defronte ao Estado do Rio Grande do Sul) às variações do comportamento oceânico ocorridas entre 19.000 e 14.000 anos cal A.P.;

- Determinar as variações das paleotemperaturas superficiais marinhas baseadas em razões de magnésio e cálcio $(\mathrm{Mg} / \mathrm{Ca})$ e das paleossalinidades superficiais marinhas baseadas em isótopos de oxigênio $\left(\delta^{18} \mathrm{O}_{\mathrm{ivc}-\mathrm{sw}}\right)$ em testas da espécie planctônica rasa Globigerinoides ruber (white, strictu sensu), correlacionando-as com eventos paleoclimático-paleoceanográficos de âmbito regional e/ou global reconhecidos na literatura; 
- Verificar se há conexão e/ou similaridades entre as variações paleoambientais de fundo e as modificações de paleotemperaturas e paleossalinidades superficiais da região do Cone do Rio Grande entre 19.000 e 14.000 anos cal A.P.;

- Associar as possíveis mudanças paleoclimáticas indicadas pelas associações microfaunísticas aos eventos paleoambientais reconhecidos em âmbito mundial e/ou regional (e.g., Eventos 8.2K, Heinrich Stadial 1, modificações climáticoambientais brasileiras) ocorridos durante os últimos 19.000 anos.

\subsection{Justificativa}

Os modelos evolutivos das variações climáticas, ambientais e, principalmente, das oscilações do nível do mar nas regiões sul e sudeste da costa brasileira, resultantes dos diversos estudos realizados sobre o tema, apresentam, ainda, lacunas e aspectos pouco compreendidos que se devem não apenas às distintas características geográficas, geológicas e ambientais dessas áreas como, também, a divergências nos métodos, nas interpretações e nos proxies utilizados nessas pesquisas, bem como à escassez de dados pertinentes ao tema (Angulo et al., 2006; Sallun et al., 2012).

Em estudos sobre variações do nível do mar na região costeira brasileira, muitos são os trabalhos que versam sobre o comportamento dos paleoníveis relativos do mar para o período compreendido entre $\sim 7.800$ anos cal A.P. e o Presente, mas poucos trabalhos analisam a fase compreendida entre o início do Holoceno ( 11.700 anos cal A.P.) e 7.800 anos cal A.P. (Mahiques et al., 2010). E, mesmo para os últimos 7.800 anos cal A.P., há ainda aspectos da Transgressão Santos que são controvertidos (Angulo et al., 2006).

No tocante às variações climático-oceânico-ambientais, principalmente aquelas que ocorreram nos últimos 19.000 anos, são muitos os dados existentes para o hemisfério norte, oposto ao que ocorre no hemisfério sul na região da América do Sul e, mais especificamente, na margem atlântica sul do Brasil, onde há pouca documentação que vincule os estados climático-oceânico-ambientais reconhecidos principalmente na Europa e na América do Norte aos acontecimentos que aqui se sucederam (Bard et al., 2000).

Por esses motivos, o presente trabalho pretende contribuir para sanar algumas das dúvidas ainda persistentes para as evoluções das regiões costeira e de talude superior das margens sudeste e sul brasileiras (e.g., o comportamento do nível do mar anteriormente a 7.800 anos cal A.P. na região costeira sudeste brasileira e a correlação do comportamento marinho das margens sudeste sul brasileiras com as modificações climático-ambientais 
registradas na literatura para os últimos 19.000 anos cal A.P.), colaborando para o avanço do conhecimento acerca do comportamento dessas regiões e possibilitando não apenas a correlação com eventos paleoclimáticos mundiais e/ou regionais como, também, a previsão de eventos futuros para essas áreas, que estão cada vez mais sendo utilizadas e ocupadas pelo homem. 


\section{CAPÍTULO 4: Organização da Tese}

Os argumentos desta tese dividem-se em três estudos diferenciados.

O primeiro versa sobre as variações relativas do nível do mar durante parte do Holoceno Inferior (entre 9.400 e 8.385 anos cal A.P.), em região costeira na margem sudeste brasileira (Testemunho S03).

O segundo trata de variações paleoclimáticas e paleoceanográficas de ordem regional e mundial durante o período do Heinrich Stadial 1 (HS1) e da transição entre este período e a Reversão Fria Antártica (ACR) (Entre 19.000 e 14.000 anos cal A.P.), em região marinha de talude superior na margem sul brasileira (Testemunho GeoB6211-2).

O terceiro aborda as variações de temperatura e salinidades superficiais marinhas da região de coleta do testemunho GeoB6211-2, no talude superior da margem sul brasileira, para os últimos 19.000 anos cal A.P. Aborda, portanto, tanto o período da Última Deglaciação, quanto o Holoceno.

A organização destes três assuntos no corpo da tese foi efetuada da seguinte maneira:

Primeiro, procurou-se descrever detalhadamente as duas diferentes regiões de estudo (CAPÍTULO 5): o Mosaico da Juréia-Itatins, no Estado de São Paulo, margem sudeste brasileira; e as regiões marinha e continental adjacente onde se localiza o Cone do Rio Grande, na margem sul brasileira.

Em seguida, expô-se uma descrição detalhada das metodologias empregadas para as análises realizadas nos dois testemunhos (CAPÍTULO 6).

No CAPÍTULO 7, os resultados foram descritos separadamente, por testemunho.

A discussão dos resultados encontrados (CAPÍTULO 8) foi dividida em três diferentes seções: as duas primeiras referem-se aos resultados dos dois diferentes testemunhos analisados (S03 e GeoB6211-2). A terceira integra todos os dados dos dois testemunhos, fornecendo uma abordagem que vincula as evoluções paleoambientais das regiões sul e sudeste brasileiras nos últimos 19.000 anos cal A.P.

Por fim, o CAPÍTULO 9 engloba tanto as conclusões alcançadas para cada um dos três estudos efetuados, quanto aquelas que descrevem o quadro geral paleoclimático e paleoceanográfico para as regiões sudeste e sul brasileiras nos últimos 19.000 anos cal A.P. 


\section{CAPÍTULO 5: Área de Estudos}

\subsection{Aspectos Geológicos das Áreas de Estudo}

\subsubsection{Mosaico da Juréia-Itatins}

O Mosaico da Juréia-Itatins (MJ), até há pouco tempo denominado "Estação Ecológica Juréia-Itatins", situa-se ao norte da Planície Cananéia-Iguape, no sudeste do estado de São Paulo (SP). Ela está inserida nos municípios de Peruíbe (região metropolitana da Baixada Santista), Iguape, Itariri e Miracatu (Vale do Ribeira) (Fig. 5). O MJI possui área superior a $600 \mathrm{~km}^{2}$, dos quais mais de $100 \mathrm{~km}^{2}$ são constituídos pelo domínio montanhoso, e os outros $500 \mathrm{~km}^{2}$, pela planície costeira.

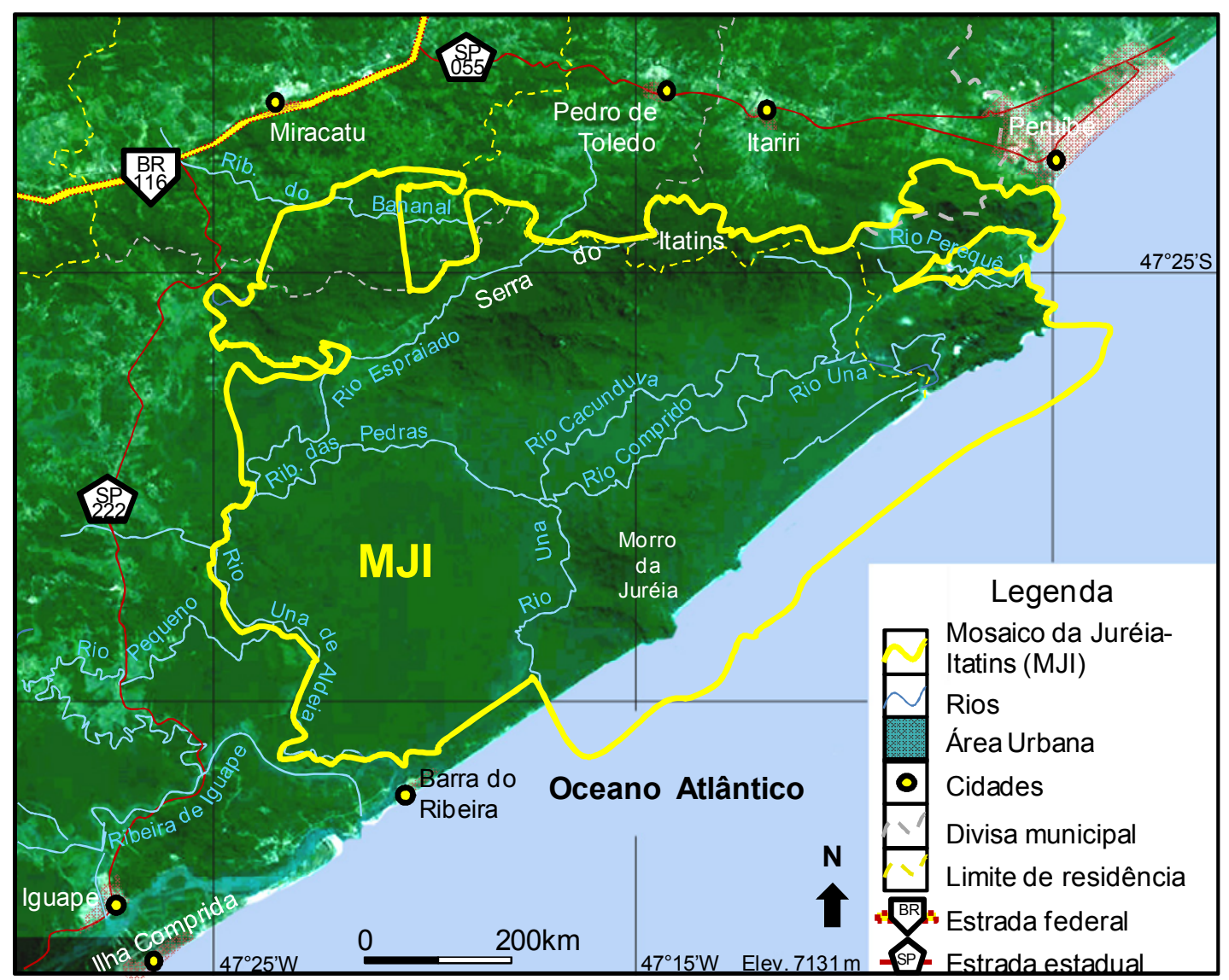

Figura 5: Limites do Mosaico da Juréia-Itatins (MJI) no Estado de São Paulo, conforme nova proposta da Secretaria do Meio Ambiente (05/06/2006), e principais vias de acesso, com destaque para o Morro da Juréia, Serra de Itatins, e principais cursos de água da região. Modificado de Suguio (2006).

O domínio montanhoso do MJI corresponde às serras de Itatins, Peruíbe e Bananal, e por unidades isoladas, como os morros da Juréia, Maceno-Itu e Grajaúna (Souza e Souza, 2004). Esse domínio montanhoso corresponde à porção meridional da Serrania de Itatins, que 
integra regionalmente o conjunto orográfico da Serra do Mar (FIBGE, 1993). Ela é formada por um bloco rochoso de direção E-W, limitado ao norte pela Falha de Cubatão e, a nordeste, pela Falha de Itariri (Sadowski, 1974). É composta por rochas graníticas e metamórficas de médio (gnaisses e migmatitos) a alto (granulitos) graus. Teve sua origem no Proterozóico inferior $(\sim 2.1 \mathrm{Ba})$ e, posteriormente, foi atingida pelas orogenias Brasiliana (650 Ma) e Rio Doce (450 Ma) (Campos Neto, 1991). Diques de diabásio ocorrem cortando as rochas précambrianas e se associam à ruptura do Gondwana no Mesozóico (Gimenez Filho et al., 1987).

Segundo Suguio (2004), a planície costeira se divide em duas áreas: uma de, aproximadamente, $200 \mathrm{~km}^{2}$, formada por paleocordões arenosos, e outra, de aproximadamente $300 \mathrm{~km}^{2}$, ocupada por depósitos paleolagunares. Atualmente, os depósitos paleolagunares têm sua área drenada pelos rios Cacunduva e Comprido, que formam o Rio Una de Aldeia que, por sua vez, deságua no Oceano Atlântico a NE da área e, também, pelo Rio das Pedras, que flui para WSW e desemboca no Rio Ribeira de Iguape.

Seu registro sedimentar mais antigo é a Formação Pariquera-Açu, que é composta por sedimentos continentais fluviais de planície de inundação e de terraços de cascalheiras associados (Bigarella e Mousinho, 1965). Sua idade é controversa, entre Pliocênica (Sundaram e Suguio, 1985) e Miocênica (Melo, 1990). Na área do MJI, esta Formação ocorre apenas em subsuperfície (Servant-Vildare e Suguio, 1990). As sequências sedimentares aflorantes no MJI têm idade Pleistocênica Superior a Holocênica (Suguio e Martin, 1978a) e foram depositadas sob a influência de episódios tectônicos, variações climáticas e principalmente variações eustáticas do nível do mar durante a Transgressão Cananéia e a Transgressão Santos (Suguio e Martin, 1978a, 1994; Souza e Souza, 2004). São elas:

- Formação Cananéia, de idade Pleistocênica superior, depositada durante o evento transgressivo-regressivo denominado Transgressão Cananéia (sedimentos arenosos e lamosos de baía e praia, areias praiais e de dunas eólicas).

- Formação Ilha Comprida, de idade Holocênica, depositada no evento transgressivo-regressivo posterior, denominado Transgressão Santos (depósitos marinhos praiais, fluviais, lagunares, lacustres e eólicos arenosos e lamosos).

- Depósitos continentais (depósitos de encosta, dos colúvios das baixadas ou fluviais de retrabalhamento dos sedimentos das formações Pariquera-Açu, Cananéia e Ilha Comprida). 
Vários sambaquis de substratos compostos principalmente pela Formação Cananéia (Pleistocênica) ocorrem nas margens e nas proximidades dos rios que fluem pela Planície Costeira, e alguns deles parecem estar sobre depósitos holocênicos de paleopraias e paleolagunas. De acordo com as posições geográficas que esses sambaquis ocupam, bem como por suas idades, eles parecem vincular-se à evolução geológica holocênica da paleolaguna (Suguio et al., 1992).

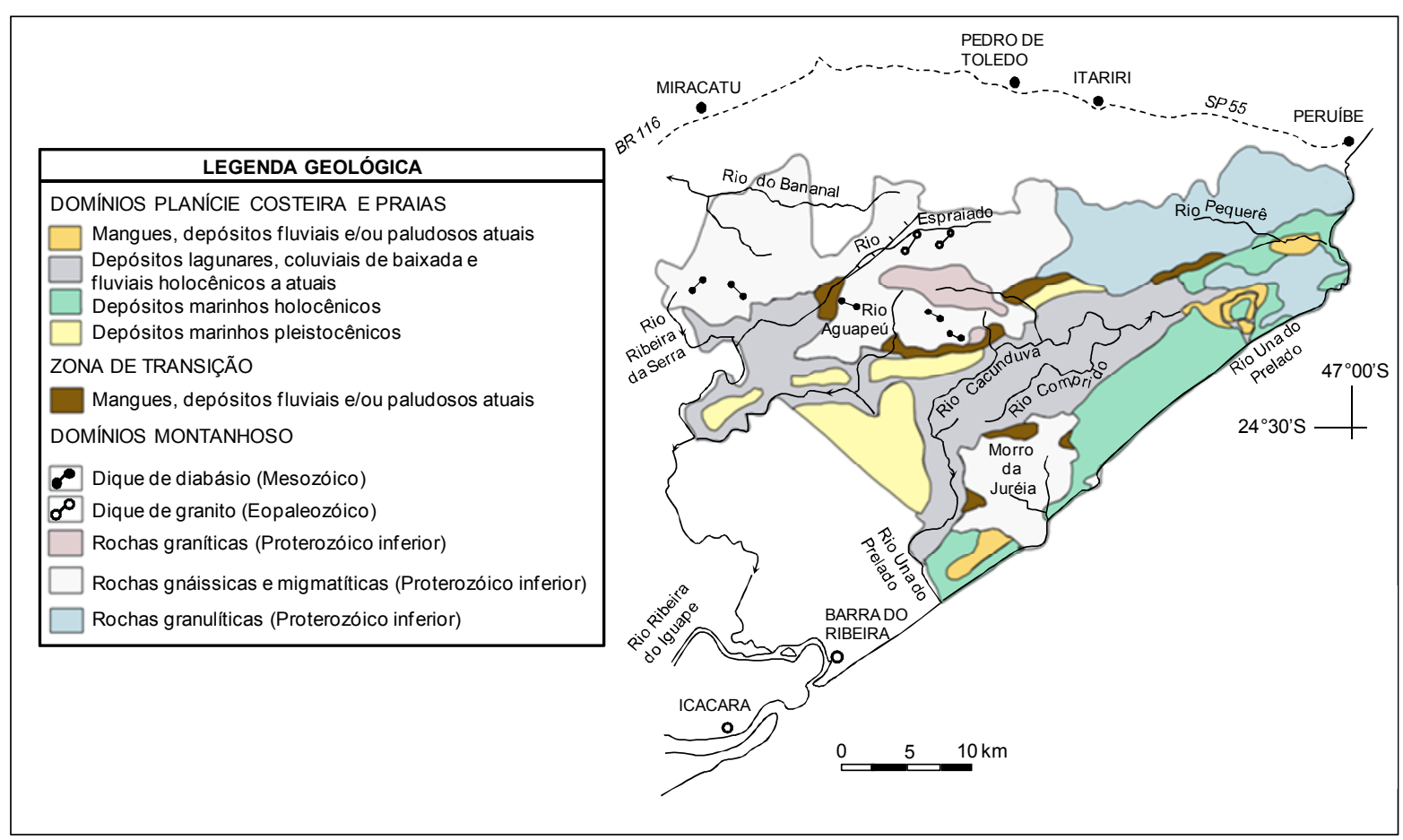

Figura 6: Mapa geológico do Mosaico da Juréia-Itatins. Retirado de Souza e Souza (2004).

Suguio e Martin (1978a) propuseram modelo evolutivo para a região do MJI composto de seis estágios evolutivos (Fig. 7). Segundo esses autores, no primeiro estágio, durante a Transgressão Cananéia $\left(\sim 120.000{ }^{14} \mathrm{C}\right.$ anos A.P.) (Suguio e Martin, 1978a; Bittencourt et al., 1979; Villwock et al., 1986), o mar invadiu a região do MJI até o sopé da Serra do Mar e formou uma baía que recobriu a Formação Pariquera-Açu com areias e lamas arenosas transicionais a marinhas da Formação Cananéia (Suguio e Martin, 1978a; Martin et al., 1996). A seguir, no segundo estágio, depósitos de cristas praiais (cordões arenosos litorâneos) foram depositados pelo mar regressivo, que acompanhou a implantação do último episódio glacial do hemisfério norte (Última Glaciação).

No terceiro estágio, há aproximadamente $17.500{ }^{14} \mathrm{C}$ anos A.P. (21.227-20.448 anos cal A.P.), o nível do mar se encontrava entre 120 e 130m abaixo do nível marinho atual (Suguio e Martin, 1978a; Corrêa, 1996; Lambeck e Chappell, 2001), quando a rede de drenagem que se estabeleceu sobre a planície costeira erodiu parcialmente as formações 
Pariquera-Açu e Cananéia (Suguio e Martin, 1978a). Em seguida, no quarto estágio, iniciouse a Transgressão Santos, que promoveu a penetração de águas marinhas até o sopé da Serra do Mar em muitos pontos do MJI (Suguio e Martin, 1978a). Em sua fase culminante, essa transgressão formou uma baía na área do MJI, onde ocorreu a proliferação de moluscos, conforme atestam os frequentes sambaquis que comprovam a ocupação humana pré-histórica na região (Suguio e Martin, 1978a; Martin et al., 1996) (Fig. 7).

Há cerca de $5.150{ }^{14} \mathrm{C}$ anos A.P. (5.912-5.750 anos cal A.P.), durante o quinto estágio, a conexão entre a baía e o oceano aberto foi interrompida pelo início da formação de uma ilha-barreira, que originou amplas lagunas na região, cujos sedimentos retrabalhados recobriram parcialmente a Formação Cananéia, dando origem à Formação Ilha Comprida (Suguio e Martin, 1994, 1978a). Essa laguna foi se desconectando gradualmente do oceano aberto à medida que o nível relativo do mar foi alcançando o seu nível atual, com a formação consequente de linhas de praia regressivas de várias gerações e da dessalinização das águas do sistema lagunar até então existente, durante o sexto estágio (Suguio e Martin, 1978a) (Fig.7). Atualmente, a região dos sedimentos paleolagunares do MJI é drenada principalmente pelos rios Comprido e Cacunduva, que formam o rio Una do Prelado, que fluem para o Oceano Atlântico (Duleba e Debenay, 2003; Sallun et al., 2012).

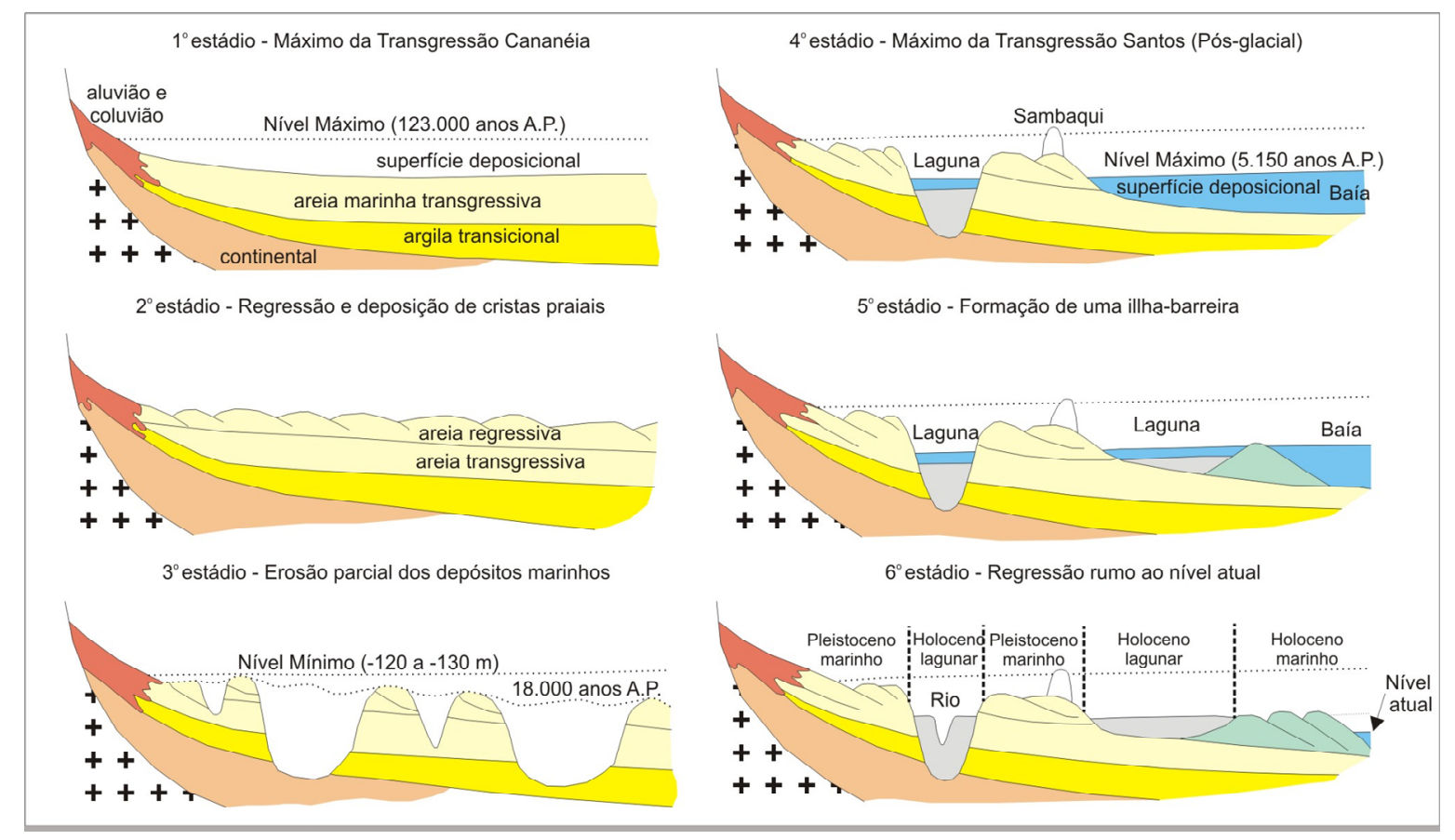

Figura 7: Estágios da evolução geológica entre o Pleistoceno Superior e o Holoceno da região circundante ao Morro da Juréia. Retirado de Suguio (2004). 


\subsubsection{Cone do Rio Grande e Região Continental Adjacente}

A área da Plataforma Continental defronte ao estado do Rio Grande do Sul (Fig. 8) apresenta largura média de $125 \mathrm{~km}$, com terraços continentais que possuem mergulho que diminui gradativamente, representando marcante progradação deltaica. O relevo é suave e monótono, com contornos batimétricos que acompanham a morfologia costeira, sem formas topográficas de grande amplitude e com quebra de plataforma/talude geralmente transicional, sem muitos canyons (Coutinho, 1996; Vital et al., 2005; Castro et al., 2006).

Exceção à monotonia do relevo é a feição conhecida como Cone do Rio Grande (Fig. 8), que se desenvolve desde a borda da plataforma até $4.000 \mathrm{~m}$ de profundidade e apresenta declividade suave (1:800). No flanco sul dessa feição há o Vale do Rio Grande, canyon que se estende desde a plataforma externa até o sopé continental. O talude continental se estreita entre o Alto de Torres e o Cone do Rio Grande, apresentando nessa região larguras médias de $40 \mathrm{Km}$, onde se tornam comuns vales e canyons. (Coutinho, 1996; Vital et al., 2005; Castro et al., 2006).

O Cone do Rio Grande (CRG) é uma proeminente feição sedimentar submarina semicircular situada aproximadamente entre as latitudes $31^{\circ}$ a $34^{\circ} \mathrm{S}$ e as longitudes $45^{\circ}$ a $51^{\circ} \mathrm{W}$. Ele se alonga para leste, abrange o talude, a elevação continental e a bacia oceânica e tem largura máxima situada entre 350 e 400 km (Martins, 1984; Gonçalves e Dehnhardt, 1999). Sua deposição tem idade quaternária, com provável início entre o Mioceno Superior e o Plioceno Inferior e duração até o Pleistoceno/Holoceno (Alves, 1977). É formado predominantemente por sedimentos lamosos provenientes do planalto e do cráton brasileiros que apresentam progradações e retrogradações, além de períodos de não-deposição (Martins et al., 1972; Martins, 1984; Castilho et al., 2009).

$\mathrm{O}$ clima, aliado à relativa baixa produtividade e ao marcante aporte terrígeno desse setor da margem brasileira, condicionam sedimentos pobres em carbonato. O mapa textural dessa região apresenta oito províncias texturais, dominadas por sedimentos terrígenos, que variam de areia (média a fina) a argila síltica (Vital et al., 2005). Essas províncias são representadas principalmente por sedimentos relíquias.

Recentemente, o aporte de sedimentos modernos na plataforma e no talude é escasso, pois sistemas de lagoas costeiras e lagunas na planície costeira retêm a maioria dos sedimentos transportados pelos rios (Vital et al., 2005). 

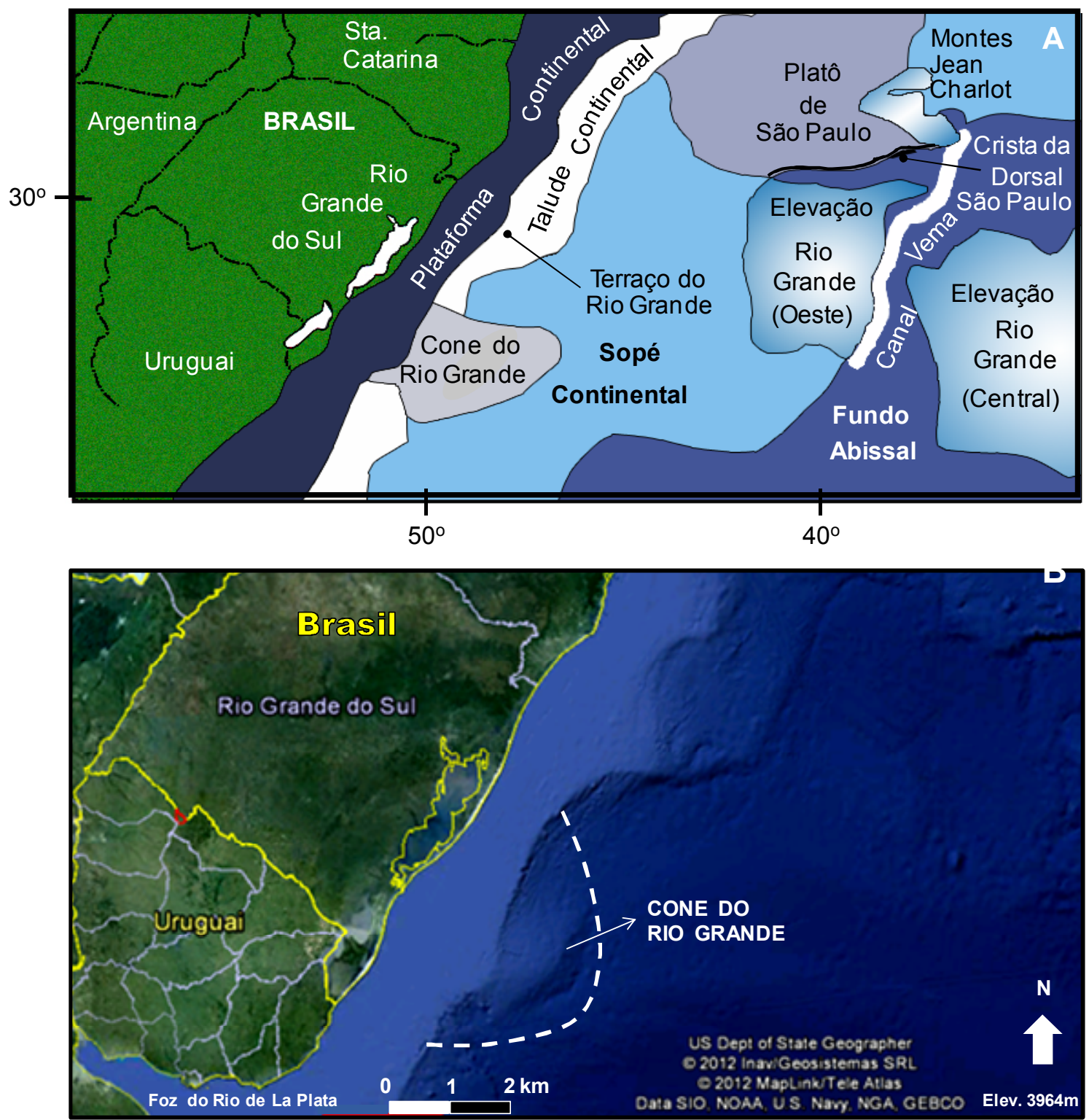

Figura 8: A. Fisiografia do fundo marinho na região do Rio Grande do Sul. Modificada de Tessler e Mahiques (2000). B. Imagem do Cone do Rio Grande com sua localização em relação ao Rio Grande do Sul e à foz do Rio de La Plata. Retirado de Google Earth.

Como os sedimentos que formam o Cone do Rio Grande são provenientes da região continental sul-americana, sua composição sedimentar e geoquímica está vinculada à evolução geológica desses terrenos emersos adjacentes, especialmente daqueles do Estado do Rio Grande do Sul e dos que alimentam a Bacia do Rio de La Plata. Esses sedimentos são provenientes das rochas do escudo Pré-Cambriano; da Bacia do Paraná e da drenagem platina dessas regiões continentais (Martins, 1984).

O escudo Pré-Cambriano forma o embasamento do Estado do Rio Grande do Sul. Este escudo, denominado Escudo Sul-Riograndense, é constituído por rochas ígneas, metamórficas e sedimentares pré-paleozóicas. Ele é parte da Província Mantiqueira, cuja gênese se vincula 
aos ciclos Transamazônico (Paleoproterozóico) e Brasiliano (Neoproterozóico) (Almeida et al., 1981; Tomazelli et al., 2000; CPRM, 2006). Encimando-o, estão as sequências sedimentares e vulcanogênicas, pós-orogênicas, da Bacia Camacuã (CPRM, 2006) (Fig. 8).

A Bacia do Paraná (Villwock, 1984; Milani, 1997; Milani et al., 2007) teve sua evolução estratigráfica dividida em seis Supersequências, cada uma envelopada por superfícies de discordância de caráter interregional. (Milani, 1997; Milani et al., 2007). Milani (1997) indica que a evolução tectono-estratigráfica dessa bacia se relaciona a quatro orogenias pré-andinas, que afetaram a borda oeste da Plataforma Sul-Americana.

Segundo Milani et al. (2007), as três primeiras supersequências são formadas por sequências sedimentares que representam ciclos transgressivos-regressivos correlacionados às oscilações do nível do mar durante o Paleozóico:

- Supersequência Rio Avaí, de idade Ordoviciana a Siluriana (diamictitos glaciogênicos, folhelhos micáceos lacustres e arenitos de granulação fina);

- Supersequência Paraná, de idade Devoniana (arenitos ricos em caolinita de granulação grossa lacustres, siltitos e arenitos deltaicos);

- Supersequência Gondwana I, de idade Carbonífera a Permiana (Diamictitos, arenitos, folhelhos, siltitos, ritmitos e conglomerados glaciogênicos; arcósios, siltitos, arenitos, folhelhos, calcários, margas e conglomerados marinhos; arenitos turbidíticos; pelitos e arenitos lacustres; siltitos e arenitos deltaicos, eólicos e fluviais).

As outras três supersequências foram formadas por sedimentação continental, com rochas ígneas associadas, segundo esses mesmos autores (Milani et al., 2007).

- Supersequência Gondwana II, de idade Triássica (arenitos, conglomerados, brechas, siltitos e folhelhos lacustres e fluviais);

- Supersequência Gondwana III, de idade Neojurássica a Eocretácea (arenitos continentais eólicos recobertos por extensos derrames basálticos);

- Supersequência Bauru, de idade Neocretácea (conglomerados e arenitos fluviais, eólicos e aluviais).

Atualmente, a Supersequência Gondwana III é a principal supridora de sedimentos à porção mais ao sul da bacia de drenagem do Rio de La Plata, uma das principais fontes de sedimento para a região do Cone do Rio Grande (Schobbenhaus et al., 1981; Milani e Tomaz Filho, 2000). Já a Supersequência Bauru é a principal supridora de sedimentos para a porção mais nordeste da Bacia do Rio de La Plata (Fig. 9). 
Sobrepondo as supersequências da Bacia do Paraná, existem depósitos sedimentares cenozoicos de margem passiva da Bacia de Pelotas (arenitos, conglomerados, diamictitos, lamitos, cascalhos, areias e argilas depositados nas sequências de ilhas-barreira pleistocências a holocênicas de Tomazelli e Villwock, 1996), e depósitos colúvio-aluviais recentes (conglomerados, arenitos, siltitos e lamitos) (Fig. 9).

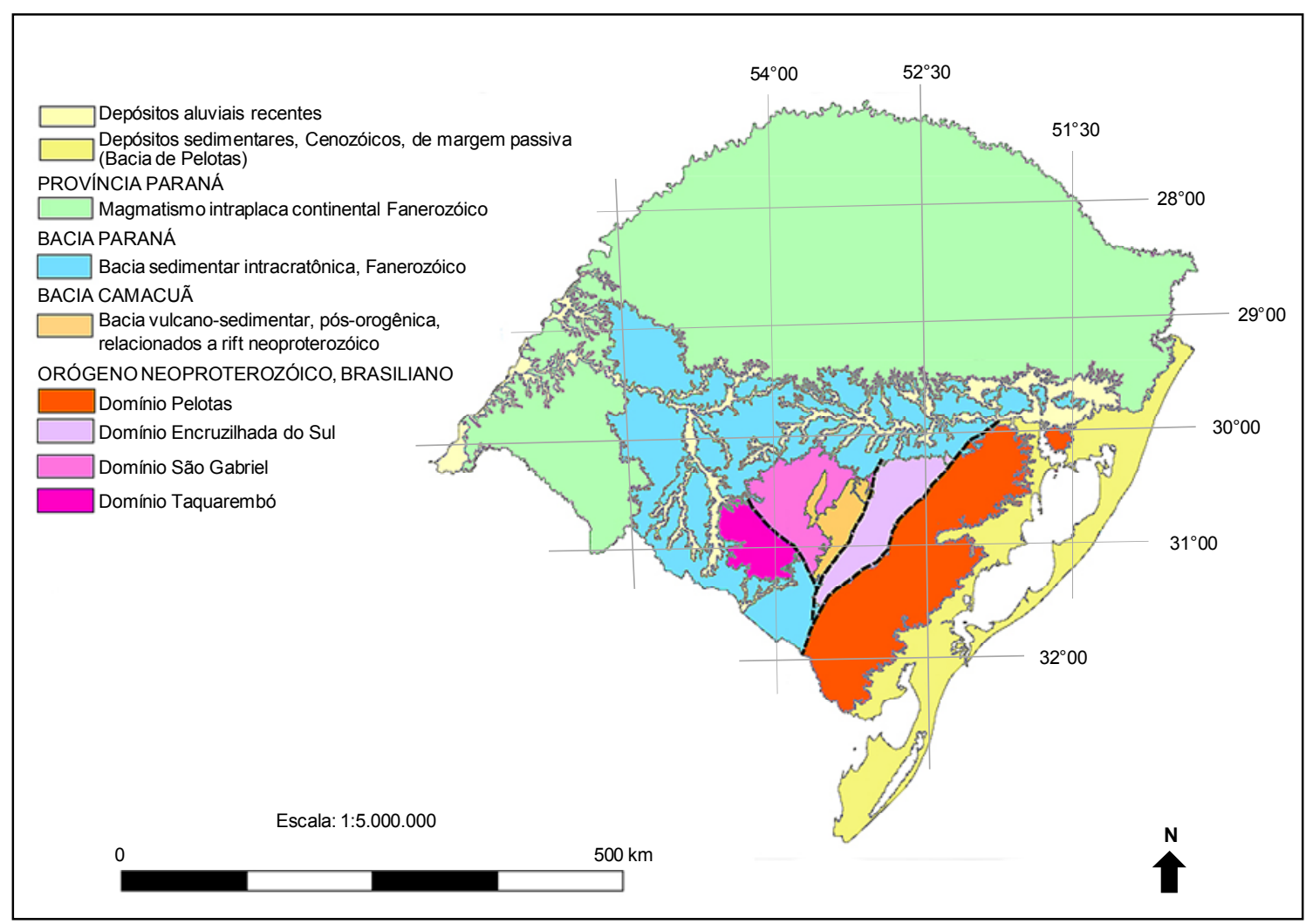

Figura 9: Mapa de domínios tectônicos do Estado do Rio Grande do Sul. Retirado de CPRM (2006).

Tomazelli e Villwock (1996) e Tomazelli et al. (2000) estudaram a evolução da formação dos Sistemas de Ilhas Barreiras/Lagunas que formam a Bacia de Pelotas (Fig. 10). Segundo esses autores, esses Sistemas foram depositados sob a influência de episódios transgressivo-regressivos do nível do mar entre o Pleistoceno e o Holoceno ocorridos na região do Rio Grande do Sul. Compreendem sequências sedimentares transgressivas e regressivas depositadas em ambientes de planícies lagunares de retrobarreiras, compostas por grãos geralmente mal selecionados; e em ambientes de barreiras, compostas por grãos geralmente bem selecionados (Tomazelli et al., 2000).

O Sistema de Ilhas-Barreira/Lagunas I foi produto do primeiro evento local reconhecido de transgressão-regressão marinha. É composto por conglomerados, diamictitos, arenitos conglomeráticos, areias, areias síltico-argilosas e lamitos. O Sistema de IlhasBarreira/Lagunas II foi formado durante o segundo episódio regressivo-transgressivo local, e 
compreende areias síltico-argilosas mal selecionadas e areias quartzosas bem selecionadas. $\mathrm{O}$ Sistema de Ilhas-Barreira/Lagunas III é o mais bem conservado deste período, e foi o responsável pela formação final das lagoas Patos e Mirim, hoje existentes na região costeira do Rio Grande do Sul. Ele é formado por areias quartzosas bem selecionadas e por areias síltico-argilosas, mal selecionadas (Tomazelli et al., 2000; CPRM, 2006) (Fig. 10).

O Sistema de Ilhas-Barreira/Lagunas IV é holocênico e se formou durante a Transgresão Santos. Ele é constituído por areias quartzosas praiais finas a muito finas e com altas concentrações de minerais pesados, e por campo de dunas arenosas que tem entre 2 e 8 $\mathrm{km}$ de largura. É também composto por complexo sistema deposicional lagunar que se estende entre a Barreia IV e o continente (Sistema de Ilhas-Barreira/Lagunas III, pleistocênico), no qual se depositaram turfas, areias síltico-argilosas e quartzosas lagunares, areias quartzosas fluvio-lagunares; areias síltico-argilosas, siltes e argilas deltaicos, areias, cascalhos e siltitos aluviais e cascalhos, areias e argilas colúvio-aluviais (Tomazelli et al., 2000; CPRM, 2006).

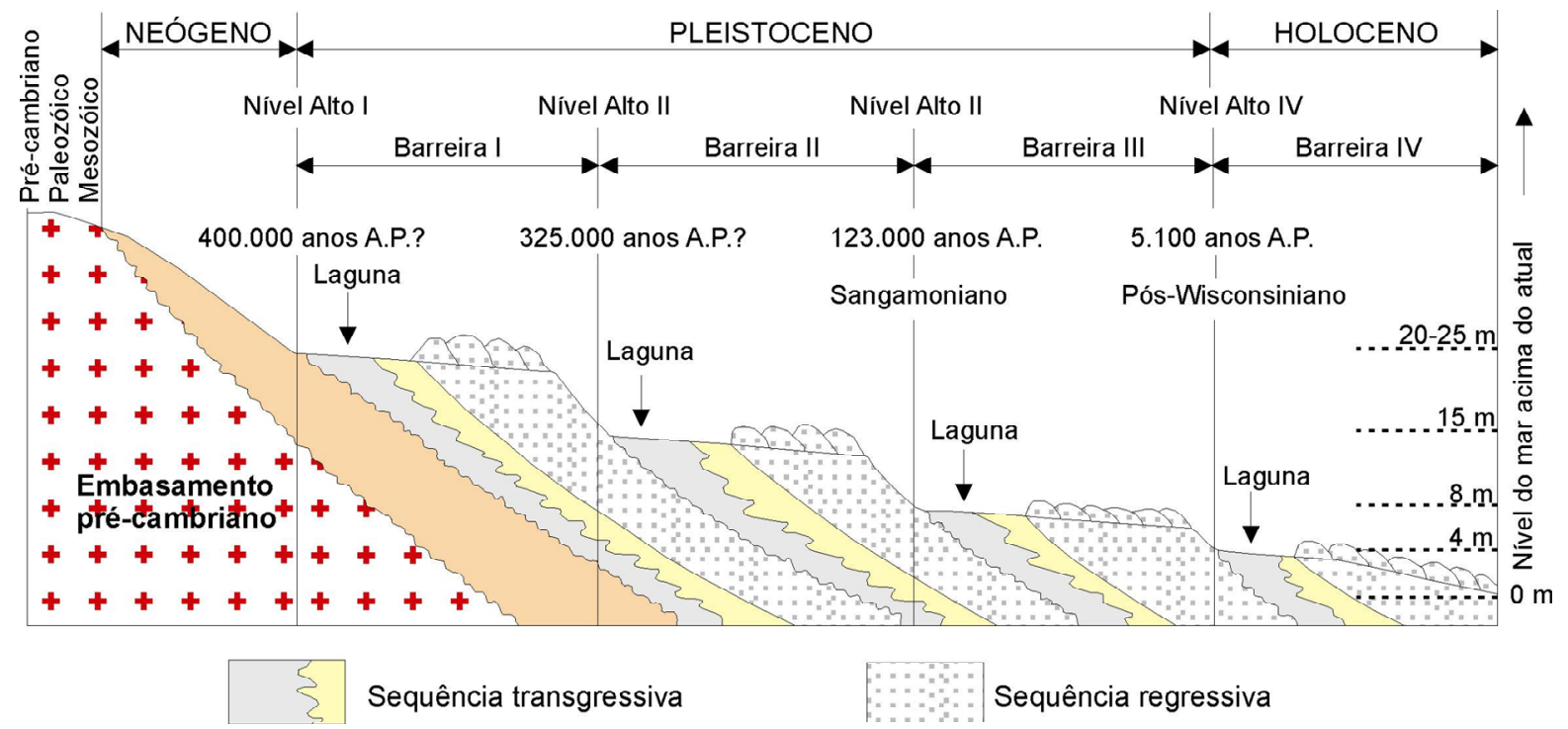

Figura 10: Perfil esquemático transversal aos sistemas de ilha barreira/lagunas do Estado do Rio Grande do Sul. Retirado de Tomazelli et al., (2000).

\subsection{Aspectos Climatológicos das Áreas de Estudo}

Os componentes da circulação atmosférica em larga escala sobre a América do Sul compreendem os Ventos Alíseos de NE e de SE; a região de baixa pressão atmosférica equatorial, que é comumente denominada Zona de Convergência Intertropical (ZCIT); a zona de alta pressão subtropical, que se constitui de células anticiclônicas de alta pressão (e.g., 
Anticiclone Subtropical do Atlântico Sul; Anticiclone Polar Migratório); os Ventos de Oeste; e a baixa subpolar, que forma uma zona contínua de baixa pressão no hemisfério sul entre as latitudes $50^{\circ}$ e $70^{\circ} \mathrm{S}$ (Lutgens e Tarbuck, 2001; Pidwirny, 2006) (Fig. 11).

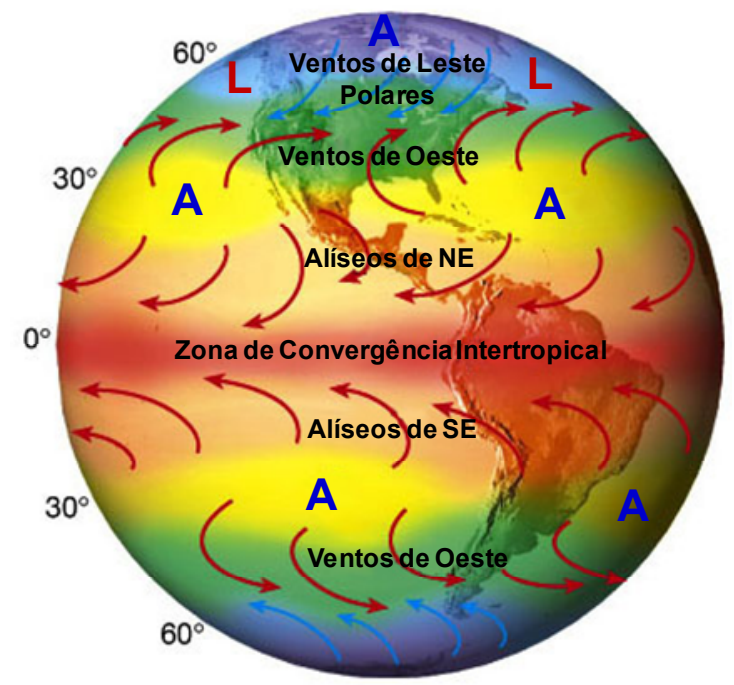

Figura 11: Circulação atual atmosférica com padrões reais de ventos devido à distribuição de massas de terra. Retirado de Lutgens e Tarbuck (2001).

Os climas e regimes chuvosos das regiões sudeste e sul brasileiras, bem como de toda a América do Sul, são controlados pelo Anticiclone Tropical do Atlântico Sul (ATAS), centro de alta pressão que origina os ventos alíseos e está correlacionado à Massa Tropical Atlântica (Ta); pelos Anticiclones Polares Migratórios (APM), centros de alta pressão que estão vinculados à Massa Polar Atlântica $(\mathrm{Pa})$; pelas massas de ar continentais (Tropical continental, Tc, também conhecida como Baixo do Chaco; e Equatorial continental, Ec); pela massa de ar marítima Equatorial atlântica (Ea, ou Anticiclone de Santa Helena Oceano Atlântico Norte); pelo Jato de Baixo Nível da América do Sul (SALLJ); pela ZCIT, que se forma pela radiação solar e pela convergência dos Ventos Alíseos; e pela Zona de Convergência da América do Sul (ZCAS) (Neto e Nery, 2005; Tessler e Goya, 2005; Vera et al., 2002,2006) (Fig. 12).

Ao leste da América do Sul, a cadeia montanhosa dos Andes impede que as massas de ar provenientes do Oceano Pacífico (massas Polar Pacífica, Tropical Pacífica e Equatorial Pacífica) alcancem posições mais interiores na América do Sul (Nimer, 1990) (Fig. 12).

Os sistemas atmosféricos $\mathrm{Ta}$ e Pa, e o sistema frontal úmido e instável gerado pelo encontro deles no Atlântico Sul, denominado Frente Polar Atlântica (FPA) (Conti e Furlan, 1996 apud Neto e Nery, 2005), controlam o sistema de ondas que são geradas no Atlântico Sul e se propagam para os litorais sudeste e sul brasileiros, a atuação da Corrente das 
Malvinas e, também, as plumas de água pouco salinas provenientes do Rio de La Plata e da Lagoa dos Patos sobre a plataforma sul do Brasil (Tessler e Goya, 2005; Castro et al., 2006; Gonzales-Silveira et al., 2006; Mahiques et al., 2008; Möller Jr. et al., 2008).
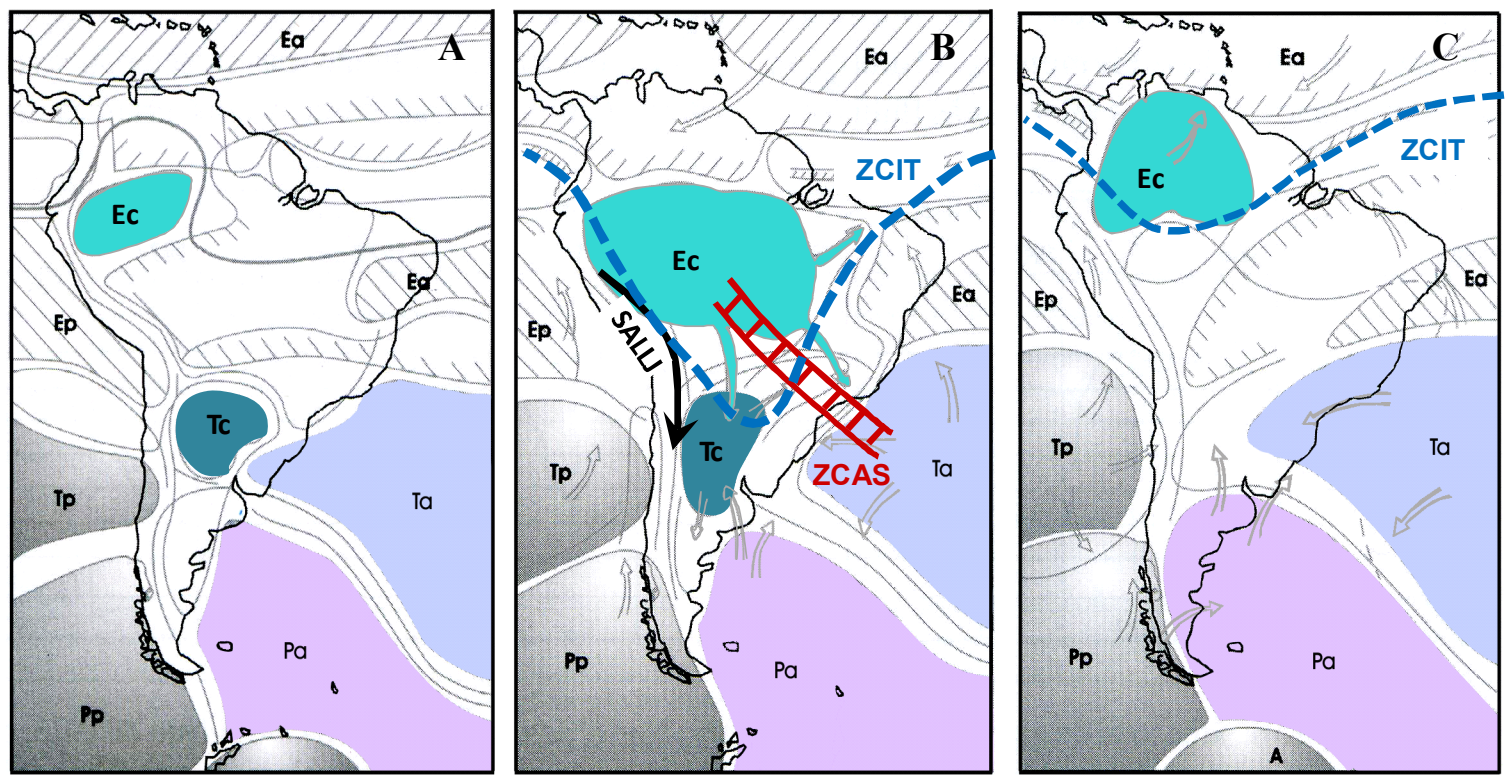

Figura 12: Áreas fontes e principais trajetórias dos sistemas atmosféricos da América do Sul em A. média anual, B. meses de verão e C. meses de inverno. Ea: Massa Equatorial Atlântica. Ec: Massa Equatorial Continental. Pa: Massa Polar Atlântica. SALLJ: Jato de Baixo Nível da América do Sul. Ta: Massa Tropical Atlântica. Tc: Massa Tropical Continental. ZCAS: Zona de Convergência da América do Sul. ZCIT: Zona de Convergência Intertropical. Modificada de Neto e Nery, 2005.

A circulação atmosférica sobre a América do Sul se modifica sazonalmente, gerando diferenças pluviométricas e climáticas, especialmente entre os meses de verão e inverno (Neto e Nery, 2005). Nas regiões tropical e subtropical da América do Sul, a precipitação é influenciada principalmente pela intensidade e pelo posicionamento da ZCIT (Neto e Nery, 2005; Panarello e Dapeña, 2009) e pela ocorrência da Monção de Verão da América do Sul (MVAS) durante o verão. Durante os meses de inverno, a precipitação dessa região é principalmente devida à atividade anticiclônica atlântica (Ta e Pa) (Zhou e Lau, 1998; Vera et al., 2002; Cruz Jr. et al., 2006).

A ZCIT tem forte comportamento sazonal. Ela se posiciona entre $0^{\circ} \mathrm{e} \sim 8^{\circ} \mathrm{S}$ durante $\mathrm{o}$ inverno austral, e migra para o sul, alcançando latitudes de até $30^{\circ} \mathrm{S}$ entre $50^{\circ}$ e $60^{\circ} \mathrm{W}$ durante os meses do verão austral (Rozanski e Araguás-Araguás, 1995) (Fig. 13). A MVAS faz parte do sistema de monções das Américas e se constitui em uma reversão sazonal na direção dos ventos causada pelo aquecimento diferencial do continente Sul Americano e do oceano Atlântico (Zhou e Lau, 1988). Ela começa a se formar no final da primavera, sobre a Bacia 
Amazônica noroeste, e se intensifica e atinge regiões sul-americanas mais ao sul durante os meses de verão (Zhou e Lau, 1998; Gan et al., 2004).

Durante os meses de verão típico, as massas de ar continentais (Ec e Tc) avançam sobre as regiões Nordeste, Centro-Oeste, Sudeste e Sul (Neto e Nery, 2005) (Fig. 12). A ZCIT migra para o sul (Fig. 13), e a intensificação dos Alíseos de NE causa maior transporte da umidade atlântica equatorial para a bacia Amazônica, o que ocasiona intensa convecção nessa região (Zhou e Lau, 1998), desenvolvendo a MVAS. A umidade existente sobre essa região então é transportada para o sul pelo Jato de Baixo Nível da América do Sul (SALLJ) (Vera et al., 2002) (Fig. 13).

O transporte da umidade gerada na Amazônia pelo Jato de Baixo Nível da América do Sul de direção noroeste forma a Zona de Convergência da América do Sul (ZCAS), uma importante feição da MVAS que é definida como uma banda convectiva de direção NW-SE que se estende desde a Bacia Amazônica até o Oceano Atlântico Subtropical (Vera et al., 2002; Carvalho et al., 2004) (Figs. 12 e 13). Ela é influenciada pela topografia das regiões central e leste brasileiras (Vera et al., 2006) e interage com o ATAS (Bastos e Ferreira, 2000) no Atlântico subtropical sudoeste. A MVAS é o principal fator responsável pela precipitação sobre a Bacia do Río de La Plata nos meses de verão (Rao et al., 1996; Zhou e Lau, 1998; Vera et al., 2002).

Durante os meses de inverno típico, a Tc desaparece, a Ec se retrai atingindo menor extensão na América do Sul, a Ta (ATAS) se expande especialmente sobre o sudeste e nordeste brasileiros, e a Pa avança sobre o sul da América do Sul (Neto e Nery, 2005) (Fig. 12). A ZCIT migra para o norte, (Rozanski e Araguás-Araguás, 1995), a MVAS e a ZCAS desaparecem (Zhou e Lau, 1998; Carvalho et al., 2004) (Figs. 12 e 13). A entrada de massas de ar frias de médias latitudes a polares induzem atividade ciclônica ampliada sobre o Oceano Atlântico Sul subtropical e, por conseguinte, a entrada de massas de ar úmidas provenientes do oceano no continente sul-americano, o que gera chuvas de inverno que progridem em direção ao norte ao longo da costa atlântica subtropical (Fig. 13) (Gan e Rao, 1991; Vera et al., 2002). 


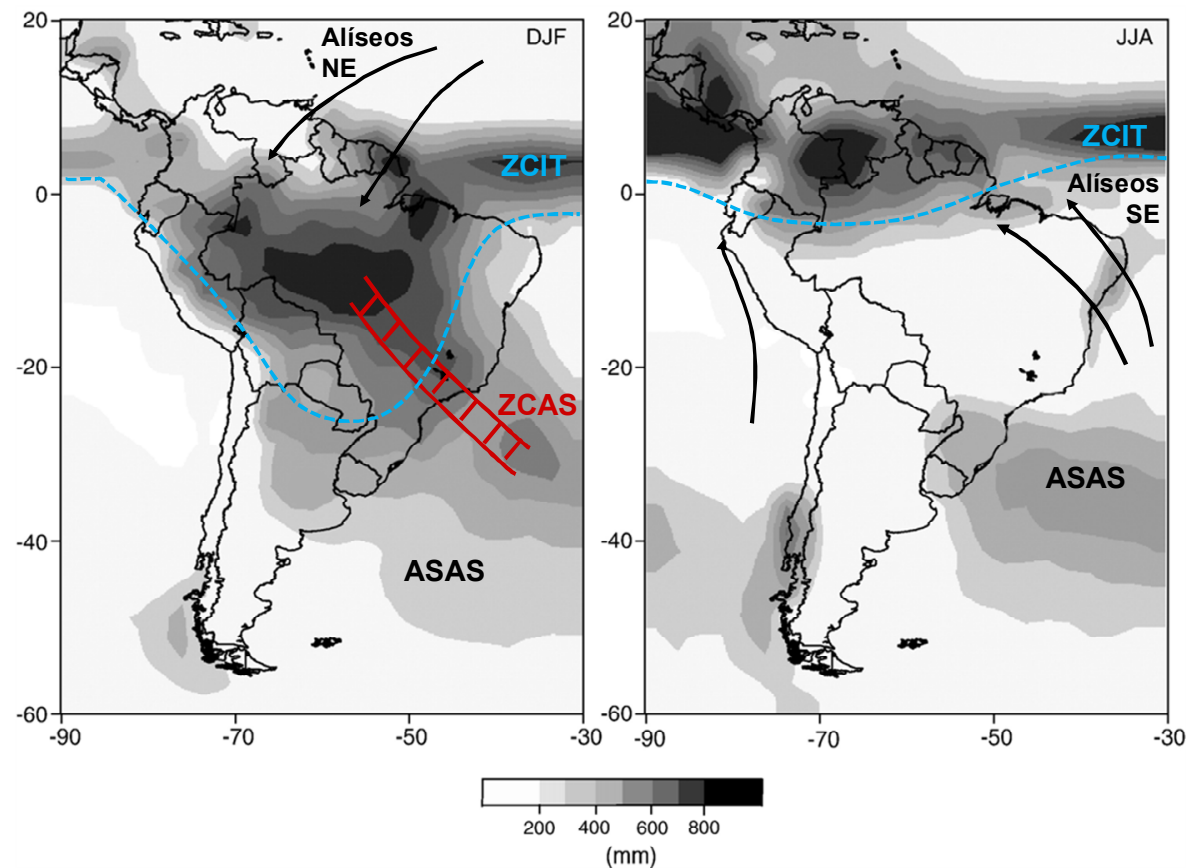

Figura 13: Precipitação total sazonal (em mm) de longo termo (1979-2000) CMAP para A. Dezembro-Fevereiro e B. Junho-Agosto. ZCAS: Zona de Convergência da América do Sul. ZCIT: Zona de Convergência Intertropical. DJF: Dezembro-Fevereiro. JJA: Junho-Agosto Modificado de Panarello e Dapeña (2009) e Cruz Jr et al. (2006).

Todos esses sistemas atmosféricos sofrem influência dos fenômenos meteorológicos conhecidos como El-Niño-Oscilação Sul (ENOS) e La-Niña, fenômenos oceânicoatmosféricos que se caracterizam pelo aumento anômalo da temperatura superficial marinha (TSM) (El-Niño) ou por sua diminuição anômala (La-Niña) no Pacífico equatorial leste e que ocorrem conectados à modificação das flutuações das temperaturas deste mesmo oceano (Oscilação Sul), responsável por causar mudanças nos padrões normais meteorológicos e climáticos da América do Sul (Coelho et al., 2002; Panarello e Dapeña, 2009).

A circulação atmosférica sobre a América do Sul também sofre influência da Oscilação Atlântica Multidecadal (OAM), uma flutuação de larga escala na TSM no Oceano Atlântico com período de $\sim 65$ anos que é possivelmente relacionada à variabilidade na AMOC (Delworth e Mann, 2000; Kerr, 2000); de mudanças no relevo; e de aspectos climáticos locais (Robertson et al., 2003; Chiessi et al., 2009; Panarello e Dapeña, 2009).

\subsection{Aspectos Oceanográficos das Áreas de Estudo}

A circulação oceânica geral no Oceano Atlântico Sul é formada pelo Giro Subtropical (Fig. 14). No Atlântico Sul ocidental, a até aproximadamente $1.500 \mathrm{~m}$ de profundidade, essa circulação é composta por três correntes principais: a Corrente do Brasil (CB), a Corrente de Contorno Oeste Intermediária (CCOI) e a Corrente das Malvinas (CM) (Silveira et al., 2000, 2004). Já a circulação da região costeira brasileira está vinculada à massa de Água Costeira 
(AC). Estudos prévios de alguns autores (Matsuura, 1986; Castro Filho et al., 1987) demonstraram que os padrões de distribuição da $\mathrm{AC}$ e das massas de água mais superficiais da CB (Água Tropical - AT e Água Central do Atlântico Sul - ACAS) são distintos para os períodos de verão e de inverno na costa brasileira.

A CB é uma corrente oceanográfica de contorno oeste, que apresenta velocidade máxima de $0,8 \mathrm{~m} \cdot \mathrm{s}^{-1} \mathrm{em} 31^{\circ} \mathrm{S}$, a $500 \mathrm{~m}$ de profundidade. Ela se origina ao sul de $10^{\circ} \mathrm{S}$ de latitude e flui para o sul, bordejando o continente sul-americano, até atingir a Confluência Brasil-Malvinas, na latitude $33-38^{\circ} \mathrm{S}$. Na Confluência Brasil-Malvinas, ela se une à $\mathrm{CM}$, a qual flui para o norte carreando águas frias. Então ambas as correntes se afastam da costa (Peterson e Stramma, 1991; Silveira et al., 2000) (Fig. 14). Já a CCOI é uma corrente que flui abaixo da $\mathrm{CB}$, para norte, carreando massas de água de profundidade subpicnoclínicas. Em torno de $23^{\circ} \mathrm{S}$, a $800 \mathrm{~m}$, sua velocidade máxima é de $0,3 \mathrm{~m} \cdot \mathrm{s}^{-1}$ (Silveira et al., 2000, 2004).

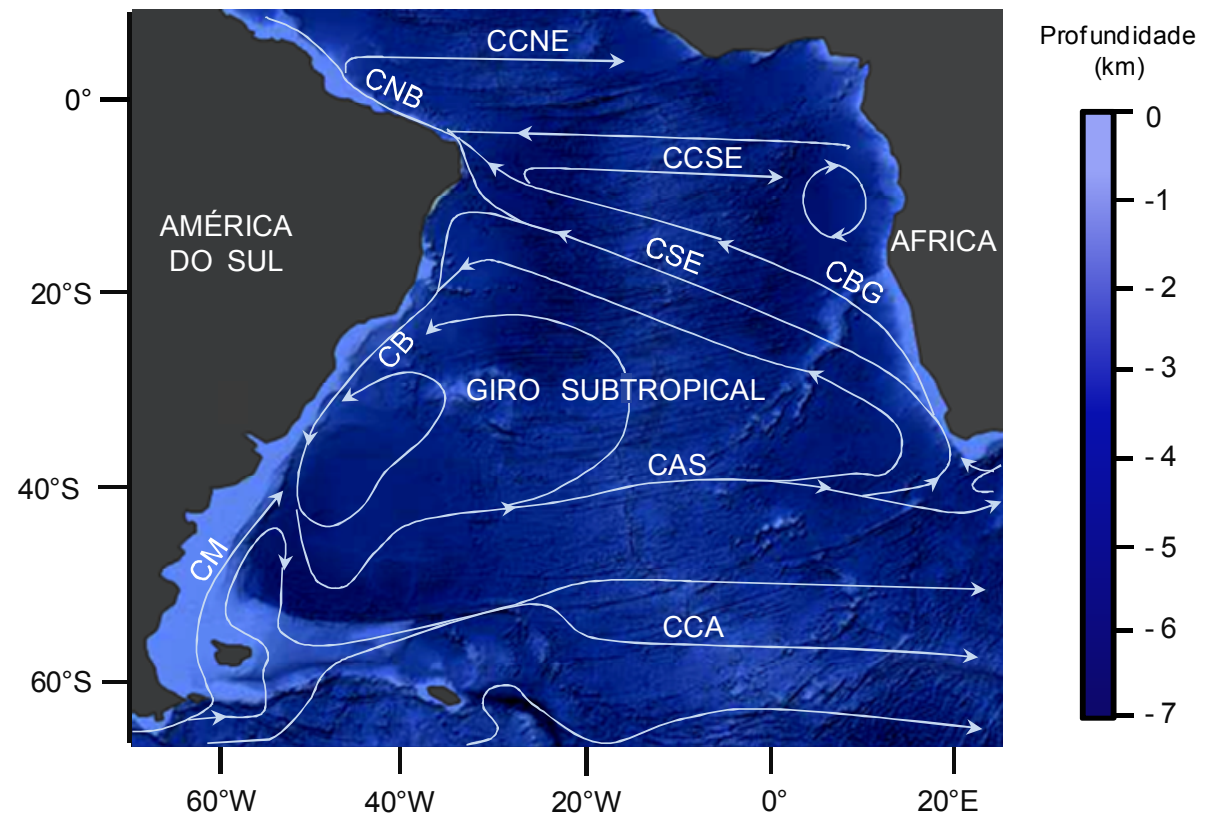

Figura 14: Circulação superficial geral do Oceano Atlântico Sul. CAS: Corrente do Atlântico Sul. CB: Corrente do Brasil. CBG: Corrente de Benguela. CCA: Corrente Circumpolar Antártica. CCNE: Contra Corrente Norte Equatorial. CCSE: Contra Corrente Sul Equatorial. CM: Corrente das Malvinas. CNB: Corrente Norte do Brasil. CSE: Corrente Sul Equatorial.

Na região costeira e no talude continental até a profundidade de coleta do testemunho GeoB6211-2, as massas de água presentes são a Água Costeira (AC), Água Superficial do Atlântico Sul (ASAS), Água Central do Atlântico Sul (ACAS) e a Água Intermediária Antártica (AIA) ( Fig. 15).

A AC $\left(>20^{\circ} \mathrm{C} ; 33\right.$ a 33,7$)$ é uma massa de água que banha toda a costa brasileira e que é definida como a mistura entre águas marinhas e águas de origem continental (Miranda e Katsuragawa, 1991; Kampel e Gaeta, 2003). 
A ASAS $\left(\sim 20^{\circ} \mathrm{C}\right.$; 37) (Silveira et al., 1994, Scott et al., 1995) é formada pela mistura da Água Tropical (AT, $>20^{\circ} \mathrm{C} ;>36$ ups), que se forma na região dos trópicos e é então carreada para o sul pela $\mathrm{CB}$, com águas menos quentes e menos salinas de origem costeira (Silveira et al., 2000).

A ACAS $\left(6^{\circ} \mathrm{C}\right.$ e $20^{\circ} \mathrm{C} ; 34,6$ a 36) flui para o sul a partir de $22^{\circ} \mathrm{S}$, com profundidades entre 150 e 600-750 m, na região da picnoclina, e é composta por combinação das massas de Água Central do Atlântico Sul leve (em inglês, light South Atlantic Central Water -1SACW), Água Modal Subtropical do Atlântico Sul (AMSAS) e Água Modal Subantártica (AMSA) (Stramma e England, 1999; Silveira et al., 2000; Donners et al., 2005). Atualmente, em torno de $32^{\circ} \mathrm{S}$ e em $550 \mathrm{~m}$ de profundidade, seu conteúdo de oxigênio dissolvido é de aproximadamente $4,6 \mathrm{ml} . \mathrm{L}^{-1}$, o de nitrato é de $\sim 20 \mu \mathrm{m} . \mathrm{Kg}^{-1}$, e o de fosfato, de $\sim 1,4 \mu \mathrm{m} . \mathrm{Kg}^{-1}$ (Tsuchiya et al., 1994).

Já a $\operatorname{AIA}\left(2^{\circ} \mathrm{C}\right.$ a $6^{\circ} \mathrm{C} ; 34,2$ a 34,6) flui abaixo da ACAS, atingindo profundidades de até $1.400 \mathrm{~m}$, e é caracterizada por salinidades mínimas. Ela flui para o sul abaixo de $28^{\circ} \mathrm{S}$, e para norte a partir dessa latitude, em níveis subpicnoclínicos. Forma-se no Pacífico Sudeste e no Atlântico Sudoeste, na região da Corrente Circumpolar Antártica (Piola e Gordon, 1989; Silveira et al., 2000; Donners et al., 2005). Atualmente, em aproximadamente $32^{\circ} \mathrm{S}$ e à profundidade de $\sim 800 \mathrm{~m}$, os seu conteúdo de oxigênio dissolvido é de aproximadamente 5,6 ml. $\mathrm{L}^{-1}$, o de nitrato é de $\sim 29 \mu \mathrm{m} . \mathrm{Kg}^{-1}$, e o de fosfato, de $\sim 1,8 \mu \mathrm{m} . \mathrm{Kg}^{-1}$ (Tsuchiya et al., 1994).

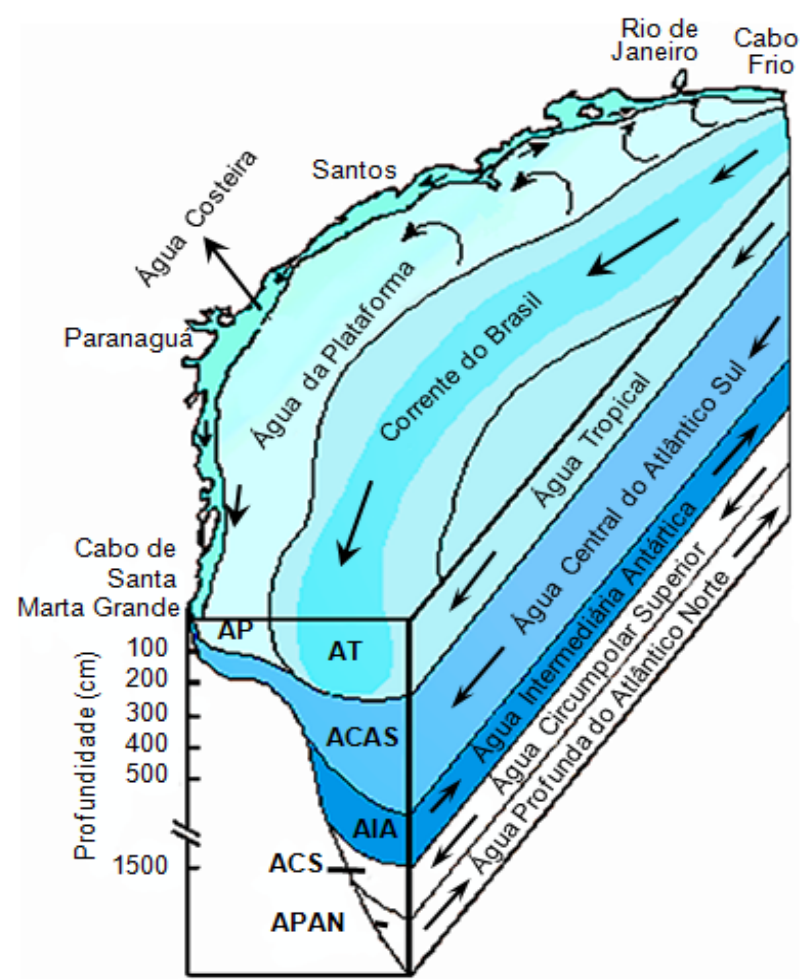

Figura 15: Massas de água da costa sudeste brasileira. Modificada de Matsuura (1986) conforme Netto Jr. (2008). 
Atualmente, os 20m superficiais de água da região do testemunho GeoB6211-2 recebem influência da pluma de baixa salinidade do Rio de La Plata (em inglês, La Plata Plume Water - PPW), que torna suas águas superficiais menos salinas ( 34.5) e com menor $\delta^{18} \mathrm{O}(0,01 \%)$ (Conkright et al., 2002; LeGrande e Schmidt, 2006), quando comparadas às de regiões adjacentes de mesma latitude (Chiessi et al., 2009). A bacia hidrográfica do Rio de La Plata tem área de $3.100 .000 \mathrm{~km}^{2}$ no sudeste da América do Sul e descarrega $22.000 \mathrm{~m}^{3} / \mathrm{s} \mathrm{de}$ água doce no Oceano Atlântico Sul (Barros et al., 2006; Simionato et al., 2010). Em escala de tempo interdecadal, a variabilidade dessa descarga se correlaciona com as variações da TSM do Atlântico Sul oeste (Robertson e Mechoso, 2000). Segundo Robertson e Mechoso (2000), anomalias positivas de temperatura superficial oceânica nessa região do Atlântico Sul foram encontradas em épocas de maior descarga do Rio de La Plata.

A PPW geralmente se restringe à plataforma continental, raramente atingindo a quebra da plataforma (Piola et al., 2005; Chiessi et al., 2009). Ela se alonga para o norte durante o inverno, atingindo até $26^{\circ} \mathrm{S}$ (Piola et al., 2008). Durante o verão, se restringe a porções ao sul de $32^{\circ} \mathrm{C}$ na plataforma brasileira (Piola et al., 2008). Essa variação sazonal da zona de influência da PPW sobre a plataforma continental brasileira (Zhou e Lau, 1998; Berbery e Barros 2002) é controlada principalmente por variações da força dos ventos que sopram ao longo da costa e pelas correntes superficiais oceânicas (Piola et al., 2008). 


\section{CAPÍTULO 6: Materiais e Métodos}

\subsection{Procedência, coleta e datação das amostras}

O testemunho S03, de 5,79m, foi coletado no Mosaico da Juréia-Itatins (MJI), na margem esquerda do Rio Comprido, nas coordenadas: 24²9'16.45”S e 47¹5’09”W, a cerca de $8 \mathrm{~km}$ da linha de costa adjacente no sudeste brasileiro, por testemunhador a vibração (Martin et al., 1995) (Fig.16). As 35 amostras do testemunho S03 analisadas neste trabalho foram gentilmente cedidas pelo Prof. Dr. Kenitiro Suguio e pertencem ao projeto "Estação Ecológica Juréia-Itatins (SP): Flutuações de Níveis Marinhos Abaixo do Atual no Holoceno", da USP (Projeto I, Suguio, 2006).

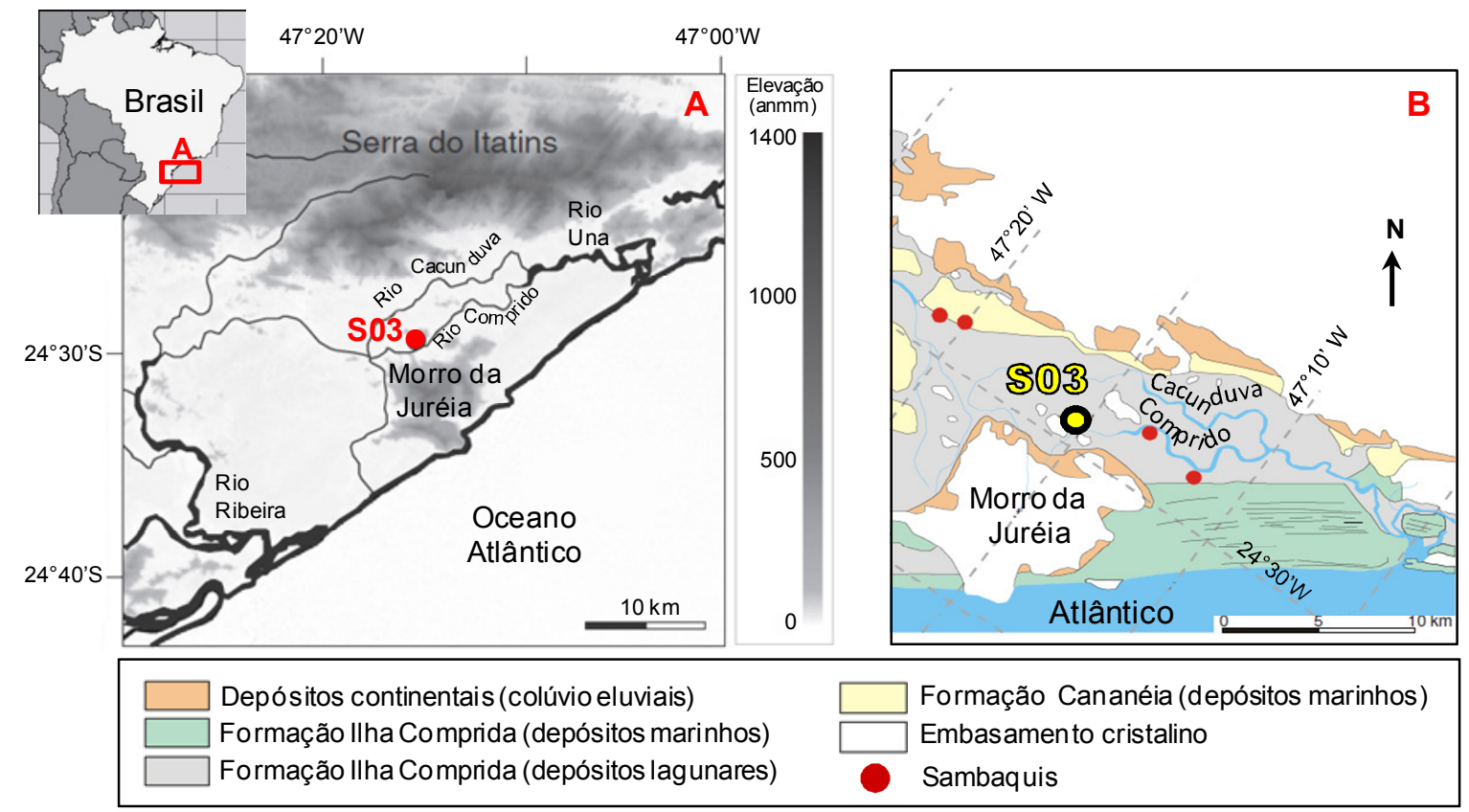

Figura 16: Localização do testemunho S03. A. mapa topográfico da região do MJI onde o testemunho S03 foi coletado. Retirado de Sallun et al., 2012. B. mapa geológico da da região do MJI onde o testemunho S03 foi coletado. Retirado de Suguio e Martin (1978b).

O testemunho GeoB6211-2, de 5,73 m, foi coletado no talude superior da margem sul brasileira, no Cone do Rio Grande, em frente ao estado do Rio Grande do Sul, nas coordenadas $32,50^{\circ} \mathrm{S}$ e $50,24^{\circ} \mathrm{W}$, à profundidade de $657 \mathrm{~m}$ de lâmina de água, por meio de testemunhador a gravidade (Fig.17). As 279 amostras analisadas neste trabalho (45 amostras para análise micropaleontológica de associação de foraminíferos bentônicos e 234 amostras para análise geoquímica de testas de foraminíferos planctônicos) foram gentilmente cedidas 
pelo Dr. Juergen Paetzold e pelo Prof. Dr. Cristiano M. Chiessi e foram coletadas pelo projeto "Berichte aus dem Fachbereich Geowissenschaften, Meteor-Cruise M46-2, Recife (Brazil)Montevideo (Uruguai), December, 2- December, 29, 1999 e Meteor-Cruise M46-4, Mar del Plata (Argentina) - Salvador (Brazil), 10.2-13.3/2000”, da Universidade de Bremen (Projeto II, Schulz et al., 2001; Wefer et al., 2001). O testemunho GeoB6211-2 encontra-se arquivado no GeoB Core Repository da Universidade de Bremen, Alemanha.
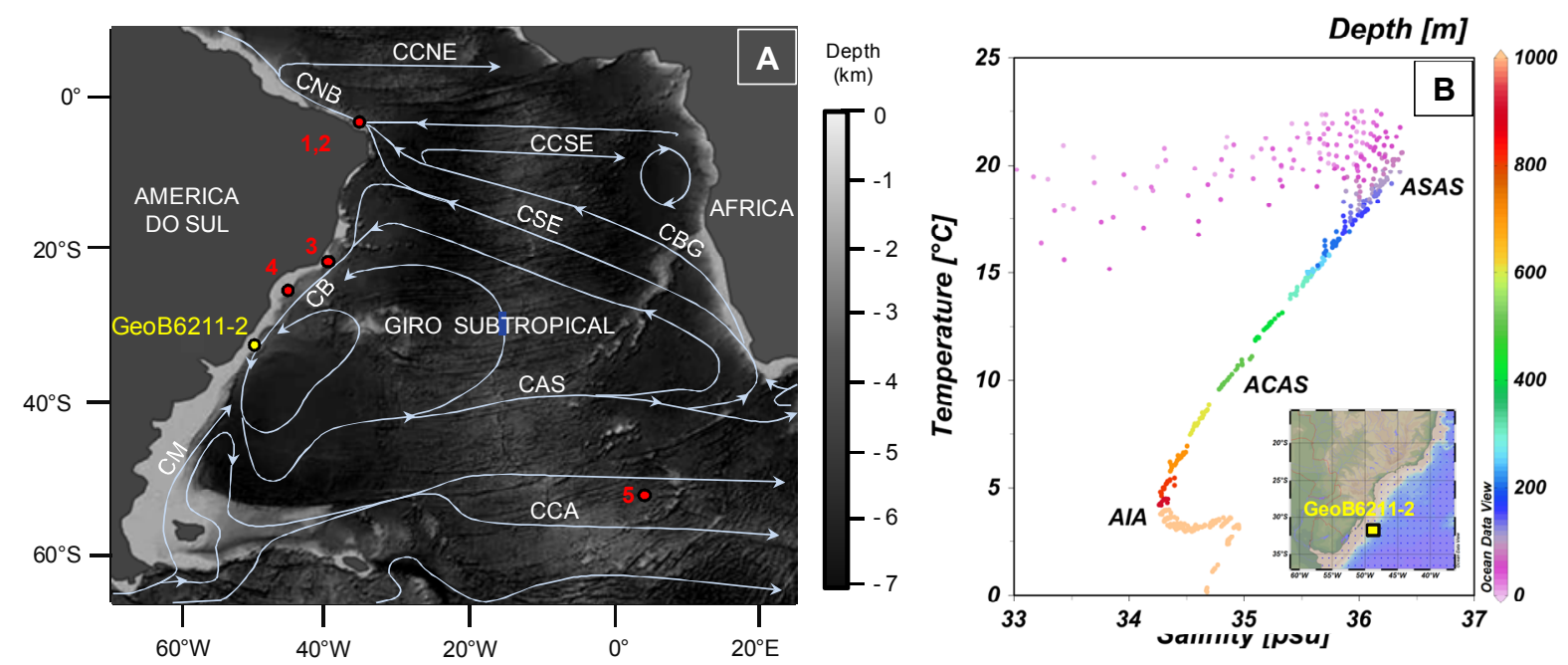

Figura 17: A. Circulação geral do Atlântico Sul, modificada de Peterson e Stramma (1991), com localização do GeoB6211-2. CAS: Corrente do Atlântico Sul. CB: Corrente do Brasil. CBG: Corrente de Benguela. CCA: Corrente Circumpolar Antártica. CCNE: Contra Corrente Norte Equatorial. CCSE: Contra Corrente Sul Equatorial. CM: Corrente das Malvinas. CNB: Corrente Norte do Brasil. CSE: Corrente Sul Equatorial.. Representados, os locais de coleta dos testemunhos dos trabalhos utilizados para comparações ambientais nesse estudo: 1. GeoB3129/3911 (Weldeab et al., 2006); 2. GeoB 3910-2 (Jaeschke et al., 2007); 3. GeoB3202-1 (Arz et al., 1999); 4. KNR159-5-36GGC (Pahnke et al., 2008); 5. TN057-13 (Shemesh et al., 2002; Anderson et al., 2009). B. Diagrama de salinidade vs. temperatura vs. profundidade da região do testemunho GeoB6211-2. ACAS: Água Central do Atlântico Sul. AIA: Água Intermediária Antártica. ASAS: Água Superficial do Atlântico Sul.

Sob a supervisão de seus respectivos pesquisadores responsáveis, os testemunhos foram abertos, fotografados, medidos e descritos, nos laboratórios do IGc-USP, São Paulo (Testemunho S03) e durante o cruzeiro Meteor-Cruise M46-4 (Testemunho GeoB6211-2). Níveis mais ricos em matéria orgânica e em conchas carbonáticas foram coletados para a realização de datação absoluta pelo método do ${ }^{14} \mathrm{C}$ nos Laboratórios Beta Analytic, Flórida, EUA (Testemunho S03) e Leibniz-Laboratory for Radiometric Dating and Stable Isotope Research, Kiel, Alemanha (Testemunho GeoB6211-2). 
As idades foram convertidas em idades calendário (anos cal A.P.) por seus respectivos pesquisadores responsáveis. Para o testemunho S03, utilizou-se a curva de calibração INTCAL04 (Talma e Vogel, 1993; Reimer et al., 2004) com erro de $2 \sigma$ nas medidas radiocarbônicas com erro multiplicador de 1,0. As idades obtidas foram recalculadas utilizando-se a Calibração do Hemisfério Sul com a curva de calibração SHCAL 04 (McCormac et al., 2004). O modelo geocronológico foi construído baseado nas idades calendário obtidas com ajustes para a profundidade e para as mudanças nas taxas de sedimentação encontradas ao longo do testemunho S03 (Sallun et al., 2012).

Para o testemunho GeoB6211-2, sete idades radiocarbônicas foram calibradas com o programa CALIB 6.1.0 (Stuiver e Reimer, 1993) com a curva de calibração Marine04 (Hughen et al., 2004). A partir dessas idades, o modelo geocronológico foi obtido por meio de interpolação linear (Chiessi, 2008; Chiessi et al., 2008). Quatro idades radiocarbônicas foram medidas para o testemunho GeoB6211-1 na mesma localização do testemunho GeoB6211-2 (Chiessi, com. pess.), que foram convertidas em onze idades calibradas pela mesma metodologia acima descrita (Chiessi, com. pess.) e utilizadas para o modelo de idades do testemunho composto obtido desses dois testemunhos, GeoB6211-1 e GeoB6211-2, aqui denominado GeoB6211CC (GeoB6211-2 composite core).

Após a descrição e coleta de material para datação, os testemunhos foram fatiados, a critério de cada pesquisador responsável, para obtenção de amostras que foram subdivididas para as diversas análises empregadas (e.g., granulométricas, químicas, isotópicas, microfaunísticas).

Descrições criteriosas das metodologias empregadas para a coleta, armazenagem, descrição, datação e separação de amostras, realizadas nesses testemunhos por seus respectivos pesquisadores responsáveis, podem ser encontradas nos relatórios dos projetos acima mencionados (Projetos I e II) e nos trabalhos de Chiessi (2008), Chiessi et al. (2008) e de Sallun et al. (2012). Para esse trabalho, foram utilizadas amostras retiradas a cada dez centímetros (S03 e GeoB6211-2) de cada testemunho para análise das associações microfaunísticas bentônicas. Amostras retiradas a cada $1 \mathrm{~cm}$ (entre 17 e $124 \mathrm{~cm}$ de profundidade) e a cada $4 \mathrm{~cm}$ (entre 127 e $583 \mathrm{~cm}$ de profundidade) do testemunho GeoB62112, e onze amostras do testemunho GeoB6211-1 (equivalentes às amostras mais superficiais entre 0 e $17 \mathrm{~cm}$ de profundidade - do testemunho GeoB6211-2) foram empregadas para análise de $\delta^{18} \mathrm{O}$ (complementares aos já existentes) e de $\mathrm{Mg} / \mathrm{Ca}$ em testas de Globigerinoides ruber white, stricto sensu (G. ruber white, s.s.). 


\subsection{Análises Sedimentológicas}

As análises sedimentológicas foram realizadas para os testemunhos S03 e GeoB62112 por seus respectivos pesquisadores responsáveis. Descrições mais criteriosas das metodologias empregadas podem ser encontradas em Chiessi (2008); Chiessi et al. (2008, 2009); Sallun et al. (2012); e nos relatórios dos projetos vinculados a esses dois testemunhos (Projetos I e II).

Para o testemunho S03, a determinação do tamanho médio dos grãos sedimentares foi efetuada por método de peneiramento e pipetagem descritos em Suguio (1973) no Laboratório de Sedimentologia do Instituto de Geociências da USP (Labsed, IGc-USP) (Sallun et al., 2012). Este método consiste no peneiramento para frações mais grossas que $0,062 \mathrm{~mm}$ com peneiras de malhas que obedecem à escala granulométrica de Wentworth (1922) e pipetagem para frações lamosas do sedimento. Os intervalos de pipetagem foram calculados segundo a lei de Stokes sob temperatura constante de $20^{\circ} \mathrm{C}$. Após obtidos, os dados granulométricos foram convertidos para parâmetros estatísticos de diâmetro médio, desvio-padrão, assimetria e curtose (Suguio et al., 2008; Sallun et al., 2012).

Os parâmetros granulométricos do testemunho GeoB6211-2 integram a tese de doutorado de Sebastian Razik (doutorando da Universidade de Bremen, Bremen, Alemanha) e foram gentilmente cedidos por ele. Além dos parâmetros granulométricos, o testemunho GeoB6211-2 possui descrição macroscópica efetuada à bordo do Meteor-Cruise M46-4, que o descreve quanto à litologia, separando-a grosseiramente entre areia, quartzo e argila e identifica diferentes níveis de acordo com as colorações e presença/ausência de fragmentos de conchas e nanofósseis (Wefer et al., 2001).

Para este trabalho, os dados granulométricos dos testemunhos S03 e GeoB6211-2 foram classificados de acordo com a escala granulométrica de Wentworth (1922), de assimetria e curtose de Folk e Ward (1957), e com as classificações sedimentológicas de Shepard (1954), classificação da escala phi de Krumbein (1936) e de selecionamento dos grãos de Folk \& Ward (1957). Foram então representados em tabelas e em gráficos de parâmetros granulométricos e estatísticos versus profundidade.

\subsection{Análises Químicas dos Sedimentos}

As análises químicas elementares, de carbonatos, carbono orgânico, carbono inorgânico e de carbono e nitrogênio totais dos sedimentos dos testemunhos S03 e 
GeoB6211-2 foram executadas por seus respectivos pesquisadores responsáveis. Descrições das metodologias empregadas por eles podem ser também encontradas em Chiessi (2008); Chiessi et al. (2008, 2009); Sallun et al. (2012); e nos relatórios dos projetos vinculados a esses dois testemunhos (Projetos I e II).

Para o testemunho S03, os elementos-traço foram medidos com o uso de espectômetro de massa com plasma acoplado (ICPMS), os elementos maiores com a utilização de fluorescência de raios-X (XRF), e o conteúdo de carbonatos $(\% \mathrm{CaO})$ estimado por perda de peso em ignição (LOI) a $1000^{\circ} \mathrm{C}$, após dissolução da amostra em ácido hidroclorídrico, de acordo com Gross (1971), no Laboratório SGS da GEOSOL (Sallun et al., 2012). Já para o testemunho GeoB6211-2, os elementos químicos foram obtidos por meio da utilização do Avaatech X-ray fluorescence core scanner (XRF-CS), e os teores de $\mathrm{CaCO}_{3}$ foram calculados por meio da equação de Müller et al. (1994): $\left[\mathrm{CaCO}_{3}=8,33 *\left(C_{\text {total }} C_{\text {org. }}\right)\right]$, com resultados expressos na forma de porcentagens-peso para sedimento salt-free, na Universidade de Bremen, Alemanha.

Para este trabalho, foram utilizados os elementos químicos alumínio $(\mathrm{Al})$, cálcio $(\mathrm{Ca})$, ferro $(\mathrm{Fe})$, potássio $(\mathrm{K})$ e titânio (Ti), obtidos em porcentagem (testemunho S03) e em contagens por segundo (testemunho GeoB6211-2). Os elementos $\mathrm{Ca}, \mathrm{Fe}, \mathrm{K}$ e Ti foram normalizados pelo elemento de referência $\mathrm{Al}$, para anular as diferenças de distribuição dos elementos químicos devido a diferenças no tamanho dos grãos (Araújo et al., 2002; Herut e Sandler, 2006). Em seguida, foram elaboradas as razões elementares $\mathrm{Ti} / \mathrm{Ca}$ e $\mathrm{Fe} / \mathrm{K}$ para determinar possíveis modificações nos padrões climático-ambientais. A razão Ti/Ca foi utilizada especialmente como indicadora da fonte dos sedimentos presentes nos testemunhos S03 e GeoB6211-2 (se predominantemente continentais ou marinhas). A razão Fe/K foi utilizada como indicadora de diferentes áreas ou períodos climáticas no continente americano, especialmente para indicar períodos mais secos ou mais chuvosos nas áreas-fonte dos sedimentos (Govin et al., 2012).

Para correção de efeitos de diluição de $\mathrm{CaCO}_{3}$ por sedimentos terrígenos no testemunho GeoB6211-2, calculou-se o fluxo de $\mathrm{CaCO}_{3}$, dado pela fórmula:

Fluxo $\mathrm{CaCO}_{3}=\left(\% \mathrm{CaCO}_{3} *\right.$ taxa de sedimentação*densidade do sedimento seco $) / 100($ Naidu e Malmgren, 1999)

Para o emprego dessa fórmula, os valores de densidade do sedimento seco e da taxa de sedimentação utilizados foram os obtidos por Chiessi (2008). Para evitar aumento do erro de 
cálculo, foram medidos valores de fluxo de $\mathrm{CaCO}_{3}$ apenas para os intervalos com idades radiocarbônicas medidas.

A classificação desses testemunhos analisados de acordo com a quantidade de carbonatos presentes em seus sedimentos baseou-se em Larssoneur et al. (1977), modificado por Dias (1996).

Para a análise do carbono total $\left(\mathrm{C}_{\text {total }}\right)$, carbono orgânico $\left(\mathrm{C}_{\mathrm{org}}\right)$. e nitrogênio total $\left(\mathrm{N}_{\text {total }}\right)$ dos dois testemunhos (S03 e GeoB6211-2) cada amostra foi liofilizada e moída. Para o testemunho S03, essas amostras foram submetidas à combustão em analisador elemental ECS 4010 (Costech Analytical) e os gases resultantes medidos por espectômetro de massa Delta Plus XP (ThermoFinnigan), no Stable Isotope Core Laboratory da Washington State University, EUA. As estimativas elementares de $\mathrm{C}_{\text {total }}$ e $\mathrm{N}_{\text {total }}$ foram calculadas de uma correção multi-ponto com a utilização de acetanilida. Já para o testemunho GeoB6211-2 essas leituras foram feitas em aparelho analisador Heraeus CHN-O-Rapid Elemental Analyzer, na Universidade de Bremen, Alemanha. Para o testemunho S03, o $\mathrm{C}_{\text {inorg. }}$ foi removido com três lavagens sucessivas das amostras em ácido fosfórico ${ }^{3} \mathrm{~N}$. As porcentagens de carbono inorgânico $\left(\% \mathrm{C}_{\text {inorg }}\right)$, para os dois testemunhos, foram obtidas pela subtração das porcentagens de carbono total pelas de carbono orgânico.

Neste trabalho, as porcentagens de $\mathrm{C}_{\text {org. }}$ e $\mathrm{N}_{\text {total }}$ foram utilizadas para confecção da razão $\mathrm{C} / \mathrm{N}$, que permite que se estabeleça a origem da matéria orgânica presente nos sedimentos analisados (e.g., origem marinha, mista ou continental), já que organismos com ciclos fotossintéticos diferentes possuem valores dessa razão distintos. Os valores considerados discriminantes para essa razão estão de acordo com Bordwosky (1965) apud Yoshikazu e Massumoto (2001) e com Stein (1991).

\subsection{Análises isotópicas de sedimentos e de testas de foraminíferos}

As análises isotópicas de $\delta^{18} \mathrm{O}$ e $\delta^{13} \mathrm{C}$ de sedimentos do testemunho $\mathrm{S} 03$ e de testas de foraminíferos do testemunho GeoB6211-2 foram executadas por seus respectivos pesquisadores responsáveis. Descrições mais criteriosas das metodologias empregadas por eles podem ser encontradas em Chiessi (2008); Chiessi et al. (2008, 2009); Sallun et al. (2012); e nos relatórios dos projetos vinculados a esses dois testemunhos (Projetos I e II).

No testemunho S03 foram realizadas análises isotópicas de $\delta^{13} \mathrm{C}$ em amostras de solo. As subamostras referentes a essas análises foram enviadas ao Stable Isotope Core Laboratory da Washington State University, EUA, onde foram preparadas, e submetidas à combustão em 
analisador elemental ECS 4010 (Costech Analytical). Os gases resultantes foram medidos por espectômetro de massa Delta Plus XP (ThermoFinnigan). Os resultados finais foram calculados com correção de três pontos que consiste em executar padrões calibrados a um conjunto internacional de materiais de referência. A precisão típica da análise foi de $<0,2 \% 01$ (1DS).

Para este trabalho, os valores de $\delta^{13} \mathrm{C}$ dos sedimentos do testemunho S03 foram considerados para avaliação da origem da matéria orgânica de acordo com Lamb et al. (2006) (Fig.18).

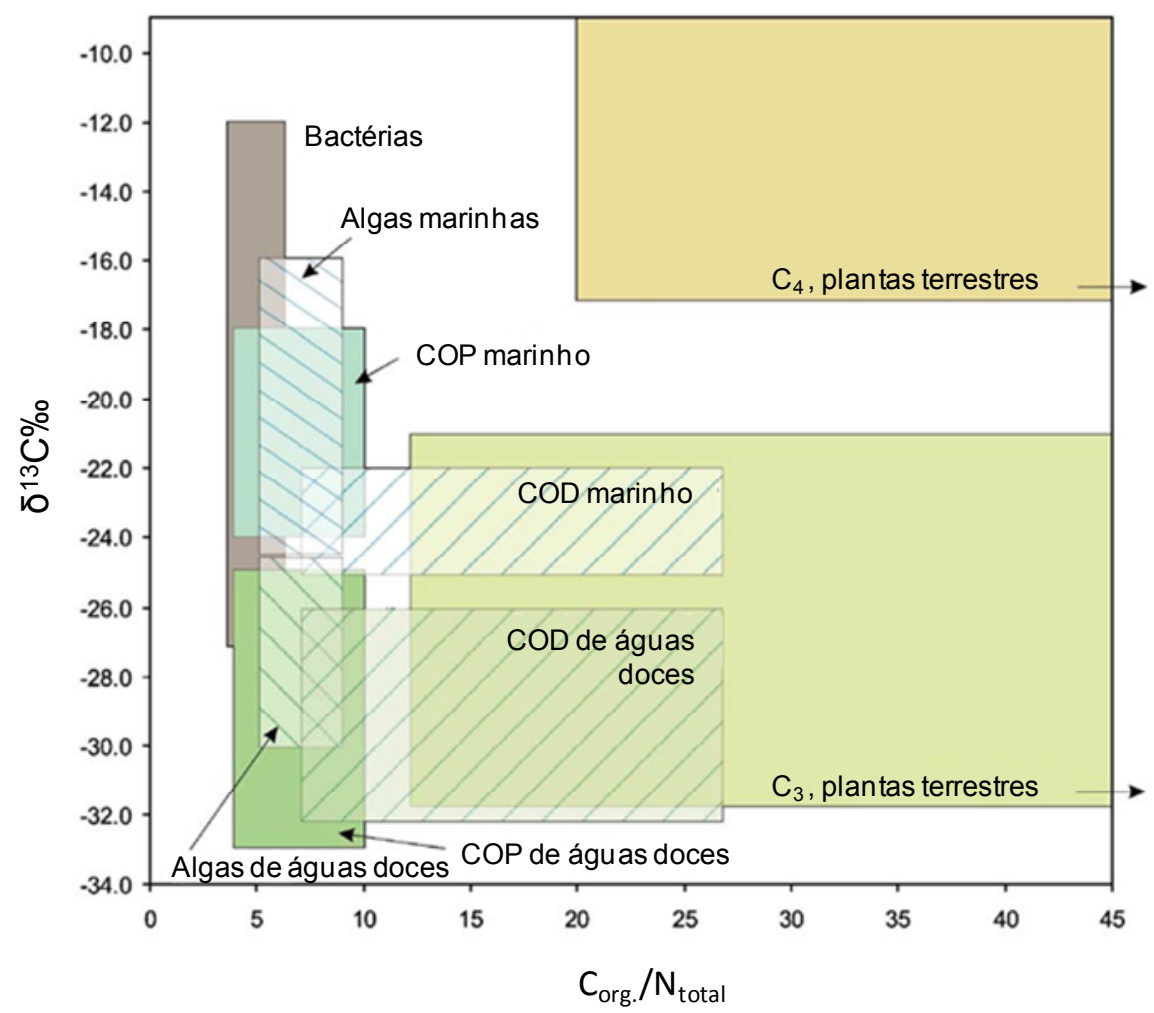

Figura 18: Valores típicos de $\delta^{13} \mathrm{C}$ e $\mathrm{C}_{\text {org. }} / \mathrm{N}_{\text {total }}$ para origem da matéria orgânica em ambientes costeiros. COP: carbono orgânico particulado. COD: carbono orgânico dissolvido. Retirado de Lamb et al. (2006).

No testemunho GeoB6211-2, valores de $\delta^{18} \mathrm{O}$ e $\delta^{13} \mathrm{C}$ foram obtidos em testas de duas espécies planctônicas (Globigerinoides ruber white s.s.; e Globorotalia inflata) e de uma espécie bentônica (Uvigerina bifurcata). Para tanto, foram triadas em torno de 10 testas por amostra de cada uma dessas três espécies, com tamanhos $(250-350 \mu \mathrm{m}$ para G. ruber, 350$500 \mu \mathrm{m}$ para $G$. inflata e $500-650 \mu \mathrm{m}$ para $U$. bifurcata) e estágio ontogenético específicos, para cada amostra de fração $>0,125 \mathrm{~mm}$ obtida a cada $1 \mathrm{~cm}$ do testemunho GeoB6211-2 (Chiessi et al., 2008, 2009). As testas triadas foram analisadas nos laboratórios da Universidade de Bremen, Alemanha. Os resultados encontrados foram parte do trabalho de 
doutorado do Prof. Dr. Cristiano M. Chiessi e foram gentilmente cedidos por ele. Adicionalmente, utilizou-se dados de $\delta^{18} \mathrm{O}$ Globigerinoides ruber white do testemunho GeoB6211-1 como complementares aos primeiros $17 \mathrm{~cm}$ do testemunho GeoB6211-2 (Chiessi, com. pess.).

Em geral, quanto maior for o valor do $\delta^{13} \mathrm{C}$ em testas da espécie planctônica Globigerinoides ruber, maior a produtividade primária oceânica da região onde ele vive (Spero e Williams, 1988). Os valores de $\delta^{13} \mathrm{C}$ G. ruber (white) do testemunho GeoB6211-2 (Chiessi et al., 2008) foram utilizados neste estudo como indicadores do aporte de nutriente lábil às águas superficiais na região do testemunho GeoB6211-2. Entretanto, observou-se com cautela a exportação dessa produtividade primária marinha ao substrato oceânico, devido à complexidade envolvida na exportação de nutrientes entre a superfície e o fundo marinhos, conforme indicado por Rühlemann et al. (1999) e Nadon e Himmelman, (2006). Levou-se ainda em consideração que a matéria orgânica (M.O.) mais lábil que atingiu o substrato do Cone do Rio Grande entre 19.000 e 14.000 anos cal A.P. pode ter sido trazida pelas correntes de fundo que banharam essa região marinha no intervalo de tempo estudado.

Já os valores de $\delta^{18} \mathrm{O}$ desta mesma espécie foram utilizados para o cálculo dos valores de $\delta^{18} \mathrm{O}_{\mathrm{ivc}-\mathrm{sw}}$, indicador das paleossalinidades superficiais do local de coleta do testemunho GeoB6211-2, conforme descrito na seção seguinte deste capítulo (item 6.5).

Valores de $\delta^{18} \mathrm{O}$ e $\delta^{13} \mathrm{C}$ da espécie planctônica $G$. inflata foram utilizados para que se pudesse comparar as mudanças das paleotemperaturas e paleossalinidades superficiais do local de coleta do testemunho GeoB6211-2 com aquelas que Chiessi et al. (2008) encontraram para a profundidade da termoclina permanente dessa mesma região, entre 19.0000 e 10.000 anos cal A.P.

\subsection{Mg/Ca em testas da espécie planctônica Globigerinoides ruber (white, s.s.)}

Executou-se triagem para a análise química de $\mathrm{Mg} / \mathrm{Ca}$ das testas de G. ruber (white, s.s.), na qual em torno de 40 testas da espécie planctônica G. ruber (white, s.s.), sem inclusões ou incrustações, inteiras, e com tamanho entre 250 e $350 \mu \mathrm{m}$ foram retiradas de 223 amostras obtidas ao longo do testemunho GeoB6211-2. Devido à diferença na taxa de sedimentação, as amostras entre 17 e $124 \mathrm{~cm}$ de profundidade do testemunho foram tomadas de $1 \mathrm{em} 1 \mathrm{~cm}$ e as amostras entre 124 e $548 \mathrm{~cm}$ foram coletadas de $4 \mathrm{em} 4 \mathrm{~cm}$. Para os primeiros $17 \mathrm{~cm}$, foram obtidos 11 valores de $\mathrm{Mg} / \mathrm{Ca}$ G. ruber (White, s.s.) do testemunho GeoB6211-1. As testas 
selecionadas foram limpas e mensuradas no Laboratório de Preparação de Amostras do Departamento de Geociências da Universidade de Bremen, Bremen, Alemanha.

A metodologia empregada para preparação e mensuração das amostras seguiu Barker et al. (2003), com pequenas modificações indicadas em Groeneveld e Chiessi (2011). Em cada amostra, 40 testas bem preservadas e com tamanhos entre 250-350 $\mu \mathrm{m}$ da espécie $G$. ruber (white, s.s.) foram coletadas e gentilmente quebradas. Os fragmentos de cada amostra foram submetidos à limpeza ultrasônica. Cada limpeza ultrassônica foi alternada com lavagens em água Seralpur (desionizada) e metanol. As amostras foram oxidadas, e a oxidação foi neutralizada com múltiplas lavagens em água Seralpur. Em seguida, foram transferidas para frascos limpos e lixiviadas com ácido fraco $\left(0,001 \mathrm{M}\right.$ QD $\left.\mathrm{HNO}_{3}\right)$. Foram então dissolvidas em $0,075 \mathrm{M}$ QD $\mathrm{HNO}_{3}$ e centrifugadas durante 10 minutos (6000rpm) para exclusão de qualquer partícula insolúvel remanescente. Por fim, o sobrenadante foi diluído em água Seralpur.

As amostras limpas e diluídas foram submetidas à análise no ICP-OES (Perkin Elmer Optima 3300RL com amostrador automático e nebulizador ultrasônico U-5000AT, Cetac Technologies Inc.). A precisão instrumental do ICP-OES foi monitorada pela análise de uma solução padrão in-house com $\mathrm{Mg} / \mathrm{Ca}$ de 3,05 $\mathrm{mmol} / \mathrm{mol}$, depois de cada cinco amostras (desvio padrão de longo prazo de 0,032 ou 0,80\%). A precisão analítica baseada em três medições repetidas de cada amostra foi de $0,29 \%$ para o $\mathrm{Mg} / \mathrm{Ca}$. Os elementos $\mathrm{Mn}$ e $\mathrm{Al}$ foram analisados para verificar a presença de contaminação nas testas. Cada valor obtido de $\mathrm{Mg} / \mathrm{Ca}$ representa a média de 3 análises replicadas da mesma amostra. O padrão internacional ECRM752-1 (Greaves et al., 2008) também foi analisado para validar os resultados.

A equação de Anand et al. (2003) foi utilizada para a aquisição das paleotemperaturas da superfície marinha baseadas em $\mathrm{Mg} / \mathrm{Ca}(\mathrm{Mg} / \mathrm{Ca} \mathrm{SST})$ entre 19.000 anos cal A.P. e o Presente a partir dos valores obtidos de $\mathrm{Mg} / \mathrm{Ca}$ nas testas da espécie G. ruber (white, s.s.):

$\mathrm{Mg} / \mathrm{Ca}($ G. ruber $)=0,45$ exp0,09*SST, onde SST $=$ temperatura superficial do mar.

Esta equação foi escolhida por ter sido construída a partir de amostras do Oceano Atlântico, por possuir metodologia similar à utilizada neste trabalho, e por mostrar valores de SST nas amostras mais superficiais do testemunho GeoB6211-2 condizentes àquelas encontradas para a superfície do atlântico atuais na região de estudo. 
Para a obtenção das salinidades superficiais marinhas (SSS), os valores de $\delta^{18} \mathrm{O}_{\mathrm{c}} G$. ruber (VPDB) fornecidos pelo Prof. Dr. Cristiano Chiessi foram tratados de acordo com a equação de Mulitza et al (2003) para a obtenção dos valores de $\delta^{18} \mathrm{O}_{\mathrm{sw}}(\%$ VSMOW):

$$
\mathrm{Mg} / \mathrm{Ca} \mathrm{SST}=-4,44\left(\delta^{18} \mathrm{O}_{\mathrm{c}}-\delta^{18} \mathrm{O}_{\mathrm{sw}}\right)+14,20, \text { onde: }
$$

$\mathrm{Mg} / \mathrm{Ca} \mathrm{SST}=$ temperatura $\mathrm{Mg} / \mathrm{Ca}$ obtida para testas de G. ruber; $\delta^{18} \mathrm{O}_{\mathrm{c}}=\delta^{18} \mathrm{O}$ calcita e $\delta^{18} \mathrm{O}_{\mathrm{sw}}$ $=\delta^{18} \mathrm{O}$ da água do mar.

A equação de Mulitza et al. (2003) foi escolhida devido a ter sido construída a partir de amostras do Oceano Atlântico, por possuir metodologia harmônica com a utilizada neste trabalho, e por mostrar valores de SSS nas amostras mais superficiais do testemunho GeoB6211-2 condizentes àquelas encontradas para a superfície do atlântico atuais na região de estudo.

As considerações de Hut (1987) e Schrag et al. (2002) foram então aplicadas para obter os valores de $\delta^{18} \mathrm{O}_{\mathrm{sw}}$ com as correções do volume global do nível do mar e do gelo, ou seja, de $\delta^{18} \mathrm{O}_{\text {ivc-sw }}$ (\%oVSMOW), aqui utilizado como indicador das paleosalinidades superficiais (SSS) da região de coleta do testemunho GeoB6211-2. A curva de variação do volume de gelo continental utilizada para obter $\delta^{18} \mathrm{O}_{\text {ivc-sw }}$ foi a de Lambeck e Chappell (2001).

\subsection{Análises Microfaunísticas}

As análises microfaunísticas constaram do estudo das associações de foraminíferos bentônicos encontradas ao longo dos testemunhos S03 e GeoB6211-2 e foram efetuadas nos laboratórios de Micropaleontologia (LabMicro), Petrografia (LabPetro) e Microscopia Eletrônica de Varredura (LabMev) do Instituto de Geociências da Universidade de São Paulo (IGc-USP). Os mesmos critérios foram utilizados para os dois testemunhos.

Foram analisadas 35 amostras do testemunho S03, das quais 23 amostras possuíam conteúdo microfaunístico. As 23 amostras analisadas correspondem ao intervalo temporal entre 9.400 e 8.385 anos cal A.P. Já para o testemunho GeoB6211-2, foram analisadas 45 amostras correspondentes à parte do intervalo da Última Deglaciação (19.000 a 14.000 anos cal A.P.) para o estudo das associações de foraminíferos bentônicos. 
Inicialmente, efetuou-se tratamento laboratorial visando separar os foraminíferos do sedimento. Para tanto, $10 \mathrm{~cm}^{3}$ de sedimento foram retirados a cada $10 \mathrm{~cm}$ no testemunho $\mathrm{S} 03 \mathrm{e}$ $1 \mathrm{~g}$ de sedimento seco foi retirado a cada $10 \mathrm{~cm}$ do testemunho GeoB6211-2. Cada amostra retirada de seu respectivo testemunho foi lavada com água corrente em peneiras de 0,500, 0,125 e $0,062 \mathrm{~mm}$. As frações retidas nas peneiras foram secas em estufa a $60^{\circ} \mathrm{C}$ e submetidas à flotação em tricloroetileno $\left(\mathrm{C}_{2} \mathrm{HCl}_{3}\right)$ (Schröder et al., 1987; Scott et al., 2001). Uma primeira análise efetuada em cada uma das frações permitiu notar-se a presença de testas de foraminíferos bentônicos em todas elas. Dessa forma, decidiu-se triar as amostras integralmente (i.e., as três frações $0,062+0,125+0,500 \mathrm{~mm}$ foram somadas para a realização da triagem).

Procedeu-se então à obtenção de 200 espécimes bentônicos para os testemunhos S03 e GeoB6211-2, independentemente de tamanho, coloração ou grau de fragmentação das testas, com a utilização de lupa Zeiss Stemi SV11. Amostras com mais de 200 testas foram quarteadas por meio de microquarteador até que se atingisse aproximadamente a quantidade necessária de testas. Amostras com quantidades de testas inferiores a 200 espécimes foram triadas integralmente. As testas triadas foram fixadas com goma adragante em portaforaminíferos (i.e., lâminas quadriculadas de fundo escuro) (Schröder et al., 1987; Scott et al., 2001).

Em uma segunda etapa, as testas triadas nos dois testemunhos foram identificadas com a utilização de lupa Zeiss Stemi VS11, de acordo com Semensatto Jr. et al. (2008), Loeblich e Tappan (1964, 1988), Boltovskoy et al. (1980), com o World Modern Foraminifera Database (Hayward et al., 2011) e com exemplares da coleção micropaleontológica do IGc-USP.

Foram calculadas a densidade (número de testas $/ \mathrm{cm}^{3}$ para o testemunho S03 e número de testas/1g de sedimento seco para o testemunho GeoB6211-2) e a riqueza (número de espécies/amostra), para se classificar as associações de foraminíferos bentônicos quanto à abundância de testas e de espécies por amostra.

A diversidade de Shannon-Wiener (H', de Shannon e Weaver, 1999) foi obtida por meio da fórmula:

$$
H^{\prime}=-\Sigma p_{i} \log p_{i} \text { onde: }
$$

$p_{i}=$ proporção da espécie em relação ao número total de espécies da amostra. 
Já a equitabilidade de Pielou (J', de Pielou, 1969) foi obtida por meio da fórmula:

$$
\mathrm{J}^{\prime}=\mathrm{H}^{\prime} / \log \mathrm{S} \text {, onde: }
$$

$\mathrm{H}^{\prime}=$ diversidade de Shannon-Wiener e $\mathrm{S}=$ número total de espécies da amostra.

para expressar a maneira pela qual os indivíduos de uma mesma amostra se distribuíram entre si (J'), e como essa correlação se deu em relação à riqueza da amostra (H'). O índice Benthic Foraminiferal Accumulation Rate (BFAR, de Herguera e Berger, 1991) foi calculado para determinar se as modificações nas taxa de sedimentação influenciaram o acúmulo de testas nas amostras do testemunho GeoB6211-2 por meio da fórmula:

$\mathrm{BFAR}=\mathrm{D} * \mathrm{TS} * \mathrm{DSS}$, onde:

$\mathrm{D}=$ densidade de foraminíferos por amostra (número de foraminíferos $/ 1 \mathrm{~g}$ sedimento seco), TS = taxa de sedimentação do testemuho GeoB6211-2 (cm/ka) e DSS = densidade de sedimento seco do testemunho GeoB6211-2 $\left(\mathrm{g} / \mathrm{cm}^{3}\right)$.

As espécies encontradas foram classificadas quanto às suas indicações paleoambientais (e.g., Buzas, 1968; Murray, 1991; Kitazato, 1994; Baas et al., 1998; Badawi et al., 2005; Duleba et al., 2005; Langezaal et al., 2006; Semensatto-Jr et al., 2008; Basak et al., 2009).

Para o testemunho S03, as espécies identificadas foram agrupadas em indicadoras de águas mais rasas, costeiras (AC), e de águas mais profundas, francamente marinhas (AT e ACAS); em porcentagens de espécies representativas de águas de salinidades euhalinas (>30\%); polihalinas/mesohalinas (30-5\%o) e oligohalinas/limnéticas $(5-0,5 \% 0 /<0,5 \%$ ).

Para o testemunho GeoB6211-2, as espécies encontradas foram agrupadas em espécies bentônicas (\% bentônicos) e planctônicas (\% planctônicos) em todo o testemunho. A razão planctônicos/bentônicos (razão P/B, de acordo com Culver, 1988 e Smart, 2002) foi utilizada para determinação de diferenças na profundidade da coluna de água do mar. Segundo Culver (1988) e Smart (2002), quanto mais profunda a coluna de água e mais afastada da costa estiver a amostra analisada, maior a porcentagem de foraminíferos planctônicos em relação à de foraminíferos bentônicos. A razão P/B foi calculada em porcentagem para este trabalho. Para tanto, utilizou-se a fórmula: 
Razão $\mathrm{P} / \mathrm{B}=[($ número total de planctônicos/número total de planctônicos + bentônicos)*100 $]$

Para o intervalo compreendido entre 19.000 e 14.000 anos cal A.P., apenas espécies bentônicas foram analisadas no testemunho GeoB6211-2. Para este intervalo temporal, as espécies de foraminíferos bentônicos foram agrupadas em espécies pertencentes à epifauna (espécies que vivem sobre os sedimentos), infauna (aquelas que vivem no sedimento) e epifauna-infauna (aquelas capazes de habitar os dois ambientes), para determinar se a oscilação do nível marinho influenciou as associações no talude continental.

Os índices Benthic Foraminifer High Productivity Index (BFHP, segundo Martins et al., 2007) e Benthic Foraminiferal Oxygen Index (BFOI, segundo Kaiho, 1991, 1994; modificado por Baas et al., 1998) foram calculados para as associações de foraminíferos bentônicos dos dois testemunhos. Para se calcular o índice BFHP, indicador do acúmulo de matéria orgânica (M.O.) nos sedimentos, espécies típicas do acúmulo de matéria orgânica no meio foram agrupadas nos dois testemunhos. Para o cálculo do índice BFOI, indicador dos graus de oxigenação do meio, as espécies de ambos os testemunhos foram agrupadas em típicas de ambientes disaeróbicos/subóxicos (0,1 a 1,5 ml/L de $\mathrm{O}_{2}$; Baas et al., 1998) e oxigenados $\left(>1,5 \mathrm{ml} / \mathrm{L}\right.$ de $\mathrm{O}_{2}$; Baas et al., 1998). O índice BFOI foi obtido por meio da fórmula:

$$
\mathrm{BFOI}=[100 *(\mathrm{O} / \mathrm{O}+\mathrm{D})], \text { onde: }
$$

$\mathrm{O}=$ número de espécies típicas de ambiente oxigenado, e $\mathrm{D}=$ número de espécies típicas de ambiente disóxico.

Para confirmar a validação da utilização desse índice nos dois ambientes marinhos considerados neste trabalho, as espécies utilizadas para a soma de óxicas e disaeróbicas foram avaliadas criteriosamente. Espécies de afinidade desconhecida ou dúbia foram descartadas. Para o testemunho GeoB6211-2, apenas espécies acima de $125 \mathrm{~mm}$ foram consideradas, para evitar a interferência daquelas que pudessem ser alóctones ao sítio de estudos.

As espécies utilizadas para a obtenção desses dois gráficos são listadas a seguir. 
Tabela 1: Espécies de foraminíferos bentônicos utilizadas para a confecção do índice BFOI.

\begin{tabular}{|c|c|c|}
\hline $\begin{array}{c}\text { Espécies Disaeróbicas } \\
\text { (ambientes disaeróbicos/subóxicos) }\end{array}$ & $\begin{array}{c}\text { Espécies Óxicas } \\
\text { (ambientes óxicos) }\end{array}$ & $\begin{array}{l}\text { Espécies típicas de matéria orgânica } \\
\text { (M.O.) (Ambiente rico em nutrientes) }\end{array}$ \\
\hline $\begin{array}{c}\text { Ammonia parkinsoniana } \\
\text { Ammonia tepida } \\
\text { Bolivina doniezi } \\
\text { Bolivina alata } \\
\text { Bolivina pulchella } \\
\text { Bolivinellina translucens } \\
\text { Brizalina subaenariensis } \\
\text { Bulimina elongata } \\
\text { Bulimina marginata } \\
\text { Buliminella elegantissima } \\
\text { Brizalina striatula } \\
\text { Cassidulinoides brasiliensis } \\
\text { Cribroelphidium poeyanum } \\
\text { Elphidium advenum limbatum } \\
\text { Elphidium discoidale } \\
\text { Elphidium excavatum } \\
\text { Eponides repandus } \\
\text { Fursenkoina pontoni } \\
\text { Globocassidulina minuta } \\
\text { Globobulimina pacifica } \\
\text { Melonis barleeanus } \\
\text { Nonionella atlantica } \\
\text { Nonionella auris } \\
\text { Nonionella opima } \\
\text { Nonionellina labradorica } \\
\text { Nonion depressulus } \\
\text { Nonionoides grateloupii } \\
\text { Pseudononion pulchella } \\
\text { Rutherfordoides rotundiformis } \\
\text { Stainforthia concava } \\
\text { Uvigerina bifurcata } \\
\text { Uvigerina peregrina } \\
\text { Uvigerina striata }\end{array}$ & $\begin{array}{c}\text { Cibicides dispars } \\
\text { Cibicides kullenbergi } \\
\text { Cibicides refulgens } \\
\text { Cibicidoides pseudohungerianus } \\
\text { Fissurina laevigata } \\
\text { Gyroidina altiformis } \\
\text { Hanzawaia boweana } \\
\text { Lagena laevis } \\
\text { Lagena striata } \\
\text { Lobatula lobatula } \\
\text { Miliolinella subrotunda } \\
\text { Pararotalia cananeiaensis } \\
\text { Poroeponides lateralis } \\
\text { Pyrgo murhina } \\
\text { Pyrgo nasuta } \\
\text { Pyrgo ringens } \\
\text { Pyrgo subsphaerica } \\
\text { Pyrgo williamsoni } \\
\text { Quinqueloculina atlantica } \\
\text { Quinqueloculina lamarckiana } \\
\text { Quinqueloculina milletti } \\
\text { Quinqueloculina patagonica } \\
\text { Rosalina williamsoni } \\
\text { Triloculina sp. }\end{array}$ & $\begin{array}{c}\text { Bolivina alata } \\
\text { Bolivina doniezi } \\
\text { Bolivina pulchella } \\
\text { Bolivinellina translucens } \\
\text { Brizalina subaenariensis } \\
\text { Brizalina striatula } \\
\text { Bulimina elongata } \\
\text { Bulimina marginata } \\
\text { Buliminella elegantissima } \\
\text { Cassidulina laevigata } \\
\text { Globocassidulina minuta } \\
\text { Cassidulinoides brasiliensis } \\
\text { Cribroelphidium poeyanum } \\
\text { Elphidium advenum limbatum } \\
\text { Elphidium discoidale } \\
\text { Elphidium excavatum } \\
\text { Fursenkoina pontoni } \\
\text { Globobulimina pacifica } \\
\text { Hopkinsina pacifica } \\
\text { Melonis barleeanus } \\
\text { Nonionella atlantica } \\
\text { Nonionella auris } \\
\text { Nonionella opima } \\
\text { Nonionellina labradorica } \\
\text { Nonion depressulus } \\
\text { Nonionoides grateloupi } \\
\text { Pseudonion pulchella } \\
\text { Stainforthia concava } \\
\text { Textularia agglutinans } \\
\text { Uvigerina bifurcata } \\
\text { Uvigerina peregrina } \\
\text { Uvigerina striata }\end{array}$ \\
\hline
\end{tabular}

O estudo morfométrico agrupou as testas identificadas nos dois testemunhos em pequenas $(<125 \mu \mathrm{m})$, médias $(125-250 \mu \mathrm{m})$, grandes $(250-500 \mu \mathrm{m})$ e macro $(>500 \mu \mathrm{m}) \mathrm{de}$ acordo com a escala granulométrica de Wentworth (1922). Para tanto, cada uma das testas das espécies bentônicas dos dois testemunhos foi fotografada por câmara digital acoplada em microscópio estereoscópico (Lupa Zeiss Stemi SV11) e medidas com a utilização do analisador de imagens AnalySis.

A análise tafonômica foi realizada para que se pudesse avaliar até que ponto os processos post mortem teriam afetado as associações de foraminíferos bentônicos fósseis e sub-fósseis, desde sua deposição até sua coleta para análise. Segundo Bekeley (2009), este estudo é importante devido ao fato de que esses processos podem (ou não) modificar o registro fossilífero, bem como as indicações paleoambientais que eles fornecem.

Nesse estudo, as características tafonômicas das testas dos foraminíferos bentônicos dos testemunhos S03 e GeoB6211-2 foram observadas em lupa binocular Zeiss Stemi SV11 e por meio de microfotografias obtidas em microscópio eletrônico de varredura (MEV). Essa 
análise levou em consideração adaptações dos aspectos considerados nos trabalhos de Mayklem (1967), Brett e Baird (1986), Martin e Lidell (1991), Duleba (1994) e Berkeley et al. (2007).

Esses aspectos se resumiram às análises de coloração e dos graus de fragmentação das testas. Quanto à coloração, verificou-se a impregnação e/ou preenchimento das testas. Elas foram agrupadas em brancas (sem nenhum tipo de impregnação e/ou preenchimento), douradas (com impregnação e/ou preenchimento por minerais de coloração dourada), pretas (com preenchimento e/ou impregnação por minerais de coloração preta) e acastanhadas (com impregnação por coloração acastanhada).

Como não foram realizadas análises químicas para identificação dos minerais e/ou compostos que preenchiam e/ou impregnavam as testas, optou-se por denominá-los genericamente de "monossulfeto de ferro $(\mathrm{FeS})$ ", quando as testas tiveram coloração preta, de "sulfeto de ferro $\left(\mathrm{FeS}_{2}\right)$ ", quando apareceram douradas, e de "hidróxido de ferro", quando sua coloração foi acastanhada. Essa classificação genérica levou em conta estudos realizados por Mayklem, (1967) e Berner (1970).

Para a análise dos graus de fragmentação das testas, foram consideradas inteiras aquelas que não exibiram qualquer desgaste estrutural externo visível. Testas parcialmente fragmentadas foram aquelas que apresentaram estrutura externa desgastada com até $50 \%$ de seu tamanho original, e puderam ser classificadas em nível genérico. Fragmentos constituíram testas destruídas em mais de $50 \%$ de sua estrutura original, o que impediu a classificação do espécime inclusive em nível genérico. Como agentes responsáveis pelo desgaste e/ou destruição das testas, foram considerados aqui os processos post mortem de abrasão, bioerosão e corrosão/dissolução.

Processos de abrasão seriam causados por atritos externos, resultando na fragmentação das testas. A bioerosão, pela ação de organismos que se alimentariam das testas, resultando em orifícios originalmente arredondados nas mesmas. E a corrosão/dissolução seria causada por processos químicos, resultando em fragilização das testas. Optou-se por considerar a frequência de cada processo separadamente. Dessa forma, quando uma testa apresentava mais de um desses processos post mortem, cada um deles foi considerado para a caracterização final dos processos responsáveis pelo desgaste das testas.

Alguns espécimes triados dos dois testemunhos foram escolhidos para serem fotografados em microscópio eletrônico de varredura (MEV) para auxílio na identificação taxonômica e da caracterização dos processos tafonômicos encontrados nas associações (Lea, 1999; Sen Gupta, 1999). 
Por fim, realizou-se análise estatística de agrupamento modo-R (espécies vs. espécies) para agrupar as associações de foraminíferos bentônicos em diferentes grupos nos testemunhos S03 e GeoB6211-2. Para esta análise, a distância euclidiana e o método de agrupamento de Ward (Everitt et al., 2011) foram aplicados a todas as espécies encontradas no testemunhos S03 e às 22 espécies mais abundantes do testemunho GeoB6211-2. A análise estatística foi efetuada por meio do software Minitab 15 for Windows.

Os diferentes grupos encontrados pela análise estatística de agrupamento modo-R foram denominados "Associações". Suas paleoindicações basearam-se nos trabalhos de Bandi (1953); Boltovskoy (1959); Boltovskoy e Lena (1971); Corliss (1985, 1991); Brönnimann (1988); Caralp (1989); Cassel e Sen Gupta (1989); Walton e Sloan (1990); Alve, (1991 apud Le Cadre e Debenay 2006); Boltovskoy et al. (1991); Murray (1991); Mackensen et al. (1993); Yanko (1994, apud Le Cadre e Debenay 2006); Alve e Bernhard (1995); Jorissen et al. (1995); Thomas et al. (1995); Sen Gupta et al. (1996); Harloff e Mackensen (1996); Baas et al. (1998); Moodley et al. (1998); Alve (1999); Bernhard e Sen Gupta, (1999); Oliveira (1999); De Rijk et al. (2000); Karlsen et al. (2000, apud Sen Gupta e Platon 2006); Kennet et al. (2000); Li et al. (2000); Debenay et al. (2001); Mercone et al. (2001); Fontainier et al. (2002); Gooday e Hughes (2002); Kaminski et al. (2002); Polyak et al. (2002); Rasmussen et al. (2002); Bergamin et al. (2003, 2009); Scott et al., (2003); Duleba e Debenay (2003); Drinia et al. (2003); Eichler et al. (2003, 2004); Guilbault et al. (2003); Javaux e Scott (2003); Licari et al. (2003); Osterman (2003); Scott et al. (2003); Vilela et al. (2003); Frenzel et al. (2004); Girardeau et al. (2004); Martins e Gomes (2004); Semensatto Jr. e Dias-Brito (2004); Badawi et al. (2005); Duleba et al. (2005); Lançone et al. (2005); Morigi et al. (2005); Eberwein e Mackensen (2006); Langezaal et al. (2006); Martins et al. (2006, 2007); Sen Gupta e Platon (2006); Sousa et al. (2006); Thibodeau et al. (2006); Cardoso e Senra (2007); Jorrisen et al. (2007); Kunht et al. (2007); Diz e Francés (2008); Eichler et al. (2008); Koho et al. (2008); Pascual et al. (2008); Semensatto Jr. et al. (2008, 2009); Basak et al. (2009); Ghosh et al. (2009); Milker et al. (2009); Riveiros e Patterson (2009); De e Gupta (2010); Dhahri (2010); Souza et al. (2010); Zarris e Mackensen (2010); Hromic (2011); Laprida et al. (2011); McCarthy (2011); Van Hengstum e Scott (2011). 


\section{CAPÍTULO 7: Resultados}

\subsection{Testemunho S03}

\subsubsection{Resultados Abióticos}

As idades calendário obtidas para o testemunho S03 revelaram idade geológica de 9.400 anos cal A.P. em sua base $(5,79 \mathrm{~m})$ (Tabela 2).

Tabela 2: Idades geológicas obtidas para o testemunho S03. pMC: resultado reportado como \% da referência padrão moderna, indicando que o material estava vivendo nos últimos 50 anos. NRMA (nível relativo do mar atual): altitude atual acima do nível médio do mar. Dados retirados de Sallun et al., (2012).

\begin{tabular}{|c|c|c|c|c|}
\hline Profundidade & $\begin{array}{c}\text { Idade }{ }^{14} \mathrm{C} \text { (anos } \\
\text { A.P.) }\end{array}$ & $\begin{array}{l}\text { Idade calendário (anos cal } \\
\text { A.P.) (probabilidade média) }\end{array}$ & $\begin{array}{c}\text { Intervalo de Idade calendário } \\
\text { (anos cal. A.P.) }\end{array}$ & Elevação NRMA (m) \\
\hline $0.00 \mathrm{~m}$ & $108.1 \pm 0.4 \mathrm{pMC}$ & Moderno & - & 2,63 \\
\hline $0.10-0.12 \mathrm{~m}$ & $280 \pm 40$ & 305 & 460 to 280 & 2,53 \\
\hline $0.30-0.32 \mathrm{~m}$ & $2180 \pm 40$ & 2120 & $\begin{array}{l}2090 \text { to } 2060 \\
2320 \text { to } 2100\end{array}$ & 2,32 \\
\hline $0.38-0.40 \mathrm{~m}$ & $3890 \pm 40$ & 4240 & $\begin{array}{l}4200 \text { to } 4160 \\
4420 \text { to } 4230\end{array}$ & 2,25 \\
\hline $0.50-0.52$ & $4190 \pm 40$ & 4640 & $\begin{array}{l}4840 \text { to } 4780 \\
4770 \text { to } 4580\end{array}$ & 2,13 \\
\hline $0.60-0.62 \mathrm{~m}$ & $5440 \pm 40$ & 6205 & 6300 to 6190 & 2,03 \\
\hline $0.80-0.82 \mathrm{~m}$ & $6620 \pm 50$ & 7450 & 7580 to 7430 & 1,83 \\
\hline $0.90-0.92 \mathrm{~m}$ & $6760 \pm 50$ & 7575 & 7680 to 7560 & 1,73 \\
\hline $1.00-1.02 \mathrm{~m}$ & $6830 \pm 50$ & 7615 & 7750 to 7580 & 1,63 \\
\hline $1.70-1.72$ & $7220 \pm 50$ & 7975 & 7950 to 8170 & 0,93 \\
\hline $2.00-2.02 \mathrm{~m}$ & $7600 \pm 50$ & 8375 & 8460 to 8350 & 0,63 \\
\hline $3.00-3.02 \mathrm{~m}$ & $7620 \pm 50$ & 8385 & 8520 to 8360 & $-0,37$ \\
\hline $4.00-4.02 \mathrm{~m}$ & $7810 \pm 50$ & 8545 & $\begin{array}{l}8700 \text { to } 8670 \\
8650 \text { to } 8510 \\
8500 \text { to } 8470\end{array}$ & $-1,37$ \\
\hline $5.00-5.02 \mathrm{~m}$ & $7970 \pm 50$ & 8700 & 9010 to 8630 & $-2,37$ \\
\hline $5.79 \mathrm{~m}$ & $8370 \pm 50$ & 9400 & 9490 to 9280 & $-3,16$ \\
\hline
\end{tabular}

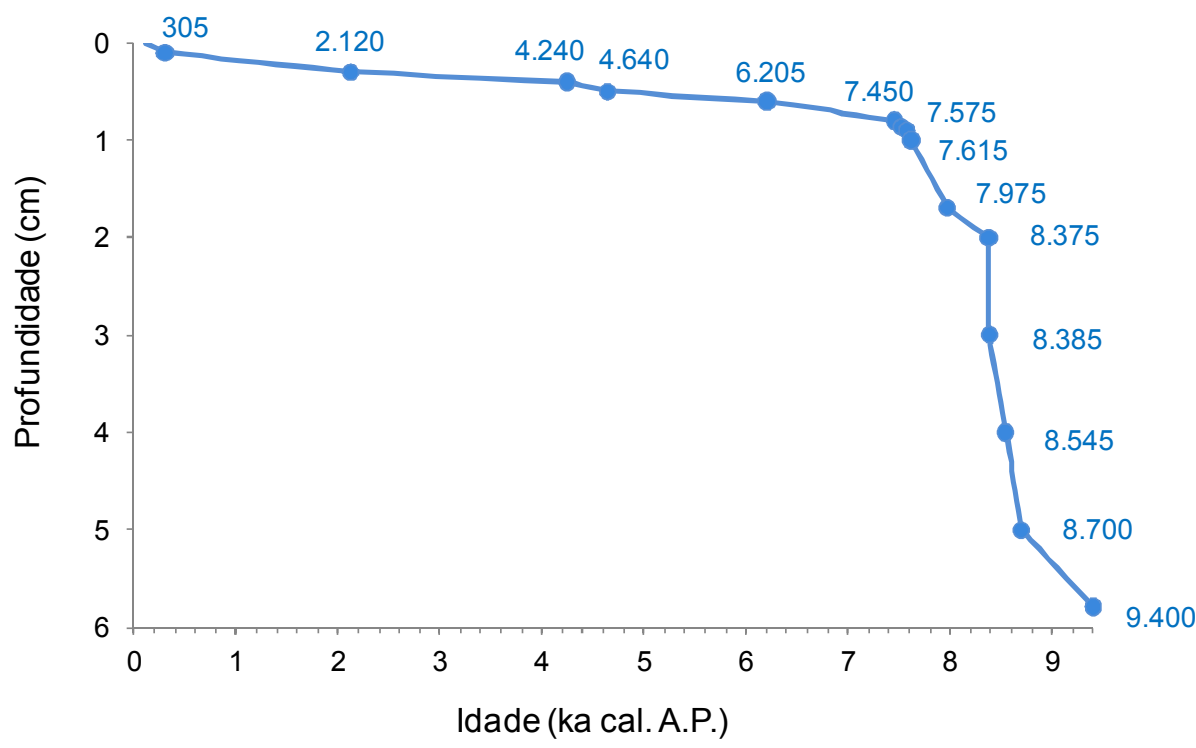

Figura 19: Modelo de idades para o testemunho S03. Retirado de Sallun et al. (2012). As idades indicadas na imagem correspondem àquelas medidas para o testemunho S03 e estão expressas em anos calculados (cal A.P.). 
A análise granulométrica do testemunho S03 revelou predominância de sedimentos pelíticos, majoritariamente sílticos, muito pobremente selecionados a pobremente selecionados. As porcentagens de sedimentos pelíticos situaram-se entre 7,77\% (7.583 anos cal A.P.) e 58,14\% (8.500 anos cal A.P.) do total de sedimento das amostras, e as de areias, entre $1,05 \%$ (1.394 anos cal A.P.) e 9,80\% (8.484 anos cal A.P.) do total de sedimentos das amostras (Tabela 3, em anexo; fig. 20).

Os valores do diâmetro médio dos grãos expressos em phi (ø) variaram de 4,39 a 7,58 e foram classificados de acordo com Krumbein (1936) entre silte muito fino (de 7 a 8) e silte grosso (de 4 a 5) (Tabela 3, em anexo; fig. 20). A assimetria dos grãos variou de -1,27 (1.394 anos cal A.P.) a 1,74 (8.579 anos cal A.P.). Já os valores de curtose variaram de 1,59 (8.484 anos cal A.P.) a 5,67 (8.579 anos cal A.P.). De acordo com Folk e Ward (1957), a assimetria dos grãos variou entre muito negativa e muito positiva; e a curtose, entre muito leptocúrtica a extremamente leptocúrtica (Tabela 3, em anexo; fig. 20).

As porcentagens de carbonatos $(\% \mathrm{CaO})$ nos sedimentos do testemunho $\mathrm{S} 03$ se situaram entre 0,11 e 1,97\%, em 1.576 e 8.513 anos cal A.P., respectivamente. Entre 7.607 e 7.583 anos cal A.P. e entre 7.550 e 7.500 anos cal A.P. os valores de \% $\mathrm{CaO}$ não foram determinados (Fig. 20). De acordo com as classificações de Larsonneur et al. (1977) e Dias (1996), esses valores indicam sedimentos litoclásticos para o testemunho S03.

As porcentagens de carbono orgânico $\left(\mathrm{C}_{\text {org }}\right.$ ) (entre $0,7 \%$ e 3,98\%) seguiram a mesma tendência dos valores de nitrogênio total $\left(\mathrm{N}_{\text {total }}\right)$ (entre $0,05 \%$ e $0,17 \%$ ) entre a base e aproximadamente 486 anos cal A.P. Nos primeiros 486 anos cal. A.P. do testemunho S03, os valores de $\mathrm{C}_{\text {org. }}$ aumentaram e os de $\mathrm{N}_{\text {total }}$, diminuíram (Fig. 20).

A razão $\mathrm{C} / \mathrm{N}$ mostrou valores entre 11,10 e 24,92 , ou seja, sua origem variou entre mista (i.e., marinha e continental) e continental. Seus valores demonstraram tendência geral de aumento até 8.376 anos cal A.P., onde atingiram seu maior valor. Sequencialmente, diminuíram até 4.320 anos cal A.P., onde alcançaram seu menor valor e, dessa profundidade ao topo do testemunho, tornaram a aumentar (Fig. 20). Os valores de $\delta^{13} \mathrm{C}$ encontrados ao longo do testemunho S03 variaram entre -24,1 (8.685 anos cal A.P.) e -26,8 (2.120 anos cal A.P.) (Fig. 20). De acordo com Lamb et al. (2006), esses valores, em conjunto com os valores da razão $\mathrm{C} / \mathrm{N}$, indicaram origem tanto terrestre quanto marinha para a matéria orgânica que atingiu os sedimentos do MJI, corroborando os resultados da razão C/N (Fig. 18). 


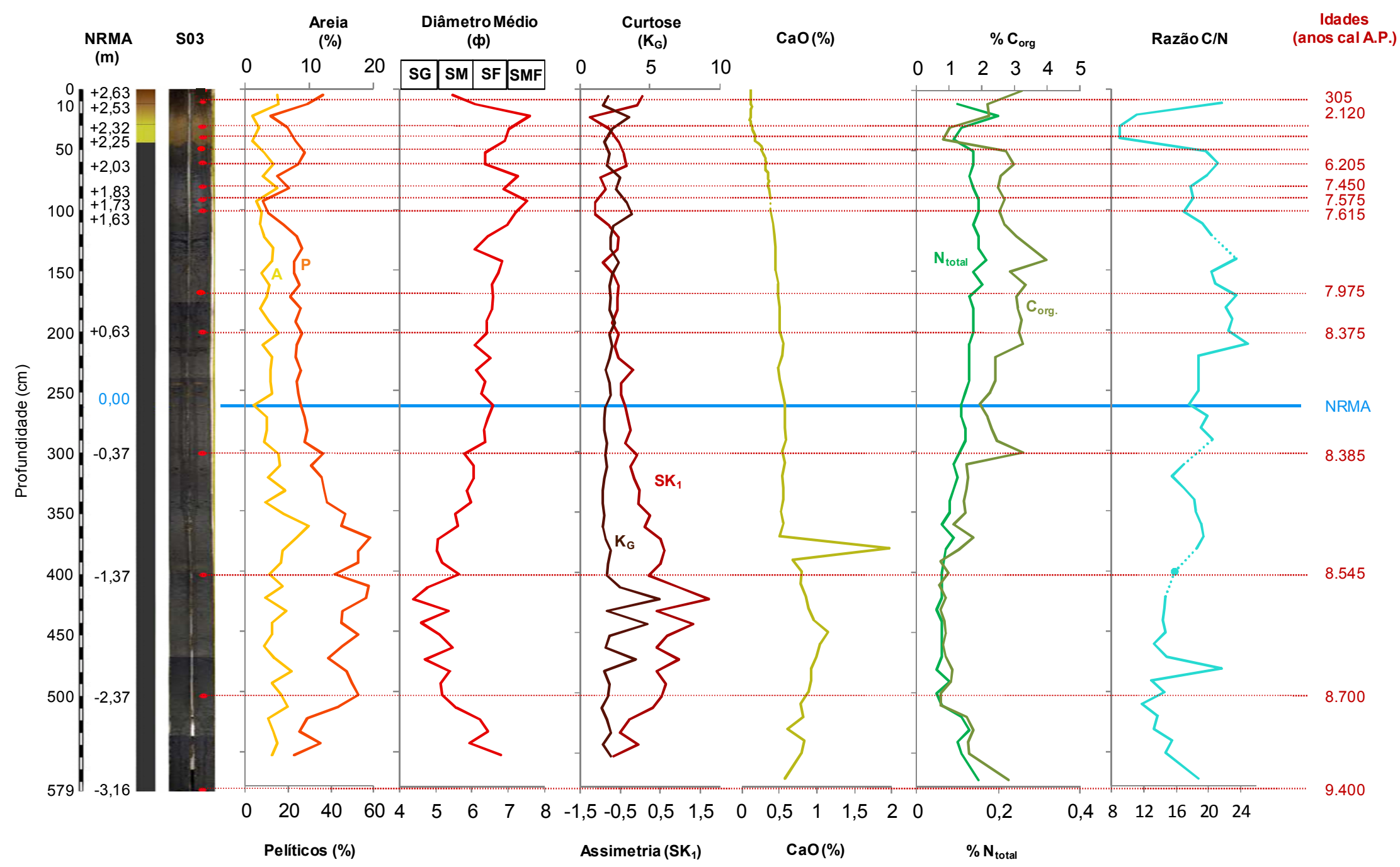

Figura 20: Dados de granulometria (\% total de areias e \% total de pelitos), diâmetro médio em escala phi (ø), assimetria $\left(\mathrm{SK}_{1}\right)$, curtose $\left(\mathrm{K}_{\mathrm{G}}\right)$, porcentagem de carbonatos $(\% \mathrm{CaO})$, porcentagens de carbono orgânico $\left(\mathrm{C}_{\text {org }}\right)$ e nitrogênio total $\left(\mathrm{N}_{\text {total }}\right)$ do testemunho $\mathrm{S} 03$. ENRM- elevação em relação ao nível médio do mar atual. A- areia. Ppelíticos. $\mathrm{K}_{\mathrm{G}^{-}}$curtose. $\mathrm{SK}_{1}$ - assimetria. Modelo de idades retirado de Sallun et al. (2012). NRMA- nível relativo do mar atual. Dados estratigráficos, granulométricos e químicos originais cedidos por Sallun et al. (2012) e Suguio et al. (2008). 
Dentre os elementos químicos analisados no testemunho S03, o alumínio (Al) foi o único que mostrou valores (entre 0,57 e $3 \%$ ) que tiveram tendência geral de aumento rumo ao topo do testemunho. Os valores normalizados dos elementos cálcio ( $\mathrm{Ca}$, entre 0,006 e 1,579), ferro (Fe, entre 0,600 e 2,794) e potássio $(\mathrm{K}$, entre 0,075 e 0,515$)$ tiveram tendência ao decréscimo da base do testemunho até em torno de 2.500 anos cal A.P., a partir de quando apresentaram leve tendência crescente rumo ao topo do testemunho. Os valores do elemento titânio ( $\mathrm{Ti}$, entre 0,008 e 0,020) aumentaram até 5.266 anos cal A.P., diminuíram até 1.213 anos cal A.P. e voltaram a aumentar até o topo do S03. (Tabela 4, Fig. 21).

A razão $\mathrm{Ti} / \mathrm{Ca}$ foi obtida apenas em alguns intervalos deposicionais do testemunho. Nesses intervalos, essa razão demonstrou menores valores (entre 0,008 e 0,444) entre a base do testemunho e 6.329 anos cal A.P. Já entre 486 anos cal A.P. e 108 anos cal A.P., seus valores aumentaram ficando entre 3 e 1,5, respectivamente (Tabela 4, Fig. 21).

Já a razão $\mathrm{Fe} / \mathrm{K}$, mostrou valores entre 5,29 (em 8.687 anos cal A.P.) e 25,55 (em 4.320 anos cal A.P.). Seus valores aumentaram até 4.320 anos cal A.P. e diminuíram a partir dessa idade, rumo ao topo do testemunho (Tabela 4, Fig. 21).

Em $8.789 ; 8.385 ; 7.575 ; 6.827$ e 6.205 anos cal A.P. e entre 4.320 e 4.200 anos cal A.P., os elementos químicos apresentaram picos de aumento ou diminuição consideráveis no testemunho S03 (Fig. 21).

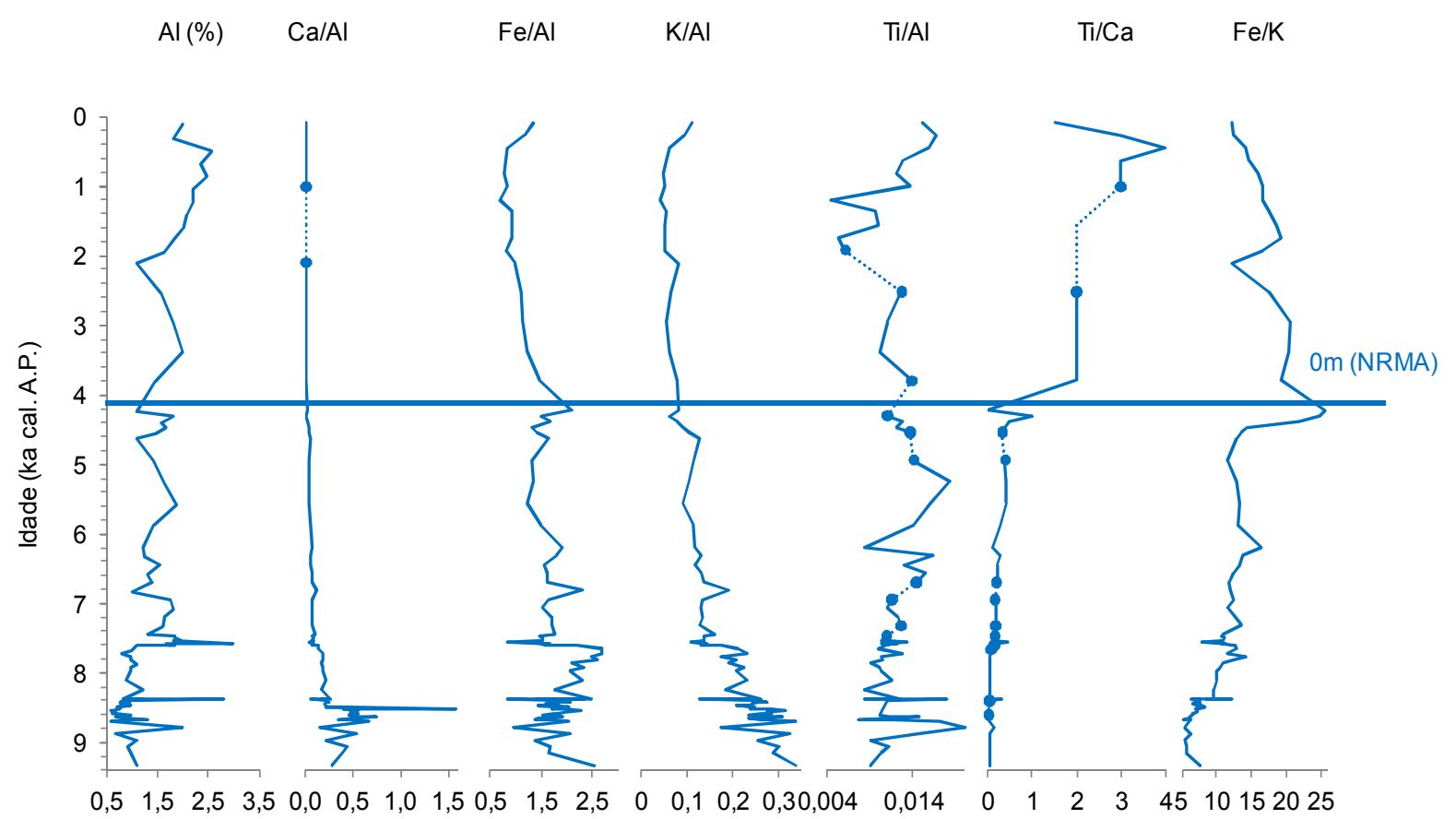

Figura 21: Valores dos elementos químicos obtidos ao longo do testemunho S03. Os valores originais cedidos por Sallun et al. (2012) foram normalizados pelo elemento Al. NRMA: nível relativo do mar atual. Modelo de idades obtido de Sallun et al. (2012). 


\subsubsection{Resultados Microfaunísticos}

Associações de foraminíferos bentônicos foram encontradas nos intervalos de idade de 9.400 anos cal A.P. a 8.894 anos cal A.P.; de 8.656 anos cal A.P. a 8.641 anos cal A.P.; em 8.610 anos cal A.P. e de 8.579 anos cal A.P. a 8.500 anos cal A.P. (Tabela 5, em anexo).

As densidades dessas associações, entretanto, não foram abundantes, e não atingiram a quantidade de testas considerada padrão para análise microfaunística, isto é, 200-300 espécimes por amostra. O intervalo deposicional de maior densidade de testas, equivalente à 8.685 anos cal A.P., apresentou 264 testas. Nos intervalos de menor densidade, equivalentes às idades de $8.894 ; 8.449$ e 8.385 anos cal A.P., foram encontradas 84 testas (Tabela 5, em anexo).

A densidade das testas de foraminíferos bentônicos foi baixa entre 9.400 e 8.894 anos cal A.P., com média de 87,9 testas por $10 \mathrm{~cm}^{3}$ de sedimento (Fig. 22). Em 8.656 anos cal A.P. as associações de foraminíferos bentônicos tiveram sua maior densidade. Essa densidade se reduziu em aproximadamente 33\% nos $\sim 15$ anos seguintes, até 8.641 anos cal A.P. (Fig. 22) Foraminíferos bentônicos ocorreram novamente em 8.610 anos cal A.P., com densidade de 85 testas em $10 \mathrm{~cm}^{3}$ de sedimento. Entre 8.579 e 8.385 anos cal A.P., a densidade demonstrou tendência geral de queda, com média de 94 testas por $10 \mathrm{~cm}^{3}$ de sedimento (Fig. 22). Entre 8.894 e 8.656 ; entre 8.641 e 8.610 e entre 8.610 e 8.563 anos cal A.P., não ocorreram associações de foraminíferos bentônicos nas amostras do testemunho S03 (Tabela 5, em anexo; fig. 22).

O índice de Equitabilidade de Pielou (J') mostrou valores entre 0,0001 (em 8.465 e em 8.401 anos cal A.P.) e 1,0 (em 8.894; 8.516 e 8.433 anos cal A.P.). Entre 8.579 e 8.385 anos cal A.P., seus valores sofreram variações maiores (Fig.22).

A riqueza das espécies teve valores entre 1 (em 9.338; 9.072; 8.465; 8.433 e 8.401 anos cal A.P.) e 20 (em 8.656 anos cal A.P.). Ela demonstrou tendência geral de aumento entre 9.338 e 8.983 anos cal A.P, e teve média de 3,4 espécies por amostra entre 9.400 e 8.894 anos cal A.P. (Fig. 22). Entre 8.656 e 8.641 anos cal A.P. seus valores diminuíram dez vezes (passaram de 20 espécies para 2 espécies por amostra). Em 8.610 houve apenas duas espécies diferentes de foraminíferos bentônicos nos sedimentos do testemunho S03 (Fig. 22). Entre 8.579 e 8.385 anos cal A.P., a riqueza teve tendência geral de diminuição (Fig. 22), e apresentou média de 4,9 espécies por amostra.

O índice de diversidade de Shannon-Wiener (H') variou entre 0,001 (em 9.338; 9.072; 8.465 e 8.401 anos cal A.P.) e 2,316 em 9.400 anos cal A.P. Os valores desse índice seguiram 
similarmente as tendências de aumento e diminuição dos valores de riqueza de espécies do testemunho S03 (Fig.22).

Os foraminíferos bentônicos mostraram tendência de aumento do equilíbrio de suas associações entre 9.338 e 9.213 anos cal A.P.; entre 8.465 e 8.433 anos cal A.P. e entre 8.401 e 8.385 anos cal A.P. (tarjas azuis na fig. 22). Já entre 9.213 e 9.160 anos cal A.P., entre 8.656 e 8.641 anos cal A.P.; entre 8.579 e 8.563 anos cal A.P.; entre 8.500 e 8.465 anos cal A.P.; e entre 8.433 e 8.401 anos cal A.P. as associações mostraram tendência à diminuição desse equilíbrio (tarjas cinzas na fig. 22). Nos demais intervalos temporais, por vezes as associações de foraminíferos bentônicos se tornaram menos diversas e esse menor número de espécies por amostra mostrou maior equivalência entre si, ou as associações se tornaram mais diversas, e as espécies que as compuseram se tornaram menos equivalentes entre si (Fig. 22).

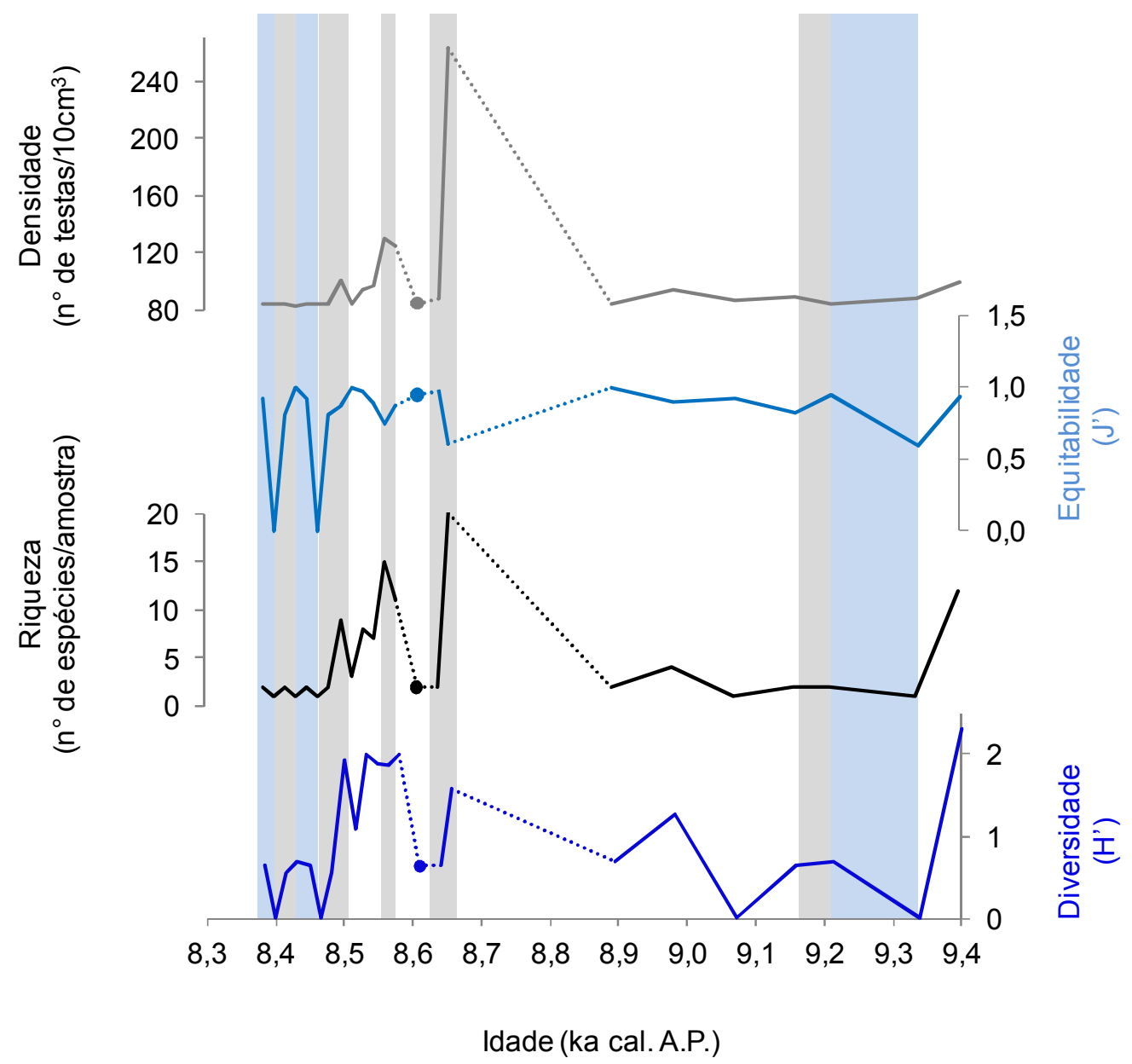

Figura 22: Densidade (número de testas $/ 10 \mathrm{~cm}^{3}$ de sedimento), equitatividade de Pielou (J'), riqueza (número de espécies/amostra) e diversidade de Shannon-Wiener (H') das associações de foraminíferos bentônicos do testemunho S03. Linhas pontilhadas: intervalos em que não houve testas de foraminíferos bentônicos nas amostras. Linha contínua e pontos: intervalos analisados. Tarja azul: intervalos de maior aumento do equilíbrio das associações. Tarja cinza: intervalos de queda mais acentuada do equilíbrio das associações. J' e H' calculados com log base 10. Modelo de idades retirado de Sallun et al. (2012). 
Foram encontradas 25 espécies pertencentes a 20 gêneros diferentes entre 9.400 e 8.385 anos cal A.P. no testemunho S03 (Tabela 5, em anexo). Dentre as espécies de foraminíferos encontradas, as mais abundantes foram Pararotalia cananeiaensis e Ammonia spp. e, secundariamente, Elphidium spp., Cribroelphidium poeyanum e Blysmasphaera spp.; (Tabela 5, em anexo). Quando somadas ao longo de todo o testemunho, foram espécies dominantes (i.e., ocorreram com mais de $50 \%$ do total de testas em todo o S03): Ammonia spp.; Blysmasphaera brasiliensis; Blysmasphaera sp.; Elphidium discoidale e Pararotalia cananeiaensis (Tabela 5, em anexo; fig. 23; prancha 1).

Já espécies subdominantes (i.e., aquelas que, somadas ao longo de todo o S03, apresentaram porcentagens entre 50 e $25 \%$ do total de testas) foram Blysmasphaera broennimanni, Elphidium excavatum e Lagena striata, além das formas jovens. Por sua vez, espécies acessórias (i.e., espécies que, quando somadas ao longo do testemunho, mostraram porcentagens entre 25 e $5 \%$ do total de testas) foram Buliminella elegantissima, Cribroelphidium sp., Fissurina laevigata, Fursenkoina pontoni e Nonionoides grateloupi (Tabela 5; fig. 22).

As demais espécies, mesmo quando somadas ao longo de todo o testemunho S03, foram espécies raras (Tabela 5, em anexo). 


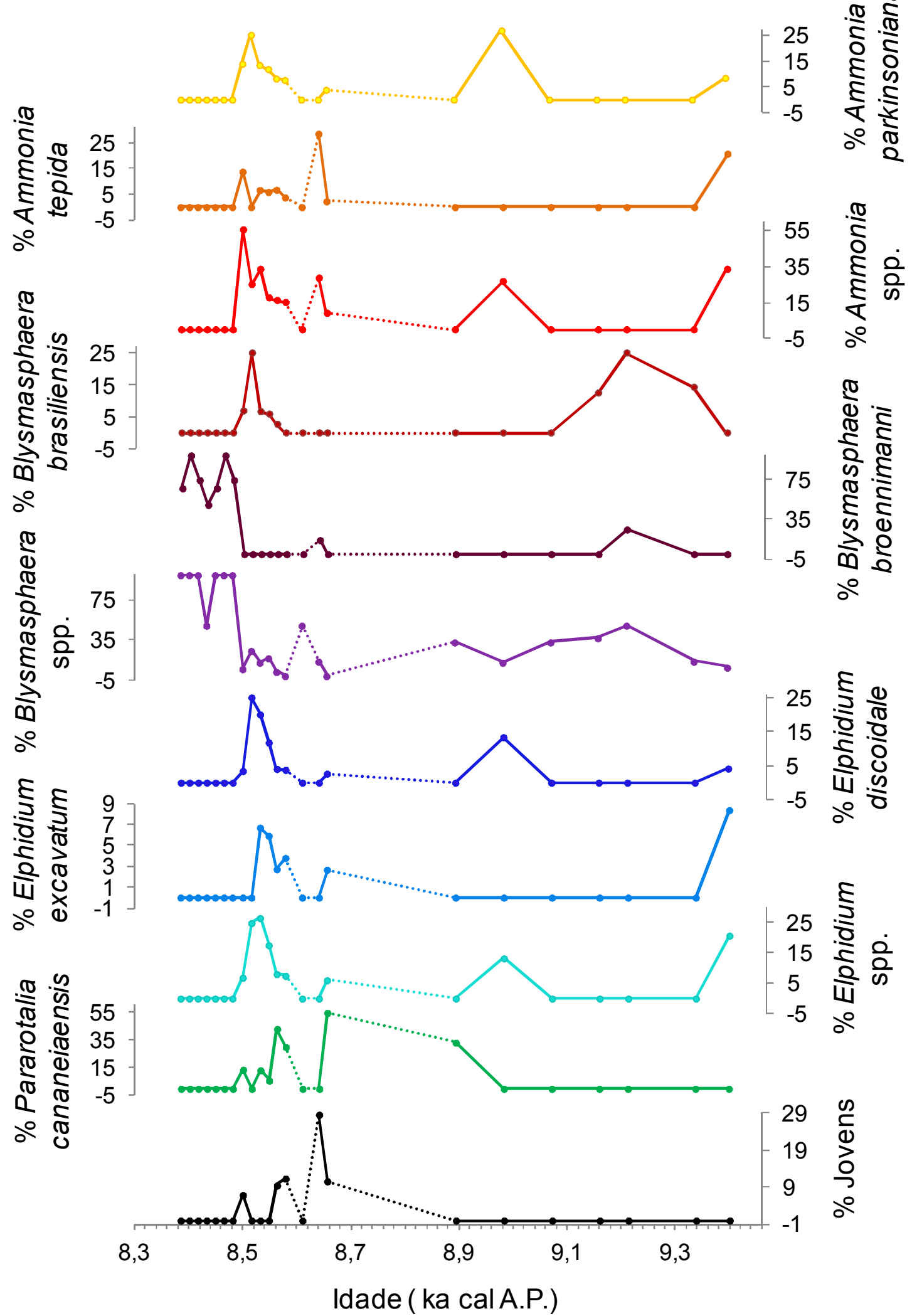

Figura 23: Porcentagens das principais espécies de foraminíferos bentônicos encontradas entre 9.400 e 8.385 anos cal A.P. no testemunho S03. Linhas pontilhadas: intervalos em que não houve testas de foraminíferos bentônicos nas amostras. Linha contínua com pontos e pontos: intervalos analisados. Modelo de idades retirado de Sallun et al. (2012). 
As espécies proxies de águas mais rasas, costeiras (AC), foram expressivas apenas em 9.400 anos cal A.P. (54,1\%); entre 8.983 e 8.894 anos cal A.P. (entre 40\% e 33,3\% das associações); entre 8.656 e 8.641 anos cal A.P. (entre 70\% e 28,6\% das associações); e entre 8.579 e 8.500 anos cal A.P. (entre 75,9\% e 41,2\% das associações) (Fig. 24). Já espécies típicas de águas mais profundas, francamente marinhas (AT e ACAS), ocorreram apenas em 8.656 anos cal A.P. (1,51\%) e em 8.500 anos cal A.P. (3,45\%).

Espécies típicas de águas euhalinas foram mais expressivas entre 8.894 e 8.656 anos cal A.P., 8.579 e 8.563 anos cal A.P. e há 8.500 anos cal A.P. Em 8.656 anos cal A.P. espécies euhalinas representaram $63,6 \%$ das associações de foraminíferos bentônicos da amostra (Fig. 24). Já espécies típicas de águas polihalinas/mesohalinas tiveram frequências mais significativas há 9.400 anos cal A.P. (54\%), e entre 8.532 e 8.500 anos cal A.P. (entre 62 e 50\%), onde foram dominantes nas associações de foraminíferos bentônicos (Fig. 24). Espécies típicas de águas oligohalinas/limnéticas apareceram especialmente há 9.213 anos cal A.P. e há 8.610 anos cal A.P., representando 50\% das associações; e entre 8.481 e 8.385 anos cal A.P., onde somaram o total (100\%) das associações de foraminíferos bentônicos. (Fig. 24).

Essas espécies indicaram que houve quatro épocas de maior salinidade (9.400-9.338; 9.072-8.894; 8.656-8.641 e 8.594-8.500 anos cal A.P.) intercaladas por quatro fases de menor salinidade (9.338-9.072; 8.500-8.385; 8.806-8.672 e 8,625-8,594 anos cal A.P.) entre 9.400 e 8.385 anos cal A.P. no sítio de coleta do testemunho S03.

$\mathrm{O}$ índice BFHP, formado por espécies indicadoras de ambiente rico em matéria orgânica (M.O.), teve valores diferentes de zero em 9.400 anos cal A.P. (37,5\% da amostra), 8.983 anos cal A.P. (13,3\% da amostra); 8.656 anos cal A.P. (15,5\% da amostra); e entre 8.579 e 8.500 anos cal A.P., onde suas porcentagens variaram entre $28,3 \%$ a $10,3 \%$ das associações de foraminíferos bentônicos. (Fig. 24).

$\mathrm{O}$ índice BFOI, que indica o grau da oxigenação do meio, teve valores diferentes de zero em 9.400 anos cal A.P. (5,6\% da associação), entre 8.983 anos cal A.P. (14,28\% da associação) e 8.894 anos cal A.P. (97\% da associação); há 8.656 anos cal A.P. (70,6\% da associação); há 8.610 anos cal A.P. (97\% da amostra); e entre 8.579 e 8.532 anos cal A.P. (entre 46,3\% e 14,3\% da associação) (Fig. 24). De acordo com a classificação de Baas et al. (1998), esses valores do índice BFOI indicam ambiente com baixa quantidade de oxigênio disponível no meio $\left(1,5\right.$ a $3 \mathrm{ml} / \mathrm{L}$ de $\left.\mathrm{O}_{2}\right)$. 


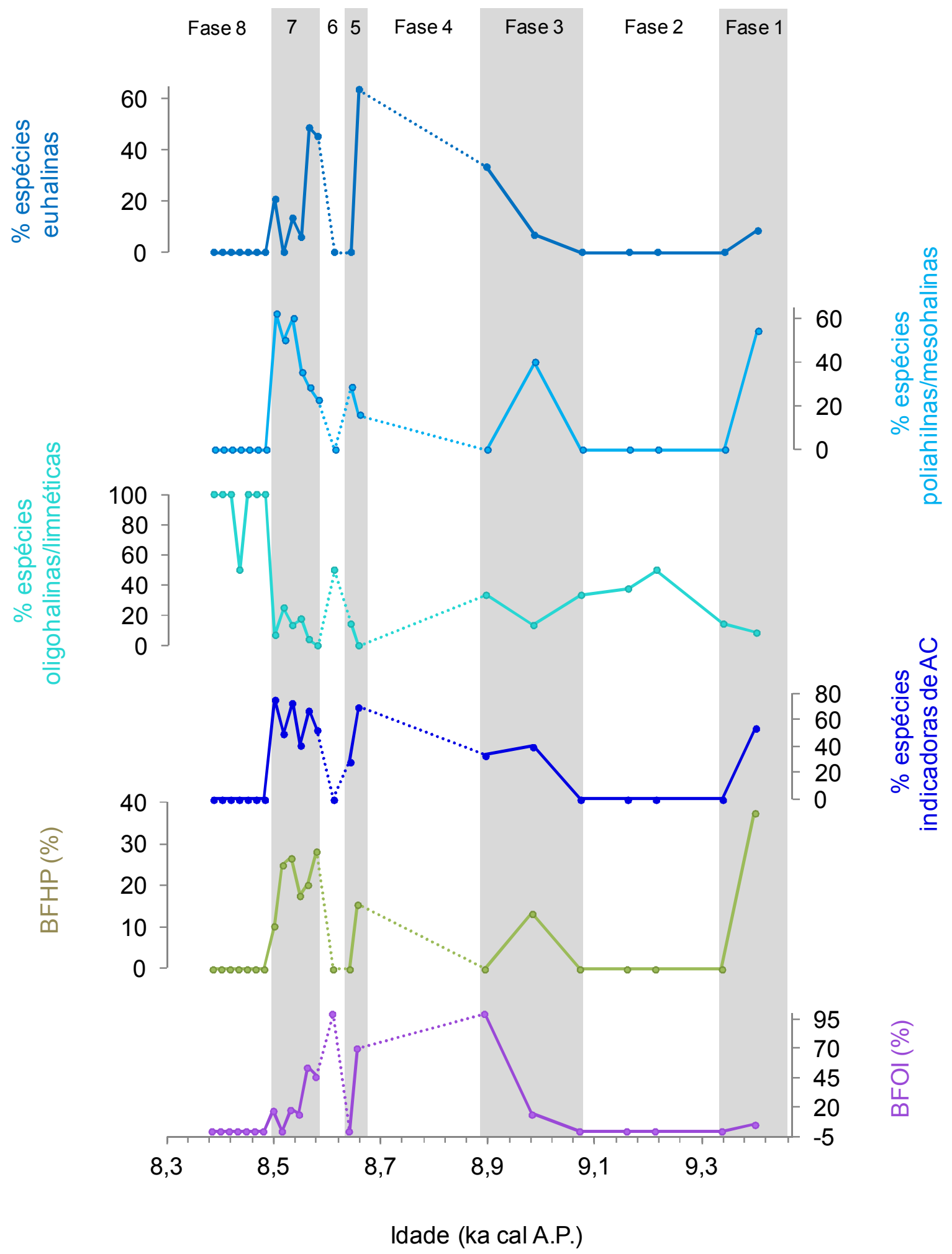

Figura 24: Porcentagens das espécies de foraminíferos bentônicos bioindicadores do testemunho S03. AC: águas mais rasas, costeiras. BFHP: Benthic Foraminifer High Productivity Index (de acordo com Martins et al., 2007), indicador da quantidade de matéria orgânica disponível no meio. BFOI: Benthic Foraminiferal Oxygen Index (segundo Kaiho, 1991, 1994; modificado por Baas et al., 1998), indica o grau de oxigenação do meio. Tarjas cinzas: diferentes fases paleoambientais encontradas no testemunho S03 entre 9.400 e 8.385 anos cal A.P. de acordo com as associações de foraminíferos bentônicos. Modelo de idades retirado de Sallun et al. (2012). 
Testas médias predominaram ao longo do testemunho S03, com porcentagens variando entre 47,2\% (em 8.579 anos cal A.P.) e $100 \%$ (em 9.213; 8.610;8.481; 8.449 e 8.433 anos cal A.P.) (Fig. 25).

Testas pequenas apresentaram porcentagens entre 14,3\% (em 8.641 anos cal A.P.) e $52,8 \%$ (em 8.579 anos cal A.P.), onde se tornaram predominantes sobre testas médias e grandes. Entre 9.213 e 9.072 anos cal A.P.; há 8.610 anos cal A.P.; há 8.548 anos cal A.P.; há 8.481 anos cal A.P., e entre 8.449 e 8.433 anos cal A.P., testas pequenas não ocorreram (Fig. 25). Elas foram mais expressivas que testas grandes, com exceção do intervalo de tempo entre 9.160 e 9.062 anos cal A.P., e há 8.548 anos cal A.P., quando tamanhos grandes sobrepujaram tamanhos pequenos (Fig. 25).

Ainda, há 8.641 anos cal A.P., testas pequenas e grandes representaram a mesma porcentagem (14,3\%) da associação bentônica (Fig. 25). Testas grandes só ocorreram entre 9.160 e 8.983 anos cal A.P., há 8.641 anos cal A.P.; há 8.548 anos cal A.P., e há 8.500 anos cal A.P., com porcentagens que variaram entre 0,4\% (em 8.656 anos cal A.P.) e 16.7\% (em 9.072 anos cal A.P.) (Fig. 25).

Testas brancas, sem alteração de cor, predominaram entre 9.400 e 8.385 anos cal A.P. no testemunho S03, com exceção da idade de 9.160 anos cal A.P., onde testas douradas tiveram maiores porcentagens que testas brancas e pretas (Fig. 25). Suas porcentagens variaram entre 37,5\% (em 9.160 anos cal A.P.) e 100\% (entre 9.338 e 9.213 anos cal A.P.; há 9.072 anos cal A.P.; há 8.894 anos cal A.P.; 8.641 anos cal A.P.; 8.516 anos cal A.P.; há 8.481 anos cal A.P.; entre 8.449 e 8.417 anos cal A.P.; e há 8.385 anos cal A.P.) (Fig. 25).

Já testas douradas (que contêm $\mathrm{FeS}_{2}$ ), não ocorreram nos intervalos de tempo em que testas brancas somaram $100 \%$ das associações das amostras. Nos demais intervalos temporais, suas porcentagens somaram entre 6,7\% (em 8.532 anos cal A.P.) e 62,5\% (em 9.160 anos cal A.P.) das associações de foraminíferos bentônicos das amostras (Fig. 25). Testas pretas (que contêm FeS) ocorreram apenas há 8.656 anos cal A.P.; entre 8.579 e 8.563 anos cal A.P.; e há 8.532 anos cal A.P., com porcentagens que variaram entre 0,4\% (em 8.656 anos cal A.P.) e 6,7\% (em 8.532 anos cal A.P.) (Fig. 25).

As associações de foraminíferos bentônicos demonstraram alto índice de fragmentação parcial e/ou total das testas. (Figura 25). Se somadas, testas parcial e totalmente fragmentadas representaram 100\% das associações nos intervalos temporais entre 9.338 e 9.072 anos cal A.P.; há 8.894 anos cal A.P.; há 8.610 anos cal A.P.; há 8.516 anos cal A.P. e há 8.433 anos cal A.P. Testas inteiras predominaram há 8.641 anos cal A.P.; há 8.579 anos cal A.P.; entre 
8.465 e 8.449 anos cal A.P.; e entre 8.417 e 8.401 anos cal A.P., onde suas porcentagens variaram entre 50,9\% e 75\% das associações de foraminíferos bentônicos (Figura 25).

Há 8.563 anos cal A.P. e há 8.481 anos cal A.P., testas inteiras e testas parcialmente fragmentadas representaram, cada uma, metade das associações de foraminíferos bentônicos (Fig.25). Nos demais intervalos, testas inteiras tiveram porcentagens entre 13,3\% (em 8.532 anos cal A.P.) e 45,5\% (em 8.656 anos cal A.P.).

Fragmentos foram predominantes (porcentagens entre 62,5\% e 85,7\%) há 9.338 anos cal A.P. e entre 9.160 e 9.072 anos cal A.P. Há 9.213 anos cal A.P. e há 8.433 anos cal A.P., fragmentos representaram metade das associações bentônicas, enquanto a outra metade foi representada por testas parcialmente fragmentadas (Fig.25). Nos demais intervalos em que ocorreram, fragmentos mostraram porcentagens entre 3,4\% (em 8.500 anos cal A.P.) e 41,2 em 8.548 anos cal A.P. (Fig. 25) Entre 8.481 e 8.449 anos cal A.P. e entre 8.417 e 8.385 anos cal A.P. não ocorreram fragmentos nas amostras do testemunho S03 (Fig. 25).

Testas parcialmente fragmentadas predominaram (porcentagens entre 50,3\% e 75\%) nos intervalos temporais em que nem testas inteiras e nem fragmentos predominaram, com exceção das idades de 8.983 anos cal A.P. (40\% das associações) e 8.548 anos cal A.P. (29,5\% das associações). Há 9.213 anos cal A.P.; há 8.481 anos cal A.P.; e há 8.433 anos cal A.P. suas porcentagens somaram metade das associações bentônicas das amostras. Nos demais intervalos temporais, elas variaram entre 14,3\% (em 8.641 anos cal A.P.) e 40\% (em 8.983 anos cal A.P.) (Fig.25).

Quando comparadas as análises morfométricas e tafonômicas, notou-se que nos intervalos em que houve porcentagens mais altas de testas douradas e inteiras (tarjas cinzas na figura 25), houve também aumento de testas de tamanhos pequenos, com exceção do intervalo temporal de 9.160 anos cal A.P., onde os tamanhos grandes e os fragmentos passaram a ter maiores porcentagens nas associações de foraminíferos bentônicos (tarja azul na figura 25) (Fig. 25).

A análise dos tipos de desgaste das testas indicou predominância de processos de corrosão/dissolução seguidos por processos de abrasão. Processos bioerosivos foram encontrados em menor quantidade nas testas de foraminíferos bentônicos do testemunho S03 (prancha 1, em anexo). 


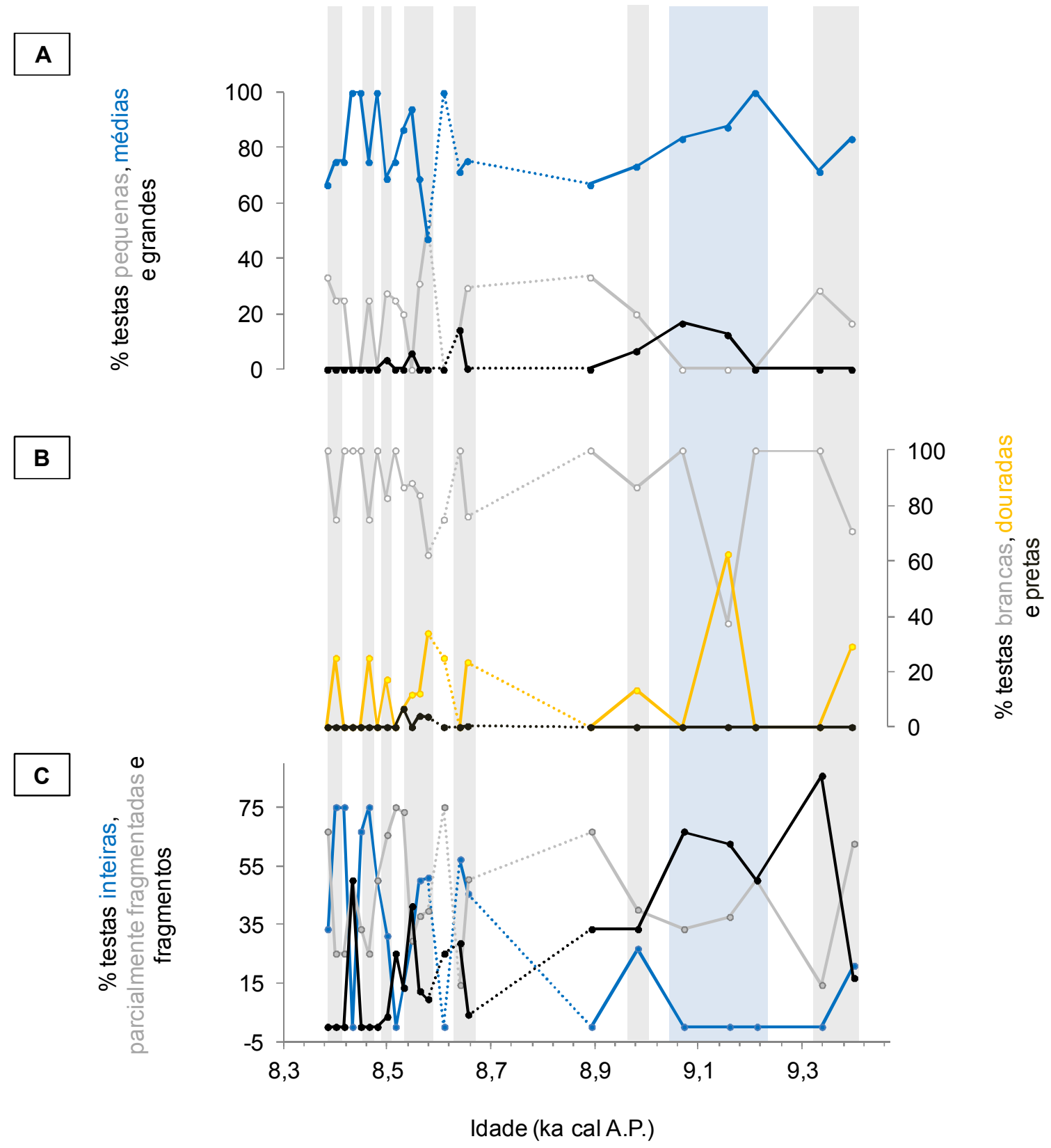

Figura 25: Análise tafonômica dos foraminíferos do testemunho S03. A. Análise morfométrica: porcentagens de testas pequenas $(<125 \mu \mathrm{m})$, médias $(125-250 \mu \mathrm{m})$ e grandes $(250-500 \mu \mathrm{m})$. B. Análise tafonômica de coloração: porcentagem das testas brancas (sem alteração de cor), douradas (impregnadas e/ou preenchidas por sulfeto de ferro $-\mathrm{FeS}_{2}$ ) e pretas (impregnadas e/ou preenchidas por monossulfeto de ferro $-\mathrm{FeS}$ ). C. Análise tafonômica de grau de fragmentação: porcentagem de testas inteiras (sem desgaste externo visível), parcialmente fragmentadas (até $50 \%$ de desgaste e/ou fragmentação) e fragmentos (acima de 50\% de desgaste e/ou fragmentação). Tarjas cinzas: intervalos temporais em que ocorreram predominantemente testas douradas, inteiras e pequenas. Tarja azul: intervalo em que ocorreram predominantemente testas douradas, grandes, e fragmentos. Modelo de idades retirado de Sallun et al. (2012).

A análise estatística de agrupamento modo-R agrupou todas as espécies de foraminíferos bentônicos encontradas entre 9.400 anos cal A.P. e 8.385 anos cal A.P. em três diferentes grupos (Fig. 26). 


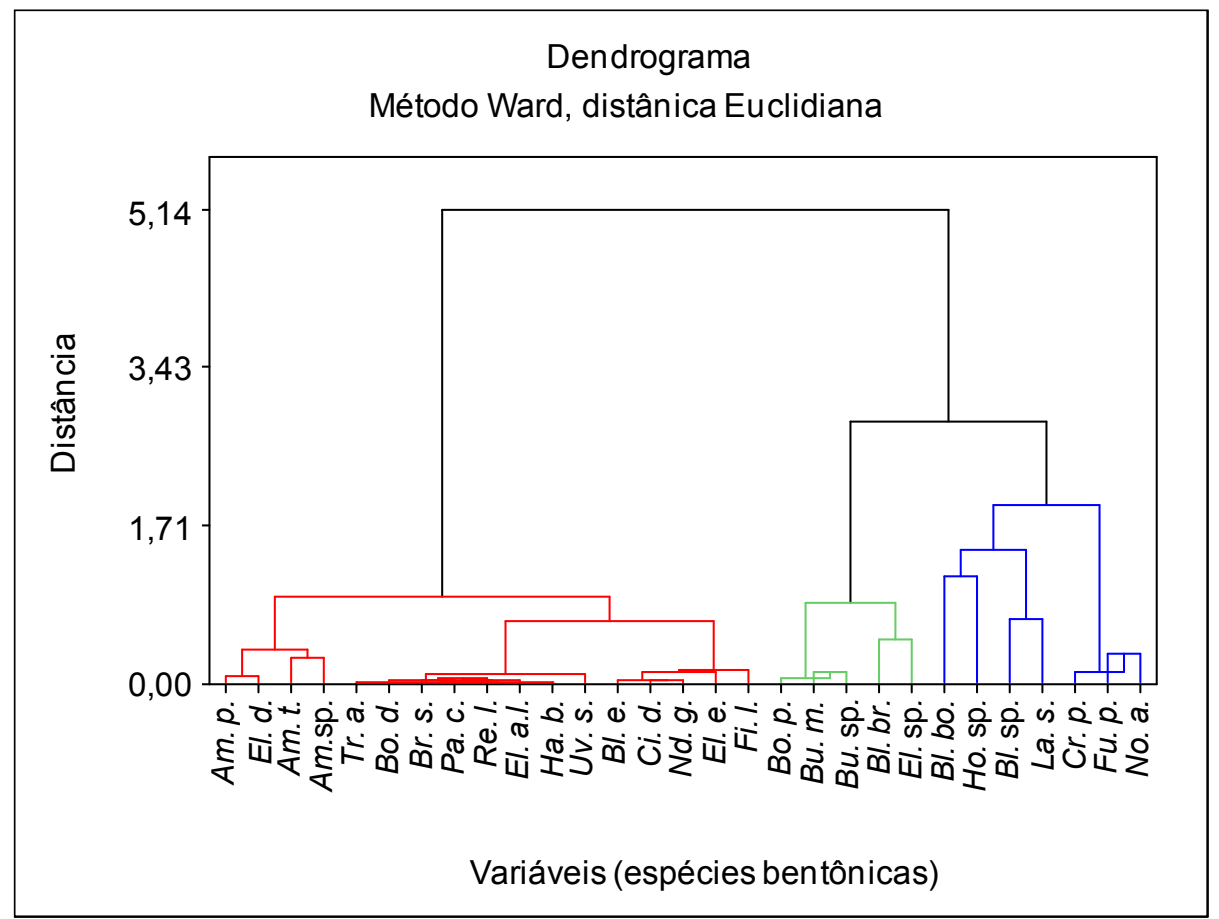

Figura 26: Dendrograma da análise estatística de agrupamento modo-R. Am.p.: Ammonia parkinsoniana. Am.t.: Ammonia tepida. Am.sp.: Ammonia sp. Bl.br.: Blysmasphaera brasiliensis. Bl.bo.:Blysmasphaera broennimanni. Bl.sp.: Blysmasphaera sp. Bl.e.: Buliminella elegantissima. Bo.d.: Bolivina doniezi. Bo.p.: Bolivina pulchella. Bu.m.: Bulimina marginata. Bu.sp.: Bulimina sp. Br.s.: Brizalina striatula. Ci.d.: Cibicides dispars. Cr.p.: Cribroelphidium poyeanum. El.a.l.: Elphidium advenum limbatum. El..d.: Elphidium discoidale. El..e.: Elphidium excavatum. El.sp.: Elphidium sp. Fi.l.: Fissurina laevigata. Fu.p.: Fursenkoina pontoni. Ha.b.: Hanzawaia boueana. Ho.sp.: Hopkinsina sp. La.s.: Lagena striata. Pa.c.: Pararotallia cananeiaensis. No.a.: Nonionella atlantica. Nd.g.: Nonionoides grateloupi. Re.l.: Reussoolina laevis. Tr.a: Trifarina angulosa. Uv.s.: Uvigerina striata.

A Associação 1 foi composta por Ammonia spp., Bolivina doniezi, Buliminella elegantissima, Brizalina striatula, Cibicides dispars, Elphidium advenum limbatum, Elphidium discoidale, Elphidium excavatum, Fissurina laevigata, Hanzawaia boueana, Pararotalia cananeiaensis, Nonionoides grateloupi, Reussoolina laevis, Trifarina angulosa e Uvigerina striata. Ela ocorreu especialmente há 9.400 anos cal A.P.; entre 8.983 e 8.894 anos cal A.P.; entre 8.656 e 8.641 anos cal A.P.; e entre 8.579 e 8.500 anos cal A.P. (Fig. 27).

Essa associação indica ambiente menos oxigenado, com maior quantidade de matéria orgânica no meio, mas com incremento da oxigenação do meio em algumas épocas. As espécies que a compõem são majoritariamente epifaunais a infaunais rasas, com exceção de C. dispars e H. boueana, espécies epifaunais. São majoritariamente detritívoras, com alguma contribuição de espécies herbívoras. Vivem em solos constituídos por substratos cuja granulometria vai de areia à lama, e são majoritariamente euhalinas a polihalinas/mesohalinas. As espécies $U$. striata e $T$. angulosa são consideradas típicas águas mais frias, plataformais (como, por exemplo, a ACAS). 
A Associação 2 foi composta por Blysmasphaera brasiliensis, Bolivina pulchella, Bulimina marginata, Bulimina sp. e Elphidium sp. Ela ocorreu principalmente entre 9.400 e 9.160 anos cal A.P. e entre 8.563 e 8.500 anos cal A.P. (Fig. 27). Essas espécies indicam ambiente menos oxigenado, com maiores contribuições de matéria orgânica para o meio, com sedimentos cuja granulometria vai de areia à lama, e com águas com alguma estratificação. São espécies que pertencem à epifauna-infauna, vivendo preferencialmente entre os ambientes epifaunais a infaunais rasos. São detritívoras ou herbívoras, e indicam majoritariamente águas que variam entre polihalinas/mesohalinas a oligohalinas. A espécie $B$. pulchella é considerada mais apta a habitar ambientes euhalinos.

A Associação 3 foi composta por Blysmasphaera broennimanni, Blysmasphaera sp, Cribroelphidium poyeanum, Fursenkoina pontoni, Hopkinsina sp., Lagena striata e Nonionella atlantica. Ela ocorreu principalmente há 9.400 anos cal A.P.; entre 9.213 e 8.894 anos cal A.P.; há 8.610 anos cal A.P.; e entre 8.481 e 8.385 anos cal A.P. (Fig. 26). Essa associação concentra dois grupos: o primeiro, formado pelo gênero Blysmaphaera, parece ser mais abundante em ambientes melhor oxigenados, de águas limnéticas. O segundo é composto por espécies detritívoras ou herbívoras que indicam ambiente disóxico, rico em M.O., com sedimentos cuja granulometria varia entre areia e lama, de águas polihalinas/mesohalinas.

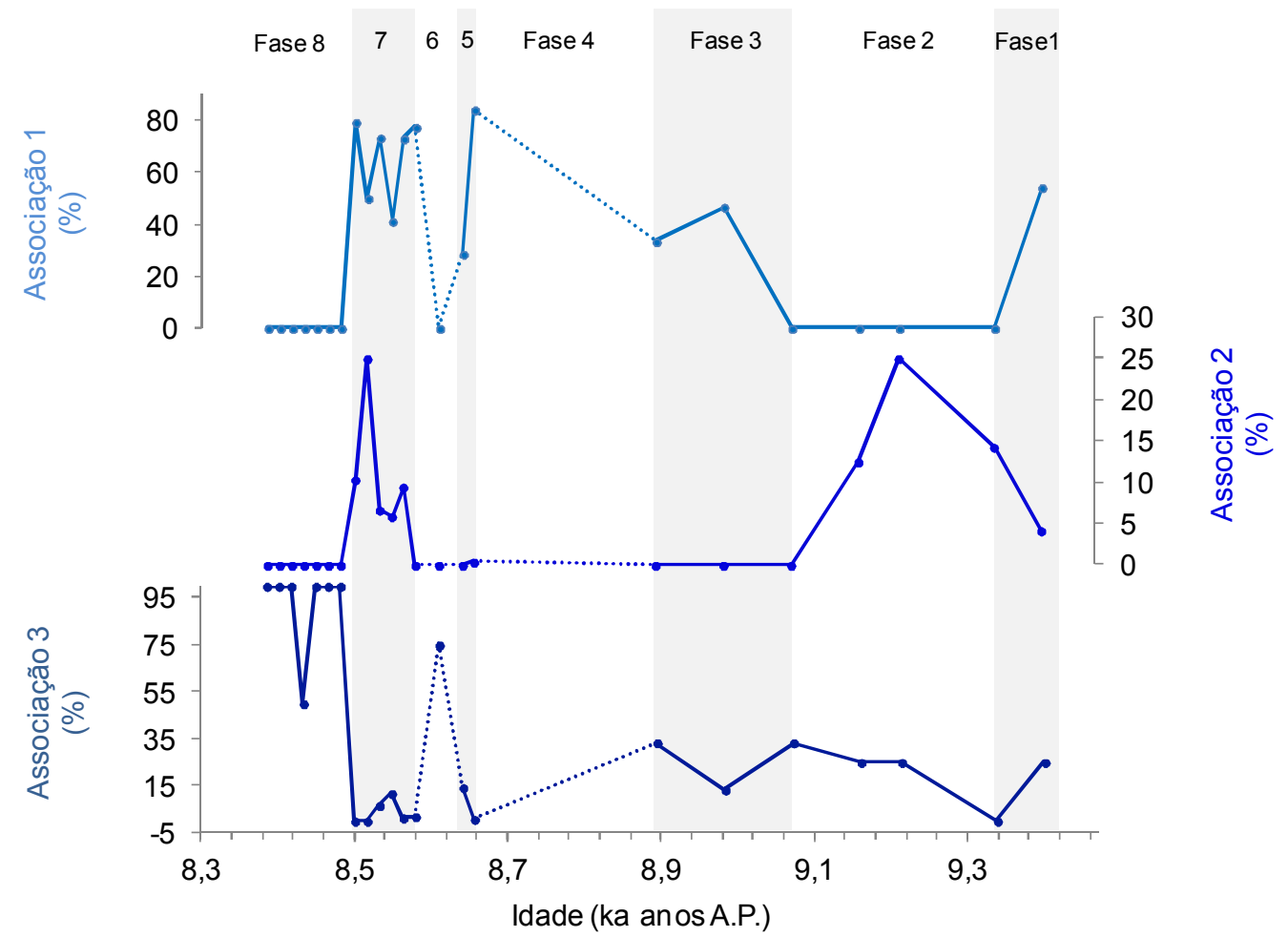

Figura 27: Distribuições das três diferentes associações microfaunísticas do testemunho S03 obtidas pela análise estatística de agrupamento modo-R. Tarjas cinzas: diferentes fases paleoambientais entre 9.400 e 8.385 anos cal A.P.de acordo com as associações de foraminíferos bentônicos.Modelo de idades retirado de Sallun et al. (2012). 


\subsection{Testemunho GeoB6211-2}

\subsubsection{Resultados Abióticos}

O testemunho GeoB6211-2 possui 7,13m de comprimento. Entretanto, valores considerados anômalos devido à contaminação de sua base durante a coleta (Chiessi, com. pess.) foram descartados, reduzindo o tamanho do testemunho para 5,83m. As idades calendário obtidas para o testemunho GeoB6211-2 revelaram idade geológica de 19.150 anos cal A.P. em sua base $(5,83 \mathrm{~m})$ (Tabela 6$)$.

Tabela 6: Idades geológicas obtidas para o testemunho GeoB6211-2. Taxas de sedimentação obtidas por meio da fórmula (P2-P1/I2-I1), onde P = profundidade e I = idade calibrada. Dados de idade e taxa de sedimentação retirados de Chiessi et al. (2008).

\begin{tabular}{|c|c|c|c|c|}
\hline $\begin{array}{c}\text { profundidade } \\
\mathbf{( c m})\end{array}$ & $\begin{array}{c}\text { Idade de radiocarbono } \\
\mathbf{( \pm 1 0} \text { erro) anos A.P. }\end{array}$ & $\begin{array}{c}\text { Idade calibrada } \\
\text { (anos cal A.P.) }\end{array}$ & $\begin{array}{c}\text { Intervalo de idades calendário } \\
\text { (anos cal A.P.) }\end{array}$ & $\begin{array}{c}\text { Taxa de } \\
\text { sedimentação } \\
\text { (cm/ka) }\end{array}$ \\
\hline 18 & $1685 \pm 30$ & 1250 & $1300-1160$ & 9 \\
\hline 73 & $7145 \pm 55$ & 7610 & $7730-7500$ & 8 \\
\hline 123 & $12600 \pm 70$ & 14050 & $14240-13840$ & 79 \\
\hline 218 & $13340 \pm 80$ & 15250 & $15630-14980$ & 75 \\
\hline 358 & $14860 \pm 90$ & 17400 & $17860-16880$ & 245 \\
\hline 583 & $15590 \pm 100$ & 18600 & $18790-18430$ & 75 \\
\hline
\end{tabular}

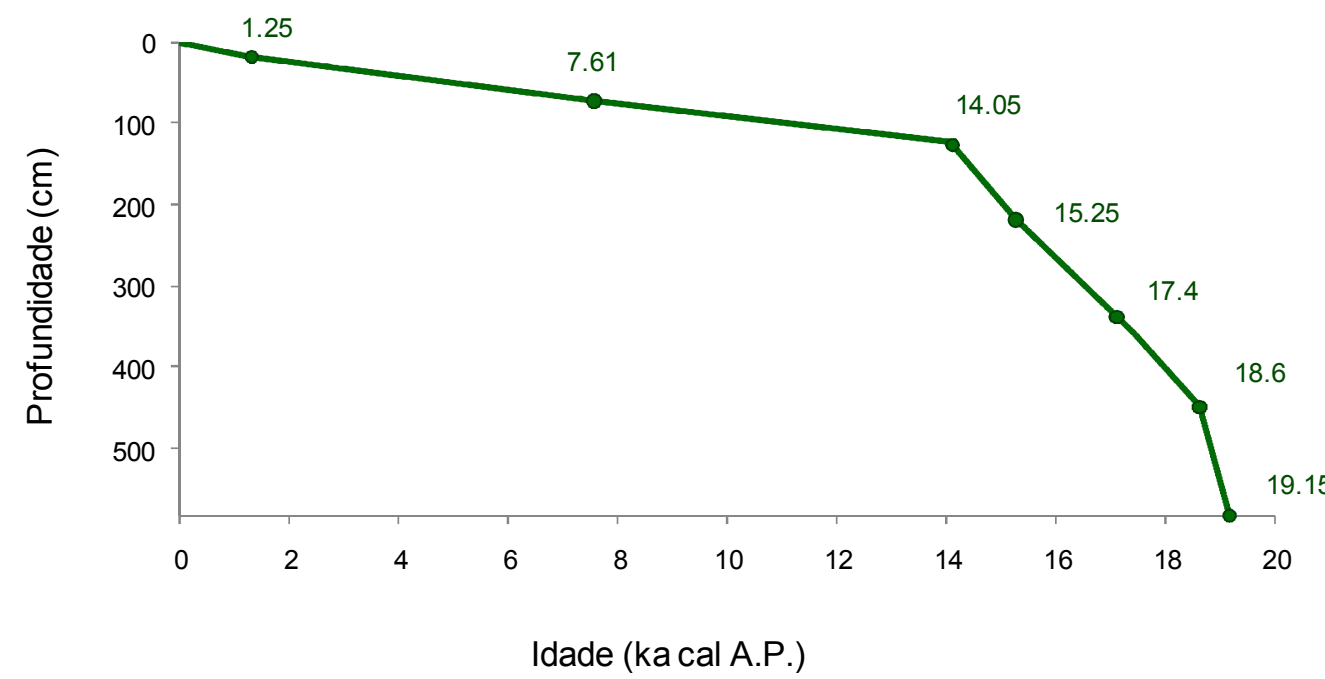

Figura 28: Modelo de Idades para o testemunho GeoB6211-2. Retirado de Chiessi et al. (2008). As idades indicadas na imagem correspondem àquelas medidas para o testemunho e estão expressas em mil anos cal. A.P. (ka cal A.P.). 
Ao longo do testemunho GeoB6211-2, a análise granulométrica revelou predominância de sedimentos pelíticos, majoritariamente sílticos, muito pobremente selecionados a pobremente selecionados. As porcentagens de sedimentos pelíticos perfizeram entre 63,49\% (8.407 anos cal A.P.) e 97,02\% (17.080 anos cal A.P.) do total de sedimentos das amostras. As porcentagens de sedimentos arenosos situaram-se entre 3\% (17.080 anos cal A.P.) e $36,05 \%$ (8.407 anos cal A.P.) do total de sedimentos das amostras (Tabela 7, em anexo; fig. 29).

Os valores do diâmetro médio dos grãos expressos em phi (ø) variaram de 1,75 (17,144 anos cal A.P.) a 2,21 (6.690 anos cal A.P.) e foram classificados de acordo com Krumbein (1936) entre silte muito fino (de 7 a 8) e silte médio (de 5 a 6) (Tabela 7, em anexo; fig. 29). A assimetria dos grãos variou de $-0,23$ (em 5.461 anos cal A.P.) a 0,79 (em 8.407 anos cal A.P.). Já os valores de curtose variaram de 1,96 (14.988 anos cal A.P.) a 2,64 (18.000 anos cal A.P.). De acordo com a classificação de Folk e Ward (1957), a assimetria variou entre negativa a muito negativa, e a curtose foi muito leptocúrtica (Tabela 7, em anexo; fig. 29).

Os comportamentos do fluxo de carbonato de cálcio (Fluxo $\mathrm{CaCO}_{3}$ ) e da taxa de sedimentação (TS) nos seis pontos de idades calibradas medidas no testemunho GeoB6211-2 foram similares. Ambos diminuíram entre 19.150 e 18.600 anos cal A.P., quando a taxa de sedimentação passou de 245 para $75 \mathrm{~cm} / \mathrm{ka}$ e o fluxo $\mathrm{CaCO}_{3}$, de 5,3 para $1,1 \% \mathrm{~g} / \mathrm{ka}^{*} \mathrm{~cm}^{2}$. Mantiveram-se com valores praticamente constantes até 15.000 anos cal A.P., quando a taxa de sedimentação ficou entre 65 e $79 \mathrm{~cm} / \mathrm{ka}$ e o fluxo de $\mathrm{CaCO}_{3}$, entre 1,07 e, $13 \% \mathrm{~g} / \mathrm{ka}^{*} \mathrm{~cm}^{2}$. Entre 14.000 e 7.610 anos cal A.P., a taxa de sedimentação teve valores decrescentes entre 8 e $9 \mathrm{~cm} / \mathrm{ka}$, e o fluxo de $\mathrm{CaCO}_{3}$ apresentou valores crescentes entre 0,2 e $0,7 \% \mathrm{~g} / \mathrm{ka}^{*} \mathrm{~cm}^{2}$. (Fig. 29).

Similares, também, foram os comportamentos das porcentagens de carbono orgânico $\left(\% \mathrm{C}_{\text {org. }}\right)$ e nitrogênio total $\left(\% \mathrm{~N}_{\text {total }}\right)$ ao longo do testemunho. Esses valores apresentaram tendência levemente crescente da base ao topo do testemunho. As porcentagens de carbono orgânico ficaram entre $0,40 \%$ (em 18.946 anos cal A.P.) e 1,22\% (em 8.824 e 1.471 anos cal A.P.). Já os valores percentuais de nitrogênio total se situaram entre 0,6\% (em 18.946 anos cal A.P.) e $0,16 \%$ (em 8.824 e 1.471 anos cal A.P.) (Fig. 29).

A razão $\mathrm{C} / \mathrm{N}$ teve valores entre 6,30 (em 19.196 anos cal A.P.) e 8,86 (em 19.193 anos cal A.P.). Ela apresentou padrão crescente da base do testemunho até 14.303 anos cal A.P., diminuiu até 14.050 anos cal A.P. e voltou a aumentar até o topo do testemunho (Fig. 29). Seus valores apontaram para matéria orgânica de origem predominantemente marinha. 


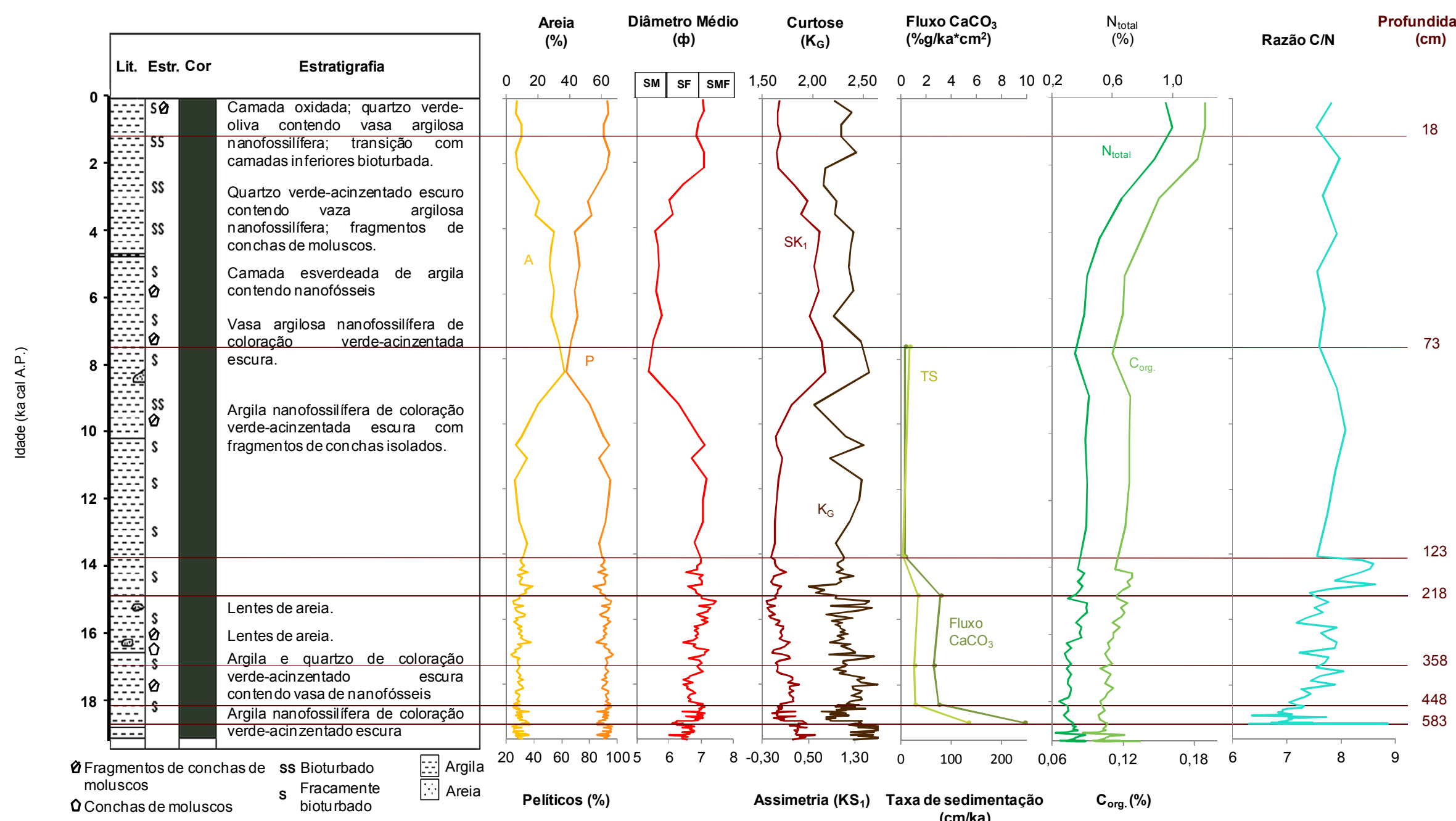

Figura 29: Dados de granulometria (\% total de areias e \% total de pelitos), diâmetro médio em escala phi (ø), assimetria $\left(\mathrm{SK}_{1}\right)$, curtose $\left(\mathrm{K}_{\mathrm{G}}\right)$, porcentagem de carbonatos fluxo de carbonato de cálcio (Fluxo $\left.\mathrm{CaCO}_{3}\right)$, taxa de sedimentação (TS), porcentagens de carbono orgânico $\left(\mathrm{C}_{\mathrm{org}}\right)$ e nitrogênio total $\left(\mathrm{N}_{\text {total }}\right)$, e razão $\mathrm{C} / \mathrm{N}$ do testemunho GeoB6211-2. Dados granulométricos originais cedidos por Sebastian Razik (universidade de Bremen, Bremen, Alemanha). Dados estratigráficos, geoquímicos, taxa de sedimentação e modelo de idades cedidos de Wefer et al. (2001), Chiessi (2008) e Chiessi et al. (2008, 2009). 
Os elementos químicos $\mathrm{Al}, \mathrm{Ca}, \mathrm{Fe}, \mathrm{K}$ e Ti obtidos nos sedimentos do testemunho GeoB6211-2 foram medidos em contagens por segundo (cont./seg). Esses elementos foram obtidos de dez em dez centímetros ao longo de todo o testemunho e normalizados pelo elemento A1. (Tabela 8, em anexo; Fig. 30).

O elemento alumínio (Al) mostrou valores entre 35,67 (4.141 anos cal A.P.) e 69,27 (18.661 anos cal A.P.) e teve tendência geral à diminuição da base ao topo do testemunho (Tabela 8, em anexo; Fig. 30). Os valores normalizados do elemento cálcio (Ca) permaneceram entre 1,35 e 3,11 até 12.762 anos cal A.P., quando apresentaram aumento brusco (valores entre 5,26 e 14) rumo ao topo do testemunho (Fig. 30). O ferro (Fe) apresentou valores entre 17,10 (7.610 anos cal A.P.) e 31,25 (11.474 anos cal A.P.), o elemento potássio (K) apresentou valores normalizados entre 3,49 (19.196 anos cal A.P.) e 5,37 (11.474 anos cal A.P.) e o elemento titânio (Ti) teve valores normalizados entre 3,06 (19.196 anos cal A.P.) e 5,18 (11.474 anos cal A.P.).

Os elementos Fe, $\mathrm{K}$ e Ti tiveram tendências similares ao longo do testemunho GeoB6211-2. Seus valores tiveram tendência geral de aumento da base até 11.474 anos cal A.P., de diminuição dessa época até 6.454 anos cal A.P. e de novo aumento entre essa época e o topo do testemunho. (Tabela 8, em anexo; Fig. 30).

A razão Ti/Ca mostrou valores entre 0,30 (4.141 e há 5.297 anos cal A.P.) e 2,78 (17.016 anos cal A.P.), que apresentaram tendência geral de aumento até 16.860 anos cal A.P. A partir dessa época, seus valores diminuíram até 11.474 anos cal A.P., voltaram a aumentar até 7.610 anos cal A.P., quando sofreram diminuição mais forte até 6.454 anos cal A.P., a partir de onde voltaram a aumentar levemente rumo ao topo do testemunho (Fig. 30). Já a razão Fe/K apresentou valores entre 4,36 (6.454 anos cal A.P.) e 6,34 (18.743 anos cal A.P.), que demonstraram ligeiro aumento da base até 12.762 anos cal A.P. Dessa época até 6.454, seus valores diminuíram, e então voltaram a aumentar rumo ao topo do testemunho (Tabela 8 , em anexo; Fig. 30).

Há 19.157 anos cal A.P.; há 18.702 anos cal A.P.; há 16.863 anos cal A.P.; há 16.248 anos cal A.P.; há 15.060 anos cal A.P.; há 14.176 anos cal A.P.; há 11.474 anos cal A.P.; há 8.898 anos cal A.P.; há 6.454 anos cal A.P.; e há 2.985 anos cal A.P., os elementos químicos apresentaram picos de aumento ou diminuição consideráveis no testemunho GeoB6211-2 (Fig. 30). 


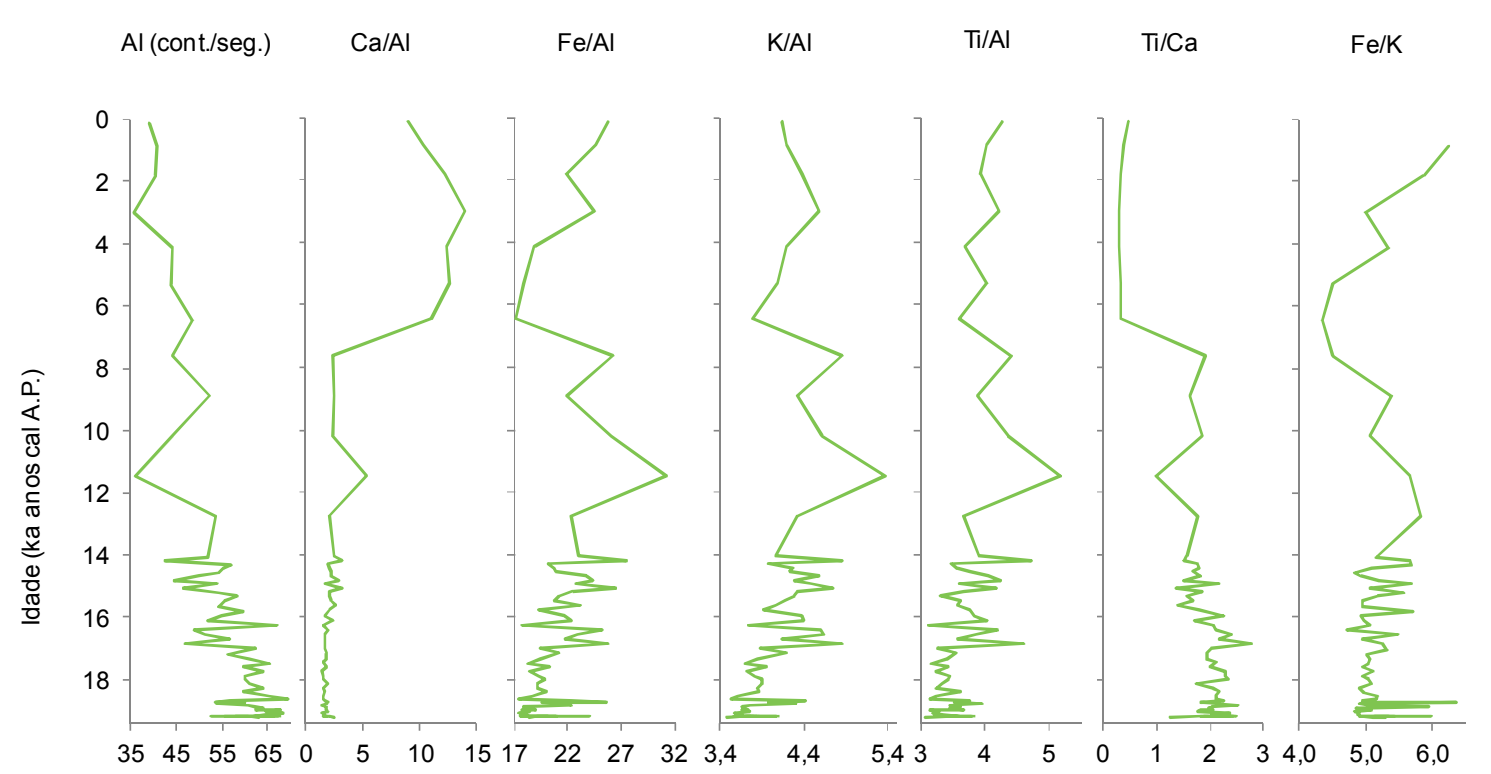

Figura 30: Valores dos elementos químicos obtidos ao longo do testemunho GeoB6211-2. Os valores originais cedidos por Chiessi (2008) e Chiessi et al. $(2008,2009)$ foram normalizados pelo elemento Al. Modelo de idades obtido de Chiessi et al. (2008).

\subsubsection{Resultados Microfaunísticos}

Testas de foraminíferos bentônicos e planctônicos foram encontradas ao longo de todo o testemunho GeoB6211-2 em grande abundância (Fig. 31). A densidade total de testas (i.e., a densidade de testas bentônicas e planctônicas) por amostra mostrou tendência ao aumento entre 19.000 e 14.303 anos cal A.P., entre o Heinrich Stadial 1 (HS1) e o Antarctic Cold reversal (ACR) (Fig. 31). A partir dessa época, diminuiu até 2.985 anos cal A.P., e teve pico expressivo de aumento há 10.186 anos cal A.P. Então tornou a aumentar rumo ao topo do testemunho (Fig. 31). A densidade total de testas apresentou valores entre 218 testas por amostra (18.987 anos cal A.P.), e 9.493 testas por amostra (14.303 anos cal A.P.).

As porcentagens de testas bentônicas (Fig. 31) indicaram que foraminíferos bentônicos contribuíram majoritariamente para as associações do testemunho GeoB6211-2 entre 19.000 e 14.000 anos cal A.P. (durante o HS1 e parte do ACR). Nesse intervalo de tempo, foraminíferos bentônicos representaram entre 51,1\% das associações (15.327 anos cal A.P.) e 95,3\% das associações (18.987 anos cal A.P.), com média de 75,8\% de testas bentônicas por amostra.

Entre 14.000 anos cal A.P. e o Presente (desde o ACR até o final do Holoceno), testas planctônicas predominaram nas associações de foraminíferos do testemunho GeoB6211-2 (Fig. 31). Nesse intervalo temporal, testas planctônicas representaram entre 52,7\% das associações (12.762 anos cal A.P.) e 92,6\% das associações (4.161 anos cal A.P.), com média de $70,9 \%$ de testas por amostra. 
Exceção foram as idades de 15.480 anos cal A.P., em que formas planctônicas representaram 55,3\% das associações de foraminíferos, e o intervalo entre 11.474 e 10. 186, onde foraminíferos bentônicos representaram aproximadamente $55 \%$ das associações de foraminíferos (Fig. 31).

A razão planctônicos/bentônicos (razão P/B) mostrou valores entre 4,7\% (18.987 anos cal A.P.) e 88,9\% (4.141 anos cal A.P.). No Último Máximo Glacial, a média de seus valores foi de 29,1\%. No Heinrich Stadial 1, de 21,8\%. Durante a Reversão fria Antártica, de 25,2\%. No Younger Dryas, de 48,8\%. No Holoceno Inferior, de 58,6\%, no Holoceno Médio de $84,6 \%$ e no Holoceno Superior, de $83 \%$. Seus valores mostraram tendência geral de aumento entre 19.000 anos cal A.P. e o Presente notavelmente similares às porcentagens de formas planctônicas e ao modelo de curva de variação do nível do mar de Lambeck e Chappell (2001).

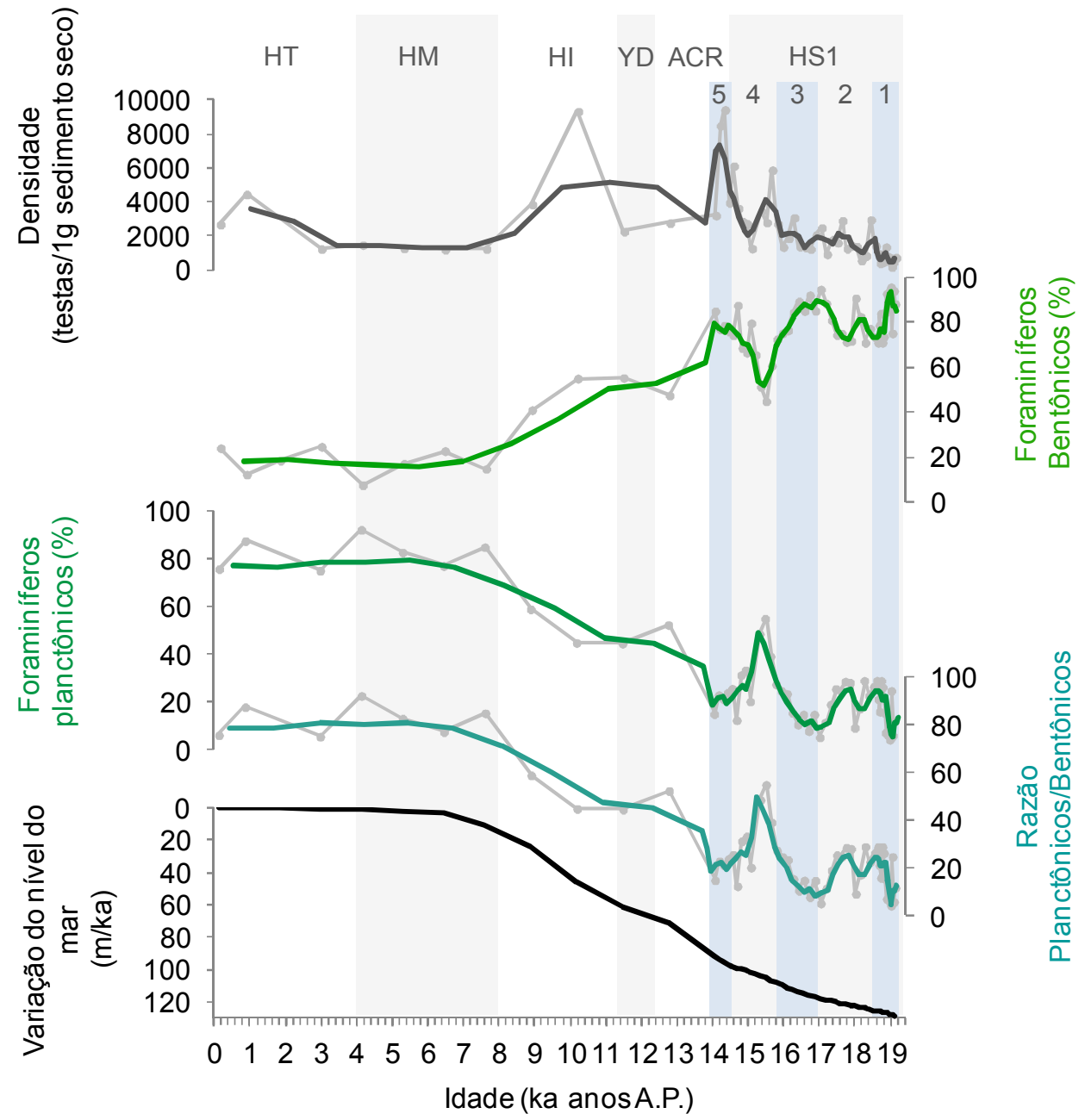

Figura 31: Densidade total de testas [(testas plactônicas + bentônicas)/1g de sedimento seco], porcentagem de testas bentônicas (\% bentônicos) e planctônicas (\% planctônicos) e razão planctônicos/bentônicos $\left(\left[\mathrm{n}^{\circ}\right.\right.$ de planctônicos $\left./\left(n^{\circ} \text { total de testas }\right)^{*} 100\right]$ do testemunho GeoB6211-2. Linhas cinza: dados originais obtidos. Linhas coloridas: média móvel de três pontos. Tarjas cinzas: diferentes épocas paleoambientais entre 19.000 anos cal A.P. e o Presente. HS1: Heinrich Stadial 1. ACR: Antarctic Cold reversal. YD: Younger Dryas. HI: Holoceno Inferior. HM: Holoceno Médio. HT: Holoceno tardio. Tarjas azuis: fases paleoambientais entre 19.000 e 14.000 anos cal A.P. Modelo de idades retirado de Chiessi et al. (2008). 
Apesar de testas de foraminíferos bentônicos terem sido encontradas em todos os intervalos deposicionais do testemunho GeoB6211-2, optou-se por delimitar a análise principal das associações de foraminíferos bentônicos entre as profundidades de $123 \mathrm{~cm}$ e $573 \mathrm{~cm}$, compreendendo o período de tempo pleistocênico, durante a Última Deglaciação, entre 19.000 e 14.000 anos cal A.P., quando importantes modificações paleoambientais se deram em larga escala. Essa decisão foi tomada com base na diferença na taxa de sedimentação apresentada pelo testemunho GeoB6211-2, e devido à enorme gama de resultados obtidos (Tabela 9 , em anexo).

A densidade das associações bentônicas variou entre 207 (18.987 anos cal A.P.) e 7.392 testas por $1 \mathrm{~g}$ de sedimento seco (14.303 anos cal A.P.). Seus valores apresentaram tendência ao aumento entre 19.000 e 14.000 anos cal A.P. Eles se mantiveram menores entre 19.000 e 15.060 anos cal A.P., com média de 1.178 testas por $1 \mathrm{~g}$ de sedimento seco e aumentaram entre 15.060 e 14.000 anos cal A.P., com média de 3.900 testas por $1 \mathrm{~g}$ de sedimento seco (Fig. 32). A densidade mostrou correlação positiva fraca $\left(r^{2}=0,188 ; p=0,001\right)$ com as variações da taxa de sedimentação do testemunho GeoB6211-2.

O índice BFAR flutuou entre 18.535 testas $/ \mathrm{ka}^{*} \mathrm{~cm}^{2}$ (14.050 anos cal A.P.) e 50.3272 testas $/ \mathrm{ka}^{*} \mathrm{~cm}^{2}$ (14.304 anos cal A.P.). Seus valores mostraram tendências de aumento e diminuição similares às da densidade entre 18.600 e 14.000 anos cal A.P., e diferentes das apresentadas por ela entre 19.000 e 18.600 anos cal A.P., quando a tendência de diminuição do BFAR foi mais acentuada (Fig. 32). A correlação entre a densidade e o BFAR ao longo do testemunho GeoB6211-2 foi forte $\left(\mathrm{r}^{2}=0,783 ; \mathrm{p}=0,001\right)$, o que corrobora a ausência de influência das modificações da taxa de sedimentação do testemunho GeoB6211-2 sobre a distribuição das testas de foraminíferos bentônicos nos sedimentos desse testemunho.

Tanto a densidade das associações de foraminíferos bentônicos quanto o índice BFAR demonstraram padrão inverso ao da taxa de sedimentação do testemunho, com maior número de testas encontradas em períodos de sedimentação menos volumosa (Fig. 32).

O índice de equitabilidade de Pielou (J') apresentou valores entre 0,46 (14.050 anos cal A.P.) e 0,82 (18.661 anos cal A.P.). Seus valores tiveram tendência geral de diminuição entre 19.000 e 14.000 anos cal A.P., com oscilações secundárias (Fig. 32).

Já a riqueza de espécies variou entre 19 (15.327 anos cal A.P.) e 35 espécies por amostra (entre 18.267 e 18.133 anos cal A.P. e há 16.095 anos cal A.P.). Seus valores aumentaram entre 19.000 e 18.133 anos cal A.P.; entre 17.733 e 17.323 anos cal A.P. e entre 15.327 e 14.000 anos cal A.P. Esses períodos foram intercalados por épocas em que os valores de riqueza mostraram tendência à diminuição (Fig. 32). O índice de diversidade de 
Shannon-Wiener (H') teve valores entre 1,61 (14.050 anos cal A.P.) e 2,56 (18.611 anos cal A.P.). Os valores de $\mathrm{H}^{\prime}$ mostraram tendência à diminuição e ao aumento similares àqueles demonstrados pelos valores do índice de equitabilidade de Pielou (J') (Fig. 32).

Foraminíferos bentônicos demonstraram tendência de aumento do equilíbrio de suas associações nos intervalos temporais em que houve aumento dos índices J' e H', ou seja, entre 19.000 e 18.661 anos cal A.P., entre 16.402 e 15.788 anos cal A.P. e entre 14.682 e 14.303 anos cal A.P. (Fig.32). Já nos períodos de tempo compreendidos entre 18.661 e 16.401 anos cal A.P.; entre 15.788 e 14.682 anos cal A.P. e entre 14.303 e 14.000 anos cal A.P., as associações de foraminíferos bentônicos demonstraram tendência a um maior desequilíbrio.

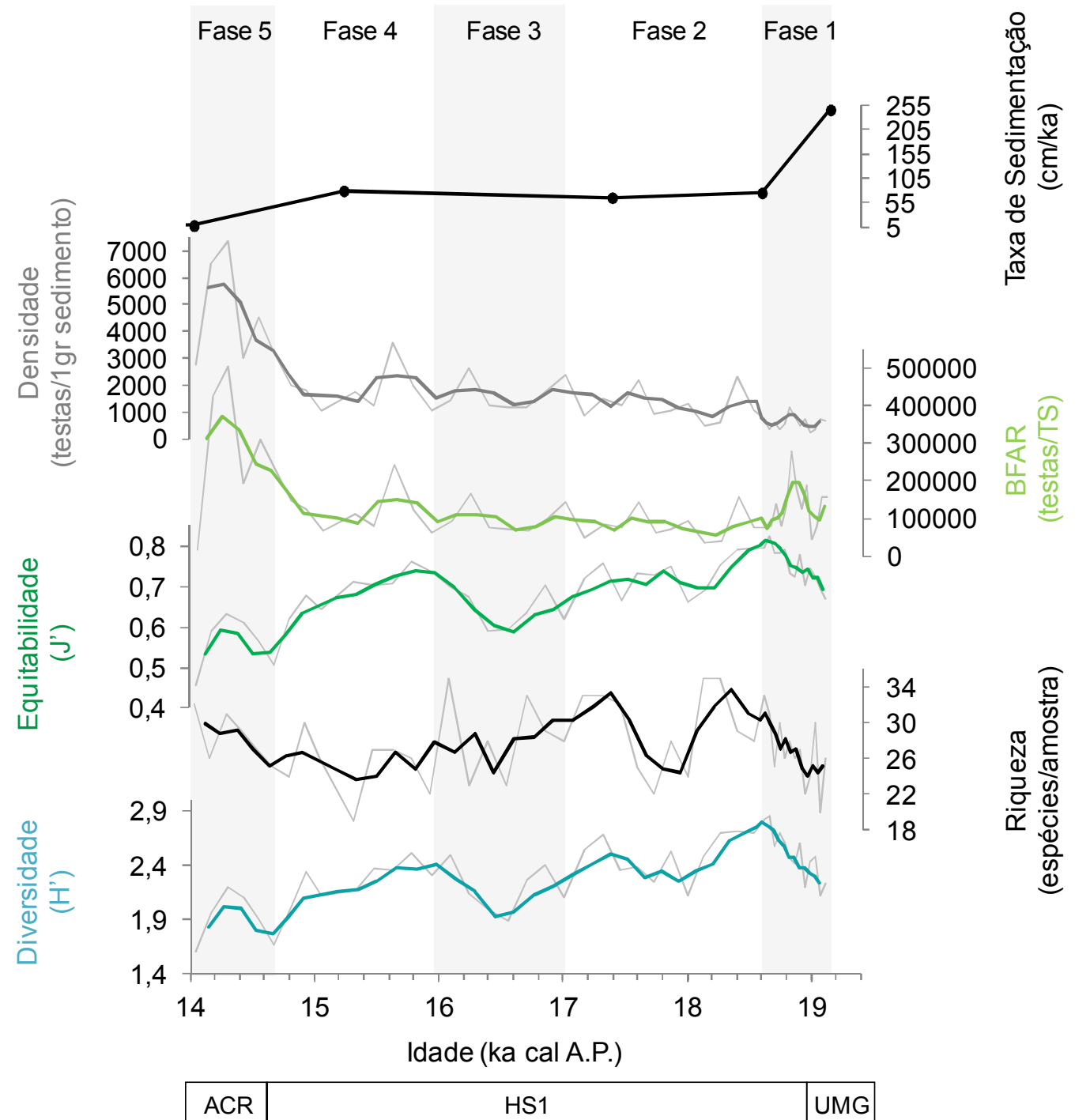

Figura 32: Densidade (número de testas/ 1g de sedimento seco), índice BFAR (Benthic Foraminiferal Accumulation Rate - testas $/ \mathrm{ka}^{*} \mathrm{~cm}^{2}$ ) equitatividade de Pielou (J'), riqueza (número de espécies/amostra) e diversidade de Shannon-Wiener (H') das associações de foraminíferos bentônicos do testemunho GeoB6211-2. Linhas cinzas: dados originais obtidos. Linhas coloridas: média móvel de três pontos. Barra horizontal: intervalo das épocas paleoclimáticas existentes entre 19.000 e 14.000 anos cal A.P. ACR: Antarctic Cold reversal. HS1: Heinrich Stadial 1. UMG: Último Máximo Glacial. Tarjas cinzas: diferentes fases paleoambientais indicadas pelas associações de foraminíferos bentônicos entre 19.000 e 14.000 anos cal A.P. no testemunho GeoB6211-2. Modelo de idades retirado de Chiessi et al. (2008). 
Foram encontradas 79 espécies ao longo do testemunho GeoB6211-2, pertencentes a 59 gêneros diferentes (Tabela 9, em anexo; fig. 33; prancha 2). Dentre as espécies de foraminíferos bentônicos encontradas entre 19.000 e 14.000 anos cal A.P., as mais abundantes foram aquelas pertencentes às famílias Bolivinidae (especialmente a Brizalina subaenariensis), Buliminidae (Bulimina elongata e Bulimina marginata) e Nonionidae (especialmente Nonionella atlantica e Nonionoides grateloupi) (Tabela 9, em anexo; fig. 33).

Espécies dominantes (i.e., ocorreram com mais de $50 \%$ do total de testas em todo o testemunho GeoB6211-2) foram Bolivinellina translucens, Brizalina subaenariensis, Bulimina elongata, Bulimina marginata, Cassidulina crassa, Fursenkoina pontoni, Globobulimina pacifica, Nonionella opima, Nonionella atlantica, Nonionoides grateloupi, Quinqueloculina atlantica, Rutherfordoides rotundiformis e Uvigerina bifurcata. Espécies subdominantes (i.e., aquelas que, somadas no GeoB6211-2, apresentaram porcentagens entre 50 e $25 \%$ do total de testas) foram Adelosina laevigata, Buliminella elegantissima, Cassidulinoides brasiliensis, Melonis barleeanus, Nonionellina labradorica, Quinqueloculina milletti e Stainforthia concava (Tabela 9, em anexo; fig. 33).

Já espécies acessórias (i.e., espécies que, quando somadas no testemunho, mostraram porcentagens entre 25 e $5 \%$ do total de testas) foram Buccella peruviana, Cancris sagra, Cassidulina crassa var. porrecta, Cibicides refulgens, Cribrostomoides sp., Fissurina spp., Globocassidulina subglobosa, Lenticulina spp., Nonionella auris, Nonion depressulus, Pseudononion spp., Pyrgo nasuta, Quinqueloculina lamarckiana, Quinqueloculina patagonica, Quinqueloculina seminula, Rosalina williamsoni, Textularia agglutinans, Uvigerina peregrina e Uvigerina striata (Tabela 9, em anexo; fig. 33).

As demais espécies foram raras (i.e., espécies que, quando somadas no testemunho GeoB6211-2, mostraram porcentagens abaixo de 5\% do total de testas) entre 19.000 e 14.000 anos cal A.P. ao longo do testemunho GeoB6211-2 (Tabela 9, em anexo; fig. 33).

Com exceção das espécies Brizalina subaenariensis, Bulimina elongata, Bulimina marginata e Nonionella atlantica, todas as demais espécies não ocorreram em todos os intervalos amostrados entre 19.000 e 14.000 anos cal A.P. no testemunho GeoB6211-2 (Tabela 9, em anexo; fig. 33). 


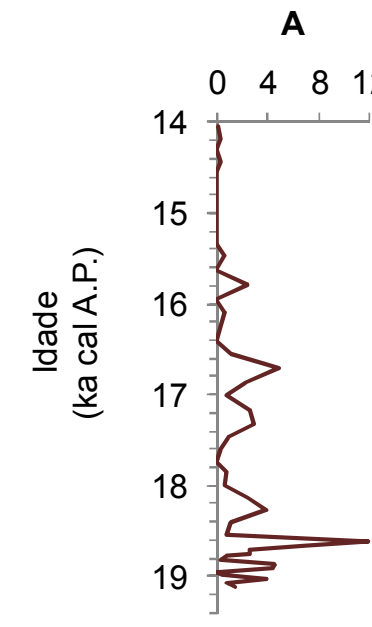
H

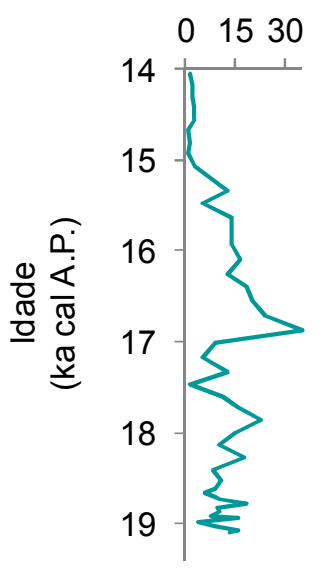

P

0246

B

C

D

E

$\mathbf{F}$

G
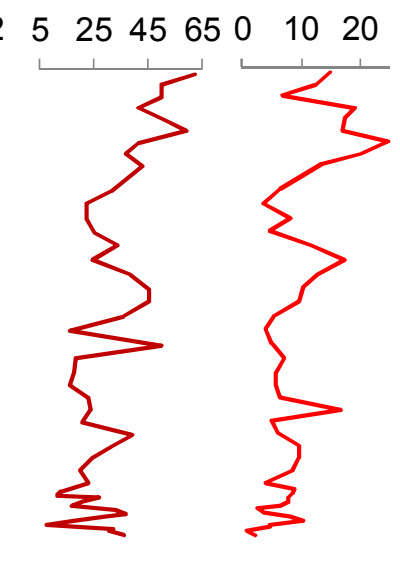

0102030
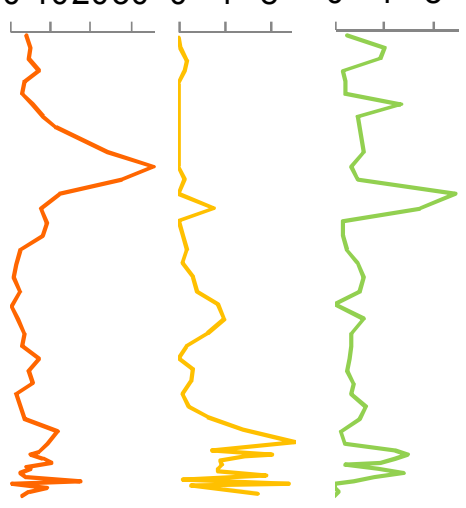

012345

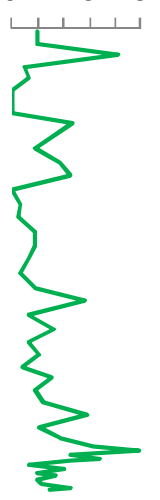

J

K

L

M

N

0

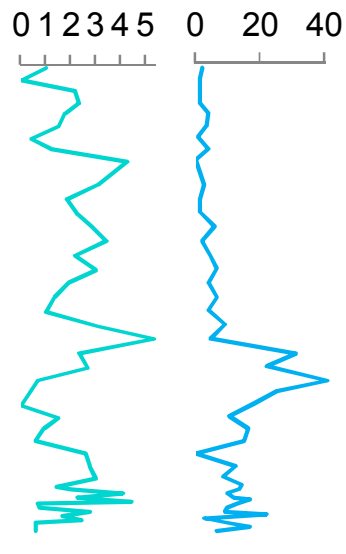

Q

R

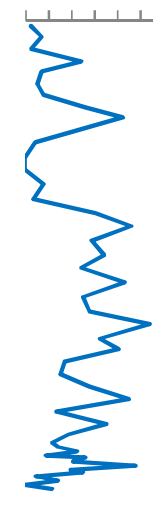

01020300246

0123

012
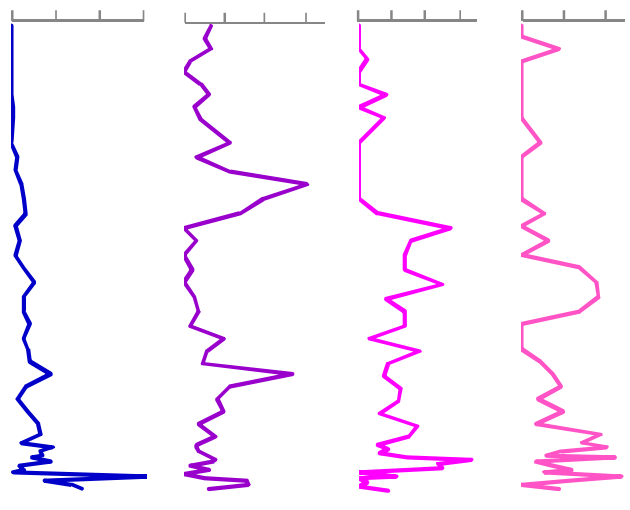

S

T

U

V
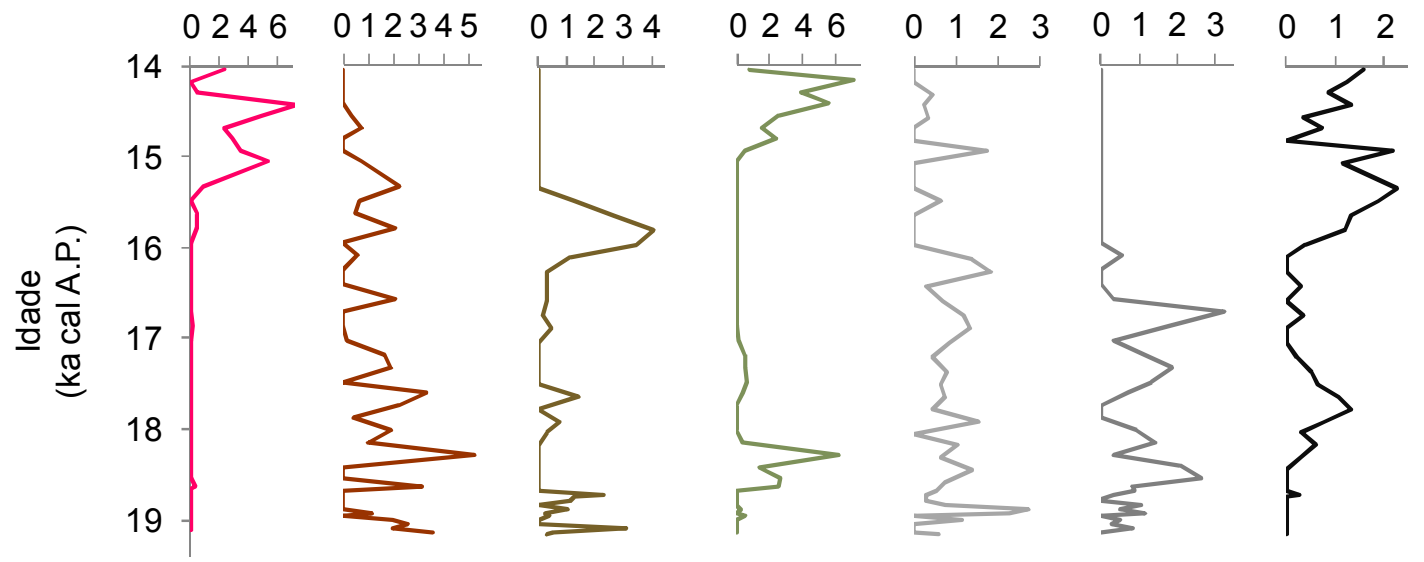

Figura 33: Porcentagens das principais espécies de foraminíferos bentônicos encontradas ao longo do testemunho GeoB6211-2. A. Bolivinellina translucens. B. Brizalina subaenariensis C. Bulimina elongata. D. Bulimina marginata. E. Cassidulina crassa. F. Fursenkoina pontoni. G. Globobulimina pacifica. H. Nonionella atlantica. I. Nonionella opima. J. Nonionoides grateloupi. K. Quinqueloculina atlantica. L. Rutherfordoides rotundiformis. M. Uvigerina bifurcada. N. Adelosina laevigata. O. Buliminella elegantissima. P. Cassidulinoides brasiliensis. Q. Fursenkoina sp. R. Melonis barleeanus. S. Nonionellina labradorica. T. Quinqueloculina milletti. U. Stainforhia concava. V. Uvigerina peregrina. Modelo de idades retirado de Chiessi et al. (2008). 
Espécies infaunais tiveram porcentagens que variaram entre 6,6\% (14.050 anos cal A.P.) e 57,9\% da associação bentônica (16.863 anos cal A.P.). Elas foram predominantes nas associações de foraminíferos bentônicos há 19.069 anos cal A.P. (54,5\% da associação); há 18.987 anos cal A.P. (55,6\% da associação bentônica); há 17.467 anos cal A.P. (53,8\% da associação bentônica); há 17.170 anos cal A.P. (51,9\% da associação) e há 16.863 anos cal A.P. Apesar de serem predominantes nessas épocas, espécies infaunais mostraram tendência geral de diminuição entre 19.000 e 14.000 anos cal A.P. (Fig. 34).

Espécies que ocupam nichos tanto epifaunais quanto infaunais (epifauna-infauna) tiveram porcentagens entre 18,4\% (18.987 anos cal A.P.) e 88,3\% da associação (14.050 anos cal A.P.). Essas espécies foram predominantes nas associações de foraminíferos bentônicos especialmente entre 16.709 e 14.000 anos cal A.P. (Fig. 34). Entre 19.000 e 16.286 anos cal A.P., espécies da epifauna-infauna e espécies infaunais revezaram a predominância das associações bentônicas (Fig. 34).

Já espécies pertencentes exclusivamente à epifauna foram menos abundantes entre 19.000 e 14.000 anos cal A.P. (Fig. 34). Suas porcentagens variaram entre 0,5\% (15.327 anos cal A.P.) e 15,9\% da associação (18.987 anos cal A.P.). Seus valores foram maiores entre 19.000 e 18.824 anos cal A.P., aumentaram levemente entre 18.620 e 17.323 anos cal A.P. e decaíram até 15.327 anos cal A.P. Aumentaram novamente até 15.060 anos cal A.P. e diminuíram dessa época até 14.000 anos cal A.P. (Fig. 34).

A diminuição das porcentagens de espécies infaunais (e.g., Globobulimina pacifica) e o aumento das porcentagens das espécies pertencentes à epifauna (e.g., Eponides repandus) e à epifauna-infauna (e.g., Brizalina subaenariensis) (Fig. 34) mostraram que, em geral, houve decréscimo da ocupação de nichos ecológicos mais profundos entre 19.000 e 14.000 anos cal A.P. (Fig. 34).

Os valores elevados do índice BFHP mostraram aporte nutricional abundante à área do Cone do Rio Grande, com tendência geral ao aumento entre 19.000 e 14.000 anos cal A.P. Seus valores variaram entre 54,1\% (18.987 anos cal A.P.) e 93,6\% da associação (14.050 anos cal A.P.) (Fig. 34).

O índice BFOI (Fig. 34) apresentou valores entre 0,3 (19.069 anos cal A.P.) e 11,2 (14.934 anos cal A.P.). De acordo com a classificação de Baas et al. (1998), os valores encontrados entre 19.000 e 14.000 anos cal A.P. no testemunho GeoB6211-2 indicaram ambiente variando de altos a baixos conteúdos de oxigênio dissolvido $\left(>1,5 \mathrm{ml} \mathrm{L}^{-1} \mathrm{O}_{2}\right)$. $\mathrm{O}$ índice BFOI exibiu picos positivos há 18.865 anos cal A.P. e entre 17.467 e 14.934 anos cal 
A.P.. Houve maior oxigenação do meio há 18.865 anos cal A.P., entre 18.133 e 16.248 anos cal A.P., e há 14.934 anos cal A.P. (Fig. 34).

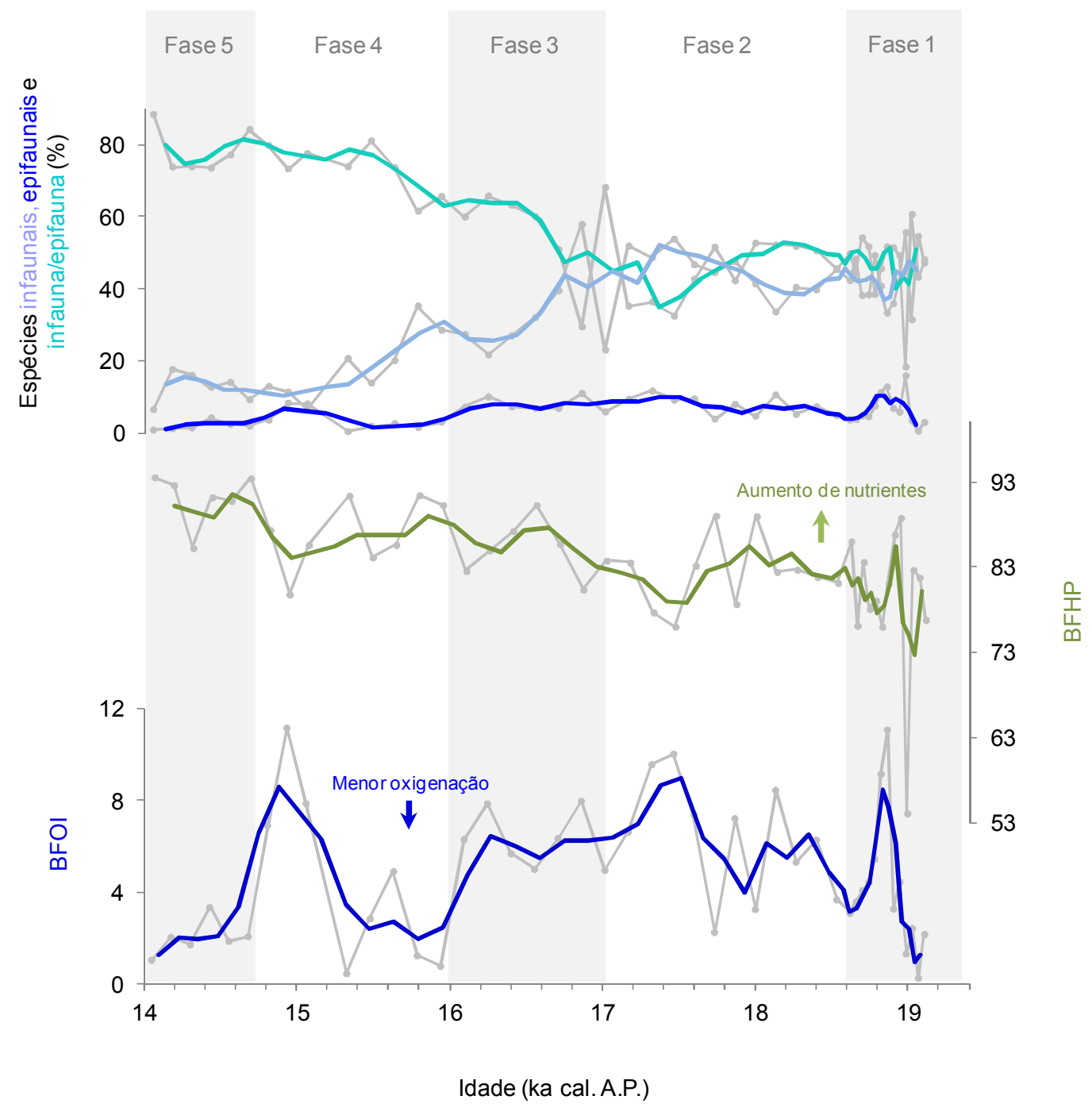

\begin{tabular}{|l|l|l|}
\hline ACR & HS1 & UMG \\
\hline
\end{tabular}

Figura 34: Porcentagens das espécies de foraminíferos bentônicos bioindicadores do testemunho GeoB6211-2. Porcentagens de espécies infaunais, epifaunais e epifauna-infauna. BFHP: Benthic Foraminifer High Productivity Index (de acordo com Martins et al., 2007), indicador da quantidade de matéria orgânica disponível no meio. BFOI: Benthic Foraminiferal Oxygen Index (segundo Kaiho, 1991, 1994; modificado por Baas et al., 1998), indica o grau de oxigenação do meio. Barra horizontal: intervalo das épocas paleoclimáticas existentes entre 19.000 e 14.000 anos cal A.P. ACR: Antarctic Cold reversal. HS1: Heinrich Stadial 1. UMG: Último Máximo Glacial. Tarjas cinzas: diferentes fases paleoambientais indicadas pelas associações de foraminíferos bentônicos entre 19.000 e 14.000 anos cal A.P. no testemunho GeoB6211-2. Modelo de idades retirado de Chiessi et al. (2008).

Quando comparados a outros registros paleoambientais existentes para a região atlântica (Fig. 35), considerando-se os erros associados aos modelos geocronológicos, pode-se notar que épocas de maior oxigenação do meio (maiores valores do índice BFOI) são também épocas de menores acúmulos de nutrientes no meio (diminuição dos valores do índice BFHP) (Fig. 35I, J), de menor contribuição continental à região de coleta do testemunho GeoB6211-2 
(Fig. 35A); de maior pluviosidade na região nordeste do Brasil (Fig.35B), de maior contribuição de águas provenientes da região austral à área plataformal da América do Sul (Fig. 35C), de aumento da temperatura marinha (Fig. 35D) e salinidade na margem atlântica nordeste brasileira. Ainda, os comportamentos das associações de foraminíferos bentônicos (Fig.35H, I, J) seguem o padrão paleoclimático descrito para as regiões da Antártica e da Groelândia (Fig. 35E, F). Fase 5 Fase $4 \quad$ Fase $3 \quad$ Fase $2 \quad$ Fase 1

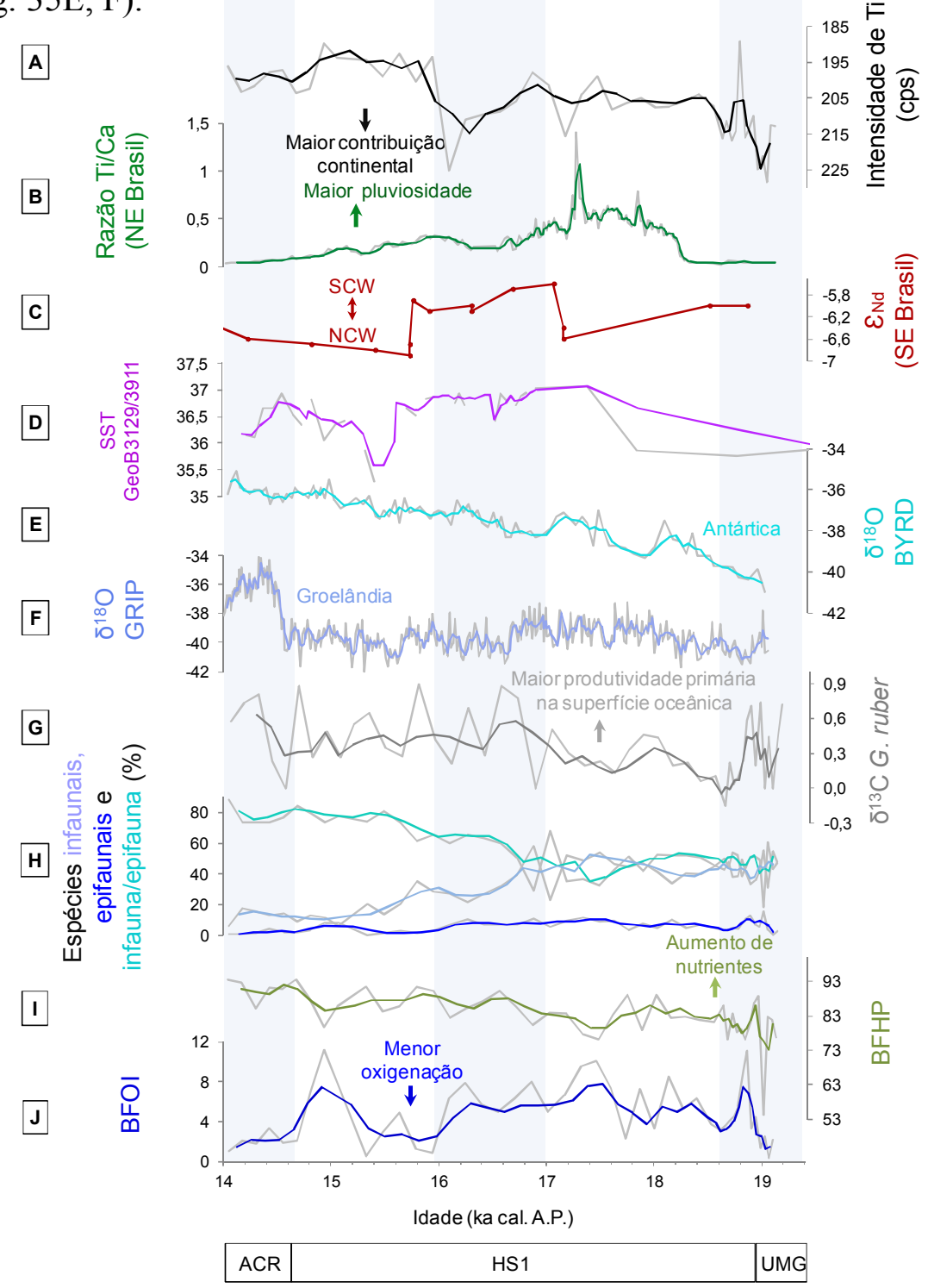

Figura 35: Variações paleoclimáticas entre 19.000 e 14.000 anos cal A.P. A. Intensidade do Ti (contagens por segundo) do testemunho GeoB6211-2 (Chiessi et al., 2009). B. Razão Ti/Ca do testemunho GeoB3910-2 (Jaeschke et al., 2007). C. $\varepsilon_{\mathrm{Nd}}$ do testemunho KRN159-5-36GGC (Pahnke et al., 2008). D. SST do testemunho GeoB3129/3911 (Weldeab et al., 2006). E. $\delta^{18} \mathrm{O}$ do testemunho BYRD (Blunier e Brook, 2001) e F. $\delta^{18} \mathrm{O}$ do testemunho NGRIP (Blunier e Brook, 2001). G. $\delta^{13} \mathrm{C}$ da espécie G. ruber do testemunho geoB6211-2 (Chiessi et al., 2008, 2009). H. espécies de foraminíferos bentônicos da epifauna, infauna e epifauna-infauna do testemunho GeoB6211-2. Índices I. BFHP e J. BFOI das associações de foraminíferos bentônicos do testemunho GeoB6211-2. SST: temperatura superficial marinha. Linhas cinzas: dados originais. Linhas coloridas: média móvel de três pontos. Barra horizontal: ACR: Antarctic Cold reversal. HS1: Heinrich Stadial 1. UMG: Último Máximo Glacial. Tarjas azuis: diferentes fases paleoambientais indicadas pelas associações de foraminíferos bentônicos entre 19.000 e 14.000 anos cal A.P. no testemunho GeoB6211-2. Modelo de idades retirado de Chiessi et al. (2008). 
Testas de tamanhos grandes $(250-500 \mu \mathrm{m})$ predominaram entre 19.000 e 14.000 anos cal A.P. nos sedimentos do testemunho GeoB6211-2, com exceção das idades de 18.987 anos cal A.P.; há 18.905 anos cal A.P.; há 18.661 anos cal A.P.; há 18.000 anos cal A.P.; há 17.016 anos cal A.P.; há 16.402 anos cal A.P.; há 14.682 anos cal A.P.; há 14.303 anos cal A.P. e há 14.000 anos cal A.P. (Fig. 36A). Tamanhos grandes representaram entre 11,6\% (18.987 anos cal A.P.) e 69,8\% (15.327 anos cal A.P.) do total de espécies por amostra.

Tamanhos macro $(>500 \mu \mathrm{m})$ tiveram porcentagens entre 1,4\% (18.620 anos cal A.P.) e 49,8\% (18.000 anos cal A.P.) (Fig. 36A). Esses tamanhos foram os segundos mais abundantes entre as espécies de foraminíferos bentônicos entre 19.000 e 14.000 anos cal A.P.(Fig. 36A). Há 18.000 anos cal A.P.; há 16.402 anos cal A.P.; há 14.682 anos cal A.P. e há 14.000 anos cal A.P., tamanhos macro foram os mais abundantes nas associações de foraminíferos bentônicos (Fig. 36A).

Tamanhos médios $(125-250 \mu \mathrm{m})$ representaram entre 0,5\% (18.987 anos cal A.P.) e $22,9 \%$ (18.400 anos cal A.P.). Testas médias foram mais expressivas entre 18.620 e 18.267 anos cal A.P.; e entre 15.634 e 14.429 anos cal A.P. (Fig. 36A). Já tamanhos pequenos (>125 $\mu \mathrm{m})$ apresentaram porcentagens entre 2,5\% (14.682 anos cal A.P.) e 60,4\% (18.987 anos cal A.P.). Testas pequenas foram mais expressivas entre 19.000 e 18.133 anos cal A.P.; entre 17.323 e 16.709 anos cal A.P.; e entre 14.303 e 14.000 anos cal A.P. (Fig. 36A).

Entre aproximadamente 19.000 e 18.500 anos cal A.P., há cerca de 17.000 anos cal A.P. e há cerca de 15.500 anos cal A.P., tamanhos médios e pequenos sobrepujaram tamanhos macro (Fig. 36A).

Testas brancas (sem alteração de cor) foram predominantes entre 19.000 e 14.000 anos cal A.P., exceto nas idades de 18.533 anos cal A.P.; 17.867 anos cal A.P.; entre 17.467 e 17.170 anos cal A.P.; e entre 14.303 e 14.000 anos cal A.P., quando testas douradas (contendo $\mathrm{FeS}_{2}$ ), indicativas de ambiente redutor, foram mais abundantes nas associações de foraminíferos bentônicos (Fig. 36B). Testas brancas tiveram percentagens entre 29,5\% (18.987 anos cal A.P.) e 83,4\% (15.941 anos cal A.P.). Já testas douradas representaram entre 2,2\% (17.016 anos cal A.P.) e 57,5\% (18.533 anos cal A.P.) (Fig. 36B).

Já testas pretas (contendo FeS) e acastanhadas (contendo hidróxido de ferro) foram menos representativas entre 19.000 e 14.000 anos cal A.P. (Fig. 36B). As primeiras foram mais expressivas entre 19.000 e 18.000 anos cal A.P., e entre 14.303 e 14.000 anos cal A.P., quando apresentaram porcentagens acima de 5\% das associações de foraminíferos bentônicos. As testas acastanhadas, alusivas a ambiente oxidante, tiveram porcentagens mais representativas há 19.000 anos cal A.P. e há 17.170 anos cal A.P., quando também mostraram 
valores percentuais acima de 5\% das associações bentônicas. Nos demais intervalos amostrados, testas pretas e acastanhadas foram raras (Fig. 36B).

Testas inteiras também predominaram entre 19.000 e 14.000 anos cal A.P. no testemunho GeoB6211-2, o que indica que as associações de foraminíferos bentônicos não foram modificadas de forma comprometedora por desgaste ou transporte de testas nesse intervalo temporal (Fig. 36C). Testas inteiras tiveram porcentagens entre 45,4\% (18.987 anos cal A.P.) e 82,9\% (17.016 anos cal A.P.). Elas tiveram comportamento oposto ao apresentado por testas parcialmente fragmentadas no período de tempo analisado (Fig. 36C).

Testas parcialmente fragmentadas apresentaram porcentagens entre 15\% (17.016 anos cal A.P.) e 48,3\% (18.987 anos cal A.P.) (Fig. 36C). Já os fragmentos ocorreram em porcentagens muito baixas entre 19.000 e 14.000 anos cal A.P. (Fig. 36C), que se situaram entre 0,3\% (18.824 anos cal A.P.) e 6,3\% (18.987 anos cal A.P. (Fig. 36C).

As frequências de testas inteiras e parcialmente fragmentadas (Fig. 36C) indicaram ambientes mais estressantes entre aproximadamente 18.600 e 17.700 anos cal A.P., entre cerca de 16.400 e 16.000 anos cal A.P., e entre aproximadamente 15.600 e 14.600 anos cal A.P. (Fig. 36C).

A análise de imagens de MEV permitiu distinguir os processos de abrasão (predominantes), bioturbação e corrosão em testas parcialmente fragmentadas (prancha 3, em anexo), sugerindo que a maior porcentagem de desgaste sofrido pelas testas teria sido causado pelo aumento da força hidrodinâmica de fundo no Cone do Rio Grande. 


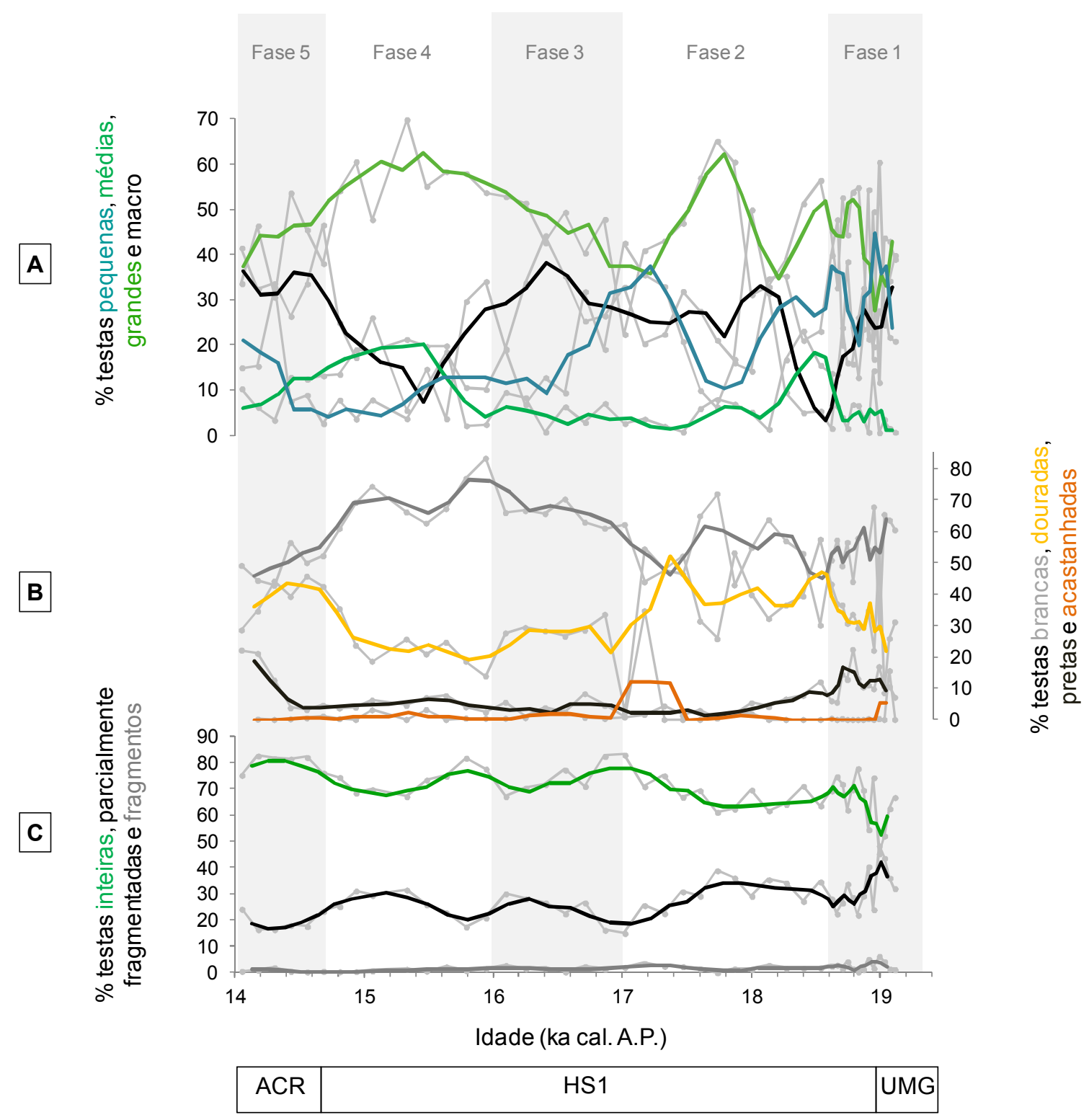

Figura 36: Análise tafonômica dos foraminíferos do testemunho GeoB6211-2. A. Análise morfométrica: porcentagens de testas pequenas $(<125 \mu \mathrm{m})$, médias $(125-250 \mu \mathrm{m})$, grandes $(250-500 \mu \mathrm{m})$ e macro $(>500 \mu \mathrm{m})$. B. Análise tafonômica de coloração: porcentagem das testas brancas (sem alteração de cor), douradas (impregnadas e/ou preenchidas por sulfeto de ferro $-\mathrm{FeS}_{2}$ ), pretas (impregnadas e/ou preenchidas por monossulfeto de ferro - FeS) e acastanhadas (impregnadas por hidróxido de ferro). C. Análise tafonômica de grau de fragmentação: porcentagem de testas inteiras (sem desgaste externo visível), parcialmente fragmentadas (até 50\% de desgaste e/ou fragmentação) e fragmentos (acima de 50\% de desgaste e/ou fragmentação). Linhas cinzas com pontos: dados originais obtidos. Linhas coloridas: média móvel de três pontos. Barra horizontal: intervalo das épocas paleoclimáticas existentes entre 19.000 e 14.000 anos cal A.P. ACR: Antarctic Cold reversal. HS1: Heinrich Stadial 1. UMG: Último Máximo Glacial. Tarjas cinzas: diferentes fases paleoambientais indicadas pelas associações de foraminíferos bentônicos entre 19.000 e 14.000 anos cal A.P. no testemunho GeoB6211-2. Modelo de idades retirado de Chiessi et al. (2008).

A análise estatística de agrupamento modo- $\mathrm{R}$ agrupou as 22 espécies mais frequentes de foraminíferos bentônicos encontradas entre 19.000 e 14.000 anos cal A.P. em quatro diferentes grupos (Fig. 37). 


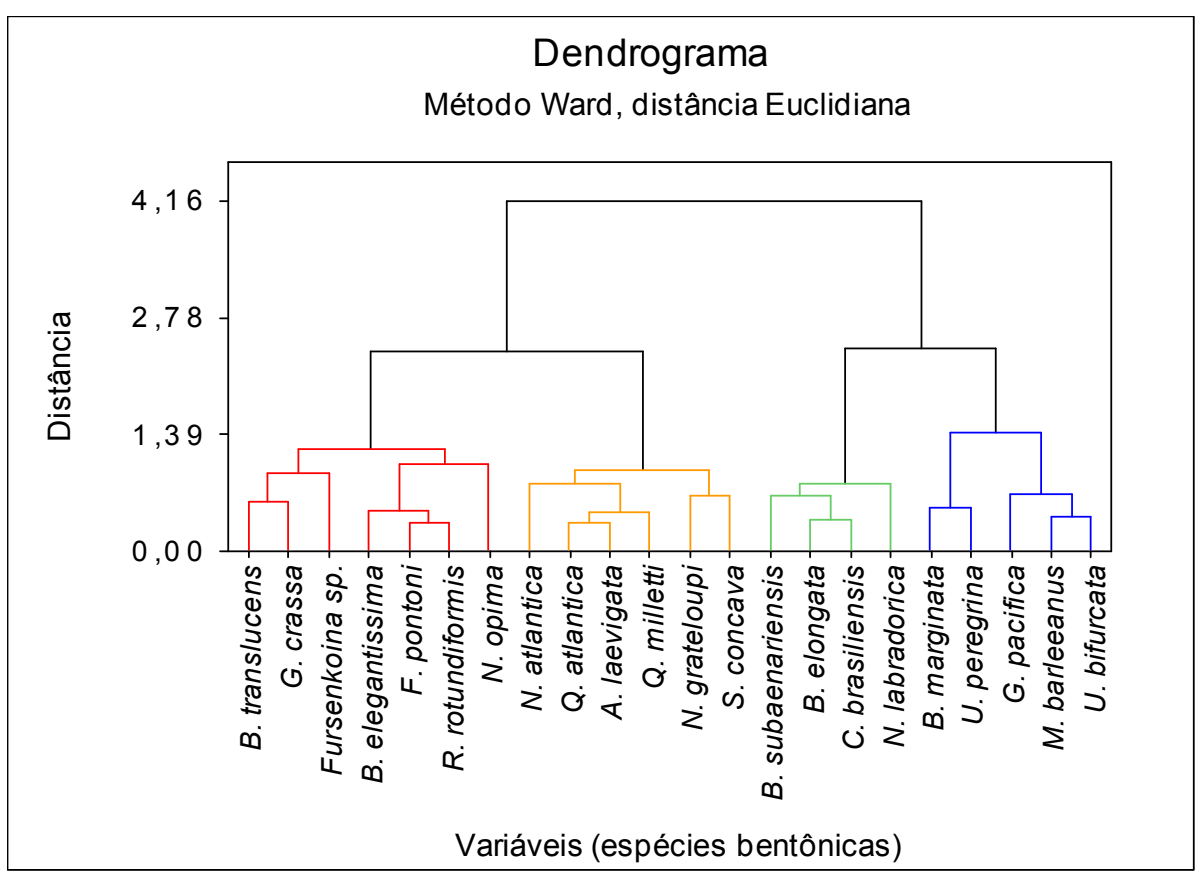

Figura 37: Dendrograma da análise estatística de agrupamento modo-R das 22 espécies mais abundantes do testemunho GeoB6211-2 entre 19.000 e 14.000 anos cal A.P.

As características das quatro diferentes associações de foraminíferos bentônicos estão indicadas na tabela 10 .

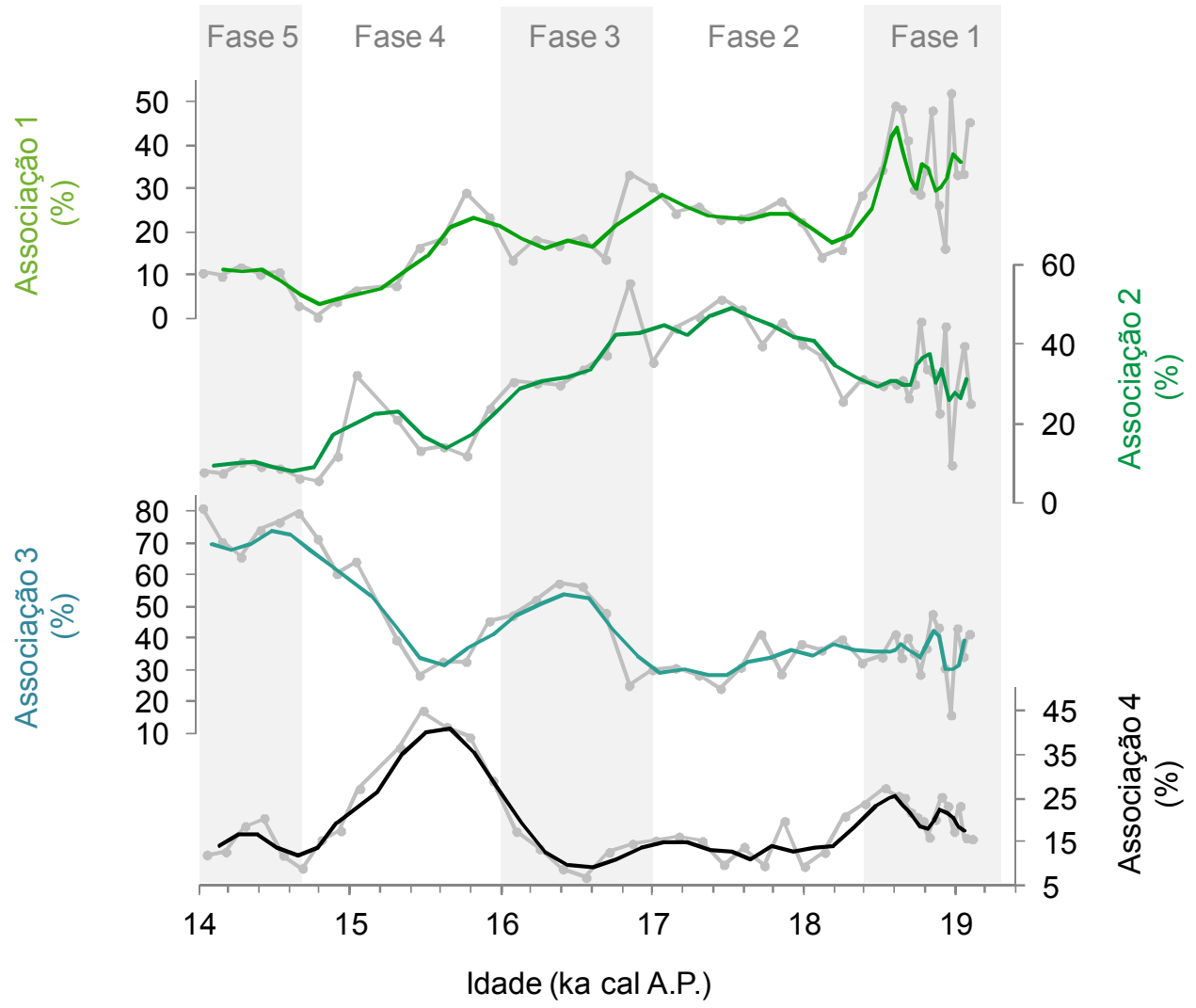

Figura 38: Distribuições das quatro diferentes associações microfaunísticas do testemunho GeoB6211-2 obtidas pela análise estatística de agrupamento modo-R. Linhas cinzas com pontos: pontos originais. Linhas coloridas: média móvel de três pontos. Tarjas cinzas: diferentes fases paleoambientais indicadas pelas associações de foraminíferos bentônicos entre 19.000 e 14.000 anos cal A.P. no testemunho GeoB6211-2. Modelo de idades retirado de Chiessi et al. (2008). 
Tabela 10: Características das diferentes associações de foraminíferos bentônicos do testemunho GeoB6211-2.

\begin{tabular}{|c|c|c|c|c|}
\hline $\begin{array}{l}\text { Associa- } \\
\text { ções }\end{array}$ & $\begin{array}{l}\text { Principais } \\
\text { períodos de } \\
\text { ocorrência }\end{array}$ & $\begin{array}{l}\text { Principais espécies } \\
\text { (Dominantes e } \\
\text { subdominantes) }\end{array}$ & Espécies secundárias (acessórias e raras) & Principais características das principais espécies \\
\hline 1 & $\begin{array}{l}\text { Entre } 19 \text { e } 18,6 \\
\text { ka cal A.P., } \\
\text { entre } \sim 18 \text { e } \sim 17 \\
\text { ka cal A.P. e há } \\
\sim 16 \text { ka cal A.P. }\end{array}$ & $\begin{array}{l}\text { Bolivinellina translucens, } \\
\text { Buliminella elegantissima, } \\
\text { Cassidulina crassa, } \\
\text { Fursenkoina pontoni, } \\
\text { Nonionella opima e } \\
\text { Rutherfordoides rotundiformis }\end{array}$ & $\begin{array}{c}\text { Buccella peruviana, Cancris sagra, Cibicides spp., } \\
\text { Eponides repandus, Fissurina spp., } \\
\text { Globocassidulina subglobosa, Lagena spp., } \\
\text { Quinqueloculina lamarkiana, Quinqueloculina } \\
\text { seminula, Pyrgo spp., Rosalina williamsoni, } \\
\text { Uvigerina peregrina e Uvigerina striata }\end{array}$ & $\begin{array}{l}\text { Disóxicas, indicativas de ambiente com alto acúmulo de M.O., detritívoras, com } \\
\text { predominância de epifauna-infauna, indicativas de substrato formado por areia fina a lama. } \\
\text { R. rotundiformis e C. crassa indicam águas mais frias. C. crassa é proxy da Corrente das } \\
\text { Malvinas. B. translucens e } N \text {. opima, de águas estratificadas. N. opima é tolerante à anoxia. } \\
\text { B. elegantissima indica menor hidrodinâmica do meio. }\end{array}$ \\
\hline 2 & $\begin{array}{l}\text { Entre } 19 \text { e } \sim 16 \\
\text { ka cal A.P. e há } \\
\sim 15 \text { ka cal A.P. }\end{array}$ & $\begin{array}{l}\text { Nonionella atlantica, } \\
\text { Nonionoides grateloupii, } \\
\text { Quinqueloculina atlantica, } \\
\text { Adelosina laevigata, } \\
\text { Quinqueloculina milleti e } \\
\text { Stainforthia côncava }\end{array}$ & $\begin{array}{l}\text { Bolivina alata, Buccella peruviana, Cancris sagra, } \\
\text { Cassidulina spp., Cibicides spp., Discorbis sp., } \\
\text { Eponides repandus, Globocassidulina subglobosa, } \\
\text { Melonis barleeanus, Oolina spp., Poroeponides } \\
\text { lateralis, Pseudononion pulchella, Pyrgo nasuta, } \\
\text { Pyrgo ringens, Quinqueloculina lamarkiana, } \\
\text { Quinqueoculina patagonica, Quinqueloculina } \\
\text { seminula, Rubratela intermedia e Uvigerina spp. }\end{array}$ & $\begin{array}{l}\text { Espécies divididas em } 2 \text { grupos: i) infaunais, típicas de ambiente com alto conteúdo de } \\
\text { M.O. e baixo de } \mathrm{O}_{2} \text {, detritívoras ou herbívoras, de substrato formado por lama e ambiente } \\
\text { menos energético. ii) epifaunais, típicas de ambiente com alto conteúdo de } \mathrm{O}_{2} \text { e menor de } \\
\text { M.O., de águas com menor estratificação, predominantemente herbívoras, de ambiente mais } \\
\text { energético. } N \text {. atlantica é indicador de hipoxia. A. laevigata sobrevive em ambiente } \\
\text { disóxico com alto aporte de M.O. } Q \text {. atlantica e } Q \text {. milleti são intolerantes à disoxia. } S \text {. } \\
\text { concava existe em sedimentos com alto conteúdo de nitrogênio e carbono orgânico e indica } \\
\text { águas frias }\left(\sim 3.4^{\circ} \mathrm{C}\right) \text { e salinidade de } \sim 34.4 \% \text {. }\end{array}$ \\
\hline 3 & $\begin{array}{l}\text { Entre } \sim 17 \text { e } \\
\sim 16 \text { ka cal A.P. } \\
\text { e entre } \sim 15 \text { e } \\
\sim 14 \text { ka cal A.P. }\end{array}$ & $\begin{array}{l}\text { Brizalina subaenariensis, } \\
\quad \text { Bulimina elongata, } \\
\text { Cassidulinoides brasiliensis e } \\
\text { Nonionellina labradorica }\end{array}$ & $\begin{array}{l}\text { Bolivinellina translucens, Buliminella elegantissima, } \\
\text { Cancris sagra, Cassidulina spp., Cibicides dispars, } \\
\text { Cibicides kullenbergi, Cibicides refulgens, Eponides } \\
\text { repandus, Fissurina spp., Gyroidina spp., Haynesina } \\
\text { spp., Hopkinsina pacifica, Lagena spp., Lenticulina } \\
\text { spp., Lobatula lobatula, Nonionella auris, } \\
\text { Oridosalis umbonatus, Rosalina williamsoni, } \\
\text { Sigmoilopsis schlumbergeri e Uvigerina striata }\end{array}$ & $\begin{array}{l}\text { Indicativas de ambiente com baixas concentrações de oxigênio e altas de M.O. São } \\
\text { majoritariamente detritívoras, com preferência por M.O. mais lábil. Vinculam-se a regiões } \\
\text { de upwelling, de águas mais frias a temperadas e de sedimentos de granulometria de areia } \\
\text { fina a lama. } \text { B. subaenariensis reage ao bloom fitodetrítico com crescimento rápido e indica } \\
\text { águas mais estratificadas e presença de } \mathrm{H}_{2} \mathrm{~S} \text { no meio. } \text { B. elongata se alimenta de M.O. mais } \\
\text { degradada e indica menor energia hidrodinâmica e sedimentos lamosos. } N \text {. labradorica } \\
\text { indica águas mais frias e sobrevive à disoxia. }\end{array}$ \\
\hline 4 & $\begin{array}{c}\text { Entre } \sim 16 \mathrm{e} \\
\sim 15 \text { ka cal A.P. }\end{array}$ & $\begin{array}{l}\text { Bulimina marginata, } \\
\text { Globobulimina pacifica, } \\
\text { Melonis barleeanus, } \\
\text { Uvigerina bifurcata } \mathrm{e} \\
\text { Uvigerina peregrina }\end{array}$ & $\begin{array}{l}\text { Bolivinellina translucens, Buliminella elegantissima, } \\
\text { Cancris sagra, Cassidulina spp., Cassidulinoides } \\
\text { brasiliensis, Cibicides spp., Eponides repandus, } \\
\text { Fissurina lucida, Fursenkoina pontoni, } \\
\text { Globocassidulina subglobosa, Gyroidina altiformis, } \\
\text { Haynesina depressula, Hopkinsina pacifica, Lagena } \\
\text { spp., Lenticulina spp., Nonionella spp., Nonion } \\
\text { depressulus, Oridorsalis umbonatus, Pseudononion } \\
\text { pulchella, Quinquelcoulina patagonica, Rosalina } \\
\text { williamsoni, Sigmoilopsis schlumbergeri e } \\
\text { Uvigerina striata }\end{array}$ & $\begin{array}{l}\text { Típicas de altas concentrações de M.O. e baixa de } \mathrm{O}_{2} \text {. São majoritariamente detritívoras, } \\
\text { com predominância de infauna rasa, sendo capazes de ocupar nichos epifaunais se } \\
\text { necessário. Habitam sedimentos de granulometria de areia lamosa a lama. B. marginata e } \\
\text { U. peregrina indicam zona de mínima oxigenação. B. marginata recoloniza ambientes } \\
\text { anóxicos lentamente, prefere M.O. fresca, é estenohalina e relacionada a águas da pluma do } \\
\text { Rio da Prata, de águas frias e estratificadas. G. pacifica e M. barleeanus indicam zona de } \\
\text { redução do nitrato. G. pacifica é infauna média a profunda e indica águas frias a } \\
\text { temperadas. M. barleeanus consome M.O. mais degradada, se vincula à ação de bactérias } \\
\text { denitrificantes, a sedimentos lamosos e águas frias. U. bifurcata indica alta produtividade } \\
\text { oceânica e é típica da AIA e da Corrente das Malvinas. U. peregrina se favorece de carbono } \\
\text { sedimentar, indica nutrientes transportados pela ACAS e tolera M.O. mais degradada. }\end{array}$ \\
\hline
\end{tabular}




\subsubsection{Resultados geoquímicos em testa de Globigerinoides ruber}

As temperaturas superficiais marinhas baseadas em $\mathrm{Mg} / \mathrm{Ca}$ da testa da espécies planctônica Globigerinoides ruber (white, s.s.) ( $\mathrm{Mg} / \mathrm{Ca} \mathrm{SST}$ ) tiveram seu menor valor $\left(18,2^{\circ} \mathrm{C}\right)$ há 18.975 anos cal A.P., e seu maior valor $\left(27,5^{\circ} \mathrm{C}\right)$ há 10.057 anos cal A.P. As $\mathrm{Mg} / \mathrm{Ca}$ SST apresentaram tendência geral a leve aumento entre 19.000 e o Presente (Tabela 11, em anexo; Fig. 39). Houve oscilações secundárias de aumento e diminuição que apresentaram picos positivos há 16.878 anos cal A.P.; há 15.650 anos cal A.P.; há 15.111 anos cal A.P.; há 14.062 anos cal A.P.; há 13.406 anos cal A.P.; há 10.959 anos cal A.P. e há 10.057 anos cal A.P. (Tabela 11, em anexo; Fig. 39).

Os valores de $\delta^{18} \mathrm{O}_{\text {ivc-sw }}$ (\% VSMOW) indicaram que, em geral, a tendência da salinidade superficial do Atlântico Sul sudoeste na região analisada apresentou valores crescentes entre 19.000 e 16.878 anos cal A.P.; entre 13.921 e 13.406 anos cal A.P.; entre 10.830 e 9.800 anos cal A.P.; entre 9.027 e 8.512; entre 7.032 e 6.800 anos cal A.P.; entre 6.570 e 5.875 ; entre 5.529 e 4.488 anos cal A.P.; entre 3.216 e 2.753 anos cal A.P.; e entre 1.366 e o Presente (Tabela 11, em anexo; Fig. 39). Esses períodos de aumento foram intercalados a períodos de diminuição das salinidades superficiais dessa região atlântica. Esses períodos de aumento e diminuição acompanharam as modificações secundárias das $\mathrm{Mg} / \mathrm{Ca}$ SST da região (Tabela 11, em anexo; Fig. 39).

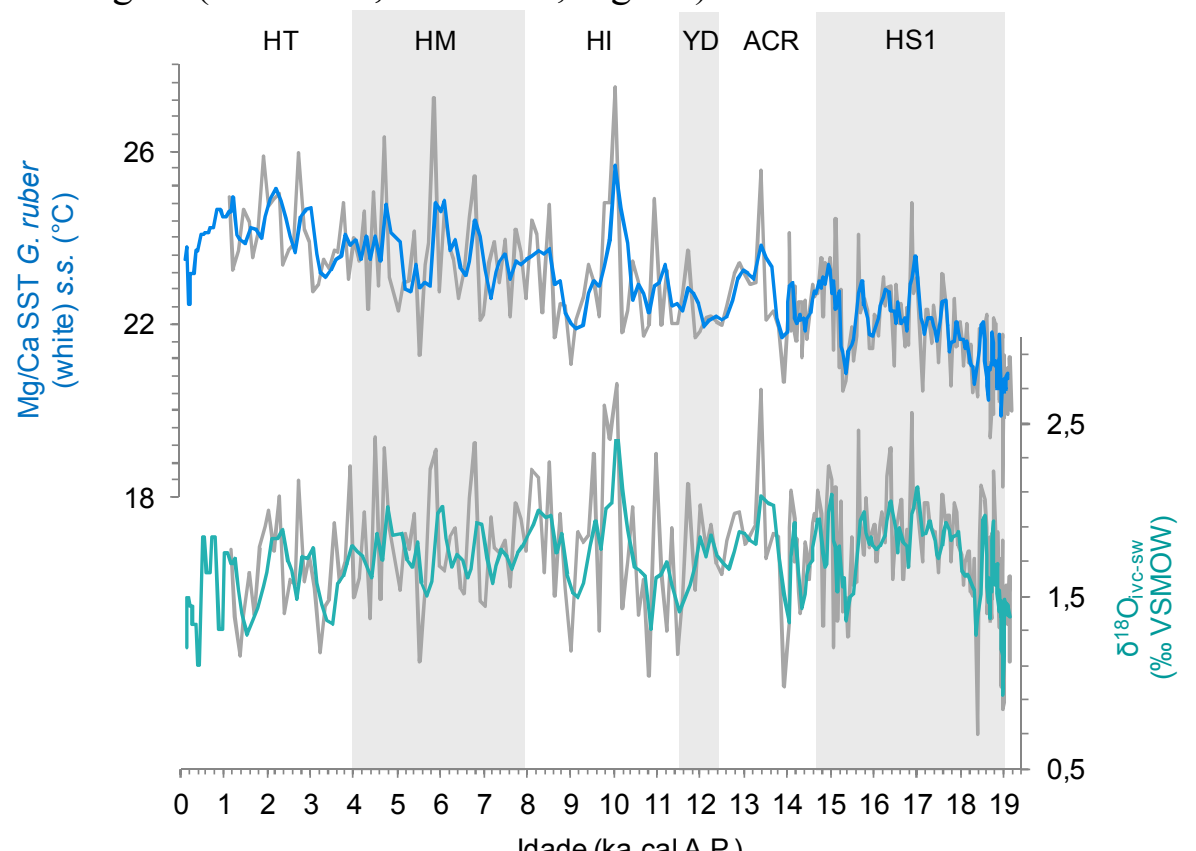

Figura 39: Valores de $\mathrm{Mg} / \mathrm{Ca} \operatorname{SST}\left({ }^{\circ} \mathrm{C}\right)$ e $\delta^{18} \mathrm{O}_{\text {ivc-sw }}(\%$ VSMOW) de testas de G. ruber (white, s.s.) do testemunho GeoB6211-2. Linhas cinzas: dados originais. Linhas coloridas: média móvel de três pontos. Tarjas cinzas: divisão das diferentes épocas paleoambientais entre 19.000 anos cal A.P. e o Presente. HS1: Heinrich Stadial 1. ACR: Antarctic Cold reversal. YD: Younger Dryas. HI: Holoceno Inferior. HM: Holoceno Médio. HT: Holoceno tardio. Modelo de idades retirado de Chiessi et al. (2008). 
As médias de $\mathrm{Mg} / \mathrm{Ca} \mathrm{SST}$ calculadas para os períodos da Última Deglaciação e do Holoceno tiveram aumento de $2,9^{\circ} \mathrm{C}$ entre o Último Glacial $(\sim 19.000$ anos cal A.P.) e o Presente. Já os valores de $\delta^{18} \mathrm{O}_{\text {ivc-sw }}(\%$ VSMOW) tiveram diferença de apenas $0,008 \%$, embora entre 11.603 e 11.474 anos cal A.P. tenha ocorrido diminuição de 0,35\% VSMOW (Figs. 39, 40, 41).

Durante o Heinrich Stadial 1 (HS1), entre 19.000 e 14.700 anos cal A.P., a média das $\mathrm{Mg} / \mathrm{Ca} \mathrm{SST}$ foi de $21,6^{\circ} \mathrm{C}$. Durante este intervalo paleoclimático, as $\mathrm{Mg} / \mathrm{Ca} \mathrm{SST}$ apresentaram tendência geral de aumento até 16.878 anos cal A.P., com picos positivos há 18.587 anos cal A.P., há 17.853 anos cal A.P. e há 17.587 anos cal A.P. (Fig. 40), seguido de decréscimo até 15.280 anos cal A.P., com picos positivos de temperatura há 16.202 anos cal A.P. e há 15.649 anos cal A.P. (Fig. 40).

Entre 15.280 e 14.605 anos cal A.P. as $\mathrm{Mg} / \mathrm{Ca} \mathrm{SST}$ voltaram a aumentar, e apresentaram pico positivo há 15.224 anos cal A.P. e há 15.111 anos cal A.P. A variação entre o menor $\left(18,2^{\circ} \mathrm{C}\right.$ em 18.975 anos cal A.P.) e o maior $\left(24,8^{\circ} \mathrm{C}\right.$ em 16.878 anos cal A.P.) valores das $\mathrm{Mg} / \mathrm{Ca}$ SST nesse intervalo geológico foi de $6,5^{\circ} \mathrm{C}$ (Fig.40).

A média dos valores de $\delta^{18} \mathrm{O}_{\mathrm{ivc}-\mathrm{sw}}(\% \mathrm{VSMOW})$ foram de $1,73 \%$ VSMOW durante o HS1. Nesse período paleoclimático, o maior valor de $\delta^{18} \mathrm{O}_{\mathrm{ivc}-\mathrm{sw}}$ (\%o VSMOW) foi de 0,69\%o VSMOW (18.387 anos cal A.P.) e 2,56\% VSMOW (16.878 anos cal A.P.). Os valores de $\delta^{18} \mathrm{O}_{\text {ivc-sw }}(\%$ VSMOW) apresentaram tendências gerais de aumento e diminuição de valores bastante similares às das $\mathrm{Mg} / \mathrm{Ca} \mathrm{SST}$ dessa mesma região atlântica (Fig. 40). Houve aumento desses valores entre 19.000 e 16.878 anos cal A.P., com picos positivos há 18.772 anos cal A.P., e há 18.493 anos cal A.P., e entre 16.878 e 15.388 anos cal A.P., com picos positivos há 16.386 e há 15.649 anos cal A.P. (Fig. 40). Entre 15.388 anos cal A.P. e 14.972 anos cal A.P., os valores de $\delta^{18} \mathrm{O}_{\text {ivc-sw }}$ (\%o VSMOW) voltaram a aumentar, e então diminuíram até 14.605 anos cal A.P. (Fig. 40).

No período correspondente à Reversão Fria Antártica (ACR, entre 14.600 e 12.500 anos cal A.P.), a média das temperaturas foi de $22,5^{\circ} \mathrm{C}$. A menor temperatura $\left(20,6^{\circ} \mathrm{C}\right)$ ocorreu há 13.921 anos cal A.P., e a maior $\left(25,6^{\circ} \mathrm{C}\right)$, há 13.406 anos cal A.P. (Fig. 40). Entre 14.605 e 13.921 anos cal A.P., as Mg/Ca SST diminuíram e, dessa época até 13.406, voltaram a aumentar (Fig. 40). Houve pico positivo de temperatura há 14.063 anos cal A.P. Entre 13.921 e 12.504 anos cal A.P. (Fig. 40).

Os valores de $\delta^{18} \mathrm{O}_{\mathrm{ivc}-\mathrm{sw}}$ (\%o VSMOW) apresentaram média de 1,79\% durante o ACR. Esses valores ficaram entre 0,97\% VSMOW (13.921 anos cal A.P.) e 2,69\%o VSMOW (13.406 anos cal A.P.). Diminuíram até 13.921 anos cal A.P., com presença de pico positivo 
há 14.100 anos cal A.P. E entre 13.921 e 13.406 anos cal A.P. esses valores voltaram a aumentar, e então tornaram a diminuir até 12.505 anos cal A.P. (Fig. 40).

Já durante o Younger Dryas (YD, de 12.500 a 11.500 anos cal A.P.), a média da $\mathrm{Mg} / \mathrm{Ca}$ SST foi de $22,3^{\circ} \mathrm{C}$. A menor temperatura foi de $21,7^{\circ} \mathrm{C}$ (11.860 anos cal A.P.), e a maior, de 23, $7^{\circ} \mathrm{C}$ (11.732 anos cal A.P.). Houve diminuição das Mg-Ca SST até 11.860 anos cal A.P., seguida de aumento de $\sim 2{ }^{\circ} \mathrm{C}$ até 11.732 anos cal A.P. As $\mathrm{Mg} / \mathrm{Ca}$ SST então diminuíram $1,6^{\circ} \mathrm{C}$ até 11.500 anos cal A.P. (Fig. 40).

No YD, a média dos valores de $\delta^{18} \mathrm{O}_{\text {ivc-sw }}(\%$ VSMOW) foi de 1,74 \%o VSMOW. O menor valor foi de 1,16\% VSMOW (11.474 anos cal A.P.), e o maior foi de 2,15\% VSMOW (11.732 anos cal A.P.). Os valores aumentaram entre 12.505 e 11.732 anos cal A.P., e diminuíram cerca de 1\%o VSMOW até 11.474 anos cal A.P. (Fig. 40).

Os comportamentos das tendências gerais de aumento e diminuição dos valores de $\mathrm{Mg} / \mathrm{Ca} \mathrm{SST}$ e de $\delta^{18} \mathrm{O}_{\text {ivc-sw }}$ (\%o VSMOW) foram semelhantes às tendências de aumento e diminuição das temperaturas e salinidades superficiais das regiões nordeste (Weldeab et al., 2006) e sudeste (Carlson et al., 2008) da margem brasileira, especialmente durante o período do Heinrich Stadial 1 (HS1) (Fig. 40A, B, C, D, E e F). Mas foram diferentes das variações de temperaturas e salinidades da região da termoclina da mesma região de coleta do testemunho GeoB6211-2 nessa mesma época (Fig. 40, A, B, G e H).

Durante o Younger Dryas, as tendências dos valores de $\mathrm{Mg} / \mathrm{Ca} \mathrm{SST}$ e os valores de $\delta^{18} \mathrm{O}_{\text {ivc-sw }}$ (\% VSMOW) foram diferentes daquelas apresentadas por Weldeab et al. (2006) para a região da margem nordeste brasileira (Fig. 40A, B, C eD), mas apresentaram certa semelhança com as tendências apresentadas por Carlson et al. (2008) para a região sudeste da margem brasileira (Fig. 40A, B, E e F).

Os comportamentos das tendências dos valores de $\mathrm{Mg} / \mathrm{Ca} \mathrm{SST}$ e de $\delta^{18} \mathrm{O}_{\text {ivc-sw }}$ (\%o VSMOW) foram semelhantes aos valores das temperaturas e salinidades da região da termoclina permanente para este mesmo setor atlântico, e seguiram a tendência geral de aumento de temperaturas encontradas para a região do continente antártico e do hemisfério sul por Shakun et al. (2012) (Fig. 40A, B, G, H, I, J). 


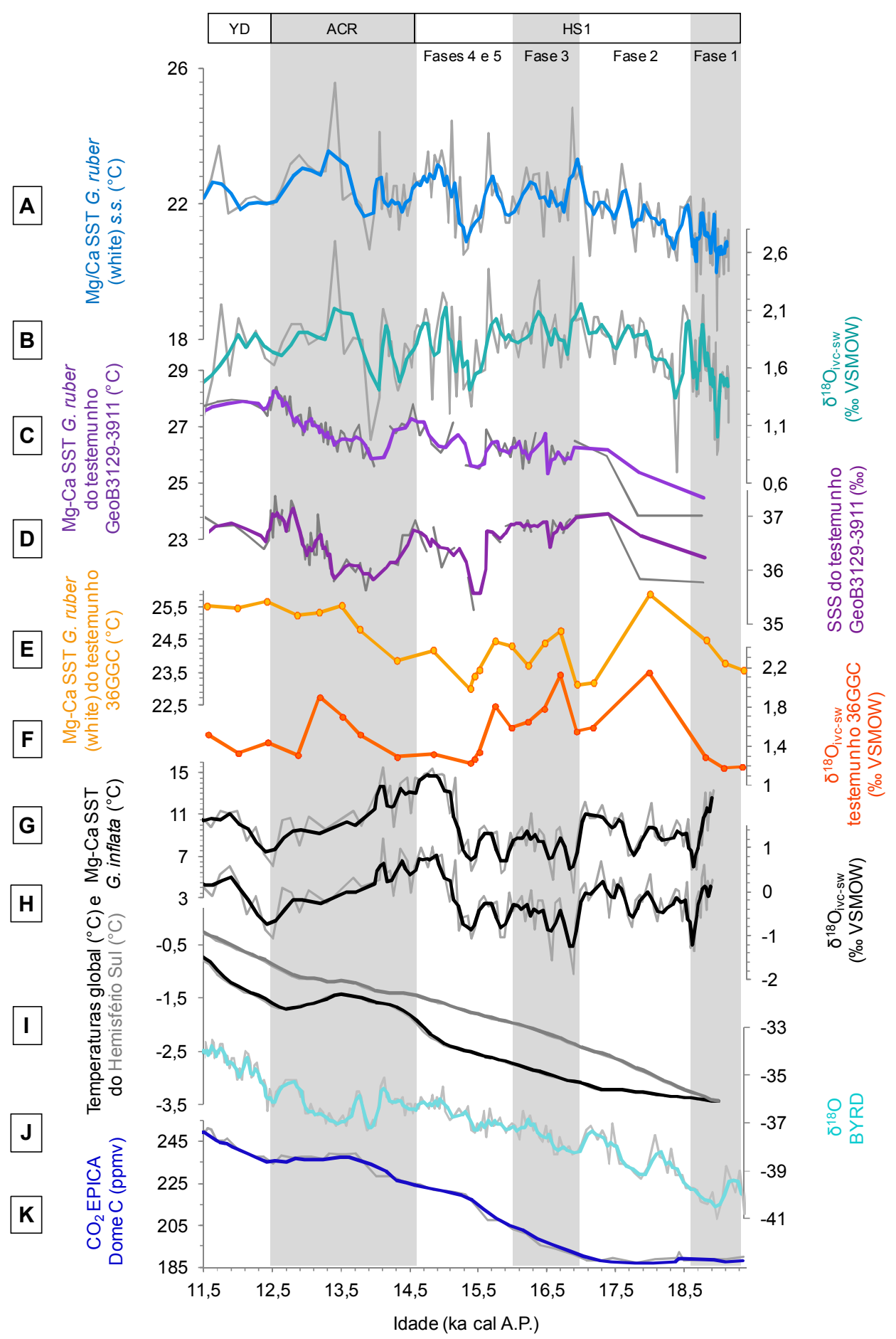

Figura 40: Valores de paleotemperaturas e paleossalinidades para o atlântico subtropical sudoeste. A. $\mathrm{Mg}$-Ca SST G. ruber (white, s.s.) $\left({ }^{\circ} \mathrm{C}\right)$ do testemunho GeoB6211CC (este estudo). B. $\delta^{18} \mathrm{O}_{\mathrm{ivc}-\mathrm{sw}}$ (\%o VSMOW) do testemunho GeoB6211CC (este estudo). C. Mg/Ca G. ruber (white) do testemunho GeoB3129-3911 (Weldeab et al., 2006). D. salinidades superficiais (SSS) do testemunho GeoB3129-3911 (Weldeab et al., 2006). E. Mg-Ca SST G. ruber (white) do testemunho 36GGC (Carlson et al., 2008). F. $\delta^{18} \mathrm{O}_{\text {ivc-sw }}(\%$ VSMOW) do testemunho 36GGC (Carlson et al., 2008). G. Temperatura baseada em Mg-Ca G. inflata do testemunho geoB6211-2 (Chiessi et al., 2008). H. $\delta^{18} \mathrm{O}_{\text {ivc-sw }}$ (\% VSMOW) G. inflata do testemunho GeoB6211-2 (Chiessi et al., 2008). I. diferença do "montante de temperatura" global e do hemisfério sul dadas como anomalias de suas médias do período holocênico entre 11.500 e $6.500 \mathrm{ka}$ cal A.P. (Shakun et al., 2012). J. $\delta^{18} \mathrm{O}$ BYRD (Antártica, Blunier e Brook, 2001). K. $\mathrm{CO}_{2}$ (ppmv) do testemunho EPICA Dome C (Monnin et al., 2004). Linhas cinzas: dados originais. Linhas coloridas: média móvel de três pontos. Tarjas cinzas: HS1: Heinrich Stadial 1. ACR: Antarctic Cold reversal. YD: Younger Dryas. Modelo de idades retirado de Chiessi et al. (2008). 
Houve tendência geral suave ao aumento das $\mathrm{Mg} / \mathrm{Ca} \mathrm{SST}$ na região de coleta do testemunho GeoB6211-2 durante todo o Holoceno (Fig. 41A). No Holoceno Inferior e no Holoceno Médio (HI e HM, de 11.500 a 4.000 anos cal A.P.), houve aumento considerável das SST há 10.057 anos cal A.P., quando elas demonstraram seu maior valor $\left(27,5^{\circ} \mathrm{C}\right)$. Um segundo pico apreciável de $\mathrm{Mg} / \mathrm{Ca}$ SST foi encontrado há 5.875 anos cal A.P. $\left(27,2^{\circ} \mathrm{C}\right)$. Esses consideráveis picos de aumento das $\mathrm{Mg} / \mathrm{Ca} \mathrm{SST}$ foram seguidos por diminuição das temperaturas superficiais na ordem de $6,4^{\circ} \mathrm{C}$ (até 9.027 anos cal A.P.) e de $6^{\circ} \mathrm{C}$ (até 5.528 anos cal A.P.), respectivamente (Fig. 41A), indicando que estes foram intervalos de mais amplas variações térmicas superficiais nesse setor do atlântico subtropical sudoeste.

No Holoceno Inferior, os valores de $\delta^{18} \mathrm{O}_{\text {ivc-sw }}$ (\%o VSMOW) aumentaram 1,68\%o VSMOW entre 11.500 e 10.057 anos cal A.P., onde atingiram seu maior valor (2,73\%o VSMOW) (Fig. 41B). Então diminuíram 1,54 \% VSMOW até 9.027 anos cal A.P. Entre 9.027 e 8.512 anos cal A.P., houve aumento de 1,08 \%o VSMOW (Fig. 41B). Assim como as SST, as salinidades superficiais do atlântico subtropical sudoeste apresentaram amplas variações neste período de transição entre a Última Deglaciação e o Holoceno (Fig. 41B).

A partir do Holoceno Médio (8.000 anos cal A.P.) até o Presente, a tendência geral foi de leve diminuição das salinidades superficiais desse setor atlântico (Fig. 41B). Houve variações mais intensas do sinal de $\delta^{18} \mathrm{O}_{\text {ivc-sw }}$ (\% VSMOW) entre 7.032 e 1.176 anos cal A.P. (média de 0,89 \% VSMOW de variação nos valores de $\delta^{18} \mathrm{O}_{\text {ivc-sw }}$ ) (Fig. 41B).

Os valores de $\mathrm{Mg} / \mathrm{Ca} \mathrm{SST}$ do testemunho GeoB6211-2 seguiram as mesmas tendências de variação que aquelas apresentadas pelas temperaturas do hemisfério sul (Fig. 41A, E e F). Já os valores de $\delta^{18} \mathrm{O}_{\text {ivc-sw }}(\%$ VSMOW) seguiram as mesmas tendências de diminuição que as salinidades superficiais encontradas por Weldeab et al. (2006) para a região marginal nordeste brasileira (Fig. 41 B, D). 


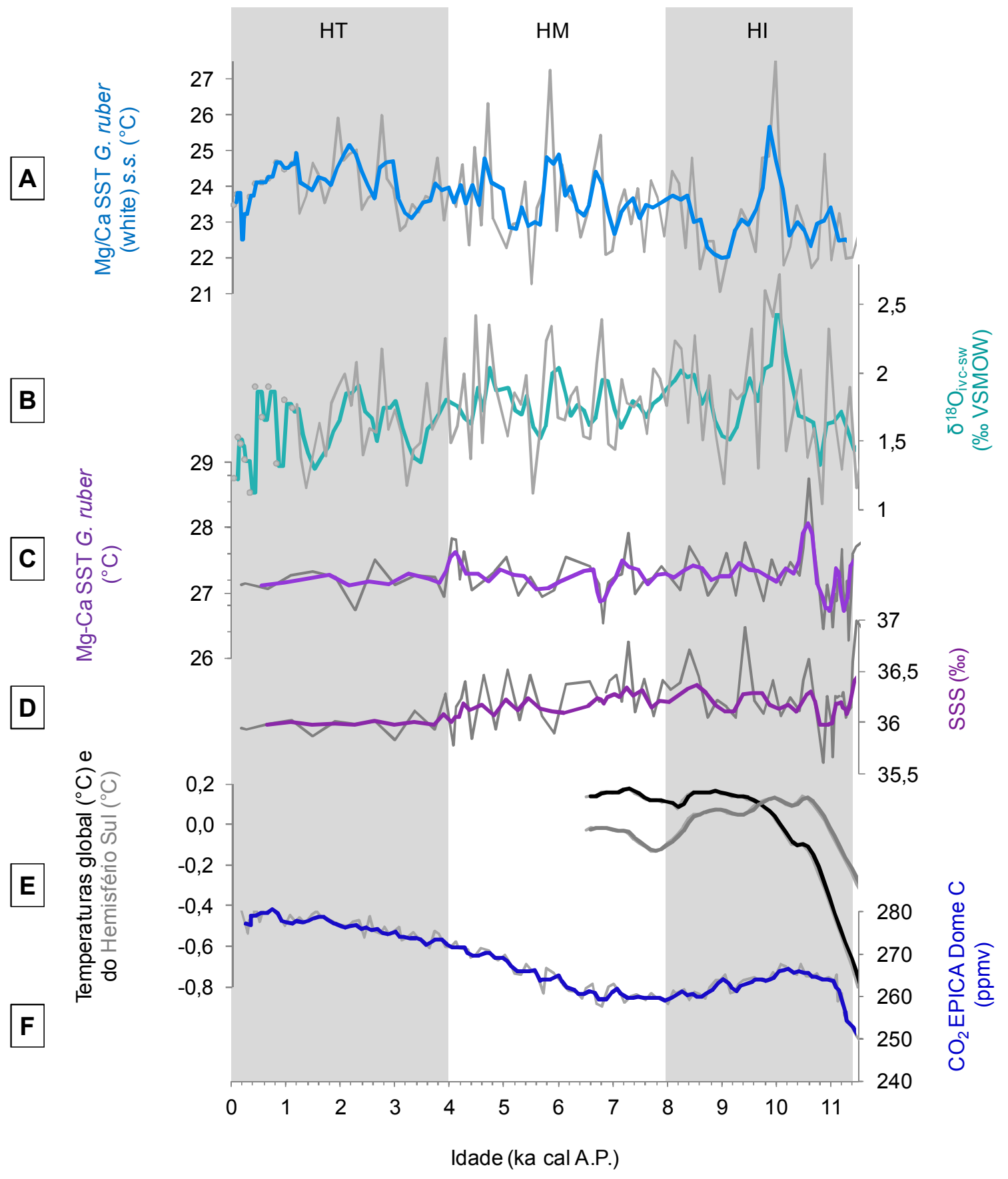

Figura 41: Valores de paleotemperaturas e paleossalinidades para o atlântico subtropical sudoeste. A. $\mathrm{Mg}-\mathrm{Ca}$ SST G. ruber (White, s.s.) $\left({ }^{\circ} \mathrm{C}\right)$ do testemunho GeoB6211CC (este estudo). B. $\delta^{18} \mathrm{O}_{\text {ivc-sw }}$ (\%o VSMOW) do testemunho GeoB6211CC (este estudo). C. Mg/Ca G. ruber (white) do testemunho GeoB3129-3911 (Weldeab et al., 2006). D. salinidades superficiais (SSS) do testemunho GeoB3129-3911 (Weldeab et al., 2006). E. diferença do "montante de temperatura" global e do hemisfério sul dadas como anomalias de suas médias do período holocênico entre 11,5 e 6,5 cal kyr B.P. (Shakun et al., 2012). F. $\mathrm{CO}_{2}$ (ppmv) do testemunho EPICA Dome C (Monnin et al., 2004). Linhas cinzas: dados originais. Linhas coloridas: média móvel de três pontos. Tarjas cinzas: HI: Holoceno Inferior. HM: Holoceno Médio. HT: Holoceno tardio. Modelo de idades retirado de Chiessi et al. (2008). 
Os resultados microfaunísticos dos testemunhos S03 e GeoB6211-2, entre 19.000 e 14.000 anos cal A.P. e entre 9.400 e 8.385 anos cal A.P. mostraram padrões de aumento e de diminuição de valores em períodos de tempo similares, levando-se em conta a diferença dos modelos de idade dos dois testemunhos. Em geral, quando os valores de $\mathrm{Mg} / \mathrm{Ca} \mathrm{SST}$ e de $\delta^{18} \mathrm{O}_{\mathrm{ivc}-\mathrm{sw}}$ aumentaram, os valores de espécies euhalinas e polihalinas/mesohalinas do testemunho S03 e os valores do índice BFOI do testemunho GeoB6211-2 também tiveram tendência ao aumento (Fig. 42 e 43).

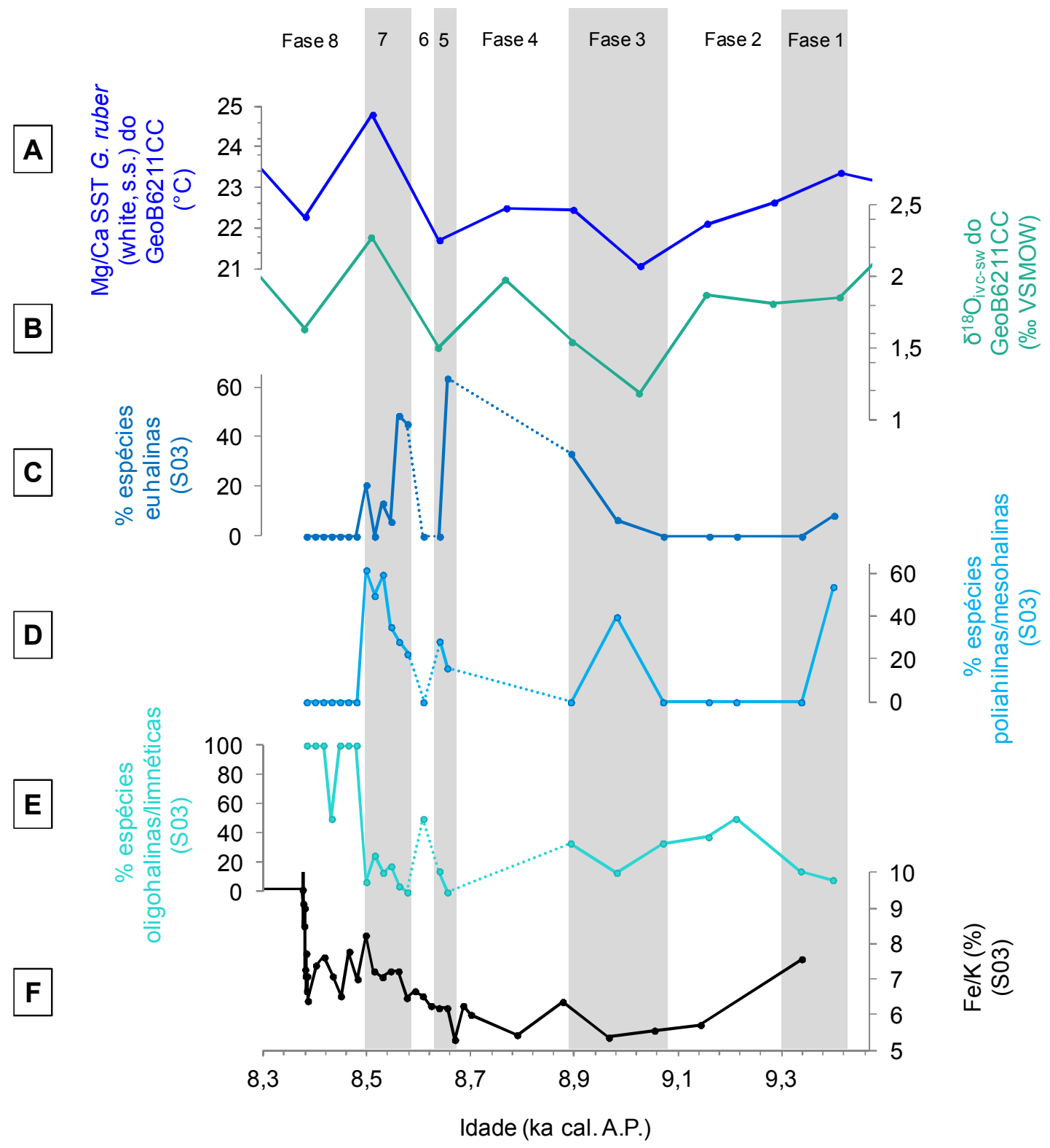

Figura 42: Comparação entre os dados dos testemunhos S03 e GeoB6211CC entre 9.400 e 8.385 anos cal A.P. A. paleotemperaturas (Mg/Ca SST) do testemunho GeoB6211CC (este estudo). B. paleossalinidades $\left(\delta^{18} \mathrm{O}_{\text {ivc-sw }}\right)$ do testemunho GeoB6211CC (este estudo). C, D e E. dados microfaunísticos indicadores de salinidade (\% espécies euhalinas; \% espécies polihalinas/mesohalinas e \% espécies oligohalinas/limnéticas) do testemunho S03 (este estudo). F. razão $\mathrm{Fe} / \mathrm{K}$ do testemunho S03 (Sallun et al., 2012). Tarjas cinza: diferentes épocas paleoclimáticas da região do MJI entre 9.400 e 8.385 anos cal A.P. Modelo de idades e razão Fe/K retirados de Sallun et al. (2012). 


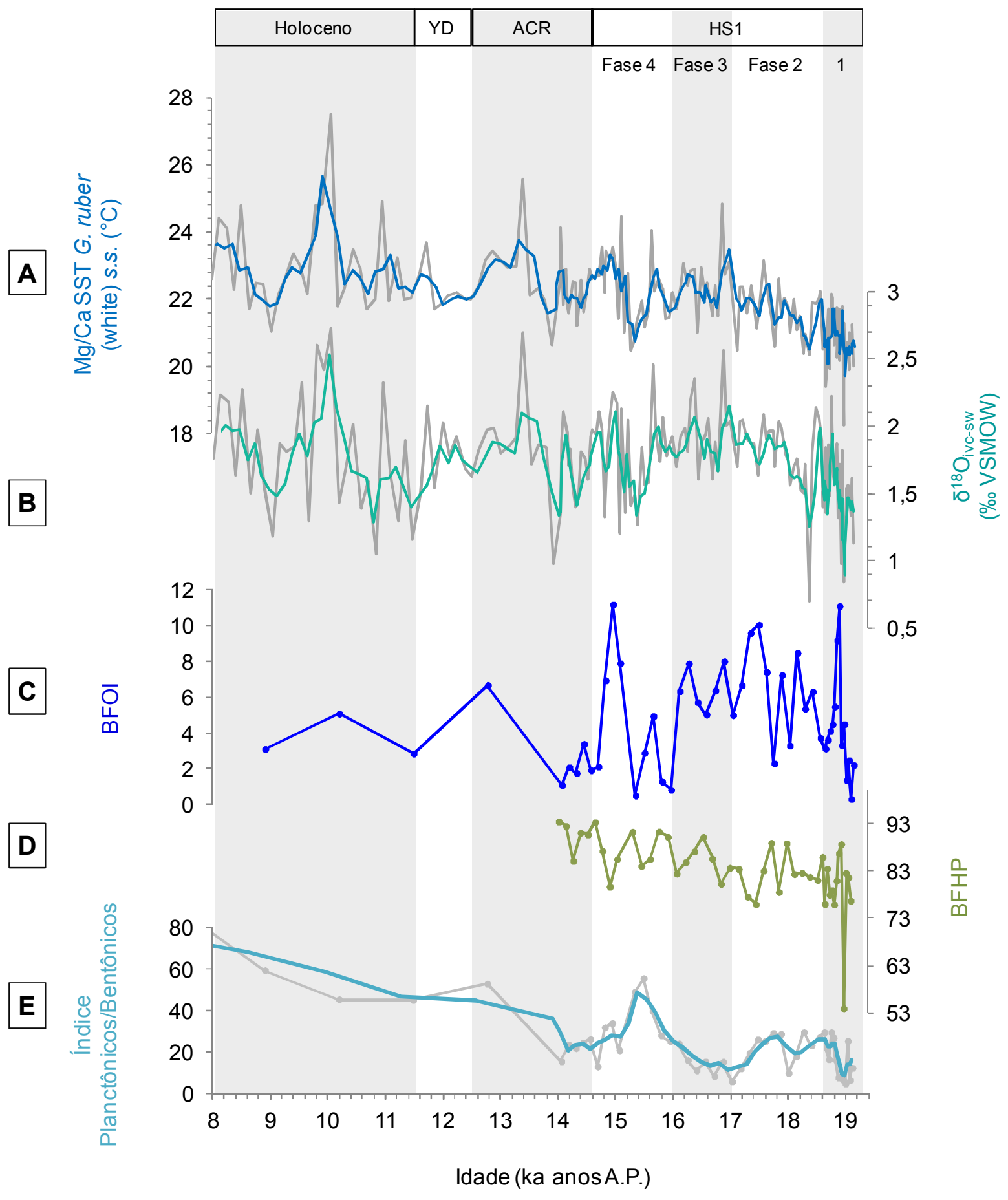

Figura 43: Comparação entre os dados do testemunho GeoB6211-2 entre 19.000 e 8.000 anos cal A.P. A. paleotemperaturas (Mg/Ca SST) do testemunho GeoB6211CC (este estudo). B. paleossalinidades $\left(\delta^{18} \mathrm{O}_{\text {ivc-sw }}\right)$ do testemunho GeoB6211CC (este estudo). C. índice BFOI (indicador da disponibilidade de oxigênio no meio) do testemunho GeoB6211-2. (este estudo). D. índice BFHP (indicador da disponibilidade nutricional do meio) do testemunho GeoB6211-2. (este estudo). E. ríndice planctônicos/bentônicos do testemunho GeoB6211-2 (este estudo). Tarjas cinzas: diferentes épocas paleoclimáticas entre 19.000 e 8.000 anos cal A.P. HS1: Heinrich Stadial 1. ACR: Antarctic Cold Reversal. YD: Younger Dryas. Modelo de idades retirado de Chiessi et al. (2008). 


\section{CAPÍTULO 8: Discussão}

\subsection{Testemunho S03}

Segundo Le Cadre et al. (2003), as testas calcárias são freqüentemente dissolvidas em águas com pH inferiores à 7,5. Por (1986) observou que os rios de águas escuras do MJI, como os rios Una do Prelado e Comprido (local de coleta do testemunho S03) apresentam baixo pH ( 4) devido à forte concentração de ácidos húmicos. Duleba e Debenay (2003), ao analisarem o estuário do Rio Una do Prelado, sugeriram que testas calcárias eram possivelmente raras em sedimentos do seu canal pela dissolução sofrida pelo carbonato de cálcio em águas ácidas. Entre 9.400 e 8.400 anos cal A.P., Sallun et al. (2012) descreveram variação mais acentuada do $\mathrm{pH}$ e do Eh no local de coleta do S03. Além disso, a análise tafonômica dos tipos de desgaste das testas de foraminíferos bentônicos ao longo do testemunho S03 mostrou predomínio de processos de corrosão/dissolução (Prancha 1, em anexo).

Dessa maneira, considerou-se que a baixa densidade encontrada nas associações de foraminíferos bentônicos do testemunho S03 seria devida a valores mais baixos do $\mathrm{pH}$ das águas mixohalinas, que causaram maior ou menor dissolução de testas de acordo com a flutuação das influências continental ou oceânica no local de coleta do testemunho S03, entre 9.400 e 8.385 anos cal A.P.

Entretanto, como foram encontrados espécimes jovens e/ou testas inteiras (não desgastadas) para todas as espécies nas amostras que continham testas calcárias (Tabela 5; figs. 23 e 25C), concluiu-se que as alterações de densidade sofridas pelas associações de foraminíferos bentônicos, presentes nas amostras do S03, não teriam causado modificações nas diversidades das associações analisadas em relação às suas contrapartes pretéritas e que, portanto, as análises paleoambientais aqui realizadas são válidas.

Duas prováveis hipóteses poderiam ser aventadas para explicar a ausência das associações dos foraminíferos bentônicos entre 8.806 e 8.672 anos cal A.P., há 8.625 anos cal A.P. e há 8.594 anos cal A.P.: i) forte aporte de águas doces, que poderiam ter causado o desaparecimento de espécies calcárias polihalinas/mesohalinas e euhalinas e, ao mesmo tempo, carreado as testas das espécies de Blysmasphaera spp. para outro sítio deposicional e/ou ii) exposição subaérea do sítio deposicional com consequente oxidação e/ou dissolução das testas durante essas fases. 
Segundo Sallun et al. (2012), durante esses intervalos de tempo, existiria ambiente lagunar nesse local do MJI. Além disso, a ausência de testas acastanhadas nas associações de foraminíferos bentônicos no testemunho S03 (Fig. 25B) indica que não houve períodos em que as testas bentônicas se oxidaram. Ou seja, que é improvável que elas tenham ficado expostas a ambiente oxigenado, o que seria de se esperar em caso de exposição subaérea. Também, a relação fino/grosso e o diâmetro médio dos sedimentos (Tabela 3; fig. 20), bem como a mudança da taxa de sedimentação (de $0,11 \mathrm{~cm} /$ ano para $0,645 \mathrm{~cm} / \mathrm{ano}$ ) entre $8.700 \mathrm{e}$ 8.684 anos cal A.P. (Sallun et al., 2012), são sugestivas de maior aporte sedimentar em função do incremento da energia hidrodinâmica do meio.

Dessa forma, considerou-se que não houve exposição subaérea do sítio deposicional. Entre 9.400 e 8.385 anos cal A.P., a região de coleta do testemunho S03 foi ambiente lagunar raso, mixohalino, que deve ter recebido maior aporte fluvial nessas épocas. Esse maior aporte fluvial poderia ter ocasionado decréscimos da salinidade e do $\mathrm{pH}$ das águas de fundo, impossibilitando a sobrevivência e/ou preservação das testas calcárias e carreando testas do gênero Blysmasphaera spp. para outro sítio deposicional, o que teria causado o desaparecimento dos foraminíferos.

As análises do comportamento das associações de foraminíferos bentônicos, bem como das características de suas testas, entre 9.400 e 8.385 anos cal A.P. (Figs. 22, 23, 24, 25 e 27), quando comparadas com as análises abióticas do testemunho S03 (Sallun et al., 2012) (Figs. 20 e 21), permitiram notar que houve quatro episódios de maior salinidade, intercaladas por duas fases de menor salinidade, nas águas da paleolaguna existente no MJI.

Há duas alternativas para os quatro episódios de maior salinidade das águas da paleolaguna: i) intrusão mais acentuada de águas marinhas na paleolaguna e ii) diminuição da pluviosidade continental em ambiente parálico, o que levaria à evaporação das águas da paleolaguna, e ocasionaria maior concentração de sais em menores volumes de água.

A primeira alternativa levaria à conclusão de que teriam ocorrido picos na elevação do nível relativo do mar na região do MJI durante sua fase transgressiva, quando as águas do mar afluíram com maior intensidade para a paleolaguna mixohalina em quatro intervalos temporais. A segunda suporia que o nível relativo do mar, apesar de crescente, não foi suficiente para atingir a paleolaguna mixohalina até $\sim 8.385-8.375$ anos cal A.P. quando, segundo Sallun et al. (2012), o nível do mar ultrapassou o atual pela primeira vez na região do MJI durante a Transgressão Santos. Nesse segundo caso, as quatro fases mais salinas da paleolaguna equivaleriam a períodos paleoclimáticos continentais mais secos e o nível marinho não influenciaria a salinidade das águas de fundo da paleolaguna. 
A presença de espécies indicativas de massas de água marinhas de diferentes propriedades físico-químicas, mais rasas (e.g. Ammonia tepida) ou mais profundas (e.g., Uvigerina striatula) (Tabela 5, em anexo; fig. 23), em conjunto com a razão $\mathrm{C} / \mathrm{N}$, que indicou que a M.O. teria origem mista para todo este intervalo temporal, embora os seus valores variassem em função da maior ou menor contribuição continental ou oceânica para o sítio de estudos (Fig. 20, Sallun et al., 2012), suportam a conclusão de que a primeira hipótese é a mais acertada.

Os dados microfaunísticos de espécies indicadoras de diferentes massas de água, de diferentes graus de salinidade das águas e do hidrodinamismo de fundo da paleolaguna, quando comparados aos resultados abióticos do testemunho S03 (Sallun et al., 2012), permitem supor que provavelmente tanto o regime pluvial, que aumentava a descarga fluvial na região de estudos, quanto o comportamento transgressivo marinho, foram importantes para o controle da salinidade das águas de fundo da paleolaguna do MJI.

Segundo Duleba e Debenay (2003), atualmente, o estuário do Una do Prelado, a NE da área de estudos, possui dois regimes hidrodinâmicos diferentes, sazonais: um com maior contribuição marinha, quando águas oceânicas adentram o estuário até o canal do rio Una do Prelado, durante o inverno, e outro com maior contribuição continental (fluvial) durante os meses de verão. Caso essas flutuações tenham se mantido ao longo do tempo geológico, como sugerem os dados microfaunísticos e abióticos do testemunho S03, pode-se supor que tenham ocorrido épocas paleoclimáticas com menor pluviosidade continental, quando houve maior aporte de águas marinhas à paleolaguna do MJI, e épocas paleoclimáticas com maior pluviosidade continental, quando a vazão dos rios se ampliava e eles então carreavam maior quantidade de sedimentos para a região de coleta do testemunho S03, aumentando o hidrodinamismo local e modificando os padrões físico-químicos das águas e dos sedimentos de fundo da paleolaguna então existente nessa área.

Trabalhos paleoclimáticos realizados no Brasil (De Oliveira, 1992; Ledru et al., 1996; Coelho et al., 2002; Behling et al., 2004; Garcia, 2004; Cordeiro et al., 2008; Dillenburg e Hesp, 2009; Stríkis et al., 2011) sugerem comportamentos paleoclimáticos distintos (mais quentes ou mais frios e mais úmidos ou mais secos) em épocas aproximadamente equivalentes em regiões brasileiras distintas. Entretanto, essa correlação deve ser feita com cautela, devido às diferentes escalas temporais e, também, devido ao provável diacronismo na propagação desses paleoclimas. É, portanto, provável que tenha havido fases alternadas mais úmidas ou mais secas e mais quentes ou mais frias para a região do MJI entre 9.400 e 8.385 
anos cal A.P., o que possibilitaria o maior ou menor aportes marinho ou fluvial na região de coleta do testemunho S03.

Assim, pode-se supor que, durante a Transgressão Santos, a influência de águas marinhas foi predominante na paleolaguna do MJI, pelo menos na região onde o testemunho S03 foi coletado, em ao menos quatro fases, intercaladas por fases com maior influência de águas continentais.

As três diferentes associações de foraminíferos bentônicos assinaladas pela análise estatística de agrupamento modo- $\mathrm{R}$ indicaram oito fases paleoambientais diferentes para a região de coleta do testemunho S03 na planície costeira do MJI:

- Primeira Fase: 9.400 a 9.338 anos cal A.P.

Este primeiro intervalo de tempo parece ter sido caracterizado por espécies das Associações 1 e 3 há 9.400 anos cal A.P., e por espécies da Associação 2 há 9.338 anos cal A.P. (Fig. 27). Foram compostas predominantemente pelos gêneros Ammonia spp. e Elphidium spp., além de fragmentos não identificados.

Os gêneros Ammonia spp. e Elphidium spp. são típicos de ambientes disaeróbicos, com substratos lamosos a arenosos, apresentam hábitos de vida epifaunal a infaunal profundo, são herbívoros e/ou detritívoros e comuns em ambientes costeiros, tais como lagoas, lagunas e estuários, onde as águas vão desde hipersalinas a polihalinas/mesohalinas (e.g., Bandi, 1953; Cassel e Sen Gupta, 1989; Murray, 1991; Kitazato, 1994; Ratburn e Corliss, 1994; Bernhard e Sen Gupta, 1999; Duleba et al., 2005).

Segundo Duleba et al. (2005), Elphidium spp. é um gênero que indica águas com estratificação salina forte a moderada, enquanto Ammonia spp. é mais típico de águas homogêneas a fortemente estratificadas. Esses mesmos autores consideram que Ammonia spp. seria típica de ambiente com disponibilidade baixa a moderada de M.O., enquanto Walton e Sloan (1990) sugerem que este gênero seria típico de ambiente com abundante disponibilidade de alimentos. Por outro lado, Elphidium spp., segundo Samir (2000), seria um gênero extremamente dependente da disponibilidade nutricional do meio, especialmente de diatomáceas.

As associações dessa fase são sugestivas de ambiente semiconfinado, de águas que foram perdendo a maior contribuição de águas marinhas mais profundas e se tornando polihalinas/mesohalinas e estratificadas, com contribuição de águas marinhas mais rasas, com considerável M.O. de origem mista nos sedimentos e baixa oxigenação intersticial (Fig. 24). 
O decréscimo da oxigenação dos sedimentos entre 9.400 anos cal A.P., bem como a provável diminuição do $\mathrm{pH}$ das águas de fundo da área do MJI no local de coleta do testemunho S03, fez com que as testas dos foraminíferos bentônicos se tornassem menores e mais desgastadas e/ou fragmentadas entre 9.400 e 9.338 anos cal A.P. (Fig. 25). O ambiente de fundo, de energia hidrodinâmica fraca a moderada (Fig. 25A), teria se tornado mais estressante às associações de foraminíferos bentônicos, fazendo com que testas calcárias terminassem por desaparecer há 9.338 anos cal A.P. (Figs. 22, 23).

A presença de testas calcárias há 9.400 anos cal A.P., permite supor que os valores de pH das águas da paleolaguna não eram tão baixos nessa época, pois possibilitaram ainda a preservação dessas testas, embora houvesse baixa oxigenação intersticial (Fig. 24) e subsaturação em carbonato de cálcio $\left(\mathrm{CaCO}_{3}\right)$ (Fig. 20; Sallun et al., 2012) no ambiente de fundo da paleolaguna. Entre 9.400 e 9.338 anos cal A.P., a influência fluvial deve ter aumentado, o que diminuiu os valores do $\mathrm{pH}$ das águas de fundo da paleolaguna, terminando por impedir a existência e/ou preservação das testas calcárias há 9.338 anos cal A.P. na área de estudos (Tabela 5, em anexo).

Especialmente há 9.400 anos cal A.P., as testas corroídas e preenchidas por sulfeto de ferro $\left(\mathrm{FeS}_{2}\right)$ (Fig. 25B, C) aludiram a ambientes subsaturados em $\mathrm{CaCO}_{3}$ e/ou redutores (Alexandersson, 1979; Berger, 1979). Sallun et al. (2012) encontraram menores teores de $\mathrm{CaO}$ nos sedimentos do testemunho S03 nesse intervalo de tempo (Fig. 20), e Berner (1970) demonstrou que a formação de $\mathrm{FeS}_{2}$ em sedimentos marinhos ocorre pela atuação de sulfobactérias em ambientes com baixa oxigenação intersticial, quando superpostos por águas oxigenadas, com valores neutros de $\mathrm{pH}(\sim 7)$.

- $\quad$ Segunda Fase: 9.338 a 9.072 anos cal A.P.

A segunda fase foi marcada pelo desaparecimento das testas calcárias nas associações de foraminíferos bentônicos, que foram substituídos pelo gênero Blysmasphaera spp. (Figs. 23, 24 e 27), principalmente na forma de fragmentos. Segundo Brönnimann (1988), a espécie Blysmasphaera brasiliensis é típica de ambientes estuarinos oligohalinos. Semensatto-Jr. et al. (2008) caracterizaram a espécie Blysmasphaera broennimanni como típica de ambientes com salinidades variáveis entre 0 e 0,03 , com temperaturas situadas entre 16,5 e $25^{\circ} \mathrm{C}, \mathrm{pH}$ entre 4,4 e 5,79 e oxigênio dissolvido de 22 a 73\%, como as encontradas no rio Aguapeú (SP); e, nos manguezais do rio São Francisco, com salinidades entre 0 a 2 e pH entre 7,3 e 8. Segundo esses autores, a espécie $B$. brasiliensis seria típica de ambientes oligohalinos, 
enquanto a espécie B. broennimanni seria característica de ambientes limnéticos (de águas doces). Além disso, Semensatto-Jr. et al. (2009) encontraram a espécie B. brasiliensis associada a formas bentônicas aglutinantes, em planície lamosa de mangue com sedimentos ricos em M.O., com exposição subaérea durante 48,5 a 65,6\% do tempo, e concluíram que essas espécies estão associadas à lama e que são tolerantes à exposição subaérea.

A composição microfaunística oligohalina a limnética das associações, em que a espécie B. broennimanni ocorreu apenas há 9.213 anos cal A.P. e, nos demais intervalos, esteve ausente, quando só ocorreram testas de B. brasiliensis e de Blysmasphaera sp. (Tabela 4, em anexo; fig. 23), aliada ao fato de que a maior porcentagem de fragmentos foi encontrada há 9.338 anos cal A.P. e depois decaiu (Tabela 5, em anexo; fig. 25C) e de que a razão C/N e o diâmetro médio dos grãos foram se tornando menores e as porcentagens de $\mathrm{CaO}$ maiores (Fig. 20), permitem supor que entre 9.338 e 9.213 anos cal A.P. houve ainda maior queda da influência marinha na paleolaguna, e que essa influência marinha foi se tornando novamente maior entre 9.213 e 9.072 anos cal A.P.

Ainda que mais baixa, especialmente entre 9.338 e 9.213 anos cal A.P., a influência marinha não deve ter cessado por completo no local de coleta do testemunho S03 durante essa fase, como indicam a maior presença da espécie oligohalina em detrimento da espécie limnética, o decréscimo da razão $\mathrm{C} / \mathrm{N}$ e o aumento dos valores de $\% \mathrm{CaO}$ encontrados por Sallun et al. (2012) (Fig. 20).

Portanto, pode-se supor que, entre 9.338 e 9.072 anos cal A.P., teria ocorrido modificação nos parâmetros físico-químicos da água de fundo da paleolaguna pelo maior aporte de água doce e com decréscimo dos valores de $\mathrm{pH}$. As altas freqüências de foraminíferos aglutinantes e a ausência de formas calcárias, associados aos demais resultados, permitiram supor que ocorreu aumento do aporte fluvial para a paleolaguna.

Esse maior aporte fluvial deve ter diminuído o pH das águas de fundo da paleolaguna e gerado maior energia hidrodinâmica do meio (Fig. 25C). Em um primeiro momento, há 9.338 anos cal A.P., essa situação ocasionou o maior desgaste (corrosão/dissolução e/ou abrasão) de testas calcárias e promoveu seu desaparecimento. Em um segundo momento, entre 9.338 e 9.213 anos cal A.P., deve ter rebaixado ainda mais a salinidade das águas de fundo da paleolaguna, o que permitiu o aparecimento da espécie limnética e, em seguida, causou um aumento do grau de oxigenação do meio, permitindo aos foraminíferos aglutinantes construírem testas maiores que aquelas do período anterior (Fig. 25A). Aos poucos, entre 9.338 e 9.072 anos cal A.P., condições mais marinhas foram se estabelecendo novamente no local de coleta do testemunho S03. 
- Terceira Fase: 9.072 a 8.894 anos cal A.P.

As associações 1 e 3 que coexistiram nessa fase, em um primeiro momento, foram compostas predominantemente por Ammonia parkinsoniana (26,67\% das associações) e, secundariamente, por Elphidium discoidale, Blysmasphaera sp. e Fissurina laevigata. As porcentagens de fragmentos se tornaram menores nesse primeiro período. Em seguida, as associações passaram a ser dominadas por Pararotalia cananeiaensis $(33,33 \%)$, seguida por Blysmasphaera sp., com diminuição ainda mais acentuada da frequência de fragmentos (Tabela 5, em anexo; fig. 23).

Em ambientes marinhos rasos, a razão entre Ammonia parkinsoniana e Elphidium excavatum é utilizado como índice para indicar fases anóxicas nos sedimentos, sendo a primeira espécie considerada mais tolerante à falta de oxigênio que Elphidium (Kitazato, 1994; Sen Gupta e Platon, 2006). F. laevigata é espécie disóxica que vive preferencialmente em águas salinas (31-32\%o) e costeiras (Buzas, 1968). Segundo Duleba e Debenay (2003), P. cananeiaensis só ocorre no canal do Rio Una do Prelado, a NE da área de coleta do testemunho S03, em períodos de inverno, quando há menor pluviosidade e as águas marinhas invadem o estuário e penetram pelo canal do rio. Essa espécie é típica de ambientes marinhos mais rasos, sendo comum em áreas costeiras, parálicas, estuarinas e lagunares com influência marinha, de águas euhalinas a mixohalinas, homogêneas a moderadamente estratificadas, com correntes de maré fortes a médias e sedimentos arenosos a arenolamosos, com teores baixos a moderados de M.O. e bem oxigenados (e.g., Debenay et al., 2001; Duleba et al., 2005).

As associações dessa fase remontam a ambiente semiconfinado, mesohalino/polihalino a euhalino, raso, com teores cada vez menores de M.O. nos sedimentos, e com grau de oxigenação crescente nos interstícios sedimentares (Fig. 24). Mesmo com o aumento de tamanhos pequenos em detrimento de tamanhos médios e grandes nessa fase, que aludem às baixas porcentagens de $\mathrm{CaCO}_{3}$ (Figs. 20 e 25A), e ao empobrecimento em M.O. nos sedimentos (Fig. 24), a predominância dos tamanhos médios sugere que o ambiente não foi completamente desprovido de oxigenação e de M.O. no meio.

A presença de testas douradas há 8.983 anos cal A.P. foi condizente com o maior aporte de M.O. e com o menor grau de oxigenação do meio dessa idade, quando comparados aos da idade seguinte (Figs. 24 e 25B), o que permitiu maior produção de sulfeto de ferro nos sedimentos (Berner, 1970). O decréscimo dos valores da razão $\mathrm{C} / \mathrm{N}$ nessa fase, o aumento do diâmetro médio dos grãos expresso em phi (Fig. 20), e o crescente menor desgaste químico e/ou mecânico das testas calcárias (Fig. 25C) corroboram o maior afluxo de águas marinhas 
na paleolaguna, em ambiente que se tornou cada vez mais estável (Fig. 22) e favorável às associações de foraminíferos bentônicos calcários.

A presença de espécies relacionadas a águas mais salinas (e.g., F. laevigata e $P$. cananeiaensis), indicou que o aumento de salinidade das águas de fundo da paleolaguna foi significante desde o início. Esse aumento de salinidade provavelmente corresponde a uma nova incursão mais pronunciada de águas marinhas, dessa vez pouco mais forte, à paleolaguna mixohalina, associada a uma menor contribuição continental nessa fase.

Supõe-se que essa foi uma época mais seca sobre o continente sul-americano, quando as correntes marinhas foram mais importantes para a paleolaguna que a contribuição continental, já que as espécies dominantes nessas associações indicaram águas com pouca ou nenhuma estratificação e, portanto, sugestivas de um corpo de água inteiramente mais salino, e não apenas mais salino em sua porção mais profunda.

- Quarta Fase: 8.894 a 8.672 anos cal A.P.

Entre 8.806 e 8.672 anos cal A.P., não foram encontradas testas calcárias ou aglutinantes de foraminíferos bentônicos nas amostras do testemunho S03. Nessa mesma fase, houve aumento da granulometria sedimentar (Tabela 3, em anexo; Fig. 20). Os valores de \% CaO diminuíram até 8.789 anos cal A.P. e depois foram crescentes, apesar de indicarem ainda, ambiente subsaturado em carbonatos (Fig. 20). Já o comportamento da razão C/N (Sallun et al., 2012) sugeriu a presença de M.O. de origem mista até 8.685 anos cal A.P. (Fig. 20). Entre 8.700 e 8.684 anos cal A.P., a taxa de sedimentação aumentou consideravelmente. Passou de 0,11cm/ano para 0,645cm/ano (Sallun et al., 2012).

Supõe-se que o ambiente se tornou mais energético, com menor contribuição marinha à área estudada, com decréscimo da salinidade e do $\mathrm{pH}$ das águas de fundo da paleolaguna. A diminuição das $\% \mathrm{CaO}$, de 0,81 para $0,78 \%$, logo no início dessa fase, contribuiu provavelmente para o desaparecimento de espécies calcárias, impedidas de construírem suas testas, ainda que, no início, o ambiente possa não ter sido completamente limnético e a contribuição continental tenha sido ainda incipiente. A contribuição fluvial à paleolaguna deve ter se ampliado e tornou o ambiente cada vez menos salino, com pH também menor, o que impediu a preservação de testas calcárias apesar do novo aumento das \% $\mathrm{CaO}$ (Sallun et al., 2012). A ausência de espécies de Blysmasphaera spp. provavelmente se deve à maior energia do meio, que deve ter carreado as testas deste gênero para outro sítio deposicional, juntamente com as frações mais finas do sedimento. 
- Quinta Fase: 8.672 a 8.641 anos cal A.P.

Entre 8.672 e 8.656 anos cal A.P., as associações de foraminíferos bentônicos reapareceram, e há 8.656 anos cal A.P. ocorreu a associação mais estável em todo o testemunho S03, com a maior densidade (264 testas) entre 9.400 e 8.385 anos cal A.P. (Fig. 22). As rápidas modificações do equilíbrio entre as espécies nessas associações nesse intervalo de tempo, especialmente entre 8.656 e 8.641 anos cal A.P. (Fig. 22), provavelmente se vincularam à diminuição da densidade de testas nos sedimentos do testemunho S03 (Fig. 22), sugerindo que o ambiente tenha se tornado rapidamente menos propenso à vida e à preservação de associações de foraminíferos bentônicos.

A principal espécie encontrada há 8.656 anos cal A.P. foi Pararotalia cananeiaensis (54,92\%), seguida por Ammonia spp., Buliminella elegantissima, Cribroelphidium poeyanum e Elphidium spp. Também contribuíram para a composição dessas associações espécies pertencentes às associações 1 e 3 (Figs. 23 e 27). Há 8.641 anos cal A.P., as porcentagens de fragmentos aumentaram consideravelmente (de 4,17\% para 28,57\%), e as únicas espécies presentes foram Ammonia tepida, Blysmasphaera broennimanni e formas jovens.

B. elegantissima é uma espécie oportunista, detritívora, euhalina a mixohalina, que habita áreas marinhas rasas costeiras e neríticas, que é resistente a ambientes rasos estressados, com sedimentos de fundo variáveis de areias finas a lama, disóxicos, com alto conteúdo de M.O., sendo resistente ao $\mathrm{H}_{2} \mathrm{~S}$ e preferindo áreas com condições hidrodinâmicas mais calmas (Murray, 1991; Moodley et al., 1998; Eichler et al., 2004; Vilela et al., 2003; Duleba et al., 2005).

A associação presente há 8.656 anos cal A.P. indicou ambiente marinho raso, euhalino a mixohalino, com exportação mais elevada de M.O. ao fundo da paleolaguna e sedimentos mais oxigenados (Fig. 24). A razão $\mathrm{C} / \mathrm{N}$ e as $\% \mathrm{CaO}$ indicaram maior contribuição marinha (Fig. 20) nessa época. A relação fino/grosso e o diâmetro médio dos grãos (Tabela 3, em anexo; fig. 20), sugeriram sedimentos de maior granulometria, o que pode indicar hidrodinamismo um pouco mais acentuado há 8.656 anos cal A.P., que foi se tornando menos ativo até 8.641 anos cal A.P.

O maior hidrodinamismo do meio nessa época foi o principal responsável pelo desgaste das testas há 8.656 anos cal A.P. (Fig. 25C) que, ao contrário dos demais períodos analisados neste testemunho, foi majoritariamente mecânico. Ainda assim, este desgaste não foi intenso, já que houve predominância de testas menos ou nada desgastadas nessa época (Fig. 25C). O maior hidrodinamismo há 8.656 anos cal A.P. também deve ter contribuído 
para o aumento da oxigenação do meio nessa idade (Fig. 24). Aliado ao maior índice de oxigenação intersticial, o provável aumento do $\mathrm{pH}$ das águas de fundo da paleolaguna devido à menor contribuição de águas fluviais nessa época devem ser os responsáveis pela considerável diminuição de fragmentos nessa fase (Fig. 25C).

É nessa idade também que foram encontradas espécies típicas da massa de água ACAS (e.g., T. angulosa, U. striata), ainda que em baixas porcentagens $(1,52 \%$ das associações), associadas a espécies típicas da AC (Tabela 5, em anexo; fig. 24), indicando que a contribuição marinha na paleolaguna nessa época foi mais importante que os que ocorreram em épocas anteriores, porque o ambiente se tornou bem mais favorável à vida e preservação das formas calcárias de foraminíferos bentônicos.

Uma maior quantidade de testas pequenas nas associações de foraminíferos bentônicos pode ser devida tanto à baixa oxigenação intersticial (Murray, 1991) quanto à maior disponibilidade de M.O. nos sedimentos, que fazem com que os foraminíferos se reproduzam antes de alcançarem tamanhos maiores (Bradshaw, 1961). Como havia abundante disponibilidade de oxigênio no meio nessa fase, descarta-se a primeira hipótese, atribuindo-se as maiores porcentagens dos tamanhos menores à grande quantidade de M.O. no meio. A presença de organismos juvenis (Tabela 5, em anexo; Fig. 23) nessa época comprova essa conclusão.

Segundo Berner (1970), a transformação de $\mathrm{FeS}$ em $\mathrm{FeS}_{2}$ se dá de forma lenta, pela ação de bactérias sulfato-redutoras, e a não ocorrência do segundo mineral pode estar associada a dois motivos: (i) falta de enxofre (S) dissolvido suficiente nos sedimentos marinhos, e/ou (ii) falta de tempo para que o $\mathrm{S}$ reaja com o FeS, gerando sulfeto de ferro. A presença de $B$. elegantissima nessa época atesta a presença de $\mathrm{S}$ nos sedimentos, já que ela é indicativa da presença de $\mathrm{H}_{2} \mathrm{~S}$ no meio. Ainda, Sallun et al. (2012) sugerem que havia disponibilidade de S nos sedimentos do testemunho S03. Portanto, considera-se que a presença de testas pretas (i.e., contendo $\mathrm{FeS}$ ) nesse período, ainda que em menores porcentagens que testas douradas (i.e., contendo $\mathrm{FeS}_{2}$ ), foi devida à falta de tempo para que houvesse transformação do $\mathrm{FeS}$ em $\mathrm{FeS}_{2}$. Essa falta de tempo se correlaciona, provavelmente, ao aumento da taxa de sedimentação a partir de 8.684 anos cal A.P. (Sallun et al., 2012).

Por outro lado, a associação presente há 8.641 anos cal A.P. sugeriu um ambiente mesohalino/polihalino, com menor influência marinha e maior influência de águas fluviais, que teria causado a provável diminuição do pH das águas da paleolaguna (Figs. 22, 23 e 24). O aumento de testas inteiras e grandes, e o desaparecimento de testas preenchidas (Fig. 25) se vincularam especialmente aos gêneros Blysmasphaera e Ammonia, enquanto o aumento dos 
fragmentos (Fig. 25C) foi devido principalmente ao desgaste químico e físico de testas de outros gêneros, muitos dos quais desapareceram há 8.641 anos cal A.P. Esses fatores microfaunísticos, aliados aos parâmetros abióticos do testemunho S03, indicaram que entre 8.656 e 8.641 anos cal A.P., o ambiente da paleolaguna foi se tornando menos salino, teve provável queda do $\mathrm{pH}$ de suas águas de fundo, e queda da oxigenação e do conteúdo de M.O. dos sedimentos (Figs. 24 e 25).

Dessa forma, pode-se supor que a maior contribuição marinha à paleolaguna há 8.656 anos cal A.P. foi episódica, diminuindo rápida e intensamente em $\sim 30$ anos.

- Sexta Fase: 8.641 a 8.594 anos cal A.P.

Entre 8.641 e 8.625 anos cal A.P., as associações de foraminíferos bentônicos tornaram a desaparecer, e há 8.610 anos cal A.P. reapareceram associações compostas predominamente pelo gênero Blysmasphaera spp. e por uma testa da espécie Lagena striata, que logo em seguida, até 8.594 anos cal A.P., tornaram a desaparecer.

A baixa densidade e a ausência de testas inteiras na associação de foraminíferos bentônicos existente há 8.610 anos cal A.P. (Figs. 22 e 25C), em conjunto com o aumento da granulometria sedimentar (Tabela 3, em anexo; fig. 20), permitem pressupor que as testas encontradas nesta amostra do testemunho S03 são alóctones, provavelmente levadas à área de deposição do testemunho S03 pela maior energia hidrodinâmica do meio. A queda dos valores de \% $\mathrm{CaO}$ (Fig. 20) encontradas por Sallun et al. (2012) atesta a menor contribuição marinha nesse período.

Supõe-se que o período de maior pluviosidade tenha ocorrido nessa época, o que aumentou a energia hidrodinâmica do meio, diminuiu a contribuição marinha, bem como a salinidade e os valores de $\mathrm{pH}$ das águas de fundo da paleolaguna. Fatores estes que, mais uma vez, impossibilitaram a sobrevivência e/ou a preservação das associações de foraminíferos bentônicos entre 8.625 e 8.594 anos cal A.P. Este incremento da contribuição continental parece ter se iniciado há 8.641 anos cal A.P., e se intensificado consideravelmente entre 8.641 e 8.625 anos cal A.P.

- Sétima Fase: 8.594 a 8.500 anos cal A.P.

Entre 8.594 e 8.579 anos cal A.P., voltaram a aparecer espécies de foraminíferos bentônicos nos sedimentos do testemunho S03. As associações bentônicas presentes entre 
8.579 e 8.500 anos cal A.P. foram compostas principalmente por Pararotalia cananeiaensis, e secundariamente por Ammonia spp., Elphidium spp. e Cribroelphidium poeyanum. Contribuíram também para essas associações espécies pertencentes às associações 1 e 2 e formas jovens (Tabela 5, em anexo; figs. 23 e 27).

Essas associações indicaram ambiente euhalino a mesohalino/polihalino, com contribuição de águas marinhas rasas, com sedimentos contendo M.O., moderadamente a bem oxigenados (Fig. 24). O ambiente parece ter se tornado mais estressante entre 8.594 e 8.548 anos cal A.P. (Fig. 22), com o decréscimo da contribuição oceânica e do acúmulo de M.O. nos sedimentos (Fig. 24) e aumento seguido de diminuição do tamanho dos grãos (Tabela 5, em anexo; fig. 20). Sallun et al. (2012) sugerem que há 8.548 anos cal A.P. houve alteração da área-fonte dos sedimentos depositados na paleolaguna.

$\mathrm{Na}$ fase entre 8.548 e 8.500 anos cal A.P., houve novo aumento de contribuição oceânica, que culminou há 8.500 anos cal A.P., com a entrada na paleolaguna de águas oceânicas pouco mais profundas (ACAS), conforme indicado pela presença de espécies tais como Uvigerina striata, ainda que em baixas frequências (3,33\%) (Fig. 23 e 24), aumento considerável das \% $\% \mathrm{CaO}$ e valores da razão $\mathrm{C} / \mathrm{N}$ que indicam M.O. de origem mista, isto é, continental e oceânica (Fig. 20).

- Oitava Fase: 8.500 a 8.385 anos cal A.P.

Há 8.500 anos cal A.P., Sallun et al. (2012) reconheceram curtas fases de sedimentação com aumento significativo da produtividade orgânica, além de aumento da contribuição marinha entre 8.500 e 8.400 anos cal A.P. e contribuição mais homogênea de minerais máficos entre 8.500 e 7.600 anos cal A.P. que segundo esses autores, poderiam sugerir maior contribuição continental aos sedimentos do testemunho S03. Esses autores admitiram a ocorrência de forte mudança nos padrões paleoambientais a partir de 8.500 anos cal A.P. Nessa mesma época, Keigwin et al. (2005) e Rohling e Pälike (2005) teriam reconhecido modificações rápidas nos padrões deposicionais sedimentares da costa sudeste brasileira que duraram entre 250 e 500 anos.

As associações de foraminíferos bentônicos presentes nesse período no testemunho S03 foram compostas por espécies do gênero Blysmasphaera spp. que ocorreram com baixas densidades e testas majoritariamente inteiras, brancas e médias (Figs. 22, 23 e 25A, B, C). A ausência de espécies euhalinas e polihalinas/mesohalinas, calcárias (Fig. 24), bem como a queda das $\% \mathrm{CaO}$ e o comportamento da razão $\mathrm{C} / \mathrm{N}$ (Fig. 20), sugerem que tenha havido 
menor contribuição marinha durante essa fase, com provável diminuição do valor de $\mathrm{pH}$ das águas de fundo da paleolaguna. Sallun et al. (2012) encontraram evidências de que foi entre 8.385 e 8.375 anos cal A.P. que o paleonível marinho alcançou e/ou ultrapassou o nível relativo do mar existente na região costeira do MJI pela primeira vez no Holoceno e que, em torno de 8.375 anos cal A.P., teria ocorrido modificação paleoambiental, quando o registro sedimentar do MJI passou a apresentar dominância de fontes continentais.

Considerou-se que a partir de 8.500 anos cal A.P. a contribuição marinha para as águas de fundo do sítio de deposição do testemunho S03 foi diminuindo. Provavelmente, a maior contribuição continental rebaixou o pH dessas águas e impediu a vida e/ou preservação de testas calcárias, e o paleoambiente foi se tornando cada vez menos propício às associações de foraminíferos bentônicos, até que esses desapareceram completamente há 8.385 anos cal A.P.

Apesar do novo aporte marinho no MJI há cerca de 8.385-8.375 anos cal A.P., conforme proposto por Sallun et al., (2012), o ambiente já não era mais propício à existência de foraminíferos euhalinos e/ou polihalinos/mesohalinos, compostos por formas calcárias, já que nessa época as $\% \mathrm{CaO}$ indicaram subsaturação ainda maior em $\mathrm{CaCO}_{3}$ na paleolaguna (Fig. 20), o que teria impedido a vida e/ou preservação de foraminíferos de testas calcárias no local do testemunho S03. Por outro lado, a presença de águas mais salinas devido à nova contribuição marinha impediu a existência das espécies limnéticas na paleolaguna.

\subsection{Testemunho GeoB6211-2}

\subsubsection{Associação total: foraminíferos planctônicos e bentônicos}

Segundo Smart (2002), a razão planctônicos/Bentônicos (razão P/B) aumenta com o aumento da profundidade da coluna de água e com o distanciamento da costa. Sem atentar-se a particularidades, Culver (1988) construiu uma correlação entre os valores percentuais da razão P/B e a batimetria da região analisada. Considerando-se essa correlação, as associações planctônicas e bentônicas de foraminíferos ao longo do testemunho GeoB6211-2 (Fig. 31) indicaram que esse testemunho se encontrava sob coluna de água bem mais rasa durante a fase do Último Glacial ( 19.000 anos cal A.P.), no HS1 ( 19.000 a 14.600 anos cal A.P.) e durante o $\operatorname{ACR}(\sim 14.600$ a 12.500 anos cal A.P.).

No YD ( 12.500 a 11.500 anos cal A.P.), a média dos valores da razão P/B indicou que o testemunho ocuparia lugar sob uma coluna de água mais profunda (equivalente a se 
localizar na plataforma externa). A partir do Holoceno (11.500 ao Presente), a profundidade da coluna de água teria aumentado ainda mais, especialmente durante o Holoceno Médio (equivalente a ambiente de talude continental).

Chiessi et al. (2009) e Mahiques et al. (2010) argumentaram que enquanto o paleonível marinho foi mais baixo que o atual, especialmente em torno de 19.000 e 18.000 anos cal A.P., a plataforma continental esteve exposta nas regiões sudeste e sul brasileiras, o que acarretava em maior transporte sedimentar e/ou de material orgânico (M.O.) ao talude por meio da atuação dos rios, especialmente do Rio de La Plata, e das correntes costeiras dessa região. Corrêa (1996) indicou que ainda em aproximadamente 8.700-9.000 anos cal A.P. (equivalentes há $8.000{ }^{14} \mathrm{C}$ anos A.P.) o paleonível marinho estaria em torno de 20 a $25 \mathrm{~m}$ mais baixo que o atual na costa brasileira.

Entre 19.000 anos cal A.P. e o Presente, a transgressão marinha (Corrêa, 1996; Lambeck e Chappell, 2001) fez com que o nível do mar subisse entre 130 e 120m, tendo alcançado seu ponto máximo transgressivo durante o Holoceno Médio, entre 5.100 e 5.700 anos cal A.P. nas costas sul e sudeste brasileiras (Suguio e Martin, 1978a; Angulo et al., 2006), a partir de quando passou a regredir até alcançar seus valores atuais (Angulo et al., 2006).

As concentrações de foraminíferos bentônicos e planctônicos ao longo do testemunho GeoB6211-2, que hoje se encontra no talude superior do Rio Grande do Sul, parecem ter acompanhado essa tendência transgressiva marinha. Foraminíferos planctônicos só se tornaram predominantes nas associações do testemunho GeoB6211-2 a partir do YD, tornando-se realmente expressivas a partir do Holoceno Inferior (Fig. 31). Segundo Sallun et al. (2012), o paleonível marinho atingiu o nível atual e o ultrapassou em torno de 8.385 a 8.375 anos cal A.P. na costa do Estado de São Paulo, a NE dessa região de estudos, na transição entre o Holoceno Inferior e o Holoceno Médio. Já a partir de aproximadamente 7.700 anos cal A.P., as porcentagens de foraminíferos bentônicos decaíram consideravelmente, o que indica que, muito provavelmente nessa época, a plataforma continental já não se encontrava mais exposta na região sul brasileira.

As variações de porcentagem de espécies planctônicas e bentônicas entre 19.000 anos cal A.P. e o Presente parecem ter seguido o padrão de densidade total das associações de foraminíferos do testemunho GeoB6211-2 (Fig. 31). As associações de foraminíferos do testemunho GeoB6211-2 responderam às estabilizações dos paleoníveis marinhos (Corrêa, 1996) com aumento considerável de espécies há $11.000{ }^{14} \mathrm{C}$ anos A.P. (equivalentes a 12.500-13.200 anos cal A.P.; Corrêa, 1996) e aumento da densidade total das associações do 
testemunho GeoB6211-2, com incremento principalmente de espécies bentônicas dentro dessas associações há $9.000{ }^{14} \mathrm{C}$ anos A.P. (equivalentes a 10.100-10.200 anos cal A.P.) e há $8.000{ }^{14} \mathrm{C}$ anos A.P. (equivalentes a $\sim 8.700-9.000$ anos cal A.P.; Corrêa, 1996) (Fig. 31).

Propõe-se que as associações de foraminíferos do testemunho GeoB6211-2 foram se ajustando à profundidade oceânica ao longo dos últimos 19.000 anos cal A.P., respondendo à Transgressão Marinha com a diminuição de espécies bentônicas, que vivem em maior abundância em ambientes marinhos mais rasos, e aumento de espécies planctônicas, que vivem em ambientes francamente marinhos, adquirindo maior abundância mais ao largo da costa continental, onde as águas são limpas e a coluna de água tem profundidade suficiente para que possam realizar suas migrações verticais ontogenéticas (Culver, 1988; Smart 2002; Duleba et al., 2005).

\subsubsection{Análises microfaunísticas bentônicas}

Períodos de maior oxigenação do meio indicadas pelas associações de foraminíferos bentônicos (Fig. 34) foram também períodos de maiores hidrodinamismo de fundo e instabilidade nos sedimentos do Cone do Rio Grande (CRG), local de coleta do testemunho GeoB6211-2 (Figs. 29 e 32), que receberam menor contribuição continental (Fig. 35A). Houve também menor produtividade primária na superfície oceânica (Fig. 35G) em épocas de maior oxigenação nos sedimentos do CRG, bem como diminuição do acúmulo de matéria orgânica (M.O.) nos seus sedimentos (Fig. 34).

Essas épocas de maior oxigenação do meio foram épocas, também, em que a AMOC sofreu variações em sua intensidade (Stanford et al., 2011), a Corrente do Brasil (CB) em seu hidrodinamismo (Arz et al., 1999) e a AIA em sua formação (Pahnke et al., 2008). Entre aproximadamente 18.200 e 16.500 anos cal A.P., ocorreram maior pluviosidade e elevação das temperaturas (Figs. 35B, D) e salinidades superficiais na margem NE do Brasil (Weldeab et al., 2006; Jaeschke et al., 2007).

Sugere-se aqui que as fases de maior oxigenação do meio há 18.865 anos cal A.P. e entre aproximadamente 18.600 e 16.000 anos cal A.P. foram concomitantes e relacionadas a épocas de AMOC mais reduzida (Bard et al., 2000; Stanford et al., 2006). Com a AMOC mais reduzida e a menor formação da APAN (Stanford et al., 2011), a AIA ganhou mais força e mais espaço em profundidades intermediárias atlânticas (Pahnke et al., 2008), e a CB se fortaleceu devido à intensificação dos ventos alíseos de $\mathrm{NE}$, que também enfraqueceram a Corrente Norte do Brasil (Arz et al., 1999). 
Já em 14.934 anos cal A.P., o aumento considerável da oxigenação do meio (Fig. 34), provavelmente se vinculou à reestruturação da AMOC (Stanford et al., 2011). A AMOC mais fortalecida tornou a enfraquecer a CB (Arz et al., 1999) devido à intensificação do transporte inter-hemisférico das massas de água (Arz et al., 1999; Weldeab et al., 2006), e à reestruturação da Passagem das Agulhas em torno de 15.000 anos cal A.P. (Chiessi et al., 2009). Esta última alteração modificou as assinaturas físico-químicas das águas intermediárias atlânticas, incluindo aquelas da CB (Chiessi et al., 2008). Pahnke et al. (2008) detectaram diminuição da contribuição da AIA na margem SE brasileira entre aproximadamente 15.700 e 14.200 anos cal A.P. (Fig. 35C).

Propõem-se aqui que o aumento da oxigenação do meio nesses períodos se deveu ao incremento do hidrodinamismo de fundo na região do CRG. Duas hipóteses foram aventadas para explicar este quadro paleoclimático. A primeira considera que esses períodos de maiores oxigenação e hidrodinamismo seriam atribuíveis ao fortalecimento da $\mathrm{CB}$, com possível melhor ventilação da ACAS. Arz et al. (1999) indicaram que durante o HS1 a CB estaria fortalecida, devido à maior intensidade dos Alíseos de NE. Provavelmente, o fortalecimento da $\mathrm{CB}$ ocasionou maior energia hidrodinâmica na região do $\mathrm{CRG}$, levando à maior instabilidade ambiental encontrada pelas associações de foraminíferos bentônicos nesses períodos (Fig. 32). Uma maior energia hidrodinâmica teria maior capacidade para aumentar a oxigenação do meio e para carrear maior quantidade de partículas de M.O. dos sedimentos, deixando o CRG com menor conteúdo nutricional nessas épocas (Fig. 34).

Concomitantemente, a ACAS pode ter se tornado mais ventilada nesses momentos devido às características de sua formação. Donners et al. (2005) e Stramma e England (1999) consideram que a ACAS seria em parte composta pela Água Modal Subantártica (AMSA), e em parte por massas de água vinculadas à Corrente das Agulhas e à CB (Água Central do Alântico Sul leve e Água Modal Subtropical do Atlântico Sul). A AMSA é formada parcialmente pela subducção de águas superficiais na Frente Subantártica da região circumpolar sul (Donners et al., 2005). A maior ressurgência das águas circumpolares durante o HS1 pode ter tornado a AMSA mais ventilada (Anderson et al., 2009). A AMSA teria então transmitido seu sinal de maior ventilação para a ACAS.

Além disso, as massas de água que contribuem para a formação da ACAS na região tropical sul atlântica (Stramma e England, 1999; Donners et al., 2005) provavelmente tinham assinaturas físico-químicas diferenciadas nessa época, devido à menor contribuição da Corrente das Agulhas (Chiessi et al., 2009) e do maior acúmulo de salinidade e calor no NE 
da margem brasileira (Arz et al., 1999; Weldeab et al., 2006). Uma maior ventilação da ACAS contribuiria para a maior oxigenação do meio nos sedimentos do CRG nesse período.

A segunda hipótese considera que houve um deslocamento vertical do limite entre a ACAS e a AIA, que se tornaria mais superficial. Neste caso, a AIA, que hoje é mais ventilada que a ACAS (Tsuchiya et al., 1994), aumentaria a oxigenação do meio nos sedimentos do CRG nesses intervalos temporais. Segundo Pahnke et al. (2008), durante o HS1 a formação da AIA estaria intensificada e essa massa de água alcançaria latitudes mais elevadas no Oceano Atlântico. Considera-se que a intensificação na formação da AIA não apenas promoveu a sua entrada até latitudes mais elevadas no Oceano Atlântico, como também causou um deslocamento vertical de seu contato com a ACAS, devido ao maior volume que ela deve ter apresentado nessa época.

Em $32^{\circ} \mathrm{S}$, a AIA flui para sul, depois de recircular pelo Giro Subtropical (Stramma e England, 1999; Silveira et al., 2000). Existe impasse em considerar a AIA como parte da CB ou da CCOI nessa latitude (Silveira et al., 2000). Se a AIA nessa latitude for considerada como parte da CB, o fortalecimento desta corrente oceânica durante o HS1 (Arz et al., 1999) também teria influenciado a AIA, contribuindo para mantê-la com maior hidrodinamismo, o que também afetaria a estabilidade ambiental dos sedimentos do CRG. Isso, aliado à maior formação dessa massa de água, a manteriam mais oxigenada. Consequentemente, apesar do maior hidrodinamismo e da possível maior oxigenação da ACAS, a AIA ainda assim se manteria mais oxigenada que a ACAS. Portanto, incursões da AIA no sítio de estudos do testemunho GeoB6211-2 ocasionariam o aumento da oxigenação do meio indicado pelas associações de foraminíferos bentônicos (Fig. 34).

Atualmente, região de coleta do testemunho GeoB6211-2 se encontra sob a influência da ACAS, localizada muito próxima do limite entre esta e a AIA (Tsuchyia et al. 1994; Chiessi et al., 2008). Entre 18.600 e 17.000 anos cal A.P., segundo Lambeck e Chappell (2001), o paleonível marinho se encontrava entre 120 e 130m abaixo do atual. Entretanto, ainda não foi realizado nenhum estudo sobre a possível estruturação da coluna de água dessa época nessa região de estudos. Chiessi et al. (2008) propõem que em torno de 19.000 anos cal A.P. a contribuição da AIA na região do GeoB6211-2 poderia estar mais realçada por um contato ACAS/AIA mais raso que o atual.

As associações de foraminíferos bentônicos costumam reagir secundariamente em relação às diferenças das propriedades físico-químicas e isotópicas das massas de água. Portanto, mensurações diretas dessas propriedades são necessárias para a comprovação da maior pertinência das duas hipóteses apresentadas. 
As variações dessas associações encontradas entre 19.000 e 14.000 no testemunho GeoB6211-2 (Figs. 32, 33, 34, 36 e 38) indicaram vínculo entre as cinco fases das mudanças paleoambientais ocorridas no CRG e as modificações paleoclimáticas das regiões da Antártica e da Groelândia, considerados os erros associados à datação (Fig. 35E, F, H, I e J).

- Primeira Fase: 19.000 a 18.620 anos cal A.P.

Moodley et al. (1998) relatam que a espécie Buliminella elegantissima indicaria presença de gás sulfídrico $\left(\mathrm{H}_{2} \mathrm{~S}\right)$ nos sedimentos. Segundo Berner (1970), em sedimentos contendo $\mathrm{H}_{2} \mathrm{~S}$, o FeS ocorre quando não há tempo suficiente para que o FeS se transforme em $\mathrm{FeS}_{2}$. Nesse período, a frequência acentuada de B. elegantissima (Fig. 33O) e as mais altas quantidades de $\mathrm{FeS}$ e $\mathrm{FeS}_{2}$ nos sedimentos do $\mathrm{CRG}$ (Fig. 36B) sugerem que não houve tempo para que todo o $\mathrm{FeS}$ se transformasse em $\mathrm{FeS}_{2}$.

A mais alta taxa de sedimentação (ca. $270 \mathrm{~cm} / \mathrm{ka}$ ) encontrada por Chiessi et al. (2008) no CRG nesta época (Figs. 29 e 32) provavelmente fez com que as testas dos foraminíferos bentônicos transpusessem mais rapidamente a Zona Tafonomicamente Ativa (ZTA de Davies et al., 1989). Com isso, elas se mantiveram menos tempo sofrendo processos post-mortem (Berkeley et al., 2007). O pouco tempo de modificações tafonômicas impediu a transformação completa do $\mathrm{FeS}$ em $\mathrm{FeS}_{2}$ nessas testas.

Nessa mesma fase, o nível do mar estaria entre 120 e 130m mais baixo que o atual (Lambeck e Chappell, 2001). Isso causava a exposição subaérea da plataforma continental, o que acarretava em maior transporte sedimentar e/ou de material orgânico (M.O.) ao talude por meio da atuação dos rios, especialmente do Rio de La Plata, e das correntes costeiras dessa região (Chiessi et al., 2009; Mahiques et al., 2010).

A maior taxa de sedimentação (Figs. 29 e 32), aliada aos altos conteúdos de M.O. nos sedimentos do GeoB6211-2 (Fig. 34), além do provável enfraquecimento das correntes de fundo do CRG (Fig. 36C), proporcionaram a baixa oxigenação do meio nesse intervalo de tempo (Fig. 34). Há 18.865 anos cal A.P., o rápido aumento da oxigenação do meio (Fig. 34), a diminuição de testas inteiras e o aumento de testas pretas (Fig. 36B, C) podem ter sido causados ou por distúrbios na taxa de sedimentação, ou em decorrência da primeira perturbação da hidrodinâmica de fundo do CRG, associada às mudanças da AMOC há aproximadamnete 19.000 anos cal A.P. no hemisfério norte descritas por Stanford et al. (2011). 
- Segunda Fase: 18.620 a 17.016 anos cal A.P.

Essa fase pode ser subdividida em dois intervalos de tempo distintos (18.620 a 17.733 anos cal A.P., e 17.733 a 17.016 anos cal A.P.), de acordo com as associações de foraminíferos bentônicos. Ambos foram, genericamente, bem oxigenados. (Fig. 34). Eles representam três pulsos fortes de oxigenação para o meio, com ápices há 18.133 anos cal A.P.; há 17.867 anos cal A.P. e há 17.467 anos cal A.P. (Fig. 34).

Durante o primeiro intervalo temporal, os aumentos do grau de oxigenação do meio (Fig. 34) parecem ter ocorrido especialmente na interface sedimento-água e nas porções mais superficiais do sedimento. Isso fez com que as espécies das associações de foraminíferos bentônicos ocupassem preferencialmente nichos ecológicos mais superficiais (epifaunais a infaunais rasos) (Fig. 34). No segundo intervalo de tempo, o pico de oxigenação do meio há 17.467 anos cal A.P. parece ter sido ainda mais forte (Fig. 34). Essa maior oxigenação do meio atingiu não apenas a interface sedimento-água e as porções mais superficiais do sedimento, mas também suas porções mais profundas. Isso permitiu a ocupação de nichos ecológicos epifaunais a infaunais mais profundos ao mesmo tempo (Fig. 34).

Esses picos de oxigenação do meio acompanharam as variações de temperatura na Antártica e na Groelândia (Fig. 35E, F, H, I e J), bem como o aumento da pluviosidade no NE do Brasil (Fig. 35B). Eles ocorreram ao mesmo tempo em que houve provável aumento da energia hidrodinâmica de fundo no CRG (Fig. 36C). Especialmente há 17.467 anos cal A.P., o maior pico de oxigenação do meio parece se relacionar, também, ao aumento das temperaturas (Fig. 35D) e salinidades no NE da margem brasileira (Arz et al., 1999; Weldeb at el., 2006).

Considera-se que durante essa segunda fase a diminuição da força da AMOC (Stanford et al., 2011) e o consequente fortalecimento da CB (Arz et al., 1999) alcançaram a região de fundo do CRG em pulsos descontínuos. Isso deve ter causado aumento cada vez maior da oxigenação do meio, com picos positivos entremeados por diminuições dessas oxigenações (Fig. 34). Também deve ter aumentado cada vez mais a energia hidrodinâmica de fundo do CRG até em torno de 17. 467 anos cal A.P.

Depois de 17.467 anos cal A.P., o decaimento da energia hidrodinâmica de fundo no CRG ocasionou a diminuição do grau de oxigenação do meio (Figs. 34 e 35C). A maior oxigenação do meio há 17.467 anos cal A.P., pouco antes da diminuição da energia hidrodinâmica e da sequente queda dessa oxigenação do meio, está provavelmente relacionada ao estado de quase colapso em que chegou a AMOC devido à descarga mais 
massiva de Ice-Rafted Debries (IRD) nas altas latitudes do Atlântico Norte (Bard et al., 2000; Stanford et al., 2011)

Espécies herbívoras que consomem preferencialmente M.O. mais fresca (e.g., Quinqueloculina spp.) apareceram em maiores frequências nas associações de foraminíferos bentônicos dessa fase (Tabela 9, em anexo; Tabela 10; fig. 38). O gênero Quinqueloculina (Fig. 33K, T) seria também indicativa de mais alta oxigenação do meio (Corliss, 1991; Duleba et al., 2005). Entretanto, esse gênero predominou nas associações compostas pela epifauna, embora tenham ocorrido outras espécies de mesmo hábito com preferência por M.O. mais degradada (e.g., Pyrgo spp.; Eponides repandus) (Murray, 1991; De e Gupta, 2010). Portanto, a predominânica do gênero Quinqueloculina coadunaria com a hipótese de aporte de M.O. mais lábil nos sedimentos do testemunho GeoB6211-2 nessa fase.

Houve menor produtividade primária marinha na região do CRG nessa segunda fase (Fig. 35G). O processo de exportação da M.O. ao fundo oceânico é bastante complexo. Mas, em termos gerais, uma menor produtividade primária marinha na superfície oceânica resultará em menor acúmulo de M.O. lábil exportada da superfície ao substrato marinho (Rühlemann et al., 1999). Dessa forma, pode-se considerar que a M.O. mais lábil que atingiu a região do CRG nesse período foi provavelmente majoritariamente trazida pela massa de água que banhou o CRG, seja ela a ACAS ou a AIA.

- Terceira Fase: 17.016 a 16.095 anos cal A.P.

Há 17.016 anos cal A.P. as associações de foraminíferos bentônicos sofreram modificações drásticas (Figs. 32, 33, 34, 36 e 38). A diminuição da energia de fundo no CRG (Fig. 36C) deve ter causado a queda da oxigenação do meio e o maior acúmulo de M.O. nos sedimentos do CRG (Fig. 34). Essa diminuição da oxigenação pode ter levado espécies infaunais a adotarem habitats mais rasos nos sedimentos. Com isso, elas oxidaram suas testas (Figs. 34, 36B). Essa diminuição da energia de fundo do $\mathrm{CRG}$ foi provavelmente causada pelas mudanças paleoclimáticas que ocorreram na Antártica em 17.000 anos cal A.P., quando o manto de gelo atingiu sua menor extensão, a quantidade de $\mathrm{CO}_{2}$ lançado à atmosfera passou a aumentar (Shemesh et al., 2002), e as temperaturas tiveram leve queda (Fig. 35E). Essas modificações paleoclimáticas devem ter afetado a força da energia hidrodinâmica de fundo do CRG, causando sua diminuição mais acentuada nessa época. Após cerca de 200 anos, ocorreu incremento na oxigenação do meio e os teores de M.O. no substrato do CRG diminuíram (Fig. $34)$. 
Nessa terceira fase paleoambiental, os dois picos de aumento da oxigenação do meio centralizados há 16.862 e há 16.248 anos cal A.P. foram menos intensos que aqueles descritos para a segunda fase paleoambiental (Fig. 34). Essa maior oxigenação do meio deve ter ficado restrita à interface sedimento-água e às porções mais superficiais do sedimento, o que impediu as associações de foraminíferos bentônicos de ocuparem nichos ecológicos mais profundos (Fig. 34).

O novo aumento crescente da energia hidrodinâmica de fundo no CRG (Fig. 36C) possivelmente causou esses novos picos de oxigenação do meio. Esse aumento da energia hidrodinâmica pode ter sido devido ao fortalecimento da CB (Arz et al., 1999; Weldeab et al., 2006), à maior formação da AIA (Pahnke et al., 2008); à possível melhor ventilação dessa massa de água e da ACAS (Anderson et al., 2009); às modificações climáticas no continente antártico (Fig. 35E; Blunier e Brook, 2001; Shemesh et al., 2002; Shakun et al., 2012) e às variações de circulação no Oceano Atlântico devidas ao quase colapso da AMOC (Stanford et al., 2011).

Apesar do aumento da contribuição continental durante essa terceira fase (Fig. 35A), especialmente em torno de 16.000 anos cal A.P., o menor acúmulo de M.O. nos sedimentos do CRG durante os aumentos da oxigenação intersticial (Fig. 34) provavelmente impediu a produção de $\mathrm{FeS}_{2}$ pelas batcérias sulfato-redutoras (Berner, 1970), o que diminuiu a quantidade de testas douradas nas associações de foraminíferos bentônicos desse período (Fig. 36B).

Há 17.016 e entre 16.555 e 16.402 anos cal A.P., ocorreram as maiores frequências da espécie Brizalina subaenariensis dentro dessa fase paleoambiental (Tabela 9, em anexo; fig. 33B). Essa espécie é considerada rápida em colonizar ambientes estressantes, respondendo ao bloom fitoplanctônico com rápido crescimento (Langezaal et al., 2006). Também em torno de 16.500 anos cal A.P., o maior acúmulo de M.O. nos sedimentos do CRG auxiliou, provavelmente, a diminuir o oxigênio nos interstícios sedimentares do CRG (e.g., Berner, 1970; Rühlemann et al., 1999) (Fig. 34).

A presença de B. subaenariensis, e a também frequência mais acentuada de Quinqueloculina spp. (Fig. 33K,T), além dos maiores valores de $\delta^{13} \mathrm{C}$ G. ruber especialmente há aproximadamente 16.500 anos cal A.P. (Fig. 35G), atestam aporte majoritário de M.O. lábil aos sedimentos do $\mathrm{CRG}$ nessa época.

Espécies típicas de águas mais frias, como Bulimina marginata, Cassidulina crassa, Stainforthia concava, Uvigerina bifurcata e Uvigerina peregrina (Murray, 1991; Badawi et al., 2005; Pascual et al., 2008), tornaram-se menos frequentes ou desapareceram nessa época 
(Tabela 7, em anexo; figs. 32 e 37). Espécies típicas de águas temperadas e/ou de condições oceânicas mais estratificadas, como Bulimina elongata, Brizalina subaenariensis, Buliminella elegantissima, Nonionella atlantica e Noninella opima, (Murray, 1991; Kaminski et al., 2002; Martins et al., 2007) apareceram em frequências mais elevadas (Tabela 9, em anexo; figs. 33 e 38).

Isso sugere que as águas oceânicas que atingiam os sedimentos do CRG nessa época teriam se tornado mais quentes e/ou apresentaram características de coluna de água mais estratificada em relação à fase anterior. O aquecimento, ainda que baixo, das águas no sítio de coleta do testemunho GeoB6211-2, acompanharam a elevação do $\mathrm{CO}_{2}$ atmosférico e consequente aquecimento do hemisfério sul (Fig. 35E; Shemesh et al., 2002; EPICA 2006; Shakun et al., 2012) nesse período.

- Quarta Fase: 16.095 a 14.682 anos cal A.P.

Essa foi a fase das mudanças paleoambientais mais acentuadas no ambiente de fundo do CRG. A amplitude de variação dos graus de oxigenação do meio parecem ter aumentado entre 16.095 e 14.682 anos cal A.P. (Fig. 34). A diminuição considerável da infauna, bem como o aumento da epifauna-infauna e da epifauna durante essa fase (Fig. 34) permitiram que se supusesse que as maiores oxigenações do meio encontradas nessa fase ocorreram especialmente na interface sedimento-água, e nos centímetros mais superficiais do sedimento.

Os momentos de maior oxigenação do meio (Fig. 34) também foram aqueles em que houve cada vez menor acúmulo de M.O. nos sedimentos do CRG (Fig. 34). Durante toda essa fase, a contribuição continental foi menor no local de coleta do testemunho GeoB6211-2 (Fig. 35A), e a produtividade primária oceânica apresentou variações significativas (Fig. 35G). Pahnke et al. (2008) detectaram queda da contribuição da AIA em latitudes mais elevadas no Oceano Atlântico a partir de 15.700 anos cal A.P. (Fig. 35C).

As modificações causadas pela segunda maior descarga de IRD nas altas latitudes do Atlântico Norte na AMOC (Bard et al., 2000; Stanford et al., 2011) e no calor e salinidade das águas superficiais na margem NE brasileira (Weldeab et al., 2006) devem ter alcançado o CRG em pulsos. Em um primeiro momento, geraram diminuição da energia hidrodinâmica de fundo do CRG até há 15.787 anos cal A.P., o que diminuiu a oxigenação do meio em seus sedimentos (Figs. 34 e 36C). Logo em seguida, a aumentaram, o que elevou a oxigenação do meio há 15.634 anos cal A.P., mas apenas nas porções mais superficiais do sedimento (Fig. 34 e 36C). 
A segunda diminuição do grau de oxigenação do meio ocorreu simultaneamente à diminuição das temperaturas na margem NE brasileira (Fig. 34, 35D, J). Weldeab et al. (2006) propuseram que essa queda das temperaturas ocorreu devido ao início do fortalecimento do transporte inter-hemisférico das massas de água. A energia hidrodinâmica de fundo no CRG continuava elevada, mas sofreu leve diminuição entre 15.327 e 15.060 anos cal A.P. (Fig. 36C). Há aproximadamente 15.327 anos cal A.P. a reestruturação da AMOC (Stanford et al., 2011), em conjunto com a diminuição do aumento do $\mathrm{CO}_{2}$ lançado na atmosfera na Antártica (Shemesh et al., 2002), possivelmente ocasionaram a leve diminuição da energia hidrodinâmica de fundo no CRG. Esse arrefecimento provavelmente levou à diminuição da oxigenação do meio (Fig. 34). Como a maior oxigenação que até então existia no CRG atingira apenas as porções mais superficiais do sedimento (Fig. 34), a atenuação do hidrodinamismo, ainda que leve, gerou a redução bem mais acentuada dessa oxigenação.

O maior aumento da oxigenação do meio há 15.060 anos cal A.P., bem como o incremento do teor de M.O. nos sedimentos do CRG a partir de aproximadamente 14.807 anos cal A.P. e o aumento considerável das densidades das associações de foraminíferos bentônicos a partir de 14.934 anos cal A.P. parecem ter marcado a transição entre o HS1 e o ACR (Blunier et al., 1997; Stenni et al., 2001; Köhler et al., 2011) no sítio de estudos do testemunho GeoB6211-2.

O incremento do acúmulo de M.O. nos sedimentos do CRG a partir de 14.807 anos cal A.P. levaram à maior produção de $\mathrm{FeS}_{2}$, que aumentaram consideravelmente as porcentagens de testas douradas nas associações de foraminíferos bentônicos (Fig. 36B). Esse aumento dos teores de M.O. provavelmente ocorreram devido à diminuição da energia hidrodinâmica de fundo do CRG (Fig. 36C), o que levou à diminuição da oxigenação do meio a partir de aproximadamente 14.934 anos cal A.P. (Fig. 34).

Chiessi et al. (2008) relataram que teria ocorrido diminuição considerável da taxa de sedimentação no CRG a partir de cerca de 15.200 anos cal A.P. Além disso, Chiessi et al. (2008, 2009) descreveram aumento de temperatura no sítio do GeoB6211-2 a partir de aproximadamente 15.000 anos cal A.P. Esse aumento da temperatura estaria em concordância com a tendência apresentada pelas associações de foraminíferos bentônicos entre 16.095 a 14.682 anos cal A.P. (Tabela 9, em anexo; figs. 33 e 38). Segundo essas associações, as águas de fundo e intersticiais gradualmente se tornaram mais quentes e menos estratificadas no CRG. (e.g., Kaminski et al., 2002; Scott et al., 2003; Eichler et al., 2008). 
- Quinta Fase: 14.682 a 14.050 anos cal A.P.

Entre 14.682 e 14.050 anos cal A.P. espécies típicas de níveis marinhos mais baixos (e.g., Fig. 33H, J) desapareceram nas associações de foraminíferos bentônicos. Essas associações também indicaram diminuição da energia de fundo (Fig. 36C) e altas concentrações de M.O. nos sedimentos (Fig. 34). Esses maiores teores de M.O. ocasionaram o aumento de $\mathrm{FeS}_{2}$ nos sedimentos do $\mathrm{CRG}$, aumentando a frequência de testas douradas durante essa fase (Fig. 36B).

Espécies exclusivamente epifaunais ou infaunais aludiram à menor oxigenação do meio (Fig. 34). O menor hidrodinamismo do CRG e as altas concentrações de M.O. em seus sedimentos condicionaram melhor ambiente para a existência de formas bentônicas de hábito epifaunal a infaunal raso com maior tolerância a ambientes menos oxigenados (e.g., Nonionellina labradorica, Nonionella opima, Brizalina subaenariensis, Bulimina elongata, Cassidulina crassa) (Figs. 33, 34, 38).

As associações de foraminíferos bentônicos existentes entre 14.682 e 14.050 anos cal A.P. (Tabela 10; figs. 33 e 38), indicaram também águas um pouco mais frias que aquelas encontradas na fase anterior (e.g., Murray, 1991; Martins e Gomes, 2004; Badawi et al., 2005). Isso reflete o período mais frio do hemisfério sul nessa época (e.g., Blunier et al., 1997; Stenni et al., 2001; Köhler et al., 2011).

Chiessi et al. (2008) encontraram taxa de sedimentação mais baixa (ca. $8 \mathrm{~cm} / \mathrm{ca}$ ) no GeoB6211-2 a partir de 14.050 anos cal A.P. Supôs-se que o clima no hemisfério sul durante o ACR e o aumento do nível marinho (Lambeck e Chappell, 2001; Köhler et al., 2011) tenham contribuído para manter baixo o aporte sedimentar continental para o CRG (Fig. 35A), bem como para manter diminuída a sua energia hidrodinâmica de fundo (Fig. 36C).

\subsubsection{Mg/Ca SST $\delta^{18} \mathrm{O}_{\text {ivc-sw }}$ em testas de G. ruber (white, s.s.)}

Quando os valores da média das $\mathrm{Mg} / \mathrm{Ca} \mathrm{SST}$ das três amostras mais superficiais do testemunho GeoB6211CC $\left(23,3^{\circ} \mathrm{C}\right)$; de sua amostra mais superficial $\left(23,5^{\circ} \mathrm{C}\right)$; e de suas menor $\left(18,2^{\circ} \mathrm{C}\right)$ e maior $\left(27,5^{\circ} \mathrm{C}\right) \mathrm{Mg} / \mathrm{Ca} \mathrm{SST}$ são comparados com as atuais temperaturas médias anual $\left(20,3^{\circ} \mathrm{C}\right)$, de verão $\left(24,3^{\circ} \mathrm{C}\right)$ e de inverno $\left(17,7^{\circ} \mathrm{C}\right)$ superficiais para o local de coleta do testemunho GeoB6211CC (Conkright et al., 2002), pode-se admitir que a espécie $G$. ruber (white, s.s.) calcifica sua testa principalmente durante os meses de verão nesse setor atlântico. 
Portanto, pode-se admitir que as temperaturas superficiais marinhas baseadas na razão magnésio-cálcio ( $\mathrm{Mg} / \mathrm{Ca} \mathrm{SST})$, bem como os valores de $\delta^{18} \mathrm{O}_{\mathrm{ivc}-\mathrm{sw}}(\% \mathrm{VSMOW})$ obtidas nas testas dessa espécie planctônica, representam as temperaturas $(\mathrm{Mg} / \mathrm{Ca} \mathrm{SST})$ e as salinidades (SSS) médias superficiais de verão deste sítio de estudos.

$\mathrm{O}$ aumento de $2,9^{\circ} \mathrm{C}$ das $\mathrm{Mg} / \mathrm{Ca} \mathrm{SST}$ entre o Último Máximo Glacial (19.000 anos cal A.P.) e o Presente (Fig. 39) está em concordância com o padrão encontrado por Ballantyne et al. (2005), que encontraram diferença de temperaturas superficiais oceânicas entre $30^{\circ} \mathrm{S}$ e $30^{\circ} \mathrm{N}$ para este intervalo geológico de $2,7^{\circ} \mathrm{C} \pm 0,5( \pm \sigma)$, com diferença regional de $3^{\circ} \mathrm{C}$ no Atlântico. Esse valor é superior àquele apresentado no Projeto MARGO (MARGO, 2009), que indicaram $1,5^{\circ} \mathrm{C} \pm 0,2( \pm \sigma)$ para a região entre $0^{\circ}$ e $30^{\circ} \mathrm{S}$ do Atlântico oeste. Weldeab et al. (2006) também encontraram aumento de $3^{\circ} \mathrm{C}$ das SST na margem NE do Brasil entre a última parte do Último Máximo Glacial (UMG, há 23.000-19.000 anos cal A.P.) e o Holoceno.

Esse aumento indica que o Atlântico subtropical sudoeste deve ter tido a mesma variação de aumento de temperatura entre o Último Máximo Glacial e o Presente observado para o Atlântico tropical (e.g., Rühlemann et al., 1999; Weldeab et al., 2006).

Ainda, o padrão geral de aumento contínuo das $\mathrm{Mg} / \mathrm{Ca}$ SST na margem sul brasileira (Fig. 39) segue o comportamento geral de aumento do $\mathrm{CO}_{2}$ atmosférico na Antártica (Figs. 40J e 41F; Monnin et al., 2004), bem como o de aumento da temperatura global e do hemisfério sul (Figs. 40I e 41E, Shakun et al., 2012). Deve haver, portanto, um vínculo direto entre o aumento das médias de temperatura superficial de verão no Atlântico subtropical sudoeste e o aumento do $\mathrm{CO}_{2}$ e da temperatura no Polo Sul.

Entretanto, esse padrão geral de aumento não parece ser influenciado apenas pela elevação da temperatura nas altas latitudes do hemisfério sul. Apesar de haver essa similaridade, ocorreram oscilações secundárias das $\mathrm{Mg} / \mathrm{Ca} \mathrm{SST}$ dessa região do Atlântico subtropical sudoeste que não são encontradas no comportamento evolutivo do aumento do $\mathrm{CO}_{2}$ atmosférico e da temperatura na Antártica.

As oscilações apresentadas pelos valores de $\delta^{18} \mathrm{O}_{\mathrm{ivc}-\mathrm{sw}}$ acompanham as variações secundárias apresentadas pelas Mg/Ca SST do sítio de estudos do GeoB6211CC (Fig. 39). Isso indica que esses comportamentos são influenciados por um ou por alguns fatores capazes de influenciar tanto as temperaturas quanto as salinidades superficiais dessa região do Atlântico.

Essas oscilações diferiram daquelas encontradas para as temperaturas e para os valores de $\delta^{18} \mathrm{O}_{\text {ivc-sw }}$ na profundidade da termoclina permanente dessa mesma região (Fig. 40G, H) 
encontradas por Chiessi et al. (2008) durante a terceira fase do HS1, e no intervalo de tempo que abrange a segunda metade do ACR e todo o YD (Fig.40A, B, G, H). Nos demais intervalos paleoclimáticos compreendidos na Última Deglaciação, os aumentos e diminuições das temperaturas e valores de $\delta^{18} \mathrm{O}_{\text {ivc-sw }}$ superficiais e da região da termoclina permanente são similares (Fig. 40A, B, G, H), mas as temperaturas e valores de $\delta^{18} \mathrm{O}_{\text {ivc-sw }}$ obtidos da espécie planctônica Globorotalia inflata (Chiessi et al., 2008) sugerem mudanças mais abruptas que aquelas encontradas na superfície oceânica.

Propõe-se, portanto, que as variações das $\mathrm{Mg} / \mathrm{Ca} \mathrm{SST}$ e dos valores de $\delta^{18} \mathrm{O}_{\text {ivc-sw, }}$, encontradas nesse estudo, se vincularam tanto aos fatores ambientais que modificaram as temperaturas e salinidades da região da termoclina permanente dessa mesma região, (e.g., comportamento das correntes oceânicas atlânticas) quanto a outros fatores ambientais que não foram capazes de influenciar diretamente a coluna de água em níveis mais profundos (e.g., radiação solar, influência de águas continentais adjacentes). Dessa forma, as modificações bruscas encontradas na região da termoclina teriam atingido a superfície oceânica abrandadas por esses outros fatores ambientais.

Isso implica em considerar que as mudanças encontradas nas $\mathrm{Mg} / \mathrm{Ca} \mathrm{SST}$ e nos valores de $\delta^{18} \mathrm{O}_{\mathrm{ivc}-\mathrm{sw}}$ foram resposta tanto a fatores que influenciaram apenas a massa de Água Superficial do Atlântico Sul (ASAS), quanto a fatores que afetaram a Corrente do Brasil (CB) como um todo.

Concomitantemente às variações do clima no continente antártico (Monnin et al., 2001; Leventer et al., 2006; Cremer et al., 2007; Shakun et al., 2012) que influenciaram especialmente as temperaturas superficiais da região atlântica de coleta do testemunho GeoB6211CC (Figs. 40A, B, I, J e 41A, B, E, F), outros fatores devem ter ocasionado as oscilações secundárias dos valores de $\mathrm{Mg} / \mathrm{Ca} \mathrm{SST}$ e as oscilações dos valores de $\delta^{18} \mathrm{O}_{\text {ivc-sw. }}$.

$\mathrm{O}$ primeiro fator capaz de influenciar os valores de $\delta^{18} \mathrm{O}_{\mathrm{ivc}-\mathrm{sw}}$ do sítio de estudos do testemunho GeoB6211CC é a pluma de baixa salinidade proveniente do deságue do Rio de La Plata (PPW) no Oceano Atlântico.

De acordo com Lonardi e Ewing (1971) e com Chiessi et al. (2009), durante o período da Última Deglaciação, canais submarinos indicam que a bacia de drenagem do Rio de La Plata se estendia para o norte sobre a plataforma continental exposta, devido ao nível do mar mais baixo (Lambeck e Chappell, 2001). Dessa forma, o Rio de La Plata desaguava uma carga sedimentar mais volumosa no Cone do Rio Grande, local de coleta do GeoB6211CC (Lonardi e Ewing, 1971; Chiessi et al., 2009). Isso tornava a influência da PPW ainda maior sobre esse setor atlântico nessa época (Chiessi et al., 2009). 
Entre 19.000 e 14.000 anos cal A.P., Chiessi et al. (2009) encontraram oscilações secundárias com períodos de $\sim 60$ e $\sim 300$ anos nos valores de $\delta^{18} \mathrm{O}$ G. ruber (white) coletados nas mesmas amostras analisadas neste estudo entre 19.000 e 10.000 anos cal A.P. Esses autores atribuíram essas oscilações a variações na atividade da Monção de Verão da América do Sul (MVAS) e na Zona de Convergência da América do Sul (ZCAS) associadas à Oscilação Multidecadal Atlântica, que também influenciariam a descarga da PPW (Chiessi et al., 2009).

Os dados de $\mathrm{Mg} / \mathrm{Ca} \mathrm{SST}$ e de $\delta^{18} \mathrm{O}_{\text {ivc-sw }}$ analisados no testemunho GeoB6211CC não apresentam resolução temporal capaz de capturar as oscilações multidecadais apresentadas por Chiessi et al. (2009). Ainda assim, era de se esperar que, caso ocorresse variação significativa da descarga da PPW nesse sítio de estudos nos últimos 19.000 anos cal A.P., ela se manifestasse nos dados de $\delta^{18} \mathrm{O}_{\text {ivc-sw }}$ desse testemunho.

Nesse caso, com a elevação do nível marinho durante a Transgressão Santos (Flandriana) (Suguio e Martin, 1978a; Lambeck e Chappell, 2001; Angulo et al., 2006), deveria haver tendência geral de aumento contínuo da salinidade e, por conseguinte, dos valores de $\delta^{18} \mathrm{O}_{\text {ivc-sw }}$ das amostras desse testemunho. Entretanto, os valores de $\delta^{18} \mathrm{O}_{\text {ivc-sw }}$ não indicaram aumento contínuo das SSS da área de estudos do testemunho GeoB6211CC nos últimos 19.000 anos cal A.P. (Fig. 39).

Segundo Zhou e Lau (1998) e Berbery e Barros (2002), atualmente há distinção marcante no comportamento da PPW entre os meses de verão e inverno. Ainda assim, atualmente a PPW exerce influência nas águas superficiais na região de coleta do testemunho GeoB6211CC durante todo o ano (Conkright et al., 2002; LeGrande e Schmidt, 2006).

Pode-se considerar, portanto, que a PPW vem influenciando a região de coleta do testemunho GeoB6211CC desde 19.000 anos cal A.P. até o Presente (Conkright et al., 2002; Chiessi et al., 2009; Razik et al., no prelo). Entretanto, como os dados de $\delta^{18} \mathrm{O}_{\text {ivc-sw }}$ não apresentam oscilações marcantes que possam ser vinculadas às variações da PPW sobre o sítio de estudos do testemunho GeoB6211CC, considera-se que variações mais marcantes centenárias a milenares da PPW para os resultados isotópicos do testemunho GeoB6211CC podem ser descartados, especialmente durante o período da Última Deglaciação (entre 19.000 e 11.500 anos cal A.P.), e a influência da PPW sobre esses resultados, considerada secundária, quando comparada aos demais fatores ambientais influentes.

Outro fator que pode ser responsável pelas variações dos valores de $\mathrm{Mg} / \mathrm{Ca} \mathrm{SST}$ e de $\delta^{18} \mathrm{O}_{\text {ivc-sw }}$ ao longo do testemunho GeoB6211CC são as modificações do comportamento 
oceânico no Oceano Atlântico Sul e suas interações com os sistemas atmosféricos atuantes sobre essa região atlântica e sobre o continente sul-americano.

As mudanças nas temperaturas e salinidades superficiais do Atlântico desse estudo, encontradas em $32,5^{\circ} \mathrm{S}$, no sul do Brasil, são similares àquelas descritas por Weldeab et al. (2006) para a margem NE do Brasil e por outros autores para a margem SE e NE brasileiras (e.g., Arz et al., 1999; Carlson et al., 2008), especialmente durante o período da Última Deglaciação (Figs. 40A, B, C, D, E e F; e 41A, B, C, D). As dissimilaridades encontradas entre esses trabalhos e os resultados obtidos no testemunho GeoB6211CC provavelmente se devem à utilização de diferentes espécies planctônicas (G. ruber pink e G. sacculifer - Arz et al., 1999; G. ruber withe - Weldeab et al., 2006; Carlson et al., 2008; G. ruber white, s.s. este trabalho), a diferenças dos modelos de idades e/ou a efeitos locais.

As semelhanças encontradas entre os dados do testemunho GeoB6211CC e aqueles do Atlântico no NE e SE brasileiros (Arz et al., 1999; Weldeab et al., 2006; Carlson et al., 2008) indicam que os mesmos fatores ambientais que provocaram as modificações das $\mathrm{Mg} / \mathrm{Ca} \mathrm{SST}$ e dos valores de $\delta^{18} \mathrm{O}_{\text {ivc-sw }}$ na região atlântica do $\mathrm{NE}$ e SE do Brasil, contribuíram para as modificações desses parâmetros encontradas no Atlântico subtropical sudoeste no sul do Brasil. Isso significa que as temperaturas e salinidades superficiais apresentaram padrão similar nos últimos 19.000 anos cal A.P. em toda a extensão da CB e ao menos em parte da Corrente Norte do Brasil (CNB) no Atlântico tropical e subtropical sudoeste.

Trabalhos anteriores propuseram dois fatores ambientais como responsáveis pelas variações das temperaturas e salinidades superficiais do Atlântico tropical e subtropical oeste: as migrações das posições da ZCIT; e as mudanças da intensidade da AMOC (e.g., Arz et al., 1999; Weldeab et al., 2006; Toledo et al., 2007b; Carlson et al., 2008). Essas mudanças teriam ocasionado aumento da força da $\mathrm{CB}$ e diminuição da força da CNB em épocas de AMOC enfraquecida, gerando acúmulo de calor e salinidade no Atlântico Sul (e.g., Arz et al. 1999; Chiessi et al., 2008). Ainda, em períodos mais frios, como por exemplo durante o HS1, a Passagem das Agulhas teria permanecido enfraquecida. Seu fortalecimento em aproximadamente 15.000 anos cal A.P. ocasionaria aumento do $\delta^{18} \mathrm{O}_{\text {ivc-ptsw }}$ e diminuição do $\delta^{18} \mathrm{O}$ G. inflata em nossa área de estudos, e aumento das temperaturas e salinidades das águas centrais do Atlântico Sul (Chiessi et al., 2008).

Propõe-se aqui que durante a Última Deglaciação (19.000 a 11.500 anos cal A.P.), o padrão geral de aumento das temperaturas superficiais do Atlântico subtropical sudoeste no sul do Brasil seguiu a tendência geral de aumento de temperatura global indicada na literatura para este período paleoclimático (e.g., Monnin et al., 2004; Shakun et al., 2012). Ao mesmo 
tempo, as oscilações secundárias de aumento e diminuição dessas temperaturas e os aumentos e diminuições dos valores de $\delta^{18} \mathrm{O}_{\text {ivc-ptsw }}$ desse setor atlântico devem ter tido como principal fator controlador as mudanças sofridas pela AMOC.

Em períodos de AMOC enfraquecida, o calor e a salinidade retidos na região tropical atlântica (Arz et al., 1999; Weldeab et al., 2006) devem ter contribuído para aumentar a temperatura e a salinidade da Água Tropical (AT). Como a AT se forma na região do Atlântico Sul tropical e flui para sul bordejando o continente sul-americano pela CB (Stramma e England, 1999; Silveira et al., 2000), o calor e a salinidade retidos na margem NE brasileira foram provavelmente transportados em parte para a margem sul brasileira, carreados por essa massa de água mais superficial da $\mathrm{CB}$, colaborando para aumentar as $\mathrm{Mg} / \mathrm{Ca} \mathrm{SST}$ e as SSS da região de coleta do testemunho GeoB6211CC.

Quando a AMOC se recuperava, o calor e a salinidade acumulados na margem NE brasileira diminuíam. Eles eram transportados em parte para o norte pela $\mathrm{CNB}$, agora mais fortalecida (Arz et al., 1999; Weldeab et al., 2006). A CB, enfraquecida e sem receber maior quantidade de calor e salinidade, transportava menor quantidade desses elementos para o sul em suas águas superficiais. Isso provavelmente colaborou para diminuir as temperaturas e salinidades superficiais no sítio de estudos do testemunho GeoB6211CC.

Concomitantemente, modificações no posicionamento da ZCIT/ZCAS, com implicações nos padrões pluviométricos sobre o continente e, portanto, sobre a descarga de águas doces sobre a margem brasileira (e.g., Cruz Jr. et al., 2006; Jaeschke et al., 2007; Chiessi et al., 2009), influenciaram as temperaturas e salinidades superficiais da região do GeoB6211CC de forma secundária. Isso porque, no NE do Brasil, essas modificações atmosféricas interviram na quantidade de calor e salinidade retidos no Atlântico tropical (Weldeab et al., 2006; Jaeschke et al., 2007). Além disso, influenciaram os padrões pluviométricos no Brasil como um todo (Cruz Jr. et al., 2006; Chiessi et al., 2009), implicando em diferenças na descarga de águas doces sobre a margem brasileira entre o NE e o sul do Brasil.

A descarga de águas continentais ao longo da margem brasileira, atualmente, modifica o padrão da AT. Isso porque, à medida que a AT percorre a margem brasileira, ela se torna menos quente e salina devido às interações com essas águas continentais e passa a ser denominada Água Superficial do Atlântico Sul (ASAS) (e.g. Silveira et al., 2000). Dessa forma, o calor e a salinidade transportados por essa massa de água do NE do Brasil para a região sul da margem brasileira devem ter sofrido provável diminuição devido a esta 
dinâmica. Essa diminuição deve ter sido diferenciada ao longo do tempo geológico, de acordo com o comportamento pluviométrico continental.

Considera-se, portanto, que houve vínculo entre o acúmulo de calor e salinidade superficiais nas margens NE e sul brasileiras devido à circulação da massa de água mais superficial da CB, e que esse calor e essa salinidade transportados pela ASAS da margem NE para a margem sul brasileiras devem ter sido abrandados em sua trajetória. Essa atenuação deve ter sido inconstante e vinculada ao padrão pluviométrico sobre o continente. Em períodos de menor descarga de águas doces continentais, a região sul brasileira deve ter recebido o calor e a salinidade da margem NE brasileira menos abrandados. Já em épocas de maior pluviosidade e, portanto, de maior descarga de águas doces continentais, a margem sul brasileira deve ter recebido calor e salinidades mais abrandados.

Esse padrão estaria em concordância com outros trabalhos realizados no Atlântico Sul (e.g., Weldeab et al., 2006; Carlson et al., 2008; Barker et al., 2009), que notaram vínculo entre as variações de temperatura e salinidade superficiais atlânticas e as oscilações climáticooceanográficas vinculadas à AMOC durante a Última Deglaciação.

Já entre o Holoceno (11.500 anos cal A. P.) e o Presente, especialmente a partir do Holoceno Médio, não houve variações consideráveis da força da AMOC (e.g., Keigwin e Boyle, 2000; Schulz et al., 2007; Thornalley et al., 2009). As únicas duas alterações mais consideráveis encontradas no hemisfério norte foram as vinculadas ao evento $8.2 \mathrm{ka}$, e à Pequena Idade do Gelo ( 1.500 a 1.900 A.D.) (Keigwin e Boyle, 2000). Dessa forma, as modificações da AMOC parecem ter deixado de ter influência marcante sobre as temperaturas e salinidades do Atlântico subtropical sudoeste no sul do Brasil. O transporte de calor e salinidade pela CB da região tropical para o sul da margem brasileira deve ter acontecido sem grandes oscilações, já que não houve outra grande retenção de calor e salinidade no Atlântico tropical (Weldeab et al., 2006). Dessa forma, supomos que esses fatores passaram a influenciar nas temperaturas e salinidades superficiais da margem sul brasileira de forma secundária.

Por outro lado, neste mesmo período, o clima do continente antártico (Monnin et al., 2001; Leventer et al., 2006; Cremer et al., 2007; Shakun et al., 2012) parece ter passado a exercer influência mais marcante sobre as características das temperaturas e salinidades superficiais do sítio de coleta do testemunho GeoB6211CC.

Masson et al. (2000) encontraram ótimo climático na Antártica entre 11.500 e 9.000 anos cal A.P. Este período engloba o aumento considerável das $\mathrm{Mg} / \mathrm{Ca} \mathrm{SST}$ e SSS do GeoB6211CC com ápice há 10.057 anos cal A.P. (Fig. 39). Esses autores descreveram clima 
mais frio na Antártica a partir desse ótimo climático, com mínimo em torno de 8.000 anos cal A.P. e em torno de 7.000 anos cal A.P. para a região do Law Dome. Entretanto, Cremer et al. (2007) encontraram melhora climática na costa leste antártica entre 8.600 e 8.200 anos cal A.P., o que estaria em concordância com o aumento das temperaturas e salinidades superficiais do Atlântico subtropical sudoeste na margem sul brasileira neste período demonstrado pelos dados de Mg/Ca SST e $\delta^{18} \mathrm{O}_{\text {ivc-ptsw }}$ do GeoB6211CC (Fig. 41A, B).

Masson et al. (2000) ainda detectaram melhora climática no setor do Mar de Ross entre 8.000 e 6.000 anos cal A.P., época em que as $\mathrm{Mg} / \mathrm{Ca}$ SST do Atlântico Subtropical sudoeste na margem sul brasileira tiveram tendência geral ao aumento (Fig. 41A). Steig et al. (1998) demonstraram queda das temperaturas no Mar de Ross em aproximadamente 5.500 anos cal A.P., quando os valores de $\mathrm{Mg} / \mathrm{Ca} \mathrm{SST}$ e de $\delta^{18} \mathrm{O}_{\text {ivc-ptsw }}$ também demonstraram diminuição (Fig. 41A, B). Masson et al. (2000) descreveram clima mais frio em torno de 5.000 anos cal A.P., seguido de melhora climática. Os dados de $\mathrm{Mg} / \mathrm{Ca} \mathrm{SST}$ e de $\delta^{18} \mathrm{O}_{\text {ivc-ptsw }}$ do testemunho GeoB6211CC mostraram diminuição das temperaturas e salinidades superficiais neste mesmo período, também seguidas de aumento das $\mathrm{Mg} / \mathrm{Ca} \mathrm{SST}$ e dos valores de $\delta^{18} \mathrm{O}_{\text {ivc-ptsw }}$ (Fig. 41A, B).

Provavelmente, a influência das mudanças nos padrões de interação atmosféricooceânicos se tornaram também mais importantes para a modulação das $\mathrm{Mg} / \mathrm{Ca} \mathrm{SST}$ e dos valores de $\delta^{18} \mathrm{O}_{\text {ivc-sw }}$ da região de estudos do testemunho GeoB6211CC a partir do Holoceno Médio. Fatores tais como o avigoramento ou arrefecimento da Monção de Verão da América do sul, os deslocamentos para sul e norte da ZCIT e as migrações da posição da Confluência Brazil-Malvinas (Robertson e Mechoso, 2000; Wainer et al., 2000), conjuntamente com os deslocamentos para sul e norte dos Ventos de Oeste e do hemisfério sul (Lamy et al., 2007; Monnin et al., 2004; Ljung e Björck, 2007; Razik et al., no prelo), e a interferência de outros eventos atmosférico-oceanográficos, tais como o ENOS, a La-Niña, e a OAM (Delworth e Mann, 2000; Kerr, 20000; Coelho et al., 2002; Robertson et al., 2003; Chiessi et al., 2009; Panarello e Dapeña, 2009; Razik et al., no prelo), além das variações da descarga do Rio de La Plata e, portanto, da influência da PPW na região de coleta do testemunho GeoB6211CC, a própria composição isotópica das massas de água que banham essa região de estudos e as variações de SST dessas massas de água (e.g., Robertson e Mechoso, 2000; Wainer et al., 2000), provavelmente contribuíram majoritariamente para as oscilações secundárias encontradas para as $\mathrm{Mg} / \mathrm{Ca} \mathrm{SST}$ e os valores de $\delta^{18} \mathrm{O}_{\text {ivc-sw }}$ do Atlântico subtropical sudoeste.

Razik et al. (no prelo) encontraram diferenças dos comportamentos do sistema de Monção da América do Sul, dos Ventos de Oeste do hemisfério sul, da circulação oceânica no 
Atlântico subtropical sudoeste, da PPW e do posicionamento da Frente Subtropical e da Zona de Confluência Brasil-Malvinas que afetaram a deposição sedimentar no Cone do Rio Grande entre o Holoceno Inferior e o Holoceno tardio.

Todos esses fatores devem ter atingido a região de estudos de forma mais abrupta e com menor duranção, contribuindo para as oscilações mais fortes das SST e SSS encontradas no sítio de estudos desse estudo a partir do Holoceno Médio (Fig. 41A, B).

\subsection{Evolução paleoceanográfica das margens sudeste e sul brasileiras}

Durante o HS1 e na transição entre este período paleoclimático e o ACR (entre 19.000 e 14.000 anos cal A.P.), o comportamento marinho era transgressivo. Há 19.000 anos cal A.P., paleonível marinho se encontrava entre 120 e 130m abaixo do nível atual (Corrêa, 1996; Lambeck e Chappell, 2001). As plataformas continentais sudeste e sul brasileiras estavam quase completamente expostas.

Durante essa fase da Última Deglaciação, a razão P/B (Fig. 31) do testemunho GeoB6211-2 indicou que esse testemunho deveria estar posicionado em uma coluna de água menos profunda que aquela em que se encontra hoje. Isso implica em considerar que a plataforma no sul do Brasil deveria estar, ao menos, parcialmente exposta. As lagoas dos Patos e Mirim ainda não estavam formadas e a desembocadura do Rio de La Plata deveria se encontrar mais próxima do talude continental, o que fazia com que a região do Cone do Rio Grande $(\mathrm{CRG})$ recebesse maior contribuição continental dessas áreas durante essa época (Alves, 1977; Tomazelli e Villwock, 1996; Tomazelli et al., 2000; Chiessi et al., 2009).

Os resultados microfaunísticos obtidos entre 19.000 e 14.000 anos cal A.P. indicaram que em épocas em que houve maior oxigenação intersticial nos sedimentos do CRG, as paleotemperaturas e paleossalinidades marinhas superficiais dessa região oceânica tenderam a aumentar (Fig. 43). Épocas de menor oxigenação intersticial corresponderam, por sua vez, a momentos em que as $\mathrm{Mg} / \mathrm{Ca} \mathrm{SST}$ e $\mathrm{SSS}$ da região do $\mathrm{CRG}$ diminuíram (Fig. 43). Esse comportamento similar permite supor que um (ou mais) mesmo(s) fator(ers) paleoambiental(is) deve(m) ter contribuído para que essas mudanças ocorressem, tanto na superfície da água, quanto no ambiente de fundo da região do $\mathrm{CRG}$, provavelmente afetando a Corrente do Brasil (CB) como um todo.

Propõe-se que esses fatores paleoclimáticos oceanográfico-atmosféricos responsáveis pelas alterações paleoambientais encontradas nos sedimentos do CRG (Item 8.2.2 da Discussão) e na superfície oceânica dessa região (Item 8.2.3 da Discussão) se desenvolveram 
gradualmente, atingiram seu ápice em torno de 17.500 anos cal A.P. e então regrediram também gradativamente.

No litoral do estado de São Paulo, a linha de costa estava $200 \mathrm{~km}$ mar adentro e se constituía em extensa planície costeira entalhada por canais fluviais e de maré (Corrêa, 1979). Os sedimentos da Formação Cananéia que formavam a região de planície costeira do MJI estavam sendo erodidos e carreados para o mar pelos rios que então drenavam essa baixada litorânea (Suguio e Martin, 1978a).

Ainda durante o ACR e o YD ( 14.600 - 11.700 anos cal A.P. $)$ as paleotemperaturas e paleossalinidades superficiais da margem atlântica sul brasileira eram controladas pelos mesmos fatores paleoclimáticos que as influenciaram durante o HS1 (Item 8.2.3 da Discussão). As associações de foraminíferos bentônicos presentes nesse intervalo temporal continuaram a indicar que a oxigenação de fundo do CRG persistiu síncrona aos aumentos das paleotemperaturas e paleossalinidades superficiais dessa região atlântica (Fig. 43).

A partir de 14.050 anos cal A.P., a razão P/B indicou aumento da coluna de água no local de coleta do testemunho GeoB6211-2 (Fig. 31). Lambeck e Chappell (2001) encontraram aumento de $\sim 2 \mathrm{~m}$ do paleonível marinho entre 14.050 e 13.921 anos cal A.P. (Fig. 31). Segundo Corrêa (1996), as plataformas sudeste e sul brasileiras já se encontravam em parte recobertas pelas águas oceânicas nessa época, e entre as plataformas média e externa havia ambiente pré-litorâneo.

Há 14.050 anos cal A.P., Chiessi et al. (2008) encontraram queda da taxa de sedimentação do testemunho GeoB6211-2 (ca. 8cm/ka). Considera-se que, a partir dessa época, as lagoas dos Patos e Mirim já impediam o maior transporte sedimentar da costa sul brasileira para a região do Cone do Rio Grande. Ainda, a plataforma coberta por águas marinhas afastou a desembocadura do Rio de La Plata do local de coleta do testemunho GeoB6211-2, diminuindo também o aporte sedimentar suprido por esta fonte ao Cone do Rio Grande.

Propõe-se que, ainda durante o ACR e o YD, as modificações climáticas oceanográfico-atmosféricas (Itens 8.2.2 e 8.2.3 da Discussão) continuaram a ser os principais fatores responsáveis pelas modificações da oxigenação de fundo no $\mathrm{CRG}$, bem como das paleotemperaturas e paleossalinidades superficiais dessa região do Atlântico sudoeste. Segundo McManus et al. (2004), a desaceleração da AMOC durante o YD não foi tão robusta e nem tão duradoura quanto à que ocorreu no HS1. Supõe-se, portanto, que o aumento notado nos parâmetros microfaunísticos do testemunho GeoB6211-2 nesse período (Fig. 43) tenham sido menos intensos e mais rápidos que aqueles que se deram durante o HS1, devido à menor 
força das transformações oceanográfico-atmosféricas e à reestruturação mais rápida da AMOC e dos demais fenômenos paleoclimáticos correlatos.

Também durante esse período geológico essas modificações ocorreram de forma gradual, tiveram ápice em torno de 13.400 anos cal A.P. e depois foram regredindo. Esses fenômenos também parecem ter afetado a CB como um todo.

No YD, a razão $\mathrm{P} / \mathrm{B}$ passou a mostrar aumento mais considerável de formas planctônicas, até que estas se tornaram predominantes no final do YD e no início do Holoceno (Fig. 31). Lambeck e Chappell (2001) indicaram que o paleonível do mar aumentou em torno de 8,6 m nesse período, a uma taxa de $0,6 \mathrm{~cm} / \mathrm{ano}$, que é a mesma taxa de aumento do nível marinho dessa época proposta por Corrêa (1996) para as costas sul e sudeste brasileiras. É ainda durante o YD que houve a segunda estabilização do paleonível marinho segundo Corrêa (1996) nas margens sul e sudeste brasileiras, em torno de -60 a -70m abaixo do nível do mar atual.

A estabilização do paleonível marinho durante o YD, em conjunto com a tendência geral de diminuição das temperaturas e salinidades superficiais da região marinha sul brasileira, seguidas pela diminuição da oxigenação intersticial de fundo dessa área oceânica e pelo decaimento da razão P/B (Fig. 43), permitem supor que o resfriamento climático na Antártica (Figs. 31 e 41) desacelerou o processo de aquecimento e de subida do nível do mar, muito provavelmente, da costa sul brasileira até, ao menos, a costa NE do Brasil, como atestado por Weldeab et al. (2006).

Durante essas fases da Última Deglaciação, épocas em que a ZCIT permaneceu mais ao sul e que o paleonível marinho esteve mais rebaixado (Vera, 2002; Corrêa, 1996; Lambeck e Chappell, 2001), a maior pluviosidade que se estabeleceu nas regiões da MVAS e da ZCAS (Zhou e Lau, 1998; Carvalho et al., 2004) muito provavelmente auxiliaram os rios da região do MJI a erodirem os sedimentos depositados anteriormente nessa região, conforme descrito por Suguio e Martin (1978a) para o terceiro estágio evolutivo dessa área.

A transgressão marinha durante o Holoceno ( 11.500 ao Presente) aumentou de 0,6 cm/ano para 1,6 cm/ano (Corrêa, 1996). Entre 10.200 e 9.400 anos cal A.P., Corrêa (1996) indicou a terceira estabilização do paleonível marinho e, entre 9.000 e 8.700 anos cal A.P., segundo esse mesmo autor, ocorreu a última estabilização do paleonível marinho durante a Transgressão Santos, quando o mar esteve entre 20 e $25 \mathrm{~m}$ abaixo do nível atual nas regiões sudeste e sul brasileiras (Corrêa, 1996). Em torno de 10.500 anos cal A.P., houve maior estabilização climática no hemisfério sul e na Antártica, quando as temperaturas atingiram valores próximos aos atuais (Fig. 41). 
No início do Holoceno, a razão P/B (Fig. 31) demonstrou que o testemunho GeoB6211-2 se localizava em coluna de água mais profunda que no estágio anterior, entre as zonas de plataforma externa e talude continental (Culver, 1988; Smart, 2002). Essa coluna de água parece ter se ampliado cada vez mais, e já a partir de $\sim 9.500$ anos cal A.P., o índice planctônicos/bentônicos indicou coluna de água compatível com região de talude superior (Culver, 1988; Smart, 2002), ou seja, já a partir dessa época, a profundidade do testemunho GeoB6211-2 era similar ou idêntica à atual.

$\mathrm{O}$ aumento expressivo das $\mathrm{Mg} / \mathrm{Ca} \mathrm{SST}$ e dos valores de $\delta^{18} \mathrm{O}_{\text {ivc-sw }}$ do Atlântico subtropical sudoeste na margem sul brasileira entre 10.830 e 9.027 anos cal A.P.,com pico há 10.057 anos cal A.P., foi concomitante ao considerável aumento da fauna total de foraminíferos do testemunho GeoB6211-2 (Fig. 31, 41 e 43).

Esses aumentos das paleotemperaturas e das paleossalinidades superficiais, em conjunto com o expressivo aumento das associações de foraminíferos nos sedimentos de fundo dessa mesma região atlântica, sugerem maior estabilidade ambiental para essa região marinha da margem sul brasileira nesse período, o que estaria em concordância com a maior estabilização climática no hemisfério sul e na Antártica (Fig. 41).

Já há 9.400 anos cal A.P., Sallun et al. (2012) descreveram a presença de ambiente lagunar na área do MJI. Dillenburg e Hesp (2009) indicaram que já entre 11.280 e 10.510 anos cal A.P., a laguna da região de Tramandaí no rio Grande do Sul já recebia importante contribuição marinha. Segundo Dominguez (2011), há 9.400 anos cal A.P. a plataforma leste brasileira já havia começado a ser inundada.

Segundo Suguio e Martin (1978a), a erosão dos sedimentos previamente depositados na área do MJI rebaixou essa região e, então, durante o quinto estágio evolutivo do MJI, a transgressão marinha holocênica permitiu que águas marinhas adentrassem essas áreas, até atingir, em muitos pontos, o sopé da Serra do Mar.

Entre 9.400 e 8.385 anos cal A.P., as associações de foraminíferos bentônicos presentes no testemunho S03 demonstraram que na região de planície costeira do MJI existia ambiente lagunar raso, mixohalino, que sofreu influência de águas continentais e marinhas (Figs. 22, 24, 25 e 27). Esse intervalo temporal equivale ao estágio evolucionário 1 encontrado na região de Tramandaí, na área costeira do Rio Grande do Sul, por Dillenburg e Hesp (2009). Segundo esses autores, nessa região havia ambiente lagunar já por volta de 10.895 anos cal A.P., que perdurou até 7.355 anos cal A.P.

Apesar da diferença de escalas temporais, algumas das modificações paleoclimáticas encontradas por meio das associações de foraminíferos bentônicos do testemunho S03 foram 
concomitantes a mudanças das temperaturas e salinidades superficiais encontradas na margem sul brasileira (Fig. 42).

Em épocas em que a contribuição marinha foi mais importante para a paleolaguna do MJI, suplantando a contribuição continental para essa região (Item 8.1 da Discussão), as paleotemperaturas e paleossalinidades superficiais da margem sul brasileira aumentaram (Fig. 42). Já em épocas nas quais houve maior contribuição continental para a paleolaguna do MJI (Item 8.1 da Discussão), as paleotemperaturas e paleossalinidades superficiais da margem sul brasileira diminuíram (Fig. 42).

Propõe-se que, durante o Holoceno, essas mudanças paleoambientais na região do MJI e da margem sul brasileira se correlacionaram principalmente ao comportamento de transgressão marinha e ao clima sobre o continente sul americano (Itens 8.1 e 8.3 da Discussão). Em épocas de menor pluviosidade sobre as regiões sudeste e sul brasileiras, o mar teve maior influência na paleolaguna do MJI por ter maior vigor e, assim, conseguir atingir regiões continentais mais interiores. Ao mesmo tempo, a menor pluviosidade continental sobre essas regiões causava redução da influência de águas continentais, especialmente aquelas carreadas pela PPW, na região de coleta do testemunho GeoB6211-2, na margem sul brasileira. Assim, as paleotemperaturas e paleossalinidades superficiais dessa região marinha ficavam mais elevadas.

Já em épocas de maior pluviosidade sobre as regiões sudeste e sul brasileiras, a capacidade dos rios que cortavam o MJI nessa época se ampliava, o que gerava maior contribuição continental à paleolaguna e impedia a afluência mais robusta de águas marinhas nessa região. Ao mesmo tempo, essa maior pluviosidade aumentava, também, a capacidade dos rios que desaguam no Oceano Atlântico nas margens sudeste e sul brasileiras, bem como aumentava a descarga do Rio de La Plata, o que gerava maior força da PPW, que então chegava à região de coleta do testemunho GeoB6211-2 com maior vigor, causando redução das paleotemperaturas e paleossalinidades superficiais dessa região marinha.

Durante esse período, a influência das modificações na intensidade da CB se tornaram fatores secundários no controle tanto da subida do nível relativo do mar na região do MJI, quanto no controle das paleotemperaturas e paleossalinidades da margem sul brasileira. Isso devido à maior estabilidade da AMOC, especialmente a partir do Holoceno Médio (e.g., Keigwin e Boyle, 2000; Schulz et al., 2007; Thornalley et al., 2009).

Entre 8.600 e 8.500 anos cal A.P., mudanças significativas parecem ter ocorrido tanto na região do MJI quanto na margem sul brasileira (Figs. 22, 23, 24, 25, 27, 41 e 42). 
Durante essa mesma fase, a partir de 8.600 anos cal A.P., uma melhora climática foi detectada por Cremer et al. (2007) na costa leste antártica, e Ljung e Björck (2007) indicaram aumento da umidade na Ilha de Nightingale (Arquipélago de Tristão da Cunha), no Atlântico Sul, e supuseram que esta variação climática estaria vinculada ao reposicionamento mais para norte dos Ventos de Oeste. Também há 8.500 anos cal A.P. outras modificações sedimentares ocorreram na costa sudeste brasileira (Rohling e Pälike, 2005). Razik et al. (no prelo) também encontraram modificações bastante acentuadas nos parâmetros abióticos do testemunho GeoB6211-2 nessa mesma época, entre 8.500 e 8.400 anos cal A.P., que atribuíram ao fortalecimento e deslocamento para norte dos Ventos de Oeste do hemisfério sul, da Frente Subtropical e da Zona de Confluência Brasil-Malvinas.

Supõe-se que o deslocamento para norte dos Ventos de Oeste e da Zona de Confluência Brasil-Malvinas tenham provocado mudanças climáticas sobre o continente sulamericano e no Atlântico subtropical sudoeste, diminuindo as chuvas nas regiões sudeste e sul brasileiras, de forma que a contribuição marinha se ampliou na região do MJI (Fig. 24) e a contribuição da PPW, bem como de outras fontes de águas continentais, ao sítio de estudos na margem sul brasileira, diminuíram, o que elevou as $\mathrm{Mg} / \mathrm{Ca} \mathrm{SST}$ e as SSS das águas atlânticas dessa região até aproximadamente 8.500 anos cal A.P. (Fig. 42).

Após aproximadamente 8.500 anos cal A.P., a transição entre o Holoceno Inferior e o Holoceno Médio foi marcada por variações paleoclimáticas rápidas e significantes nas regiões sul e sudeste brasileiras (Itens 8.1 e 8.3 da Discussão; figs. 21, 41 e 42). Essas variações de temperaturas e salinidades superficiais na margem sul brasileira provavelmente se vincularam às mudanças atmosféricas e de temperatura da Antártica e na América do Sul (Masson et al., 2000; Cremer et al., 2007; Cheng et al., 2009).

A transgressão marinha na costa do Rio Grande do Sul se tornou mais rápida $(\sim 1,9$ $\mathrm{cm} / \mathrm{yr}$ entre 8.000 e 6.500 anos cal A.P.) (Dillenburg e Hesp, 2009). O paleonível relativo do mar havia ultrapassado o nível atual entre 7.700 e 6.900 anos cal A.P. (Angulo et al., 2006). Razik et al. (no prelo) encontraram maior contribuição da PPW ao CRG no Holoceno Tardio, e a atribuíram à intensificação do sistema de Monção da América do Sul sobre o SE da América do Sul, e ao aumento da força do fenômeno ENOS, bem como à mais alta insolação de verão austral típica do Holoceno Tardio.

Segundo Suguio e Martin (1978a), após o máximo transgressivo da Transgressão Santos, que ocorreu por volta de $5.150{ }^{14} \mathrm{C}$ anos A.P. (entre 5.912 e 5.750 anos cal A.P.) na região do MJI, o comportamento regressivo do paleonível marinho formou uma ilha-barreira 
que passou a impedir a intrusão marinha na região do MJI, até que se atingisse a configuração atual.

Ao mesmo tempo, na costa sul brasileira, se formou o Sistema de Sistema de IlhasBarreira/Lagunas IV, (Tomazelli et al., 2000) fazendo com que a região costeira do Rio Grande do Sul tomasse a configuração atual, o que diminuiu ainda mais o aporte sedimentar à região do Cone do Rio Grande. 


\section{CAPÍTULO 9: Conclusões}

As associações de foraminíferos bentônicos do testemunho S03 permitiram reconhecer oito diferentes fases de mudanças paleoambientais distribuídas entre 9.400 e 8.385 anos cal A.P. para o ambiente lagunar raso mixohalino que existia no MJI, no local de coleta do testemunho S03, que hoje compreende as terras baixas entre os rios Comprido e Cacunduva, situada a cerca de $8 \mathrm{~km}$ da linha de costa adjacente no sudeste brasileiro.

De acordo com essas associações, houve quatro épocas de influência oceânica mais conspícua na paleolaguna mixohalina da baixada litorânea do MJI (9.400 a 9.338; 9.072 a 8.894; 8.656 a 8.641 e 8.594 a 8.500 anos cal A.P.), com clímax há 8.656 anos cal A.P., que apresentaram melhores condições para a existência e/ou preservação de foraminíferos bentônicos. Elas foram intercaladas a duas fases de influência continental mais acentuada (9.338 a 9.072 e 8.500 a 8.385 anos cal A.P.), de maior hidrodinamismo do meio. Houve, ainda, períodos em que os foraminíferos bentônicos estiveram ausentes (8.806 a 8.672 e 8.625 a 8.594 anos cal A.P.), provavelmente devido a uma contribuição continental ainda mais acentuada para essa paleolaguna.

A análise dos dados microfaunísticos e sua comparação com os dados abióticos do testemunho S03 permitiram que se supusesse que essas diferentes épocas paleoambientais teriam como principais fatores responsáveis o regime pluviométrico dessa região continental, bem como o comportamento marinho na costa sudeste brasileira durante essa época da Transgressão Santos.

Por sua vez, as associações de foraminíferos totais (bentônicos + planctônicos) do testemunho GeoB6211-2 tiveram comportamento que demonstrou a transgressão marinha na região do Cone do Rio Grande entre 19.000 anos cal A.P. e o Presente. Elas indicaram que no início da Última Deglaciação o testemunho GeoB6211-2 se encontrava sob coluna de água mais rasa, com predominância de formas bentônicas. No final desse período paleoclimático e durante o Holoceno, houve predominância cada vez maior de formas planctônicas, demonstrando que a coluna de água do local de coleta do testemunho GeoB6211-2 se tornou cada vez maior até 7.600 anos cal A.P. e que, a partir de então, se manteve estável.

Já as associações de foraminíferos bentônicos encontradas no testemunho GeoB62112 entre 19.000 e 14.000 anos cal A.P. permitiram diferenciar cinco fases paleoambientais distintas para a região do Cone do Rio Grande durante a Última Deglaciação. Essas fases foram concomitantes e relacionadas às mudanças paleoclimáticas que ocorreram durante o HS1 e na transição entre este período paleoclimático e o ACR. 
A primeira fase (19.000 a 18.620 anos cal A.P.) se caracterizou por ambiente de fundo redutor e maior contribuição continental no Cone do Rio Grande. Na segunda fase (18.620 a 17.016 anos cal A.P.), houve maior oxigenação do meio. Na terceira (17.016 a 16.095 anos cal A.P.), houve aumento do hidrodinamismo e da temperatura no ambiente de fundo do Cone do Rio Grande. A quarta fase (16.095 a 14.682 anos cal A.P.), apresentou mudanças paleoambientais mais acentuadas e caracterizou a transição entre o HS1 e o ACR. A quinta e última fase (14.682 a 14.050 anos cal A.P.) mostrou ambiente de fundo mais frio, menos oxigenado e com hidrodinamismo reduzido no Cone do Rio Grande.

As respostas das associações de foraminíferos bentônicos, quando comparadas aos dados abióticos desse mesmo testemunho e a outros dados paleoclimáticos existentes na literatura, permitiram que se supusesse que durante esse período da Última Deglaciação os principais fatores paleoclimáticos responsáveis pelas mudanças paleoambientais dos sedimentos do Cone do Rio Grande foram as variações na intensidade da AMOC e as modificações oceanográfico-atmosférico-climáticas correlatas.

As variações do grau de oxigenação do meio, fator paleoambiental que conforme os dados microfaunísticos apresentou variações significativas, se deram em decorrência das mudanças do hidrodinamismo na região de fundo no Cone do Rio Grande. Essas mudanças do hidrodinamismo podem ter sido devidas tanto a uma aceleração e maior ventilação da Água Central do Atlântico Sul, como a trocas da massa de água que banhou essa região entre 19.000 e 14.000 anos cal A.P., entre a Água Central do Atlântico Sul e a Água Intermediária Antártica.

Entretanto, como as associações de foraminíferos bentônicos costumam reagir de forma secundária às diferenças das propriedades físico-químicas e isotópicas das massas de água oceânicas, acredita-se que mensurações diretas dessas propriedades sejam necessárias para a comprovação da maior pertinência das duas hipóteses acima apresentadas.

Quanto à análise dos valores de $\mathrm{Mg} / \mathrm{Ca} \mathrm{SST}$ e de $\delta^{18} \mathrm{O}_{\text {ivc-sw }}$ no testemunho composto GeoB6211CC, pôde-se concluir que as temperaturas superficiais baseadas em $\mathrm{Mg} / \mathrm{Ca}$ de testas da espécie planctônica rasa Globigerinoides ruber (white, s.s.) demonstraram padrão geral de aumento entre 19.000 anos cal A.P. e o Presente, enquanto os valores de $\delta^{18} \mathrm{O}_{\text {ivc-sw, }}$, índices da salinidade superficial oceânica local, só apresentaram padrão geral, de diminuição, entre $\sim 8.500$ anos cal A.P. e o Presente.

As variações secundárias dessas paleotemperaturas e paleossalinidades marinhas superficiais tiveram como principais fatores paleoclimáticos controladores as variações da 
AMOC e dos elementos oceanográfico-atmosférico-climáticos a ela correlatos durante a Última Deglaciação.

As variações dessas paleossalinidades e paleotemperaturas marinhas superficiais foram síncronas, consideradas as diferenças de amostragem, às alterações paleoambientais dos sedimentos do Cone do Rio Grande entre 19.000 e 14.000 anos cal A.P., o que permitiu que se supusesse que as alterações da AMOC e dos fatores oceanográfico-atmosféricoclimáticos correlatos atingiram a Corrente do Brasil como um todo, ao menos até a profundidade da Água Intermediária Antártica, durante essa fase paleoclimática.

Já entre 9.400 e 8.385 anos cal A.P., no final do Holoceno Inferior, as paleotemperaturas e paleossalinidades marinhas superficiais foram síncronas, consideradas as diferenças de amostragem e dos modelos cronológicos, às mudanças paleoambientais que se deram na baixada litorânea do MJI.

Para este período paleoclimático e durante todo o Holoceno, fatores paleoambientais tais como o clima na região antártica, o aumento da temperatura global, a pluviosidade continental, a circulação atmosférica que afeta essa pluviosidade, e as oscilações secundárias do paleonível marinho durante a Transgressão Santos se tornaram os principais fatores controladores das variações paleoambientais das regiões sudeste e sul brasileiras. 


\section{Referências Bibliográficas}

Ahn, J.; Wahlen, M.; Deck, B. L.; Brook E.J.; Mayewski, P. A.; Taylor, K. C.; White, J. W. C. 2004. A record of atmospheric $\mathrm{CO}_{2}$ during the last 40,000 years from the Slipe Dome, Antarctica ice core. Journal of Geophysical Research, 109: D13305.

Alexandersson, E. T. 1979. Marine maceration of skeletal carbonates in Skagerrak, North Sea. Sedimentology, 26: 845-852.

Alley, B. e Ágústsdóttir, A. M. 2005. The 8k event: cause and consequences of a major Holocene abrupt climate change. Quaternary Science Reviews, 24: 1123-1149.

Almeida, F. F. M.; Hasui, Y.; Brito Neves, B. B.; Fuck, R. A. 1981. Brazilian structural provinces: an introduction. Earth Science Reviews, 17: 1-29.

Alve, E. 1999. Colonization of new habitats by benthic foraminifera: a review. Earth-Sciences Reviews, 46: 167-185.

Alve, E. e Bernhard, M. 1995. Vertical migratory response of benthic foraminifera to controlled oxygen concentrations in an experimental mesocosm. Marine Ecology Progress Series, 116: 137-151.

Alves, E. C. 1977. Estrutura rasa do talude e sopé da Margem Continental do Rio Grande do Sul e Uruguai. Tese de Mestrado. Instituto de Geociências, Universidade Federal do Rio Grande do Sul, Porto Alegre, RS. 77p.

Anand, P.; Elderfield, H.; Conte, M. C. 2003. Calibration of $\mathrm{Mg} / \mathrm{Ca}$ thermometry in planktonic foraminifera from a sediment trap time series. Paleoceanography, 18(2):1050. doi: 10.1029/2002PA000846.

Anderson, R. F.; Ali, S.; Bradtmiller, L. I.; Nielsen, S. H. H.; Fleisher, M. Q.; Anderson, B. E.; Burckle, L. H. 2009. Wind-Driven Upwelling in the Southern Ocean and the Deglacial Risein Atmospheric $\mathrm{CO}_{2}$. Science, 323: 1443-1448.

Angulo, R. J. e Suguio, K. 1995. Re-evaluation of the Holocene sea-level máxima for the state of Paraná, Brazil. Palaeogeography, Palaeoclimatology, Palaeoecology, 113: 385 393.

Angulo, R. J.; Lessa, G. C.; Souza, M. C. de. 2006. A critical review of mid- to late-Holocene sea-level fluctuations on the eastern Brazilian coastline. Quaternary Science Reviews, 25: 486-506.

Angulo, R. J.; Giannini, P. C. F.; Suguio, K.; Pessenda, L. C. R. 1999. Relative sea-level changes in the last 5500 years in southern Brazil (Laguna-Imbituba region, Santa Catarina State) based on vermetid 14C ages. Marine Geology, 159: 323-339. 
Araújo, M. F.; Jouanneau, J-M.; Valério, P.; Barbosa, T.; Gouveia, A.; Weber, O.; Oliveira, A.; Rodrigues, A.; Dias, J. M. A. 2002. Geochemical tracers of northern Portuguese estuarine sediments on the shelf. Progress in Oceanography, 52(2-4): 277-297.

Arz, H. W.; Pätzold, J.; Wefer, G. 1999. The deglacial history of the western tropical Atlantic as inferred from high resolution stable isotope records of northeastern Brazil. Earth and Planetary science Letters, 167: 105-117.

Baas, J. H.; Schönfeld, J.; Zahn, R. 1998. Mid-depth oxygen drawdown during Heinrich events: evidence from benthic foraminiferal community structure, trace-fossil tiering, and benthic $\delta 13 \mathrm{C}$ at the Portuguese Margin. Marine Geology, 152: 25-55.

Badawi, A.; Schmiedl, G.; Hemleben, C. 2005. Impact of late Quaternary environmental changes on deep-sea benthic foraminiferal faunas of the Red Sea. Marine Micropaleontology, 58: 13-30.

Ballantyne, A. P.; Lavine, M.; Crowley, T. J.; Liu, J.; Baker, P. B. 2005. Metanalysis of tropical surface temperatures during the Last Glacial Maximum. Geophysical Research Letters, 32(5): doi: 10.1029/2004GL021217.

Bandi, O. I. 1953. Ecology and paleoecology of some California foraminifera. Part I. The frequency distribution of recent foraminifera off California. Journal of Paleontology, 27(2): pt. 1, 161-182; pt. 2, 21-25.

Bard, E.; Rostek, F.; Turon, J-L.; Gendreau, S. 2000. Hydrological impact of Heinrich Events in the subtropical northeast atlantic. Science, 289: 1321-1324.

Barker, S.; Diz, P.; Vautravers, M. J.; Pike, J.; Knorr, G.; Hall, I. R.; Broecker, W. S. 2009. Interhemispheric atlantic seesaw response during the last deglaciation. Nature, 457: 1097-1103.

Barker, S.; Greaves, M.; Elderfield, H. 2003. A study of cleaning procedures used for foraminiferal $\mathrm{Mg} / \mathrm{Ca}$ paleothermometry. Geochemistry, Geophysics, Geosystems, 4(9): 8407, doi:10.1029/2003GC000559.

Barron, J. A. e Anderson, L. 2011. Enhanced Late Holocene ENSO/PDO expression along the margins of the eastern North Pacific. Quaternary International, 235: 3-12.

Barros, V.; Clarke, R.; Días, P. S. (eds.). 2006. Climate Change in the La Plata Basin. CIMA - Centro de investigaciones del mar e la atmósfera. Univerisdade de Buenos Aires, Aregentina. 219p. 
Basak, C.; Rathburn, A. E.; Pérez, M. E.; Martin, J. B.; Kluesner, J. W.; Levin, L. A.; Deckker, P. D.; Gieskes, J. M.; Abrini, M. 2009. Carbon and oxygen isotope geochemistry of live (stained) benthic foraminifera from the Aleutian Margin and the Southern Australian Margin. Marine Micropaleontology, 70: 89-101.

Behling, H.; Dipond, L.; Safford, H. D.; Wefer, G. 2007. Late Quaternary vegetation and climate dynamics in the Serra da Bocaina, southeastern Brazil. Quaternary International, 161: $22-31$.

Behling, H.; Pillar, V. D.; Orlóci, L.; Bauermann, S. G. 2004. Late Quaternary Araucaria forest grassland (Campos), fire and climate dynamics, studied by high-resolution pollen, charcoal and multi variate analysis of the Cambará do Sul core in southern Brazil. Palaeogeography, Palaeoclimatology, Palaeoecology, 203: 277-297.

Berbery, E. H. e Barros, V. R. 2002. The hidrologic cycle of the La Plata basin in South America. Journal of Hydrometeorology, 3: 630-645.

Bergamin, L.; Romano, E.; Finoia, M. G.; Venti, F.; Bianchi, J.; Colasanti, A.; Ausili, A. 2009. Benthic foraminífera from the coastal zone of Baia (Naples, Italy): assemblage distribution and modification as tools for environmental characterization. Marine Pollution Bulletin, 59: 234-244.

Bergamin, L.; Romano, E.; Gabellini, M.; Ausili, A.; Carboni, M. G. 2003. Chemical-physical and ecological characterization in the environmental projeto f a polluted coastal área: the Bagnoli case study. Mediterranean Marine Science, 4/2: 5-20.

Berger, W. 1979. Preservation of foraminifera. American Association of Petroleum Geologist, SEMP Short Course, 6: 105-155.

Berkeley, A.; Perry, C. T.; Smithers, S. G. 2009. Taphonomic signatures and patterns of test degradation on tropical, interdital benthic foraminifera. Marine Micropaleontology, 73: 148-163.

Berkeley, A.; Perry, C. T.; Smithers, S. G.; Horton, B. P.; Taylor, K. G. 2007. A review of the ecological and taphonomic controls on foraminiferal assemblage development in intertidal environments. Earth-Science Reviews, 83: 205-230.

Berner, R. A. 1970. Sedimentary Pyrite Formation. American Journal of Science, 268: 1-23.

Bernhard, J. M. e Sen Gupta, B. K. 1999. Foraminifera of oxygen depleted environments. In:

Sen Gupta, B.K. (ed.), Modern Foraminifera. Kluwer Academic Publishers, Norwell, Massachusetts, EUA. pp. 201-216.

Bigarella, J. J. e Mousinho, R. 1965. Contribuição ao estudo da Formação Pariqüera-Açu (Estado de São Paulo). Boletim Paranaense de Geografia, 16/17: 17-41. 
Bittencourt, A. C. S. P.; Martin, L.; Dominguez, J. M. L.; Vilas-Boas, G. S. 1979. Quaternary marine formations of the coasts of the state of Bahia, Brazil. Proceedings of International Symposium on Coastal Evolution in the Quaternary. São Paulo, SP, USP, 232-253.

Blunier, T. e Brook, E. J. 2001. Timing of millenial-scale climate change in Antarctica and Greenland during the Last Glacial Period. Science, 291: 109-112.

Blunier, T.; Schwander, J.; Stauffer, B.; Stocker, T.; Dällenbach, A.; Indermühle, A.; Tschumi, J. 1997. Timing of the Antacrtic Cold Reversal and the atmospheric $\mathrm{CO}_{2}$ increase with respect to the Younger Dryas event. Geophysical Research Letters, 24(21): $2683-2686$.

Boersma, A. 1998. Chapter 2: Foraminifera. In: Haq, B.U.; Boersma, A. (eds.). Introduction to Marine Micropaleontology. Elsevier, New York, pp. 19-78.

Boltovskoy, E. 1959. Foraminifera as Biological Indicators in the Study of Ocean Currents. Micropaleontology, 5(4): 473-481.

Boltovskoy, E. e Wright, R. 1976. Recent Foraminifera. Dr. W. Junk bv Publishers, The Hague, Netherlands. 515p.

Boltovskoy, E. e Lena, H. 1971. The foraminífera (except Family Allogromiidae) which dwell in fresh water. Journal of Foraminiferal Research, 1(2): 71-76.

Boltovskoy, E.; Boltovskoy, D.; Correa, N.; Brandini, F. 1996. Planktic foraminífera from the southwestern Atlantic $\left(30^{\circ}-60^{\circ} \mathrm{S}\right)$ : species-specific patterns in the upper $50 \mathrm{~m}$. Marine Micropaleontology, 28: 53-72.

Boltovskoy, E.; Scott, D. B.; Medioli, F. S. 1991. Morphological variations of benthic foraminiferal tests in response to changes in ecological parameters: a review. Journal of Paleontology, 65(2): 175-185.

Boltovskoy, E.; Giussani, G.; Watanabe, S; Wright, R. 1980. Atlas of Benthic Shelf Foraminifera of the Southwest Atlantic. DR. W. Junk bv Publishers, The Hague, BostonLondon. $147 \mathrm{p}$.

Bond, G.; Heinrich, H.; Broecker, W.; Labeyrie, L.; McManus, J.; Andrews, J.; Huon, S.; Jantschik, R.; Clasen, S.; Simet, C.; Tedesco, K.; Klas, M.; Bonani, G.; Ivy, S. 1992. Evidence for massive discharges of icebergs into the North Atlantic ocean during the last glacial period. Letters to Nature, 360: 245-249.

Boyle, E. A. e Keigwin, L. 1997. North Atlantic thermohaline circulation during the past 20,000 years linked to high-latitude surface temperature. Nature, 330: 35-40.

Bradshaw, J. S. 1961. Laboratory experiments on the ecology of foraminifera. Cushman Foundation of Foraminiferal Research, 12: 87-106. 
Brett, C. E. e Baird, G. C. 1986. Comparative taphonomy: a key to paleoenvironment interpretation based on fossil preservation. Palaios, 1: 207-227.

Brönnimann, P. 1988. Two new recent Allogromiine and Textulariine genera (Protozoa: Foraminiferida) from the Brazilian shelf. Revue de Paléobiologie, 7(1): 33-42.

Buzas, M. A. 1968. On the spatial distribution of Foraminifera. Contribution to Cushman Foundation Foraminiferal Research, 19: 1-11.

Caldas, L. H. O.; Stattegger, K.; Vital, H. 2006. Holocene sea-level history: Evidence from coastal sediments of the northern Rio Grande do Norte coast, NE Brazil. Marine Geology, 228: 39-53.

Came, R. E.; Oppo, D. W.; Curry, W. B. 2003. Atlantic Ocean circulation during the Younger Dryas: Insights from a new $\mathrm{Cd} / \mathrm{Ca}$ record from the western subtropical South Atlantic. Paleoceanography, 18(4): 1086, doi:10.1029/2003PA000888.

Campos, E.; Garcia, C.; Tanajura, C. A. S.; Lorenzetti, J. A.; Sifeddine, A.; Camargo, R.; Goni, G.; Melo, E.; Polito, P.; Siegle, E. 2012. Observações costeiras e oceânicas. In: Base Científica das Mudanças Climáticas, Volume 1. Primeiro Relatório de Avaliação Nacional. PBCM: Painel Brasileiro de Mudanças Climáticas, pp. 95-155.

Campos Neto, M. C. 1991. A porção ocidental da Faixa Alto Rio Grande: Ensaio de Evolução Tectônica. Tese de Doutorado. Instituto de Geociências, Universidade de São Paulo, São Paulo, São Paulo. 210 p.

Caralp, M. H. 1989. Abundance of Bulimina exilis and Melonis barleeanum: relationship to the quality of marine organic matter. Geo-Marine Letters, 9: 37-43.

Cardoso, M. N. e Senra, M. C. E. 2007. Tafonomia de foraminíferos bentônicos em sedimentos siliciclásticos e carbonáticos. Anuário do Instituto de Geociências da Universidade Federal do Rio de Janeiro, 30(1): 101-108.

Carlson, A. E.; Oppo, D. W.; Came, R. E.; LeGrande, A. N.; Keigwin, L. D.; Curry, W. B. 2008. Subtropical Atlantic salinity variability and Atlantic meridional circulation during the last deglaciation. Geology, 36 (12): 991-994.

Carvalho, L. M. V.; Jones, C.; Liebmann, B. 2004. The South Atlantic Convergence Zone: Intensity, Form, Persistence, and Relationships with Intraseasonal to Interannual Activity and Extreme Rainfall. Journal of Climate, 17: 88-108.

Cassel, D. T. e Sen Gupta, B. K. 1989. Foraminiferal stratigraphy and paleoenvironments of the tertiary Uscari Formation, Lomon Basin, Costa Rica. Journal of Foraminiferal Research, 19(1): 52-71. 
Castilho, L. L. A.; Kazmierczak, T. S.; Chemale Jr., F. 2009. Rio Grande Cone tectonostratigraphic model - Brazil: Seismic sequences. Earth Sciences Research Journal, 13: 40-53.

Castro, B. M.; Lorenzzetti, J. A.; da Silveira, I. C. A.; Miranda, L. B. 2006. Estrutura termohalina e circulação na região entre Cabo de São Tomé (RJ) e o Chuí (RS). In: Rossi-Wongtschowski, C.L.D.B \& Madureira, L.S.P. (Eds.). O ambiente oceanográfico da plataforma continental e do talude na região sudeste-sul do Brasil. EDUSP, São Paulo, São Paulo. pp. 11-120.

Castro Filho, B. M.; Miranda, L. B.; Miyao, S. Y. 1987. Condições hidrográficas na Plataforma Continental ao largo de Ubatuba: variações sazonais em média escala. Boletim do Instituto Oceanográfico, 35(2): 135-151.

Cheng, H.; Flitmann, D.; Edwards, R. L.; Wang, X.; Cruz, F. W.; Auler, A. S.; Mangini, A.; Wang, Y.; Kong, X.; Burns, S. J.; Matter, A. 2009. Timing and structure of the $8.2 \mathrm{ky}$ event inferred from $\delta^{18} \mathrm{O}$ records of stalagmites from China, Oman and Brazil. Geology, 37(11): $1007-1010$.

Chiessi, C. M. 2008. Ocean circulation and climate variability in the western South Atlantic and eastern South America during the last deglaciation. Tese de Doutorado. Universidade de Bremen, Bremen, Alemanha. 98p.

Chiessi, C. M.; Mulitza, S.; Pätzold, J.; Wefer, G.; Marengo, A. 2009. Possible impact of the Atlantic Multidecadal Oscillation in the South American summer monsoon. Geophysical Research Letters, 36: L21707.

Chiessi, C. M.; Mulitza, S.; Paul, A.; Pätzold, J.; Groeneveld, J.; Wefer, G. 2008. South Atlantic interocean exchange as the trigger for the Bølling warm event. Geology, 36: 919922.

Cléroux, C.; Cortijo, N.; Anand, P.; labeyrie, L.; Bassinot, F.; Caillon, E.; Duplessy, J-C. 2008. $\mathrm{Mg} / \mathrm{Ca}$ and $\mathrm{Sr} / \mathrm{Ca}$ ratios in planktonic foraminifera: Proxies for upper water column temperature reconstruction. Paleoceanography, 23: PA3214, doi:10.1029/2007PA001505.

Coelho, C. A. S.; Uvo, C. B.; Ambrizzi, T. 2002. Exploring the impacts of the tropical Pacific SST on the precipitation patterns over South America during ENSO periods. Theoretical and Applied Climatology, 71: 185-197.

Companhia de Pesquisa de Recursos Minerais. 2006. Mapa Geológico do Estado do Rio Grande do Sul. Escala 1: 750.000. Disponível em: http://www.cprm.gov.br/publique /media/mapa_rio_grande_sul.pdf. Acesso em: 20 de outubro de 2012. 
Conkright, M. E.; Locarnini, R. A.; Garcia, H. E.; O’Brien, T. D.; Boyer, T. P.; Stephens, C.; Antonov, J. I. 2002. World Ocean Atlas 2001: Objective Analyses, Data Statistics, and Figures, CD-ROM Documentation. National Oceanographic Data Center, Silver Spring, $\mathrm{MD}, 17 \mathrm{p}$.

Cordeiro, R.; Turcq, B.; Suguio, K.; Oliveira da Silva, A.; Sifeddine, A.; Volkmer Ribeiro, C., 2008. Holocene fires in east Amazonia (Carajás), new evidences, chronology and relation with paleoclimate. Global and Planetary Change, 61: 49-62.

Corliss, B. H. 1991. Morphology and microhabitat preferences of benthic foraminifera from the Northwest Atlantic Ocean. Marine Micropaleontology, 17: 195-236.

Corliss, B. H. 1985. Microhabitats of benthic foraminifera within deep-sea sediments. Letters to Nature, 31: 435-438.

Corrêa, L. C. S. 1996. Les variations du niveau de la mer durant lês derniers 17.500 ans B.P.: L'exemple de la plate-forme continentale du Rio Grande do Sul, Brésil. Marine Geology, 130: $163-178$.

Coutinho, P. N. (Coord). 1996. Levantamento do estado da arte da pesquisa dos recursos vivos marinhos do Brasil - Oceanografia Geológica. Programa REVIZEE, FEMAR/SECIRM, 75p.

Cremer, H.; Heiri, O.; Wagner, B.; Wagner-Cremer, F. 2007. Abrupt climate warming in East Antarctica during the early Holocene. Quaternary Science Reviews, 26: 2012-2018.

Cruz Jr., F. W.; Burns, S. J.; Karmann, I.; Sharp, W. D.; Vuille, M. 2006. Reconstruction of regional atmospheric circulation features during the late Pleistocene in subtropical Brazil from oxygen isotope composition of speleothems. Earth and Planetary Science Letters, 248: $495-507$.

Culver, S. J. 1988. New foraminiferal depth zonation of the northwestern Gulf of Mexico. Palaios, (3): 69-85.

Dansgaard, W.; White, J. W. C.; Johnson, S. J. 1989. The abrupt termination of the Younger Dryas climate event. Nature, 339: 532-533.

Davies, D. J.; Powell, E. N.; Stanton, R. J. 1989. Taphonomic signature as a function of environmental process: shell and shell beds in a huricane-influenced inlet in Texas coast. Palaeogeography, Palaeoclimatology, Palaeoecology, 72: 317-356.

De, S. e Gupta, A. K. 2010. Deep-sea faunal provinces and their inferred environments in the Indian Ocean based on distribution of Recent benthic foraminifera. Palaeogeography, Palaeoclimatology, Palaeoecology, 291(3,4): 429-442. 
De Oliveira, P. E. 1992. A palynological record of Late Quaternary vegetational and climatic change in Southeastern Brazil. Tese de Doutorado, Ohio State University, Ohio, EUA. $238 p$.

De Rijk, S.; Jorissen, F. J.; Rohling, E.; Troelstra, S. R. 2000. Organic flux control on bathymetric zonation of Mediterranean benthic foraminifera. Marine Micropaleontology, 40: $151-166$.

Debenay, J. P.; Tsakiridis, E.; Soulard, R.; Grossel, H. 2001. Factors determining the distribuition of foraminiferal assemblages in Port Joinville Harbor (Ille d'Yeu, France): the influence of pollution. Marine Micropaleontology, 43: 75-118.

Debenay, J-P.; Eichler, B. B.; Guillou, J. J.; Eichler-Coelho, P.; Coelho, C., and Porto-Filho, E. 1996. Comportment dês peuplements de foraminifers et comparision avec l'avifaune dans une lagune fortment stratifiée: La Lagoa da Conceição (SC, Brésil). Revue de Paléobiologie, 16: 55-75.

Delworth, T. L. e Mann, M. E. 2000. Observed and simulated multidecadal variability in the Northern Hemisphere. Climate Dynamics, 16: 661-676.

Delworth, T. L.; Clark, P. U.; Holland, M.; Johns, W. E.; Kuhlbrodt, T.; Lynch-Stieglitz, J.; Morrill, C.; Seager, R.; Weaver, A. J.; Zhang, R. 2008: The potential for abrupt change in the Atlantic Meridional Overturning Circulation. In: McGeehin, J. P.; Watson, J. M.; Hedrick, K. E. (eds.). Abrupt Climate Change. A report by the U.S. Climate Change Science Program and the Subcommittee on Global Change Research. U.S. Geological Survey, Reston, VA, pp. 117-162.

Den Dulk, M.; Reichart, G. J.; van Heyst, S.; Zachariasse, W. J.; Van der Zwaan, G. J. 2000. Benthic foraminifera as proxies of organic matter flux and bottom water oxygenation? A case history from the northern Arabian Sea. Palaeogeography, Palaeoclimatology, Palaeoecology, 161: 337-359.

Dhahri, N. 2010. Natural variability of pelagic and benthic conditions in the Gulf of St. Lawrence during the Late Holocene. Dissertação de Mestrado. Université du Québec à Montréal, Montreal, Canadá. 84p.

Dias, G. T. M. 1996. Classificação de sedimentos marinhos: proposta de representação em cartas sedimentológicas. Anais do XXXIX Congresso Brasileiro de Geologia, 3:423-426.

Dillenburg, S. R. e Hesp, P. A. 2009. Geology and Geomorphology of Holocene Coastal Barriers of Brazil. Springer, Heidelberg, Alemanha, 390p.

Diz, P. e Francés, G. 2008. Distribution of live benthic foraminifera in the Ría de Vigo (NW Spain). Marine Micropaleontology, 66: 165-191. 
Dominguez, J. M. L. 2011. A evolução pós-barreiras da costa leste do Brasil. In: XIII Congresso da Associação Brasileira de Estudos do Quaternário ABEQUA XIII ABEQUA Congress - The South American Quaternary: Challenges and Perspectives / III Encontro do Quaternário Sulamericano. Armação de Búzios, RJ, Brasil.

Dominguez, J. M. L.; Bittencourt, A. C. S. P.; Leão, Z. M. A. N.; Azevedo, A. E. G. 1990. Geologia do Quaternário costeiro do estado de Pernambuco. Revista Brasileira de Geociências, 20: 208-215.

Donners, J.; Drijfhout, S. S.; Hazeleger, W. 2005. Water Mass Transformation and Subduction in the South Atlantic. Journal of Physical Oceanography, 35: 1841-1860.

Drinia, H.; Tsaparas, N.; Antonarakou, A.; Goumas, G. 2003. Benthic foraminiferal biofácies associated with middle to early Late Miocene oxygen deficient conditions in eastern Mediterranean. Proceedings of $8^{\text {th }}$ International Conference on Environemntal Science and Tecnology, Lemnos island, Greece. pp. 191-198.

Duleba, W. 1994. Interpretações paleoambientais obtidas a partir das variações na coloração das carapaças de foraminíferos da Enseada do Flamengo, SP. Boletim do Instituto Oceanográfico, 42(1/2): 63-72.

Duleba, W. e Debenay, J-P., 2003. Hydrodynamic circulation in the estuaries of Estação Ecológica Juréia-Itatins, Brazil, inferred from foraminifera and thecamoebian assemblages. Journal of Foraminiferal Research, 33(1): 62-93.

Duleba, W.; Coimbra, J. C.; Petri, S.; Barbosa, C. F. 2005. Foraminíferos, tecamebas e ostracodes recentes utilizados como bioindicadores em estudos ambientais brasileiros. In: Souza, C. R. G.; Suguio, K.; Oliveira, A. M. S.; Oliveira, P. E. (eds.). Quaternário do Brasil. Ed. Holos, Ribeirão Preto, São Paulo, pp.176-210.

Eberwein, A. e Mackensen, A. 2006. Regional primary productivity differences off Morocco (NW-Africa) recorded by modern benthic foraminifera and their stable carbon isotopic composition. Deep-Sea Research I, 53: 1379-1405.

Eichler, P. P. B.; Gupta, B. K. S.; Eichler, B. B.; Braga, E. S.; Campos, E. J. 2008. Benthic foraminiferal assemblages of the South Brazil: Relationship to water masses and nutrient distributions. Continental Shelf Research, 28: 1674- 1686.

Eichler, P. P. B.; Castelão, G. P.; Pimenta, F. M.; Eichler, B. B.; Miranda, L. B.; Rodrigues, A. R.; Pereira, E. R. M. 2004. Foraminifera and Thecamoebians as indicator of hydrodynamic process in a choked coastal lagoon, Laguna Estuarine System, SC, Brazil. Journal of Coastal Research, 39: 1144-1148. 
Eichler, P. P. B.; Eichler, B. B.; Miranda, L. B.; Pereira, E. R. M.; Kfouri, P. B. P.; Pimenta, F. M.; Bérgamo, A. L.; Vilela, C. G. 2003. Benthic foraminiferal response to variations in temperature, salinity, dissolved oxygen and organic carbon, in the Guanabara Bay, Rio de Janeiro, Brazil. Anuário do Instituto de Geociências da Universidade Federal do Rio de Janeiro, 26: 36-51.

EPICA Community Members. 2006. One-to-one coupling of glacial climate variability in Greenland and Antarctica. Nature, 444: 195-198.

EPICA community members. 2004. Eight glacial cycles from an Antarctic ice core. Nature, 429: 623-628.

Everitt, B. S.; Landau, S.; Leese, M.; Stahl, D. (eds.). 2011. Cluster Analysis. $5^{\mathrm{a}}$ ed. Wiley Series in Probability and Statistics. New Jersey, USA. 346p.

Fairbanks, R. G. 1989. A 17,000-year glacio-eustatic sea level record: influence of glacial melting rates on the Younger Dryas event and deep ocean circulation. Nature, 342: 637642.

Fisher, T. G.; Smith, D. G.; Andrews, J. T. 2002. Preboreal oscillation caused by a glacial Lake Agassiz flood. Quaternary Science Reviews, 21: 873-878.

Fleming, K.; Johnston, P.; Zwartz, D.; Yokoyama, Y.; Lambeck, K.; Chappell, J. 1998. Refining the eustatic sea-level curve since the Last Glacial Maximum using far - and intermediate - fields sites. Earth and Planetary Science Letters, 163: 327-342.

Folk, R. L. e Ward, W. C. 1957. Brazos river bar: study of the significance of grain size parameters. Journal of Sedimentary Petrology, 17: 3-27

Fontanier, C.; Jorissen, F. J.; Licari, L.; Alexandre, A.; Anschutz, P.; Carbonel, P. 2002. Live benthic foraminiferal faunas from the Bay of Biscay: faunal density, composition, and microhabitats. Deep-Sea Research I, 49: 751-785.

Frenzel, P.; Tech, T.; Bartholdy, J. 2004. Checklist and annotated bibliography of recent foraminiferida from the German Baltic Sea Coast. Studia Geologica Polonica, 124: 6786.

Fundação Instituto Brasileiro de Geografia e Estatística. 1993. Mapa de Unidades de Relevo. Escala: 1:5.000.000. FIBGE, Rio de Janeiro.

Gan, M. A. e Rao, V. B. 1991: Surface cyclogenesis over South America. Monthly Weather Review, 119: 1293-1302.

Gan, M. A.; Kousky, V. E.; Ropelewski, C. F. 2004. The South America Monsoon Circulation and its relationship to rainfall over west-central Brazil. Journal of Climate, 17: 47-66. 
Garcia, M. J.; De Oliveira, P. E.; Siqueira, E.; Fernandes, R. S. 2004. A Holocene vegetational and climatic record from the Atlantic rainforest belt of coastal State of São Paulo, SE, Brazil. Review of Palaeobotany and Palynology, 131: 181-199.

Ghosh, A.; Saha, S.; Saraswati, P. K.; Banerjee, S.; Burley, S. (2009) Intertidal foraminifera in the macrotidal estuaries of the Gulf of Cambay: Implications for interpreting sea level change in palaeo-estuaries. Marine and Petroleum Geology, 26: 1592-1599.

Gimenez Filho, A.; Dantas, A. S. L.; Nagata, N.; Albuquerque Filho, J. L.; Fernandes, L. A.; Teixeira, A. L. 1987. Geologia da Folha Miracatu, Sul-Sudeste do Estado de São Paulo. In: Atas do Simpósio Regional de Geologia, 6, 1: 225-241.

Girardeau, J.; Jennings, A. E. e Andrews, J. T. 2004. Timing and mechanisms of surface and intermediate water circulation changes in the Nordic Seas over the last 10,000 cal years: a view from the North Iceland shelf. Quaternary Science Reviews, 23(20-22): 2127-2139

Gonçalves, H. M. S e Denhardt, B. A. 1999. Interpretação do testemunho T-101 (3205S;4735W) com base em nanofósseis calcários-Cone do Rio Grande. Revista Brasileira de Geociências, 29(4): 527-532.

Gonzales-Silveira, A.; Santamaria-Del-Angel, E.; Millán-Nuñez, R. 2006. Spatial and temporal variability of the Brazil-Malvinas confluence and the La Plata plume as seen by SeaWiFS and AVHRR imagery. Journal of Geophysical Research. 111: C06010.

Gooday, A. J. e Hughes, J. A., 2002. Foraminifera associated with phytodetritus deposits at a bathyal site in the northern Rockall Trough (NE Atlantic): seasonal contrasts and a comparison of stained and dead assemblages. Marine Micropaleontology, 46: 83-110.

Google $\operatorname{Earth}^{\mathrm{TM}}$, versão 7.0. Google Inc., 2010. Disponível em: http://www.google.com/earth/index.html.

Govin, A.; Holzwarth, U.; Heslop, D.; Keeling, L. F.; Zabel, M.; Mulitza, S.; Collins, J. A.; Chiessi, C. M. 2012. Distribution of major elements in Atlantic surface sediments $\left(36^{\circ} \mathrm{N}-\right.$ $\left.49^{\circ} \mathrm{S}\right)$ : imprint of terrigenous input and continental weathering. Geochemistry, Geophysics, Geosystems, 13(1): Q01013, doi: 10.1029/2011GC003785. 
Greaves, M.; Caillon, N.; Rebaubier, H.; Bartoli, G.; Bohaty, S.; Cacho, I.; Clarke, L.; Cooper, M.; Daunt, C.; Delaney, M.; deMenocal, P.; Dutton, A.; Eggins, S.; Elderfield, H.; Garbe-Schoenberg, D.; Goddard, E.; Green, D.; Groeneveld, J.; Hastings, D.; Hathorne, E.; Kimoto, K.; Klinkhammer, G.; Labeyrie, L.; Lea, D.W.; Marchitto, T.; Martínez-Botí, M.A.; Mortyn, P.G.; Ni, Y.; Nuernberg, D.; Paradis, G.; Pena, L.; Quinn, T.; Rosenthal, Y.; Russel, A.; Sagawa, T.; Sosdian, S.; Stotti, L.; Tachikawa, K.; Tappa, E.; Thunell, R.; Wilsn, P.A. 2008. Interlaboratory comparision study of calibration Standards for foraminiferal $\mathrm{Mg} / \mathrm{Ca}$ thermometry. Geochemical, Geophysical, Geosystems, 9: Q08010 doi: 10.1029/2008GC001974.

Groeneveld, J. e Chiessi, C. M. 2011. Mg/Ca of Globorotalia inflata as a recorder of permanent thermocline temperatures in the South Atlantic. Paleoceanography, 26: PA2203. doi:10.1029/2010PA001940.

Gross, M. G. 1971. Carbon determination. In: Carver, R. E. (Ed.). Procedures in sedimentary petrology. Wiley, Nova York, EUA, pp. 573-596.

Guilbault, J. P.; Radi, T.; Barrie, J. V.; Conway, K.; Lapointe, M. 2003. Paleoenvironments of the Strait of Georgia, British Columbia during the last deglaciation: Microfaunal and microfloral evidence. Quaternary Science Reviews, 22: 839-857.

Harloff, J. e Mackensen, A. 1996. Recent benthic foraminiferal associations and ecology of the Scotia Sea and Argentine Basin. Marine Micropaleontology, 31: 1-29.

Hart, M. B.; Hylton, M. D.; Oxford, M. J.; Price, G. D.; Hudson, W.; Smart, C.W. 2003. The search of the origin of the panktic Foraminifera. Journal of the Geological Society, 160: 341-346.

Hayward, B. W.; Cedhagen, T.; Kaminski, M.; Gross, O. 2011. World Modern Foraminifera database. Disponível em: http://www.marinespecies.org/foraminifera. Último acesso em: outubro de 2012.

Herguera, J. C. e Berger, W. H. 1991. Paleoproductivity from benthic foraminifera abundance: glacial to postglacial change in the westequatorial Pacific. Geology, 19: $1173-1176$.

Herut, B. e Sandler, A. 2006. Normalization methods for pollutants in marine sediments: review and recommendations for the Mediterranean. Draft Final Report of Israel Oceanographic \& Limnological Research. Em: http://www.sednet.org/download/0604 herut_and_sandler_report.pdf. Acesso em: outubro, 2012.

Hromic, T. M. 2011. Foraminíferos bentónicos recolectados durante la expedición cimar 14 fiordos, Patagonia Chilena. Anales do Instituto Patagonia, 39(1): 75-89. 
Hughen, K. A.; Baillie, M. G. L.; Bard, E.; Bayliss, A.; Beck, J.W.; Blackwell, P.G.; Buck, C.E.; Burr, G.S.; Cutler, K.B.; Damon, P.E.; Edwards, R.L.; Fairbanks, R.G.; Friedrich, M.; Guilderson, T.P.; Herring, C.; Kromer, B.; McCormac, F.G.; Manning, S.W.; Ramsey, C.B.; Reimer, P.J.; Reimer, R.W.; Remmele, S.; Southon, J.R.; Stuiver, M.; Talamo, S.; Taylor, F.W.; van der Plicht, J.; Weyhenmeyer, C. E. 2004. Marine04 Marine radiocarbon age calibration, 0-26 cal kyr BP. Radiocarbon, 46(3): 1059-1086

Hut, G. 1987. Stable Isotope Reference Samples for Geochemcal and Hydrological Investigations. Consultant Group Meeting IAEA, Vienna 16-18 September 1985. Report to the Director General, International Atomic Energy Agency, Vienna.

Jaeschke, A.; Rühlemann, C. R.; Arz, H.; Heil, G.; Lohmann, G. 2007. Coupling of millennial-scale changes in sea surface temperature and precipitation off northeastern Brazil with high-latitude climate shifts during the last glacial period. Paleoceanography, 22: PA4206, doi:10.1029/2006PA001391.

Javaux, E. e Scott, D. B. 2003. Illustration of modern benthic foraminifera from Bermuda and remarks on distribution in other subtropical/tropical areas. Palaeontologia Electronica, 6(4): 29pp. Disponível em: http://palaeo-electronica.org/paleo/2003 1/benthic/issue103.htm.

Jorrisen, F. J.; Fontanier, C.; Thomas, E. 2007. Paleoceanographical proxies based on deepsea benthic foraminiferal assemblage characteristics. In: Hillaire-Marcel, C. e Vernal, A. de (eds.). Proxies in Late Cenozoic Paleoceanography (Pt. 2): Biological tracers and biomarkers. Elsevier. pp. 263-326.

Jorissen, F. J.; De Stigter, H. C.; Widmark, J. G. V. 1995. A conceptual model explaining benthic foraminiferal microhabitats. Marine Micropaleontology, 22: 3-15.

Kaiho, K. 1994. Benthic foraminiferal dissolved-oxygen index and dissolved-oxygen levels in the modern ocean. Geology, 22: 719-722.

Kaiho, K. 1991. Global changes of Paleogene aerobic/anaerobic benthic foraminifera and deep-sea circulation. Palaeogeography, Palaeoclimatology, Palaeoecology, 83: 65-85.

Kaminski, M. A.; Aksu, A.; Box, M.; Hiscott, R. N.; Filipescu, S.; Al-Salameen, M. 2002. Late Glacial to Holocene benthic foraminifera in the Marmara Sea: implications for Black Sea - Mediterranean Sea connections following the last deglaciation. Marine Geology, 190: 165-202.

Kampel, M. e Gaeta, S. A. 2003. Calculation of primary production from remotely-sensed ocean color data: SE Brasil, SW Atlantic. Anais do XI Simpósio Brasileiro de Sensoriamento Remoto, Belo Horizonte, INPE. pp. 1575-1586. 
Keigwin, L. D. e Boyle, E. A. 2000. Detecting Holocene changes in thermohaline circulation. Proceeding of the National Academy of Science, 97(4): 1343-1346.

Kennet, J. P.; Cannariato, K. G.; Hendy, I. L.; Behl, R. J. 2000. Carbon Isotopic Evidence for Methane Hydrate Instability During Quaternary Interstadials. Science, 288: 128-133.

Kerr, R. A. 2000. A North Atlantic climate pacemaker for the centuries. Science, 288: 19841985.

Kitazato, H., 1994. Foraminiferal microhabitats in four marine environments around Japan. Marine Micropaeontology, 24(1): 29-41.

Kobashi, T.; Severinghaus, J. P.; Barnola, J.-M. 2008. $4 \pm 1.5^{\circ} \mathrm{C}$ abrupt warming 11,270yr ago identified from trapped air in Greenland ice. Earth and Planetary Science Letters, 268: $397-407$.

Köhler, P.; Knorr, G.; Buiron, D.; Lourantou, A.; Chappellaz, J. 2011. Abrupt rise in atmospheric $\mathrm{CO}_{2}$ at the onset of Bolling-Allerod: in-situ ice core data versus true atmospheric signals. Climate of the Past, 7: 473-486.

Koho, K. A.; García, R.; Stigter, H. C.; Epping, E.; Koning, E.; Kouwenhoven, T. J.; van der Zwaan, G. J. 2008. Sedimentary labile organic carbon and pore water redox control on species distribution of benthic foraminifera: A case study from Lisbon-Setúbal Canyon (southern Portugal). Progress in Oceanography, 79: 55-82.

Kosh, M. C. e Friedrich, O. 2012. Campanian-Maastrichtian intermediate- to deep- water changes in the high latitudes: benthic foraminiferal evidence. Paleoceanography, 27: PA2209, doi: 10.1029/2011PA002259.

Krumbein, W. C. 1936. Application of logarithmic moments to size frequency distributions of sediments. Journal of Sedimentary Petrology, 6: 35-47.

Kuhnt, T.; Schmiedl, G.; Ehmann, W.; Hamann, Y.; Hemleben, C. 2007. Deep-sea ecosystem variability of the Aegean Sea during the past $22 \mathrm{kyr}$ as revealed by Benthic Foraminifera. Marine Micropaleontology, 64: 141-162.

Lamb, A. L.; Wilson, G. P.; Leng, M. J. 2006. A review of coastal palaeoclimate and relative sea-level reconstructions using $\mathrm{d} 13 \mathrm{C}$ and $\mathrm{C} / \mathrm{N}$ ratios in organic material. Earth-Science Reviews, 75: 29- 57.

Lambeck, K. e Chappell, J., 2001. Sea level change through the Last Glacial Cycle. Science, 292: 679-686. Ok na metodologia.

Lamy, F.; Kaiser, J.; Arz, H. W.; Hebbeln, D.; Ninnemann, U.; Timm, O.; Timmermann, A.; Toggweileir, J. R. 2007. Modulation of the bipolar seesaw in the Southeast Pacific during Termination 1. Earth and Planetary Science Letters, 259: 400-413. 
Lançone, R. B.; Duleba, W.; Mahiques, M. M. 2005. Dinâmica de fundo da Enseada do Flamengo, Ubatuba, Brasil, inferida a partir da distribuição espacial, morfometria e tafonomia de foraminíferos. Revista Brasileira de Paleontologia, 8(3): 181-192.

Langer, M. R. 1999. Origin of foraminifera: Conflicting molecular and paleontological data? Marine Micropaleontology, 38: 1-5.

Langezaal, A. M.; Jorissen, F. J.; Braun, B.; Chaillou, G.; Fontanier, C.; Anschutz, P.; van der Zwaan, G. J. 2006. The influence of seasonal processes on geochemical profiles and foraminiferal assemblages on the outer shelf of the Bay of Biscay. Continental Shelf Research, 26: 1730-1755.

Laprida, C.; Chandler, D. D. E.; Mercau, J. R.; López, R. A.; Marcomini, S. 2011. Modern foraminífera from coastal settings in northern Argentina: implications for the paleoenvironmental interpretation of mid Holocene littoral deposits. Revista Mexicana de Ciencias Geológicas, 28(1): 45-64.

Larsonneur, C. 1977. La cartographie des dépôt meubles sur le plateau continental français: méthode mise au point et utilisée en Manche. Journal de Recherche Oceanographique, 2: 34-39.

Lea, D., Pak, D. K.; Peterson, L. C.; Hughen, K. A. 2003. Synchroneity of Tropical and HighLatitude Atlantic Temperatures over the Last Glacial Termination, Science, 301: 13611364.

Lea, D. 1999. Trace elements in foraminiferal calcite. In: Sen Gupta, B. K. (ed.). Modern Foraminifera. Kluwer Academic Publishers, Norwell, MA, EUA. 371p.

Le Cadre, V. e Debenay, J.-P. 2006. Morphological and cytological responses of Ammonia (foraminífera) to copper contamination: implication for the use of foraminifera as bioindicators of pollution. Environmental Pollution, 143: 304-317.

Le Cadre, V.; Debenay, J.-P.; Lesourd, M. 2003. Low pH effects on Ammonia beccarii test deformation: implications for studying test deformation as pollution indicator. Journal of Foraminiferal Research, 33(1): 1-9.

Ledru, M-P.; Braga, P. I. S.; Soubiès, F.; Fournier, M.; Martin, L.; Suguio, K., and Turcq, B. 1996. The last 50,000 years in the Neotropics (Southern Brazil): evolution of vegetation and climate. Palaeogeography, Palaeoclimatology, Palaeoecology, 123: 239-257.

LeGrande, A. N. e Schmidt, G. A. 2006. Global gridded data set of the oxygen isotopic composition in seawater. Geophysical Research Letters, 33: LI2604. doi: 10.1029/2006GL026011. 
Leventer, A.; Domack, E.; Dunbar, R.; Pike, J.; Stickley, C.; Maddison, E.; Brachfeld, S.; Manley, P.; McClennen, C. 2006. Marine sediment record from the East Antarctic margin revels dynamics of ice sheet recession. GSA Today, 16(12): doi: 10.1130/GSAT01612A.1.

Li, L.; Gallagher, S.; Finlayson, B. 2000. Foraminiferal response to Holocene environmental changes of a tidal estuary in Victoria, southeastern Australia. Marine Micropaleontology, 38: $229-246$.

Licari, L. N.; Schumacher, S.; Wenzhöfer, F.; Zabel, M.; Mackensen, A. 2003. Communities and microhabitats of living benthic foraminifera from the tropical east atlantic: impact of different productivity regimes. Journal of Foraminiferal Research, 33(1): 10-31.

Liu, J. P. e Milliman, J. D. 2004. Reconsidering Melt-water Pulses 1A and 1B: global impact of sea level rise. Journal of Ocean University of China, 3(2): 183-190.

Liu, Z.; Otto-Bliesner, B. L.; He, F.; Brady, E. C.; Tomas, R.; Clark, P. U.; Carlson, A. E.; Lynch-Stieglitz, J.; Curry, W.; Brook, E.; Erickson, D.; Jacob, R.; Kutzbach, J.; Cheng, J. 2009. Transient simulation of Last Deglaciation with a new mechanism for BøllingAllerød warming. Science, 325: 310-314.

Ljung, K.; e Björck, S. 2007. Holocene climate and vegetation dynamics on Nightingale Island, South Atlantic - an apparent interglacial bipolar seesaw in action? Quaternary Science Reviews, 26: 3150-3166.

Loeblich, A. R. e Tappan, H. 1988. Foraminiferal genera and their classification. Van Nostrand, New York,EUA. v.1, 970p.; v.2, 847 pranchas.

Loeblich, A. R e Tappan, H. 1964. Protista. In: Moore, R. C. Treatise on invertebrate paleontology, Part C. New York, The University Kansas Press, EUA. v1: 510 p., v2: 390 .

Lonardi, A. G. e Ewing, M. 1971. Sediment transport and distribution in the Argentine Basin. 4. Bathimetry of the continental margin, Argentine Basin and other related provinces, canyons and sources of sediments. In: Ahrens, L.H.; Press, F.; Rucorn, S.K.; Urey, H.C. (eds.). Physics and Chemistry of the Earth, v.8. Pergamon, Oxford, Reino Unido. pp.79121.

Lutgens, F. K. e Tarbuck, E. J. 2001. The Atmosphere: and Introduction to Meteorology. 8th edition. Prentice Hall, New Jersey, EUA. 512p.

Mackensen, A.; Rudolph, M.; Kuhn, G. 2001. Late Pleistocene deep-water circulation in the subantarctic eastern Atlantic. Global and Planetary Change, 30: 197-229. 
Mackensen, A.; Hubberten, H. W. B.; Ickert, T.; Fischer, G.; Futterer, D. K. 1993. The $\delta^{13}$ C in benthic foraminiferal tests of Fontbotia wuellerstorfi (Schwager) relative to the $\delta^{13} \mathrm{C}$ of dissolved inorganic carbon in southern ocean deep water: implications for glacial ocean circulation models. Paleoceanography, 8(5): 587-610.

Mahiques, M. M.; Souza, S. H. M.; Furtado, V. V.; Tessler, M. G.; Toledo, F. A. L.; Burone, L.; Figueira, R. C. L.; Klein, D. A.; Martins, C. C.; Alves, D. P. V. 2010. The southern Brazilian shelf: general characteristics, Quaternary evolution and sediment distribution. Brazilian Journal of Oceanography, 58(special issue PGGM): 25-34.

Mahiques, M. M.; Wainer, I. K. C.; Burone, L.; Nagai, R.; Sousa, S. H. M.; Figueira, R. C. L.; Silveira, I. C. A.; Bícego, M. C.; Alves, D. P. V.; Hammer, Ø. 2008. A high-resolution Holocene record on the Southern Brazilian shelf: paleoenvironmental implications. Quaternary International, 206 (1-2): 52-61.

Manabe, S. e Stoufer, R. J. 2000. Study of abrupt climate change by a coupled oceanatmosphere model. Quaternary Science Reviews, 19: 285-299.

Mangini, A.; Godoy, J. M.; Godoy, M. L.; Kowsmann, R.; Santos, G. M.; Ruckelshausen, M.; Schroeder-Ritzrau, A.; Wacker, L. 2010. Deep sea corals off Brazil verify a poorly ventilated Southern Pacific Ocean during H2, H1 and the Younger Dryas. Earth and Planetary Science Letters, 293: 269-276.

MARGO Project Members. 2009. Constrains on the magnitude and patterns of ocean cooling at the Last Glacial Maximum. Nature Geoscience, 2: 127-132.

Martin, R. E. e Liddell, W. D. 1991. The taphonomy of foraminifera in modern carbonate environments: implications for the formation of foraminiferal assemblages. In: Donovan, S. K. (ed.) The Processes of Fossilization. Columbia University Press, Nova York, EUA. pp. 170-193.

Martin, L.; Dominguez, J. M. L.; Bittencourt, A. C. S. P. 2003. Fluctuating Holocene sea levels in eastern and southeastern Brazil: evidence from a multiple fossil and geometric indicators. Journal of Coastal Research, 19: 101-124.

Martin, L.; Bittencourt, A. C. S. P.; Dominguez, J. M. L.; Flexor, J. M.; Suguio, K. 1998. Oscillations or not oscillations, that is the question: comment on Angulo, R.J. And Lessa, G.C. "The Brazilian sea-level curves: a critical review with emphasis on the curves from the Paranaguá and Cananéia regions" [Mar. Geol. 140, 141-166]. Marine Geology, 150: 179-187.

Martin, L.; Suguio, K.; Flexor, J. M.; Dominguez, J. M. L.; Bittencourt, A. C. S. P. 1996. Quaternary sea-level history and variation in dynamics along the central Brazilian coast: 
consequences on coastal plain construction. Anais da Academia Brasileira de Ciências, 68: $303-354$.

Martin, L.; Flexor, J.M.; Suguio, K. 1995. Vibro-testemunhador leve: construção, utilização e potencialidades. Revista IG, 16 (1/2): 59-66.

Martin, L.; Suguio, K.; Flexor, J. M.; Bittencourt, A. C. S. P.; Vilas-Boas, G. S. 1979/1980. Le quaternaire marin brésilien (littoral pauliste, sud fluminense et bahianais). Cahiers O.R.S.T.O.M., Série Géologie, 11: 95-124.

Martins I. L. R. 1984. Modelo Sedimentar no Cone de Rio Grande. Tese de Doutorado, Instituto de Geociências, Universidade Federal do Rio Grande do Sul, Porto Alegre. $222 p$.

Martins L. R.; Urien C. M.; Butler L.W. 1972. Províncias fisiográficas e sedimentos da margem continental atlântica. In: Anais do XXVI Congresso Brasileiro de Geologia, Belém. pp. 105-114.

Martins, M. V.; Dubert, J.; Jouanneau, J-M. ; Weber, O. ; Ferreira da Silva, E.; Patinha, C.; Dias, J. M. A.; Rocha, F. 2007. A multiproxy approach of the Holocene evolution of shelf-slope circulation on the NW Iberian Continental Shelf. Marine Geology, 239: 1-18.

Martins, M. V.; Jouanneau, J.-M.; Weber, O.; Rocha, F. 2006. Tracing the late Holocene evolution of the NW Iberian upwelling system. Marine Micropaleontology, 59: 35-55.

Martins, M. V. e Gomes, V. C. R. D. 2004. Foraminiferos da Margem Continental NW Ibérica: Sistemática, Ecologia. Portugal, 377p.

Maslin. M. A.; Shackleton. N.; Pflaumann, U. 1995. Surface water temperature, salinity and density changes in the North East Atlantic during the last 45.000 years: Heinrich events, deep water formation and climatic rebounds. Paleoceanography, 10: 527-544.

Masson, V.; Vimeux, F.; Jouzel, J.; Morgan, V.; Delmotte, M.; Ciais, P.; Hammer, C.; Johnsen, S.; Lipenkov, V. Y.; Mosley-Thompson, E.; Petit, J.-R.; Steig, E. J.; Stievenard, M.; Vaikmae, R. 2000. Holocene climate variability in Antarctica based on 11 ice-core isotopic records. Quaternary Research, 54: 348-358.

Matsuura, Y. 1986. Contribuição ao estudo da estrutura oceanográfica da região sudeste entre Cabo Frio (RJ) e Cabo de Santa Marta Grande (SC). Ciência e Cultura, 38(8): 14391450 .

Mayewski, P. A.; Rohling, E. E.; Stager, J. C.; Karlén, W.; Maasch, K. A.; Meeker, L. D.; Meyerson, E. A.; Gasse, F.; Kreveld, S.; Holmgren, K.; Lee-Thorp, J.; Rosqvist, G.; 
Rack, F.; Staubwasser, M.; Schneider, R. R.; Steig, E. J. 2004. Holocene climate variability. Quaternary Research, 62: 243- 255.

Mayklem, W. R. 1967. Black and brown speckled foraminiferal sand from the southern part of the Great Barrier Reef. Journal of Sedimentary Research, 37: 1023-1030.

McCarthy, D. J. 2011. Late Quaternary ice-ocean interactions in central West Greenland. Tese de Doutorado. Universidade Durham, Duhman, Reino Unido. 310p.

McCormac, F. G.; Hoog, A. G.; Blackwell, P. G.; Buck, C. E.; Higham, T. F. G.; Reimer, P. J. 2004. SHCAL04 Southern Hemisphere Calibration, 0-11.0 CAL KYR BP. Radiocarbon, 46(3): 1087-1092.

McCulloch, R. D.; Bentley, M. J.; Purves, R. S.; Hulton, N. R. J.; Sugden, E. D.; Clapperton, C. M. 2000. Climatic inferences from glacial and palaeoecological evidence at the last glacial termination, southern South America. Journal of Quaternary Science, 15(4): 409417.

McManus, J. F.; Francois, R.; Gherardi, J.-M.; Keigwin, L. D.; Brown-Leger, S. 2004. Collapse and rapid resumption of Atlantic meridional circulation linked to deglacial climate changes. Nature, 428: 834-837.

Melo, M. S. 1990. A Formação Pariqüera-Açu e depósitos relacionados: sedimentação, tectônica e geomorfogênese. Dissertação de Mestrado. Instituto de Geociências, Universidade de São Paulo, São Paulo, São Paulo. 211p.

Mercone, D. Thompson, J.; Abu-Zied, R. H.; Croudace, I. W.; Rohling, E. J. 2001. Highresolution geochemical and micropaleontological profiling of the most recent eastern Mediterranean sapropel. Marine Geology, 177: 25-44.

Milani, E. J. 1997. Evolução tectono-estratigráfica da Bacia do Paraná e seu relacionamento com a geodinâmica fanerozóica do Gondwana sul-ocidental. Tese de Doutorado. Instituto de Geociências, Universidade Federal do Rio Grande do Sul, Porto Alegre, Rio Grande do Sul. 255p.

Milani E. J. e Thomaz Filho A. 2000. Sedimentary Basins of South America. In: Cordani, U. G.; Milani, E. J.; Thomaz Filho, A.; Campos, D. A. Tectonic Evolution of South America, Edição Especial do $31^{\text {st }}$ International Geological Congress, p. 389-449.

Milani, E. J.; Melo, J. H. G.; Souza, P. A.; Fernandes, L. A.; Frabça, A. B. 2007. Bacia do Paraná. Boletim de Geociências da Petrobrás, 15(2): 265-287.

Milker, Y.; Schmiedl, G.; Betzler, C.; Römer, M.; Jaramillo-Vogel, D.; Siccha, M. 2009. Distribution of recent benthic foraminifera in shelf carbonate environments of the Western Mediterranean Sea. Marine Micropaleontology, 73: 207-225. 
Miranda, L. B. e Katsuragawa, M. 1991. Estrutura térmica na região sudeste do Brasil (outono/novembro de 1988). Publicação Especial do Instituto Oceanográfico, 8: 1-14.

Möller Jr., O. O.; Piola, A. R.; Freitas, A. C.; Campos, E. J. D. 2008. The effects of river discharge and seasonal winds on the shelf off southeastern South America. Continental Shelf Research. 28: 1607-1624.

Monnin, E.; Steig, E. J.; Siegenthaler, U.; Kawamura, K.; Schwander, J.; Stauffer, B.; Stocker, T. F.; Morse, D. L.; Barnola, J.-M.; Bellier, B.; Raynaud, D.; Fisher, H. 2004. Evidence for substantial accumulation rate variability in Antarctica during the Holocene, through synchronization of $\mathrm{CO}_{2}$ in the Taylor Dome, Dome $\mathrm{C}$ and DML ice cores. Earth and Planetary Science Letters, 224: 45-54.

Monnin, E.; Indermühle, A.; Dällenbach, A.; Flückiger, J.; Stauffer, B.; Stocker, T. F.; Raynauld, D.; Barnola, J.-M. 2001. Atmospheric $\mathrm{CO}_{2}$ concentrations over the Last Glacial Termination. Science, 291: 112-114.

Moodley, L.; Zwaan, G. L.; Rutten, G. M. W.; Boom, R. C. E., and Kempers, A. J., 1998. Subsurface activity of benthic foraminifera in relation to porewater oxygen content: laboratory experiments. Marine Micropaleontology, 34: 91-106.

Morigi, C.; Jorissen, F. J.; Fraticelli, S.; Horton, B. P.; Principi, M.; Sabbatini, A.; Capotondi, L.; Curzi, P. V.; Negri, A. 2005. Benthic foraminiferal evidence for the formation of the Holocene mud-belt and bathymetrical evolution in the central Adriatic Sea. Marine Micropaleontology, 57: 25-49.

Mulitza, S.; Boltovskoy, D.; Donner, B.; Meggers, H.; Paul, A.; Wefer, G. 2003. Temperature: $\delta^{18} \mathrm{O}$ relationships of plaktonic foraminifera collected from surface waters. Palaeoceanography, Palaeoclimatology, Palaeoecology, 202: 143-152.

Müller P. J.; Schneider R.; Ruhland, G. 1994. Late Quaternary $\mathrm{PCO}_{2}$ variations in the Angola Current: Evidence from organic carbon $\delta 13 \mathrm{C}$ and alkenone temperatures. In: Zahn R, Pedersen TF, Kaminski MA, Labeyrie L (eds). Carbon Cycling in the Glacial Ocean: Constraints on the Ocean's Role in Global Change. NATO ASI Series, Springer, Berlin Heidelberg, Nova York, EUA. pp. 343-366.

Murgese, D. S. e De Deckker, P. 2007. The Late Quaternary evolution of water masses in the eastern Indian Ocean between Australia and Indonesia, based on benthic foraminifera faunal and carbon isotopes analyses. Palaeogeography, Palaeoclimatology, Palaeoecology, 247: 382-401. 
Murray, J. W. 2001. The niche of benthic foraminifera, critical thresholds and proxies. Marine Micropaleontology, 41(1-2): 1-7.

Murray, J. W. 1991. Ecology and Paleoecology of Benthic Foraminifera. Longman, Horlow, Londres, Inglaterra, 397p.

Nadon, M.-O. e Himmelman, J. H. 2006. Stable isotopes in subtidal food webs: have enriched carbon ratios in benthic consumers been misinterpreted? Limnology and Oceanography, 51(6): 2828-2836.

Naidu, P. D. e Malmgren, B. A. 1999. Quaternary carbonate record from the Equatorial Indian Ocean and its relationship with productivity changes. Marine Geology, 161(1): 49-62.

Neto, J. L. S. e Nery, J. T. 2005. Variabilidade e mudanças climáticas no Brasil e seus impactos regionais. In: Souza, C. R. G.; Suguio, K.; Oliveira, A. M. S.; Oliveira, P. E. (eds.). Quaternário do Brasil. Ed. Holos, Ribeirão Preto, São Paulo. pp. 28-51.

Netto Jr., J. P. B. 2008. Hidrografia e massas de água da plataforma continental sudeste brasileira em $26^{\circ} 45^{\prime}$ S. Dissertação de Mestrado. Departamento de Ciências da Terra, Universidade Federal do Paraná, Pontal do Paraná, Paraná. 132p.

Nimer, E., 1990. Clima. In: IBGE. Fundação Instituto Brasileiro de Geografia e Estatística. Geografia do Brasil: região Sul. Rio de Janeiro. pp. 151-187.

NOOA/AOML. Physical oceanography Division: South Atlantic Meridional Overturning Circulation (SAMOC) Workshops. Disponível em: http://www.aoml.noaa.gov. Acesso em: novembro/2012.

Oliveira, D. 1999. Análise Ambiental dos canais da bacia hidrográfica do Rio Itanhaém - SP, Brasil, com base em tecamebas e foraminíferos. Dissertação de Mestrado. Universidade Estadual Paulista, São Paulo. 252p.

Osterman, L. E. 2003 Benthic foraminifers from the continental shelf and slope of the Gulf of Mexico: An indicator of shelf hypoxia. Estuarine, Coastal and Shelf Science, 58: 17-35.

Pahnke, K. e Zahn, R. 2005. Southern Hemisphere Water Mass Conversion Linked with North Atlantic Climate Variability. Science, 307: 1741-1746.

Pahnke, K.; Goldstein, S. L.; Hemming, S. R. 2008. Abrupt changes in Antarctic Intermediate Water circulation over the past 25,000 years. Nature Geoscience, 1: 870-874. Ok na metodologia.

Panarello, H. O. e Dapeña, C. 2009. Large scale meteorological phenomena, ENSO and ITCZ, define the Paraná River isotope composition. Journal of Hidrology, 365: 105-112. 
Pascual, A.; Rodriguyez-Lazaro, J.; Martín-Rubio, M.; Jouanneau, J.-M.; Weber, O. 2008. A survey of the benthic microfauna (foraminifera, Ostracoda) on the Basque shelf, southern Bay of Biscay. Journal of Marine Systems, 72: 35-63.

Pawlowski, J.; Holzmann, M.; Nerney, C.; Fahrni, J.; Gooday, A. J.; Cedhagen, T.; Habura, A., and Bowser, S. S. 2003. The evolution of early Foraminifera. Proceedings of National Academy of Science, 100(20): 11494-11498.

Peterson, L. C. e Haug, G. H. 2006. Variability in the mean latitude of the Atlantic Intertropical Convergence Zone as recorded by riverine input of sediments to the Cariaco Basin (Venezuela). Palaeogeography, Palaeoclimatology, Palaeoecology, 234: 97- 113.

Peterson, R. e Stramma, L. 1991. Upper-level circulation in the South Atlantic Ocean. Progress in Oceanography, 26(1): 1-73.

Pidwirny, M. 2006. Climate Classification and Climatic Regions of the World. In: Fundamentals of Physical Geography, 2nd Edition. Disponível em: http://www.physicalgeography.net/fundamentals/7v.html. Acesso em: outubro de 2012.

Pielou, E. C. 1969. Mathematical Ecology. John Wiley and Sons, Nova York, EUA. 286p.

Piola, A. R. e Gordon, A. L. 1989. Intermediate waters of the western South Atlantic. Deep Sea Research, 36: 1-16.

Piola, A. R.; Romero, S. I.; Zajaczkovski, U. 2008. Space-time variability of the Plata plume inferred from ocean color. Continental Shelf Research, 28: 1556-1567.

Piola, A. R.; Matano, R. P.; Palma, E. D.; Möller Jr., O. O.; Campos, E. J. D. 2005. The influence of the Plata River discharge on the western South Atlantic shelf. Geophysical Research Letters, 32: L01603, doi: 10.1029/2004GL021638.

Polyak, L.; Korsun, S.; Febo, L.; Stanovoy, V.; Khusid, T.; Mald, M.; Paulsen, B. E.; Lubinski, D. A. 2002. Benthic foraminiferal assemblages from the southern Kara Sea, a river-influenced arctic marine environment. Journal of Foraminiferal Research, 32: 252273.

Por, D. F. 1986. Stream type diversity in the Atlantic lowland of the Juréia area (subtropical Brazil). Hydrobiologia, 131: 39-46.

Putnam, A. E.; Denton, G. H.; Schaefer, J. M.; Barrell, D. J. A.; Andersen, B. G.; Finkel, R. C.; Schwartz, R.; Doughty, A. M.; Kaplan, M. R.; Schlüchter, C. 2010. Glacier advance in southern middle-latitudes during the Antarctic Cold Reversal. Nature Geoscience, 3: 700-704.

Rahmstorf, S. 2003. The concept of the thermohaline circulation. Nature, 421: 699. 
Rao, V. B.; Cavalcanti, I. F. A.; Hada, K. 1996: Annual variations of rainfall over Brazil and water vapor characteristics over South América. Journal of Geophysical Ressearch, 101: 26539-26551.

Rasmussen, T. L.; Thomsen, E.; Troelstra, S. R.; Kuijpers, A.; Prins, M. A. 2002. Millenialscale glacial variability versus Holocene stability: changes in planktic and benthic foraminifera faunas and ocean circulation in the North Atlantic during the last 60.000 years. Marine Micropaleontology, 47: 143-176.

Rathburn, A. E. e Corliss, B. H. 1994. The ecology of living (stained) deep-sea benthic foraminifera from Sulu Sea. Paleoceanography, 9(1): 87-150.

Razik, S.; Chiessi, C. M.; Romero, O. E.; von Dobeneck, T. Interactions of the South American Monsoon System and the Southern Westerly Wind Belt during the last 14 kyr. Palaeogeography, Palaeoclimatology, Palaeoecology (no prelo).

Reimer, P. J.; Baillie, M. G. L.; Bard, E.; Bayliss, A.; Beck, J. W.; Blackwell, P. G.; Buck, C. E.; Burr, G. S.; Cutler, K. B.; Damon, P. E.; Edwards, R. L.; Fairbanks, R. G.; Friedrich, M.; Guilderson, T. P.; Herring, C.; Hughen, K. A.; Kromer, B.; McCormac, F. G.; Manning, S. W.; Ramsey, C. B.; Reimer, P. J.; Reimer, R. W.; Remmele, S.; Southon, J. R.; Stuiver, M.; Talamo, S.; Taylor, F. W.; van der Plicht, J.; Weyhenmeyer, C. E. 2004. IntCal04 Terrestrial radiocarbon age calibration, 0-26 cal kyr BP. Radiocarbon, 46(3): 1029-1058.

Regenberg, M.; Steph, S.; Nümberg, D.; Tiedemann, R.; Garbe-Schönberg, D. 2009. Calibrating $\mathrm{Mg} / \mathrm{Ca}$ ratios of multiple planktonic foraminiferal species with $\delta 18 \mathrm{O}-$ calcification temperatures: Paleothermometry for the upper water column. Earth and Planetary Science Letters, 278: 324-336.

Rickaby, R. E. M. e Elderfield, H. 2005. Evidence from the high-latitude North Atlantic for variations in Antarctic Intermediate Water flow during the last deglaciation. Geochemisrty, Geophysics, Geosystems, 6(5): Q05001.

Rind, D.; Russel, G. L.; Schmidt, G. A.; Sheth, S.; Collins, D.; Demenocal, P.; Teller, J. 2001: Effects of glacial meltwater in the GISS coupled atmosphere-ocean model - 2. A bipolar seesaw in Atlantic Deep Water production. Journal of Geophysical Research, 106: $27355-27365$.

Riveiros, N. V. e Patterson, R. T. 2009. Late Holocene paleoceanographic evidence of the influence of the Aleutian Low and North Pacific High on circulation in the SeymourBelize Inlet Complex, British Columbia, Canada. Quaternary Science Reviews, 28: 28332850 . 
Robertson, A. W. e Mechoso, C. R. 2000. Interannual and interdecadal variability of the South Atlantic Convergence Zone. Monthly Weather Review, 128: 2947-2957.

Robertson, A. W.; Farrara, J. D.; Mechoso, C. R. 2003. Simulations of the atmospheric response to South Atlantic sea surface temperature anomalies. Journal of Climate, 16: $2540-2551$.

Rohling, E. J. e Pälike, H. 2005. Centennial-scale climate cooling with a sudden cold event around 8,200 years ago. Nature, 434: 975-979.

Rozanski, K. e Araguas-Araguas, L. 1995. Spatial and temporal variability of stable isotope composition of precipitation over the South American continent. Bulletin de l'Institut Français d'Etudes Andines, 23: 379-390.

Rühlemann, C.; Mulitza, S.; Lohmann, G.; Paul, A.; Prange, M.; Wefer, G. 2004. Intermediate depth warming in the tropical Atlantic related to weakened thermohaline circulation: Combining paleoclimate data and modeling results for the last deglaciation. Paleoceanography, 19: PA1025.

Rühlemann, C.; Mulitza, S.; Müller, P. M.; Wefer, G.; Zahn, R. 1999. Warming of the tropical Atlantic Ocean and slowdown of thermohaline circulation during the last deglaciation, Nature, 402: 511 - 514.

Sadowski, G. R. 1974. Tectônica do complexo migmatítico da Serra de Cubatão. In: Resumos do Congresso Brasileiro de Geologia, 28, pp.557-561.

Sallun, A. E. M.; Sallun Filho, W.; Suguio, K.; Babinski, M.; Gioia, S. M. C. L.; Harlow, B.; Duleba, W.; De Oliveira, P. E.; Garcia, M. J.; Weber, C. Z.; Christofoletti, S. R.; Santos, C. S.; Medeiros, V. B.; Silva, J. B.; Santiago-Hussein, M. C., and Fernandes, R. S. 2012. Geochemical evidence of the $8.2 \mathrm{ka}$ event and other Holocene environmental changes recorded in paleolagoon sediments, southeastern Brazil. Quaternary Research, 77(1): 3143.

Samir, A. M. 2000. The response of benthic foraminifera and ostracods to various pollution sources: a study from two lagoons in Egypt. Journal of Foraminiferal Research, 30(2): $83-98$.

Sato, K.; Oda, M.; Chiyonobu, S.; Kimoto, K.; Domitsu, H.; Ingle Jr., J. C. 2008. Establishment of the western Pacific warm pool during the Pliocene: Evidence from planktic foraminifera, oxygen isotopes, and $\mathrm{Mg} / \mathrm{Ca}$ ratios. Palaeogeography, Palaeoclimatology, Palaeoecology, 265: 140-147. 
Schobbenhaus, C.; Campos, D. A.; Derze, G. R.; Asmus, H. E. 1981. Mapa geológico do Brasil e da Área Oceânica Adjacente Incluindo Depósitos Minerais. esc. 1: 2.500.000, MME - DNPM.

Schrag, D. P.; Berner, R. A.; Hoffman, P. F.; Halverson, G. P. 2002. On the initiation of a snowball Earth. Geochemistry, Geophysics, Geosystems, 3: 10.1029/2001GC000219.

Schröder, C. J.; Scott, D. B.; Medioli, F. S. 1987. Can smaller benthic foraminifera be ignored in paleoenviromental analyses? Journal of Foraminiferal Research, 4: 101-110.

Schulz, M.; Prange, M.; Klocker, A. 2007. Low-frequency oscillations of the Atlantic Ocean meridional overturning circulation in a coupled climate model. Climate of the Past, 3: 97107.

Schulz, H. D. e Cruise Participants. 2001. Report and preliminary results Meteor Cruise M46/2, Recife-Montevideo, December 2-December 29, 1999. Berichte, Fachbereich Geowisswnsachaften, 174. Universidade de Bremen, Bremen, 107p.

Scott, G. A.; Scourse, J. D.; Austin, W. E. N. 2003. The distribution of benthic foraminifera in the Celtic Sea: the significance of seasonal stratification. Journal of Foraminiferal Research, 33(1): 32-61.

Scott, D. B.; Medioli, F. S.; Schafer, C. T. 2001. Monitoring in coastal environments using foraminifera and thecamoebian indicators. Cambridge University Press, Cambridge. $177 \mathrm{p}$.

Scott, F.; Stramma, L.; Fisher, J. 1995. The warm water inflow into the western tropical Atlantic boundary regime, spring 1994. Journal of Geophysical Research, 100 (24): 745760.

Semensatto Jr., D. L. e Dias-Brito, D. 2004. Análise ambiental de uma área parálica no delta do Rio São Francisco, Sergipe - Brasil, com base na sinecologia de foraminíferos e tecamebas (Protista). Revista Brasileira de Paleontologia, 7(1): 53-66.

Semensatto, D. L.; Funo, R. H. F.; Dias-Brito, D.; Coelho Jr., C. 2009. Foraminiferal ecological zonation along a Brazilian mangrove transect: diversity, morphotypes and the influence of subaerial expore time. Revue de micropaléontologie, 52: 67-74.

Semensatto, D. L.; Oliveira, D.; Dias-Brito, D. 2008. Blysmasphaera Broennimanni: a new recent allogromiine species (Order Foraminiferida, Eichwald, 1830) from Brazil. Revue de Paléobiologie, Genève, 27 (2): 525-531.

Sen Gupta, B. K. (ed). 1999. Modern Foraminifera. Kluwer Academy Publishers, Norwell, MA, EUA. 384p. 
Sen Gupta, B. K. e Platon, E. 2006. Tracking past sedimentary records of oxygen depletion in coastal waters: use of the Ammonia-Elphidium Foraminiferal Index. Journal of Coastal Research, 39: 1351-1355.

Sen Gupta, B. K.; Turner, R. E.; Rabalais, N. N. 1996. Seasonal oxygen depletion in continental-shelf waters of Louisiana: Historical record of benthic foraminifers. Geology, 24(3): $227-230$.

Servant-Vildary, S. e Suguio, K. 1990. Marine diatom study and statigraphy of Cenozoic sediments in the coastal plain between Morro da Juréia and Barra do Una, State of São Paulo, Brazil. Quaternary of South America and Antarctic Peninsula, 6: 267-296.

Shakun, J. D.; Clark, P. U.; He, F.; Marcott, S. A.; Mix, A. C.; Liu, Z.; Otto-Bliesner, B.; Schmittner, A.; Bard, E. 2012. Global warming preceded by increasing carbon dioxide concentrations during the last deglaciation. Nature, 484: 49-55.

Shannon, C. e Weaver, W. 1999. The Mathematical Theory of Communication. 5th Ed. University of Illinois Press. Illinois, EUA. 144p.

Shemesh, A.; Hodell, D.; Crosta, X.; Kanfoush, S.; Charles, C.; Guilderson, T. 2002. Sequence of events during the last deglaciation in Southern Ocean sediments and Antarctic ice cores. Paleoceanography, 17(4): 1056, doi:10.1029/2000PA000599.

Shepard, F. P. 1954. Nomenclature based on sand-silt-clay ratios. Journal Sedimentary Petrology, 24: 151-158.

Silveira, I. C. A.; Calado, L.; Castro, B. M.; Cirano, M.; Lima, J. A. M.; Mascarenhas, A. d. S. 2004. On the baroclinic structure of Brazil Current - Intermediate Western Boundary Current system at $22^{\circ}-23^{\circ} \mathrm{S}$.

Silveira, I. C. A.; Schmidt, A. C. K.; Campos, E. J. D.; Godoi, S. S.; Ikeda, Y. 2000. A Corrente do Brasil ao Largo da Costa Leste Brasileira. Revista Brasileira de Oceanografia, 48(2): 171-183.

Silveira, I. C. A.; Miranda, L. B.; Brown, W. S. 1994. On the origins of North Brazil Current. Journal of Geophysical Research, 99(C11): 22501-22512.

Simionato, C. G.; tehedor, M. L. C.; Campetella, C.; Guerrero, R.; Moreira, D. 2010. Patterns of sea surface temperature variability on seasonal to sub-annual scales at and offshore the Río de la Plata estuary. Continental Shelf Research, 30: 1983-1997.

Skinner, L. C.; Fallon, S.; Waelbroeck, C.; Michel, E.; Barker, S. 2010. Ventilation of the Deep Southern Ocean and Deglacial $\mathrm{CO}_{2}$ Rise. Science, 328: 1147-1151.

Smart, C. W. 2008. Abyssal NE Atlantic benthic foraminifera during the last $15 \mathrm{kyr}$ : relation to variations in seasonality of productivity. Marine Micropaleontology, 69: 193-211. 
Smart, C. W. 2002. Environmental applications of deep-sea benthic foraminifera. In: Haslett, S. K. (ed.). Quaternary Environmental Micropalaeontology. Hodder Arnold, Londres, Inglaterra. pp.14-58.

Smart, C. W.; Waelbroeck, C.; Michel, E.; Mazaud, A. 2010. Benthic foraminiferal abundance and stable isotope changes in the Indian Ocean sector of the Southern Ocean during the last 20 kyr: Paleoceanographic implications. Palaeogeography, Palaeoclimatology, Palaeoecology, 297: 537-548.

Sousa, S. H. M.; Passos, R. F.; Fukumoto, M.; Silveira, I. C.; Figueira, R. L.; Koutsoukos, E. A. M.; Mahiques, M. M.; Rezende, C. E. 2006. Mid-lower bathyal benthic foraminifera of the Campos Basin, Southeastern Brazilian margin: Biotopes and controlling ecological factors. Marine Micropaleontology, 61: 40-57.

Souza, C. R. G. e Souza, A. P. 2004. Geologia e geomorfologia da área da Estação Ecológica Juréia-Itatins. In: Marques, O.A.V. \& Duleba, W. (Eds.). Estação Ecológica JuréiaItatins, ambiente físico, flora e fauna. Ribeirão Preto, Holos Editora. pp. 16-33.

Souza, V. M.; Laut, L. L. M.; da Silva, F. S.; Figueiredo, A. G. de; Vital, H.; Frazão, E. 2010. Benthic foraminífera and bacterial activity as a Proxy for environmental characterization in Potengi Estuary, Rio Grande do Norte, Brazil. Anuário do Instituto de Geociências da Universidade Federal do Rio de Janeiro, 33(1): 20-34.

Spero, H. J. e Williams, D. F. 1988. Extracting environmental information from planktonic foraminiferal $\delta^{13} \mathrm{C}$ data. Nature, 355: 717-719.

Stanford, J. D.; Rohling, E. J.; Bacon, S.; Roberts, A. P.; Grousset, F. E.; Bolshaw, M. 2011. A new concept for the paleoceanographic evolution of Heinrich event 1 in the North Atlantic. Quaternary Science Reviews, 30(9-10): 1047-1066.

Stanford, J. D.; Rohling, E. J.; Hunter, S. E.; Roberts, A. P.; Rasmussen, S. O.; Bard, E.; McManus, J.; Fairbanks, R. G. 2006. Timing of meltwater pulse 1a and climate responses to meltwater injections. Paleoceanography, 21: PA4103.

Steig, E. J.; Hart, C. P.; White, J. W. C.; Cunnigham, M. L.; Davis, M. D.; Saltzman, E. S. 1998. Changes in climate, ocean and ice-sheet conditions in the Ross embayment, Antartica, at 6ka. Annals of Glaciology, 27: 305-310.

Stein, R. 1991. Accumulation of organic carbon in marine sediments. Results from the $D S D P / O D P$, Berlin, Springer-Verlag. $217 \mathrm{p}$

Stenni, B.; Mason-Delmotte, V.; Johnsen, S.; Jouzel, J.; Longinelli, A.; Monnin, E.; Röthlisberger, R.; Selmo, E. 2001. An Oceanic Cold Reversal During the Last Deglaciation. Science, 293: 2074-2077. 
Stocker, T. F. e Johnsen, S. J. 2003. A minimum thermodynamic model of the bipolar seesaw. Paleoceanography, 18(4): 1087, doi:10.1029/2003PA000920.

Stramma, L. e England, M. 1999. On the water masses and mean circulation of the South Atlantic Ocean. Journal of Geophysical Ressearch, 104(20): 863 - 883.

Stríkis, N. M.; Cruz, F. W.; Cheng, H.; Karmann, I.; Edwards, R. L.; Vuille, M.; Wangs, X.; Paula, M. S.; Novello, V. F.; Auler, A. S. 2011. Abrupt variations in South American monsoon rainfall during the Holocene based on a speleothem record from centraleastern Brazil. Geology, 39(11): 1075-1078.

Stuiver, M. e Reimer, P. J. 1993. Extended ${ }^{14} \mathrm{C}$ data base and revised CALIB $3.0{ }^{14} \mathrm{C}$ age calibration program, Radiocarbon, 35: 215-230.

Suguio K. 2004. O papel das variações do nível relativo do mar durante o Quaternário tardio na origem da Baixada Litorânea de Juréia, SP. In: Marques, O.A.V. e Duleba, W. (eds.) Estação Ecológica Juréia-Itatins - Ambiente Físico, Flora e Fauna. Holos Ed., Ribeirão Preto, pp.34-41.

Suguio, K. 1973. Introdução à sedimentologia. Edgard Blucher, São Paulo, São Paulo. 317p.

Suguio, K. e Martin, L. 1994. Geologia do Quaternário. In: Falconi, F.F.; Nigro Junior, A. (org.) Solos do litoral de São Paulo. Santos, SP: Mesa Redonda ABMS/ASSECOB, p. 69-97.

Suguio K. e Martin L. 1978a. Quaternary marine formations of the States of São Paulo and southern Rio de Janeiro. In: USP, International Symposium on Coastal Evolution in the Quaternary, Special Publication 1, pp. 55.

Suguio K. e Martin L. 1978b. Mapas geológicos da Planície costeira do Estado de São Paulo e sul do Rio de Janeiro (1:100.000). DAEE/ Secretaria de Obras e do Meio Ambiente, Governo do Estado de São Paulo.

Suguio, K. e Tessler, M. G. 1984. Planícies de cordões litorâneos quaternários do Brasil: origem e nomenclatura. In: Lacerda, L. D. ; Cerqueira, R.; Turco, B. (orgs.) Restingas: Origens, Estruturas, Processos. CEUFF, Niterói, Rio de Janeiro, pp. 15-25.

Suguio, K.; de Oliveira, P. E.; Garcia, M. J.; Fernandes, R. S.; Vilela, M. C. S. H.; Santos, C. S. S.; Medeiros, V. B.; Sallun, A. E. M.; Sallun Filho, W.; Christofoletti, S. R.; Petri, S.; Duleba, W.; Babinski, M.; Gioia, S.; Ruiz, I. 2008. Relatório do Projeto Estação Ecológica Juréia-Itatins (SP): Flutuações de níveis marinhos abaixo do atual no Holoceno. Projeto de Pesquisa FAPESP 06/04467-7. 78p.

Suguio, K.(coord.). 2006. Estação Ecológica Juréia-Itatins (SP) : Flutuações de níveis marinhos abaixo do atual no Holoceno. Projeto de Pesquisa FAPESP 06/04467-7. 
Suguio, K.; Angulo, R. J.; Carvalho, A. M.; Corrêa, I. C. S.; Tomazelli, L. J.; Willwock, J. A.; Vital, H. 2005. Paleoníveis do mar e paleolinhas de costa. In: Souza, C. R. G.; Suguio, K.; Oliveira, A. M. S.; Oliveira, P. E. (eds.). Quaternário do Brasil. Ed. Holos, Ribeirão Preto, São Paulo, pp.114-129.

Suguio, K.; Barreto, A. M. F.; Bezerra, F. H. R. 2001. Barra de Tabatinga and Touros Formations: evidence for pleistocene hich sea level stillstands of the Rio Grande do Norte coast. Pesquisa em Geociências, 28: 5 - 12.

Suguio, K.; Martin, L.; Flexor, J. M. 1992. Paleoshorelines and the sambaquis of Brazil. In: Johnson, L. L. e Stright, M. (eds.). Paleoshorelines and prehistory: an investigation of method. Boca Raton, CRC Press, Florida, EUA. pp. 83-99.

Suguio, K.; Martin, L.; Bittencourt, A. C. S. P.; Dominguez, J. M. L.; Flexor, J. M.; Azevedo, A. E. G., 1985. Flutuações do nível relativo do mar durante o Quaternário superior ao longo do litoral brasileiro e suas implicações na sedimentação costeira. Revista Brasileira de Geociências, 15: 273-286.

Sundaram, D. e Suguio K. 1985. Nota preliminar sobre uma assembléia microflorística da Formação Pariqüera-Açu, Estado de São Paulo. Série Geologia. Seção Paleontologia e Estratigrafia, 27(2): 503-506.

Tabela Internacional Estratigráfica 2013: http://www.stratigraphy.org/ICSchart/Cronostrat Chart2013-01.pdf. Acesso em: fevereiro/2013.

Talma, A. S. e Vogel, J. C. 1993. A simplified approach to calibrating 14C dates. Radiocarbon, 35(2): 317-322A.

Teller, J. T.; Leverington, D. W.; Mann, J. D. 2002. Freshwater outbursts to the oceans from glacial Lake Agassiz and their role in climate change during the last deglaciation. Quaternary Science Reviews, 21: 879-887.

Tessler, M. G. e Goya, S. C. 2005. Processos costeiros condicionantes do litoral brasileiro. Revista do Departamento de Geografia, 17: 11-23.

Tessler, M. G. e Mahiques, M. M. 2000. Processos oceânicos e a fisiografia dos fundos marinhos. In: Teixeira, W.; Toledo, M. C. M.; Fairchild, T. R.; Taioli, F. (org.). Decifrando a Terra. Ed. Oficina de Textos, São Paulo, São Paulo. pp. 261-284.

Thibodeau, B.; Vernal, A.; Mucci, A. 2006. Recent eutrophication and consequent hypoxia in the bottom waters of the Lower St. Lawrence Estuary: Micropaleontological and geochemical evidence. Marine Geology, 231: 37-50. 
Thomas, E.; Booth, L.; Maslin, M.; Shackleton, N. J. 1995. Northeastern Atlantic benthic foraminifera during the last 45,000 years: Changes in productivity seen from the bottom up. Paleoceanography, 10: 545-562.

Thornalley, D. J. R.; Elderfield, H.; McCave, I. N. 2009. Holocene oscillations in temperature and salinity of the surface subpolar North Atlantic. Letters to Nature, 457: doi:10.1038/nature07717.

Toledo, F. A. L.; Cachão, M.; Costa, K. B.; Pivel, M. A. G. 2007a. Plaktonic foraminífera, calcareous nannoplankton and ascidian variations during the last $25 \mathrm{kyr}$ in the Southwestern Atlantic: a paleoproductivity signature? Marine Micropaleontology, 64: $67-79$.

Toledo, F. A. L.; Costa, K. B.; Pivel, M. A. G. 2007b. Salinity changes in the western tropical South Atlantic during the last 30 kyr. Global and Planetary Change, 57: 383-395.

Tomazelli, L. J. e Villwock, J. A. 1996. Quaternary geological evolution of Rio Grande do Sul coastal plain, southern Brazil. Anais da Academia Brasileira de Ciências, 68: 373382.

Tomazelli, L. J.; Dillenburg, S. R.; Villwock, J. A. 2000. Late Quaternary geological history of Rio Grande do Sul coastal plain, southern Brazil. Revista Brasileira de Geociencias, 30(3): 470-472.

Tsuchiya, M.; Talley, L. D.; McCartney, M. S. 1994. Water-mass distributions in the western South Atlantic: a section from South Georgia Island (54S) northward across the Equator. Journal of Marine Research, 52: 55-81.

Unkel, I.; Björck, S.; Wohlfarth, B. 2008. Deglacial environmental changes on Isla de los Estados (54.41S), southeastern Tierra del Fuego. Quaternary Science Reviews, 27: 15411554.

Van Hengstum, P. J. e Scott, D. B. 2011. Ecology of foraminifera and habitat variability in an underwater cave: distinguishing anchialine versus submarine cave environments. Journal of Foraminiferal Research, 41(3): 201-229.

Vera, C.; Baez, J.; Douglas, M.; Emmanuel, C.B.; Marengo, J.; Meitin, J.; Nicolini, M.; Nogues-Paegle, J.; Paegle, J.; Penalba, O.; Salio, P.; Saulo, C.; Silva Dias, M.A.; Silva Dias, P.; Zipser, E. 2006. The South American Low-level Jet experiment. Bulletin of American Meteorological Society, 87(1): 63-77.

Vera, C. S.; Vigliarolo, P. K.; Berbery, E. H. 2002. Cold season synoptic-scale waves over subtropical South America. Monthly Weather Reviews, 130: 684-699. 
Vilela, C. G.; Sanjinés, A. E. S.; Ghiselli Jr., R. O.; Mendonça Filho, J. G.; Baptista Neto, J. A.; Barbosa, C. F. 2003. Search for bioindicators of pollution in the Guanabara Bay: integrations of ecologic patterns. Anuário do Instituto de Geociências da Universidade Federal do Rio de Janeiro, 26: 25-35.

Villwock, J. A. 1984. Geology of the Coastal Province of Rio Grande do Sul, Southern Brazil. A synthesis. Pesquisas em Geociências, 16(16): 5-49.

Villwock, J. A.; Tomazelli, L. J.; Loss, E. L.; Dehnhardt, E. A.; Horn, P. N. O.; Bachi, F. A.; Dehnhardt, B. A. 1986. Geology of The Rio Grande do Sul Coastal Province. Quaternary of South America and Antarctic Peninsula, 4:79-97.

Vital, H.; Esteves, L. S.; Araújo, T. C. M.; Patchineelam, S. M. 2005. Oceanografia geológica e geofísica da plataforma continental brasileira. In: Souza, C. R. G; Suguio, K.; Oliveira, A. M. S.; Oliveira, P. E. (eds). Quaternário do Brasil. Ed. Holos, Ribeirão Preto, São Paulo, São Paulo. pp. 153-173.

Walton, W. R. e Sloan, B. J. 1990. The genus Ammonia Brünnich, 1772: its geographic distribution and morphology variability. Journal of Foraminiferal Research, 20(2): 128136.

Wainer, I.; Gent, P.; Goni, G. 2000. Annual cycle of the Brazil-Malvinas confluence region in the National Center for Atmospheric Research Climate System Model. Journal of Geophysical Research, 105 (26): 167-177.

Wanner, H.; Solomina, O.; Grosjean, M.; Ritz, S. P.; Jetel, M. 2011. Structure and origin of Holocene cold events. Quaternary Science Reviews, 30: 3109-3123.

Wanner, H.; Beer, J.; Bütikofer, J.; Crowley, T. J.; Cubasch, U.; Flückiger, J.; Goosse, H.; Grosjean, M.; Joos, F.; Kaplan, J. O.; Küttel, M.; Müller, S. A.; Prentice, I. C.; Solomina, O.; Stocker, T. F.; Tarasov, P.; Wagner, M.; Widmann, M. 2008. Mid-to Late Holocene climate change: an overview. Quaternary Science Reviews, 27: 1791-1828.

Weaver, A. J.; Saenko, O. A.; Clark, P. U.; Mitrovika, J. X. 2003. Meltwater Pulse 1A from Antarctica as a Trigger of the Bølling-Allerød Warm Interval. Science, 299: 1709-1713.

Wefer, G. e Cruise Participants. 2001. Report and Preliminary results Meteor Cruise M46/4, Mar del Plata (Argentina) - Salvador da Bahia (Brazil), February 10-March 13, 2000. With partial results of: Meteor Cruise M46/2. Berichte, Fachbereich Geowisswnsachaften, 173. Universidade de Bremen, Bremen, Alemanha. 136p.

Weldeab, S.; Schneider, R. R.; Kölling, M. 2006. Deglacial sea surface temperature and salinity increase in the western tropical Atlantic in synchrony with high latitude climate instabilities. Earth and Planetary Science Letters, 241: 699-706. 
Wentworth, C. R. 1922. A scale of grade and class terms for clastic sediments. Journal of Geology, 30: 377-392.

Ybert, J. P.; Bissa, W. M.; Catharino, E. L. M.; Kutner, M. 2003. Environmental and sea level variation on the southeastern Brazilian coast on Late Holocene with comment on prehistoric human occupation. Palaeogeography, Palaeoclimatology, Palaeoecology, 189: $11-24$.

Yoshikazu, S. e Massumoto, E. 2001. C/N ratios in a sediment core from Nakaumi Lagoon, Soutwest Japan - Usefulness as an organic source indicator. Geochemical Journal, 35:189-205.

Zarries, M. e Mackensen, A. 2010. The tropical rainbelt and productivity changes off northwest Africa: A 31,000-year high-resolution record. Marine Micropaleontology, 76(3-4): 76-91.

Zhou, J. e Lau, K. M. 1998. Does a monsoon climate exist over South America? Journal of Climate, 11: 1020-1040. 
ANEXOS 
Tabela 3: Distribuição granulométrica dos sedimentos do testemunho S03. Dm (Ø)- diâmetro médio, SG- silte grosso, SMsilte médio, $\mathrm{SF}$ - silte fino, $\mathrm{SMF}$ - silte muito fino, $\sigma_{\mathrm{I}^{-}}$desvio padrão, $\mathrm{K}_{\mathrm{G}^{-}}$curtose, $\mathrm{Sk}_{1^{-}}$assimetria, m.p.s.- muito pobremente selecionado, p.s.- pobremente selecionado. Dados de Sallun et al. (2012). Classificação granulométrica de acordo com Wentworth (1922), classificação da escala phi de acordo com Krumbein (1936), classificação do grau de selecionamento dos grãos de acordo com Folk \& Ward (1957) e classificação sedimentológica de acordo com Shepard (1954).

\begin{tabular}{|c|c|c|c|c|c|c|c|c|c|c|c|c|c|c|c|c|c|}
\hline \multicolumn{8}{|c|}{ Parâmetros estatísticos (phi) } & \multicolumn{9}{|c|}{ Faixa Granulométrica (\%) } & \multirow{3}{*}{$\begin{array}{c}\text { Relação } \\
\text { fino/grosso }\end{array}$} \\
\hline \multirow{2}{*}{$\begin{array}{c}\text { Idades (anos } \\
\text { cal A.P.) }\end{array}$} & \multirow{2}{*}{ Dm (ø) } & \multirow{2}{*}{$\begin{array}{c}\text { Krumbein } \\
(1936)\end{array}$} & \multirow{2}{*}{$\sigma_{1}$} & \multirow{2}{*}{\begin{tabular}{|c|} 
Folk \& Ward \\
$(1957)$
\end{tabular}} & \multirow{2}{*}{$\mathrm{SK}_{1}$} & \multirow{2}{*}{\begin{tabular}{|c|} 
Shepard \\
$(1954)$
\end{tabular}} & \multirow{2}{*}{$\mathbf{K}_{\mathrm{G}}$} & Cascalho & & & Areia & & & & Pelít & icos & \\
\hline & & & & & & & & Cascalno & Muito grossa & Grossa & Média & Fina & Muito Fina & Total & Argila & Total & \\
\hline 108 & 5,46 & SM & 2,59 & m.p.s. & 0,05 & Silte & 1,96 & 0,00 & 0,30 & 0,30 & 0,98 & 2,06 & 3,79 & 4,92 & 24,74 & 36,49 & 25,20 \\
\hline 486 & 6,08 & SF & 2,46 & m.p.s. & $-0,09$ & Silte & 1,64 & 0,00 & 0,14 & 0,14 & 0,15 & 0,43 & 1,28 & 5,11 & 21,83 & 28,80 & 32,72 \\
\hline 1394 & 7,58 & SMF & 2,16 & m.p.s. & $-1,27$ & Silte & 3,53 & 0,00 & 0,23 & 0,23 & 0,17 & 0,21 & 0,42 & 1,05 & 9,81 & 11,66 & 65,22 \\
\hline 2544 & 6,99 & $\mathrm{SF}$ & 2,38 & m.p.s. & $-0,76$ & Silte & 2,27 & 0,00 & 0,34 & 0,34 & 0,08 & 0,23 & 0,40 & 2,04 & 17,04 & 19,80 & 50,29 \\
\hline 4320 & 6,90 & SF & 2,39 & m.p.s. & $-0,55$ & Silte & 1,72 & 0,00 & 0,01 & 0,01 & 0,11 & 0,16 & 0,33 & 1,12 & 21,58 & 23,30 & 50,22 \\
\hline 4953 & 6,35 & SF & 2,54 & m.p.s. & $-0,41$ & Silte & 2,05 & 0,00 & 0,96 & 0,96 & 0,07 & 0,37 & 0,61 & 2,88 & 23,48 & 27,42 & 38,61 \\
\hline 6329 & 6,36 & SF & 2,39 & m.p.s. & $-0,34$ & Silte & 1,87 & 0,00 & 0,15 & 0,15 & 0,21 & 0,43 & 1,02 & 4,32 & 18,95 & 24,93 & 34,29 \\
\hline 6952 & 7,24 & SMF & 2,24 & m.p.s. & $-1,01$ & Silte & 2,88 & 0,00 & 0,11 & 0,11 & 0,20 & 0,36 & 0,73 & 2,64 & 10,94 & 14,87 & 52,99 \\
\hline 7475 & 6,88 & SF & 2,57 & m.p.s. & $-0,87$ & Silte & 2,61 & 0,00 & 0,61 & 0,61 & 0,56 & 0,76 & 1,16 & 4,99 & 12,64 & 20,11 & 50,79 \\
\hline 1583 & 1,52 & SMF & $1, y y$ & p.s. & $-1,14$ & Silte & 3,28 & 0,00 & 0,00 & 0,00 & 0,09 & 0,25 & 0,48 & 1,64 & 5,31 & $1,1 /$ & 56,03 \\
\hline 7625 & 7,17 & SMF & 2,14 & m.p.s. & $-1,13$ & Silte & 3,68 & 0,00 & 0,27 & 0,27 & 0,36 & 0,45 & 0,85 & 2,55 & 6,32 & 10,54 & 43,64 \\
\hline 7676 & 6,98 & SF & 2,32 & m.p.s. & $-0,76$ & Silte & 2,36 & 0,00 & 0,05 & 0,05 & 0,22 & 0,47 & 1,16 & 2,26 & 13,87 & 17,98 & 48,06 \\
\hline 7728 & 6,45 & SF & 2,58 & m.p.s. & $-0,53$ & Silte & 2,16 & 0,00 & 0,49 & 0,49 & 0,53 & 1,35 & 1,62 & 2,91 & 17,63 & 24,05 & 41,63 \\
\hline 7779 & 6,06 & SF & 2,92 & m.p.s. & $-0,58$ & Silte & 2,20 & 0,00 & 0,84 & 0,84 & 2,55 & 3,66 & 3,74 & 4,38 & 12,12 & 26,46 & 37,97 \\
\hline 7831 & 6,81 & SF & 2,69 & m.p.s. & $-0,94$ & Silte & 2,72 & 0,00 & 0,43 & 0,43 & 1,44 & 1,55 & 2,12 & 4,16 & 13,64 & 22,92 & 50,24 \\
\hline 7882 & 6,71 & SF & 2,47 & m.p.s. & $-0,66$ & Silte & 2,24 & 0,00 & 0,15 & 0,15 & 0,37 & 0,90 & 1,85 & 2,56 & 17,33 & 23,00 & 43,82 \\
\hline 7933 & 6,54 & SF & 2,55 & m.p.s. & $-0,53$ & Silte & 2,05 & 0,00 & 0,27 & 0,27 & 0,41 & 0,97 & 1,67 & 3,61 & 18,68 & 25,34 & 42,71 \\
\hline 8001 & 6,56 & SF & 2,38 & m.p.s. & $-0,57$ & Silte & 2,18 & 0,00 & 0,05 & 0,05 & 0,26 & 1,05 & 1,74 & 3,35 & 14,44 & 20,83 & 35,15 \\
\hline 8135 & 6,53 & SF & 2,61 & m.p.s. & $-0,58$ & Silte & 2,14 & 0,00 & 0,14 & 0,14 & 0,66 & 1,99 & 1,99 & 2,26 & 18,72 & 25,63 & 44,03 \\
\hline 8268 & 6,41 & SF & 2,71 & m.p.s. & $-0,69$ & Silte & 2,46 & 0,00 & 0,65 & 0,65 & 1,01 & 2,49 & 2,40 & 3,68 & 14,03 & 23,62 & 41,01 \\
\hline 8375 & 6,39 & SF & 2,70 & m.p.s. & $-0,55$ & Silte & 2,07 & 0,00 & 0,21 & 0,21 & 1,12 & 1,67 & 2,50 & 5,05 & 16,33 & 26,66 & 42,25 \\
\hline 8376 & 6,08 & SF & 2,94 & m.p.s. & $-0,63$ & Silte & 2,32 & 0,00 & 0,65 & 0,65 & 2,88 & 4,66 & 3,72 & 2,76 & 9,83 & 23,85 & 38,20 \\
\hline 8377 & 6,51 & SF & 2,55 & m.p.s. & $-0,54$ & Silte & 2,10 & 0,00 & 0,05 & 0,05 & 0,65 & 1,16 & 2,09 & 4,22 & 15,24 & 23,35 & 42,19 \\
\hline 8378 & 6,11 & SF & 2,51 & m.p.s. & $-0,16$ & Silte & 1,86 & 0,00 & 0,18 & 0,18 & 0,64 & 0,81 & 1,37 & 3,99 & 19,31 & 26,12 & 35,69 \\
\hline 8379 & 6,35 & SF & 2,60 & m.p.s. & $-0,47$ & Silte & 2,05 & 0,00 & 0,13 & 0,13 & 0,85 & 1,35 & 2,73 & 3,90 & 15,29 & 24,12 & 39,27 \\
\hline 8380 & 6,26 & SF & 2,65 & m.p.s. & $-0,48$ & Silte & 2,16 & 0,00 & 0,27 & 0,27 & 1,34 & 1,70 & 2,35 & 4,02 & 14,96 & 24,37 & 38,57 \\
\hline 8381 & 6,59 & SF & 2,32 & m.p.s. & $-0,36$ & Silte & 1,82 & 0,00 & 0,07 & 0,07 & 0,15 & 0,40 & 0,51 & 1,20 & 23,74 & 25,99 & 39,75 \\
\hline 8382 & 6,43 & SF & 2,46 & m.p.s. & $-0,32$ & Silte & 1,73 & 0,00 & 0,10 & 0,10 & 0,20 & 0,59 & 1,04 & 3,38 & 22,24 & 27,46 & 39,71 \\
\hline 8383 & 6,33 & SF & 2,48 & m.p.s. & $-0,24$ & Silte & 1,70 & 0,00 & 0,16 & 0,16 & 0,23 & 0,56 & 1,07 & 3,39 & 23,37 & 28,63 & 38,93 \\
\hline 8384 & 6,37 & SF & 2,52 & m.p.s. & $-0,37$ & Silte & 1,95 & 0,00 & 0,45 & 0,45 & 0,38 & 0,64 & 0,85 & 2,79 & 23,24 & 27,91 & 39,28 \\
\hline 8388 & 5,80 & SM & 2,66 & m.p.s. & $-0,07$ & Silte & 1,85 & 0,00 & 0,54 & 0,54 & 0,74 & 1,42 & 1,86 & 5,06 & 27,22 & 36,30 & 34,10 \\
\hline 8404 & 6,04 & SF & 2,60 & m.p.s. & $-0,25$ & Silte & 1,94 & 0,00 & 0,53 & 0,53 & 0,52 & 1,13 & 1,98 & 5,25 & 21,70 & 30,59 & 34,40 \\
\hline 8420 & 6,04 & SF & 2,56 & m.p.s. & $-0,13$ & Silte & 1,75 & 0,00 & 0,56 & 0,56 & 0,35 & 0,50 & 0,67 & 3,58 & 30,66 & 35,75 & 34,92 \\
\hline 8436 & 5,86 & SM & 2,63 & m.p.s. & $-0,01$ & Silte & 1,65 & 0,00 & 0,40 & 0,40 & 0,31 & 0,76 & 1,88 & 6,12 & 28,07 & 37,14 & 34,74 \\
\hline 8452 & 5,96 & SM & 2,55 & m.p.s. & $-0,03$ & Silte & 1,66 & 0,00 & 0,39 & 0,39 & 0,36 & 0,44 & 0,57 & 3,09 & 33,90 & 38,35 & 34,12 \\
\hline 8468 & 5,52 & SM & 2,58 & m.p.s. & 0,24 & Silte & 1,70 & 0,00 & 0,45 & 0,45 & 0,34 & 0,48 & 1,15 & 5,98 & 39,06 & 47,00 & 28,96 \\
\hline 8484 & 5,60 & $S M$ & 2,65 & m.p.s. & 0,13 & Silte & 1,59 & 0,00 & 0,11 & 0,11 & 0,65 & 0,77 & 1,68 & 9,80 & 31,71 & 44,61 & 30,15 \\
\hline 8500 & 5,07 & SM & 2,60 & m.p.s. & 0,52 & Argila & 1,84 & 0,00 & 0,19 & 0,19 & 0,38 & 1,11 & 2,80 & 8,04 & 45,81 & 58,14 & 25,30 \\
\hline 8516 & 5,05 & SM & 2,39 & m.p.s. & 0,61 & Argila & 2,20 & 0,00 & 0,32 & 0,32 & 0,29 & 0,82 & 1,37 & 5,85 & 44,59 & 52,92 & 20,83 \\
\hline 8532 & 5,19 & SM & 2,45 & m.p.s. & 0,53 & Argila & 1,97 & 0,00 & 0,39 & 0,39 & 0,17 & 0,52 & 0,98 & 5,62 & 45,45 & 52,74 & 23,53 \\
\hline 8548 & 5,63 & SM & 2,35 & m.p.s. & 0,21 & Silte & 1,93 & 0,00 & 0,08 & 0,08 & 0,67 & 0,50 & 1,22 & 3,70 & 35,87 & 41,96 & 23,87 \\
\hline 8563 & 4,78 & SG & 2,21 & m.p.s. & 0,99 & Argila & 2,84 & 0,00 & 0,24 & 0,24 & 0,22 & 0,37 & 0,78 & 5,72 & 50,75 & 57,85 & 17,64 \\
\hline 8579 & 4,39 & $S G$ & 1,62 & p.s. & 1,74 & Argila & 5,67 & 0,00 & 0,08 & 0,08 & 0,06 & 0,14 & 0,33 & 3,05 & 52,87 & 56,46 & 7,46 \\
\hline 8594 & 5,35 & SM & 2,42 & m.p.s. & 0,42 & Silte & 1,89 & 0,00 & 0,23 & 0,23 & 0,27 & 0,44 & 1,09 & 6,33 & 37,46 & 45,58 & 24,04 \\
\hline 8610 & 4,59 & $S G$ & 1,75 & p.s. & 1,34 & Silte & 4,80 & 0,00 & 0,15 & 0,15 & 0,16 & 0,30 & 0,82 & 4,04 & 39,40 & 44,72 & 10,36 \\
\hline 8625 & 5,09 & SM & 2,32 & m.p.s. & 0,69 & Silte & 2,12 & 0,00 & 0,14 & 0,14 & 0,20 & 0,32 & 0,95 & 4,17 & 47,37 & 53,01 & 20,26 \\
\hline 8641 & 5,45 & SM & 2,44 & m.p.s. & 0,41 & Silte & 1,81 & 0,00 & 0,21 & 0,21 & 0,19 & 0,57 & 0,95 & 2,90 & 41,08 & 45,69 & 26,09 \\
\hline 8656 & 4,70 & $S G$ & 1,85 & p.s. & 0,98 & Silte & 3,99 & 0,00 & 0,37 & 0,37 & 0,26 & 0,35 & 0,85 & 4,53 & 32,84 & 38,83 & 9,72 \\
\hline 8672 & 5,38 & SM & 2,51 & m.p.s. & 0,40 & Argila & 1,73 & 0,00 & 0,20 & 0,20 & 0,17 & 0,51 & 1,54 & 7,22 & 37,62 & 47,06 & 26,38 \\
\hline 8687 & 5,15 & SM & 2,33 & m.p.s. & 0,65 & Argila & 2,12 & 0,00 & 0,20 & 0,20 & 0,15 & 0,37 & 1,12 & 4,04 & 43,98 & 49,66 & 21,60 \\
\hline 8717 & 5,18 & SM & 2,45 & m.p.s. & 0,55 & Argila & 1,97 & 0,00 & 0,22 & 0,22 & 0,25 & 0,61 & 1,70 & 5,60 & 44,63 & 52,79 & 23,56 \\
\hline 8806 & 5,58 & SM & 2,52 & m.p.s. & 0,31 & Silte & 1,56 & 0,00 & 0,04 & 0,04 & 0,11 & 0,35 & 1,53 & 6,66 & 35,20 & 43,85 & 29,80 \\
\hline 8894 & 6,23 & SF & 2,55 & m.p.s. & $-0,27$ & Silte & 1,88 & 0,00 & 0,54 & 0,54 & 0,35 & 0,52 & 1,18 & 3,52 & 23,21 & 28,77 & 38,21 \\
\hline 8983 & 6,45 & SF & 2,58 & m.p.s. & $-0,52$ & Silte & 2,21 & 0,00 & 0,98 & 0,98 & 0,37 & 0,41 & 0,72 & 4,27 & 19,21 & 24,97 & 41,70 \\
\hline 9072 & 5,92 & SM & 2,62 & m.p.s. & $-0,04$ & Silte & 1,63 & 0,00 & 0,31 & 0,31 & 0,32 & 0,88 & 1,71 & 4,88 & 27,34 & 35,13 & 35,11 \\
\hline 9160 & 6,79 & SF & 2,44 & m.p.s. & $-0,67$ & Silte & 2,19 & 0,00 & 0,25 & 0,25 & 0,17 & 0,47 & 1,05 & 4,07 & 17,26 & 23,04 & 45,66 \\
\hline
\end{tabular}


Tabela 4: Dados geoquímicos dos sedimentos do testemunho S03. Os dados originais cedidos por Sallun et al. (2012), expressos em porcentagem (\%) foram normalizados pelo elemento Al.

\begin{tabular}{|c|c|c|c|c|c|c|c|c|c|c|c|c|c|c|c|}
\hline Idades (anos cal A.P.) & Al (\%) & $\mathrm{Ca} / \mathrm{Al}$ & Fe/Al & K/AI & Ti/AI & $\mathrm{Ti} / \mathrm{Ca}$ & $\mathrm{Fe} / \mathrm{K}$ & Idades (anos cal A.P.) & Al (\%) & $\mathrm{Ca} / \mathrm{Al}$ & $\mathrm{Fe} / \mathrm{Al}$ & K/AI & Ti/AI & $\mathrm{Ti} / \mathrm{Ca}$ & $\mathrm{Fe} / \mathrm{K}$ \\
\hline 108 & 2,00 & 0,01 & 1,35 & 0,11 & 0,02 & 1,50 & 12,27 & 7615 & 1,10 & 0,13 & 2,18 & 0,17 & & & 12,63 \\
\hline 305 & 1,80 & 0,01 & 1,17 & 0,09 & 0,02 & 3,00 & 12,35 & 7666 & 1,00 & 0,14 & 2,70 & 0,21 & 0,01 & 0,07 & 12,86 \\
\hline 487 & 2,55 & 0,00 & 0,84 & 0,06 & 0,02 & 4,00 & 14,27 & 7718 & 0,78 & 0,18 & 2,69 & 0,23 & 0,01 & 0,07 & 11,67 \\
\hline 668 & 2,36 & 0,00 & 0,81 & 0,06 & 0,01 & 3,00 & 14,69 & 7769 & 0,97 & 0,18 & 2,47 & 0,18 & 0,01 & 0,06 & 14,12 \\
\hline 850 & 2,48 & 0,00 & 0,77 & 0,05 & 0,01 & 3,00 & 16,00 & 7821 & 0,96 & 0,19 & 2,60 & 0,21 & 0,01 & 0,06 & 12,50 \\
\hline 1031 & 2,19 & 0,00 & 0,84 & 0,05 & 0,01 & 3,00 & 16,73 & 7872 & 1,10 & 0,16 & 2,09 & 0,19 & 0,01 & 0,06 & 10,95 \\
\hline 1213 & 2,20 & & 0,68 & 0,04 & 0,00 & & 16,67 & 7924 & 0,98 & 0,18 & 2,35 & 0,22 & 0,01 & 0,06 & 10,45 \\
\hline 1394 & 2,09 & & 0,92 & 0,05 & 0,01 & & 17,45 & 7975 & 0,97 & 0,18 & 2,06 & 0,21 & 0,01 & 0,06 & 10,00 \\
\hline 1576 & 2,02 & 0,00 & 0,92 & 0,05 & 0,01 & 2,00 & 18,60 & 8108 & 0,87 & 0,22 & 2,30 & 0,23 & 0,01 & 0,05 & 10,00 \\
\hline 1757 & 1,85 & & 0,94 & 0,05 & 0,01 & & 19,22 & 8242 & 1,20 & 0,17 & 1,75 & 0,18 & 0,01 & 0,05 & 9,55 \\
\hline 1939 & 1,63 & & 0,82 & 0,05 & 0,01 & & 16,63 & 8375 & 0,81 & 0,26 & 2,47 & 0,26 & 0,01 & 0,05 & 9,52 \\
\hline 2120 & 1,10 & 0,01 & 1,00 & 0,08 & & & 12,22 & 8376 & 1,10 & 0,21 & 1,91 & 0,21 & 0,01 & 0,04 & 9,13 \\
\hline 2544 & 1,58 & 0,01 & 1,10 & 0,06 & 0,01 & 2,00 & 17,40 & 8377 & 1,20 & 0,18 & 2,33 & 0,19 & 0,01 & 0,05 & 12,17 \\
\hline 2968 & 1,81 & 0,01 & 1,13 & 0,06 & 0,01 & 2,00 & 20,50 & 8378 & 1,20 & 0,16 & 1,42 & 0,17 & 0,01 & 0,05 & 8,50 \\
\hline 3392 & 1,98 & 0,01 & 1,24 & 0,06 & 0,01 & 2,00 & 20,42 & 8379 & 1,00 & 0,19 & 1,80 & 0,20 & 0,01 & 0,05 & 9,00 \\
\hline 3816 & 1,45 & 0,01 & 1,46 & 0,08 & 0,01 & 2,00 & 19,18 & 8380 & 0,89 & 0,24 & 1,80 & 0,25 & 0,01 & 0,05 & 7,27 \\
\hline 4240 & 1,10 & 0,02 & 2,09 & 0,08 & & 0,00 & 25,56 & 8381 & 1,00 & 0,23 & 1,70 & 0,24 & 0,01 & 0,04 & 7,08 \\
\hline 4320 & 1,82 & 0,01 & 1,50 & 0,06 & 0,01 & 1,00 & 24,82 & 8382 & 0,86 & 0,23 & 1,98 & 0,26 & 0,01 & 0,05 & 7,73 \\
\hline 4400 & 1,56 & 0,03 & 1,69 & 0,08 & 0,01 & 0,50 & 21,92 & 8383 & 1,20 & 0,20 & 1,50 & 0,23 & 0,01 & 0,04 & 6,67 \\
\hline 4480 & 1,65 & 0,03 & 1,32 & 0,09 & 0,01 & 0,40 & 14,47 & 8384 & 1,20 & 0,19 & 1,42 & 0,20 & 0,01 & 0,04 & 7,08 \\
\hline 4560 & 1,46 & 0,04 & 1,40 & 0,10 & 0,01 & 0,33 & 13,60 & 8385 & 2,80 & 0,05 & 0,82 & 0,13 & 0,02 & 0,33 & 6,39 \\
\hline 4640 & 1,10 & 0,05 & 1,64 & 0,13 & & & 12,86 & 8401 & 0,91 & 0,23 & 1,87 & 0,25 & 0,01 & 0,05 & 7,39 \\
\hline 4953 & 1,42 & 0,04 & 1,32 & 0,11 & 0,01 & 0,40 & 11,69 & 8417 & 0,77 & 0,25 & 2,08 & 0,27 & & & 7,62 \\
\hline 5266 & 1,64 & 0,04 & 1,35 & 0,10 & 0,02 & 0,43 & 13,00 & 8433 & 0,93 & 0,22 & 1,83 & 0,26 & & & 7,08 \\
\hline 5579 & 1,88 & 0,04 & 1,21 & 0,09 & 0,02 & 0,43 & 13,41 & 8449 & 0,95 & 0,20 & 1,58 & 0,24 & & & 6,52 \\
\hline 5892 & 1,42 & 0,05 & 1,49 & 0,11 & 0,01 & 0,29 & 13,19 & 8465 & 0,75 & 0,21 & 1,87 & 0,24 & & & 7,78 \\
\hline 6205 & 1,20 & 0,08 & 1,92 & 0,12 & 0,01 & 0,11 & 16,43 & 8481 & 0,97 & 0,21 & 1,44 & 0,21 & & & 7,00 \\
\hline 6329 & 1,23 & 0,06 & 1,79 & 0,13 & 0,02 & 0,29 & 13,75 & 8497 & 0,69 & 0,22 & 2,03 & 0,25 & & & 8,24 \\
\hline 6454 & 1,54 & 0,06 & 1,56 & 0,12 & 0,01 & 0,22 & 13,33 & 8513 & 0,76 & 1,58 & 1,71 & 0,24 & & & 7,22 \\
\hline 6579 & 1,30 & 0,07 & 1,62 & 0,13 & 0,02 & 0,22 & 12,41 & 8529 & 0,60 & 0,38 & 2,00 & 0,28 & & & 7,06 \\
\hline 6703 & 1,39 & 0,07 & 1,62 & 0,14 & 0,01 & 0,20 & 11,84 & 8545 & 0,57 & 0,54 & 2,28 & 0,32 & & & 7,22 \\
\hline 6827 & 1,00 & 0,11 & 2,30 & 0,19 & & & 12,11 & 8560 & 0,66 & 0,47 & 1,97 & 0,27 & & & 7,22 \\
\hline 6952 & 1,74 & 0,07 & 1,64 & 0,13 & 0,01 & 0,17 & 12,39 & 8576 & 0,60 & 0,55 & 1,83 & 0,28 & & & 6,47 \\
\hline 7077 & 1,82 & 0,07 & 1,52 & 0,13 & 0,01 & 0,17 & 11,50 & 8592 & 0,69 & 0,51 & 1,74 & 0,26 & & & 6,67 \\
\hline 7201 & 1,63 & 0,07 & 1,71 & 0,13 & 0,01 & 0,17 & 12,68 & 8607 & 0,98 & 0,45 & 1,53 & 0,23 & 0,01 & 0,02 & 6,52 \\
\hline 7326 & 1,59 & 0,07 & 1,72 & 0,13 & 0,01 & 0,18 & 13,65 & 8623 & 0,90 & 0,54 & 1,67 & 0,27 & 0,01 & 0,02 & 6,25 \\
\hline 7450 & 1,30 & 0,11 & 1,77 & 0,16 & & & 10,95 & 8638 & 0,68 & 0,74 & 1,91 & 0,31 & 0,01 & 0,02 & 6,19 \\
\hline 7475 & 1,83 & 0,07 & 1,46 & 0,14 & 0,01 & 0,17 & 10,68 & 8654 & 0,90 & 0,50 & 1,44 & 0,23 & 0,01 & 0,02 & 6,19 \\
\hline 7500 & 1,83 & 0,08 & 1,53 & 0,14 & 0,01 & 0,14 & 11,20 & 8669 & 1,30 & 0,35 & 1,38 & 0,26 & 0,01 & 0,02 & 5,29 \\
\hline 7535 & 1,95 & 0,07 & 1,51 & 0,14 & 0,01 & 0,14 & 10,93 & 8685 & 0,87 & 0,46 & 1,72 & 0,28 & 0,01 & 0,03 & 6,25 \\
\hline 7550 & 1,82 & 0,08 & 1,50 & 0,14 & 0,01 & 0,14 & 10,92 & 8700 & 0,59 & 0,66 & 2,03 & 0,34 & 0,02 & 0,03 & 6,00 \\
\hline 7575 & 3,00 & 0,03 & 0,83 & 0,11 & 0,01 & 0,44 & 7,81 & 8789 & 2,00 & 0,15 & 0,95 & 0,18 & 0,02 & 0,14 & 5,43 \\
\hline 7583 & 1,93 & 0,06 & 1,50 & 0,13 & 0,01 & 0,17 & 11,15 & 8877 & 0,68 & 0,53 & 2,06 & 0,32 & 0,01 & 0,03 & 6,36 \\
\hline 7591 & 1,67 & 0,08 & 1,64 & 0,14 & 0,01 & 0,15 & 11,42 & 8966 & 1,10 & 0,22 & 1,36 & 0,25 & 0,01 & 0,04 & 5,36 \\
\hline 7599 & 1,71 & 0,08 & 1,50 & 0,14 & 0,01 & 0,14 & 10,67 & 9054 & 0,90 & 0,43 & 1,67 & 0,30 & 0,01 & 0,03 & 5,56 \\
\hline \multirow[t]{2}{*}{7607} & 1,84 & 0,07 & 1,59 & 0,13 & 0,01 & 0,15 & 12,17 & 9143 & 0,97 & 0,39 & 1,65 & 0,29 & 0,01 & 0,03 & 5,71 \\
\hline & & & & & & & & 9338 & 1,10 & 0,28 & 2,55 & 0,34 & 0,01 & 0,03 & 7,57 \\
\hline
\end{tabular}


Tabela 5: Espécies de foraminíferos encontradas ao longo do testemunho S03. Espécies expressas em porcentagem. Modelo de idades retirado de Sallun et al. (2012).

\begin{tabular}{|c|c|c|c|c|c|c|c|c|c|c|c|c|c|c|c|c|c|c|c|c|c|c|c|}
\hline Profundidade $(\mathrm{cm})$ & $0-302$ & 31 & $320-3$ & 30-3 & $40-3$ & $350-35$ & $360-36$ & $370-3$ & 380-382 & $390-39$ & $400-40$ & 410-4 & $420-422$ & $440-442$ & $460-462$ & $470-472$ & $520-522$ & $530-532$ & $540-542$ & $550-552$ & $560-562$ & 570-57 & 580-582 \\
\hline Idade & 8385 & 8401 & 8417 & 8433 & 8449 & 8465 & 8481 & 8500 & 8516 & 8532 & 8548 & 8563 & 8579 & 8610 & 8641 & 8656 & 8894 & 8983 & 9072 & 9160 & 9213 & 9338 & 9400 \\
\hline Fração analisada & 1 & 1 & 1 & 1 & 1 & 1 & 1 & 1 & 1 & 1 & 1 & 1 & 1 & 1 & 1 & 1 & 1 & 1 & 1 & 1 & 1 & 1 & 1 \\
\hline Total analisado & 84 & 85 & 85 & 83 & 84 & 85 & 85 & 101 & 85 & 95 & 97 & 130 & 125 & 85 & 88 & 264 & 84 & 95 & 87 & 89 & 85 & 88 & 100 \\
\hline$n^{\circ}$ espécies & 2 & 1 & 2 & 1 & 2 & 1 & 2 & 9 & 3 & 8 & 7 & 15 & 11 & 2 & 2 & 20 & 2 & 4 & 1 & 2 & 2 & 1 & 12 \\
\hline espécimes/10 cc & 84 & 85 & 85 & 83 & 84 & 85 & 85 & 101 & 85 & 95 & 97 & 130 & 125 & 85 & 88 & 264 & 84 & 95 & 87 & 89 & 85 & 88 & 100 \\
\hline Ammonia parkinsoniana & 0,00 & 0,00 & 0,00 & 0,00 & 0,00 & 0,00 & 0,00 & 13,79 & 25,00 & 13,33 & 11,76 & 8,11 & 7,55 & 0,00 & 0,00 & 3,79 & 0,00 & 26,67 & 0,00 & 0,00 & 0,00 & 0,00 & 8,33 \\
\hline Ammonia tepida & 0,00 & 0,00 & 0,00 & 0,00 & 0,00 & 0,00 & 0,00 & 13,79 & 0,00 & 6,67 & 5,88 & 6,76 & 3,77 & 0,00 & 28,57 & 2,27 & 0,00 & 0,00 & 0,00 & 0,00 & 0,00 & 0,00 & 20,83 \\
\hline Ammonia sp. & 0,00 & 0,00 & 0,00 & 0,00 & 0,00 & 0,00 & 0,00 & 27,59 & 0,00 & 13,33 & 0,00 & 1,35 & 3,77 & 0,00 & 0,00 & 3,03 & 0,00 & 0,00 & 0,00 & 0,00 & 0,00 & 0,00 & 4,17 \\
\hline Bolivina doniezi & 0,00 & 0,00 & 0,00 & 0,00 & 0,00 & 0,00 & 0,00 & 0,00 & 0,00 & 0,00 & 0,00 & 0,00 & 0,00 & 0,00 & 0,00 & 0,38 & 0,00 & 0,00 & 0,00 & 0,00 & 0,00 & 0,00 & 0,00 \\
\hline Bolivina pulchella & 0,00 & 0,00 & 0,00 & 0,00 & 0,00 & 0,00 & 0,00 & 0,00 & 0,00 & 0,00 & 0,00 & 1,35 & 0,00 & 0,00 & 0,00 & 0,00 & 0,00 & 0,00 & 0,00 & 0,00 & 0,00 & 0,00 & 0,00 \\
\hline Blysmasphaera brasiliensis & 0,00 & 0,00 & 0,00 & 0,00 & 0,00 & 0,00 & 0,00 & 6,90 & 25,00 & 6,67 & 5,88 & 2,70 & 0,00 & 0,00 & 0,00 & 0,00 & 0,00 & 0,00 & 0,00 & 12,50 & 25,00 & 14,29 & 0,00 \\
\hline Blysmasphaera broennimanni & 66,67 & 100,00 & 75,00 & 50,00 & 66,67 & 100,00 & 75,00 & 0,00 & 0,00 & 0,00 & 0,00 & 0,00 & 0,00 & 0,00 & 14,29 & 0,00 & 0,00 & 0,00 & 0,00 & 0,00 & 25,00 & 0,00 & 0,00 \\
\hline Blysmasphaera sp. & 33,33 & 0,00 & 25,00 & 0,00 & 33,33 & 0,00 & 25,00 & 0,00 & 0,00 & 6,67 & 11,76 & 1,35 & 0,00 & 50,00 & 0,00 & 0,00 & 33,33 & 13,33 & 33,33 & 25,00 & 0,00 & 0,00 & 8,33 \\
\hline Bulimina marginata & 0,00 & 0,00 & 0,00 & 0,00 & 0,00 & 0,00 & 0,00 & 0,00 & 0,00 & 0,00 & 0,00 & 2,70 & 0,00 & 0,00 & 0,00 & 0,38 & 0,00 & 0,00 & 0,00 & 0,00 & 0,00 & 0,00 & 0,00 \\
\hline Bulimina sp. & 0,00 & 0,00 & 0,00 & 0,00 & 0,00 & 0,00 & 0,00 & 0,00 & 0,00 & 0,00 & 0,00 & 1,35 & 0,00 & 0,00 & 0,00 & 0,00 & 0,00 & 0,00 & 0,00 & 0,00 & 0,00 & 0,00 & 0,00 \\
\hline Buliminella elegantissima & 0,00 & 0,00 & 0,00 & 0,00 & 0,00 & 0,00 & 0,00 & 0,00 & 0,00 & 0,00 & 0,00 & 2,70 & 9,43 & 0,00 & 0,00 & 3,03 & 0,00 & 0,00 & 0,00 & 0,00 & 0,00 & 0,00 & 4,17 \\
\hline Brizalina striatula & 0,00 & 0,00 & 0,00 & 0,00 & 0,00 & 0,00 & 0,00 & 0,00 & 0,00 & 0,00 & 0,00 & 1,35 & 0,00 & 0,00 & 0,00 & 1,14 & 0,00 & 0,00 & 0,00 & 0,00 & 0,00 & 0,00 & 0,00 \\
\hline Cibicides dispars & 0,00 & 0,00 & 0,00 & 0,00 & 0,00 & 0,00 & 0,00 & 0,00 & 0,00 & 0,00 & 0,00 & 0,00 & 1,89 & 0,00 & 0,00 & 0,76 & 0,00 & 0,00 & 0,00 & 0,00 & 0,00 & 0,00 & 0,00 \\
\hline Cribroelphidium poyeanum & 0,00 & 0,00 & 0,00 & 0,00 & 0,00 & 0,00 & 0,00 & 0,00 & 0,00 & 0,00 & 0,00 & 0,00 & 0,00 & 0,00 & 0,00 & 0,38 & 0,00 & 0,00 & 0,00 & 0,00 & 0,00 & 0,00 & 4,17 \\
\hline Elphidium advenum limbatum & 0,00 & 0,00 & 0,00 & 0,00 & 0,00 & 0,00 & 0,00 & 0,00 & 0,00 & 0,00 & 0,00 & 0,00 & 0,00 & 0,00 & 0,00 & 0,38 & 0,00 & 0,00 & 0,00 & 0,00 & 0,00 & 0,00 & 0,00 \\
\hline Elphidium discoidale & 0,00 & 0,00 & 0,00 & 0,00 & 0,00 & 0,00 & 0,00 & 3,45 & 25,00 & 20,00 & 11,76 & 4,05 & 3,77 & 0,00 & 0,00 & 2,65 & 0,00 & 13,33 & 0,00 & 0,00 & 0,00 & 0,00 & 4,17 \\
\hline Elphidium excavatum & 0,00 & 0,00 & 0,00 & 0,00 & 0,00 & 0,00 & 0,00 & 0,00 & 0,00 & 6,67 & 5,88 & 2,70 & 3,77 & 0,00 & 0,00 & 2,65 & 0,00 & 0,00 & 0,00 & 0,00 & 0,00 & 0,00 & 8,33 \\
\hline Elphidium sp. & 0,00 & 0,00 & 0,00 & 0,00 & 0,00 & 0,00 & 0,00 & 3,45 & 0,00 & 0,00 & 0,00 & 1,35 & 0,00 & 0,00 & 0,00 & 0,00 & 0,00 & 0,00 & 0,00 & 0,00 & 0,00 & 0,00 & 4,17 \\
\hline Fissurina laevigata & 0,00 & 0,00 & 0,00 & 0,00 & 0,00 & 0,00 & 0,00 & 0,00 & 0,00 & 0,00 & 0,00 & 0,00 & 3,77 & 0,00 & 0,00 & 1,14 & 0,00 & 6,67 & 0,00 & 0,00 & 0,00 & 0,00 & 4,17 \\
\hline Fursenkoina pontoni & 0,00 & 0,00 & 0,00 & 0,00 & 0,00 & 0,00 & 0,00 & 0,00 & 0,00 & 0,00 & 0,00 & 0,00 & 0,00 & 0,00 & 0,00 & 0,00 & 0,00 & 0,00 & 0,00 & 0,00 & 0,00 & 0,00 & 8,33 \\
\hline Hanzawaia boweana & 0,00 & 0,00 & 0,00 & 0,00 & 0,00 & 0,00 & 0,00 & 0,00 & 0,00 & 0,00 & 0,00 & 0,00 & 0,00 & 0,00 & 0,00 & 1,89 & 0,00 & 0,00 & 0,00 & 0,00 & 0,00 & 0,00 & 0,00 \\
\hline Hopkinsina sp. & 0,00 & 0,00 & 0,00 & 0,00 & 0,00 & 0,00 & 0,00 & 0,00 & 0,00 & 0,00 & 0,00 & 0,00 & 1,89 & 0,00 & 0,00 & 0,00 & 0,00 & 0,00 & 0,00 & 0,00 & 0,00 & 0,00 & 0,00 \\
\hline Lagena striata & 0,00 & 0,00 & 0,00 & 0,00 & 0,00 & 0,00 & 0,00 & 0,00 & 0,00 & 0,00 & 0,00 & 0,00 & 0,00 & 25,00 & 0,00 & 0,00 & 0,00 & 0,00 & 0,00 & 0,00 & 0,00 & 0,00 & 0,00 \\
\hline Nonionella atlantica & 0,00 & 0,00 & 0,00 & 0,00 & 0,00 & 0,00 & 0,00 & 0,00 & 0,00 & 0,00 & 0,00 & 0,00 & 0,00 & 0,00 & 0,00 & 0,38 & 0,00 & 0,00 & 0,00 & 0,00 & 0,00 & 0,00 & 4,17 \\
\hline Nonionoides grateloupii & 0,00 & 0,00 & 0,00 & 0,00 & 0,00 & 0,00 & 0,00 & 3,45 & 0,00 & 0,00 & 0,00 & 2,70 & 9,43 & 0,00 & 0,00 & 4,17 & 0,00 & 0,00 & 0,00 & 0,00 & 0,00 & 0,00 & 0,00 \\
\hline Pararotalia cananeiaensis & 0,00 & 0,00 & 0,00 & 0,00 & 0,00 & 0,00 & 0,00 & 13,79 & 0,00 & 13,33 & 5,88 & 43,24 & 30,19 & 0,00 & 0,00 & 54,92 & 33,33 & 0,00 & 0,00 & 0,00 & 0,00 & 0,00 & 0,00 \\
\hline Reussoolina laevis & 0,00 & 0,00 & 0,00 & 0,00 & 0,00 & 0,00 & 0,00 & 0,00 & 0,00 & 0,00 & 0,00 & 0,00 & 0,00 & 0,00 & 0,00 & 0,38 & 0,00 & 0,00 & 0,00 & 0,00 & 0,00 & 0,00 & 0,00 \\
\hline Trifarina angulosa & 0,00 & 0,00 & 0,00 & 0,00 & 0,00 & 0,00 & 0,00 & 0,00 & 0,00 & 0,00 & 0,00 & 0,00 & 0,00 & 0,00 & 0,00 & 0,38 & 0,00 & 0,00 & 0,00 & 0,00 & 0,00 & 0,00 & 0,00 \\
\hline Uvigerina striata & 0,00 & 0,00 & 0,00 & 0,00 & 0,00 & 0,00 & 0,00 & 3,45 & 0,00 & 0,00 & 0,00 & 0,00 & 0,00 & 0,00 & 0,00 & 1,14 & 0,00 & 0,00 & 0,00 & 0,00 & 0,00 & 0,00 & 0,00 \\
\hline Jovem rotalíneo & 0,00 & 0,00 & 0,00 & 0,00 & 0,00 & 0,00 & 0,00 & 3,45 & 0,00 & 0,00 & 0,00 & 9,46 & 11,32 & 0,00 & 0,00 & 10,61 & 0,00 & 0,00 & 0,00 & 0,00 & 0,00 & 0,00 & 0,00 \\
\hline Jovem cribroelphidium & 0,00 & 0,00 & 0,00 & 0,00 & 0,00 & 0,00 & 0,00 & 3,45 & 0,00 & 0,00 & 0,00 & 0,00 & 0,00 & 0,00 & 28,57 & 0,00 & 0,00 & 0,00 & 0,00 & 0,00 & 0,00 & 0,00 & 0,00 \\
\hline Fragmentos & 0,00 & 0,00 & 0,00 & 50,00 & 0,00 & 0,00 & 0,00 & 3,45 & 25,00 & 13,33 & 35,29 & 6,76 & 9,43 & 25,00 & 28,57 & 4,17 & 33,33 & 40,00 & 66,67 & 62,50 & 50,00 & 85,71 & 16,67 \\
\hline
\end{tabular}


Tabela 7: Distribuição granulométrica dos sedimentos do testemunho GeoB6211-2. Dm (Ø)- diâmetro médio, SG- silte grosso, SM- silte médio, SF- silte fino, SMF- silte muito fino, $\sigma_{1^{-}}$desvio padrão, $\mathrm{K}_{\mathrm{G}^{-}}$curtose, $\mathrm{Sk}_{1^{-}}$ assimetria, m.p.s.- muito pobremente selecionado, p.s.- pobremente selecionado. Dados da tese de doutorado de Sebastian Razik (doutorando da Universidade de Bremen), e Razik et al. (2013). Classificação granulométrica de acordo com Wentworth (1922), classificação da escala phi de acordo com Krumbein (1936), classificação do grau de selecionamento dos grãos de acordo com Folk \& Ward (1957) e classificação sedimentológica de acordo com Shepard (1954).

\begin{tabular}{|c|c|c|c|c|c|c|c|c|c|c|c|c|}
\hline \multirow{3}{*}{$\begin{array}{c}\text { Idades } \\
\text { (anos cal A.P.) }\end{array}$} & \multicolumn{7}{|c|}{ Parâmetros estatísticos (phi) } & \multicolumn{4}{|c|}{ Faixa Granulométrica (\%) } & \multirow{3}{*}{$\begin{array}{c}\text { Relação } \\
\text { fino/grosso }\end{array}$} \\
\hline & \multirow{2}{*}{$\operatorname{Dm}(\varnothing)$} & \multirow{2}{*}{$\begin{array}{c}\text { Krumbein } \\
(1936)\end{array}$} & \multirow{2}{*}{$\sigma_{1}$} & \multirow{2}{*}{$\begin{array}{c}\text { Folk \& Ward } \\
(1957)\end{array}$} & \multirow{2}{*}{$\mathrm{SK}_{1}$} & \multirow{2}{*}{ Shepard (1954) } & \multirow{2}{*}{$\mathrm{K}_{\mathrm{G}}$} & Areia & \multicolumn{3}{|c|}{\begin{tabular}{|c|} 
Pelíticos \\
\end{tabular}} & \\
\hline & & & & & & & & Areia & Silte & Argila & Total & \\
\hline 0,074 & 7,05 & SMF & 2,00 & p.s. & $-0,01$ & Silte argiloso & 2,22 & 6,99 & 60,45 & 32,54 & 92,99 & 13,31 \\
\hline 0,441 & 7,08 & SMF & 1,93 & p.s. & $-0,03$ & Silte argiloso & 2,39 & 6,35 & 62,75 & 530,88 & 93,63 & 14,74 \\
\hline 0,809 & 6,90 & SF & 2,03 & m.p.s. & $-0,04$ & Silte argiloso & 2,29 & 9,85 & 60,85 & 29,28 & 90,13 & 9,15 \\
\hline 1,176 & 6,84 & SF & 2,01 & m.p.s. & 0,01 & Silte argiloso & 2,29 & 9,45 & 62,53 & 28,02 & 90,55 & 9,58 \\
\hline 1,652 & 7,08 & SMF & 1,91 & p.s. & $-0,05$ & Silte argiloso & 2,43 & 5,95 & 63,56 & 30,47 & 94,03 & 15,80 \\
\hline 2,155 & 7,08 & SMF & 2,04 & m.p.s. & $-0,03$ & Silte argiloso & 2,13 & 7,47 & 58,42 & 34,13 & 92,55 & 12,39 \\
\hline 2,658 & 6,43 & $\mathrm{SF}$ & 2,13 & m.p.s. & 0,26 & Silte argiloso & 2,11 & 14,24 & 61,40 & 24,36 & 85,76 & 6,02 \\
\hline 3,149 & 6,00 & SF & 2,17 & m.p.s. & 0,48 & silte areno-argiloso & 2,23 & 21,02 & 58,96 & 20,00 & 78,96 & 3,76 \\
\hline 3,574 & 6,13 & SF & 2,12 & m.p.s. & 0,37 & Silte argiloso & 2,22 & 18,66 & 61,07 & 20,27 & 81,34 & 4,36 \\
\hline 4,094 & 5,59 & SM & 2,19 & m.p.s. & 0,68 & silte arenoso & 2,40 & 30,53 & 52,27 & 717,20 & 69,47 & 2,28 \\
\hline 4,567 & 5,67 & SM & 2,19 & m.p.s. & 0,65 & silte arenoso & 2,38 & 28,36 & 53,89 & 17,73 & 71,62 & 2,53 \\
\hline 5,157 & 5,70 & SM & 2,15 & m.p.s. & 0,60 & silte arenoso & 2,36 & 27,45 & 55,33 & 17,23 & 72,56 & 2,64 \\
\hline 5,923 & 5,61 & SM & 2,18 & m.p.s. & 0,67 & silte arenoso & 2,40 & 30,45 & 52,53 & 17,03 & 69,56 & 2,28 \\
\hline 6,690 & 5,76 & SM & 2,21 & m.p.s. & 0,52 & silte arenoso & 2,21 & 28,66 & 52,99 & 18,36 & 71,35 & 2,49 \\
\hline 7,457 & 5,51 & SM & 2,20 & m.p.s. & 0,72 & silte arenoso & 2,48 & 33,25 & 50,63 & 16,14 & $+66,77$ & 2,01 \\
\hline 8,407 & 5,38 & SM & 2,18 & m.p.s. & 0,79 & silte arenoso & 2,56 & 36,50 & 48,36 & 15,13 & 63,49 & 1,74 \\
\hline 9,403 & 6,29 & SF & 2,20 & m.p.s. & 0,21 & Silte argilo-arenoso & 2,02 & 20,13 & 56,11 & 23,78 & 79,89 & 3,97 \\
\hline 10,400 & 6,94 & SF & 1,99 & p.s. & $-0,07$ & Silte argiloso & 2,33 & 9,62 & 60,60 & 29,75 & 90,35 & 9,39 \\
\hline 10,650 & 7,11 & SMF & 1,85 & p.s. & $-0,05$ & Silte argiloso & 2,50 & 5,95 & 63,31 & 30,77 & 94,08 & 15,82 \\
\hline 11,060 & 6,69 & SF & 2,06 & m.p.s. & 0,04 & Silte argiloso & 2,17 & 12,97 & 60,12 & 26,93 & 87,05 & 6,71 \\
\hline 11,710 & 7,15 & SMF & 1,86 & p.s. & $-0,03$ & Silte argiloso & 2,49 & 5,37 & 63,03 & 31,65 & 94,68 & 17,65 \\
\hline 12,360 & 7,06 & SMF & 1,89 & p.s. & $-0,06$ & Silte argiloso & 2,46 & 6,62 & 62,69 & 30,68 & 93,37 & 14,10 \\
\hline 13,010 & 7,04 & SMF & 1,96 & p.s. & $-0,10$ & Silte argiloso & 2,37 & 8,37 & 60,43 & 31,22 & 91,65 & 10,96 \\
\hline 13,660 & 6,78 & $\mathrm{SF}$ & 2,04 & m.p.s. & $-0,08$ & Silte argiloso & 2,23 & 13,09 & 58,65 & 28,29 & 86,94 & 6,64 \\
\hline 14,086 & 6,97 & SF & 2,03 & m.p.s. & $-0,15$ & Silte argiloso & 2,32 & 10,83 & 58,03 & 31,11 & 89,14 & 8,23 \\
\hline 14,175 & 7,00 & SMF & 2,01 & m.p.s. & $-0,09$ & Silte argiloso & 2,30 & 9,23 & 59,52 & 31,26 & 90,78 & 9,83 \\
\hline 14,264 & 7,00 & SMF & 2,04 & m.p.s. & $-0,09$ & Silte argiloso & 2,25 & 9,89 & 58,20 & 31,94 & $+90,14$ & 9,12 \\
\hline 14,354 & 6,87 & SF & 2,04 & m.p.s. & $-0,08$ & Silte argiloso & 2,25 & 11,50 & 58,94 & 29,60 & 88,54 & 7,70 \\
\hline 14,479 & 6,89 & SF & 1,95 & p.s. & $-0,01$ & Silte argiloso & 2,30 & 8,50 & 62,85 & 28,66 & 91,51 & 10,76 \\
\hline 14,568 & 6,52 & SF & 2,02 & m.p.s. & 0,10 & Silte argiloso & 2,23 & 13,81 & 62,62 & 23,58 & 86,20 & 6,24 \\
\hline 14,657 & 7,05 & SMF & 1,89 & p.s. & $-0,11$ & Silte argiloso & 2,40 & 7,28 & 61,56 & 31,17 & 92,73 & 12,74 \\
\hline 14,747 & 6,94 & SF & 1,99 & p.s. & $-0,12$ & Silte argiloso & 2,27 & 9,97 & 59,34 & 30,67 & 90,01 & 9,02 \\
\hline 14,836 & 7,04 & SMF & 1,96 & p.s. & $-0,15$ & Silte argiloso & 2,29 & 8,47 & 58,75 & 32,80 & 91,55 & 10,80 \\
\hline 14,925 & 7,01 & SMF & 2,00 & p.s. & $-0,12$ & Silte argiloso & 2,23 & 9,18 & 57,96 & 32,85 & 90,81 & 9,90 \\
\hline 14,988 & 6,59 & SF & 2,18 & m.p.s. & 0,02 & Silte argiloso & 1,96 & 16,84 & 54,36 & 28,82 & 83,18 & 4,94 \\
\hline 15,104 & 6,81 & SF & 2,07 & m.p.s. & $-0,04$ & Silte argiloso & 2,12 & 12,01 & 57,92 & 30,04 & 87,96 & 7,33 \\
\hline 15,193 & 6,84 & SF & 2,16 & m.p.s. & $-0,03$ & Silte argiloso & 2,03 & 12,74 & 55,45 & 31,81 & 87,26 & 6,85 \\
\hline 15,283 & 6,98 & SF & 1,96 & p.s. & $-0,10$ & Silte argiloso & 2,24 & 8,26 & 59,69 & 32,04 & $+91,73$ & 11,10 \\
\hline 15,372 & 7,03 & SMF & 2,01 & m.p.s. & $-0,07$ & Silte argiloso & 2,23 & 8,57 & 59,03 & 32,41 & 91,44 & 10,67 \\
\hline 15,461 & 7,45 & SMF & 1,83 & p.s. & $-0,23$ & Silte argiloso & 2,56 & 4,39 & 56,98 & 38,62 & 95,60 & 21,77 \\
\hline 15,539 & 7,36 & SMF & 1,84 & p.s. & $-0,22$ & Silte argiloso & 2,52 & 4,75 & 58,00 & 37,24 & $+95,24$ & 20,04 \\
\hline 15,600 & 6,94 & $\mathrm{SF}$ & 2,05 & m.p.s. & $-0,09$ & Silte argiloso & 2,18 & 10,83 & 57,18 & 31,99 & 89,17 & 8,24 \\
\hline 15,660 & 7,27 & SMF & 1,84 & p.s. & $-0,22$ & Silte argiloso & 2,60 & 5,68 & 59,11 & 35,20 & 94,31 & 16,61 \\
\hline 15,721 & 7,23 & SMF & 1,90 & p.s. & $-0,19$ & Silte argiloso & 2,46 & 6,35 & 58,49 & 35,15 & 93,64 & 14,75 \\
\hline 15,782 & 7,19 & SMF & 2,01 & m.p.s. & $-0,13$ & Silte argiloso & 2,32 & 7,57 & 57,59 & 34,81 & 92,40 & 12,21 \\
\hline 15,843 & 6,88 & SF & 2,11 & m.p.s. & $-0,08$ & Silte argiloso & 2,14 & 12,24 & 56,17 & 31,61 & 87,78 & 7,17 \\
\hline 15,903 & 6,98 & SF & 2,08 & m.p.s. & $-0,18$ & Silte argiloso & 2,25 & 11,18 & 55,65 & 33,13 & 88,78 & 7,94 \\
\hline 15,964 & 7,20 & SMF & 1,92 & p.s. & $-0,15$ & Silte argiloso & 2,40 & 6,40 & 58,63 & 34,93 & 93,56 & 14,62 \\
\hline 16,037 & 7,03 & SMF & 2,01 & m.p.s. & 0,00 & Silte argiloso & 2,19 & 7,21 & 60,46 & 32,38 & 92,84 & 12,88 \\
\hline 16,097 & 7,19 & SMF & 1,90 & p.s. & $-0,02$ & Silte argiloso & 2,29 & 4,82 & 61,22 & 33,95 & 95,17 & 19,74 \\
\hline 16,158 & 7,03 & SMF & 1,99 & p.s. & $-0,07$ & Silte argiloso & 2,23 & 7,58 & 59,40 & 33,05 & 92,45 & 12,19 \\
\hline 16,219 & 6,78 & $\mathrm{SF}$ & 1,99 & p.s. & 0,06 & Silte argiloso & 2,28 & 9,63 & 63,14 & 27,27 & 90,41 & 9,39 \\
\hline 16,280 & 6,92 & SF & 1,95 & p.s. & 0,05 & Silte argiloso & 2,28 & 7,40 & 63,25 & 29,36 & 92,61 & 12,52 \\
\hline 16,340 & 6,78 & SF & 1,97 & p.s. & 0,03 & Silte argiloso & 2,32 & 9,72 & 63,38 & 26,90 & 90,28 & 9,28 \\
\hline 16,401 & 6,88 & SF & 1,99 & p.s. & 0,01 & Silte argiloso & 2,27 & 9,02 & 61,81 & 29,11 & 90,92 & 10,08 \\
\hline 16,462 & 6,91 & SF & 1,94 & p.s. & 0,03 & Silte argiloso & 2,35 & 7,71 & 63,74 & 28,55 & 92,29 & 11,98 \\
\hline 16,522 & 6,83 & SF & 2,03 & m.p.s. & 0,05 & Silte argiloso & 2,25 & 10,06 & 61,43 & 28,53 & 89,96 & 8,94 \\
\hline
\end{tabular}


Tabela 7 (continuação): Distribuição granulométrica dos sedimentos do testemunho GeoB6211-2. Dm (Ø)diâmetro médio, SG- silte grosso, SM- silte médio, SF- silte fino, SMF- silte muito fino, $\sigma_{\mathrm{I}^{-}}$desvio padrão, $\mathrm{K}_{\mathrm{G}^{-}}$ curtose, $\mathrm{Sk}_{1}$ - assimetria, m.p.s.- muito pobremente selecionado, p.s.- pobremente selecionado. Dados da tese de doutorado de Sebastian Razik (doutorando da Universidade de Bremen), e Razik et al. (2013). Classificação granulométrica de acordo com Wentworth (1922), classificação da escala phi de acordo com Krumbein (1936), classificação do grau de selecionamento dos grãos de acordo com Folk \& Ward (1957) e classificação sedimentológica de acordo com Shepard (1954).

\begin{tabular}{|c|c|c|c|c|c|c|c|c|c|c|c|c|}
\hline \multirow{3}{*}{\begin{tabular}{|c} 
Idades \\
(anos cal A.P.)
\end{tabular}} & \multicolumn{7}{|c|}{ Parâmetros estatísticos (phi) } & \multicolumn{4}{|c|}{ Faixa Granulométrica (\%) } & \multirow{3}{*}{$\begin{array}{l}\text { Relação } \\
\text { fino/grosso }\end{array}$} \\
\hline & \multirow{2}{*}{ Dm (ø) } & \multirow{2}{*}{$\begin{array}{c}\text { Krumbein } \\
(1936)\end{array}$} & \multirow{2}{*}{$\sigma_{\mathrm{I}}$} & \multirow{2}{*}{$\begin{array}{c}\text { Folk \& Ward } \\
\quad(1957)\end{array}$} & \multirow{2}{*}{$\mathrm{SK}_{1}$} & \multirow{2}{*}{ Shepard (1954) } & \multirow{2}{*}{$\mathrm{K}_{\mathrm{G}}$} & \multirow{2}{*}{$\begin{array}{l}\text { Areia } \\
\text { Areia } \\
\end{array}$} & & Pelítico & & \\
\hline & & & & & & & & & Silte & Argila & Total & \\
\hline 16,583 & 6,88 & SF & 1,99 & p.s. & $-0,01$ & Silte argiloso & 2,31 & 9,27 & 61,80 & 28,92 & 90,72 & 9,78 \\
\hline 16,644 & 6,72 & SF & 2,01 & m.p.s. & 0,06 & Silte argiloso & 2,24 & 10,93 & 62,25 & 26,80 & 89,05 & 8,15 \\
\hline 16,704 & 6,45 & SF & 2,08 & m.p.s. & 0,17 & Silte argiloso & 2,17 & 15,26 & 61,06 & 23,72 & 84,78 & 5,56 \\
\hline 16,765 & 6,81 & SF & 1,91 & p.s. & 0,12 & Silte argiloso & 2,38 & 7,43 & 66,28 & 26,29 & 92,57 & 12,46 \\
\hline 16,826 & 6,75 & SF & 1,98 & p.s. & 0,09 & Silte argiloso & 2,29 & 9,83 & 63,68 & 26,46 & 90,14 & 9,17 \\
\hline 16,888 & 6,86 & SF & 1,94 & p.s. & 0,03 & Silte argiloso & 2,34 & 8,25 & 64,00 & 27,77 & 91,77 & 11,13 \\
\hline 16,952 & 7,21 & SMF & 1,89 & p.s. & $-0,10$ & Silte argiloso & 2,39 & 5,39 & 60,63 & 34,01 & 94,64 & 17,56 \\
\hline 17,016 & 7,12 & SMF & 1,87 & p.s. & $-0,14$ & Silte argiloso & 2,42 & 5,98 & 61,10 & 32,90 & 94,00 & 15,72 \\
\hline 17,080 & 7,12 & SMF & 1,85 & p.s. & 0,06 & Silte argiloso & 2,16 & 3,00 & 63,30 & 33,72 & 97,02 & 32,31 \\
\hline 17,144 & 6,93 & SF & 1,75 & p.s. & 0,15 & Silte argiloso & 2,61 & 4,36 & 70,25 & 25,38 & 95,63 & 21,95 \\
\hline 17,208 & 6,63 & SF & 1,84 & p.s. & 0,17 & Silte argiloso & 2,53 & 8,33 & 69,91 & 21,81 & 91,72 & 11,01 \\
\hline 17,272 & 6,93 & SF & 1,93 & p.s. & $-0,02$ & Silte argiloso & 2,30 & 7,56 & 62,51 & 29,91 & 92,42 & 12,23 \\
\hline 17,336 & 7,03 & SMF & 1,93 & p.s. & $-0,07$ & Silte argiloso & 2,31 & 7,04 & 61,15 & 31,79 & 92,94 & 13,20 \\
\hline 17,400 & 6,94 & $\mathrm{SF}$ & 1,93 & p.s. & $-0,04$ & Silte argiloso & 2,34 & 7,61 & 62,75 & 29,65 & 92,40 & 12,14 \\
\hline 17,467 & 6,89 & SF & 1,94 & p.s. & $-0,04$ & Silte argiloso & 2,31 & 8,28 & 62,75 & 28,95 & 91,70 & 11,07 \\
\hline 17,533 & 6,95 & SF & 1,98 & p.s. & $-0,05$ & Silte argiloso & 2,21 & 8,07 & 60,44 & 31,51 & 91,95 & 11,40 \\
\hline 17,600 & 7,05 & SMF & 1,91 & p.s. & $-0,06$ & Silte argiloso & 2,33 & 6,45 & 61,64 & 31,92 & 93,56 & 14,50 \\
\hline 17,667 & 6,91 & $\mathrm{SF}$ & 1,95 & p.s. & 0,00 & Silte argiloso & 2,27 & 7,75 & 62,51 & 29,79 & 92,30 & 11,91 \\
\hline 17,733 & 6,64 & SF & 1,90 & p.s. & 0,16 & Silte argiloso & 2,42 & 8,90 & 67,78 & 23,31 & 91,09 & 10,23 \\
\hline 17,800 & 6,63 & SF & 1,82 & p.s. & 0,22 & Silte argiloso & 2,52 & 7,79 & 70,35 & 21,84 & 92,19 & 11,83 \\
\hline 17,867 & 6,45 & SF & 1,89 & p.s. & 0,21 & Silte argiloso & 2,44 & 11,13 & 68,60 & 20,28 & 88,88 & 7,99 \\
\hline 17,933 & 6,74 & SF & 1,84 & p.s. & 0,15 & Silte argiloso & 2,49 & 7,24 & 68,91 & 23,85 & 92,76 & 12,81 \\
\hline 18,000 & 6,45 & SF & 1,80 & p.s. & 0,34 & Silte argiloso & 2,64 & 8,36 & 73,09 & 18,56 & 91,65 & 10,96 \\
\hline 18,067 & 6,58 & SF & 1,92 & p.s. & 0,17 & Silte argiloso & 2,40 & 10,17 & 67,27 & 22,55 & 89,82 & 8,83 \\
\hline 18,133 & 6,54 & SF & 1,93 & p.s. & 0,16 & Silte argiloso & 2,41 & 10,79 & 67,19 & 22,03 & 89,22 & 8,27 \\
\hline 18,200 & 6,72 & SF & 1,82 & p.s. & 0,24 & Silte argiloso & 2,49 & 6,19 & 70,46 & 23,34 & 93,80 & 15,15 \\
\hline 18,267 & 6,82 & SF & 1,83 & p.s. & 0,15 & Silte argiloso & 2,47 & 6,05 & 68,83 & 25,13 & 93,96 & 15,52 \\
\hline 18,333 & 6,66 & SF & 1,90 & p.s. & 0,18 & Silte argiloso & 2,39 & 8,58 & 67,69 & 23,74 & 91,43 & 10,65 \\
\hline 18,400 & 6,60 & SF & 1,85 & p.s. & 0,23 & Silte argiloso & 2,48 & 7,78 & 70,21 & 21,99 & 92,20 & 11,85 \\
\hline 18,467 & 6,68 & SF & 1,82 & p.s. & 0,21 & Silte argiloso & 2,49 & 6,63 & 70,57 & 22,83 & 93,40 & 14,09 \\
\hline 18,533 & 6,61 & SF & 1,91 & p.s. & 0,24 & Silte argiloso & 2,38 & 8,61 & 68,17 & 23,23 & 91,40 & 10,62 \\
\hline 18,600 & 7,05 & SMF & 1,86 & p.s. & 0,01 & Silte argiloso & 2,34 & 5,22 & 63,65 & 31,10 & 94,75 & 18,16 \\
\hline 18,620 & 6,98 & SF & 1,87 & p.s. & 0,02 & Silte argiloso & 2,46 & 6,47 & 65,27 & 28,23 & 93,50 & 14,45 \\
\hline 18,641 & 6,89 & SF & 1,99 & p.s. & 0,03 & Silte argiloso & 2,25 & 8,78 & 62,44 & 28,82 & 91,26 & 10,39 \\
\hline 18,661 & 7,00 & SMF & 1,88 & p.s. & $-0,01$ & Silte argiloso & 2,39 & 6,40 & 64,20 & 29,37 & 93,57 & 14,61 \\
\hline 18,681 & 7,03 & SMF & 1,97 & p.s. & $-0,04$ & Silte argiloso & 2,23 & 7,29 & 60,34 & 32,37 & 92,71 & 12,71 \\
\hline 18,702 & 7,12 & SMF & 1,84 & p.s. & 0,04 & Silte argiloso & 2,42 & 4,46 & 65,10 & 30,48 & 95,58 & 21,43 \\
\hline 18,722 & 7,03 & SMF & 1,88 & p.s. & 0,05 & Silte argiloso & 2,33 & 5,55 & 64,45 & 30,00 & 94,45 & 17,01 \\
\hline 18,743 & 6,94 & $\mathrm{SF}$ & 1,98 & p.s. & $-0,03$ & Silte argiloso & 2,28 & 8,50 & 61,44 & 30,09 & 91,53 & 10,77 \\
\hline 18,763 & 6,96 & SF & 1,84 & p.s. & 0,03 & Silte argiloso & 2,52 & 6,28 & 66,47 & 27,27 & 93,74 & 14,92 \\
\hline 18,783 & 6,98 & SF & 1,99 & p.s. & $-0,01$ & Silte argiloso & 2,24 & 7,72 & 61,04 & 31,25 & 92,29 & 11,95 \\
\hline 18,804 & 6,92 & SF & 1,95 & p.s. & $-0,04$ & Silte argiloso & 2,33 & 8,66 & 62,38 & 28,98 & 91,36 & 10,55 \\
\hline 18,824 & 6,94 & SF & 1,99 & p.s. & $-0,06$ & Silte argiloso & 2,22 & 9,08 & 59,72 & 31,21 & 90,93 & 10,01 \\
\hline 18,844 & 6,40 & SF & 2,10 & m.p.s. & 0,27 & Silte argiloso & 2,09 & 14,53 & 61,90 & 23,59 & 85,49 & 5,88 \\
\hline 18,865 & 6,94 & SF & 1,94 & p.s. & $-0,03$ & Silte argiloso & 2,25 & 8,15 & 61,45 & 30,40 & 91,85 & 11,27 \\
\hline 18,885 & 7,12 & SMF & 1,91 & p.s. & $-0,13$ & Silte argiloso & 2,33 & 6,53 & 59,89 & 33,62 & 93,51 & 14,31 \\
\hline 18,906 & 6,91 & SF & 1,99 & p.s. & $-0,04$ & Silte argiloso & 2,20 & 9,07 & 60,17 & 30,77 & 90,94 & 10,03 \\
\hline 18,926 & 6,88 & SF & 2,02 & m.p.s. & $-0,05$ & Silte argiloso & 2,17 & 9,90 & 59,19 & 30,90 & 90,09 & 9,10 \\
\hline 18,946 & 7,07 & SMF & 1,88 & p.s. & $-0,06$ & Silte argiloso & 2,36 & 6,09 & 62,25 & 31,66 & 93,91 & 15,43 \\
\hline 18,967 & 7,03 & SMF & 1,92 & p.s. & $-0,04$ & Silte argiloso & 2,28 & 6,62 & 61,68 & 31,74 & 93,42 & 14,11 \\
\hline 18,987 & 6,52 & SF & 1,96 & p.s. & 0,27 & Silte argiloso & 2,25 & 9,62 & 66,35 & 23,97 & 90,32 & 9,38 \\
\hline 19,011 & 6,71 & SF & 2,02 & m.p.s. & 0,10 & Silte argiloso & 2,14 & 10,21 & 61,86 & 27,92 & 89,78 & 8,80 \\
\hline 19,032 & 7,05 & SMF & 1,96 & p.s. & $-0,10$ & Silte argiloso & 2,23 & 7,15 & 59,30 & 33,50 & 92,80 & 12,98 \\
\hline 19,052 & 6,87 & SF & 2,01 & m.p.s. & 0,02 & Silte argiloso & 2,14 & 8,57 & 60,90 & 30,55 & 91,45 & 10,67 \\
\hline 19,073 & 6,82 & SF & 2,00 & p.s. & 0,07 & Silte argiloso & 2,16 & 8,95 & 61,76 & 29,29 & 91,05 & 10,17 \\
\hline 19,093 & 6,91 & SF & 1,99 & p.s. & 0,02 & Silte argiloso & 2,17 & 8,19 & 61,08 & 30,74 & 91,82 & 11,22 \\
\hline 19,113 & 6,75 & SF & 1,99 & p.s. & 0,07 & Silte argiloso & 2,18 & 9,66 & 62,52 & 27,81 & 90,33 & 9,35 \\
\hline 19,134 & 6,23 & SF & 1,91 & p.s. & 0,38 & Silte argiloso & 2,49 & 12,85 & 69,12 & 18,02 & 87,14 & 6,78 \\
\hline 19,154 & 6,23 & SF & 1,92 & p.s. & 0,42 & Silte argiloso & 2,46 & 12,55 & 69,06 & 18,36 & 87,42 & 6,96 \\
\hline
\end{tabular}


Tabela 8: Dados geoquímicos dos sedimentos do testemunho GeoB6211-2. Os dados originais cedidos por Chiessi (2008) e Chiessi et al. (2008,2009), expressos em contagens por segundo (cont./seg.) foram normalizados pelo elemento Al.

\begin{tabular}{|c|c|c|c|c|c|c|c|c|c|c|c|c|c|c|c|}
\hline Idade (anos cal A.P.) & Al (count/seg.) & K/AI & $\mathrm{Ca} / \mathrm{Al}$ & Ti/AI & $\mathrm{Fe} / \mathrm{Al}$ & $\mathrm{Ti} / \mathrm{Ca}$ & $\mathrm{Fe} / \mathrm{K}$ & Idade (anos cal A.P.) & Al (count/seg.) & K/AI & $\mathrm{Ca} / \mathrm{Al}$ & Ti/Al & Fe/Al & $\mathrm{Ti} / \mathrm{Ca}$ & $\mathrm{Fe} / \mathrm{K}$ \\
\hline 147 & & & & & & & & 17466 & 61,10 & 3,85 & 1,76 & 3,41 & 19,40 & 1,93 & 5,04 \\
\hline 882 & 39,07 & 4,14 & 8,89 & 4,27 & 25,81 & 0,48 & 6,24 & 17600 & 65,27 & 3,70 & 1,49 & 3,16 & 18,31 & 2,12 & 4,95 \\
\hline 1828 & 41,00 & 4,20 & 10,35 & 4,02 & 24,63 & 0,39 & 5,87 & 17733 & 59,77 & 3,96 & 1,72 & 3,43 & 20,25 & 2,00 & 5,11 \\
\hline 2984 & 40,63 & 4,38 & 12,24 & 3,94 & 21,94 & 0,32 & 5,00 & 17866 & 64,17 & 3,72 & 1,41 & 3,24 & 18,42 & 2,29 & 4,95 \\
\hline 4140 & 35,67 & 4,58 & 14,00 & 4,22 & 24,43 & 0,30 & 5,33 & 18000 & 59,97 & 3,82 & 1,51 & 3,46 & 19,27 & 2,29 & 5,05 \\
\hline 5297 & 44,10 & 4,19 & 12,40 & 3,68 & 18,87 & 0,30 & 4,50 & 18133 & 60,13 & 3,91 & 1,47 & 3,43 & 19,85 & 2,34 & 5,08 \\
\hline 6454 & 44,03 & 4,09 & 12,60 & 4,03 & 17,80 & 0,32 & 4,36 & 18266 & 61,10 & 3,91 & 1,92 & 3,34 & 19,15 & 1,74 & 4,90 \\
\hline 7610 & 48,67 & 3,80 & 11,02 & 3,59 & 17,10 & 0,33 & 4,50 & 18400 & 63,97 & 3,86 & 1,57 & 3,24 & 19,12 & 2,06 & 4,96 \\
\hline 8898 & 44,30 & 4,85 & 2,32 & 4,41 & 26,16 & 1,90 & 5,39 & 18533 & 59,77 & 3,86 & 1,66 & 3,62 & 19,97 & 2,18 & 5,17 \\
\hline 10186 & 52,40 & 4,32 & 2,39 & 3,87 & 21,84 & 1,62 & 5,06 & 18620 & 65,27 & 3,62 & 1,52 & 3,24 & 18,66 & 2,13 & 5,16 \\
\hline 11474 & 44,37 & 4,61 & 2,34 & 4,37 & 26,09 & 1,86 & 5,66 & 18661 & 69,27 & 3,53 & 1,49 & 3,13 & 17,48 & 2,10 & 4,95 \\
\hline 12762 & 36,13 & 5,37 & 5,26 & 5,18 & 31,25 & 0,98 & 5,82 & 18702 & 56,77 & 4,42 & 1,68 & 3,77 & 22,32 & 2,25 & 5,05 \\
\hline 1405 & 53,50 & 4,33 & 2,06 & 3,67 & 22,31 & 1,78 & 5,16 & 18743 & 53,70 & 4,04 & 1,92 & 3,52 & 25,61 & 1,83 & 6,34 \\
\hline 14176 & 52,07 & 4,07 & 2,51 & 3,90 & 23,07 & 1,56 & 5,66 & 18783 & 59,93 & 3,98 & 1,91 & 3,60 & 19,54 & 1,89 & 4,90 \\
\hline 14303 & 42,63 & 4,85 & 3,11 & 4,73 & 27,55 & 1,52 & 5,68 & 18824 & 53,87 & 4,31 & 1,84 & 3,96 & 21,74 & 2,15 & 5,05 \\
\hline 14429 & 57,03 & 3,97 & 1,95 & 3,47 & 20,14 & 1,78 & 5,08 & 18865 & 60,70 & 3,76 & 1,37 & 3,46 & 22,33 & 2,53 & 5,94 \\
\hline 14555 & 55,23 & 4,28 & 1,99 & 3,57 & 20,71 & 1,80 & 4,84 & 18905 & 62,10 & 3,67 & 1,79 & 3,62 & 17,83 & 2,02 & 4,85 \\
\hline 14681 & 54,23 & 4,24 & 2,24 & 3,76 & 20,87 & 1,68 & 4,93 & 18946 & 64,13 & 3,69 & 1,75 & 3,45 & 18,52 & 1,97 & 5,02 \\
\hline 14807 & 49,93 & 4,58 & 2,22 & 4,05 & 23,78 & 1,83 & 5,19 & 18987 & 62,23 & 3,75 & 1,78 & 3,67 & 19,05 & 2,06 & 5,09 \\
\hline 14934 & 44,67 & 4,28 & 2,83 & 4,25 & 24,31 & 1,50 & 5,68 & 19027 & 67,83 & 3,67 & 1,72 & 3,13 & 17,72 & 1,83 & 4,83 \\
\hline 15060 & 53,90 & 4,49 & 1,66 & 3,60 & 22,71 & 2,17 & 5,06 & 19068 & 64,60 & 3,76 & 1,85 & 3,29 & 18,42 & 1,78 & 4,90 \\
\hline 15186 & 46,50 & 4,75 & 3,08 & 4,18 & 26,51 & 1,36 & 5,58 & 19109 & 68,30 & 3,58 & 1,35 & 3,18 & 17,45 & 2,37 & 4,88 \\
\hline 15326 & 54,37 & 4,33 & 1,99 & 3,66 & 22,47 & 1,84 & 5,19 & 19150 & 64,47 & 3,67 & 1,64 & 3,35 & 18,11 & 2,04 & 4,93 \\
\hline 15480 & 58,43 & 4,28 & 2,10 & 3,30 & 21,17 & 1,57 & 4,94 & 19153 & 61,90 & 3,58 & 1,45 & 3,61 & 18,30 & 2,49 & 5,12 \\
\hline 15633 & 55,53 & 4,19 & 2,13 & 3,61 & 20,71 & 1,69 & 4,95 & 19157 & 56,40 & 4,08 & 1,89 & 3,80 & 21,01 & 2,01 & 5,15 \\
\hline 15787 & 54,30 & 4,07 & 2,56 & 3,56 & 23,22 & 1,39 & 5,70 & 19160 & 52,63 & 4,01 & 1,71 & 3,82 & 24,01 & 2,24 & 5,99 \\
\hline 15941 & 59,83 & 3,93 & 2,08 & 3,76 & 19,35 & 1,81 & 4,93 & 19164 & 59,93 & 3,91 & 1,47 & 3,52 & 21,77 & 2,40 & 5,56 \\
\hline 16094 & 54,90 & 4,37 & 1,71 & 3,84 & 21,74 & 2,25 & 4,97 & 19167 & 67,40 & 3,58 & 1,71 & 3,23 & 17,53 & 1,89 & 4,90 \\
\hline 16248 & 51,97 & 4,40 & 2,36 & 4,04 & 22,29 & 1,71 & 5,07 & 19171 & 57,97 & 3,85 & 1,80 & 3,58 & 20,94 & 1,99 & 5,44 \\
\hline 16402 & 67,20 & 3,75 & 1,51 & 3,11 & 17,66 & 2,06 & 4,72 & 19175 & 65,10 & 3,58 & 1,62 & 3,25 & 18,39 & 2,01 & 5,14 \\
\hline 16555 & 48,97 & 4,60 & 1,98 & 4,21 & 25,20 & 2,13 & 5,48 & 19178 & 61,97 & 3,77 & 1,52 & 3,41 & 20,11 & 2,24 & 5,33 \\
\hline 16708 & 51,33 & 4,63 & 1,61 & 3,86 & 22,87 & 2,40 & 4,94 & 19182 & 65,10 & 3,64 & 1,76 & 3,22 & 18,24 & 1,83 & 5,01 \\
\hline 16862 & 56,57 & 4,14 & 1,64 & 3,56 & 21,69 & 2,17 & 5,24 & 19185 & 66,23 & 3,59 & 1,76 & 3,23 & 17,57 & 1,83 & 4,90 \\
\hline 17016 & 46,93 & 4,86 & 1,65 & 4,59 & 25,81 & 2,78 & 5,31 & 19189 & 55,70 & 4,07 & 1,93 & 3,80 & 20,81 & 1,97 & 5,11 \\
\hline 17169 & 62,53 & 3,88 & 1,60 & 3,26 & 19,41 & 2,04 & 5,00 & 19193 & 60,77 & 3,71 & 2,00 & 3,57 & 19,21 & 1,79 & 5,17 \\
\hline 17323 & 56,23 & 4,19 & 1,82 & 3,54 & 21,15 & 1,94 & 5,05 & 19196 & 62,93 & 3,49 & 2,48 & 3,06 & 18,46 & 1,24 & 5,29 \\
\hline
\end{tabular}


Tabela 9: Espécies de foraminíferos encontradas ao longo do testemunho GeoB6211-2. Espécies expressas em porcentagem. Modelo de idades retirado de Chiessi et al. (2008).

\begin{tabular}{|c|c|c|c|c|c|c|c|c|c|c|c|c|c|c|c|c|c|c|c|c|c|c|}
\hline Profundidade $(\mathrm{cm})$ & 123 & 133 & 143 & 153 & 163 & 173 & 183 & 193 & 203 & 223 & 233 & 243 & 253 & 263 & 273 & 283 & 293 & 303 & 313 & 323 & 333 & 343 \\
\hline |Fração analisada & $1 / 4$ & 1/16 & $1 / 16$ & $1 / 8$ & $1 / 16$ & $1 / 8$ & $1 / 8$ & $1 / 8$ & $1 / 4$ & $1 / 8$ & $1 / 8$ & $1 / 16$ & $1 / 8$ & $1 / 4$ & $1 / 4$ & $1 / 8$ & $1 / 4$ & $1 / 4$ & $1 / 2$ & $1 / 4$ & $1 / 4$ & $1 / 2$ \\
\hline Densidade & 2744 & 6528 & 7392 & 3016 & 4544 & 3184 & 1968 & 1824 & 1032 & 1776 & 1264 & 3568 & 1976 & 1036 & 1448 & 2616 & 1260 & 1160 & 1166 & 1776 & 2372 & 852 \\
\hline Total Bentônicos & 686 & 408 & 462 & 377 & 284 & 398 & 246 & 228 & 258 & 222 & 158 & 223 & 247 & 259 & 362 & 327 & 315 & 290 & 583 & 444 & 593 & 426 \\
\hline Riqueza de espécies & 32 & 26 & 31 & 29 & 27 & 25 & 24 & 30 & 26 & 19 & 27 & 27 & 26 & 22 & 35 & 23 & 28 & 23 & 33 & 29 & 28 & 33 \\
\hline Adelosina laevigata & 0,000 & 0,000 & 0,000 & 0,265 & 0,000 & 0,000 & 0,813 & 0,000 & 0,775 & 0,000 & 0,000 & 0,000 & 0,000 & 0,000 & 0,552 & 2,752 & 1,587 & 1,379 & 1,372 & 2,477 & 0,843 & 1,408 \\
\hline Astrononion sp. & 0,000 & 0,000 & 0,000 & 0,000 & 0,000 & 0,000 & 0,000 & 0,000 & 0,000 & 0,000 & 0,000 & 0,000 & 0,000 & 0,000 & 0,276 & 0,000 & 0,317 & 0,000 & 0,000 & 0,000 & 0,000 & 0,000 \\
\hline Blysmasphaera sp. & 0,000 & 0,000 & 0,000 & 0,000 & 0,000 & 0,000 & 0,000 & 0,000 & 0,000 & 0,000 & 0,000 & 0,000 & 0,000 & 0,000 & 0,000 & 0,000 & 0,000 & 0,000 & 0,000 & 0,000 & 0,000 & 0,000 \\
\hline Bolivina alata & 0,000 & 0,000 & 0,000 & 0,000 & 0,000 & 0,000 & 0,000 & 0,000 & 0,000 & 0,000 & 0,000 & 0,000 & 0,000 & 0,000 & 0,276 & 0,000 & 0,000 & 0,000 & 0,000 & 0,000 & 0,000 & 0,000 \\
\hline Bolivina sp. & 0,146 & 0,000 & 0,000 & 0,000 & 0,000 & 0,000 & 0,000 & 0,000 & 0,000 & 0,000 & 0,633 & 0,000 & 0,000 & 0,000 & 0,000 & 0,000 & 0,000 & 0,000 & 0,000 & 0,000 & 0,000 & 0,000 \\
\hline Bolivinellina translucens & 0,146 & 0,245 & 0,000 & 0,265 & 0,000 & 0,000 & 0,000 & 0,000 & 0,000 & 0,000 & 0,633 & 0,000 & 2,429 & 0,000 & 0,552 & 0,306 & 0,000 & 1,034 & 4,803 & 2,252 & 0,843 & 2,582 \\
\hline Brizalina subaenariensis & 62,099 & 50,000 & 49,784 & 41,379 & 51,408 & 59,045 & 41,463 & 36,404 & 43,023 & 31,081 & 22,152 & 21,973 & 25,101 & 33,591 & 24,586 & 38,226 & 45,397 & 45,172 & 36,192 & 15,991 & 49,578 & 18,545 \\
\hline Buccella peruviana & 0,583 & 0,245 & 0,000 & 0,265 & 0,704 & 1,256 & 0,000 & 0,877 & 1,163 & 0,000 & 1,899 & 0,897 & 0,405 & 1,158 & 1,381 & 0,612 & 0,317 & 0,345 & 0,000 & 0,000 & 0,337 & 0,000 \\
\hline Buccella sp. & 0,000 & 0,000 & 0,216 & 0,000 & 0,000 & 0,000 & 0,000 & 0,000 & 0,000 & 0,000 & 0,000 & 0,000 & 0,000 & 0,000 & 0,552 & 0,000 & 0,000 & 0,000 & 0,000 & 0,000 & 0,000 & 0,000 \\
\hline Bulimina elongata & 14,869 & 12,255 & 6,710 & 19,098 & 17,254 & 16,834 & 24,797 & 20,175 & 13,566 & 6,306 & 3,797 & 8,072 & 4,858 & 11,583 & 17,403 & 12,844 & 10,476 & 9,655 & 5,489 & 4,054 & 4,890 & 7,042 \\
\hline Bulimina marginata & 3,790 & 5,147 & 4,545 & 7,162 & 3,521 & 3,015 & 5,691 & 8,333 & 11,240 & 24,324 & 35,443 & 27,803 & 12,146 & 7,336 & 9,392 & 7,951 & 2,540 & 1,379 & 0,858 & 2,252 & 0,506 & 1,878 \\
\hline Buliminella elegantissima & 0,000 & 0,000 & 0,866 & 0,000 & 0,000 & 0,000 & 0,000 & 0,000 & 0,000 & 0,450 & 0,000 & 0,000 & 0,000 & 0,000 & 0,552 & 0,000 & 0,635 & 0,000 & 1,372 & 1,802 & 1,855 & 1,408 \\
\hline Cancris sagra & 0,437 & 1,716 & 1,948 & 0,265 & 0,704 & 0,754 & 0,813 & 0,000 & 0,000 & 0,000 & 0,000 & 0,000 & 0,000 & 0,000 & 0,276 & 0,000 & 0,000 & 0,000 & 0,000 & 0,000 & 0,337 & 0,000 \\
\hline Cancris sp. & 0,000 & 0,000 & 0,000 & 0,265 & 0,000 & 0,000 & 0,000 & 0,000 & 0,000 & 0,000 & 0,000 & 0,000 & 0,000 & 0,000 & 0,000 & 0,000 & 0,000 & 0,000 & 0,000 & 0,000 & 0,000 & 0,000 \\
\hline Cassidulina crassa & 1,020 & 0,980 & 4,113 & 0,531 & 0,704 & 0,000 & 0,000 & 0,000 & 2,326 & 0,901 & 1,899 & 2,242 & 0,000 & 0,386 & 0,276 & 0,917 & 0,952 & 0,690 & 0,343 & 0,901 & 2,867 & 0,704 \\
\hline Cassidulina crassa var. porrecta & 0,000 & 0,000 & 0,866 & 0,796 & 1,408 & 0,503 & 0,813 & 0,877 & 0,000 & 0,450 & 0,000 & 0,000 & 0,000 & 0,000 & 0,000 & 0,000 & 0,000 & 0,000 & 0,000 & 0,000 & 0,000 & 0,000 \\
\hline Cassidulina Iaevigata & 0,000 & 0,000 & 0,000 & 0,000 & 0,000 & 0,000 & 0,000 & 0,000 & 0,000 & 0,000 & 0,000 & 0,000 & 0,000 & 0,000 & 0,276 & 0,000 & 0,000 & 0,000 & 0,000 & 0,000 & 0,000 & 0,000 \\
\hline Cassidulina sp. & 0,000 & 0,000 & 0,000 & 0,000 & 0,704 & 0,754 & 0,000 & 0,000 & 0,000 & 0,000 & 1,899 & 0,448 & 0,000 & 0,000 & 0,000 & 0,000 & 0,000 & 0,000 & 0,000 & 0,000 & 0,000 & 0,000 \\
\hline Cassidulinoides brasiliensis & 2,332 & 0,000 & 0,433 & 7,427 & 4,930 & 2,261 & 2,846 & 3,509 & 5,426 & 0,901 & 0,000 & 0,448 & 0,405 & 0,000 & 0,000 & 0,000 & 0,000 & 0,000 & 0,000 & 0,225 & 0,000 & 0,000 \\
\hline Cassidulinoides sp. & 0,146 & 5,882 & 4,762 & 0,265 & 0,000 & 0,000 & 0,000 & 0,000 & 0,000 & 0,000 & 0,000 & 0,000 & 0,000 & 0,000 & 0,000 & 0,000 & 0,000 & 0,000 & 0,000 & 0,000 & 0,000 & 0,000 \\
\hline Cibicides dispars & 0,000 & 0,000 & 0,000 & 0,265 & 0,000 & 0,000 & 0,000 & 0,000 & 0,000 & 0,000 & 0,000 & 0,448 & 0,000 & 0,000 & 0,000 & 0,000 & 0,000 & 0,000 & 0,172 & 0,000 & 0,000 & 0,000 \\
\hline Cibicides kullenbergi & 0,000 & 0,735 & 0,000 & 0,000 & 0,000 & 0,000 & 0,000 & 0,000 & 0,000 & 0,000 & 0,000 & 0,448 & 0,000 & 0,000 & 0,000 & 0,000 & 0,000 & 0,000 & 0,000 & 0,000 & 0,000 & 0,000 \\
\hline Cibicides refulgens & 0,000 & 0,000 & 0,000 & 0,000 & 0,000 & 0,000 & 2,846 & 2,193 & 0,000 & 0,000 & 0,000 & 0,000 & 0,000 & 0,000 & 0,000 & 0,000 & 0,000 & 0,000 & 0,172 & 0,000 & 0,000 & 0,000 \\
\hline Cibicides sp. & 0,146 & 0,000 & 0,000 & 0,000 & 0,000 & 0,000 & 0,407 & 0,439 & 0,388 & 0,000 & 0,633 & 0,448 & 0,000 & 0,000 & 0,000 & 0,000 & 0,000 & 0,000 & 0,000 & 0,000 & 0,000 & 0,000 \\
\hline Cibicidoides pseudohungerianus & 0,000 & 0,000 & 0,000 & 0,000 & 0,000 & 0,000 & 0,000 & 0,000 & 0,000 & 0,000 & 0,000 & 0,000 & 0,000 & 0,000 & 0,000 & 0,000 & 0,000 & 0,000 & 0,000 & 0,000 & 0,000 & 0,000 \\
\hline Cornuspira involvens & 0,000 & 0,000 & 0,000 & 0,000 & 0,000 & 0,000 & 0,000 & 1,316 & 0,000 & 0,000 & 0,000 & 0,000 & 0,000 & 0,000 & 0,000 & 0,000 & 0,000 & 0,000 & 0,000 & 0,000 & 0,000 & 0,000 \\
\hline Cribrostomoides sp. & 0,000 & 0,000 & 0,000 & 0,000 & 0,000 & 0,000 & 0,000 & 0,000 & 0,000 & 0,000 & 0,000 & 0,000 & 0,000 & 0,000 & 0,000 & 0,000 & 0,000 & 0,000 & 0,000 & 0,000 & 0,000 & 0,000 \\
\hline Dentalina sp. & 0,000 & 0,000 & 0,000 & 0,000 & 0,000 & 0,000 & 0,000 & 0,000 & 0,000 & 0,000 & 0,000 & 0,000 & 0,000 & 0,000 & 0,000 & 0,000 & 0,000 & 0,000 & 0,000 & 0,000 & 0,000 & 0,000 \\
\hline Discorbis sp. & 0,146 & 0,000 & 0,000 & 0,000 & 0,000 & 0,000 & 0,407 & 0,000 & 0,000 & 0,000 & 0,000 & 0,000 & 0,000 & 0,000 & 0,276 & 0,306 & 0,000 & 0,000 & 0,172 & 0,000 & 0,000 & 0,235 \\
\hline ides sp. & 0,000 & 0,000 & 0,216 & 0,000 & 0,000 & 0,000 & 0,000 & 0,000 & 0,000 & 0,000 & 0,000 & 0,000 & 0,000 & 0,000 & 0,000 & 000 & 0,000 & 000 & 0,000 & 000 & 0,000 & 0,000 \\
\hline Eponides repandus & 0,000 & 0,000 & 0,000 & 0,000 & 0,000 & 0,000 & 0,000 & 0,000 & 0,000 & 0,000 & 0,000 & 0,000 & 0,810 & 1,544 & 0,276 & 0,000 & 0,317 & 0,345 & 0,000 & 0,000 & 0,169 & 0,235 \\
\hline Favulina hexagona & 0,000 & 0,000 & 0,000 & 0,000 & 0,000 & 0,000 & 0,000 & 0,000 & 0,000 & 0,000 & 0,000 & 0,000 & 0,000 & 0,000 & 0,000 & 0,000 & 0,000 & 0,000 & 0,000 & 0,000 & 0,000 & 0,000 \\
\hline Fissurina lu & 0,146 & 0,245 & 0,000 & 0,000 & 0,000 & 0,000 & 0,000 & 0,439 & 0,000 & 0,000 & 0,000 & 0,000 & 0,000 & 0,000 & 0,000 & 0,000 & 0,000 & 0,000 & 0,515 & 0,000 & 0,675 & 0,000 \\
\hline Fissurina sp. & 0,292 & 0,000 & 0,000 & 0,000 & 0,000 & 0,000 & 0,000 & 0,000 & 0,000 & 0,000 & 0,000 & 0,000 & 0,405 & 0,000 & 0,000 & 0,000 & 0,000 & 0,000 & 0,000 & 0,000 & 0,000 & 0,000 \\
\hline Fursenkoina pontoni & 0,000 & 0,245 & 0,649 & 0,531 & 0,000 & 0,000 & 0,000 & 0,000 & 0,000 & 0,000 & 0,000 & 0,448 & 0,000 & 3,089 & 0,000 & 306 & 0,635 & 0,345 & 1,201 & 1,577 & 3,373 & 3,991 \\
\hline Fursenkoina sp. & 0,000 & 0,000 & 0,000 & 0,000 & 0,352 & 0,754 & 0,000 & 0,000 & 0,775 & 2,252 & 0,633 & 0,448 & 2,024 & 0,000 & 0,552 & 0,000 & 0,000 & 2,069 & 0,000 & 0,000 & 0,169 & 1,643 \\
\hline Glandulina sp. & 0,292 & 0,000 & 0,649 & 0,531 & 0,000 & 0,000 & 0,000 & 0,000 & 0,000 & 0,000 & 0,000 & 0,000 & 0,000 & 0,000 & 0,000 & 000 & 0,317 & 0,000 & 0,000 & 0,000 & 0,000 & 0,000 \\
\hline Globobulimina pacifica & 0,875 & 3,922 & 3,680 & 0,531 & 0,704 & 0,754 & 5,285 & 1,754 & 1,938 & 2,252 & 1,266 & 1,794 & 9,717 & 6,950 & 0,552 & 0,612 & 0,952 & 1,724 & 2,230 & 2,027 & 0,000 & 2,347 \\
\hline Globocassidulina minuta & 0,292 & 1,471 & 1,082 & 0,000 & & 0,000 & 0,000 & & & & 1,899 & & 0,000 & & & 000 & 0,000 & 0,000 & 0,000 & 000 & 0,000 &, 000 \\
\hline Globocassidulina subglobosa & 1,020 & 0,000 & 1,732 & 0,265 & 1,056 & 0,503 & 0,813 & 0,439 & 0,000 & 0,450 & 1,899 & 2,242 & 0,405 & 0,000 & 0,000 & 0,000 & 0,000 & 345 & 0,172 & 0,225 & 0,675 & 0,235 \\
\hline Gyroidina altiformis & 0,000 & 0,000 & 0,000 & 0,000 & 0,000 & 0,000 & 0,000 & 0,000 & & & 0,000 & 0,897 & 0,000 & & 0,000 & 0,000 & 0,000 & 000 & 0,000 & 000 & 0,000 & 000 \\
\hline Gyroidina sp. & 0,000 & 0,000 & 0,000 & 0,000 & 0,000 & 0,000 & 0,000 & 0,000 & 0,000 & 0,000 & 0,000 & 1,345 & 0,000 & 0,000 & 0,000 & 0,000 & 0,000 & 0,000 & 0,000 & 0,000 & 0,000 & 0,000 \\
\hline Haynesina depressula & 0,000 & 0,000 & 0,000 & 0,000 & 0,000 & 0,000 & 0,000 & 0,000 & 0,000 & 0,000 & 0,000 & 0,448 & 0,405 & 0,000 & 0,000 & 000 & 0,000 & 000 & 0,000 & 000 & 0,000 & 000 \\
\hline & 0,000 & 0,000 & 0,000 & 0,000 & 0,000 & 0,000 & 0,000 & 0,000 & 0,000 & 0,000 & 0,000 & 0,000 & 0,405 & 0,000 & 0,276 & 0,000 & 0,000 & 0,000 & 0,000 & 0,450 & 0,000 & 0,000 \\
\hline insina pacifica & 0,000 & 0,000 & 0,000 & 0,000 & 0,000 & 0,000 & 0,000 & 0,000 & 0,000 & 0,000 & 0,000 & 0,000 & 0,405 & 0,000 & 0,000 & 0,000 & 0,000 & 000 & 0,000 & ,000 & 0,000 & 000 \\
\hline & 0,000 & 0,490 & 0,216 & 0,000 & 0,000 & 0,000 & 0,000 & 2,193 & 0,000 & 0,000 & 0,000 & 0,000 & 0,000 & 0,000 & 0,000 & 0,000 & 0,000 & 0,000 & 0,000 & 0,225 & 0,000 & 0,235 \\
\hline Lagena gracilis & 0,000 & 0,000 & 0,000 & 0,000 & 0,352 & 0,000 & 0,000 & 0,000 & 0,000 & 0,000 & 0,000 & 0,000 & 0,000 & 0,000 & 0,000 & 0,000 & 0,000 & 0,000 & 0,000 & 0,000 & 0,000 & 0,000 \\
\hline & 0,000 & 0,245 & 0,000 & 0,000 & 0,000 & 0,000 & 0,407 & 0,000 & 0,000 & 0,000 & 0,000 & 0,000 & 0,000 & 0,000 & 0,000 & 0,000 & 0,000 & 0,000 & 0,000 & 0,000 & 0,000 & 0,000 \\
\hline Lagena sp. & 0,000 & 0,000 & 0,000 & 0,265 & 0,000 & 0,000 & 0,813 & 0,000 & 0,388 & 0,000 & 0,000 & 0,000 & 0,000 & 0,000 & 0,000 & 0,000 & 0,000 & 0,000 & 0,000 & 0,225 & 0,000 & 0,000 \\
\hline
\end{tabular}


Tabela 9 (continuação): Foraminíferos bentônicos encontrados no testemunho GeoB6211-2. Espécies expressas em porcentagem. Modelo de idades retirado de Chiessi et al. (2008).

\begin{tabular}{|c|c|c|c|c|c|c|c|c|c|c|c|c|c|c|c|c|c|c|c|c|c|c|}
\hline Profundidade $(\mathrm{cm})$ & 123 & 133 & 143 & 153 & 163 & 173 & 183 & 193 & 203 & 223 & 233 & 243 & 253 & 263 & 273 & 283 & 293 & 303 & 313 & 323 & 333 & 343 \\
\hline Fração analisada & $1 / 4$ & $1 / 16$ & $1 / 16$ & $1 / 8$ & $1 / 16$ & $1 / 8$ & $1 / 8$ & $1 / 8$ & $1 / 4$ & $1 / 8$ & $1 / 8$ & $1 / 16$ & $1 / 8$ & $1 / 4$ & $1 / 4$ & $1 / 8$ & $1 / 4$ & $1 / 4$ & $1 / 2$ & $1 / 4$ & $1 / 4$ & $1 / 2$ \\
\hline Densidade & 2744 & 6528 & 7392 & 3016 & 4544 & 3184 & 1968 & 1824 & 1032 & 1776 & 1264 & 3568 & 1976 & 1036 & 1448 & 2616 & 1260 & 1160 & 1166 & 1776 & 2372 & 852 \\
\hline Total Bentônicos & 686 & 408 & 462 & 377 & 284 & 398 & 246 & 228 & 258 & 222 & 158 & 223 & 247 & 259 & 362 & 327 & 315 & 290 & 583 & 444 & 593 & 426 \\
\hline Riqueza de espécies & 32 & 26 & 31 & 29 & 27 & 25 & 24 & 30 & 26 & 19 & 27 & 27 & 26 & 22 & 35 & 23 & 28 & 23 & 33 & 29 & 28 & 33 \\
\hline Lenticulina cultrata & 0,000 & 0,000 & 0,000 & 0,000 & 0,000 & 0,000 & 0,000 & 0,000 & 0,388 & 1,351 & 1,266 & 0,000 & 0,405 & 0,386 & 0,000 & 0,000 & 0,000 & 0,000 & 0,000 & 0,000 & 0,000 & 0,000 \\
\hline Lenticulina rotulata & 0,000 & 0,000 & 0,000 & 0,000 & 0,000 & 0,000 & 0,000 & 0,000 & 0,000 & 0,901 & 0,000 & 0,000 & 0,000 & 0,000 & 0,000 & 0,000 & 0,000 & 0,000 & 0,000 & 0,000 & 0,000 & 0,000 \\
\hline Lenticulina sp. & 0,437 & 0,000 & 0,000 & 0,000 & 0,352 & 0,503 & 0,813 & 0,877 & 0,000 & 0,000 & 0,000 & 0,897 & 0,405 & 0,000 & 0,276 & 0,000 & 0,000 & 0,000 & 0,172 & 0,000 & 0,000 & 0,000 \\
\hline Lobatula lobatula & 0,000 & 0,000 & 0,000 & 0,000 & 0,000 & 0,000 & 0,000 & 0,000 & 0,000 & 0,000 & 0,000 & 0,448 & 0,405 & 0,000 & 0,000 & 0,000 & 0,000 & 0,000 & 0,000 & 0,000 & 0,000 & 0,000 \\
\hline Melonis barleeanus & 0,000 & 0,000 & 0,000 & 0,000 & 0,000 & 0,000 & 0,000 & 0,000 & 0,000 & 0,000 & 1,266 & 2,691 & 4,049 & 3,475 & 1,105 & 0,306 & 0,317 & 0,345 & 0,172 & 0,450 & 0,000 & 0,000 \\
\hline Melonis sp. & 0,000 & 0,000 & 0,000 & 0,000 & 0,000 & 0,000 & 0,000 & 0,439 & 0,000 & 0,901 & 0,000 & 0,000 & 0,000 & 0,000 & 0,000 & 0,000 & 0,000 & 0,000 & 0,000 & 0,000 & 0,000 & 0,235 \\
\hline Miliolinella subrotunda & 0,000 & 0,000 & 0,000 & 0,000 & 0,000 & 0,000 & 0,000 & 0,000 & 0,000 & 0,000 & 0,000 & 0,000 & 0,000 & 0,000 & 0,000 & 0,000 & 0,000 & 0,000 & 0,000 & 0,000 & 0,000 & 0,000 \\
\hline Nonionella atlantica & 1,312 & 1,961 & 1,732 & 2,653 & 2,465 & 0,754 & 1,626 & 0,439 & 2,713 & 12,613 & 5,063 & 13,901 & 13,765 & 13,514 & 16,298 & 12,844 & 18,413 & 20,345 & 23,499 & 34,910 & 8,938 & 5,399 \\
\hline Nonionella auris & 0,000 & 0,000 & 0,000 & 0,000 & 0,000 & 0,503 & 0,000 & 0,000 & 0,388 & 0,000 & 0,000 & 0,000 & 0,000 & 0,000 & 0,000 & 0,612 & 0,317 & 0,000 & 0,000 & 0,225 & 2,530 & 0,235 \\
\hline Nonionella opima & 1,020 & 0,000 & 2,165 & 2,387 & 1,761 & 1,508 & 0,407 & 1,316 & 4,264 & 3,153 & 1,899 & 2,242 & 2,834 & 3,475 & 2,210 & 3,058 & 1,905 & 1,379 & 1,029 & 3,153 & 5,396 & 2,347 \\
\hline Nonionellina labradorica & 0,729 & 7,108 & 3,896 & 5,570 & 2,465 & 1,508 & 2,439 & 0,439 & 0,000 & 0,000 & 0,000 & 0,000 & 0,000 & 0,000 & 0,000 & 0,000 & 0,000 & 0,000 & 0,000 & 0,000 & 0,169 & 0,469 \\
\hline Nonion depressulus & 0,000 & 0,000 & 0,000 & 0,000 & 0,352 & 0,503 & 0,407 & 0,000 & 0,000 & 0,000 & 0,000 & 0,000 & 0,000 & 0,000 & 0,000 & 0,000 & 0,000 & 0,000 & 0,000 & 0,000 & 0,000 & 0,000 \\
\hline Nonionoides grateloupi & 2,332 & 1,716 & 1,732 & 1,592 & 4,225 & 3,518 & 1,220 & 4,386 & 0,388 & 2,703 & 1,899 & 1,794 & 6,073 & 1,931 & 4,696 & 7,034 & 4,444 & 6,552 & 4,460 & 9,459 & 4,722 & 31,221 \\
\hline Oolina lineata & 0,000 & 0,000 & 0,000 & 0,000 & 0,000 & 0,000 & 0,000 & 0,000 & 0,000 & 0,000 & 0,000 & 0,000 & 0,000 & 0,000 & 0,552 & 0,306 & 0,000 & 0,000 & 0,000 & 0,000 & 0,000 & 0,000 \\
\hline Oolina sp. & 0,000 & 0,000 & 0,000 & 0,000 & 0,000 & 0,000 & 0,000 & 0,000 & 0,388 & 0,000 & 0,000 & 0,000 & 0,000 & 0,000 & 0,000 & 0,000 & 0,000 & 0,345 & 0,000 & 0,000 & 0,000 & 0,000 \\
\hline Oridorsalis umbonatus & 0,000 & 0,245 & 0,649 & 0,000 & 0,000 & 0,000 & 0,000 & 0,000 & 0,000 & 0,000 & 3,165 & 0,000 & 0,000 & 0,000 & 0,000 & 0,000 & 0,000 & 0,000 & 0,000 & 0,000 & 0,000 & 0,000 \\
\hline Orthomorphina sp. & 0,000 & 0,000 & 0,000 & 0,000 & 0,000 & 0,000 & 0,000 & 0,000 & 0,000 & 0,000 & 0,000 & 0,000 & 0,000 & 0,000 & 0,000 & 0,000 & 0,000 & 0,000 & 0,000 & 0,000 & 0,000 & 0,000 \\
\hline Poroeponides lateralis & 0,000 & 0,000 & 0,000 & 0,000 & 0,000 & 0,000 & 0,000 & 0,000 & 0,000 & 0,000 & 0,000 & 0,000 & 0,000 & 0,000 & 0,276 & 0,000 & 0,000 & 0,000 & 0,000 & 0,000 & 0,000 & 0,000 \\
\hline Procerolagena clavata & 0,000 & 0,000 & 0,000 & 0,000 & 0,000 & 0,000 & 0,000 & 0,000 & 0,000 & 0,000 & 0,000 & 0,000 & 0,000 & 0,000 & 0,000 & 0,000 & 0,000 & 0,000 & 0,000 & 0,000 & 0,000 & 0,000 \\
\hline Pseudononion pulchella & 0,292 & 0,000 & 0,433 & 0,000 & 0,352 & 0,000 & 0,000 & 0,000 & 0,000 & 0,000 & 0,000 & 0,000 & 0,000 & 0,000 & 0,000 & 0,000 & 0,317 & 0,000 & 0,343 & 0,225 & 0,000 & 0,000 \\
\hline Pseudononion sp. & 0,292 & 0,245 & 0,649 & 0,796 & 0,000 & 0,251 & 0,000 & 0,000 & 0,000 & 0,000 & 0,000 & 0,000 & 0,000 & 0,386 & 0,000 & 0,000 & 0,000 & 0,000 & 0,000 & 0,000 & 0,000 & 1,174 \\
\hline Pullenia bulloides & 0,000 & 0,000 & 0,216 & 0,000 & 0,000 & 0,000 & 0,000 & 0,000 & 0,000 & 0,000 & 0,000 & 0,000 & 0,000 & 0,000 & 0,000 & 0,000 & 0,000 & 0,000 & 0,000 & 0,000 & 0,000 & 0,000 \\
\hline Pyrgo murnina & 0,292 & 0,245 & 0,649 & 0,000 & 0,352 & 0,000 & 0,000 & 0,000 & 0,000 & 0,000 & 0,000 & 0,000 & 0,000 & 0,000 & 0,000 & 0,000 & 0,000 & 0,000 & 0,000 & 0,000 & 0,000 & 0,000 \\
\hline Pyrgo nasuta & 0,000 & 0,000 & 0,000 & 0,000 & 0,000 & 0,503 & 1,626 & 0,000 & 0,388 & 0,000 & 0,000 & 0,000 & 0,000 & 0,000 & 0,000 & 0,000 & 0,635 & 0,000 & 0,000 & 0,000 & 0,000 & 0,000 \\
\hline Pyrgo ringens & 0,000 & 0,000 & 0,000 & 0,000 & 0,000 & 0,000 & 0,000 & 0,000 & 0,000 & 0,000 & 0,000 & 0,000 & 0,000 & 0,000 & 0,276 & 0,000 & 0,000 & 0,000 & 0,515 & 0,225 & 0,000 & 0,000 \\
\hline Pyrgo subsphaerica & 0,000 & 0,000 & 0,000 & 0,000 & 0,000 & 0,000 & 0,000 & 0,000 & 0,388 & 0,000 & 0,000 & 0,000 & 0,000 & 0,000 & 0,000 & 0,000 & 0,000 & 0,000 & 0,000 & 0,000 & 0,000 & 0,000 \\
\hline Pyrgo williamsoni & 0,000 & 0,000 & 0,000 & 0,000 & 0,000 & 0,000 & 0,000 & 1,316 & 0,000 & 0,000 & 0,000 & 0,000 & 0,000 & 0,000 & 0,000 & 0,000 & 0,000 & 0,000 & 0,000 & 0,000 & 0,000 & 0,000 \\
\hline Pyrgo sp. & 0,000 & 0,000 & 0,000 & 0,000 & 0,000 & 0,000 & 0,000 & 0,439 & 0,000 & 0,000 & 0,000 & 0,000 & 0,000 & 0,000 & 0,000 & 0,000 & 0,000 & 0,000 & 0,000 & 0,000 & 0,169 & 0,235 \\
\hline Quinqueloculina atlantica & 0,292 & 0,735 & 0,216 & 2,387 & 0,704 & 0,503 & 0,813 & 2,632 & 4,264 & 0,450 & 0,000 & 0,000 & 0,810 & 0,386 & 3,039 & 4,587 & 2,857 & 3,448 & 2,401 & 4,279 & 2,530 & 2,817 \\
\hline Quinqueloculina Iamarckiana & 0,000 & 0,000 & 0,000 & 0,000 & 0,000 & 0,503 & 0,407 & 0,439 & 0,000 & 0,000 & 0,000 & 0,000 & 0,000 & 0,000 & 0,276 & 0,000 & 0,000 & 0,000 & 0,000 & 0,000 & 0,000 & 0,000 \\
\hline Quinqueloculina milletti & 0,000 & 0,000 & 0,433 & 0,265 & 0,352 & 0,000 & 0,000 & 1,754 & 0,000 & 0,000 & 0,633 & 0,000 & 0,000 & 0,000 & 1,381 & 1,835 & 0,317 & 0,690 & 1,201 & 1,351 & 0,843 & 0,469 \\
\hline Quinqueloculina patagonica & 0,146 & 0,000 & 0,216 & 0,265 & 0,352 & 0,503 & 0,000 & 0,877 & 1,550 & 0,000 & 0,000 & 0,448 & 0,000 & 0,386 & 0,000 & 0,306 & 0,952 & 0,000 & 0,515 & 0,676 & 0,675 & 1,878 \\
\hline Quinqueloculina seminula & 0,146 & 0,000 & 0,000 & 1,061 & 0,704 & 0,000 & 0,000 & 0,877 & 0,388 & 0,000 & 0,633 & 0,000 & 0,000 & 0,772 & 0,829 & 0,612 & 0,317 & 0,345 & 0,343 & 1,126 & 0,337 & 1,174 \\
\hline Quinqueloculina sp. & 0,000 & 0,245 & 0,000 & 0,000 & 0,000 & 0,000 & 0,000 & 0,000 & 0,388 & 0,000 & 0,633 & 0,000 & 0,000 & 0,000 & 0,276 & 0,000 & 0,317 & 0,690 & 0,515 & 0,676 & 0,337 & 0,235 \\
\hline Reussoolina laevis & 0,000 & 0,000 & 0,000 & 0,000 & 0,704 & 0,000 & 0,000 & 0,439 & 0,000 & 0,000 & 0,000 & 0,000 & 0,000 & 0,000 & 0,000 & 0,000 & 0,000 & 0,000 & 0,000 & 0,000 & 0,000 & 0,000 \\
\hline Rosalina williamsoni & 0,000 & 0,000 & 0,000 & 0,000 & 0,000 & 0,000 & 0,000 & 0,000 & 0,000 & 0,000 & 0,633 & 0,000 & 0,000 & 0,000 & 0,000 & 0,306 & 0,317 & 0,000 & 0,343 & 0,000 & 0,000 & 0,235 \\
\hline Rubratella intermedia & 0,000 & 0,000 & 0,000 & 0,000 & 0,000 & 0,000 & 0,000 & 0,000 & 0,000 & 0,000 & 0,000 & 0,000 & 0,000 & 0,000 & 0,000 & 0,000 & 0,000 & 0,000 & 0,172 & 0,000 & 0,000 & 0,000 \\
\hline Rutherfordoides rotundiformis & 0,000 & 0,000 & 0,000 & 0,000 & 0,000 & 0,000 & 0,000 & 0,439 & 0,388 & 0,000 & 1,266 & 0,897 & 2,429 & 2,703 & 3,315 & 0,917 & 1,587 & 0,690 & 2,573 & 5,180 & 2,867 & 2,817 \\
\hline Sigmoilopsis schlumbergeri & 0,000 & 0,000 & 0,000 & 0,000 & 0,000 & 0,000 & 0,000 & 0,000 & 0,000 & 0,000 & 0,000 & 0,000 & 0,000 & 0,386 & 0,000 & 0,000 & 0,000 & 0,000 & 0,000 & 0,000 & 0,000 & 0,000 \\
\hline Spiroplectammina biformis & 0,000 & 0,000 & 0,000 & 0,000 & 0,000 & 0,000 & 0,000 & 0,000 & 0,000 & 0,000 & 0,000 & 0,000 & 0,000 & 0,000 & 0,000 & 0,000 & 0,000 & 0,000 & 0,000 & 0,000 & 0,000 & 0,000 \\
\hline Stainforthia concava & 0,000 & 0,000 & 0,000 & 0,000 & 0,000 & 0,000 & 0,000 & 0,000 & 0,000 & 0,000 & 0,000 & 0,000 & 0,000 & 0,000 & 0,552 & 0,000 & 0,000 & 0,345 & 3,259 & 1,802 & 0,337 & 1,174 \\
\hline Stainforthia sp. & 0,000 & 0,000 & 0,000 & 0,000 & 0,000 & 0,000 & 0,000 & 0,000 & 0,000 & 0,000 & 0,000 & 0,000 & 0,000 & 0,000 & 0,000 & 0,000 & 0,000 & 0,000 & 0,000 & 0,000 & 0,000 & 0,000 \\
\hline Textularia agg/utinans & 0,000 & 0,000 & 0,000 & 0,000 & 0,000 & 0,000 & 0,000 & 0,000 & 0,000 & 0,000 & 0,000 & 0,000 & 0,000 & 0,000 & 0,000 & 0,000 & 0,000 & 0,000 & 0,000 & 0,000 & 0,000 & 0,939 \\
\hline Textularia sp. & 0,000 & 0,000 & 0,000 & 0,000 & 0,000 & 0,000 & 0,000 & 0,000 & 0,000 & 0,000 & 0,000 & 0,000 & 0,000 & 0,000 & 0,000 & 0,000 & 0,000 & 0,000 & 0,000 & 0,000 & 0,000 & 0,000 \\
\hline Trifarina angulosa & 0,146 & 0,000 & 0,000 & 0,000 & 0,000 & 0,000 & 0,000 & 0,000 & 0,000 & 0,000 & 0,000 & 0,000 & 0,000 & 0,000 & 0,000 & 0,000 & 0,000 & 0,000 & 0,000 & 0,000 & 0,000 & 0,000 \\
\hline & 0,000 & 0,000 & 0,000 & 0,000 & 0,000 & 0,0 & 0,000 & 0,000 & 0,000 & 0,000 & 0,000 & 0,000 & & 0,000 & 0,000 & 0,000 & 0,000 & 0,000 & 0,000 & 0,225 & 0,000 & 0,000 \\
\hline & & & & & & & & & & & & & & & & & & & & & & \\
\hline & & & & & & & & & & & & & & & & & & & & & & \\
\hline & & & & & & & & & & & & & & & & & & & & & & \\
\hline & & 0,245 & 0,433 & & & & & 0,877 & & & & & & & & & & & & c & 0,506 & 0,000 \\
\hline agnentios & 0,583 & 0,980 & 1,948 & 0,531 & 0,352 & 0,503 & 0,407 & 0,439 & 0,775 & 1,351 & 0,633 & 2,242 & 0,810 & 1,544 & 2,762 & 1,529 & 1,587 & 0,345 & 2,401 & 1,351 & 2,024 & 3,521 \\
\hline
\end{tabular}


Tabela 9 (continuação): Foraminíferos bentônicos encontrados no testemunho GeoB6211-2. Espécies expressas em porcentagem. Modelo de idades retirado de Chiessi et al. (2008).

\begin{tabular}{|c|c|c|c|c|c|c|c|c|c|c|c|c|c|c|c|c|c|c|c|c|c|c|c|}
\hline Profundidade $(\mathrm{cm})$ & 353 & 363 & 373 & 383 & 393 & 403 & 413 & 423 & 433 & 443 & 453 & 463 & 473 & 483 & 493 & 503 & 513 & 523 & 533 & 543 & 553 & 563 & 573 \\
\hline Fração analisada & $1 / 4$ & $1 / 4$ & $1 / 8$ & $1 / 4$ & $1 / 4$ & $1 / 4$ & 1 & $1 / 2$ & $1 / 8$ & $1 / 4$ & $1 / 2$ & 1 & $1 / 2$ & 1 & $1 / 2$ & $1 / 4$ & $1 / 2$ & 1 & $1 / 2$ & 1 & 1 & $1 / 2$ & $1 / 2$ \\
\hline Densidade & 1472 & 1220 & 2192 & 916 & 1052 & 1276 & 491 & 614 & 2296 & 1064 & 704 & 344 & 624 & 352 & 536 & 1168 & 794 & 510 & 716 & 207 & 353 & 704 & 674 \\
\hline Total Bentônicos & 368 & 305 & 274 & 229 & 263 & 319 & 491 & 307 & 287 & 266 & 352 & 344 & 312 & 352 & 268 & 292 & 397 & 510 & 358 & 207 & 353 & 352 & 337 \\
\hline Riqueza de espécies & 33 & 32 & 25 & 22 & 28 & 24 & 35 & 35 & 29 & 28 & 33 & 31 & 25 & 30 & 26 & 28 & 26 & 27 & 22 & 24 & 30 & 20 & 26 \\
\hline Adelosina laevigata & 1,359 & 0,328 & 1,825 & 0,873 & 0,760 & 1,254 & 1,222 & 0,651 & 1,742 & 1,504 & 0,568 & 0,872 & 0,641 & 1,420 & 3,358 & 2,397 & 2,519 & 0,000 & 1,117 & 0,000 & 0,283 & 0,000 & 0,890 \\
\hline Astrononion sp. & 0,000 & 0,000 & 0,000 & 0,000 & 0,000 & 0,000 & 0,000 & 0,000 & 0,000 & 0,000 & 0,000 & 0,000 & 0,000 & 0,000 & 0,000 & 0,000 & 0,000 & 0,000 & 0,000 & 0,000 & 0,000 & 0,000 & 0,000 \\
\hline Blysmasphaera sp. & 0,000 & 0,000 & 0,000 & 0,000 & 0,000 & 0,000 & 0,000 & 0,000 & 0,000 & 0,376 & 0,000 & 0,000 & 0,000 & 0,000 & 0,000 & 0,000 & 0,000 & 0,000 & 0,000 & 0,000 & 0,000 & 0,000 & 0,000 \\
\hline Bolivina alata & 0,000 & 0,000 & 0,000 & 0,000 & 0,000 & 0,000 & 0,000 & 0,000 & 0,000 & 0,000 & 0,000 & 0,291 & 0,000 & 0,852 & 0,000 & 0,000 & 0,000 & 0,000 & 0,000 & 0,000 & 0,283 & 0,000 & 0,000 \\
\hline Bolivina sp. & 0,000 & 0,000 & 0,000 & 0,000 & 0,000 & 0,000 & 0,000 & 0,000 & 0,000 & 0,000 & 0,000 & 0,000 & 0,000 & 0,000 & 0,000 & 0,000 & 0,000 & 0,000 & 0,000 & 0,000 & 0,000 & 0,000 & 0,297 \\
\hline Bolivinellina translucens & 2,989 & 0,984 & 0,365 & 0,000 & 0,760 & 0,627 & 2,444 & 3,909 & 1,045 & 0,752 & 11,932 & 6,977 & 2,564 & 2,557 & 0,746 & 0,342 & 4,534 & 4,314 & 0,000 & 0,483 & 3,966 & 0,852 & 1,484 \\
\hline Brizalina subaenariensis & 17,663 & 16,066 & 22,628 & 24,017 & 20,913 & 38,871 & 32,179 & 24,104 & 19,861 & 22,932 & 13,352 & 11,337 & 26,603 & 21,023 & 17,164 & 32,877 & 36,524 & 29,020 & 17,598 & 7,246 & 32,295 & 30,398 & 35,608 \\
\hline Buccella peruviana & 0,000 & 0,656 & 0,000 & 0,000 & 0,760 & 0,000 & 0,611 & 0,326 & 0,000 & 0,000 & 0,284 & 0,291 & 0,000 & 0,568 & 0,000 & 0,000 & 0,000 & 0,588 & 0,838 & 0,483 & 0,000 & 0,000 & 0,000 \\
\hline Buccella sp. & 0,000 & 0,000 & 0,000 & 0,000 & 0,000 & 0,000 & 0,000 & 0,000 & 0,000 & 0,000 & 0,000 & 0,000 & 0,000 & 0,000 & 0,373 & 0,000 & 0,252 & 0,000 & 0,279 & 0,000 & 0,283 & 0,000 & 0,000 \\
\hline Bulimina elongata & 5,707 & 5,902 & 6,569 & 16,594 & 4,943 & 5,956 & 9,776 & 9,772 & 8,711 & 4,135 & 8,807 & 8,721 & 8,013 & 7,955 & 6,343 & 2,740 & 3,778 & 8,039 & 10,335 & 4,831 & 4,816 & 0,852 & 2,077 \\
\hline Bulimina marginata & 3,261 & 2,951 & 7,299 & 4,367 & 5,703 & 1,567 & 2,444 & 3,583 & 11,847 & 9,398 & 7,102 & 4,942 & 8,333 & 10,227 & 4,104 & 4,795 & 2,519 & 3,725 & 17,598 & 0,483 & 9,065 & 4,261 & 2,967 \\
\hline Buliminella elegantissima & 0,000 & 0,000 & 0,000 & 0,437 & 0,760 & 0,940 & 0,407 & 0,977 & 0,348 & 1,880 & 1,420 & 2,035 & 0,962 & 0,568 & 2,239 & 0,342 & 0,756 & 1,176 & 0,559 & 2,415 & 1,133 & 0,000 & 0,890 \\
\hline Cancris sagra & 0,000 & 0,328 & 0,000 & 0,437 & 0,000 & 0,000 & 0,000 & 0,000 & 0,000 & 0,000 & 0,000 & 0,000 & 0,000 & 0,000 & 0,000 & 0,000 & 0,000 & 0,000 & 0,279 & 0,000 & 0,000 & 0,000 & 0,000 \\
\hline Cancris sp. & 0,000 & 0,000 & 0,000 & 0,000 & 0,000 & 0,000 & 0,000 & 0,000 & 0,000 & 0,000 & 0,000 & 0,000 & 0,000 & 0,000 & 0,000 & 0,000 & 0,000 & 0,000 & 0,000 & 0,000 & 0,000 & 0,000 & 0,000 \\
\hline Cassidulina crassa & 1,630 & 0,656 & 1,095 & 0,437 & 1,521 & 0,940 & 1,222 & 2,932 & 1,045 & 1,880 & 3,125 & 4,942 & 2,244 & 3,409 & 2,239 & 0,685 & 2,015 & 0,980 & 1,676 & 0,966 & 1,133 & 2,273 & 1,484 \\
\hline Cassidulina crassa var. porrecta & 0,000 & 0,000 & 0,000 & 0,000 & 0,000 & 0,000 & 0,000 & 0,000 & 0,000 & 0,000 & 0,000 & 0,000 & 0,000 & 0,000 & 0,000 & 0,000 & 0,000 & 0,000 & 0,000 & 0,000 & 0,000 & 0,000 & 0,000 \\
\hline Cassidulina laevigata & 0,000 & 0,000 & 0,000 & 0,000 & 0,000 & 0,000 & 0,000 & 0,000 & 0,000 & 0,000 & 0,000 & 0,000 & 0,000 & 0,000 & 0,000 & 0,000 & 0,000 & 0,000 & 0,000 & 0,000 & 0,000 & 0,000 & 0,000 \\
\hline Cassidulina sp. & 0,000 & 0,000 & 0,000 & 0,000 & 0,000 & 0,000 & 0,000 & 0,326 & 0,697 & 0,000 & 0,284 & 0,000 & 0,000 & 0,000 & 0,373 & 0,000 & 0,000 & 0,000 & 0,000 & 0,000 & 0,000 & 0,000 & 0,000 \\
\hline Cassidulinoides brasiliensis & 0,000 & 0,000 & 0,000 & 0,000 & 0,000 & 0,000 & 0,000 & 0,000 & 0,000 & 0,000 & 0,284 & 0,000 & 0,000 & 0,000 & 0,000 & 0,000 & 0,000 & 0,000 & 0,000 & 0,000 & 0,000 & 0,000 & 0,000 \\
\hline Cassidulinoides sp. & 0,000 & 0,000 & 0,000 & 0,000 & 0,000 & 0,000 & 0,000 & 0,000 & 0,000 & 0,000 & 0,000 & 0,000 & 0,000 & 0,000 & 0,000 & 0,000 & 0,000 & 0,000 & 0,000 & 0,000 & 0,000 & 0,000 & 0,000 \\
\hline Cibicides dispars & 0,000 & 0,000 & 0,000 & 0,000 & 0,000 & 0,000 & 0,000 & 0,000 & 0,000 & 0,000 & 0,000 & 0,000 & 0,000 & 0,284 & 0,000 & 0,000 & 0,000 & 0,000 & 0,000 & 0,000 & 0,000 & 0,000 & 0,000 \\
\hline Cibicides kullenbergi & 0,000 & 0,000 & 0,000 & 0,000 & 0,000 & 0,000 & 0,000 & 0,000 & 0,000 & 0,000 & 0,000 & 0,000 & 0,000 & 0,000 & 0,000 & 0,000 & 0,000 & 0,000 & 0,000 & 0,000 & 0,000 & 0,000 & 0,000 \\
\hline Cibicides refulgens & 0,000 & 0,000 & 0,000 & 0,000 & 0,000 & 0,000 & 0,000 & 0,000 & 0,000 & 0,000 & 0,000 & 0,000 & 0,000 & 0,000 & 0,000 & 0,000 & 0,000 & 0,000 & 0,000 & 0,483 & 0,000 & 0,000 & 0,000 \\
\hline Cibicides sp. & 0,000 & 0,000 & 0,000 & 0,000 & 0,000 & 0,000 & 0,204 & 0,000 & 0,348 & 0,000 & 0,000 & 0,291 & 0,000 & 0,000 & 0,373 & 0,000 & 0,000 & 0,000 & 0,000 & 0,000 & 0,000 & 0,000 & 0,000 \\
\hline Cibicidoides pseudohungerianus & 0,000 & 0,000 & 0,000 & 0,000 & 0,000 & 0,000 & 0,000 & 0,000 & 0,000 & 0,376 & 0,000 & 0,000 & 0,000 & 0,000 & 0,000 & 0,000 & 0,000 & 0,000 & 0,000 & 0,000 & 0,000 & 0,000 & 0,000 \\
\hline Cornuspira involvens & 0,000 & 0,000 & 0,000 & 0,000 & 0,000 & 0,000 & 0,000 & 0,000 & 0,000 & 0,000 & 0,000 & 0,000 & 0,000 & 0,000 & 0,000 & 0,000 & 0,000 & 0,000 & 0,000 & 0,000 & 0,000 & 0,000 & 0,000 \\
\hline Cribrostomoides sp. & 0,272 & 0,656 & 0,000 & 0,000 & 0,000 & 0,000 & 0,204 & 0,326 & 0,000 & 0,752 & 0,568 & 0,581 & 0,962 & 0,000 & 2,985 & 2,055 & 0,000 & 0,000 & 0,000 & 2,415 & 0,283 & 0,000 & 0,000 \\
\hline Dentalina sp. & 0,272 & 0,000 & 0,000 & 0,000 & 0,000 & 0,000 & 0,000 & 0,000 & 0,000 & 0,000 & 0,000 & 0,000 & 0,000 & 0,000 & 0,000 & 0,000 & 0,000 & 0,000 & 0,000 & 0,000 & 0,000 & 0,000 & 0,000 \\
\hline Discorbis sp. & 0,000 & 0,000 & 0,000 & 0,000 & 0,000 & 0,000 & 0,407 & 0,326 & 0,348 & 0,000 & 0,000 & 0,000 & 0,000 & 0,000 & 0,000 & 0,000 & 0,000 & 0,000 & 0,000 & 0,000 & 0,000 & 0,000 & 0,000 \\
\hline Epistominoides sp. & 0,000 & 0,000 & 0,000 & 0,000 & 0,000 & 0,000 & 0,000 & 0,000 & 0,000 & 0,000 & 0,000 & 0,000 & 0,000 & 0,000 & 0,000 & 0,000 & 0,000 & 0,000 & 0,000 & 0,000 & 0,000 & 0,000 & 0,000 \\
\hline Eponides repandus & 0,000 & 0,328 & 0,000 & 0,000 & 0,000 & 0,000 & 0,204 & 0,000 & 0,000 & 0,000 & 0,000 & 0,000 & 0,000 & 0,000 & 0,000 & 0,000 & 0,000 & 0,196 & 0,000 & 0,000 & 0,567 & 0,000 & 0,000 \\
\hline Favulina hexagona & 0,000 & 0,000 & 0,000 & 0,000 & 0,000 & 0,000 & 0,000 & 0,326 & 0,000 & 0,000 & 0,000 & 0,000 & 0,000 & 0,000 & 0,000 & 0,000 & 0,000 & 0,000 & 0,000 & 0,000 & 0,000 & 0,000 & 0,000 \\
\hline & 0,000 & 0,000 & 0,000 & 0,000 & 0,000 & 0,000 & & 0,000 & 0,000 & 0,000 & 0,000 & 0,000 & 0,000 & & 0,373 & 342 & & 0,000 & 0,000 & 000 & 0,000 & 000 & 000 \\
\hline Fissurina sp. & 0,000 & 3,607 & 0,000 & 0,000 & 0,000 & 0,000 & 0,000 & 0,000 & 0,000 & 0,000 & 0,284 & 0,000 & 0,000 & 0,000 & 0,000 & 0,000 & 0,000 & 0,000 & 0,000 & 1,449 & 0,000 & 0,000 & 0,000 \\
\hline Fursenkoina pontoni & 2,446 & 0,656 & 0,000 & 1,310 & 1,141 & 0,313 & 0,815 & 2,606 & 5,575 & 10,150 & 2,841 & 8,140 & 5,769 & 3,693 & 3,731 & 3,425 & 3,526 & 7,647 & 0,279 & 9,662 & 1,133 & 3,977 & 6,825 \\
\hline Fursenkoina sp. & 1,902 & 0,000 & 3,285 & 2,183 & 0,380 & 1,881 & 1,018 & 5,212 & 0,000 & 0,000 & 3,125 & 0,000 & 0,000 & 0,000 & 0,000 & 0,000 & 0,000 & 1,176 & 0,000 & 1,932 & 2,550 & 1,989 & 3,561 \\
\hline Glandulina sp. & 0,000 & 0,000 & 0,000 & 0,000 & 0,000 & 0,000 & 0,000 & 0,000 & 0,000 & 0,000 & 0,000 & 0,000 & 0,000 & 0,000 & 0,000 & 0,000 & 0,000 & 0,000 & 0,000 & 0,000 & 0,000 & 0,000 & 0,000 \\
\hline Globobulimina pacifica & 1,359 & 1,311 & 1,095 & 0,873 & 1,521 & & & & & & & & & & 0,746 & & & 3,137 & 397 & 000 & 0,000 & 284 & 000 \\
\hline Globocassidulina minuta & 0,000 & 0,000 & 0,000 & 0,000 & 0,000 & 0,000 & 0,000 & 0,000 & 0,000 & 0,000 & 0,000 & 0,000 & 0,000 & 0,000 & 0,000 & 0,000 & 0,000 & 0,000 & 0,000 & 0,000 & 0,000 & 0,000 & 0,000 \\
\hline Globocassidulina subglobosa & 0,543 & 1,311 & 0,730 & 0,873 & 0,000 & 0,627 & 0,204 & 0,326 & 0,348 & 0,000 & 0,2 & 0,872 & 0,000 & 0,568 & 0,373 & 0,000 & 0,000 & 0,196 & 0,000 & 0,000 & 0,567 & 0,000 & 0,297 \\
\hline Gyroidina altiformis & 0,000 & 0,000 & 0,000 & 0,000 & 0,000 & 0,000 & & 0,000 & 0,0 & 0,000 & 0,000 & 0,000 & 0,000 & 0,000 & 0,000 & 0,000 & 000 & 0,000 & 0,000 & 0,000 & 0,000 & 0,000 & 0,000 \\
\hline Gyroidina sp. & 0,000 & 0,000 & 0,000 & 0,000 & 0,000 & 0,000 & 0,000 & 0,000 & 0,000 & 0,000 & 0,000 & 0,000 & 0,000 & 0,000 & 0,000 & 0,000 & 0,000 & 0,000 & 0,000 & 0,000 & 0,000 & 0,000 & 0,000 \\
\hline Haynesina depressula & 0,000 & 0,000 & 0,000 & & 0,000 & & & & & & & 0,000 & & & 0,000 & 0,000 & & 0,000 & 0,000 & 0,000 & 0,000 & 0,000 & 0,000 \\
\hline Hayr & 0,000 & 0,000 & 0,000 & 0,000 & 0,000 & 0,000 & 0,000 & 0,000 & 0,000 & 0,000 & 0,000 & 0,000 & 0,000 & 0,000 & 0,000 & 0,000 & 0,000 & 0,000 & 0,000 & 0,000 & 0,000 & 0,000 & 0,297 \\
\hline Hopkinsina pacifica & 0,000 & 0,000 & 0,000 & 0,000 & 0,000 & 0,000 & 0,000 & 0,000 & 0,000 & 0,000 & 0,000 & 0,000 & 0,000 & 0,000 & 0,000 & 0,000 & 0,000 & 0,000 & 0,000 & , ,000 & 0,000 & 0,000 & 0,000 \\
\hline Islandiella islandica & 0,000 & 0,000 & 0,000 & 0,000 & 0,000 & 0,000 & 0,000 & 0,326 & 0,000 & 0,000 & 0,000 & 0,000 & 0,000 & 0,000 & 0,000 & 0,000 & 0,000 & 0,000 & 0,000 & 0,000 & 0,000 & 0,000 & 0,000 \\
\hline & 0,000 & 0,000 & 0,000 & 0,000 & 0,000 & 0,000 & 0,000 & 0,326 & 0,000 & 0,000 & 0,000 & 0,000 & 0,000 & 0,000 & 0,000 & 0,000 & 0,000 & 0,000 & 0,000 & 0,000 & 0,000 & 0,000 & 0,000 \\
\hline Lagena striata & 0,000 & 0,000 & 0,730 & & 0,000 & 0,00 & & & 0,00 & & & 0,2 & & 0,000 & & & & & 0,000 & 0,000 & .000 & 0,000 & 0,000 \\
\hline Lagena sp. & 0,543 & 0,328 & 0,000 & 0,000 & 0,380 & 0,000 & 0,000 & 0,000 & 0,000 & 0,000 & 0,000 & 0,000 & 0,000 & 0,000 & 0,000 & 0,000 & 0,000 & 0,000 & 0,000 & 0,000 & 0,000 & 0,000 & 0,000 \\
\hline
\end{tabular}


Tabela 9 (continuação): Foraminíferos bentônicos encontrados no testemunho GeoB6211-2. Espécies expressas em porcentagem. Modelo de idades retirado de Chiessi et al. (2008).

\begin{tabular}{|c|c|c|c|c|c|c|c|c|c|c|c|c|c|c|c|c|c|c|c|c|c|c|c|}
\hline Profundidade $(\mathrm{cm})$ & 353 & 363 & 373 & 383 & 393 & 403 & 413 & 423 & 433 & 443 & 453 & 463 & 473 & 483 & 493 & 503 & 513 & 523 & 533 & 543 & 553 & 563 & 573 \\
\hline Fração analisada & $1 / 4$ & $1 / 4$ & $1 / 8$ & $1 / 4$ & $1 / 4$ & $1 / 4$ & 1 & $1 / 2$ & $1 / 8$ & $1 / 4$ & $1 / 2$ & 1 & $1 / 2$ & 1 & $1 / 2$ & $1 / 4$ & $1 / 2$ & 1 & $1 / 2$ & 1 & 1 & $1 / 2$ & $1 / 2$ \\
\hline Densidade & 1472 & 1220 & 2192 & 916 & 1052 & 1276 & 491 & 614 & 2296 & 1064 & 704 & 344 & 624 & 352 & 536 & 1168 & 794 & 510 & 716 & 207 & 353 & 704 & 674 \\
\hline Total Bentônicos & 368 & 305 & 274 & 229 & 263 & 319 & 491 & 307 & 287 & 266 & 352 & 344 & 312 & 352 & 268 & 292 & 397 & 510 & 358 & 207 & 353 & 352 & 337 \\
\hline Riqueza de espécies & 33 & 32 & 25 & 22 & 28 & 24 & 35 & 35 & 29 & 28 & 33 & 31 & 25 & 30 & 26 & 28 & 26 & 27 & 22 & 24 & 30 & 20 & 26 \\
\hline Lenticulina cultrata & 0,000 & 0,000 & 0,000 & 0,000 & 0,000 & 0,000 & 0,204 & 0,000 & 0,000 & 0,000 & 0,000 & 0,000 & 0,000 & 0,000 & 0,000 & 0,000 & 0,000 & 0,000 & 0,000 & 0,000 & 0,283 & 0,000 & 0,000 \\
\hline Lenticulina rotulata & 0,000 & 0,000 & 0,000 & 0,000 & 0,000 & 0,000 & 0,000 & 0,000 & 0,000 & 0,000 & 0,000 & 0,000 & 0,000 & 0,000 & 0,000 & 0,000 & 0,000 & 0,000 & 0,000 & 0,000 & 0,000 & 0,000 & 0,000 \\
\hline Lenticulina sp. & 0,000 & 0,000 & 0,000 & 0,000 & 0,000 & 0,000 & 0,000 & 0,977 & 0,000 & 0,000 & 0,000 & 0,000 & 0,000 & 0,000 & 0,000 & 0,000 & 0,000 & 0,000 & 0,000 & 0,483 & 0,283 & 0,000 & 0,000 \\
\hline Lobatula lobatula & 0,000 & 0,000 & 0,000 & 0,000 & 0,000 & 0,000 & 0,000 & 0,000 & 0,000 & 0,000 & 0,000 & 0,000 & 0,000 & 0,000 & 0,000 & 0,000 & 0,000 & 0,000 & 0,000 & 0,000 & 0,000 & 0,000 & 0,000 \\
\hline Melonis barleeanus & 0,000 & 0,000 & 1,460 & 0,000 & 0,760 & 0,313 & 0,000 & 0,000 & 0,000 & 0,000 & 0,000 & 2,326 & 1,282 & 1,136 & 0,000 & 1,027 & 0,252 & 0,392 & 0,000 & 0,000 & 3,116 & 0,568 & 0,297 \\
\hline Melonis sp. & 0,543 & 0,328 & 0,000 & 2,620 & 0,000 & 0,000 & 0,204 & 0,651 & 2,787 & 1,128 & 3,125 & 0,000 & 0,321 & 0,000 & 0,000 & 0,000 & 0,000 & 0,000 & 0,000 & 0,000 & 0,000 & 0,000 & 0,000 \\
\hline Miliolinella subrotunda & 0,000 & 0,328 & 0,000 & 0,000 & 0,000 & 0,000 & 0,000 & 0,000 & 0,000 & 0,000 & 0,000 & 0,000 & 0,000 & 0,000 & 0,000 & 0,000 & 0,000 & 0,000 & 0,000 & 0,000 & 0,000 & 0,000 & 0,000 \\
\hline Nonionella attantica & 12,772 & 1,639 & 11,314 & 15,721 & 22,814 & 15,047 & 10,387 & 17,590 & 8,362 & 10,902 & 8,807 & 5,814 & 8,654 & 9,943 & 18,284 & 9,589 & 10,327 & 7,843 & 15,642 & 3,865 & 8,782 & 15,625 & 13,056 \\
\hline Nonionella auris & 0,272 & 0,000 & 0,000 & 0,000 & 0,000 & 0,313 & 0,000 & 0,000 & 0,348 & 0,376 & 0,000 & 0,000 & 0,000 & 0,284 & 0,000 & 0,342 & 1,008 & 0,784 & 0,000 & 0,000 & 0,000 & 0,000 & 0,000 \\
\hline Nonionella opima & 2,717 & 0,656 & 0,365 & 0,000 & 1,521 & 0,940 & 0,611 & 2,606 & 2,787 & 3,008 & 1,420 & 2,035 & 4,167 & 2,273 & 4,478 & 0,685 & 0,756 & 2,745 & 1,676 & 2,415 & 0,567 & 0,568 & 0,593 \\
\hline Nonionellina Iabradorica & 0,543 & 0,656 & 0,365 & 0,000 & 0,000 & 0,000 & 0,407 & 6,189 & 1,394 & 2,632 & 2,557 & 0,000 & 0,000 & 0,000 & 0,000 & 0,000 & 0,252 & 0,000 & 0,559 & 0,000 & 0,000 & 0,000 & 0,000 \\
\hline Nonion depressulus & 0,000 & 0,000 & 0,000 & 0,000 & 0,000 & 0,000 & 0,000 & 0,000 & 0,000 & 0,000 & 0,000 & 2,035 & 0,641 & 0,568 & 1,493 & 0,342 & 0,000 & 0,000 & 0,000 & 0,966 & 0,000 & 0,568 & 0,297 \\
\hline Nonionoides gra & 22,283 & 40,984 & 25,547 & 18,341 & 10,646 & 16,301 & 15,071 & 0,000 & 12,544 & 8,647 & 14,489 & 13,663 & 10,256 & 11,932 & 17,164 & 13,014 & 10,076 & 9,216 & 22,626 & 2,899 & 9,632 & 17,330 & 6,528 \\
\hline Oolina lineata & 0,000 & 0,000 & 0,000 & 0,000 & 0,000 & 0,000 & 0,000 & 0,000 & 0,000 & 0,000 & 0,000 & 0,000 & 0,000 & 0,000 & 0,000 & 0,000 & 0,000 & 0,000 & 0,000 & 0,000 & 0,000 & 0,000 & 0,000 \\
\hline Oolina sp. & 0,000 & 0,000 & 0,000 & 0,000 & 0,000 & 0,000 & 0,000 & 0,000 & 0,000 & 0,000 & 0,000 & 0,000 & 0,000 & 0,000 & 0,000 & 0,000 & 0,000 & 0,000 & 000 & 0,000 & ,000 & 0,000 & 0,000 \\
\hline Oridorsalis umbonatus & 0,000 & 0,000 & 0,000 & 0,000 & 0,000 & 0,000 & 0,000 & 0,000 & 0,000 & 0,000 & 0,000 & 0,000 & 0,000 & 0,000 & 0,000 & 0,000 & 0,000 & 0,000 & 0,000 & 0,000 & 0,000 & 0,000 & 0,000 \\
\hline Orthomorphina sp. & 0,000 & 0,000 & 0,000 & 0,000 & 0,000 & 0,000 & 0,000 & 0,000 & 0,000 & 0,000 & 0,000 & 0,000 & 0,000 & 0,000 & 0,000 & 0,000 & 0,000 & 0,196 & 000 & 0,000 & 000 & 0,000 & 0,000 \\
\hline Poroeponides lateralis & 0,000 & 0,000 & 0,000 & 0,000 & 0,000 & 0,000 & 0,000 & 1,303 & 0,000 & 0,000 & 0,000 & 0,000 & 0,000 & 0,000 & 0,000 & 0,000 & 0,000 & 0,000 & 0,000 & 0,000 & 0,000 & 0,000 & 0,000 \\
\hline Procerolagena clavata & 0,000 & 0,000 & 0,000 & 0,000 & 0,000 & 0,000 & 0,000 & 0,000 & 0,000 & 0,000 & 0,284 & 0,000 & 0,000 & 0,000 & 0,000 & 0,000 & 0,000 & 0,000 & 0,000 & 0,000 & 0,000 & 0,000 & 0,297 \\
\hline Pseudononion pulchella & 0,000 & 0,000 & 0,000 & 0,000 & 0,380 & 0,000 & 0,000 & 0,000 & 0,697 & 0,000 & 0,000 & 0,000 & 0,321 & 0,000 & 0,000 & 0,000 & 0,000 & 1,373 & 0,000 & 0,000 & 0,000 & 0,000 & 0,000 \\
\hline Pseudononion sp. & 0,543 & 0,000 & 0,000 & 0,000 & 0,380 & 0,000 & 0,000 & 0,000 & 0,000 & 0,376 & 0,284 & 0,000 & 0,000 & 0,000 & 0,000 & 0,000 & 0,504 & 0,196 & 0,559 & 0,000 & 0,283 & 0,000 & 0,000 \\
\hline Pullenia bulloides & 0,000 & 0,000 & 0,000 & 0,000 & 0,000 & 0,000 & 0,000 & 0,000 & 0,000 & 0,000 & 0,000 & 0,000 & 0,000 & 0,000 & 0,000 & 0,000 & 0,000 & 0,000 & 0,000 & 0,000 & 0,000 & 0,000 & 0,000 \\
\hline Pyrgo murhina & 0,000 & 0,000 & 0,000 & 0,000 & 0,000 & 0,000 & 0,000 & 0,000 & 0,000 & 0,000 & 0,000 & 0,000 & 0,000 & 0,000 & 0,000 & 0,000 & 0,000 & 0,000 & 0,000 & 0,000 & 0,000 & 0,000 & 0,000 \\
\hline Pyrgo nasuta & 0,000 & 0,000 & 0,365 & 0,000 & 0,000 & 0,313 & 0,000 & 0,000 & 0,000 & 0,000 & 0,284 & 0,000 & 0,000 & 0,000 & 0,000 & 1,712 & 0,000 & 0,000 & 0,000 & 0,000 & 0,000 & 0,000 & 0,000 \\
\hline Pyrgo ringens & 0,272 & 0,000 & 0,000 & 0,000 & 0,760 & 0,000 & 0,000 & 0,000 & 0,000 & 0,000 & 0,000 & 0,291 & 0,641 & 0,000 & 0,000 & 0,000 & 1,259 & 0,196 & 0,000 & 0,000 & 0,000 & 0,000 & 0,000 \\
\hline sphaerica & 0,000 & 0,000 & 0,000 & 0,000 & 0,000 & 0,000 & 0,000 & 0,000 & 0,000 & 0,000 & 0,000 & 0,000 & 0,000 & 0,000 & 0,000 & 0,000 & 0,252 & 0,000 & 0,000 & 0,000 & 0,000 & 0,000 & 0,000 \\
\hline Pyrgo williamsoni & 0,000 & 0,000 & 0,000 & 0,000 & 0,000 & 0,000 & 0,000 & 0,000 & 0,000 & 0,000 & 0,000 & 0,000 & 0,000 & 0,000 & 0,000 & 0,000 & 0,000 & 0,000 & 0,000 & 0,000 & 0,000 & 0,000 & 0,000 \\
\hline Pyrgo sp. & 0,543 & 0,000 & 0,000 & 0,000 & 0,000 & 0,000 & 0,407 & 0,000 & 0,000 & 0,000 & 0,284 & 0,000 & 0,000 & 0,284 & 0,000 & 0,000 & 0,000 & 0,000 & 000 & 0,000 & 000 & 0,000 & 0,000 \\
\hline Quinqueloculina attantica & 5,435 & 3,279 & 4,015 & 1,747 & 1,521 & 2,821 & 4,481 & 1,303 & 3,484 & 1,880 & 1,136 & 1,453 & 2,244 & 0,852 & 2,612 & 2,055 & 4,786 & 1,961 & 2,514 & 0,483 & 1,416 & 0,000 & 1,187 \\
\hline & 0,543 & 0,000 & 0,000 & 0,000 & 1,141 & 0,000 & 0,204 & & 0,000 & 0,000 & & 0,291 & & & & 0,000 & & & & 0,000 & 283 & 0,000 & 000 \\
\hline Quinqueloculina milletti & 0,815 & 0,656 & 0,730 & 0,437 & 1,521 & 0,000 & 1,018 & 0,651 & 1,394 & 0,752 & 0,568 & 0,291 & 0,321 & 0,284 & 0,746 & 2,740 & 2,267 & 0,000 & 1,117 & 0,000 & 0,000 & 0,000 & 0,593 \\
\hline & 0,543 & 3,279 & 0,730 & 0,000 & & & 0,204 & & & & & 0, & & & & 0, & & 0 & & 0,000 & 000 & 284 & ,000 \\
\hline Quinquel & 1,902 & 0,328 & 0,730 & 0,873 & 0,380 & 0,313 & 1,629 & 0,326 & 0,348 & 0,376 & 0,284 & 0,581 & 0,321 & 0,000 & 0,000 & 0,342 & 0,000 & 0,000 & 0,559 & 0,000 & 0,000 & 0,000 & 0,000 \\
\hline & 0,272 & 0,656 & 1,095 & 0,000 & 0,760 & 0,000 & 0,815 & 0,3 & 0,000 & 0,0 & & 0,0 & & 0,8 & 000 & 1,370 & 511 & 0,784 & 279 & 0,000 & 283 & 0,000 & 0,000 \\
\hline Reusso & 0,000 & 0,328 & 0,000 & 0,000 & 0,000 & 0,000 & 0,000 & 0,000 & 0,000 & 0,376 & 0,000 & 0,000 & 0,000 & 0,000 & 0,000 & 0,000 & 0,000 & 0,000 & 0,000 & 0,000 & 0,000 & 0,000 & 0,000 \\
\hline & 0,272 & 0,656 & 0,000 & 0,000 & 0,000 & 0,0 & 0,000 & 0,3 & 0,000 & 0,0 & $0, c$ & 0,581 & 0,000 & 0,568 & 373 & 0,000 & 000 & 0,000 & 000 & 0,000 & 283 & 0,000 & 0,297 \\
\hline Rubrat & 0,000 & 0,000 & 0,000 & 0,000 & 0,000 & 0,000 & 0,000 & 0,0 & 0,000 & 0,000 & 0,000 & 0,000 & 0,000 & 0,000 & 0,000 & 0,000 & 000 & 0,000 & 0,000 & 0,000 & 0,000 & 0,000 & 0,000 \\
\hline & 4,348 & 2,951 & 3,650 & 4,367 & 9,125 & 3,448 & 1,426 & 3,9 & 6,272 & 6,767 & 2,273 & 9,302 & 6,410 & 6,818 & 4,851 & 8,904 & ,763 & 2,941 & 0,559 & 31,884 & 7,365 & 13,920 & 16,024 \\
\hline & 0,000 & 0,000 & 0,000 & 0,000 & 0,000 & 0,000 & 0,000 & & & & & & & & & 0,000 & & 0,000 & & 0,000 & 000 & 0,000 & 0,000 \\
\hline Spiroplectammina biformis & 0,000 & 0,000 & 0,000 & 0,000 & 0,000 & 0,000 & 0,000 & 0,000 & 0,000 & 0,000 & 0,000 & 0,000 & 0,000 & 0,000 & 0,000 & 0,000 & 0,000 & 0,000 & 0,000 & 0,483 & 0,000 & 0,284 & 0,000 \\
\hline & 1,902 & 1,311 & 0,730 & 0,000 & & & 1,426 & & & & & & & & & & & & & & & 0,852 & \\
\hline Stainforthia sp. & 0,000 & 0,000 & 0,000 & 0,437 & 0,000 & 1,254 & 0,204 & 0,651 & 1,394 & 0,000 & 0,000 & 0,000 & 0,000 & 0,000 & 0,000 & 0,000 & 0,000 & 0,000 & 0,000 & 0,000 & 0,000 & 0,000 & 0,297 \\
\hline Textularia agglutinans & 0,000 & 0,000 & & & & & & & & & & & & & & & & & & 14,493 & & 0,000 & \\
\hline & 0,000 & 0,000 & 0,000 & 0,000 & 0,000 & 0,000 & 0,000 & 0,000 & 0,000 & 0,000 & 0,000 & 0,000 & 0,000 & 0,000 & 0,000 & 0,000 & 0,000 & 0,000 & 0,000 & 0,966 & 0,567 & 0,284 & 0,000 \\
\hline gulosa & 0,000 & 0,000 & 0,000 & 0,000 & & & & & & & & & & & & & & & & & 000 & 0,000 & \\
\hline & 0,0 & 0,000 & 0,0 & & & 0,0 & 0,000 & & & $0, c$ & & & 0,000 & 0, & 000 & $0, c$ & 000 & 000 & 000 & 000 & 000 & 0,000 & 000 \\
\hline & & & & & & & & & & & & & & & & & & & & & & & \\
\hline & & & & & & & & & & & & & & & & & & & & & & & \\
\hline & & & & & & & & & & & & & & & & & & & & & & 0,284 & 593 \\
\hline & & 0, & & & & 00 & & & & & & & & & & & & & & & & 0,000 & 593 \\
\hline Fragnentios & 2,446 & 2,295 & 1,095 & 0,000 & 1,521 & 1,254 & 2,851 & 1,629 & 1,742 & 1,880 & 2,557 & 2,907 & 1,603 & 4,261 & 1,493 & 0,342 & 1,259 & 5,098 & 1,676 & 6,280 & 3,966 & 1,420 & 1,187 \\
\hline
\end{tabular}


Tabela 11: Dados de $\mathrm{Mg} / \mathrm{Ca}$ SST e de $\delta^{18} \mathrm{O}_{\text {ivc-sw }}$ das testas da espécie planctônica Globigerinoides ruber (white, strictu sensu) do testemunho GeoB6211-2. Modelo de idades de Chiessi et al. (2008).

\begin{tabular}{|c|c|c|c|c|c|c|c|}
\hline Idade (ka cal A.P.) & $\mathrm{Mg} / \mathrm{Ca} \mathrm{SST}$ & $\delta^{18} \mathrm{O}_{\mathrm{ivc}-\mathrm{sw}}$ & Idade (ka cal A.P.) & $\mathrm{Mg} / \mathrm{Ca} \mathrm{SST}$ & $\delta^{18} O_{\text {ivc-sw }}$ & Idade (ka cal A.P.) & $\mathrm{Mg} / \mathrm{Ca} \mathrm{SST}$ \\
\hline$-0,015$ & & & 6,338 & 23,496 & 1,892 & 15,465 & 21,948 \\
\hline 0 & & & 6,454 & 22,577 & 1,540 & 15,526 & 21,167 \\
\hline 0,015 & & & 6,569 & 23,235 & 1,512 & 15,588 & 21,721 \\
\hline 0,03 & 23,49370965 & 1,23365848 & 6,685 & 24,483 & 2,072 & 15,649 & 24,068 \\
\hline 0,045 & & & 6,801 & 25,447 & 2,390 & 15,695 & 22,245 \\
\hline 0,06 & & & 6,916 & 22,108 & 1,475 & 15,772 & 22,592 \\
\hline 0,075 & & & 7,032 & 22,203 & 1,441 & 15,834 & 22,321 \\
\hline 0,09 & 23,76992001 & 1,530587284 & 7,147 & 23,409 & 1,956 & 15,895 & 21,422 \\
\hline 0,105 & & & 7,263 & 23,918 & 1,784 & 15,956 & 21,444 \\
\hline 0,12 & & & 7,379 & 22,964 & 1,746 & 16,003 & 22,209 \\
\hline 0,135 & & & 7,494 & 23,944 & 1,824 & 16,079 & 21,718 \\
\hline 0,15 & 22,42155206 & 1,480973463 & 7,610 & 22,162 & 1,553 & 16,141 & 22,346 \\
\hline 0,165 & & & 7,739 & 24,183 & 2,035 & 16,202 & 23,067 \\
\hline 0,18 & & & 7,868 & 23,670 & 1,950 & 16,264 & 22,419 \\
\hline 0,195 & & & 7,996 & 22,597 & 1,763 & 16,310 & 22,848 \\
\hline 0,21 & 23,16304802 & 1,368884076 & 8,125 & 24,424 & 2,232 & 16,386 & 22,900 \\
\hline 0,237333333 & & & 8,254 & 24,094 & 2,181 & 16,448 & 21,011 \\
\hline 0,264666667 & & & 8,383 & 22,271 & 1,634 & 16,509 & 22,938 \\
\hline 0,292 & & & 8,512 & 24,781 & 2,274 & 16,571 & 22,019 \\
\hline 0,319333333 & 23,69820365 & 1,124712721 & 8,640 & 21,698 & 1,503 & 16,617 & 22,470 \\
\hline 0,346666667 & & & 8,769 & 22,481 & 1,980 & 16,694 & 21,480 \\
\hline 0,374 & & & 8,898 & 22,445 & 1,542 & 16,755 & 22,405 \\
\hline 0,401333333 & & & 9,027 & 21,060 & 1,185 & 16,801 & 21,507 \\
\hline 0,428666667 & 24,08101255 & 1,89886727 & 9,156 & 22,104 & 1,873 & 16,878 & 24,817 \\
\hline 0,456 & & & 9,284 & 22,623 & 1,811 & 16,924 & 22,734 \\
\hline 0,483333333 & & & 9,413 & 23,354 & 1,856 & 17,001 & 23,103 \\
\hline 0,510666667 & & & 9,542 & 22,994 & 2,322 & 17,124 & 20,463 \\
\hline 0,538 & 24,10314746 & 1,681572723 & 9,671 & 22,163 & 1,298 & 17,185 & 22,353 \\
\hline 0,565333333 & & & 9,800 & 24,800 & 2,605 & 17,231 & 22,356 \\
\hline 0,592666667 & & & 9,928 & 24,835 & 2,413 & 17,308 & 21,579 \\
\hline 0,62 & & & 10,057 & 27,505 & 2,727 & 17,369 & 22,409 \\
\hline 0,657142857 & 24,22883996 & 1,90253279 & 10,186 & 21,800 & 1,426 & 17,427 & 21,841 \\
\hline 0,694285714 & & & 10,315 & 22,323 & 1,694 & 17,480 & 21,115 \\
\hline 0,731428571 & & & 10,444 & 23,455 & 2,019 & 17,520 & 21,762 \\
\hline 0,768571429 & & & 10,572 & 22,951 & 1,385 & 17,587 & 23,158 \\
\hline 0,805714286 & 24,65848051 & 1,335244103 & 10,701 & 21,721 & 1,590 & 17,640 & 22,488 \\
\hline 0,842857143 & & & 10,830 & 21,979 & 1,043 & 17,693 & 21,911 \\
\hline 0,88 & & & 10,959 & 24,909 & 2,324 & 17,747 & 21,404 \\
\hline 0,917142857 & & & 11,088 & 21,955 & 1,640 & 17,787 & 20,577 \\
\hline 0,954285714 & 24,50072552 & 1,803950214 & 11,216 & 23,233 & 1,292 & 17,853 & 22,588 \\
\hline 0,991428571 & & & 11,345 & 21,999 & 1,897 & 17,907 & 21,460 \\
\hline 1,028571429 & & & 11,474 & 22,031 & 1,158 & 17,960 & 22,046 \\
\hline 1,065714286 & & & 11,603 & 22,716 & 1,507 & 18,013 & 21,730 \\
\hline 1,102857143 & 24,61923964 & 1,742409433 & 11,732 & 23,692 & 2,154 & 18,053 & 21,009 \\
\hline 1,14 & & & 11,860 & 21,698 & 1,537 & 18,120 & 22,008 \\
\hline 1,14879 & & & 11,989 & 21,864 & 2,026 & 18,173 & 21,098 \\
\hline 1,176470588 & 24,93516186 & 1,771107466 & 12,118 & 22,131 & 1,781 & 18,227 & 21,509 \\
\hline 1,25 & 23,24173183 & 1,377385492 & 12,247 & 22,199 & 1,919 & 18,280 & 20,403 \\
\hline 1,365636364 & 23,7202166 & 1,154512085 & 12,376 & 22,039 & 1,686 & 18,320 & 20,979 \\
\hline 1,481272727 & 24,63668408 & 1,389722892 & 12,504 & 21,972 & 1,624 & 18,387 & 20,326 \\
\hline 1,596909091 & 24,35320376 & 1,632836822 & 12,633 & 22,418 & 1,825 & 18,440 & 21,905 \\
\hline 1,712545455 & 23,54972234 & 1,388887962 & 12,762 & 23,168 & 1,978 & 18,493 & 21,873 \\
\hline 1,828181818 & 24,08541595 & 1,77948288 & 12,891 & 23,424 & 1,985 & 18,547 & 22,019 \\
\hline 1,943818182 & 25,89159193 & 1,900008664 & 13,020 & 23,128 & 1,799 & 18,587 & 22,221 \\
\hline 2,059454545 & 24,73775981 & 1,996811799 & 13,148 & 22,922 & 1,854 & 18,616 & 20,511 \\
\hline 2,175090909 & 24,90903832 & 1,757236656 & 13,277 & 22,972 & 1,912 & 18,633 & 20,494 \\
\hline 2,290727273 & 25,01143676 & 2,083693983 & 13,406 & 25,552 & 2,694 & 18,649 & 21,022 \\
\hline 2,406363636 & 23,3706617 & 1,403532449 & 13,535 & 22,097 & 1,721 & 18,665 & 21,125 \\
\hline 2,522 & 23,68447742 & 1,592616996 & 13,664 & 22,312 & 1,861 & 18,677 & 19,397 \\
\hline 2,637636364 & 23,84139978 & 1,563492547 & 13,792 & 21,950 & 1,839 & 18,698 & 20,001 \\
\hline 2,753272727 & 25,9741887 & 2,174871864 & 13,921 & 20,638 & 0,972 & 18,706 & 21,073 \\
\hline 2,868909091 & 24,18923649 & 1,584092619 & 14,050 & 22,667 & 1,345 & 18,718 & 21,700 \\
\hline 2,984545455 & 23,92265849 & 1,733371299 & 14,063 & 24,111 & 1,896 & 18,739 & 19,912 \\
\hline 3,100181818 & 22,75436425 & 1,547250386 & 14,101 & 21,838 & 2,108 & 18,755 & 21,171 \\
\hline 3,215818182 & 22,91241539 & 1,177897764 & 14,164 & 22,879 & 1,950 & 18,771 & 22,137 \\
\hline 3,331454545 & 23,48695077 & 1,440081026 & 14,189 & 21,825 & 1,703 & 18,787 & 22,011 \\
\hline 3,447090909 & 23,27867185 & 1,484169283 & 14,214 & 21,589 & 1,835 & 18,796 & 21,179 \\
\hline 3,562727273 & 23,71300381 & 1,928387302 & 14,265 & 22,514 & 1,528 & 18,812 & 21,379 \\
\hline 3,678363636 & 23,65467605 & 1,580424183 & 14,315 & 22,499 & 1,402 & 18,828 & 20,624 \\
\hline 3,794 & 24,80083578 & 1,694363429 & 14,353 & 21,222 & 1,462 & 18,840 & 20,971 \\
\hline 3,909636364 & 23,04983089 & 2,254244732 & 14,416 & 22,550 & 1,813 & 18,861 & 21,732 \\
\hline 4,025272727 & 23,99367829 & 1,490600835 & 14,467 & 21,632 & 1,758 & 18,877 & 20,252 \\
\hline 4,140909091 & 23,44430118 & 1,610406669 & 14,517 & 22,156 & 1,600 & 18,893 & 20,920 \\
\hline 4,256545455 & 24,60636358 & 1,989464382 & 14,568 & 22,902 & 1,922 & 18,910 & 20,171 \\
\hline 4,372181818 & 22,34023104 & 1,366834822 & 14,606 & 22,625 & 1,972 & 18,922 & 21,681 \\
\hline 4,487818182 & 25,07848745 & 2,420836171 & 14,669 & 22,700 & 1,938 & 18,942 & 21,675 \\
\hline 4,603454545 & 22,89136824 & 1,48360207 & 14,719 & 22,697 & 2,112 & 18,959 & 21,774 \\
\hline 4,719090909 & 26,32769798 & 2,354772144 & 14,770 & 23,537 & 1,977 & 18,975 & 18,246 \\
\hline 4,834727273 & 23,08282927 & 1,892791964 & 14,821 & 22,184 & 1,326 & 18,991 & 21,272 \\
\hline 5,066 & 22,29090179 & 1,533860345 & 14,858 & 23,419 & 1,833 & 19,003 & 19,850 \\
\hline 5,181636364 & 22,94328313 & 1,859813883 & 14,922 & 23,133 & 2,073 & 19,024 & 20,728 \\
\hline 5,297272727 & 22,98866932 & 1,773873733 & 14,972 & 23,556 & 2,250 & 19,040 & 20,650 \\
\hline 5,412909091 & 24,1395943 & 1,979015128 & 15,023 & 23,031 & 2,169 & 19,056 & 20,630 \\
\hline 5,528545455 & 21,26785932 & 1,121874532 & 15,073 & 21,416 & 1,204 & 19,073 & 19,897 \\
\hline 5,644181818 & 23,37665069 & 1,541449355 & 15,111 & 24,457 & 2,126 & 19,085 & 20,990 \\
\hline 5,759818182 & 23,88498531 & 2,237347133 & 15,174 & 21,004 & 1,357 & 19,105 & 20,427 \\
\hline 5,875454545 & 27,24961004 & 2,345134904 & 15,225 & 22,778 & 2,045 & 19,121 & 20,769 \\
\hline 5,991090909 & 22,7652031 & 1,674105967 & 15,281 & 20,468 & 1,410 & 19,138 & 21,235 \\
\hline 6,106727273 & 24,62245821 & 1,650073395 & 15,342 & 20,699 & 1,495 & 19,150 & 20,015 \\
\hline 6,222363636 & 23,73701818 & 1,838504517 & 15,388 & 21,275 & 1,263 & & \\
\hline
\end{tabular}




\section{Prancha 1: Testemunho S03}

1. Ammonia parkinsoniana. Lado umbilical. $20 \mu \mathrm{m}$. S03 (MJI).

2. Ammonia tepida. Lado umbilical. $30 \mu \mathrm{m}$. S03 (MJ).

3. Blysmasphaera sp. $20 \mu \mathrm{m}$. S03 (MJ).

4. Bolivina pulchella. $30 \mu \mathrm{m}$. S03 (MJ).

5. Bulimina marginata. $30 \mu \mathrm{m}$. S03 (MJI).

6. Buliminella elegantissima. $20 \mu \mathrm{m}$. S03 (MJ).

7. Elphidium excavatum. $30 \mu \mathrm{m}$. S03 (MJ).

8. Fissurina laevigata. $20 \mu \mathrm{m}$. S03 (MJI).

9. Fursenkoina pontoni. $10 \mu \mathrm{m}$. S03 (MJ).

10. Nonionella atlantica. $30 \mu \mathrm{m}$. S03 (MJ).

11. Pararotalia cananeiaensis. Lado umbilical. $10 \mu \mathrm{m}$. S03 (MJI).

12. Trifarina angulosa. $20 \mu \mathrm{m}$. S03 (MJ).

13. Detalhe de aspectos tafonômicos de abrasão, bioturbação e corrosão/dissolução. $20 \mu$ m. S03 (MJ).

14. Detalhe de aspectos tafonômicos de corrosão/dissolução e abrasão. $10 \mu \mathrm{m}$. S03 (MJI).

15. Detalhe de aspectos tafonômicos de corrosão/dissolução e abrasão. $10 \mu \mathrm{m}$. S03 (MJI).

16. Detalhe de aspecto tafonômico de corrosão/dissolução. $20 \mu \mathrm{m}$. S03 (MJI). 
1

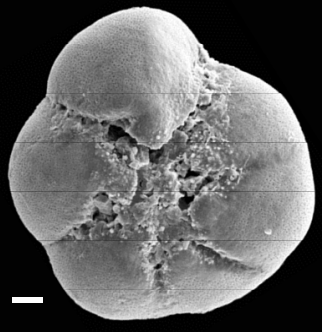

4

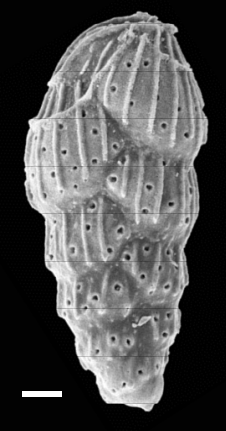

7

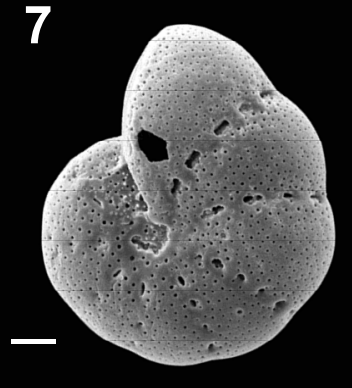

10

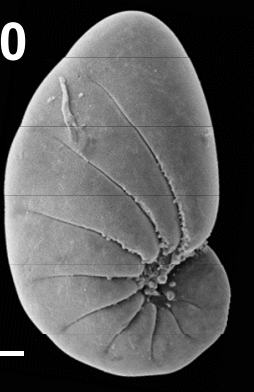

13

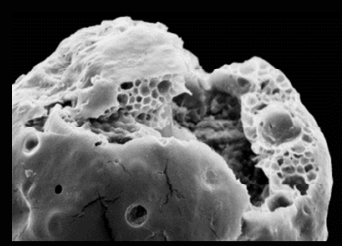

$$
-
$$

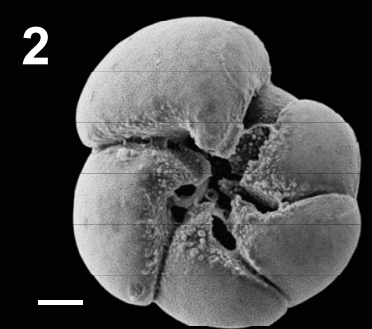

5

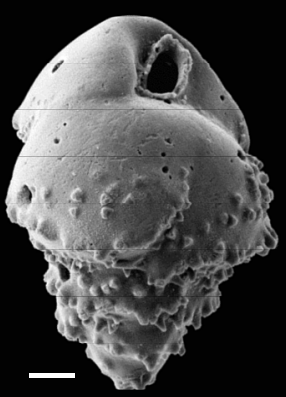

8

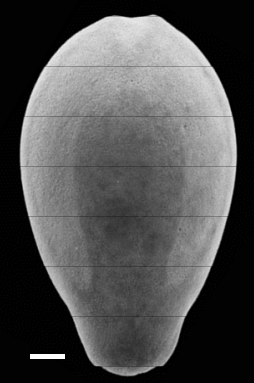

11

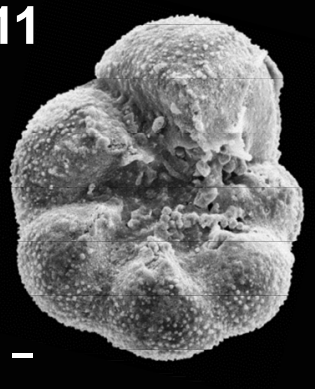

15

14

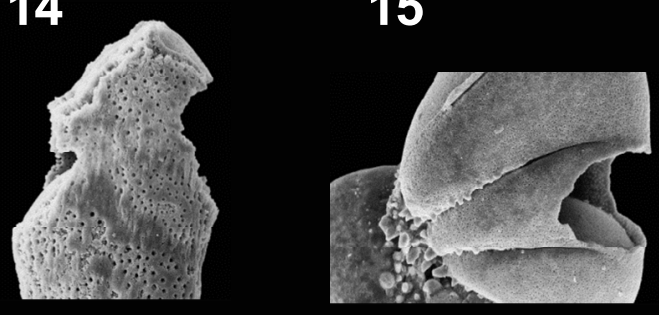

3

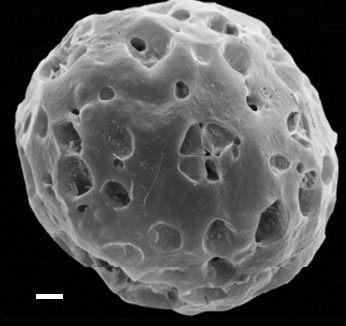

6

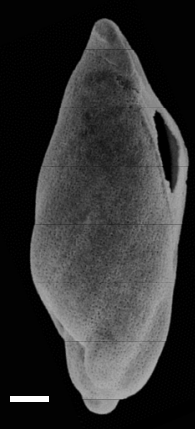

9

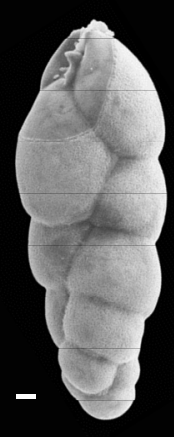

12

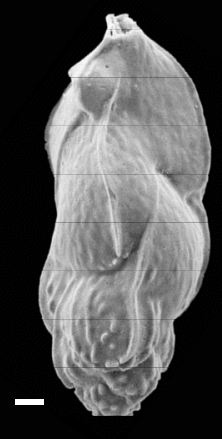

16

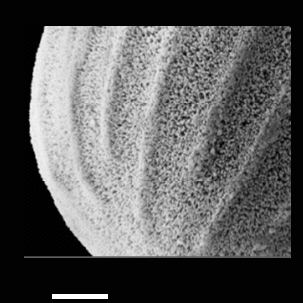




\section{Prancha 2: Testemunho GeoB6211-2}

1. Bolivina alata. $100 \mu \mathrm{m}$. GeoB6211-2 (Cone do Rio Grande).

2. Bulimina elongata. $100 \mu \mathrm{m}$. GeoB6211-2 (Cone do Rio Grande).

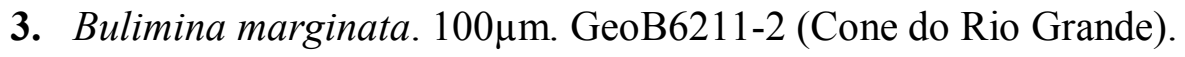

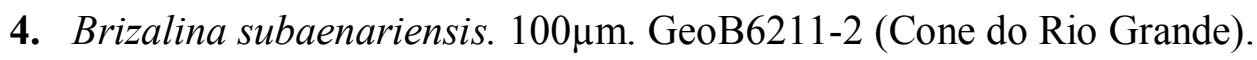

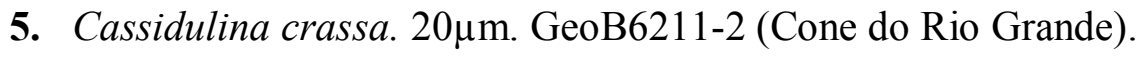

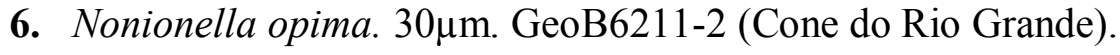

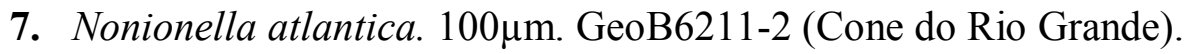

8. Nonionoides grateloupi. $30 \mu \mathrm{m}$. GeoB6211-2 (Cone do Rio Grande).

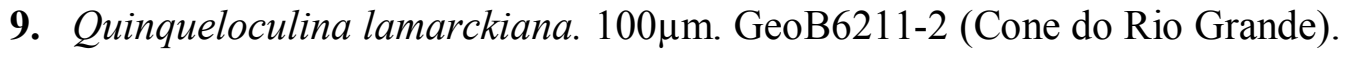

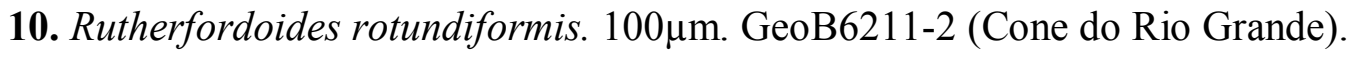

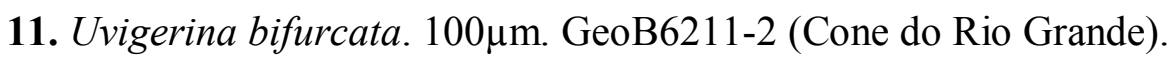

12. Uvigerina striata. $30 \mu \mathrm{m}$. GeoB6211-2 (Cone do Rio Grande). 

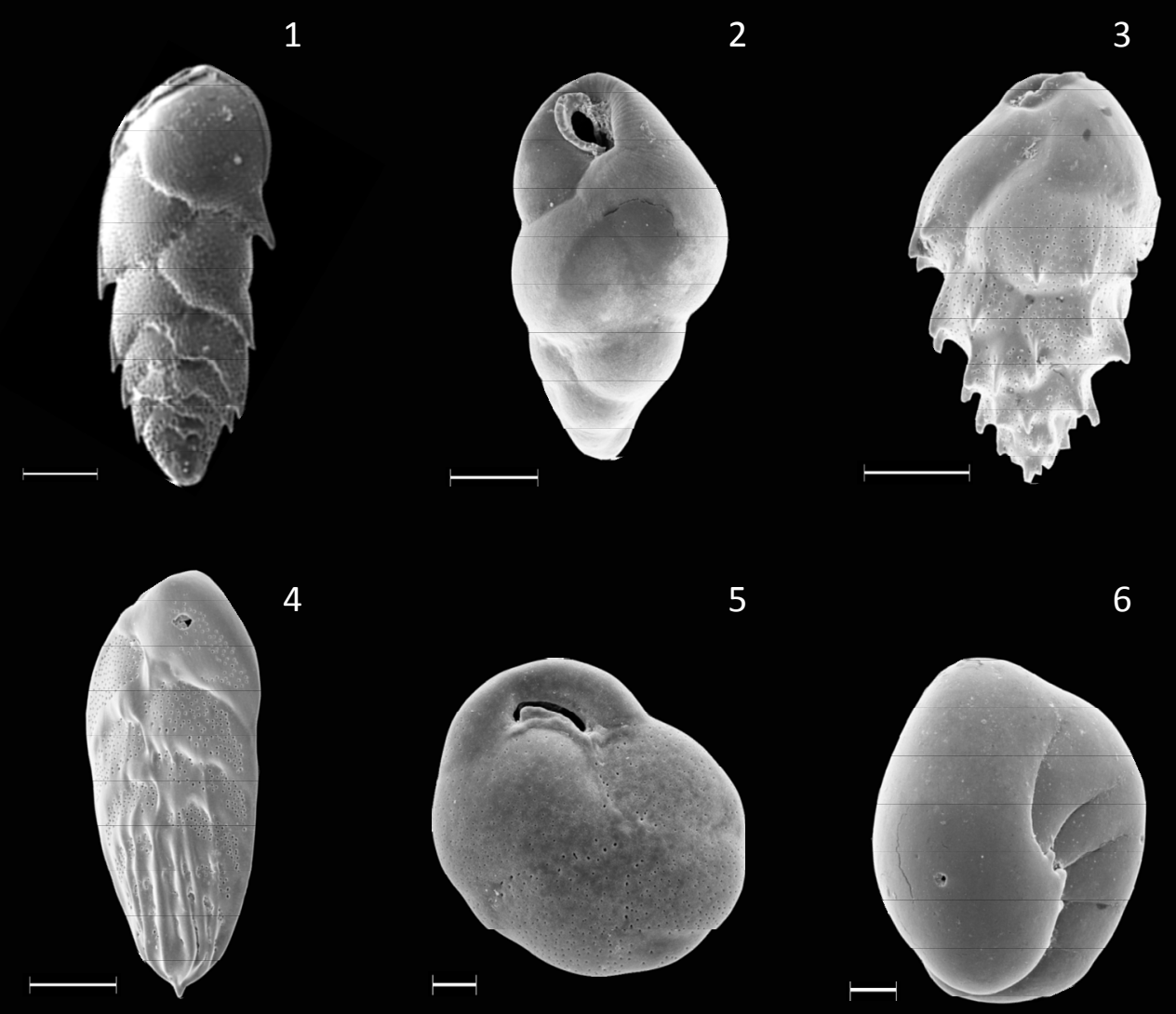

5

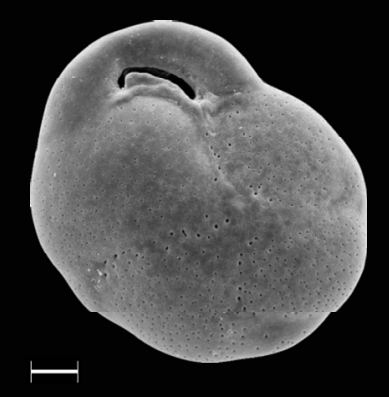

6
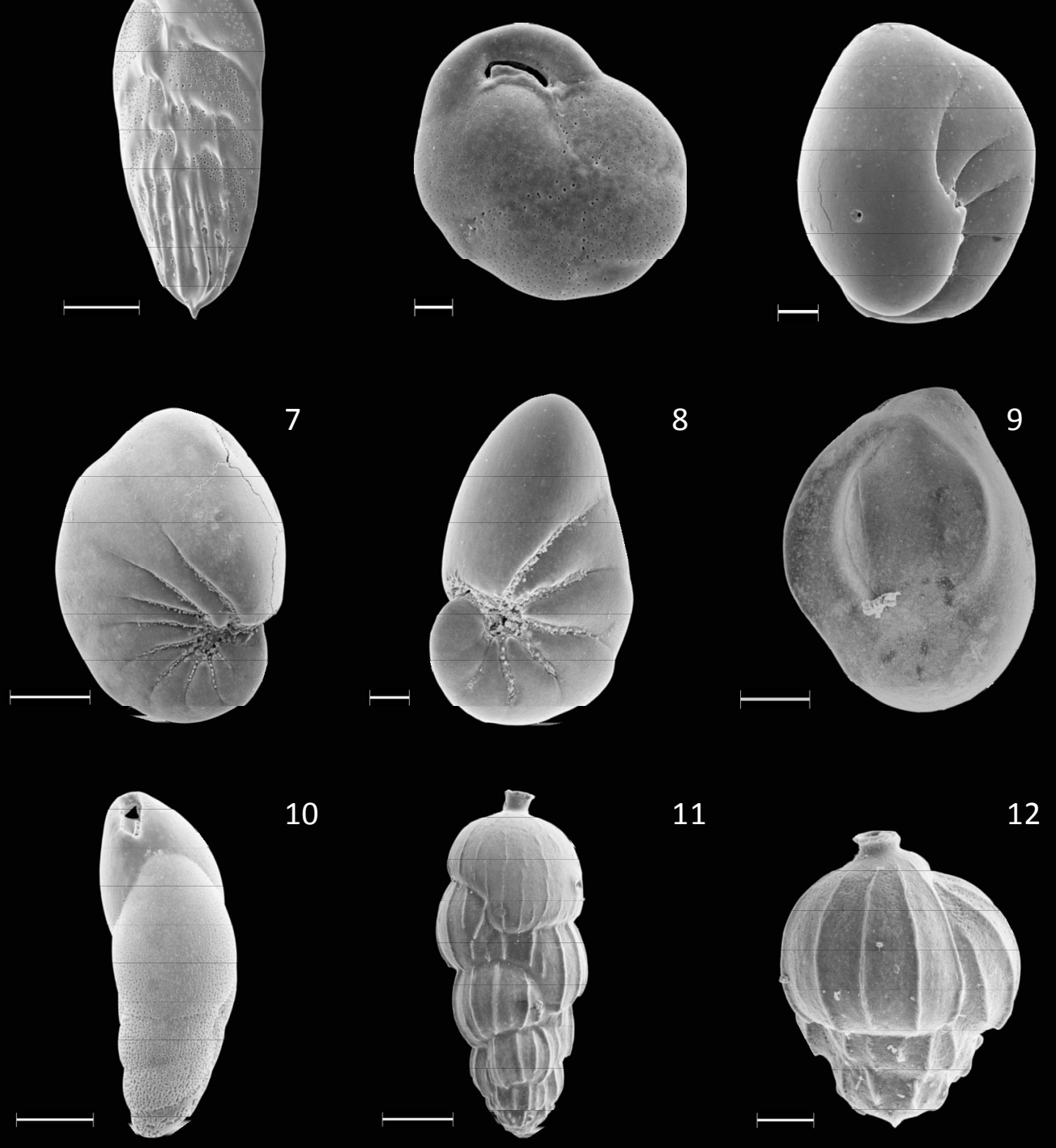

11
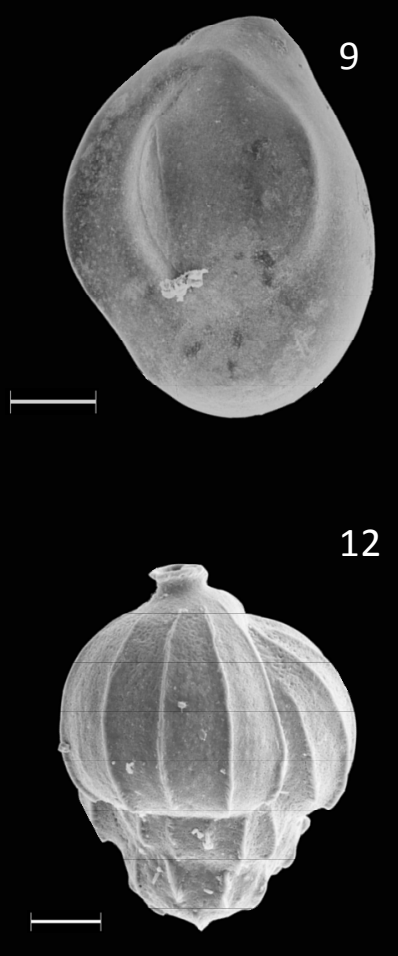


\section{Prancha 3: Testemunho GeoB6211-2}

1. Detalhe de aspectos tafonômicos de bioerosão e corrosão/dissolução. $30 \mu \mathrm{m}$. GeoB6211-2 (Cone do Rio Grande).

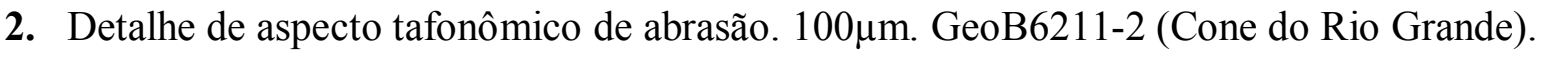

3. Detalhe de aspecto tafonômico de corrosão/dissolução. 30 $\mu \mathrm{m}$. GeoB6211-2 (Cone do Rio Grande).

4. Detalhe de aspectos tafonômicos de corrosão/dissolução e abrasão. $20 \mu \mathrm{m}$. GeoB6211-2 (Cone do Rio Grande).

5. Detalhe de aspecto tafonômico de abrasão. $20 \mu \mathrm{m}$. GeoB6211-2 (Cone do Rio Grande).

6. Detalhe de aspectos tafonômicos de corrosão/dissolução, abrasão e bioerosão. $100 \mu \mathrm{m}$. GeoB6211-2 (Cone do Rio Grande).

7. Detalhe de aspectos tafonômicos de corrosão/dissolução e abrasão. 100 $\mu \mathrm{m}$. GeoB6211-2 (Cone do Rio Grande).

8. Detalhe de aspecto tafonômico de bioerosão e corrosão/dissolução. 100 $\mu$ m. GeoB6211-2 (Cone do Rio Grande). 

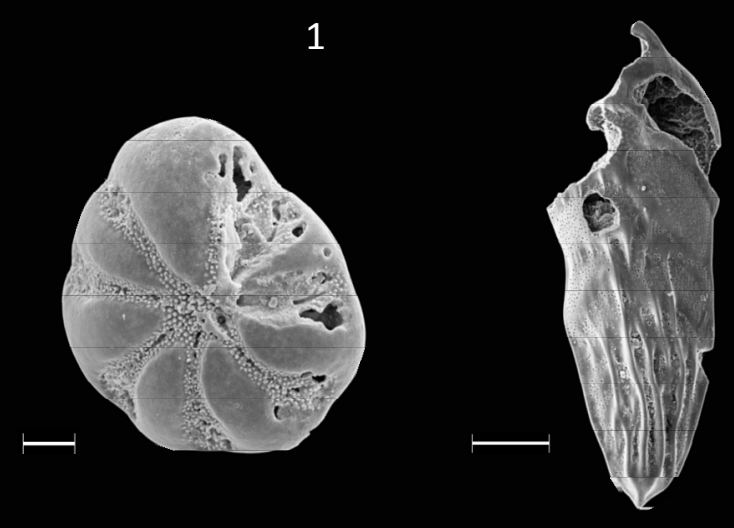

2
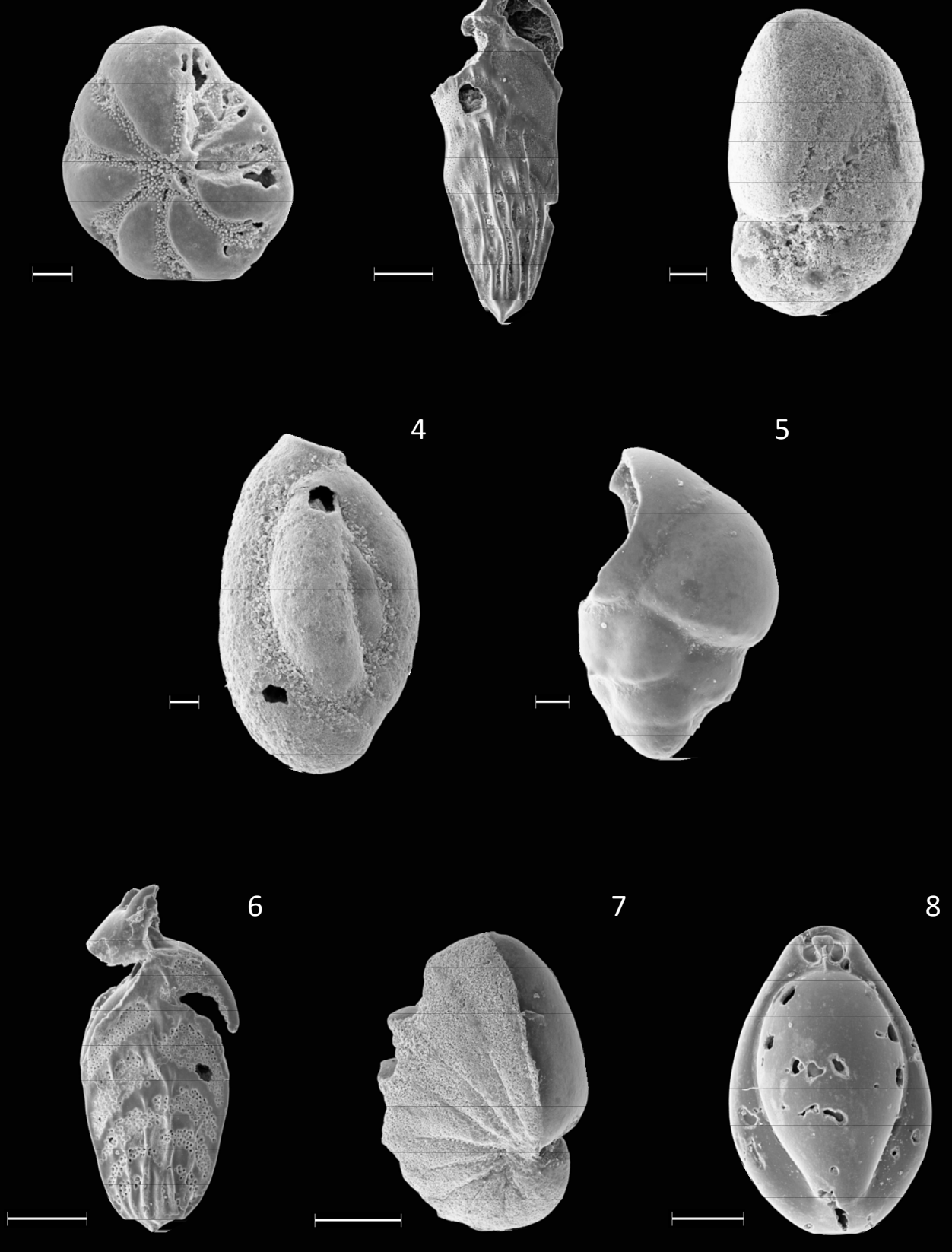


\title{
BENTHIC FORAMINIFERA AS EVIDENCE OF PALEOENVIRONMENTAL CHANGES BETWEEN 9,400 AND 8,300 CAL YR B.P. AT THE JURÉIA-ITATINS ECOLOGICAL STATION PALEOLAGOON (SP, BRASIL)
}

\author{
Juliana Braga Silva ${ }^{\dagger}$, Wânia Duleba ${ }^{\ddagger}$, Alethea M. Sallun ${ }^{\S}$, Kenitiro Suguio ${ }^{\dagger}$ \\ †Universidade de São Paulo (USP), SP, Brasil \\ Instituto de Geociências - IGc \\ Rua do Lago, 562, Cidade Universitária, 05508-080 \\ Julianabs2002@yahoo.com.br \\ *Universidade de São Paulo (USP-Leste), SP, Brasil \\ Escola de Artes, Ciências e Humanidade - EACH \\ Av. Arlindo Béttio, 1000 Ermelino Matarazzo, 03828-000 \\ ${ }^{\S}$ Secretaria do Meio Ambiente do Estado de São Paulo \\ Instituto Geológico \\ Av. Miguel Stéfano, 3900, 04301-903
}

\section{ABSTRACT}

Many aspects of the Santos Transgression ( 21,227-20,448 to 5558-4558 cal YBP) remain controversial, especially before approximately $7800 \mathrm{cal}$ YBP, because of the paucity of data for the Brazilian coast. In this context, benthic foraminiferal assemblages from between 9400 and 8385 cal YBP were analyzed from the S03 core collected at the JuréiaItatins Ecological Station (JIES) with the aim of clarifying the behavior of the relative sea level along the Brazilian coast during this period. Microfaunal, taphonomical, and morphometric analyses of these microorganisms permitted recognition of eight paleoenvironmental conditions within the lagoon then existing at JIES. There were four phases of conspicuous marine contributions (9400-9338, 9072-8894, 8656-8641, and 85948500 cal YBP) with a climax at 8656 cal YBP, when the environment became more favorable to the growth, preservation, or both of benthic foraminifera. They were intercalated with two phases of prominent continental contributions (9338-9072 and 8500-8385 cal YBP), when there was an increase in the local hydrodynamic gradient at the S03 core sampling site. Furthermore, between 8806 and 8672 cal YBP and between 8625 and 8594 cal YBP, the benthic foraminifera are absent, most likely because of the lower $\mathrm{pH}$ of the mixohaline/limnetic waters present when the continental contribution was highest. These different phases of marine and continental contributions could be explained by the higher or 
lower inflow of seawater to the paleolagoon of the JIES and by changes of the regional rainfall.

\section{INTRODUCTION}

The Santos Transgression began approximately 21,227 to 20,448 cal YBP, after the last glacial maximum, and lasted until approximately 5558 to 4558 cal YBP (Angulo, Lessa, and de Souza, 2006; Suguio and Martin, 1978b).Many studies have addressed the relative sea level (RSL) along the Brazilian coast for this transgression between around 7800 cal YBP and the present (e.g. Angulo and Suguio, 1995; Angulo, Lessa, and de Souza, 2006; Caldas, Stattegger, and Vital, 2006; Martin, Dominguez, and Bittencourt 2003; Martin et al., 1998; Suguio et al., 1985; Tomazelli and Villwock 1996; Villwock et al., 1986), but only a few studies have addressed the phase between the beginning of theHolocene $(\sim 11,500$ cal YBP) and 7800 cal YBP.

Like the aspects of the Santos Transgression that remain controversial (e.g. Angulo, Lessa, and de Souza, 2006), especially before around 7800 cal YBP, Brazilian Holocene paleoclimatology also has gaps. Studies are insufficient because of the scarcity of data on the RSL, the lack of paleoclimatic and paleoenvironmental records, and the use of different terminology with distinct interpretations (e.g. Sallun et al., 2012).

Some authors postulate drier climates for Brazil (e.g. Barberi, Salgado-Labouriau, and Suguio, 2000; Behling et al., 2004; Cordeiro et al., 2008; Salgado-Labouriau et al., 1998; Whitney et al., 2011) during the Lower Holocene (11,500-7600 cal YBP), whereas others describe wetter conditions or greater moisture (e.g. De Oliveira, Barreto, and Suguio, 1999; Ledru et al., 1996; Luz, Barth, and Martin, 1999; Stríkis et al., 2011) for the same period.

In this context, benthic foraminiferal assemblages were analyzed in the S03 core

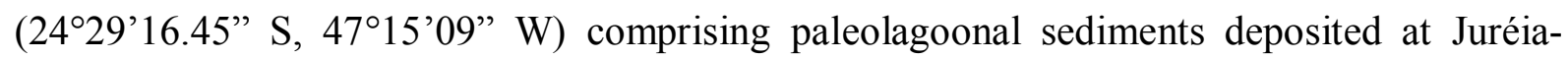
Itatins Ecological Station (JIES), SE Brazil, to detect variations in RSL behavior for the interval between 9400 and 8385 cal YBP and thus shed light on the paleosea levels along this part of the Brazilian coast.

Benthic foraminifera are commonly found in coastal or transitional environments, such as lagoons (e.g. Albani, Barbero, and Donnici, 2007; Debenay et al., 1997, 2001; Duleba and Debenay, 2003). These are important sites for paleoenvironmental and paleoclimatic studies of the interactions between continents and oceans, because they are connected to both environments and therefore respond to the variations of these two systems with equal fidelity (Albani, Barbero, and Donnici, 2007; Schallenberg, Hall, and Burns, 2003). The foraminifera, 
which are rhizopod protist microorganisms (Pawlowski et al., 2003; Sen Gupta, 1999), respond quickly to variations in the physical-chemical conditions of their habitat (Boltovskoy, Scott, and Medioli, 1991); therefore, through analyses of their assemblages and their characteristics, it is possible to detect changes in marine, transitional, or both circulation patterns and identify periods of major marine or continental contributions to the environment, thus providing information regarding the paleoclimatic and paleoceanographic behaviors of these coastal and transitional places (Callard et al., 2011; Delgado et al., 2012; Gebhardt, Kunt, and Holbourn, 2004; Longyin, Gallagher, and Finlayson, 2000; Rathburn et al., 2000; Wrightman, Scott, and Medioli, 1994).
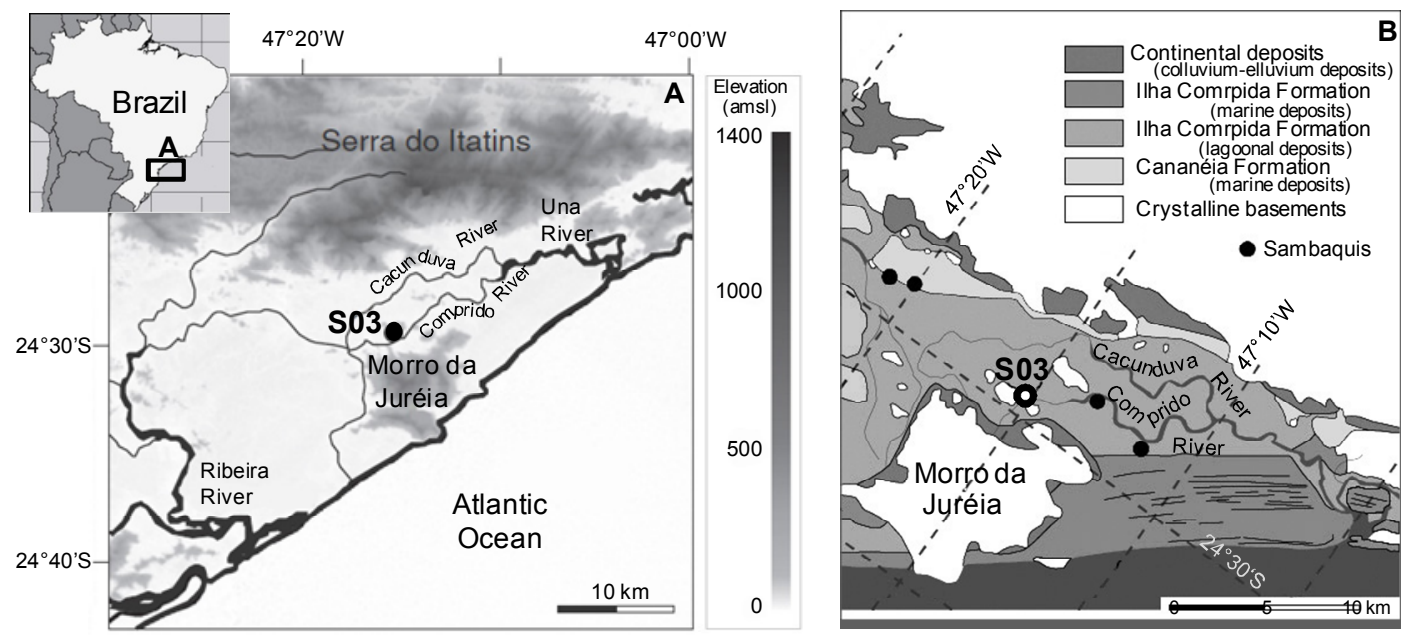

Figure 1. JIES. (a) Core location at JIES (black circle), São Paulo, Brazil (black rectangle). (b) Geological map of the area. Amsl: above mean sea level, ICF: Ilha Comprida Formation (modified from Sallun et al., 2012; Suguio and Martin, 1978a).

\section{METHODS}

The JIES has an area of more than $600 \mathrm{~km}^{2}$ between the coordinates $24^{\circ} 18^{\prime} 47^{\prime \prime}$ to $24^{\circ} 36^{\prime} 10^{\prime \prime} \mathrm{S}$ and $47^{\circ} 00^{\prime} 03^{\prime \prime}$ to $47^{\circ} 30^{\prime} 07^{\prime \prime} \mathrm{W}$ and is located north of the Cananéia-Iguape plain on the SE coast of the state of São Paulo in Brazil (Figure 1). Its current climate is tropical humid without a dry season, with greater rainfall during the summer months (Duleba and Debenay, 2003). Suguio and Martin (1978b) proposed an evolutionary model for the JIES region comprising five evolutionary stages. According to these authors, during the Santos Transgression ( 21,227-20,448 to $\sim 5558-4558$ cal YBP), a bay formed in the JIES area. For approximately 5150 14C YBP (5912-5750 cal YBP), the connection between this bay and the open ocean was interrupted by the early formation of a barrier island, which created wide 
lagoons in this region that reworked and partially recovered the Pleistocene sediments of the Cananéia Formation to generate the Ilha Comprida Formation (Suguio and Martin, 1978b).

This lagoon gradually became disconnected from the open ocean as the RSL changed, with the consequent formation of regressive beach lines (Suguio and Martin, 1978b). The paleolagoonal sediments region of JIES is drained primarily by the Comprido and Cacunduva Rivers, which form the Una do Prelado River that flows to the Atlantic Ocean (Duleba and Debenay, 2003; Sallun et al., 2012).

The 7.79-m-long S03 core was collected by vibrocore on the left bank of the Comprido River at the coordinates $24^{\circ} 29^{\prime} 16.45^{\prime \prime} \mathrm{S}$ and $47^{\circ} 15^{\prime} 09^{\prime \prime} \mathrm{W}$ (Figure 1). Sallun et al. (2012) opened, described, and dated the core, which was sampled every $10 \mathrm{~cm}$, and performed the mineralogical, textural, and geochemical analyses of this core.

For the analysis of the benthic foraminiferal content, we analyzed $10 \mathrm{~cm} 3$ of sediment sampled from every $10 \mathrm{~cm}$ along the S03 core. However, we noted the presence of benthic foraminifera only between 5.79 and $3.0 \mathrm{~m}$ (corresponding to the ages between 9400 and 8385 cal YBP). Thus, the paleoenvironmental analyses were limited to this temporal period to generate 29 samples for the microfaunal study.

Each of these samples was washed over a set of sieves with aperture sizes of 63 and $500 \mathrm{~lm}$ (Schröeder, Scott, and Medioli, 1987). Only the fraction greater than $63 \mathrm{~lm}$ was utilized, because the tests were negative for the fraction greater than $500 \mathrm{~lm}$. The samples with a fraction greater than $63 \mathrm{~lm}$ were dried at $608 \mathrm{C}$ and subjected to the densimetric separation with trichloroethylene (Boltovskoy and Wright, 1976; Scott, Medioli, and Schafer, 2001). Because of the low concentration of the tests (150 tests, except for the sample with an age of 8,656 cal YBP, for which there were 264 tests), we analyzed the samples fully.

The tests were picked, counted, and identified according to Boltovskoy et al. (1980) and Loeblich and Tappan (1964, 1988). The joule evenness (J', from Pielou, 1969) and Shannon-Wiener diversity (H', from Shannon and Weaver, 1999) indices were calculated to identify changes in the structure of the benthic foraminiferal assemblages. The benthic foraminiferal species were separated according to their paleoenvironmental indications (e.g. Buzas, 1968; Duleba et al., 2005; Kitazato, 1994; Murray, 1991; Semensatto, De Oliveira, and Dias-Brito, 2008) into species indicative of euhaline waters $(.30 \%)$, polyhaline/mesohaline waters (30-5\%), and oligohaline or limnetic waters $(5-0.5 \%$ or, $0.5 \%)$. The species were also separated into species typical of coastal water $(\mathrm{CW})$ and South Atlantic Central water $(\mathrm{SACW})$, and they were separated according to the nutrient accumulation 
(organic matter, or $\mathrm{OM}$ ) in the sediments and the oxygenation grade of the sediments. The species used for the palaeoenvironmental indications are listed at Table 2.

We further measured each of the specimens found and separated the tests into small $(125 \mu \mathrm{m})$, medium $(125-250 \mu \mathrm{m})$, and large $(250-500 \mu \mathrm{m})$ sizes according to the granulometric table of Wentworth (1922), excluding juvenile forms. Based on the taphonomic analyses, we classified them into fragments (unidentifiable), partially fragmented (classified at least at the genus level but with some post mortem alteration such as abrasion, bioerosion, corrosion, dissolution, or a combination of these), and whole (no post mortem alterations that affected their external structure), as well as white (without color alteration), gold (impregnated with iron sulfide, FeS2), and black (impregnated with iron monosulfide, FeS).

We then imaged some tests using a scanning electron microscope (SEM) to aid in the taxonomic identification and visualization of the thaphonomical processes that caused test modifications. We submitted all benthic foraminiferal species ( $\geq 84$ tests per sample) to statistical R-mode (species X species) cluster analysis (using Euclidean distance and Ward's method) to establish the distinctive assemblages. Finally, we compared the obtained data with the abiotic data defined for the same core (Sallun et al., 2012) and with paleoenvironmental and RSL modifications reported in the literature (Corrêa, 1996; Duleba and Debenay, 2003; Keigwin et al., 2005; Mahiques et al., 2010; Rohling and Pälike, 2005).

\section{RESULTS}

We identified 25 species of benthic foraminifera belonging to 20 genera in the analyzed samples. Some intervals were rich in juvenile forms that could not be identified (Table 1). Of the 25 identified species, the most abundant along the S03 core were Ammonia parkinsoniana, Ammonia tepida, Ammonia sp., Blysmasphaera brasiliensis, Blysmasphaera broennimanni, Blysmasphaera sp., Elphidium discoidale, Elphidium excavatum Elphidium limbatum, Elphidium sp., Cribroelphidium poyeanum, and Pararotalia cananeiaensis (Figures 2 and 3). These benthic foraminiferal assemblages were characterized by low densities ( $\geq 84$ tests per sample), with the exception of the sample from 8656 cal YBP (264 tests). Between 8806 and $8672 \mathrm{cal} \mathrm{YBP}$, at $8625 \mathrm{cal} \mathrm{YBP}$, and at $8594 \mathrm{cal} \mathrm{YBP}$, the benthic foraminiferal tests were absent (Figures 2 and 4-6). 
Table 1. Density of the foraminiferal species per sample found along the S03 core.

\begin{tabular}{|c|c|c|c|c|c|c|c|c|c|c|c|c|}
\hline JIES S03B depth (cm) & $300-302$ & $310-312$ & $320-322$ & $330-332$ & $340-342$ & $350-352$ & $360-362$ & $370-372$ & $380-382$ & $390-392$ & $400-402$ & $410-412$ \\
\hline Age (cal YBP) & 8385 & 8401 & 8417 & 8433 & 8449 & 8465 & 8481 & 8500 & 8516 & 8532 & 8548 & 8563 \\
\hline No. species & 2 & 1 & 2 & 1 & 2 & 1 & 2 & 9 & 3 & 8 & 7 & 15 \\
\hline \multicolumn{13}{|c|}{ Density (specimens $/ 10 \mathrm{~cm}^{3}$ ), expressed as a percentage per total of the sample } \\
\hline A. parkinsoniana & 0.00 & 0.00 & 0.00 & 0.00 & 0.00 & 0.00 & 0.00 & 13.79 & 25.00 & 13.33 & 11.76 & 8.11 \\
\hline A. tepida & 0.00 & 0.00 & 0.00 & 0.00 & 0.00 & 0.00 & 0.00 & 13.79 & 0.00 & 6.67 & 5.88 & 6.76 \\
\hline Ammonia sp. & 0.00 & 0.00 & 0.00 & 0.00 & 0.00 & 0.00 & 0.00 & 27.59 & 0.00 & 13.33 & 0.00 & 1.35 \\
\hline B. doniezi & 0.00 & 0.00 & 0.00 & 0.00 & 0.00 & 0.00 & 0.00 & 0.00 & 0.00 & 0.00 & 0.00 & 0.00 \\
\hline B. pulchella & 0.00 & 0.00 & 0.00 & 0.00 & 0.00 & 0.00 & 0.00 & 0.00 & 0.00 & 0.00 & 0.00 & 1.35 \\
\hline B. brasiliensis & 0.00 & 0.00 & 0.00 & 0.00 & 0.00 & 0.00 & 0.00 & 6.90 & 25.00 & 6.67 & 5.88 & 2.70 \\
\hline B. broennimanni & 66.67 & 100.00 & 75.00 & 50.00 & 66.67 & 100.00 & 75.00 & 0.00 & 0.00 & 0.00 & 0.00 & 0.00 \\
\hline Blysmasphaera sp. & 33.33 & 0.00 & 25.00 & 0.00 & 33.33 & 0.00 & 25.00 & 0.00 & 0.00 & 6.67 & 11.76 & 1.35 \\
\hline B. marginata & 0.00 & 0.00 & 0.00 & 0.00 & 0.00 & 0.00 & 0.00 & 0.00 & 0.00 & 0.00 & 0.00 & 2.70 \\
\hline Bulimina sp. & 0.00 & 0.00 & 0.00 & 0.00 & 0.00 & 0.00 & 0.00 & 0.00 & 0.00 & 0.00 & 0.00 & 1.35 \\
\hline B. elegantissima & 0.00 & 0.00 & 0.00 & 0.00 & 0.00 & 0.00 & 0.00 & 0.00 & 0.00 & 0.00 & 0.00 & 2.70 \\
\hline B. striatula & 0.00 & 0.00 & 0.00 & 0.00 & 0.00 & 0.00 & 0.00 & 0.00 & 0.00 & 0.00 & 0.00 & 1.35 \\
\hline C. dispars & 0.00 & 0.00 & 0.00 & 0.00 & 0.00 & 0.00 & 0.00 & 0.00 & 0.00 & 0.00 & 0.00 & 0.00 \\
\hline C. poeyanum & 0.00 & 0.00 & 0.00 & 0.00 & 0.00 & 0.00 & 0.00 & 0.00 & 0.00 & 0.00 & 0.00 & 0.00 \\
\hline E. limbatum & 0.00 & 0.00 & 0.00 & 0.00 & 0.00 & 0.00 & 0.00 & 0.00 & 0.00 & 0.00 & 0.00 & 0.00 \\
\hline E. discoidale & 0.00 & 0.00 & 0.00 & 0.00 & 0.00 & 0.00 & 0.00 & 3.45 & 25.00 & 20.00 & 11.76 & 4.05 \\
\hline E. excavatum & 0.00 & 0.00 & 0.00 & 0.00 & 0.00 & 0.00 & 0.00 & 0.00 & 0.00 & 6.67 & 5.88 & 2.70 \\
\hline Elphidium sp. & 0.00 & 0.00 & 0.00 & 0.00 & 0.00 & 0.00 & 0.00 & 3.45 & 0.00 & 0.00 & 0.00 & 1.35 \\
\hline F. laevigata & 0.00 & 0.00 & 0.00 & 0.00 & 0.00 & 0.00 & 0.00 & 0.00 & 0.00 & 0.00 & 0.00 & 0.00 \\
\hline F. pontoni & 0.00 & 0.00 & 0.00 & 0.00 & 0.00 & 0.00 & 0.00 & 0.00 & 0.00 & 0.00 & 0.00 & 0.00 \\
\hline H. boueana & 0.00 & 0.00 & 0.00 & 0.00 & 0.00 & 0.00 & 0.00 & 0.00 & 0.00 & 0.00 & 0.00 & 0.00 \\
\hline Hopkinsina sp. & 0.00 & 0.00 & 0.00 & 0.00 & 0.00 & 0.00 & 0.00 & 0.00 & 0.00 & 0.00 & 0.00 & 0.00 \\
\hline L. striata & 0.00 & 0.00 & 0.00 & 0.00 & 0.00 & 0.00 & 0.00 & 0.00 & 0.00 & 0.00 & 0.00 & 0.00 \\
\hline N. atlantica & 0.00 & 0.00 & 0.00 & 0.00 & 0.00 & 0.00 & 0.00 & 0.00 & 0.00 & 0.00 & 0.00 & 0.00 \\
\hline N. grateloupi & 0.00 & 0.00 & 0.00 & 0.00 & 0.00 & 0.00 & 0.00 & 3.45 & 0.00 & 0.00 & 0.00 & 2.70 \\
\hline P. cananeiaensis & 0.00 & 0.00 & 0.00 & 0.00 & 0.00 & 0.00 & 0.00 & 13.79 & 0.00 & 13.33 & 5.88 & 43.24 \\
\hline R. laevis & 0.00 & 0.00 & 0.00 & 0.00 & 0.00 & 0.00 & 0.00 & 0.00 & 0.00 & 0.00 & 0.00 & 0.00 \\
\hline T. angulosa & 0.00 & 0.00 & 0.00 & 0.00 & 0.00 & 0.00 & 0.00 & 0.00 & 0.00 & 0.00 & 0.00 & 0.00 \\
\hline U. striatula & 0.00 & 0.00 & 0.00 & 0.00 & 0.00 & 0.00 & 0.00 & 3.45 & 0.00 & 0.00 & 0.00 & 0.00 \\
\hline Young Rotaliine & 0.00 & 0.00 & 0.00 & 0.00 & 0.00 & 0.00 & 0.00 & 3.45 & 0.00 & 0.00 & 0.00 & 9.46 \\
\hline Young Cribroelphidium & 0.00 & 0.00 & 0.00 & 0.00 & 0.00 & 0.00 & 0.00 & 3.45 & 0.00 & 0.00 & 0.00 & 0.00 \\
\hline Fragments & 0.00 & 0.00 & 0.00 & 50.00 & 0.00 & 0.00 & 0.00 & 3.45 & 25.00 & 13.33 & 35.29 & 6.76 \\
\hline
\end{tabular}

Table 1. Extended

\begin{tabular}{|c|c|c|c|c|c|c|c|c|c|c|}
\hline $420-422$ & $440-442$ & $460-462$ & $470-472$ & $520-522$ & $530-532$ & $540-542$ & $550-552$ & $560-562$ & $570-572$ & $580-582$ \\
\hline 8579 & 8610 & 8641 & 8656 & 8894 & 8983 & 9072 & 9160 & 9213 & 9338 & 9400 \\
\hline 11 & 2 & 2 & 20 & 2 & 4 & 1 & 2 & 2 & 1 & 12 \\
\hline 7.55 & 0.00 & 0.00 & 3.79 & 0.00 & 26.67 & 0.00 & 0.00 & 0.00 & 0.00 & 8.33 \\
\hline 3.77 & 0.00 & 28.57 & 2.27 & 0.00 & 0.00 & 0.00 & 0.00 & 0.00 & 0.00 & 20.83 \\
\hline 3.77 & 0.00 & 0.00 & 3.03 & 0.00 & 0.00 & 0.00 & 0.00 & 0.00 & 0.00 & 4.17 \\
\hline 0.00 & 0.00 & 0.00 & 0.38 & 0.00 & 0.00 & 0.00 & 0.00 & 0.00 & 0.00 & 0.00 \\
\hline 0.00 & 0.00 & 0.00 & 0.00 & 0.00 & 0.00 & 0.00 & 0.00 & 0.00 & 0.00 & 0.00 \\
\hline 0.00 & 0.00 & 0.00 & 0.00 & 0.00 & 0.00 & 0.00 & 12.50 & 25.00 & 14.29 & 0.00 \\
\hline 0.00 & 0.00 & 14.29 & 0.00 & 0.00 & 0.00 & 0.00 & 0.00 & 25.00 & 0.00 & 0.00 \\
\hline 0.00 & 50.00 & 0.00 & 0.00 & 33.33 & 13.33 & 33.33 & 25.00 & 0.00 & 0.00 & 8.33 \\
\hline 0.00 & 0.00 & 0.00 & 0.38 & 0.00 & 0.00 & 0.00 & 0.00 & 0.00 & 0.00 & 0.00 \\
\hline 0.00 & 0.00 & 0.00 & 0.00 & 0.00 & 0.00 & 0.00 & 0.00 & 0.00 & 0.00 & 0.00 \\
\hline 9.43 & 0.00 & 0.00 & 3.03 & 0.00 & 0.00 & 0.00 & 0.00 & 0.00 & 0.00 & 4.17 \\
\hline 0.00 & 0.00 & 0.00 & 1.14 & 0.00 & 0.00 & 0.00 & 0.00 & 0.00 & 0.00 & 0.00 \\
\hline 1.89 & 0.00 & 0.00 & 0.76 & 0.00 & 0.00 & 0.00 & 0.00 & 0.00 & 0.00 & 0.00 \\
\hline 0.00 & 0.00 & 0.00 & 0.38 & 0.00 & 0.00 & 0.00 & 0.00 & 0.00 & 0.00 & 4.17 \\
\hline 0.00 & 0.00 & 0.00 & 0.38 & 0.00 & 0.00 & 0.00 & 0.00 & 0.00 & 0.00 & 0.00 \\
\hline 3.77 & 0.00 & 0.00 & 2.65 & 0.00 & 13.33 & 0.00 & 0.00 & 0.00 & 0.00 & 4.17 \\
\hline 3.77 & 0.00 & 0.00 & 2.65 & 0.00 & 0.00 & 0.00 & 0.00 & 0.00 & 0.00 & 8.33 \\
\hline 0.00 & 0.00 & 0.00 & 0.00 & 0.00 & 0.00 & 0.00 & 0.00 & 0.00 & 0.00 & 4.17 \\
\hline 3.77 & 0.00 & 0.00 & 1.14 & 0.00 & 6.67 & 0.00 & 0.00 & 0.00 & 0.00 & 4.17 \\
\hline 0.00 & 0.00 & 0.00 & 0.00 & 0.00 & 0.00 & 0.00 & 0.00 & 0.00 & 0.00 & 8.33 \\
\hline 0.00 & 0.00 & 0.00 & 1.89 & 0.00 & 0.00 & 0.00 & 0.00 & 0.00 & 0.00 & 0.00 \\
\hline 1.89 & 0.00 & 0.00 & 0.00 & 0.00 & 0.00 & 0.00 & 0.00 & 0.00 & 0.00 & 0.00 \\
\hline 0.00 & 25.00 & 0.00 & 0.00 & 0.00 & 0.00 & 0.00 & 0.00 & 0.00 & 0.00 & 0.00 \\
\hline 0.00 & 0.00 & 0.00 & 0.38 & 0.00 & 0.00 & 0.00 & 0.00 & 0.00 & 0.00 & 4.17 \\
\hline 9.43 & 0.00 & 0.00 & 4.17 & 0.00 & 0.00 & 0.00 & 0.00 & 0.00 & 0.00 & 0.00 \\
\hline 30.19 & 0.00 & 0.00 & 54.92 & 33.33 & 0.00 & 0.00 & 0.00 & 0.00 & 0.00 & 0.00 \\
\hline 0.00 & 0.00 & 0.00 & 0.38 & 0.00 & 0.00 & 0.00 & 0.00 & 0.00 & 0.00 & 0.00 \\
\hline 0.00 & 0.00 & 0.00 & 0.38 & 0.00 & 0.00 & 0.00 & 0.00 & 0.00 & 0.00 & 0.00 \\
\hline 0.00 & 0.00 & 0.00 & 1.14 & 0.00 & 0.00 & 0.00 & 0.00 & 0.00 & 0.00 & 0.00 \\
\hline 11.32 & 0.00 & 0.00 & 10.61 & 0.00 & 0.00 & 0.00 & 0.00 & 0.00 & 0.00 & 0.00 \\
\hline 0.00 & 0.00 & 28.57 & 0.00 & 0.00 & 0.00 & 0.00 & 0.00 & 0.00 & 0.00 & 0.00 \\
\hline 9.43 & 25.00 & 28.57 & 4.17 & 33.33 & 40.00 & 66.67 & 62.50 & 50.00 & 85.71 & 16.67 \\
\hline
\end{tabular}


Table 2. Benthic foraminiferal species used for the paleoenvironmental indications of the salinity gradient, water masses, presence of OM in the sediments, and oxygenation grade of the environment.

\begin{tabular}{ll}
\hline \hline Paleoenvironmental Indications & \multicolumn{1}{c}{ Species } \\
\hline Euhaline species & $\begin{array}{c}\text { T. angulosa, B. pulchella, B. striatula, C. dispars, F. laevigata, P. cananeiaensis, N. atlantica, N. grateloupi, U. } \\
\text { striata }\end{array}$ \\
Polyhaline/mesohaline species & Ammonia spp., B. doniezi, Bulimina spp., C. poeyanum, Elphidium spp. \\
Oligohaline/limnetic species & Blysmasphaera spp. \\
CW species & Ammonia spp., C. poeyanum, Elphidium spp., P. cananeiaensis \\
SACW species & T. angulosa, U. striata \\
Species indicative of OM & B. doniezi, B. pulchella, Bulimina spp., B. elegantissima, B. striatula, C. poeyanum, Elphidium spp., F. pontoni, \\
Species indicative of oxygen & Hopkinsina sp., N. atlantica, N. grateloupi \\
& C. dispars, F. laevigata, H. boueana, L. striata, P. cananeiaensis, R. laevis \\
\hline
\end{tabular}

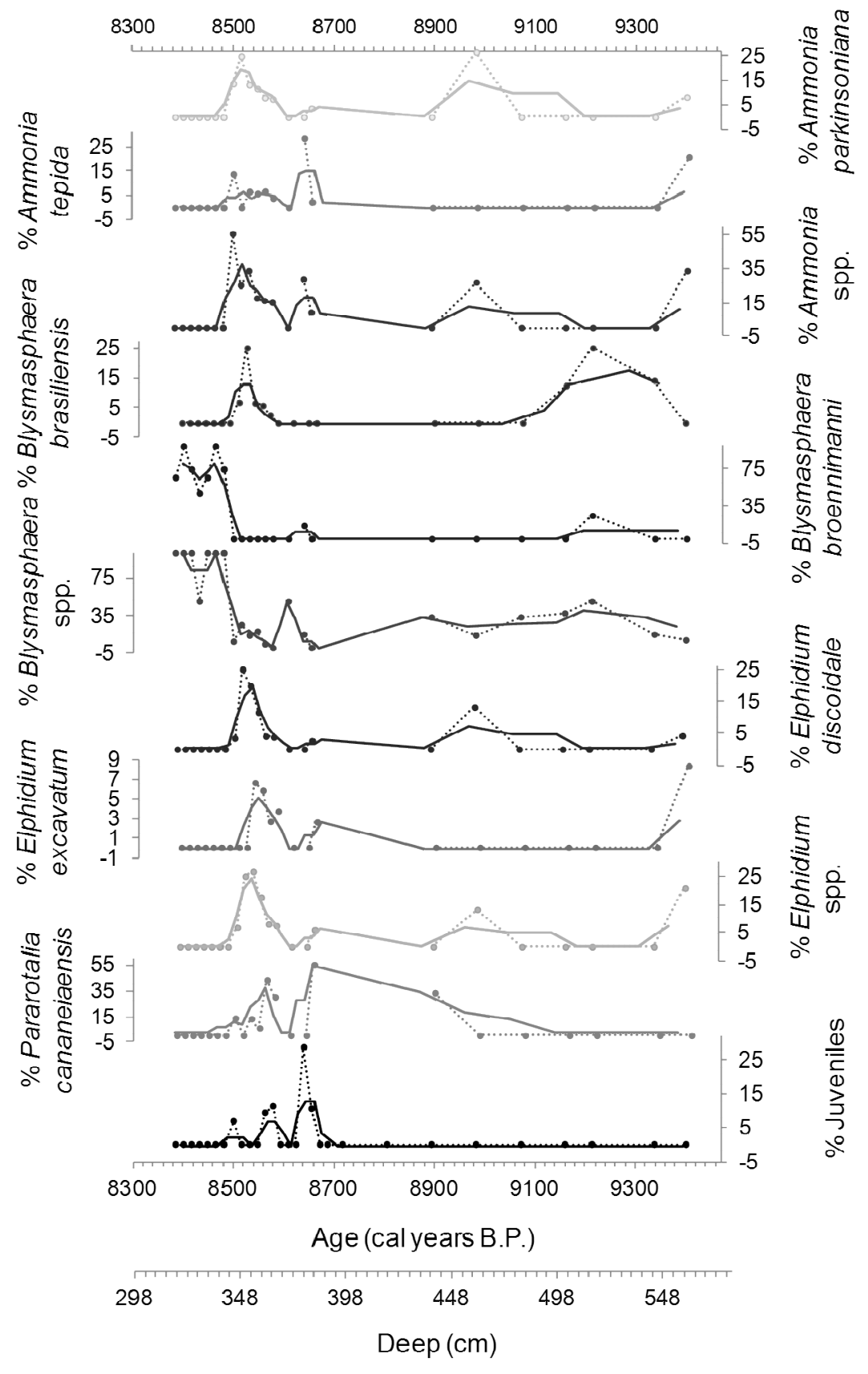


Figure 2. Primary benthic foraminiferal species found at the basal portion of the S03 core. Dashed lines with dots are the original data. Solid lines are the three-point running average of these data.

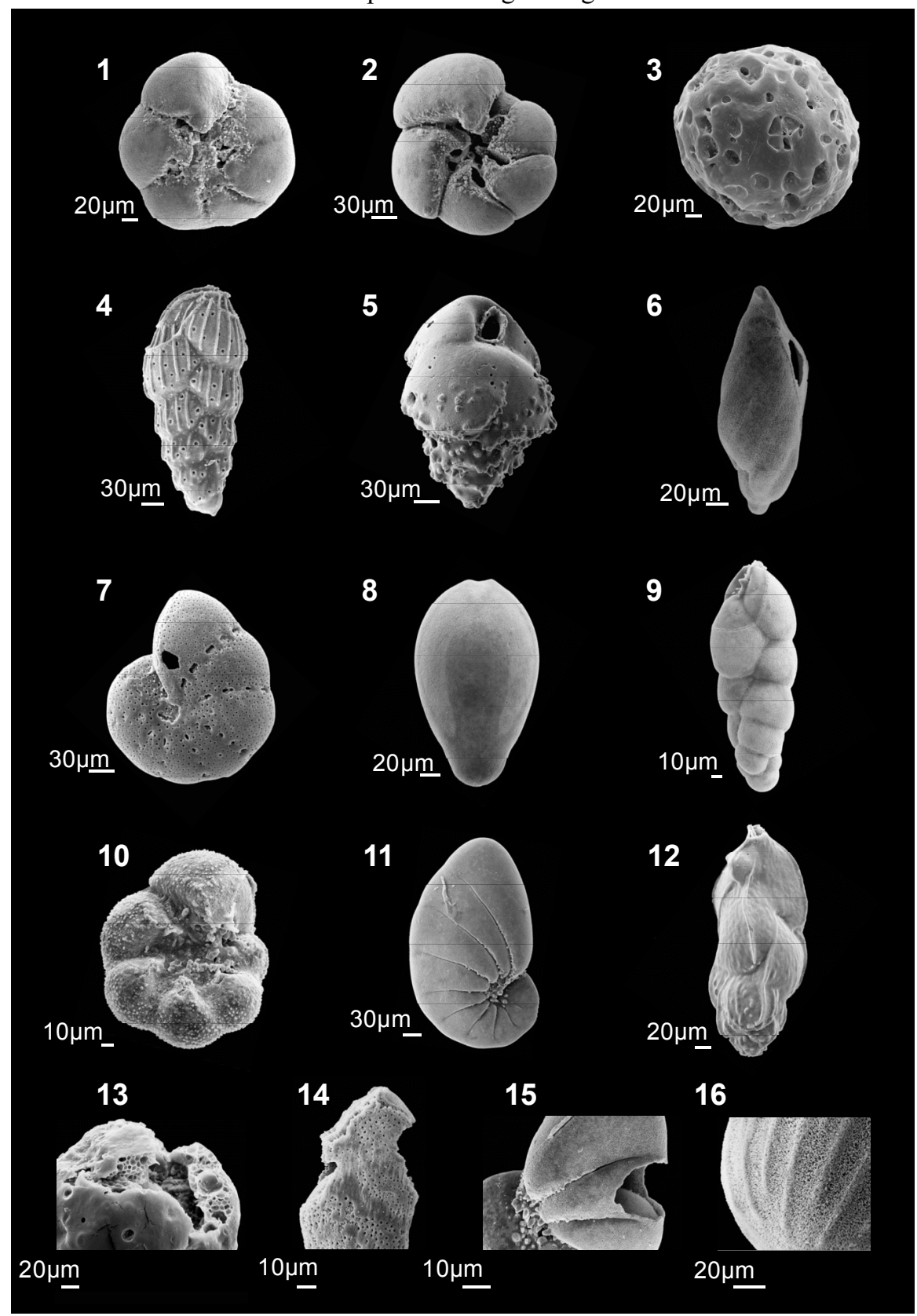

Figure 3. Board of SEM images of some benthic foraminiferal species found in the basal portion of the S03 core. (a) A. parkinsoniana, (b) A. tepida, (c) B. brasiliensis, (d) B. pulchella, (e) B. marginata, (f) B. elegantissima, (g) E. excavatum, (h) F. laevigata, (i) F. pontoni, (j) P. cananeiaensis, (k) N. atlantica, (1) $T$. angulosa, (m) Blysmasphaera sp. fragmented and bioeroded test, (n) Bolivina sp. fragmented and corroded/dissolved test, (o) N. atlantica fragmented and corroded/dissolved test, and (p) L. striata corroded/dissolved test.

The benthic foraminiferal assemblages indicated eight paleoenvironmental phases for the JIES (Figure 5). Four had major riverine contribution, and four had prominent continental 
contribution (Figures $5 \mathrm{a}-\mathrm{d}$ ). There was varying availability of oxygen and $\mathrm{OM}$ accumulation in the sediments along the S03 core between 9400 and 8385 cal YBP (Figures 5e and f).

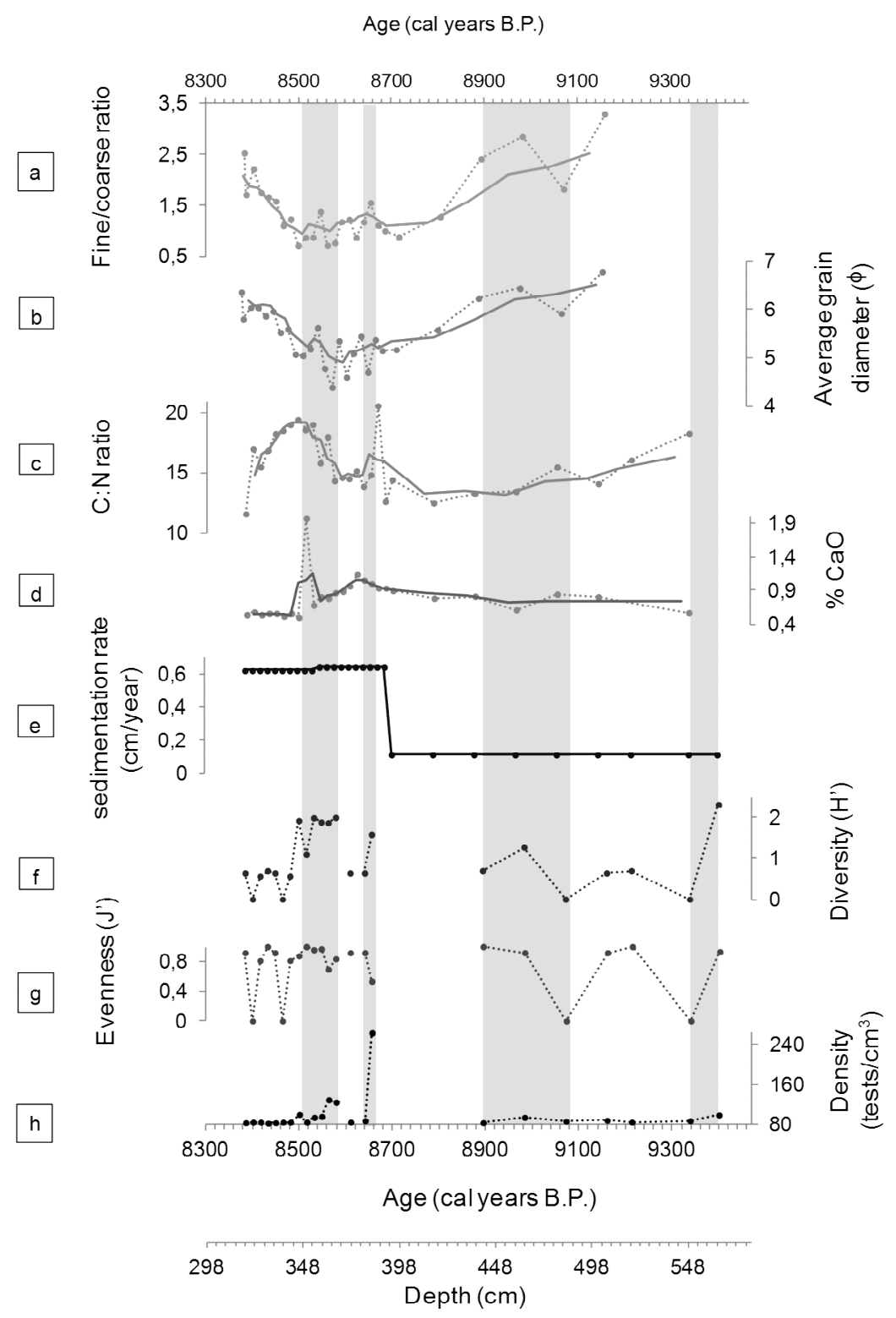

Figure 4. Abiotic and microfaunal data from the basal portion of the $\mathrm{S} 03$ core: (a) fine/coarse ratio, (b) average grain diameter $(\mathrm{U}),(\mathrm{c}) \mathrm{C}: \mathrm{N}$ ratio from sediments, $(\mathrm{d}) \% \mathrm{CaO}$, (e) sedimentation rate (centimeters per year), (f) $\mathrm{H} 0$ index of benthic foraminiferal assemblages, (g) J0 index from benthic foraminiferal assemblages, and (h) density of benthic foraminiferal assemblages (number of tests per cubic centimeter of sediment). The vertical blue bars show the intervals with greater marine contributions to the paleolagoon. Dashed lines with dots are the original data. Solid lines are the threepoint running average of these data (panels (a)-(e) obtained by Sallun et al.,2012).

The taphonomical analyses indicated that the tests were mostly white but with the presence of gold in minor proportions along the S03 core. At 9160 cal YBP, gold tests predominated (Figure 6). Whole tests prevailed only at 8641, 8579, and 8449 cal YBP. Partially fragmented tests that were mostly dissolved, corroded, or both (Figure 3) predominated throughout the rest of the core, with the exception of the interval between 9338 
and 9072 cal YBP, when fragments were predominant (Figure 6). Morphometric analyses indicated that the majority of tests were medium sized, with minor contributions of small tests and the least contribution by large sizes (Figure 6).

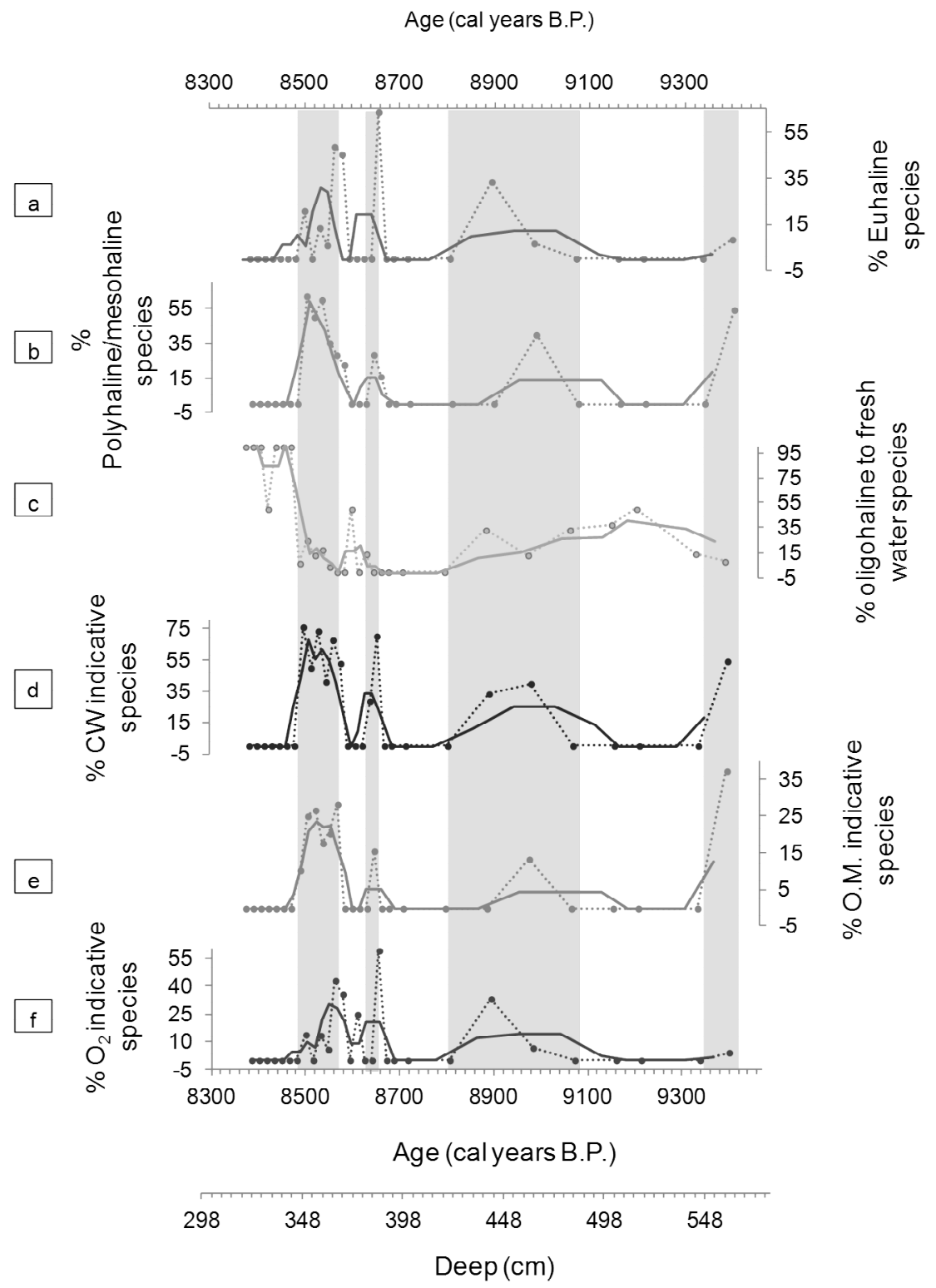

Figure 5. Percentage frequencies of benthic foraminiferal species indicative of paleoenvironments from the basal portion of the S03 core: (a) species indicative of euhaline waters $(.30 \%)$, (b) species indicative of polyhaline/mesohaline waters (30-5\%), (c) species indicative of oligohaline and limnetic waters $(5-0.5 \%$ and , $0.5 \%$ ), (d) species indicative of $\mathrm{CW}$, (e) species indicative of the amount of nutrients (OM) accumulated in the paleolagoonal sediments, and (f) species indicative of the oxygenation of the environment. The vertical blue bars show the intervals with greater marine contributions to the paleolagoon. Dashed lines with dots are the original data. Solid lines are the three-point running average of these data. 


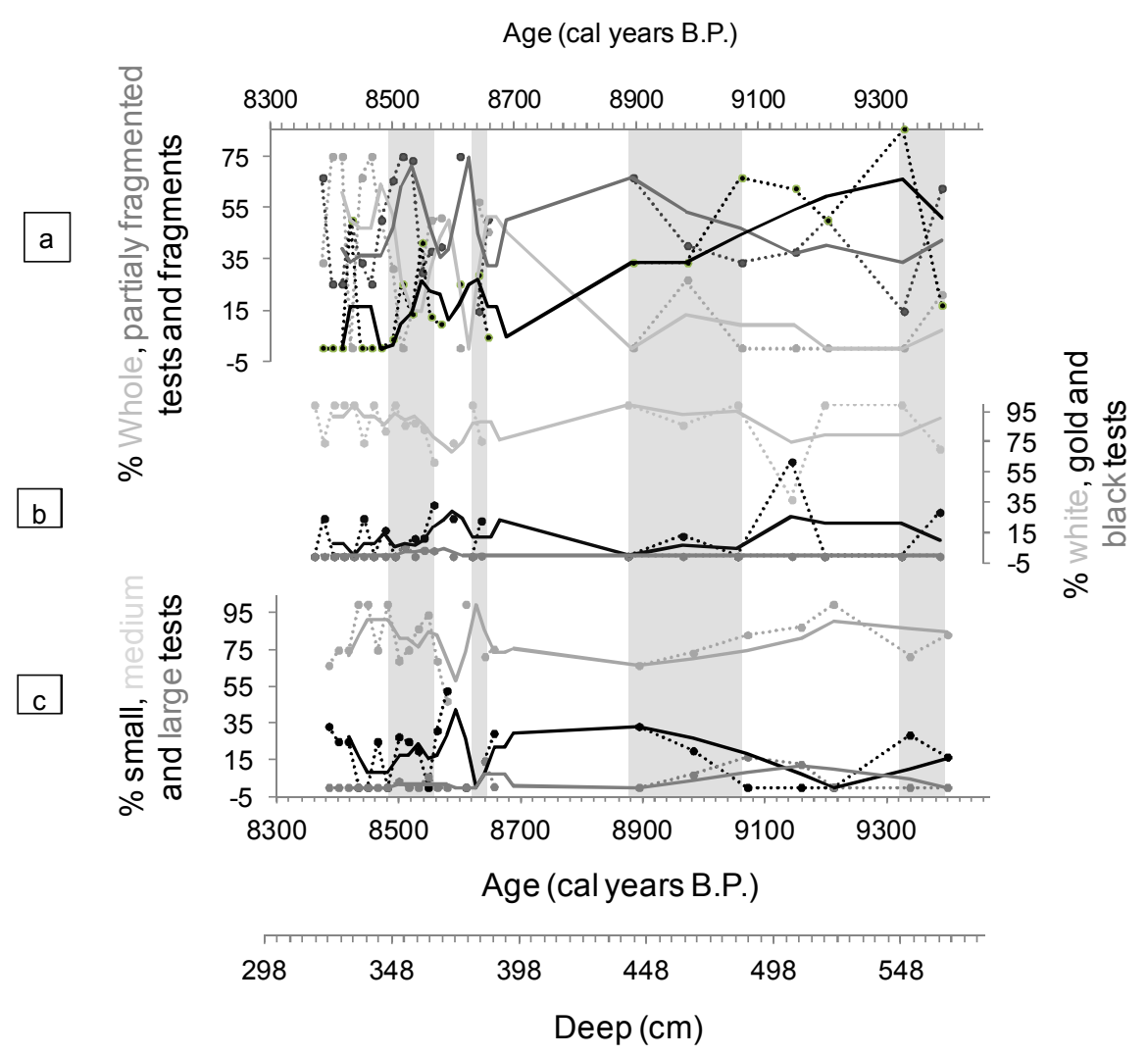

Figure 6. Taphonomical and morphometric analyses of benthic foraminiferal tests from the basal portion of the S03 core, expressed in percentage frequencies: (a) taphonomical analyses of test fragmentation, (b) taphonomical analyses of test colors, and (c) morphometric analyses of the tests. The vertical blue bars show the intervals with greater marine contributions to the paleolagoon. Dashed lines with dots are the original data. Solid lines are the three-point running average of these data.

The statistical R-mode cluster analysis (Figure 7) and the comparison with abiotic data of the S03 core revealed that the benthic foraminifera between 9400 and 8385 cal YBP could be separated into three assemblages related to eight distinct paleoclimatic periods, which were initially ( $\sim 9400$ to $\sim 8656$ cal YBP) more stressful for the foraminiferal assemblages, became less stressful until $\sim 8500$ cal YBP, and then returned to being more stressful until 8385 cal YBP, after which the benthic foraminiferal species were no longer found in the S03 core (Figures $4 \mathrm{f}$ and $\mathrm{g}$ ). The eight distinct paleoenvironmental stages founded along the S03 core were determined by the statistical analysis and by the changes of the benthic foraminiferal assemblages detected along the S03 core. 


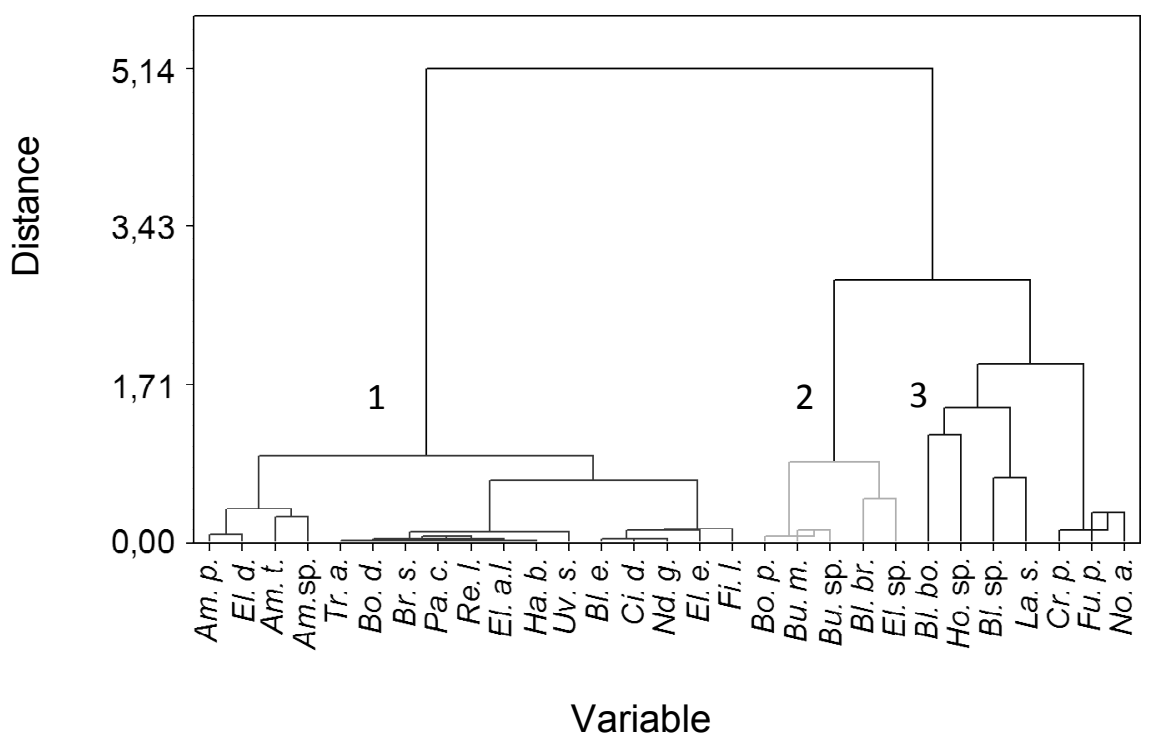

Figure 7. R-mode cluster analysis graphic of benthic foraminiferal species from the basal portion of the S03 core. The juvenile forms and the fragments were excluded from the R-mode cluster analysis. We used Euclidean distance and Ward's method. Am.p.: A. parkinsoniana, Am.t.: A. tepida, Am.sp.: Ammonia sp., Bl.br.: $B$. brasiliensis, Bl.bo.: B. broennimanni, Bl.sp.: Blysmasphaera sp., Bo.d.: B. doniezi, Bo.p.: B. pulchella, Br.s.: B. striatula, Bu.m.: B. marginata, Bu.sp.: Bulimina. sp., Bl.e.: B. elegantissima, Ci.d.: C. dispars, Cr.p.: $C$. poeyanum, El.d.: E. discoidale, El.e.: E. excavatum, El.1.: E. limbatum, El.sp.: Elphidium sp., Fi.1.: F. laevigata, Fu.p.: F. pontoni, Ha.b.: H. boueana, Ho.sp.: Hopkinsina sp., La.s.: L. striata, Pa.c.: P. cananeiaensis, No.a.: N. atlantica, No.g.: N. grateloupi, Re.1.: R. laevis, Tr.a: T. angulosa, Uv.s.: U. striata.

The first stage (9400-9338 cal YBP) was characterized by assemblages composed predominantly of Ammonia spp. (33.33\%) and Elphidium spp. (16.67\%). Other species that occurred secondarily in these assemblages were Blysmasphaera sp., Buliminella elegantissima, C. poeyanum, Fissurina laevigata, Fursenkoina pontoni, Nonionella atlantica, and unidentified fragments (Figure 2, Table 1). Weaker tests were corroded or dissolved and impregnated with $\mathrm{FeS}_{2}$ (Figures 6a and b).

The second stage (9338-9072 cal YBP) was marked by the disappearance of calcareous tests in the benthic foraminiferal assemblages, which were replaced with Blysmasphaera spp. (Figure 2, Table 1), especially in the form of fragments. We found a higher content level of fragments at $9338 \mathrm{cal}$ YBP, and gold tests occurred only at $9160 \mathrm{cal}$ YBP, when they are composed of up to $62 \%$ of the assemblages (Figures $6 a$ and $b$ ).

The third stage (9072-8894 cal YBP) was initially composed predominantly of $A$. parkinsoniana (26.67\%) and secondarily of E. discoidale, Blysmasphaera sp. and $F$. laevigata. Later, benthic assemblages were dominated by P. cananeiaensis (33.33\%) followed 
by Blysmasphaera spp. (Figure 2, Table 1). The lower limit of this stage was marked by the disappearance of benthic foraminiferal assemblages.

In the fourth stage (8806-8672 cal YBP), there were no calcareous or agglutinated tests in the sediments of the S03 core (Figures 2 and 4-6).

In the fifth stage (8672-8641 cal YBP), the main species found in the 8656 cal YBP sample was P. cananeiaensis (54.92\%), followed by Ammonia spp., B. elegantissima, and Elphidium spp. Also contributing to this assemblage were Bolivina doniezi, Bulimina marginata, Brizalina striatula, Cibicides dispars, C. poeyanum, F. laevigata, Hanzawaia boueana, N. atlantica, Nonionoides grateloupi, Reussoolina laevis, Trifarina angulosa, and Uvigerina striata (Figure 2, Table 1). This was the most stable assemblage observed along the S03 core, with a high density of tests (264 tests), increased diversity, and decreased evenness (Figures $4 \mathrm{f}-\mathrm{h}$ ). Then, at $8641 \mathrm{cal}$ YBP, the content of fragments increased substantially (from 4.17 to $28.57 \%$ ), and the only species found were A. tepida, B. broennimanni, and juvenile forms. The diversity decreased, and the evenness increased (Figures $4 \mathrm{f}$ and $\mathrm{g}$; Table 1).

At 8610 cal YBP, in the sixth stage (8641-8594 cal YBP), the benthic foraminiferal assemblages were composed especially of Blysmasphaera spp. and one test of Lagena striata (Figure 2, Table 1). Previously, between 8641 and 8625 cal YBP, there were no benthic foraminifera in the S03 core (Figure 2).

The seventh stage (8594-8500 cal YBP) was characterized by assemblages composed primarily of $P$. cananeiaensis and secondarily of Ammonia spp. and Elphidium spp. Also contributing to these assemblages were B. pulchella, Blysmasphaera spp., B. marginata, B. elegantissima, B. striatula, C. dispars, F. laevigata, Hopkinsina sp., N. grateloupi, U. striata, and juvenile forms (Figure 2, Table 1).

In the eighth stage (8500-8385 cal YBP), the benthic foraminiferal assemblages were composed of species of the Blysmasphaera genus (Table 1), which occurred with low densities. The tests were primarily whole, white, and of medium size (Figures 2 and $5 \mathrm{a}-\mathrm{c}$ ).

\section{DISCUSSION}

According to Le Cadre, Debenay, and Lesourd (2003), calcareous tests are often dissolved in waters with a $\mathrm{pH}$ lower than 7.5. Por (1986) observed that the dark-water rivers of JIES, such as Una do Prelado and Comprido (near the sampling location of the S03 core), present low $\mathrm{pH}$ values $(\sim 4)$ because of the high concentration of humic acids. Duleba and Debenay (2003) analyzed the Una do Prelado River estuary and suggested that calcareous 
tests of foraminifera were likely to be rare in the channel river sediments because of the dissolution of calcium carbonate $(\mathrm{CaCO} 3)$ in acidic waters.

Between 9400 and 8400 cal YBP, Sallun et al. (2012) described marked variations in $\mathrm{pH}$ and $\mathrm{Eh}$ in the sampling site of the S03 core. Thus, we suggest that the low density of benthic foraminiferal assemblages found for that period (Figure 4h) were the result of the lower $\mathrm{pH}$ values of mixohaline waters, which caused the dissolution of tests according to the fluctuations of continental and marine influences at the S03 core site between 9400 and 8385 cal YBP. However, because we found juvenile specimens, whole tests (not worn), or both for all species among the samples that contained calcareous tests (Figures 2 and 6), we conclude that the alterations of density exhibited by benthic foraminiferal assemblages along the S03 core did not affect the diversity of the analyzed assemblages relative to the original compositions; thus, the paleoenvironmental analyses presented here are valid.

Two mechanisms could be hypothesized to explain the absence of benthic assemblages between 8806 and $8672 \mathrm{cal} \mathrm{YBP}$, at 8625 cal YBP, and at 8594 cal YBP: (1) a strong inflow of freshwater that caused the disappearance of calcareous polyhaline/mesohaline and euhaline species and, at the same time, carried the Blysmasphaera spp. tests to another depositional site, and (2) subaerial exposure of the depositional site with consequent oxidation, dissolution, or both of tests during these phases.

According to Sallun et al. (2012), during these intervals, there was a lagoonal environment in this area of JIES, and the RSL was at least $13 \mathrm{~m}$ below the present sea level (Klein, 2005; Mahiques et al., 2010). Furthermore, the fine/coarse ratio (i.e. mud/sand ratio) and the average grain diameter of sediments (Figures $4 \mathrm{a}$ and $\mathrm{b}$ ), as well as the change of sedimentation rate (from 0.11 to $0.645 \mathrm{~cm} / \mathrm{y}$ ) between 8700 and around $8685 \mathrm{cal}$ YBP (Sallun et al., 2012), were suggestive of greater sedimentary inflow arising from the increase of hydrodynamic energy in the environment. Thus, the existing paleolagoon is likely to have received greater fluvial inflow at this time. This inflow would have caused decreases in the salinity and $\mathrm{pH}$ of the bottom water layers, thereby preventing the survival or preservation of the calcareous tests and transporting the tests of Blysmasphaera spp. to another depositional site, which resulted in the disappearance of foraminiferal tests.

\section{First Stage: 9400 to 9338 cal YBP}

The species (Ammonia spp., Elphidium spp., and C. poeyanum) that predominantly compose the assemblages in the first period have epifaunal to deep infaunal lifestyles and are 
typical of disaerobic environments with muddy to sandy substrates. They are herbivorous, detritivorous, or both and are common in coastal environments such as ponds, lagoons, and estuaries, where water conditions range from hypersaline to polyhaline/mesohaline (e.g. Bandi, 1953; Bernhard and Sen Gupta, 1999; Cassel and Sen Gupta, 1989; Duleba et al., 2005; Kitazato, 1994; Murray, 1991; Rathburn and Corliss, 1994).

According to Duleba et al. (2005), Elphidium spp. and C. poeyanum indicate waters with strong to moderate saline stratification, whereas Ammonia spp. are more typical of homogeneous to substantially stratified waters. These authors consider Ammonia spp. to be typical of environments with low to moderate OM availability. Walton and Sloan (1990) suggest that Ammonia spp. would be typical of environments with an abundant availability of food. Moreover, Samir (2000) considers Elphidium spp. to depend highly on nutritional availability in the environment, particularly on diatoms.

The assemblages present in this phase are suggestive of a lagoonal environment of polyhaline/mesohaline stratified waters, with a contribution from shallower marine waters and with considerable $\mathrm{OM}$ in the sediments and low interstitial oxygenation (Figure 5). The carbon/nitrogen $(\mathrm{C}: \mathrm{N})$ ratio (Figure 4c) obtained by Sallun et al. (2012) indicated mixed origins for the $\mathrm{OM}$ that reached the paleolagoonal substrate, which is consistent with the fluvial and marine inflows to the depositional site of the S03 core.

The taphonomical analyses indicated that the paleoenvironment would be stressful for the assemblages, with physical and chemical processes that caused wear on (primarily dissolved, corroded, or both) the tests and promoted $\mathrm{FeS}_{2}$ accumulation in the sediments (Figures 6a, 6b, and 3).

According to Alexandersson (1979) and Berger (1979), the features described earlier are characteristic of $\mathrm{CaCO}_{3}$ subsaturation, reducing environments, or both. Sallun et al. (2012) found a lower content of calcium oxide $(\mathrm{CaO})$ in the sediments of the S03 core in this interval (Figure 4d), and Berner (1970) demonstrated that the FeS2 formation in marine sediments resulted from the action of sulfur $(\mathrm{S})$ bacteria on the lower interstitial oxygenation substrates when superimposed by oxygenated waters with neutral $\mathrm{pH}$ values $(\sim 7)$. The presence of gold, corroded/dissolved tests, or both (Figures 6a and b) in this interval therefore allows us to presume that the $\mathrm{pH}$ values of the paleolagoonal waters were not too low to avoid the preservation of calcareous tests, although low interstitial oxygenation and subsaturation of $\mathrm{CaCO}_{3}$ were present in the paleolagoonal interstitial bottom waters.

The high OM concentration and the low oxygenation of the bottom sedimentary interstices still permitted the foraminifera to build tests of predominantly medium sizes, even 
if a lower proportion of small tests was present, which suggests that moderate to low energy would be present in the paleoenvironment (Figure 6c).

\section{Second Stage: 9338 to 9072 cal YBP}

According to Brönnimann (1988), the species B. brasiliensis is typical of estuarine oligohaline environments. Semensatto, De Oliveira, and Dias-Brito (2008) characterized B. broennimanni as typical of environments with salinity gradients varying from 0 to $0.03 \%$, with temperatures between 16.5 and $258 \mathrm{C}, \mathrm{pH}$ between 4.4 and 5.79, and dissolved oxygen between 22 and 73\% in the Aguapeú River, São Paulo. In the mangroves of the São Francisco River, this species was found in environments with salinities between 0 and $2 \%$ and a $\mathrm{pH}$ between 7.3 and 8 . According to these authors, B. brasiliensis is typical of oligohaline environments, whereas B. broennimanni is characteristic of limnetic environments (freshwater). In addition, Semensatto et al. (2009) found B. brasiliensis to be associated with agglutinated benthic forms in a mangrove muddy plain with sediments rich in OM and with subaerial exposure for 48.5 to $65.6 \%$ of the time, and they concluded that these species are associated with muddy sediments and tolerant of subaerial exposure.

During this same phase, Sallun et al. (2012) found a higher content of the percentage of $\mathrm{CaO}(\% \mathrm{CaO})$ and a small decrease in $\mathrm{C}: \mathrm{N}$ ratio values (Figures $4 \mathrm{c}$ and $\mathrm{d}$ ), which still suggests mixed origins for the OM but with a small increase of marine origin. These findings allow us to assume that the marine influence did not cease in the sampling site of the $\mathrm{S} 03$ core during this phase.

Therefore, we suppose that between 9338 and 9072 cal YBP, the physical-chemical parameters of the bottom waters of the paleolagoon were modified, probably because of a greater inflow of freshwater that decreased the $\mathrm{pH}$ values. The high frequency of agglutinant foraminifera and the absence of calcareous forms (Figures 2 and $3 a-c$ ), in addition to the thickening of sediments (Figure 4a) and coupled with the fragmentation grades (Figure 6a), allow us to assume that the river inflow to the paleolagoon increased, which caused increases in the gradient energy of the environment and in the fragmentation rate of tests (Figure 4a). As a result, the finer sediments and, most likely, the smaller tests were transported to another depositional site. The relatively higher river contribution would have decreased the salinity and $\mathrm{pH}$ of the bottom waters of the paleolagoon, which would have been shallow and had complete absence of calcareous tests. 


\section{Third Stage: 9072 to 8894 cal YBP}

In shallow marine environments, Kitazato (1994) and Sen Gupta and Platon (2001) utilized the ratio between A. parkinsoniana and E. excavatum as an index to indicate anoxic phases in the sediments. According to these authors, the former species is considered more tolerant of anoxia than the latter. Fissurina laevigata is a dysoxic species that lives preferentially in saline (31-32\%) CW (Buzas, 1968). According to Duleba and Debenay (2003), P. cananeiaensis only occurs in the Una do Prelado River channel during the winter, when there is less rainfall and marine waters invade the estuary and penetrate into the river channel. This species is typical of shallower marine environments and is common in coastal, paralic, estuarine, and lagoonal sites with marine influences. It occurs in euhaline to mixohaline waters that are homogeneous to moderately stratified with strong to medium tidal currents and that have well-oxygenated sandy to muddy sand sediments with low to moderate values of OM (Debenay et al., 2001; Duleba et al., 2005).

The assemblages present at this phase denote a shallow lagoonal environment that was first polyhaline/mesohaline and then became euhaline, with declining OM concentrations and an increasing degree of oxygenation in the sediments (Figure 5). The increase of small tests over medium and larger sizes in this phase alludes to the low $\mathrm{CaCO}_{3}$ content (Figure 4d) and to the lack of OM in the sediments (Figure 5e). However, the medium-sized tests were still predominant (Figure 5c), which indicates that the environment was not devoid of $\mathrm{OM}$ and oxygen in its sediments.

The increased presence of whole tests until 8983 cal YBP and the subsequent increased prevalence of partially fragmented tests (Figure 6a) denote that the environment gradient energy was increasing and that the environment was becoming more turbulent. The presence of gold tests at 8983 cal YBP was consistent with the greater inflow of OM and lower oxygenation of the sediments until this age (Figures 5e and $\mathrm{f}$ ). This scenario, according to Berner (1970), permits greater production of $\mathrm{FeS}_{2}$ in the sediments. After 8983 cal YBP, there were a decrease of $\mathrm{OM}$ concentrations and an increase of the oxygenation of sediments (Figures 5e and $\mathrm{f}$ ). The decrease of $\mathrm{C}: \mathrm{N}$ values (Figure 4c) corroborates the greater influx of marine waters into the paleolagoon, and the increase in the average grain diameter (Figure $2 \mathrm{~b}$ ), together with the increase of oxygenation of sediments (Figure 5f), supports the increase in environment gradient energy.

The benthic foraminiferal assemblages, when compared with the abiotic data from the S03 core, suggest a return of more marine conditions in the paleolagoon. The presence of 
species representative of saline waters (e.g. F. laevigata and P. cananeiaensis) indicates that the increase in the salinity of the bottom waters was significant. This salinity increase most likely corresponds to a stronger incursion of marine waters into the paleolagoon that was associated with a relatively smaller continental contribution. We assume that this was a drier epoch, when the marine currents were more important to the paleolagoon than the continental contribution, because the dominant species in these assemblages indicated waters with little or no stratification, thereby suggesting a water body with an overall increase of salinity rather than greater salinization only in the deepest layers.

\section{Fourth Stage: 8806 to 8672 cal YBP}

In the fourth phase, Sallun et al. (2012) encountered the first occurrence of reductions in the average grain diameter and in $\mathrm{CaO}$ values, followed by a period of increases in these parameters (Figures 4a, b, and d). The behavior of the C:N ratio (Sallun et al., 2012) suggests the presence of OM of mixed origins until 8685 cal YBP (Figure 4c). Between 8700 and 8684 cal YBP, the sedimentation rate increased considerably, from 0.11 to $0.645 \mathrm{~cm} / \mathrm{y}$ (Sallun et al., 2012).

We assume that the energy in the environment increased, with a decrease in the marine contribution and reductions in the salinity and $\mathrm{pH}$ of paleolagoonal bottom waters. The depletion of $\% \mathrm{CaO}$, from 0.84 to $0.61 \%$, early in this phase most likely contributed to the disappearance of calcareous species. Low content of $\mathrm{CaO}$ prevented the foraminifera from building their tests, even in the beginning of this phase, when the environment would not have been completely limnetic and the continental contribution would still have been incipient. The riverine contribution to the paleolagoon is likely to have increased, which would have decreased the salinity with a decreasing $\mathrm{pH}$ and prevented the preservation of calcareous tests despite a new increase in $\% \mathrm{CaO}$ (Figure $4 \mathrm{~d}$ ). The absence of Blysmasphaera spp. is most likely related to the higher amount of environment energy, which increased the sediment deposition rate in the paleolagoon (as indicated by the higher sedimentation rate found by Sallun et al., 2012), and transported tests of this genus to another depositional site, together with the finer fractions of the sediment.

\section{Fifth Stage: 8672 to 8641 cal YBP}

The changes in diversity and evenness at the fifth phase (Figures $4 \mathrm{f}$ and $\mathrm{g}$ ) are most likely related to the considerable decrease in test density in the S03 core sediments (Figure 
4h), which suggests that the environment quickly became less suitable for the preservation, existence, or both of benthic foraminiferal assemblages in about 15 years, between 8656 and 8641 cal YBP.

Buliminella elegantissima is a detritivorous opportunistic species of euhaline to mixohaline waters that lives in coastal to neritic marine zones with dysoxic bottom sediments varying from mud to fine sands that have a higher content of OM. It is resistant to stressed shallow environments and to hydrogen sulfide $\left(\mathrm{H}_{2} \mathrm{~S}\right)$, and it prefers sites with calm hydrodynamic conditions (Duleba et al., 2005; Eichler et al., 2004; Moodley et al., 1998; Murray, 1991; Vilela et al., 2003).

The assemblage present at 8656 cal YBP indicates a shallow euhaline to polyhaline/mesohaline environment with high exportation of $\mathrm{OM}$ to the paleolagoon bottom and more oxygenated sediments (Figure 5). The $\mathrm{C}: \mathrm{N}$ ratio and the $\% \mathrm{CaO}$ indicated a higher marine influence (Figures $4 \mathrm{c}$ and $\mathrm{d}$ ) at this time. The fine/coarse ratio and the average grain diameter (Figures $4 \mathrm{a}$ and $\mathrm{b}$ ) suggested calmer hydrodynamic conditions at 8656 cal YBP, which became more active until 8641 cal YBP. This situation is consistent with the higher frequency of the whole tests and with the substantial reduction of fragments at this time (Figure 5a). Species indicative of SACW (e.g. T. angulosa and U. striata) are also found at $8656 \mathrm{cal}$ YBP, although at a low abundance (1.52\% of the assemblages), which is associated with species typical of CW (Figure 5d). These species indicate that the marine influence into the paleolagoon at 8656 cal YBP was stronger than influences that occurred in earlier times, because the environment received an oceanic influence of deeper marine waters and became more favorable to the growth and preservation of benthic calcareous foraminifera, which increased the density of foraminiferal assemblage to its highest level (Figure 4h).

The higher quantity of small tests relative to large tests (Figure 6c) could be caused by low interstitial oxygenation (Murray, 1991) or by high OM availability in the sediments, which causes the foraminifera to reproduce before they reach larger sizes (Bradshaw, 1961). Because there was abundant available oxygen in the environment in this phase, we discard the first hypothesis and attribute the smaller sizes to the greater quantity of $\mathrm{OM}$ in the sediments. The presence of juvenile organisms (Figure 2) at this time supports this conclusion (Bradshaw, 1961).

According to Berner (1970), the transformation of FeS into $\mathrm{FeS}_{2}$ occurs slowly because of the action of sulfate-reducing bacteria, and the absence of the latter mineral may be associated with two factors: the lack of sufficient dissolved $\mathrm{S}$ in the marine sediments and insufficient time for the $\mathrm{S}$ react with the $\mathrm{FeS}$ and generate $\mathrm{FeS}_{2}$. The presence of $B$. 
elegantissima at this time provides evidence of the presence of $\mathrm{S}$ in the sediments, because this species is indicative of the presence of $\mathrm{H} 2 \mathrm{~S}$ in the environment. In addition, Sallun et al. (2012) suggested that S was available in the S03 core sediments. Therefore, we consider that the presence of black tests (with FeS) at this time, although still less prevalent than gold tests (with $\mathrm{FeS}_{2}$ ), arose from the lack of sufficient time to permit processing from $\mathrm{FeS}$ in $\mathrm{FeS}_{2}$. This lack of time is most likely related to the increase in sedimentation rate compared with the rate at 8685 cal YBP, as reported by Sallun et al. (2012).

The assemblage present at 8641 cal YBP suggests a polyhaline/mesohaline environment with a lower marine influence and greater impact of riverine waters, which would have caused a reduction in the $\mathrm{pH}$ of the paleolagoonal waters (Figures $5 \mathrm{a}-\mathrm{d}$ ). The abiotic parameters of the S03 core (Figures $4 \mathrm{a}-\mathrm{d}$ ), which are associated with the increases in the whole tests and fragments, the disappearance of filled tests (Figures 5a and b), and the increase in frequency of large tests (Figure 5c), indicate that between 8656 and 8641 cal YBP, the paleolagoonal environment was becoming less saline, with a likely decline in the $\mathrm{pH}$ of the bottom waters. These events led to increased wear of the tests, although this change would have begun smoothly, because the whole tests were predominant at this time (Figure 5a). According to Murray (1991), in better oxygenated sediments, the tests tend to be larger and white. Therefore, the higher content of white and larger tests leads us to assume that during this phase, the environment must have remained well oxygenated.

We assume that between 8672 and 8656 cal YBP, there was a strong inflow of marine waters to the paleolagoon, which generated an environment that was calmer and favorable for the benthic foraminiferal assemblages, with a higher $\mathrm{CaCO}_{3}$ concentration, a higher $\mathrm{OM}$ contribution, and better oxygenation of the bottom sediments at the location where the S03 core was collected. However, at 8641 cal YBP, the salinity decreased and hydrodynamic energy began to increase, which demonstrates that the greater marine influence into the paleolagoon was episodic, decaying quickly and intensely in about 30 years.

\section{Sixth Stage: 8641 to 8594 cal YBP}

The assemblage existing at $8610 \mathrm{cal}$ YBP was less dense, with tests that were partially or completely fragmented. The low test density and the absence of whole tests at this time (Figure 6a), together with the decrease of the fine/coarse ratio (Figure 4a), lead us to consider that the tests found in this sample are allochthonous and were most likely carried to the depositional site of the S03 core by river currents, which must have been stronger during this 
period. The decrease in the $\% \mathrm{CaO}$ values (Figure 4d) found by Sallun et al. (2012) attests to the lower marine contribution at this time.

We assume that a period of greater rainfall occurred at this time, which would increase the environment's hydrodynamic energy and decrease the marine contribution and the values of salinity and $\mathrm{pH}$ for the paleolagoon's bottom water layers. These factors again preclude the survival, preservation, or both of benthic foraminiferal assemblages between 8625 and 8594 cal YBP. This increase in the continental contribution appears to have begun at $8641 \mathrm{cal}$ YBP and intensified considerably between 8641 and 8625 cal YBP.

\section{Seventh Stage: 8594 to 8500 cal YBP}

The assemblages of the seventh phase indicate a euhaline to polyhaline/mesohaline environment, with a contribution from shallow marine waters and moderately to welloxygenated sediments with OM (Figure 5). The environment appears to have become more stressed between 8594 and 8548 cal YBP (Figure 6a) with the decreases in the ocean contribution and the OM content of the sediments (Figures 5a-c, and e) and with the increase in grain size (Figure 4b). Sallun et al. (2012) suggested that at 8548 cal YBP, there was an alteration in the source area of the paleolagoonal sediments.

We assume that between 8594 and 8548 cal YBP, the marine contribution increased again. This increase culminated at 8500 cal YBP with the inflow of deeper marine waters (SACW) into the paleolagoon, as indicated by the presence of species such as $U$. striata, which occurred at low frequencies (3.33\%), and by the abiotic data obtained by Sallun et al. (2012), indicating a \% $\mathrm{CaO}$ increase and $\mathrm{C}: \mathrm{N}$ ratio values that indicate $\mathrm{OM}$ of mixed origins.

\section{Eighth Stage: 8500 to 8385 cal YBP}

At 8500 cal YBP, Sallun et al. (2012) identified short phases of sedimentation with significant increases of organic productivity, as well as an increase in the marine contribution between 8500 and 8400 cal YBP. These authors also identify a more homogeneous contribution of mafic minerals between 8500 and 7600 cal YBP, which would suggest a greater continental contribution to the S03 core sediments. They noted the occurrence of strong changes in the paleoenvironmental standards after $8500 \mathrm{cal}$ YBP. Keigwin et al. (2005) and Rohling and Pälike (2005) recognized rapid changes in the sediment deposition patterns for the SE Brazilian coast that lasted between 250 and 500 years. 
The absence of euhaline and polyhaline/mesohaline calcareous species (Figures 5a-c), as well as the decline in $\% \mathrm{CaO}$ (from 1.97 to $0.5 \%$ ) and the behavior of the $\mathrm{C}: \mathrm{N}$ ratio, which increased to about 19 and then decreased to about 15 (Figures $4 \mathrm{c}$ and $\mathrm{d}$ ), suggests that there was a lower marine influence during this phase, with a likely accompanying decrease in the $\mathrm{pH}$ values of the paleolagoonal bottom waters. Sallun et al. (2012) found evidence that the paleosea level reached or exceeded the RSL at JIES between 8385 and 8375 cal YBP for the first time in the Holocene. These authors suggested that around 8375 cal YBP, when the JIES sedimentary record began to show a dominance of continental sources, paleoenvironmental modifications occurred.

Therefore, we assume that after 8500 cal YBP, the marine influence to the bottom waters at the depositional site of the S03 core decreased. It is likely that the greater continental contribution decreased the $\mathrm{pH}$ of these waters and prevented the growth, preservation, or both of calcareous tests. The paleoenvironment became progressively less conducive to benthic foraminiferal assemblages until they disappeared at $8385 \mathrm{cal}$ YBP.

Aside from the new marine inflow into the JIES that occurred around 8385 to 8375 cal YBP, as proposed by Sallun et al. (2012), the environment was no longer conducive to the existence of euhaline, polyhaline/mesohaline, or both foraminifera. These foraminifera are composed of calcareous tests, and at this time, Sallun et al. (2012) noted that the \% $\mathrm{CaO}$ indicated greater subsaturation of $\mathrm{CaCO} 3$ in the paleolagoon. This increase would have prevented the growth, preservation, or both of calcareous tests of foraminifera in the $\mathrm{S} 03$ core. Moreover, the presence of saline waters prevented the existence of limnetic species.

\section{General Considerations}

The micropaleontological analyses of benthic foraminiferal assemblages, when compared with the abiotic analyses of the S03 core performed by Sallun et al. (2012), allow us to project that during the Santos Transgression, there were at least four phases with a dominant influence of marine waters in the area of the JIES lowlands where the S03 core was collected, and these periods were intercalated with periods with a greater continental contribution between 9400 and 8385 cal YBP. According to Duleba and Debenay (2003), the Una do Prelado estuary has two distinct hydrodynamic seasonal regimes: one during the winter, with a greater marine contribution when marine waters enter into the estuary up to the Una do Prelado River channel, and one with a greater continental (riverine) contribution during the summer mouths. 
We propose that these fluctuations were maintained over geological time, as suggested by the S03 core data. Therefore, we can assume that paleoclimatic changes occurred in the phases with lower rainfall, when there was a greater inflow of marine waters into the JIES paleolagoon, and in phases with more humid conditions, when the rivers transported larger sediment loads to this region, thereby increasing the local hydrodynamic energy gradient and changing the physical- chemical patterns of the sediments and bottom waters of the paleolagoon.

Paleoclimatic studies performed in Brazil (Barberi, Salgado-Labouriau, and Suguio, 2000; Behling et al., 2004; Coelho, Barth, and de Araujo, 2008; Cordeiro et al., 2008; Cruz et al., 2005; Luz, Barth, and Martin, 1999; Salgado-Labouriau et al., 1998; Stríkis et al.,2011; Whitney et al., 2011) suggested distinct paleoclimatic behaviors (warmer or colder and wetter or drier) around equivalent times in distinctive Brazilian areas. However, these findings must be interpreted with caution because of the different time scales and the diachronic propagation of these paleoclimates. Thus, the different Brazilian areas most likely exhibited diverse paleoclimatic behaviors between around 9000 and 5000 cal YBP. It is possible that alternating wetter and drier, warmer and colder, or both sets of phases occurred in the JIES region between 9400 and 8385 cal YBP.

There are two alternative explanations for the four episodes with greater salinity: the larger intrusion of marine waters into the paleolagoon or the decrease in rainfall in a paralic environment, which led to the evaporation of paleolagoon waters and caused increased salt concentrations in decreased water volumes. The first explanation leads to the conclusion that the RSL elevation peaked in the JIES region during the transgressive phase, when the marine waters had a stronger influence on the paleolagoon during four intervals. The second explanation assumes that although the RSL increased, it was not sufficient to affect the paleolagoon until around 8385 to 8375 cal YBP, when according to Sallun et al. (2012), the sea level exceeded the present sea level for the first time in the JIES area. In this second case, the saline phases of the paleolagoon would correspond to dry periods in which the fresh river waters did not reach the paleolagoon.

The C: $\mathrm{N}$ ratio indicates that the $\mathrm{OM}$ of the sediments was of mixed origin, although its values varied in accordance with the continental or marine contributions (Sallun et al., 2012). Still, Sallun et al. (2012) demonstrated that the S03 core was below the paleosea level between 9400 and 8385 cal YBP. These factors and the different compositional parameters of the S03 core sediments found by Sallun et al. (2012), when considered with the presence of indicative species of marine water masses with different physical-chemical properties, 
shallower (e.g. A. tepida) or deeper (e.g. U. striata) localization (Figure 2), and other microfaunal parameters, support the first hypothesis.

\section{CONCLUSIONS}

The benthic foraminiferal assemblage analyses enabled us to identify eight phases of paleoenvironmental changes distributed between 9400 and 8385 cal YBP for the paleolagoonal environment of the JIES. It was possible to establish periods of higher or lower marine and continental contributions to the sampling site of the S03 core, which today sits in the lowlands between the Comprido and the Cacunduva Rivers, $8 \mathrm{~km}$ from the SE Brazilian coastline.

According to these benthic foraminiferal assemblages, between 9400 and 9338, 9072 and 8894, 8656 and 8641, and 8594 and 8500 cal YBP, the marine influence was more conspicuous, with a climax at 8656 cal YBP, when the environment became more favorable to the growth, preservation, or both of benthic foraminifera. A second major marine contribution occurred at 8500 cal YBP.

Intercalated between these intervals of greater marine contribution were periods with greater continental contributions, when there was an increase in the local hydrodynamic gradient, between 9338 and 9072 cal YBP and between 8500 and 8385 cal YBP.

Furthermore, between 8806 and 8672 cal YBP and between 8625 and 8594 cal YBP, the benthic foraminifera are absent, most likely because of the lower $\mathrm{pH}$ of the oligohaline/limnetic waters present when the continental contribution was highest. The present dark waters of the Comprido River are characterized by low $\mathrm{pH}$ values that are attributable to their humic acid content. We can assume that this characteristic was already present at 9400 cal YBP and could have impaired the growth, preservation, or both of benthic foraminiferal assemblages at the sampling site of the S03 core.

These different phases of marine and continental contributions could be explained by the higher or lower influence of seawater to the paleolagoon of the JIES, together with lesser or greater continental inputs. However, a more precise definition of the primordial cause of these modifications, i.e. whether they can be attributed primarily to paleoclimatic changes, to the glacioeustatic fluctuations of RSL, or both, is still a difficult task. 


\section{ACKNOWLEDGMENTS}

The authors are grateful to the Instituto Florestal and the Fundação Florestal (Secretaria do Meio Ambiente do Estado de São Paulo) for their support and permission to collect core samples. This work was supported by the Fundação de Amparo à Pesquisa do Estado de São Paulo (processes 06/04467-7 and 2008/57035-2) and Conselho Nacional de Desenvolvimento Científico e Tecnológico.

\section{LITERATURE CITED}

Albani, A.; Barbero, R.S., and Donnici, S., 2007. Foraminifera as ecological indicators in the Lagoon of Venice, Italy. Ecological Indicators, 7, 239-253.

Alexandersson, E.T., 1979. Marine maceration of skeletal carbonates in Skagerrak, North Sea. Sedimentology, 26, 845- 852.

Angulo, R.J. and Suguio, K., 1995. Re-evaluation of the Holocene sea-level máxima for the state of Paraná, Brazil. Palaeogeography, Palaeoclimatology, Palaeoecology, 113, 385393.

Angulo, R.J.; Lessa, G.C., and Souza, M.C. de, 2006. A critical review of mid- to lateHolocene sea-level fluctuations on the eastern Brazilian coastline. Quaternary Science Reviews, 25, 486-506.

Bandi, O.I., 1953. Ecology and paleoecology of some California foraminifera. Part I. The frequency distribution of recent foraminifera off California. Journal of Paleontology, 27(2), pt.1, 161-182; pr.2, 21-25.

Barberi, M.; Salgado-Labouriau, M.L., and Suguio, K., 2000. Paleovegetation and paleoclimate of "Vereda de Águas Emendadas", central Brazil. Journal of South American Earth Sciences, 13, 241-254.

Berger, W., 1979. Preservation of Foraminifera. American Association of Petroleum Geologist, SEMP Short Course, 6, 105-155.

Berner, R.A., 1970. Sedimentary Pyrite formation. American Journal of Science, 268, 1-23.

Bernhard J.M. and Sen Gupta, B.K., 1999. Foraminifera of oxygen-depleted environments. In: Sen Gupta, B.K. (ed.), Modern Foraminifera. Norwell, USA: Kluwer Academic Publishers, pp. 201-216.

Behling, H.; Pillar, V.D.; Orlóci, L., and Bauermann, S.G., 2004. Late Quaternary Araucaria forest grassland (Campos), fire and climate dynamics, studied by high-resolution pollen, 
charcoal and multivariate analysis of the Cambará do Sul core in southern Brazil. Palaeogeography, Palaeoclimatology, Palaeoecology, 203, 277-297.

Boltovskoy, E. and Wright, R., 1976. Recent Foraminifera. The Hague, Netherlands: Springer, $515 \mathrm{p}$.

Boltovskoy, E.; Giussani, G.; Watanabe, S, and Wright, R., 1980. Atlas of Benthic Shelf Foraminifera od the Southwest Atlantic. Boston, London: Kluwer Academic Publishers, The Hague, 153p.

Boltovskoy, E.; Scott, D.B., and Medioli, F.S., 1991. Morphological variations of benthic foraminiferal tests in response to changes in ecological parameters: a review. Journal of Paleontology, 65(2), 175-185.

Bradshaw, J.S., 1961. Laboratory experiments on the ecology of foraminifera. Cushman Foundation of Foraminiferal Research, 12, 87-106.

Brönnimann, P., 1988. Two new recent allogromiine and textulariine genera (Protozoa: Foraminiferida) from the Brazilian Shelf. Revue de Paléobiologie, 7(1), 33-42.

Buzas, M.A., 1968. Foraminifera from the Hadley Harbor Complex, Massachusetts. Smithsonian Miscellaneous Collections, Washington, 152(8), 187-191.

Caldas, L.H.O.; Stattegger, K., and Vital, H., 2006. Holocene sea-level history: Evidence from coastal sediments of the northern Rio Grande do Norte coast, NE Brazil. Marine Geology, 228, 39-53.

Callard, S.L.; Gehrels, W.R.; Morrison, B.V., and Grenfell, H.R., 2011. Suitability of saltmarsh foraminifera as proxy indicators of sea level in Tasmania. Marine Micropaleontology, 79(3-4), 121-131.

Cassel, D.T. and Sen Gupta, B.K., 1989. Foraminiferal stratigraphy and paleoenvironments of the Terciary Uscari Formation, Lomon Basin, Costa Rica. Journal of Foraminiferal Research, 19(1), 52-71.

Coelho, L.G.; Barth, O.M. and de Araujo, D.S.D., 2008. Pollen analysis of Holocene sediments from the Poço das Antas National Biological Reserve, Silva Jardim, Rio de Janeiro, Brazil. Anais da Academia Brasileira de Ciências, 80, 531-541.

Cordeiro, R.; Turcq, B.; Suguio, K.; Oliveira da Silva, A.; Sifeddine, A., and Volkmer Ribeiro, C., 2008. Holocene fires in East Amazonia (Carajás), new evidences, chronology and relation with paleoclimate. Global and Planetary Change, 61, 49-62.

Corrêa, I.C.S., 1996. Les variations du niveau de la mer durant les derniers 17.500 ans BP: l'exemple de la plate-forme continentale du Rio Grande do Sul-Brésil. Marine Geology, 130, 163-178. 
Cruz Jr., F.W.; Burns, S.J.; Karmann, I.; Sharp, W.D.; Vuille, M.; Cardoso, A.O.; Ferrari, J.A.; Silva Dias, P.L. and Viana Jr., O., 2005. Insolation-driven changes in atmospheric circulation over the past 116,000 years in subtropical Brazil. Nature, 434, 63-66.

Debenay, J-P.; Eichler, B.B.; Guillou, J.J.; Eichler-Coelho, P.; Coelho, C., and Porto-Filho, E., 1997. Comportment dês peuplements de foraminifers et comparision avec l'avifaune dans une lagune fortment stratifiée: La Lagoa da Conceição (SC, Brésil). Revue de Paléobiologie, 16, 55-75.

Debenay, J-P; Duleba, W.; Bonetti, C.; Mello e Souza, S.H., and Eichler, B.B., 2001. Pararotalia cananeiaensis n.sp.: indicator of marine influence and water circulation in Brazilian coastal and paralic environments. Journal of Foraminiferal Research, 31(2), $152-163$.

Delgado, J; Boski, T.; Nieto, J.M.; Pereira, L.; Moura, D.; Gomes, A.; Sousa, C., and GarcíaTenorio, R., 2012. Sea-level rise and anthropogenic activities recorded in the late Pleistocene/Holocene sedimentary infill of the Guadiana Estuary (SW Iberia). Quaternary Science Reviews 33(6), 121-141.

De Oliveira, P.E.; Barreto, A.M.C., and Suguio, K. 1999. Late Pleistocene/Holocene climatic and vegetational history of the Brazilian caatinga: the fossil dunas of the middle São Francisco River. Palaeogeography, Palaeoclimatology, Palaeoecology, 152, 319-337.

Duleba, W. and Debenay, J-P., 2003. Hydrodynamic circulation in the estuaries of Estação Ecológica Juréia-Itatins, Brazil, inferred from foraminifera and thecamoebian assemblages. Journal of Foraminiferal Research, 33(1), 62-93.

Duleba, W.; Coimbra, J.C.; Petri, S., and Barbosa, C.F., 2005. Foraminíferos, tecamebas e ostracodes recentes utilizados como bioindicadores em estudos ambientais brasileiros. In: Sousa, C.R.G.; Suguio, K., Santos, M. and Oliveira, P.E. (eds). Quaternário do Brasil. Ribeirão Preto, São Paulo: Editora Holos. pp. 176-210.

Eichler, P.P.B.; Castelão, G.P.; Pimenta, F.M.; Eichler, B.B.; Miranda, L.B.; Rodrigues, A.R., and Pereira, E.R.M., 2004. Foraminifera and Thecamoebians as Indicator of Hydrodynamic Process in a Choked Coastal Lagoon, Laguna Estuarine System, SC, Brazil. Journal of Coastal Research, 39, 1144-1148.

Gebhardt, H.; Kunt, W., and Holbourn, A., 2004. Foraminiferal response to sea level change, organic flux and oxygen deficiency in the Cenomanian of the Tarfaya Basin, southern Morocco. Marine Micropaleontology, 53 (1-2), 133-157.

Keigwin, L.D.; Sachs, J.; Rosenthal, Y., and Boyle, E.A., 2005. The 8200 year B.P. event in the slope water system, western subpolar North Atlantic. Paleoceanography, 20, PA2003. 
Kitazato, H. 1994., Foraminiferal microhabitats in four marines environments around Japan. Marine Micropaleontology, 24, 29-41.

Klein, D. A. 2005. Registros de variações ambientais no Canal de São Sebastião (Estado de São Paulo), durante o Último Ciclo Glacial. São Paulo, São Paulo: Universidade de São Paulo, Ph.D. thesis, 85 p.

Le Cadre, V.; Debenay, J.-P., and Lesourd, M., 2003. Low pH effects on Ammonia beccarii test deformation: implications for studying test deformation as pollution indicator. Journal of Foraminiferal Research, 33 (1), 1-9.

Ledru, M-P.; Braga, P.I.S.; Soubiès, F.; Fournier, M.; Martin, L.; Suguio, K., and Turcq, B. 1996. The last 50,000 years in the Neotropics (Southern Brazil): evolution of vegetation and climate. Palaeogeography, Palaeoclimatology, Palaeoecology, 123, 239-257.

Loeblich, A.R. and Tappan, H., 1964. Protista. In: Moore, R. C. (ed.), Treatise on invertebrate paleontology, Part C. New York, USA: The University Kansas Press, v1, 510 p., v2, 390p.

Loeblich, A.R. and Tappan, H., 1988. Foraminiferal genera and their classification. New York, USA: Van Nostrand, v.1, 970 p., v.2, 847 boards.

Longyin, L.; Gallagher, S., and Finlayson, B., 2000. Foraminiferal response to Holocene environmental changes of a tidal estuary in Victoria, Southeastern Australia. Marine Micropaleontology, 38, 229-246.

Luz, C.F.P.; Barth, O.M., and Martin, L., 1999. Evolução das florestas tropical estacional semidecídua e ombrófila densa durante o Holoceno Médio na região Norte do Rio de Janeiro, baseada em Palinologia. Revista Geociências, 4, 74-84.

Mahiques, M.M.; Mello e Sousa, S.H.; Furtado, V.V.; Tessler, M.G.; Toledo, F.A.L.; Burone, L.; Figueira, R.C.L.; Klein, D.A.; Martins, C.C., and Alves, D.P.V., 2010. The southern Brazilian shelf: general characteristics, Quaternary evolution and sediment distribution. Brazilian Journal of Oceanography, 58(special issue PGGM), 25-34.

Martin, L.; Bittencourt, A.C.S.P.; Dominguez, J.M.L.; Flexor, J.M., and Suguio, K., 1998. Oscillations or not oscillations, that is the question: comment on Angulo, R.J. And Lessa, G.C. "The Brazilian sea-level curves: a critical review with emphasis on the curves from the Paranaguá and Cananéia regions" [Mar. Geol. 140, 141-166]. Marine Geology, 150, 179-187.

Martin, L.; Dominguez, J.M.L., and Bittencourt, A.C.S.P., 2003. Fluctuating Holocene sea levels in eastern and southeastern Brazil: evidence from a multiple fossil and geometric indicators. Journal of Coastal Research, 19, 101-124. 
Moodley, L.; Zwaan, G.L.; Rutten, G.M.W.; Boom, R.C.E., and Kempers, A.J., 1998. Subsurface activity of benthic foraminifera in relation to porewater oxygen content: laboratory experiments. Marine Micropaleontology, 34, 91-106.

Murray, J. W., 1991. Ecology and Paleoecology of Benthic Foraminifera. London, England: Longman Scientific and Technical, 397pp.

Pawlowski, J.; Holzmann, M.; Nerney, C.; Fahrni, J.; Gooday, A.J.; Cedhagen, T.; Habura, A., and Bowser, S.S., 2003. The evolution of early Foraminifera. Proceedings of National Academy of Science, 100(20), 11494-11498.

Pielou, E. C., 1969, Mathematical Ecology. Nova Iorque, John Wiley and Sons, 286p.

Por, D.F., 1986, Stream type diversity in the Atlantic lowland of the Juréia area (subtropical Brazil): Hydrobiologia, 131, 39-46.

Rathburn, A.E. and Corliss, B.H., 1994. The ecology of living (stained) deep-sea benthic foraminifera from Sulu Sea. Paleoceanography, 9(1), 87-150.

Rathburn, A.E.; Levin, L.A.; Held, Z., and Lohmann, K.C., 2000. Benthic foraminifera associated with cold methane seeps on the Northern California margin: ecology and Stable isotopic composition. Marine Micropaleontology, 38, 247-266.

Rohling, E.J. and Pälike, H., 2005. Centennial-scale climate cooling with a sudden cold event around 8,200 years ago. Nature: 434, 975-979.

Salgado-Labouriau, M.L.; Barberi, M.; Vicentini, K.F., and Parizzi, M.G., 1998. A dry climatic event during the late Quaternary of tropical Brazil. Review of Palaeobotany and Palynology, 99, 115-129.

Sallun, A.E.M.; Sallun Filho, W.; Suguio, K.; Babinski, M.; Gioia, S.M.C.L.; Harlow, B.; Duleba, W.; De Oliveira, P.E.; Garcia, M.J.; Weber, C.Z.; Christofoletti, S.R.; Santos, C.S.; Medeiros, V.B.; Silva, J.B.; Santiago-Hussein, M.C., and Fernandes, R.S., 2012. Geochemical evidence of the $8.2 \mathrm{ka}$ event and other Holocene environmental changes recorded in paleolagoon sediments, southeastern Brazil. Quaternary Research, 77(1), 3143.

Samir, A.M., 2000. The response of benthic foraminifera and ostracods to various pollution sources: a study from two lagoons in Egypt. Journal of Foraminiferal Research, 30(2), 8398.

Schallenberg, M.; Hall, C.J., and Burns, C.W., 2003. Consequences of climate-induced salinity increases on zooplankton abundance and diversity in coastal lakes. Marine Ecological Progress Series, 251, 181-189. 
Shannon, C. and Weaver, W., 1999, The Mathematical Theory of Communication. 5th Ed. University of Illinois Press. 144 pp.

Schröeder, C.J.; Scott, D.B., and Medioli, F.S., 1987. Can smaller benthic foraminifera be ignored in paleoenviromental analyses? Journal of Foraminiferal Research, 4, 101-110.

Scott, D.B.; Medioli, F.S., and Schafer, C.T., (eds.), 2001. Monitoring in coastal environments using foraminifera and thecamoebian indicators. New York: Cambridge University Press, 177p.

Semensatto-Jr., D.L.; Oliveira, D., and Dias-Brito, D., 2008. Blysmasphaera broennimanni : a new recent allogromiine species (Order Foraminiferida, Eichwald, 1830) from Brazil. Revue de micropaléontologie, 27(2), 525-531.

Semensatto-Jr., D.L.; Funo, R.H.F.; Dias-Brito, D., and Coelho-Jr. C., 2009. Zonation écologique de foraminifères sur un profil levé dans une mangrove brésilienne: diversité, morphotypes et influence des durées d'émersion. Revue de micropaléontologie, 52, 67-74.

Sen Gupta, B.K., (ed.), 1999. Modern Foraminifera. Norwell, USA: Kluwer Academic Publishers, $371 \mathrm{p}$.

Sen Gupta, B.K., and Platon, E., 2001. Tracking Past Sedimentary Records of Oxygen Depletion in Coastal Waters: Use of the Ammonia-Elphidium Foraminiferal Index. Journal of Coastal Research, 39, 1351-1355.

Stríkis, N.M.; Cruz, F.W.; Cheng, H.; Karmann, I.; Edwards, R.L.; Vuille, M.; Wangs, X.; Paula, M.S.; Novello, V.F., and Auler, A.S., 2011. Abrupt variations in South American monsoon rainfall during the Holocene based on a speleothem record from central-eastern Brazil. Geology, 39(11), 1075-1078.

Suguio, K, and Martin, L., 1978a. Quaternary marine formations of the State of São Paulo and southern Rio de Janeiro. Proocedings of International Symposium on Coastal Evolution in the Quaternary (São Paulo, São Paulo), pp. 232-253.

Suguio, K., and Martin, L., 1978b. Mapa geológico do Quaternário costeiro do Estado de São Paulo. São Paulo, São Paulo: Governo do estado de São Paulo, Secretaria de Obras e do meio Ambiente, Departamento de Água e Energia Elétrica, scale 1:100,000, 8 sheets.

Suguio, K.; Martin, L.; Bittencourt, A.C.S.P.; Dominguez, J.M.L.; Flexor, J.M., and Azevedo, A.E.G., 1985. Flutuações do nível relativo do mar durante o Quaternário superior ao longo do litoral brasileiro e suas implicações na sedimentação costeira. Revista Brasileira de Geociências, 15, 273-286.

Tomazelli, L.J., and Villwock, J.A., 1996. Quaternary geological evolution of Rio Grande do Sul coastal plain, southern Brazil. Anais da Academia Brasileira de Ciências, 68, 373-382. 
Vilela, C.G.; Sanjinés, A.E.S.; Ghiselli, R.O.; Mendonça Filho, J.G.; Baotista Neto, J.A., and Barbosa, C.F., 2003. Search for Bioindicators of Pollution in the Guanabara Bay: Integrations of Ecologic Patterns. Anuário do Instituto de Geociências -UFRJ, 26, 25-35.

Villwock, J.A.; Tomazelli, L.J.; Loss, E.L., and Dehnhardt, B.A., 1986. Geology of the Rio Grande do Sul Coastal Province. Quaternary of South América and Antarctic Península, 4, 79-97.

Walton, W.R., and Sloan, B.J., 1990. The genus Ammonia Brünnich, 1772: its geographic distribution and morphology variability. Journal of Foraminiferal Research, 20(2), 128136.

Wentworth, C. R., 1922. A scale of grade and class terms for clastic sediments. Journal of Geology, 30, 377-392.

Whitney, B.; Mayle, F.E.; Punyasena, K.A.; Fitzpatrick, M.J.; Burn, M.J.; Guillen, R.; Chavez, E.; Mann, D.; Toby Pennington, R., and Metcalfe, S.E., 2011. A 45 kyr paleoclimate record from the lowland interior of tropical South America. Palaeogeography, Palaeoclimatology, Palaeoecology, 307 (1-4), 177-192.

Wrightman, W.G.; Scott, D.B., and Medioli, F.S. 1994. Agglutinated foraminifera and thecamoebians from the Late Carboniferous Sydney coalfield, Nova Scotia: paleoecology, paleoenvironments and paleogeographical implications. Palaeogeography, Palaeoclimatology, Palaeoecology, 106, 187-202. 